COLUMBIA LIBRARIES OFFSITE HEALTH SCIENCES STANDARD

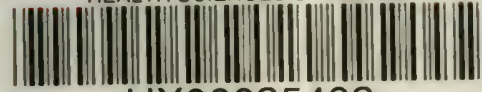

$\mathrm{HX00025402}$

LIBKAKY

OF THE

ASSOCIATION

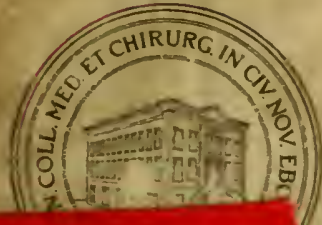

OF THE

ALUMNI

OF THE

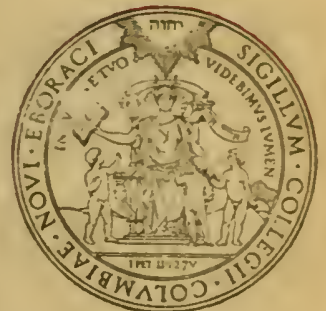

OLLEGE

OF

$111 \mathrm{ICIANS}$ AND

SURGEONS

IN THE

\title{
CITY OF NEW YORK
}


THE

\section{LIBRARY}

OF THE

\section{ASSOCIATION}
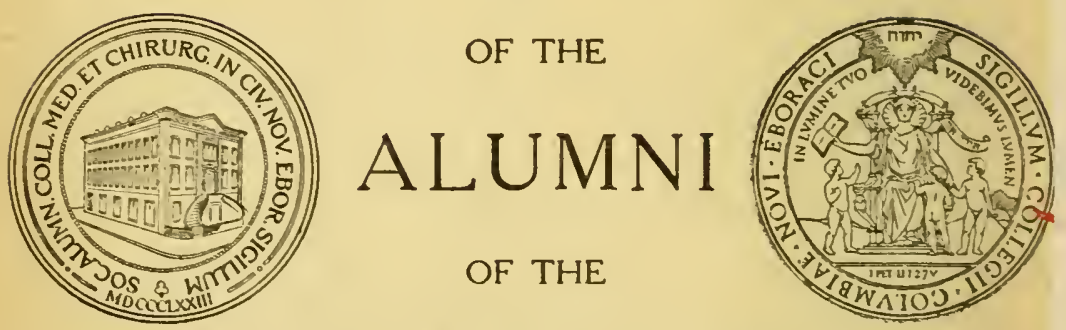

\section{COLLEGE}

OF

\section{PHYSICIANS AND}

SURGEONS

IN THE

CITY OF NEW YORK 


Digitized by the Internet Archive in 2010 with funding from Columbia University Libraries 



\section{MANUALS}

FOR

Students OF Medicine 



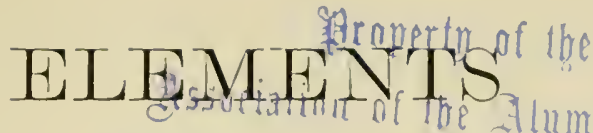 (5outeorof

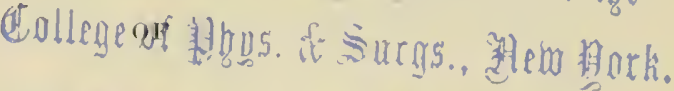 \\ H I S TOMO (- )}

Bx

E. KLEIN, M.D., F.R.S.

LECTURER ON GENETAL ANATOHY AND PHYSIOLOGY

A N D

J. S. EDKINS, M.A., MI.B.

JOINT LECTURER AND DEMONSTRATOR OF PHYSIOLOGY IN THE MEDICAL SCHOOL OF ST. BARTHOLOMEW'S HOSPITAL, LONDON

WITH 296 ILLUSTRATIONS

REVISED AND ENLARGED EDITION

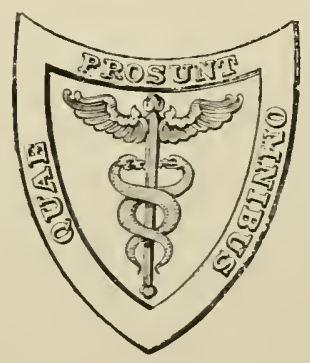

LEA BROTHERS \& CO., PHILADELPHIA AND NEW YORK. 


$$
\begin{gathered}
2 M 551 \\
k 672 \\
1898
\end{gathered}
$$




\section{Eo the ftemory}

$\mathrm{OF}$

SIR WILLIAM BOWMAN, LL.D., F.R.S.,

THIS BOOK IS DEDICATED,

IN ACKNOWLEDGMENT OF HIS MANY AND GREAT DISCOVERIES

IN ANATOMY AND PHYSIOLOGY. 



\section{PREFACE TO THE}

\section{REVISED AND ENLARGED EDITION.}

Sixce the last edition of this book in 1889 , considerable additions have been made to the knowledge of minute structural anatomy. The progress in the knowledge of the structure and life of the cell and mucleus, the remarkable discoveries in the structure of the central nervous system and sense organs -introduced by the method of Golgi, and followed up by the brilliant work of Ramón y Cajal, Kölliker, Lenhossek, Retzius, and others-have made it necessary to revise and to make considerable additions to the chapters dealing with these organs. While care has been taken to correct and amplify other parts of the book, the chapters on the central nerrous srstem have been practically rewritten.

The task of rewriting and re-editing the chapters on the brain and medulla and on the alimentary canal has derolved upon my colleague Dr. Edkins, who is now associated with me as joint-author.

While a large number of the illustrations of the former edition have been retained, a considerable number has been added; these are either original photograms prepared by Mr. Norman from Dr. Edkins's and my own specinthens, or they are copied from Kölliker's "Handbuch," from Ramón y Cajal, from Schäfer (Quain's "Anatomy"), from Halliburton (Kirke's "Physiology"), and from Klein and Noble Smith's "Atlas of Histology." To our colleague Dr. Tooth our special thanks are due for the loan of some of the lantern slirles illustrating the medulla.

ST. BARTHOLOMEW'S HOSPITAL.

$$
\text { E. KLEIN. }
$$

LONJ)ON. - 1, 98 . 



\section{CONTENTS.}

CHAPTER

PAFE

I. -Cells

II.-Blood . . . . . . . . . 19

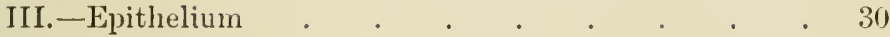

IV.-Endothelium . . . . . . . . 40

V.-Fibrous Connective Tissues . . . . . . . 46

VI.-Cartilage . . . . . . . . . 63

VII.-Bone . . . . . . . . . 68

VIII.-Non-striperl Muscular Tissue . . . . . . . 86

IX. - Striped Mnscular Tissue . . . . . . $\quad$. 90

X.-The Heart and Blood-Vessels . . . . . 105

XI.-The Lymphatic Vessels . . . . . . 117

XII.-Follicles or Simple Lymph Glands . . . . 126

XIII.-Compound Lymphatic Glands . . . . . 134

XIV.-Nerve Fibres . . . . . . . . 140

XV.-Peripheral Nerve-Endings . . . . . 15ّ

XVI.-The Spinal Cord . . . . . . . 170

XVII.-The Medulla Oblongata or Spinal Bulb . . . 202

XVIII. - Continuation of the Medulla Oblongata through the

Pons Varolii and the Region of the Crura . . 216

XIX.-The Cerebrum and Cerebellum . . . . 235

XX. -The Cerebro-Spinal Ganglia . . . . . 253

XXI.-The Sympathetic Srstem . . . . . 258

XXII. - General Considerations as to the Anatomical Constitution and Nature of the Nervous System . 268

XXIII. -The Teeth . . . . . . . . 275

XXIV.-The Salivary Glanils . . . . . . 286

XXY.-The Month, Pharynx, and Tongue . . . . 298

XXVI.-The Esophagus anil Stomach . . . . . 307 
XXVII. - The Small and Large Intestine . . . . 317

XXTIII. - The Crlands of Brumer and the Pancreas. . 328

XXIX. - The Liver . . . . . . . 333

XXX.-The Organs of Respiration . . . . . . 33!

XXXI.-The spleen. . . . . . . 3.51

XXXII.-The Kidney, Ureter and Bladder . . . 35f;

XXXIII.-The Male Genital Organs . . . . . . 37\%

XXXIT.-The Female Genital Organs . . . . . 396

XXXT. - The Nammary Glanı . . . . . f 400

XXXTI.The Skin . . . . . . 404

XXNTII.-The Conjunctiva and its Glands . . . 424

XXXYIII.-Cornea, Sclerotic, Ligamentum Pectinatum and Ciliary Muscle. . . . . 42!)

XXXIX.- Iris, Ciliary Processes and Choroid . . . 436

XL...The Lens and Vitreous Body . . . . 442

XLI. --The lictina . . . . . . 4 4.5

XLII.--The Outer and Midulle Ear . . . . 4.58

XLIII. -The Intermal Ear . . . . 46

XLIV.-The Nasal Mucous Membrane . . . . 47.)

XLV. -The Ductless Glands . . . . . . tst 


\section{Arnperty of tbe}

\section{Assucialiun lif the Mlumni of the

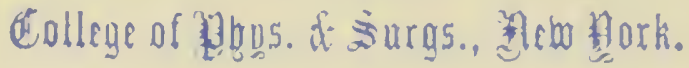

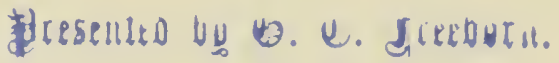

\section{Elements of Histologr.}

CHAPTER I.

\section{CELLS.}

1. The ripe ovum (Fig. 1) of man and mammals is a minute spherical mass of a soft, gelatinous, transparent, granular-looking substance, containing numerous minute particles-yolk globules. It is invested by a radially striated delicate membrane called the zona pellucida. Inside this mass, and situated more or less excentrically, is a vesiclethe germinal vesicle - and inside this, one or more solid spots - the germinal spot or spots. The gelatinous transparent substance

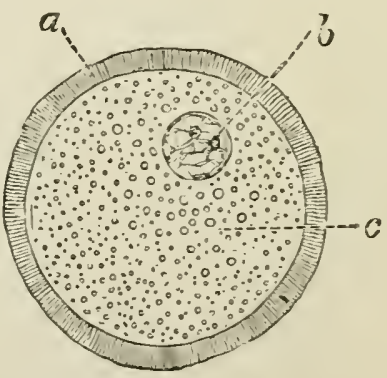

Fig. 1.-Ripe Orum of Cat. $a$, Zona pellucida; $b$. germinal vesicle; $c$, protoplism. of the ovum, containing a very large percentage of proteid material, is called protoplasm. Before and immediately after fertilisation, the protoplasm of the orum shows distinct movement, consisting in contraction and expansion. These movements are spontaneous-i.e. not caused by any directly visible external influence.

The diameter of the ripe ovum in man and domestic animals varies between $\frac{1}{200}$ and $1 \frac{1}{2} \overline{0}$ of an inch. But before it ripens the ovum is considerably 
smaller-in fact, its size is in proportion to its state of development.

2. Fertilisation causes mirked changes in the contractions of the protoplasm of the orum; these

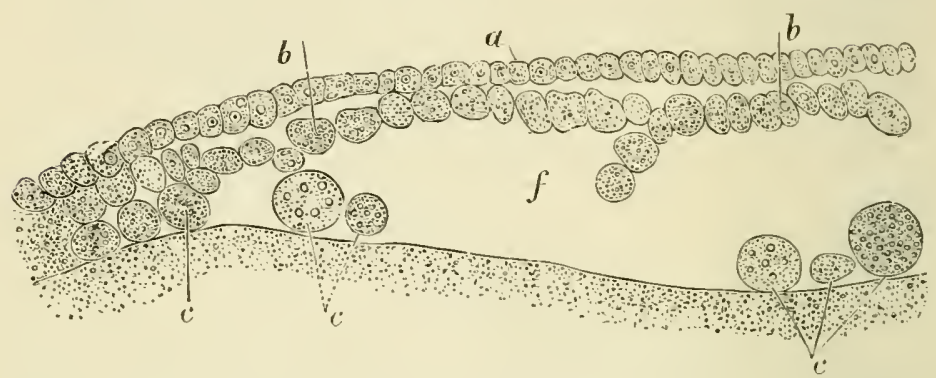

Fig. 2.-From a Section through the Blastoderm of Chick, unincubated. $a$, Cells forming the ectoderm; $b$, cells forming the endoderm ; $c$, large formative cells; $f$, segmentation cavity. (Handbook.)

lead to cleavage or division of its body into two parts, the germinal resicle having previously split up into two bodies or nuclei; so that we now find the orum

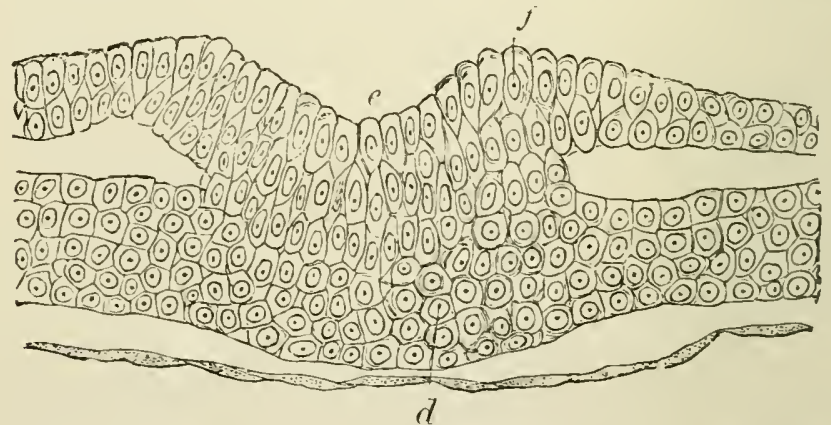

Fig. 3,-From a Section through the Rudiment of the Embryo Chick.

$\varepsilon$, Primitive groove; $f$, dorsal lamina of epihlast: $d$, mesoblast. The thin layer of spindle-shaped cells is the hypoliast. (Hundbook.)

has originated two new elements, each of which consists of protoplasm, of the same substance as that of the original ovum, and each contains one nucleus or kernel. The investment of the orum takes no 
part in this process of division. Not long afterwards, each of the two daughter elements undergoes cleavage

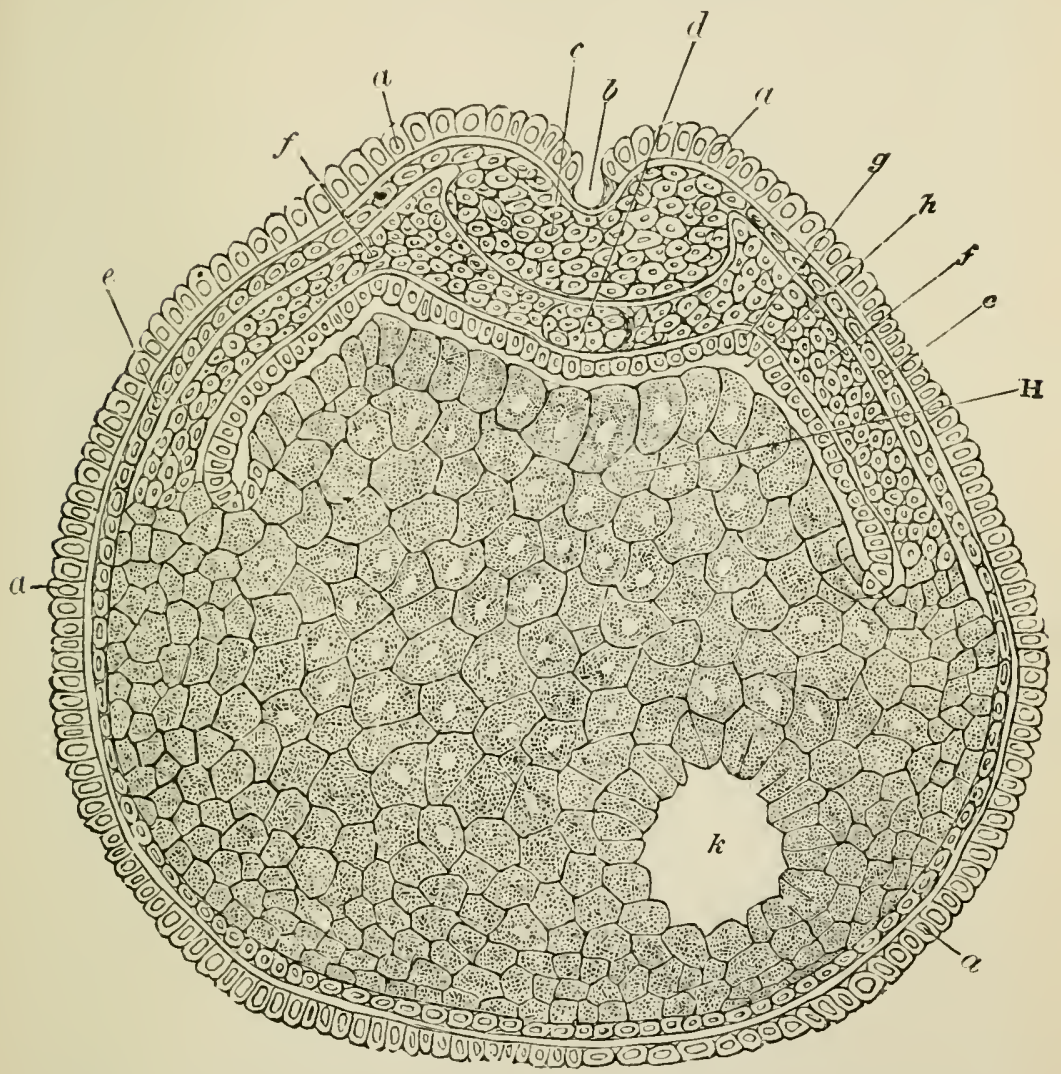

Fig. 4.- Tertical Section through the Orum of Bufo Cinereus, in the early stage of the Embryo Development.

$a$, Tegmental laser of epiblast; $b$, dorsal groove; $c$, rudiment of central nervous system ; $d$, notochord; $e$, deep layer of epiblast; $f$, mesoblast; $g$, hypoblast ; $h$, cavity of alimentary canal-Rusconi's cavity ; H, central yolk; $k$, remainder of von Baer's or segmentation cavity. (II andbook.)

or division into two new elements, the nucleus liaving previously divided into two, so that each new offispring possesses its own nucleus. This process of division is continued in the same mamner for 
many generations (Figs. 2, 3, 4), so that after a few days we find within the original investment of the orum a large number of mimute elements, each consisting of protoplasm, and each containing a nucleus.

3. From these elements, which become smaller as the process of cleavage progresses, all parts and oroms of the embryo and its membranes are formed. It can be easily shown that the inclividual elements possess the power of contractility. Either spontaneously or under the influence of moderate heat, electricity, mechanical or chemical stimulation, they throw out processes and withdraw them again, their substance flowing slowly but perceptibly along. Hence they can change their position. In this respect they completely resemble those lowest organisms which are known as amcebr, each of these being likewise a nucleated mass of protoplasm. Wherefore this morement is termed amceboid movement. It can be further shown that they, like amcere, grow in size and divide - that is to say, the individuals of a generation grow in size hefore each gives rise to two new daughter individuals.

4. Although for some time during embryonic life the elements constituting the organs of the embryo are possessed of these characters, a time arrives when only a limited number of them retain the power of contractility in any marked degree. At birth only tle white corpuscles of the blood and lymph, many of the elements of the lymphatic organs, and the muscular tissues, possess this power; while the others lose it, or at any rate do not show it except when dividing into two new elements. Some of these elements retain their protoplasmic basis; as a rule, each contains one nucleus (but some two or more), and is capable of giving origin by division to a new generation. Others, however, change their nature altogether, 
their protoplism and nucleus disappear, and they give origin to material other than protoplasm--e.y. colligenous, osseous, elastic, and other substances. As development proceeds, and after birth of the fortus, different cells assume diflerent functions, which for each kind are of a special character and constitute its specific character or its specific function.

5. Beginning with the ovum, and ending with the protoplasmic nucleated elements found constituting the organs and tissues of the embryo and adult, we have, then, one uninterrupted series of generations of
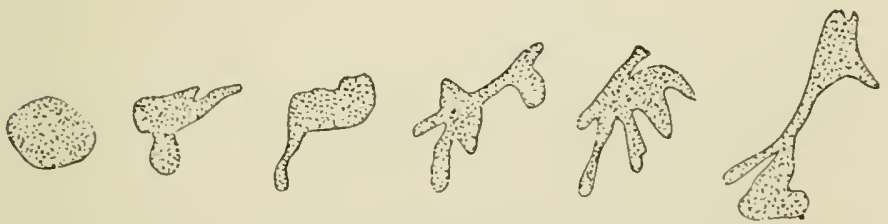

Fig. 5.-Amøboid movement of a White Blood Corpuscle of Man ; various phases of movement. (Handbook.)

elements, which with Schwann we call cells and with Brücke elementary organisms. Of these it can be said that not only is each of them derived from a cell (Virchow: omnis cellula a cellula), but each consists of the protoplasm of Max Schultze (sarcode of Dujar(lin), is without any investing membrane, and includes generally one nucleus, but may contain two or more. IVe can further say that each of these cells shows the phenomenon of growtl, which presupposes nutrition and reproduction. All of them in an early stage of their life-history, and some of them throughout it, show the phenomenon of contractility, or amoboid movement (Fig. 5).

In a recent work, and following the procedure of v. Sachs on the life and activity of regetable cells, v. Kölliker systematises and summarises those of animal cells thus: 'The protoplasm and nucleus constituting 
a regetable cell is called by v. Sachs an energid; in the animal body it is represented by a nncleated protoplasmic cell without a cellulose membrane, and is called by r. Kölliker a protoblust (germinal mitter of Beale). All protoblasts, as also all energids, are always derived from parent protoblasts; they always propagate by division, and in this manner carry on the race from generation to generation; they are the instruments of heredity.

All growth of the protoblasts takes place by internal processes-that is, by intussusception.

The active work of protoblasts consists in: $(a)$ formation of the typical organs; (b) special movements of the protoplasm-e.g. amcboid movement; (c) the formation of alloplasmatic organs (A. Meyer). These latter are derived from the living protoplasm, are organised, and are participating themselves in the living functions, but they are not capable of multiplication by division. Such alloplasmatic organs are: cilia, muscular fibres, nerre cells and nerre tibres, and the terminal cells in the sense organs. (d) The production of passive, partly non-organised, ergastic structures (A. Meyer), or formed matter (L. Beale); such are the cellulose membranes of regetable cells, cuticular formations, Huids, and intercellular and other substances (collagenous, chondrinous, osseous, elastic, dental, etc.), cell-juices and granules of all kinds.

Cells differ in shape according to kind, locality, and function, being spherical, irregular, polygonal, squamous, branched, spindle-shaped, cylindrical, prismatic, or conical. These various shapes will be more fully described when dealing in detail with the various kinds of cells. Cells in man and mammals ditfer in size within considerable limits: from the size of a small white blood corpuscle of about $\frac{1}{200}$ of an inch to that of a large ganglion cell in the anterior horns of 
the spinal cord of abont $\frac{1}{20}$ of an inch, or to that of multinucleated cells of the bone marrow-myeloplaxsome of which surpass in size eren the ganglion cells. The same holds good of the nuclens. Between the nucleus of a ganglion cell of about $\frac{1}{50 \pi}$ to $\frac{1}{1200}$ of an incl! in diameter and the nucleus of a white blood corpuscle of about $\frac{1}{5000}$ to $\frac{1}{10000}$ of an inch and less there are all intermediate sizes.

6. Protoplasm or cytoplasm is a transparent homogeneous or granular-looking sulsstance. On very careful examination with good and high powers, and especially when examined with certain reagents, in many, but not in all, instances it shows a more or less definite structure (Fig. $6)$, composed of fibrils, more or less regular, and

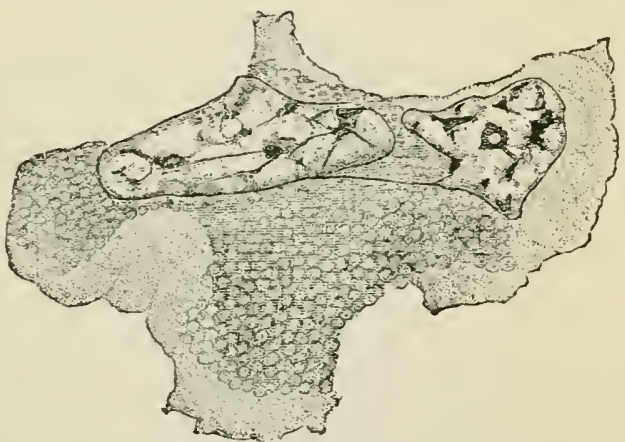

Fig. 6.-Amceoid pale lencocyte of the newt, showing the nurlel emberded in the cell protoplasm-this latter consisting of spongioplasm and hyaloplasm. (After Schöfer.)

in some instances grouped into a lioneycombed reticulum, spongioplasm, in the meshes of which is a homogeneous substance, liyaloplasm (Leydig). The closer the meshes of the reticulum, the less there is of this interstitial substance, and the more regularly granular does the reticulum appear. In the meshes of the reticulum, however, may be included larger or smaller gramules of fat, pigment, or other material. Water makes protoplasm swell up and ultimately this becomes disintegrated ; so also act dilute acids and alkalies. All substances that coagulate proteids have the same effect on protoplasm. 
In arrangement of its elements the spongioplasm differs in different cells; while in some-e.g. spheroidal or cubical epithelial cells-it is as a rule uniform ; in columnar cells it is elongated in the direction of the long axis of the cell, hence the reticulum appears as an eminently longitudinally fibrillated substance; in ganglion cells it is concentrically arranged. In some

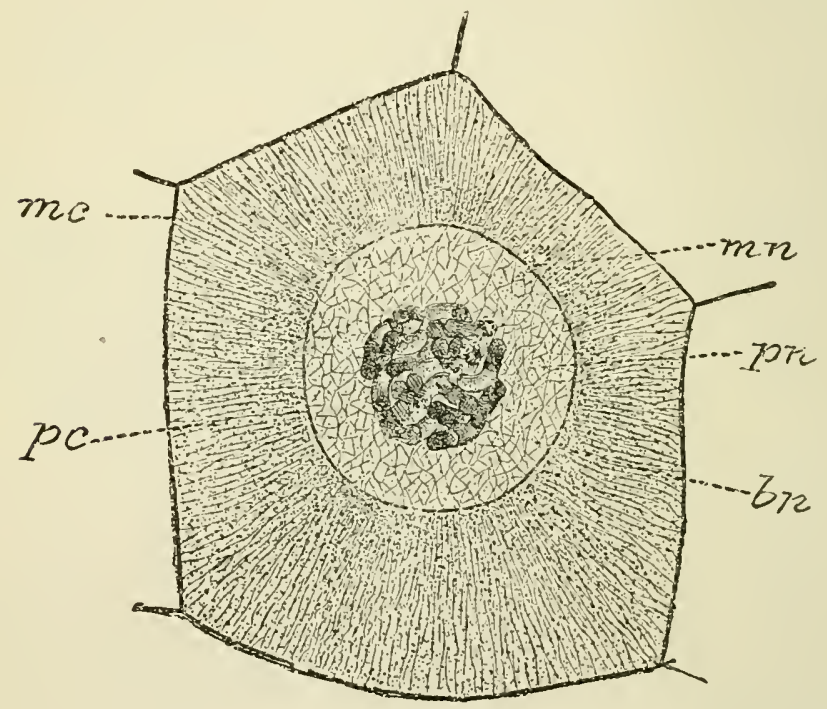

Fig. 7.-Cell with radially disposer reticulum from the intestinal epithelium of a worm. (After Carnoy, from Quain's "Anatomy.")

mc, Cell membrane; $p c$, cell jotoplasm; m. nuclear membrane; $p n$, nuclear achromatin surrounding the convoluted cbromatin tlaments bn.

cells in the outer portion the spongioplasm possesses a different arrangement from that in the middle portion, and then a division is made between ectoplasm and endoplusm (Fig. 7). The hyaloplasm differs in amount in different cells, and in the same kind of cells it varies according to different states of cell activity. Thus in gland cells during activity the amount of hyaloplasm is increased, containing in these instances more or less of gramular matter. 
In amoboid cells, such as the white corpuscles of the blood, the hyaloplasm is the substance in which the spontaneous or amoloirl changes and movement are principally lodged, as has been slown by instantaneous electric illumination by Stricker.

In the protoplasm of many cells are lodged granules of various kinds, microsomes; they differ in size, shape, colomr, and chemical nature, and are, as a rule, the result of cell activity. Such are the zymogen granules in secreting gland cells; eosinophile, basophile, and neutrophile $\mathrm{or}^{\circ}$ amphophile granules in leucocytes; glycogen granules in the liver cells, cartilage cells, and leucocytes; pigment granules in various kinds of pigmented cells; fat granules and fat globules in wandering cells, in connective-tissue cells, in liver cells, in the epithelial cells of the milk gland, etc. It is not justifiable to assume with Altmann that these microsomes or bioblasts are living entities in the sense that the whole cell is.

In the cell protoplasm of leucocytes, of epithelial and other cells, certain granules and fibrils have been described by Flemming, Boveri, Heidenhain, and others, which being of

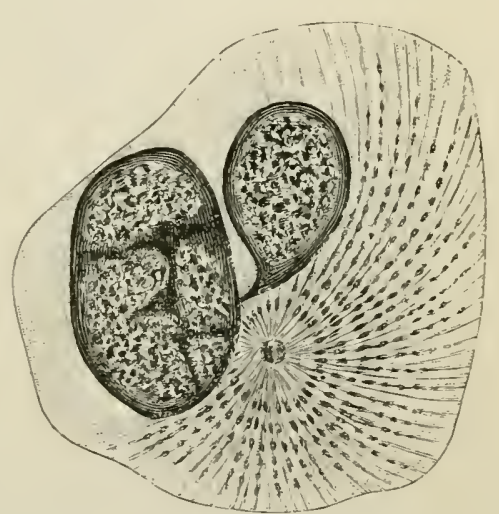

Fig. S.-Leucocyte of Salamandra containing two nuclei, and showing the attractionspliere: the centrosome is already divicled into two. (After Dr. Martin Heidenhain.) a constant and definite nature play an important part in the division of the cell and its nucleus. This is the centrosome, and with its radiating fibrillæ forms the attractionsphere (Fig. S). The centrosome is a granule surrounded by a hyaline 
spherical space; through this pass the fibrillae radiating from the former, and connect it with the spongioplasm of the cell body. The whole-i.e
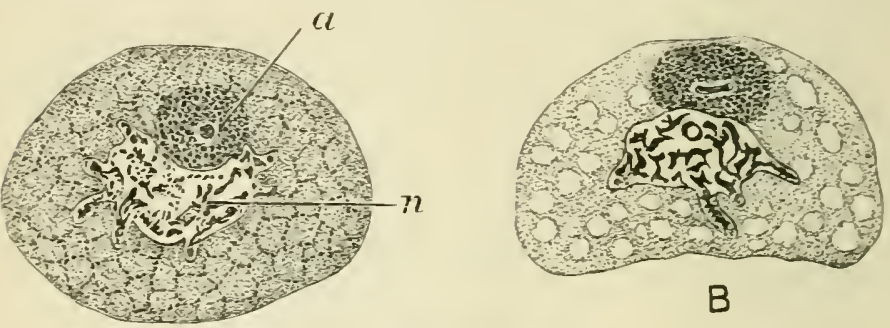

A
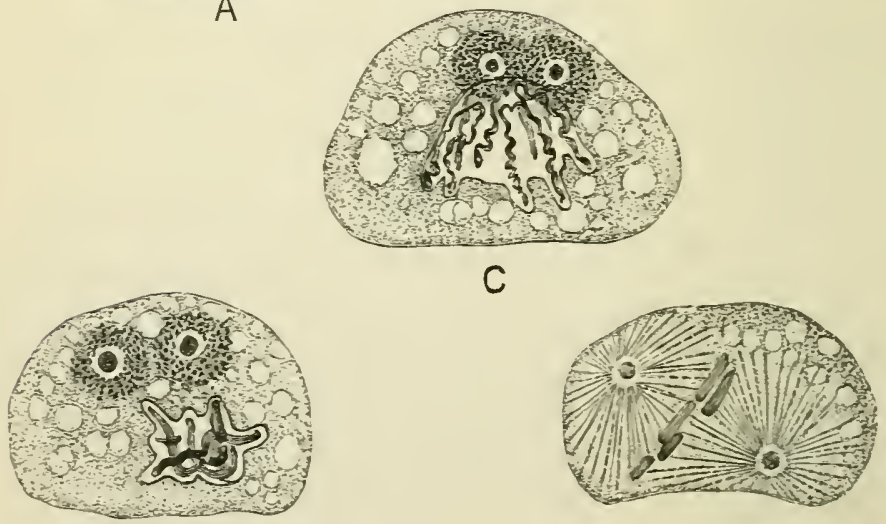

E

Fig. 9.-Blastomeres of Bi-segmented Ormm of Ascaris megalocephala (Ajtes Loceri, from Füllilitr, I.)

A: $a$, Attrattion-phere; $n$, nucleus in reting state; $b$ : nuclets in stage of convolutiou: c, attractionsphere nearly divided; D, atcractionsphere divided: E, attractionspheres arranged at the poles, chrumosumes forming tue equatorial plate.

centrosome and radiating fibrillie-represents the attractionsphere. Preceding the division of the cell nucleus, the centrosome divides into two, each daughter centrosome, with its own hyialine areola and system of radiating fibrilla, forming by - and - by a separate attractionsphere, which 
migrating towards opposite poles of the cellbody becone separate points of attraction for the divided nuclear mitoma. (See division of nucleus.) So that the division of the attractionsphere would be the first, the rlivision of the nucleus the second, and the division of the cell protoplasm the third and final stage in the dirision of a cell (Fig. 9).

7. The nuclems, the size of which is generally in proportion to that of the cell, is usually spherical or oval. It is composed of a more or less distinct investing cuticle and the nuclear contents; the former is the membrane, the latter the nuclear substance, karyoplasm, or nucleoplasm. This, again, is composed, in adult nuclei, of a stroma or network, mitoma, and the inter-fibrillar substance. The network consists of fibrils of valious thickness, and trabecule or septa more or less irregular in thickness and length. Intimately connected with and lodged in the network are angular or rounded masses called nucleoli. The number and size of these vary considerably; in young nuclei they may be large and numerous, in aduli or resting nuclei they are few, and in those about to divide they are altogether absent. Also the network is subject to great variation: while in adult or resting nuclei, and particularly those about to divide, the network is of great uniformity and well developed; it may be very imperfect in young nuclei, in which it is sometimes represented by a number of irregular masses joined by short bridges. The more perfect the nuclear network, the fewer are the nucleoli. Owing to the ready manner in which the fibrils of the nuclear network, i.e. the mitoma, take up certain dyes, their substance is called chromatin, and the fibrils are the chromosomes; while the inter-fibrillar substance not possessed of this character is called achromatin. Occasionally, also, the achromatin appears composed of fibrils, and these are then called 
secondary fibrils, as distinct from the chromosomes or primary filıils. Rabl and with him Heiclenhain maintain, however, that the achomatin in typical adult nuclei is always composed of fine tilurils, and that both the chromatin and achromatin fibrils possess a definite unipolar arrangenent and convergence, while Carnoy and van Gehuchten assume a bipolar arrangement. But this distinction holds good only for adult nuclei; in young nuclei the whole nuclear contents may possess this aftinity for the same dyes, and in this case the whole nucleus becomes uniformly stained. The nuclear membrane is a condensed outer stratum of the nuclear network. At the commencement of the division of the nucleus the membrane disappear's.

In some instances it can be shown that the nuclear fibrils are in continuity with the fibrils of the cell substance. In the moring white blood corpuscles Stricker and Unger have seen the nucleus becoming one with the cell substance, and again afterwards differentiated by the appearance of a membrane.

8. During division of the cell the nucleus generally divides before the cell protoplasm. This division of the nucleus was formerly supposed to occur in the same manner as that of the cell protoplasm-i.e. by simple cleavage. This morle is called the direct or amitotic division, or Remak's mode of division. In this division the nuclens is supposed to become constricted, kidney-shaped and lourglassshaped and, if the division is into more than two, lobed. Nuclei of these shapes are not unconmmon; but they need not necessarily indicate direct division, because, being very soft structures, pressure exerted from outside, or the motion of the cell protoplasm, may produce these shapes; and, further, the contractility of the nucleus may, and occasionally has been olserved to, cause these changes of shape. From the 
olservations of Schneider, Bütschli, Fohl, Strassburger, Mayzel, viun Benelen, Schleicher, Flenming, Rabl, and others, it is known that in the embryo and adult, in vertebrates and invertebrates, in all kinds of cells, both in the normal as well as morbid condition, the division of the cell protoplasm is preceded by complex changes of the nuclear mitoma, leading to the division of the nucleus (Fig. 10). The sum-total of these

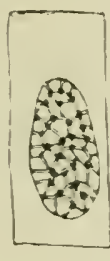

A

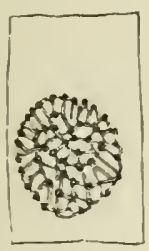

B

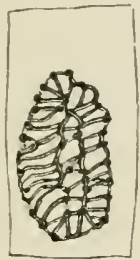

C

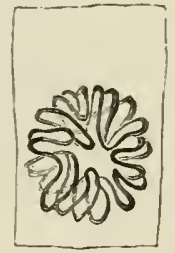

D

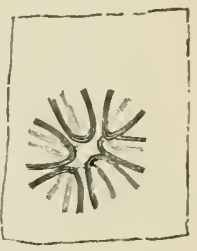

E

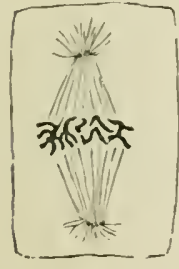

F
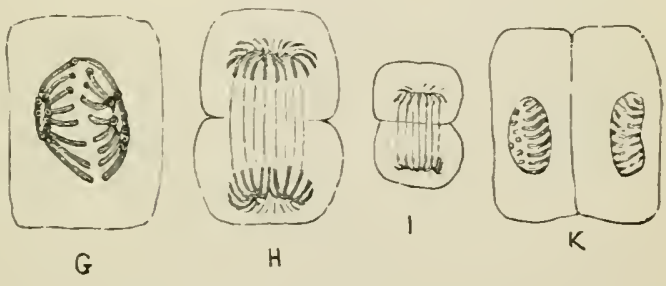

Fig. 10.-Karyomitosis.

A, Ordinary nucleus of a colmmnar epithelial cell: $\mathrm{B}, \mathrm{C}$, the same nucleus in the stage of convolution: D. the wreath, or roset te form; $\mathbf{E}$, the aster, or single star; F, a muclear spindle from the Descem't's endothelium of the fros's cornea ; G, H, I, diaster; $\mathrm{k}$, two daughter nuclei.

changes is called indirect division, karyokinesis (Schleicher) or kilryomitosis* (Flemming). Where this process occurs in its complete and typical form, the mitoma passes through the following phases (Flemming, Rabl) :

i. - Convolution or spireme or skein; disappearance of the nucleoli, increase of the fibrils constituting the

* Schleicher noticed that the fibrils during this process show morement; hence the name Karyokinesis. Mitosis indicates the grouping and changes of the fibrils ( i os $=$ fibril). 
chromatic substance, at the same time the fibrils become free, as it were, and bent and twisted at first into a clense, afterwards into a loose convolution. The fibrils of the loose convolution are thicker than before, less twisted, and more like masses of loops.

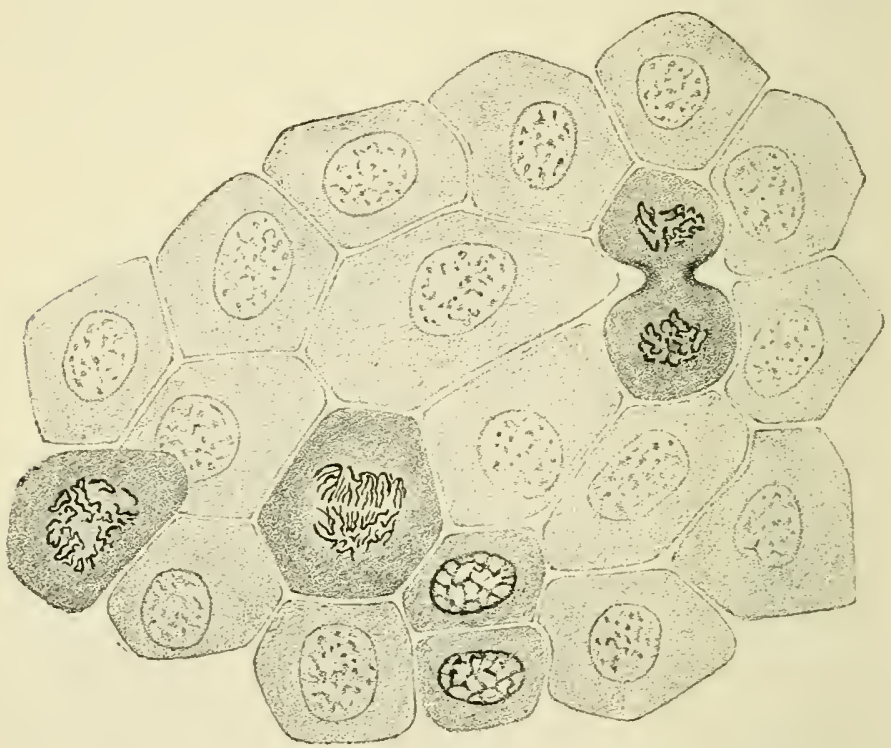

Fig. 11.-Epithelium of mouth of embryo salamanter, showing nuelei in varions stages of karyomitosis (Flemming).

These latter by cross division along the periphery of the mass increase in number, and thereby are converted into simple loops, arranged more or less like a wreath or rosette. The whole nucleus is larger than before, its membrane has disappeared, and it is surrounded by a more or less clear halo of cell protoplasm (Fig. 11).

ii.-Longitudinal division of the loops, each loop giving origin to a pair of sister loops; the whole, riewed from the surface, looks like a star of numerous fine fibrils, joined centrally so as to form single loops. 
iii.-The meclear spimelle, a spindle-shaped arrangement of tine threads of (possibly) achomatin extending between two opposite points of the cell protoplasm; these points are the poles, and the trimsverse line midway between them-i.e. at the

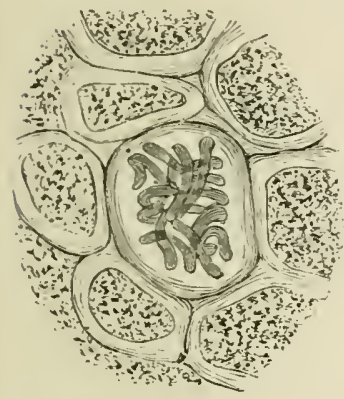

A

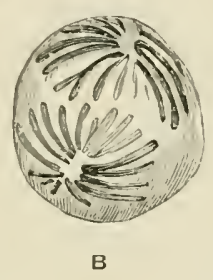

Fig. 12.--Karyomitosis. (Ajter Kolliker.)

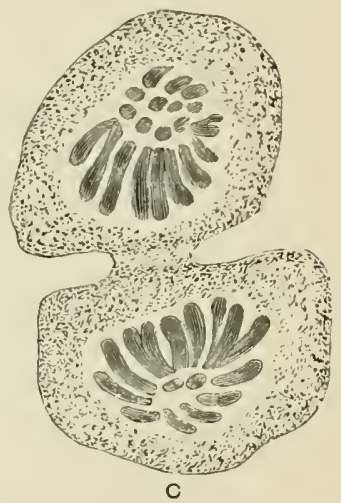

C

A, Spireme; B, diaster; $\boldsymbol{c}$, the nucleus has divided, the protuplism of the cell in the act. of dividing.

broadest part of the spindle-is called the equator. At each pole the threads of the spindle are connected with a granule of the cell protoplasm, the pole corpuscle or centrosome, mentioned on a previous page; from the centrosome radiate numerous fine fibrillie, connecting the centrosome or pole corpuscle with the cell protoplasm, thus forming "the suns" or attractionspheres, one at each pole (ran Beneden).

The above-named sister loops so ar'ange themselves about the equator of the spindle as to form a starthe mother-star, monaster, or aster. In this arrangement the vertex of the loops is directed inwards, the open limbs outwards. Seen in profile the aster would appear like a narrow granular-looking plate of chromosomes-the nuclear plate.

iv.-Metakinesis : Of each pair of sister loops forming the aster one loop is attracted by-i.e. migrates 
towards one, the other towards the other pole of the spindle: that is, towards the attractionspheres, the vertex of the loops always leading.

r-Dicister : arrived at the pole, the loops form again an aster or daughter star for each pole (Fig. 12).

ri.-Dispireme: the threads of each star become convoluted.

Now follows usually the division of the cell protoplasm in the line of the equator of the spindle.

vii.-In the last phase all traces of the spiridle are lost: a membrane appears around each of the two new nuclei, and the threads of the dispireme become branched and connected into a network.

From the foregoing it is clear that during division an intimate fusion between cell protoplasm and nucleus takes place: (a) by the fusion of the nuclear interstitial substance with the cell protoplasm after the disappearance of the nuclear membrane; and $(l)$ by the connection of the nuclear spindle with the centrosomes and attractionspheres, the fibrils of the latter being part of the cell protoplasm.

It ought to be mentioned, however, that some histologists do not regard the fibrils of the nuclear spindle as part of and derived from the original nuclear substance (achromatin). Boreri regards the fibrils of the spindle as derived from the cell protoplasm and as forming part of the attractionspheres -i.e. those fibrils which remain connecting the two attractionspheres, and which finally, after the nuclear division has been completed, by their transverse division, mark off and initiate the final stage - that is, the division of the cell body.

While these varions details and phases in the changes and division of the centrosome and attractionsphere are well enough marked in the orum, as is also their relation to the chromosomes of the dividing ovum nucleus, it is not sufficiently established that 
the above are of general occurrence in the division of arlult cells; the attractionsphere and its division have been observed only in a few such instances--e.g. in the lencocytes of salaminder and man.

In some cases the process of karyomitosis has been found to be atypical, inasmuch as some of the above phases are left out, as it were; while in other cases the nuclear division takes place already during the earlier phases--e.\%. in the phase of the spireme. When the nuclens divides into two or three or more nuclei without the cell protoplasm also undergoing division, a cell with two, three, or more nuclei is the result.

Multiplication of the nucleus by budding and direct fission has also been observed, but it is quite possible that this process is only as a sort of imperfect and abnormal karyomitosis.

This mode probalsly plays a more important part than the typical karyomitosis, whenever rapid multiplication and reproduction are necessary. Thus, for instance, while in the epithelium cells covering the anterior surface of the normal cornea of the newt and frog here and there a nucleus can be seen which shows the process of typical karyomitosis, such forms cannot be found in cases of rapid regeneration of that epithelium. For example, after removing the whole thickness of the anterior epithelium from the middle part of the cornea, rapid multiplication of the epithelium cells takes place, starting from those immediately around the defect; in consequence of this, in two or three days the defect becomes again quite covered with the new epithelium. Now, examining the epithelium cells at the margin of the defect, as well as those gradually pushed orer and covering the defect, none of the nuclei are found in any of the phases of typical karyomitosis; while a few days later, after the defect is covered by the new 
epithelium, there is no difficulty in fincling nuclei in one or another phase of the typical karyonitosis.

Paranuclei and cell cuclosures.-It was mentioned above that cells may and do inchude in their protoplasm formed substances like granules of various kinds, fat globules, pigment, etc. ; but in addition to these, and distinct from the attractionspheres mentioned on a former page, occasionally the cell substance includes corpuscles of an altogether different nature. These corpuscles, in size and staining power, resemble the cell nucleus or parts thereof, and as a matter of fact are derived from the cell nucleus. Balbiani has called such bodies in the orum cell paranuclei, and Gritzner has applied the same term to those that occur in the gland cells of the pancreas. Now it is a fact that preceding the segmentation of the ovum, and preceding the fusion of the spermand ovum-pronucleus, part of this latter is eliminated, and the same occasionally is observed to take place in other cells prior to the division of the nucleus, as also under various pathological conditions. The eliminated body or bodies, known as polar bodies, are part of the original nuclear substance, principally the chromatin. The paranucleus is as a rule smaller than the cell nucleus, lies close to this, and has similar affinity to the dyes which stain the nucleus itself. 


\section{CHAP'TER IT.}

BLOOD.

9. UxDER the microscope blood appears as a transparent Huid, the liquor sanguinis or plasma, in which float vast numbers of formed borlies, the blood corpuscles. The great majority of these are coloured ; a few of them are colourless. The latter are called white or colourless blood corpuscles, or leucocytes; the former are called red or coloured blood corpuscles, or blood-discs. They appear red only when seen in a thick layer; when in a single layer they appear of a yellow-greenish colour, more yellow if of arterial, more green if of venous, blood. The proportions of plasma and blood corpuscles are sixty-four of the former and thirty-six of the latter in one hundred volumes of blood. By measurement it has been found that there are a little over five millions of blood corpuscles in each cubic millimètre $\left(\frac{1}{1565}\right.$ of a cubic inch) of human blood. There appears to be in healthy human blood, on an average, one white corpuscle for 600-1200 red ones. In man and mammals the relative number of blood corpuscles is greater than in birds, and in birds greater than in lower vertebrates.

The number of red, and also of white, corpuscles is subject to variation, both in health and disease. After profuse hæmorrhage, the number of red corpuscles is temporarily greatly reduced, but in a short time, it may be even in twenty-four to forty-eight hours, they may approach again the normal number; 
in constitutional chronic diseases the number of red corpuscles is, as a rule, decreased ; so also in ancmia, spontaneous or following acute infectious diseases, ferer's. etc. The number of white corpuscles is always greater after a copious meal than during fasting. Certain diseases are associated with a decrease, others with an increase, of the white corpuscles of the circulating blood: the decrease when pronounced is spoken of as leucopenia, the increase as leucocythamia, leuccmia, or lencocytosis.

10. The red blood corpuscles (Fig. 13) of man and mammals are homogeneous bi-concare discs (except in the camelidx, where ther are elliptical), and do not possess any surrounding membrane or nucleus. Being bi-concare in shape, they are thinner and more transparent in the centre than at the periphery. In other rertebrates they are oval, and more or less flattened from

A

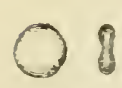

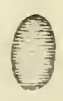

B

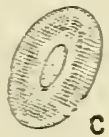

c
Fis. 13. - Various kinds of Red Blood Corpuseles.

A, Two human, one seen flat, the other edgewas: : $B$, a red curluscle of the camel: $c$, two red corpuscles of the fros, ome seen from the liroad, the other from the narrow side. side to side, and each possesses a central oral nucleus.

The diameter of the human red blood corpuscle is about $\frac{7}{300}$ of an inch in breadth, i.e. about $7 \cdot 8 \mu$, and its thickness about $\frac{1}{12000}$ of an inch. But there are always corpuscles present which are much smaller by about one-third to one-half than the others-miciocytes. In normal blood these microcytes are scarce; but in certain abnormal conditions, especially in pernicious anæmia, they are conspicuous by their number.

According to Gulliver, Welcker, and others, the following are the arerage diameters of the red blood corpuscles of various vertebrates: Man, $\frac{1}{3200}$; dog, $\frac{1}{3300}$ : cat, $\frac{1}{4000}$; sheep, $\frac{1}{5000}$; elephant, $\frac{1}{27 \overline{5}}$; 


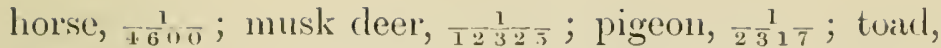
$\frac{1}{10+3}$; newt, $\frac{1}{11}$; proteus, $\frac{1}{400}$; pike, $\frac{1}{2000}$; shark, 112.

11. In a microscopic specimen of fresh mualtered blood (Fig. 1t) the red blood corpuscles form peculiar short or long rolls, like so many coins, from becoming adherent to one another by their broad surfaces. Under various conditions - such as when isolated, or when blood is diluted with a $7 \cdot 5-1$ p.c. saline solution or solutions of other salts (sulphate of sodium $\mathrm{Ol}^{\circ}$ magnesium) - the corpuscles lose their smooth circular outline, shrinking and becoming crenute
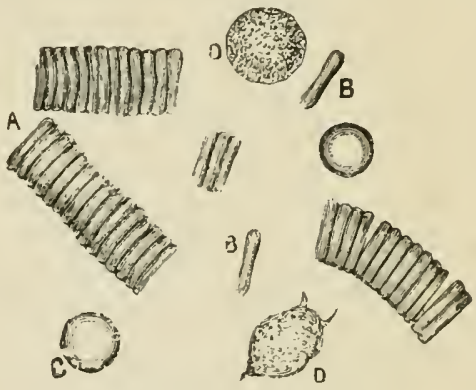

Fig. 14.-Human Blood, fresh.

A, Rouleaux of red corpuscles; $B$, isolated red corpuscle seen in profile ; $\mathrm{c}$, isolated red iorpuscle seen flat; D, white corpuscles.

(Fig. 15, a). In a further stage of shrinking they lose their discoid form, and become smaller and spherical, but beset ali over their surface with minute processes. 'This shape is called the horse-chestnut shape (Fig. 15, $b, c)$. It is probably due to the corpuscles losing carbonic acid, as the addition of the acid brings back their discoid shape and smooth circular outline. On abstracting the carbonic acid they return to the horse-chestnut shape. Water, acid, alcohol, ether, the electric
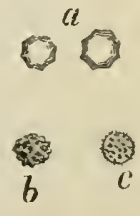

Fig. 15.-Human Red Blood Corpuscles.

$a$, Crenate; $b, c$, horse-chestnutsliaped. current, and many other reagents, produce decoloration of the red blood corpuscles, the coloured matter-generally the combination of the blood-colouring matter with globulin, known as hcemoglobin-becoming dissolved in the plasma. 
What is left of the corpuscles is called the stroma. In newt's and frog's blood a separation of the stroma from the nucleus and hremoglohin cin

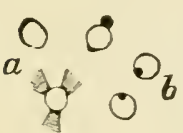

A

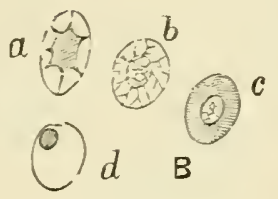

Fig. 16.-Red Blood Corpuscles of Man and Newt.

A, Human red corpuscles after the action of tannic acid; $a$, three red corlus =cles, from which the hamuglohin is pass. ins out: $b$, lioberts's corpuscles. B,

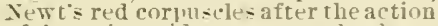
of horacic acjd: $a$. colvuscle showing Bricke's zooid and oekoid: $b$. corpuscle showing the reticulated stroma; $c$, corpuncle shoming the reticulum in the nucleus; $d$, the nucleus passing out. be effected br means of boracic acid (Fig. 16, в); the former is called by Briicke the rekoid, the latter zooid. This stroma contains amongst other things much paragiobulin. The stroma of the corpuscles of amphibians is seen, under certain reagents, to be of a reticulated structure, but in the fresh state appears homogeneons and pale. Decoloration of the blood corpuscles can also be observed to take place in blood spontaneously without the addition of any reagents or with that of indifferent fluids, such as the aqueous humour of the ere, hydrocele fluid, etc. The number of corpuscles undergoing decoloration under these conditions is, howerer, small.

When blood is dried on a grlass in a thin tilm, the corpuscles, forming a single layer only, dry on before they shrink, and thus retain their natural size and outline; their stroma can then be easily stained with aniline dyes.

12. The hamoglobin of the red blood corpuscles forms crystals ( $\mathrm{Fig} .17$ ), which differ in shape in various mammals. They are always of microscopic size, and of a bright red colour. In man and most mammals they are of the shape of prismatic needles or rhombic plates: in the squirrel they are hexagronal plates, and in the gruinea-pig they are tetrahedral or octahedral.

The blood pigment itself is an amorphous dark- 
brown or black pow der-the hamatin; but it can be obtained in a clystalline form, as hydrochlorate of hamatin (Fig. 18). These crystals also are of microscopic size, of a nut-brown colour, of the shape of nallow rhombic plates, and are called hamin $c r^{\prime} y$ stals, or Teichmann's crystals. In extravasated human blood, crystals of a bright yellow or orange colour are occasionally
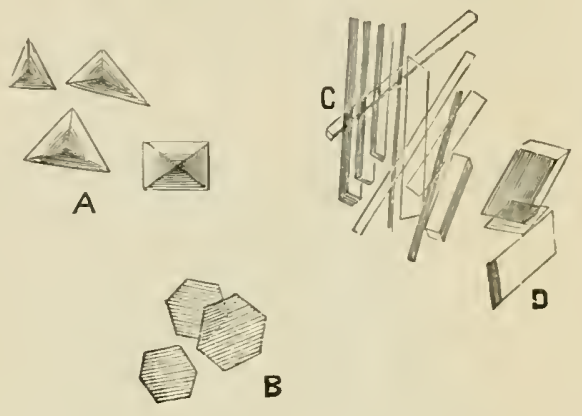
met with; they are called by Virchow, their cliscoverer', hamatoidin. They are supposed to be identical with bilirubin, obtainable from human bile.

13. The white or colourless corpuscles, or Icucocytes, are in human blood of about $\frac{1}{200}$ to $\frac{1}{500}$ of an inch in diameter $-i e$. about $10 \mu$-and are

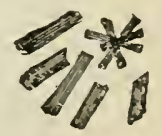
spherical in the circulating blood or in blood that has just been removed from the ressels. Their substance is transparent granular-looking protoplasm, some containing larger or smaller distinct granules. These granules are not all of the same nature, as will presently appear. In some kinds of blood, notably horse's, they are of a reddish colour, and these corpuscles were supposed by some observers (Semmer and Alexander Schmidt) to be intermediate between red and white corpuscles. The protoplasm of the colourless corpuscles contains occasionally glycogen (Ranvier, Schäfer). In the blood of the lower vertebrates the colourless corpuscles are much larger than 
in mammals. But in all cases they consist of protoplasm (spongioplasm and hyaloplasm), include one, two, or more nuclei, and show ammboid movement. This may be observed in corpuscles withont any addition to a fresh microscopic specimen of blood, but it always becomes much more pronouncerl on

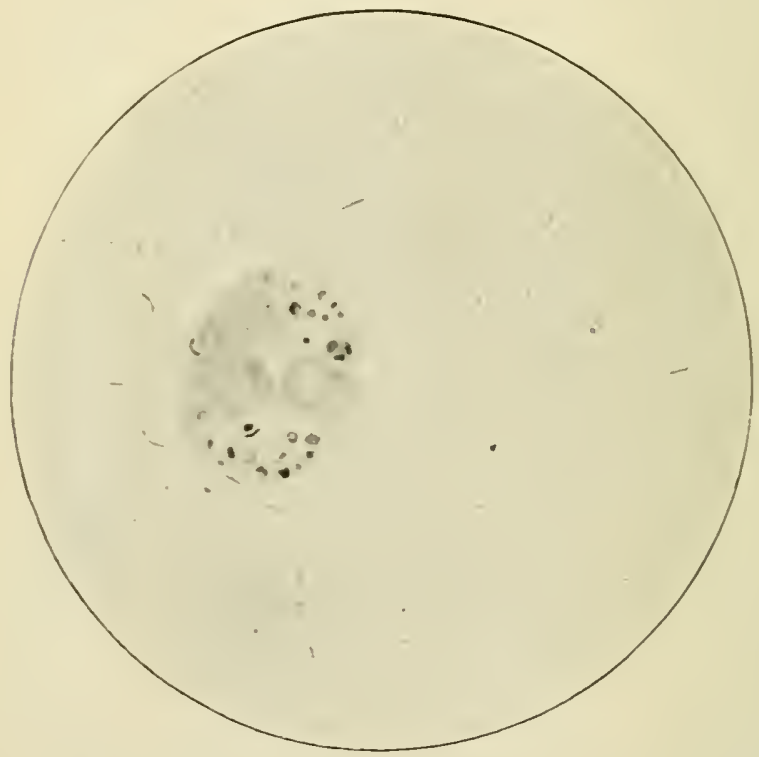

Fig. 19.-Phagneyte (with three nuclei) from the peritoneal fluid of a guinea-lig, loreriously injected intraperitoneally with cholera culture. The interior of the pharocyte contains mumerous degenerated connua bacilli. (Photo. highly magnified.)

applying artificial heat of about the degree of mammals' blood. It is then seen that either they throw out longer or shorter filamentous processes, which may gradually lengthen or be withdrawn, or the corpuscle changes its position either loy a flowing movement, or it pushes out a filamentous process and shifts its body into it. During this movement the corpuscle may take up granules from the 
surromding fluid. Lencocytes, be they in the blood or in comnective tissue or lymph glands (see below), that can, and in certain circumstances do, take up granules or similar matter are spoken of as pluegocyles (eating cells) (Figs. 19, 20). Division by simple

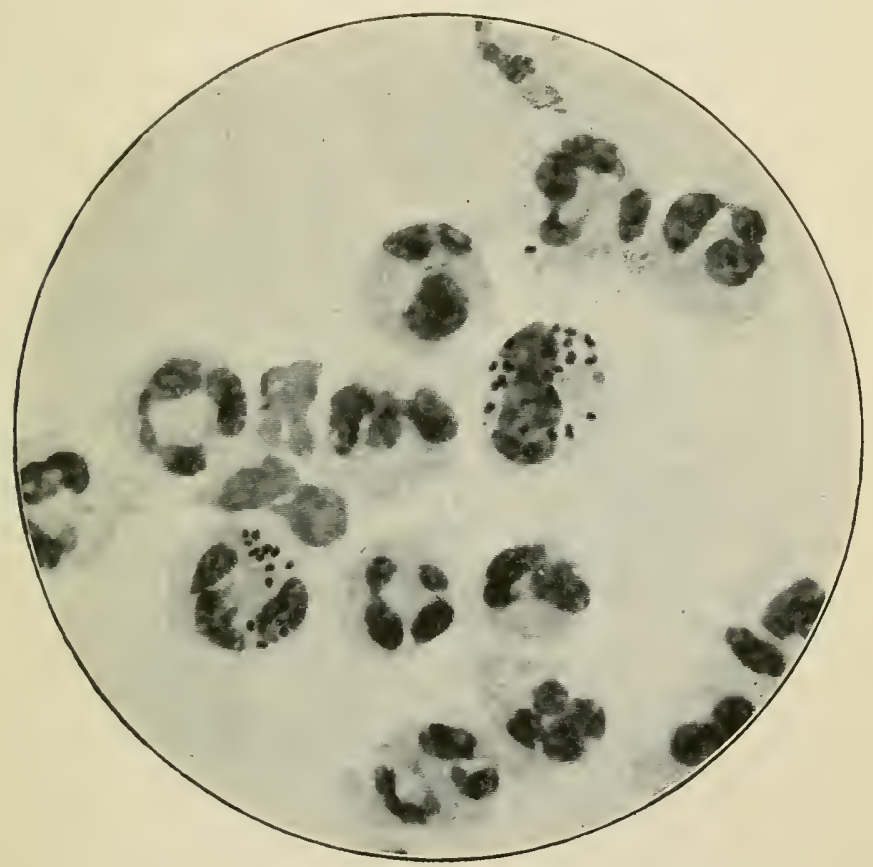

Fig. 20.-Hyaline Lencocytes (pus cells) from purulent matter'; the leucocytes contain in their hyaline protoplasm two, three, or nore nuclei two of the cells contain in their protoplasm a number of cocci, these cells acting as phagocytes. (Photo. highly magnified.)

clearage of leucocytes of the blood of lower vertebrates has been directly observed by Klein and Ranvier.

14. The white corpuscles or lencocytes in the same sample of blood differ in size and aspect. They may be classed into three groups: (a) The lymphocyte, 
a small cell possessed of a relatively large single nucleus surrounded by a narrow zone of protoplasm. (b) The typical leucocyte or hyaline leucocyte is larger than the former, contains two, three, or even four relatively small nuclei; its cell protoplasm appears liyaline, but includes a spongy network. This leucocyte is

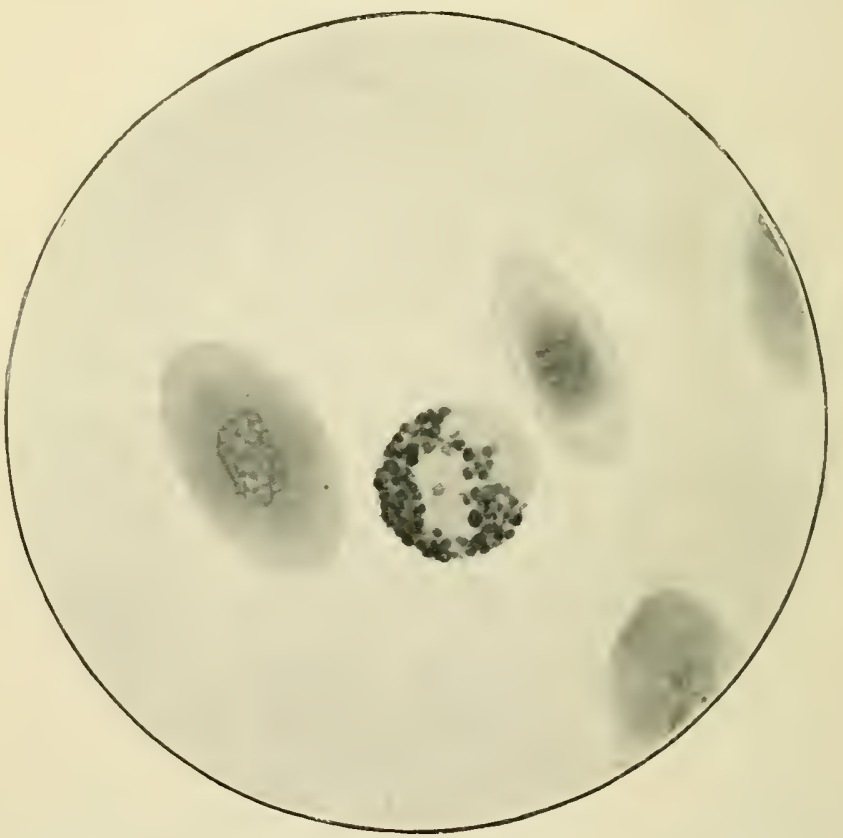

Fig. 21.-Frog's Blood, slowing red blood dises and one oxylhile white cell. (Photo. highly magnified.)

as regards numlers by far the predominating white corpuscle, and its amwboid movement is very striking. (c) The granular" leucocyte forms a small minority, it contains a single large nucleus, occasionally two, and its cell protoplasm contains conspicuous grinules.

The lymphocytes are identical with similar corpuscles of the adenoid tissue of lympli glands, from 
which in all probability they are derived. It is highly probable that they are young forms of the typical leucocytes. The gramular lencocytes-i.e. the white corpuscles that contain real granules-behave differently when subjected to staining with aniline dyes. In some the granules stain readily with acid aniline dyes-e.g. eosin-so that they become bright red-eosinophite (Ehrlich) or oxyphile cells (Fig. 21); in others the granules stain only in basic aniline dyes -basophile cells; in still others they stain both with acid and alkaline aniline dyes-nevitroplite or amphophile. What the exact relation of these different granule-cells amongst themselves and to the nongranular or hyaline cells is, is not definitely established. But it appears from the researches of Kanthack and Hardy that in the frog, at any rate, and probably also in the mammal, the oxyphile or eosinophile leucocyte does not act as a phagocyte, and that this function is monopolised by the other or hyaline variety of leucocytes.

15. In every microscopic specimen of the blood of man and mammals are found a variable number of large granules, more or less angular, singly or in groups. According to Max Schultze they are derivatives of broken-up white corpuscles; but according to Bizzozero, they are present already in the living and fresh blood, as pale, circular, or slightly oval dises (Fig. 22, b). Their size is only $\frac{1}{4}$ to $\frac{1}{3}$ of that of the red blood corpuscles. They are called by him b7ood platelets, and he supposes them to be of

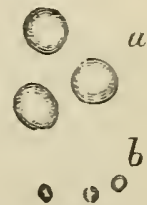

Fig. 22.-Human Bloni.

a, Red rinorl corpustscles: $b$, hlooul platelets of Bizzuzero. essential importance in the coagulation of the blood, originating the tibrin ferment. Hayem described them previously as being intermediate forms in the derelopment of red blood corpuscles, and called them hæinatoplasts, 
16. Development of bloud corpuscles.At an early stage of embryonic life, when blood makes its appearance it is a colourless fluid, containing only white corpuscles (each with a nucleus), which are derived from certain cells of the mesol,last. These white corpuscles change into red ones; the protoplasm becomes homogreneous and rellow; then it assumes it flattened shape, and is in reality a coloured blood corpuscle containing a pale nucleus. All through embryonic life new white corpuscles are transformed into red ones. In the embrro of man and mammals these red corpuscles contain their nuclei for some time, but ultimately lose them. New red blood corpuscles may, howerer, be formed also by division of nucleated red corpuscles. Such division has been observed even in adult blood of lower rertebrates (Peremeschko) as well as in the fretus of mammals.

The cells of the mesoblast which give origin to vessels (crsts and strands) are capable of producing by budding and cleavage new white cells, which ultimately change into red corpuscles. (See formation of blood-ressels.)

An important source for the new formation of red corpuscles in the embryo and adult is the red marrow of bones (Neumann, Bizzozero, Rindfleisch), in which numerous nucleated protoplasmic cells (marow cells) are converted into nucleated red blood corpuscleserythroblasts. The protoplasm of the corpuscle becomes homogeneous and tinged with vellow, the nucleus being ultimately lost. The spleen is also assumed to be a place for the formation of red blood corpuscles. Again, it is assumed that ordinary white blood corpuscles are transformed into red ones, but of this there is no conclusive evidence. In all these instances the protoplasm becomes homogeneous and filled with hæmoglobin, while the cell grows flattened, discoid, and the nucleus in the end disappears. 
Schüfer described intracellular (endogenous) formation of red blood corpuscles at first as small hiemoslobin particles, but soon growing into red blood corpuscles in certain cells of the subcutaneous tissue of young animals. Malassez describes the red blood corpuscles originating by a process of continued budding from the marrow cells.

The white corpuscles appear to be derived from the lymphatic organs, whence they are carried by the lymph into the circulating blood. 


\section{CHAPTEP I I I.}

EPITHFLICY.

17. Epithelial cells (Fig. 23) are nucleated piotoplasmic cells forming continuous musses on the surface of the skin, of the lining membrane of the alimentary canal, the respiratory organs, the urinars and genital organs, the free suriace of the conjunctiva, and the anterior surface of the cornea. The lining of the tubes and alreoli of secreting and excreting glands, such as the kidney, lirer, mammart gland, testis and orary, the salivary glands, mucors: peptic, and Lieberkuhn's glands, the sweat and sebaceous glands, the hair follicles, etc., consists of epithelial cells. Such is the case also with the sensors or terminal parts of the organs of the special senses. And, finally. epithelial cells occur in other organs, such as the thrroid, the pituitary body, etc.

The hairs and nails, the cuticle of the skin, certain parts of the rods and cones of the retina, and the rods of Corti in the organ of hearing, are modified epithelial structures.

Epithelial cells are grouped together by exceedingly thin lasers of an albuminous interstitial cement substance, which during life is of a semifluid nature, and belongs to the group of bodies known as globulins.

18. A- regards shape, we distinguish two kinds of epithelial cells-columnar and squamous. The columinar cells are short or long, crlindrical or prismatic, prramidal, conical, club-shaped, pear-shaped, 
or spindle-shaped ; their nucleus is always more or lesis oval, their protoplatsm more or less longitudinally striated, being a spongrgereticulum with predominantly longitudinal arrangement. (On the fiee surface of the cells -i.e. the part facing a carity, canal, $\mathrm{rr}^{2}$ general surface-in many instances a bright thimmer or thicker cuticulas structure is seen, with more or less distinct vertical striation. The conical or spindle - shaped, club - shaped, and pear-shaped cells are drawn out into longer or shorter single or branched extremities.
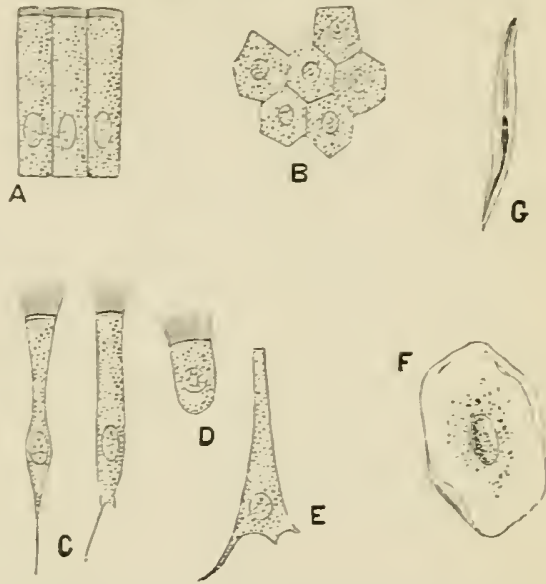

Fig. 23.- Various kinrls of Epithelial Cells.

A, Cislumnar cell of intestine: B. polrhedral cells of the conjunctiva; $c$, ciliated conical cells of the trachea: $\mathrm{D}$, ciliated cell of frog's mouth; $\mathbb{E}_{2}$ inverted conical cell of trachea; F, squamous cell of the carity of mouth, seen from its broal surface; $G$, squamous cell, seen edgeways.

The squamous or parement cells are cubical, polyhedral or scaly. The nucleus of the former is almost spherical, that of the latter tiattened in proportion to the thinness of the scales. In polyhedral cells it can be shown that the uniform granulation is due to the regular honercombed nature of the cell protoplasm.

19. As regards size, the epithelial cells differ considerably from one another in different parts, and even in the same part. Thus, the columnar cells, covering the surface of the villi of the small intestine, are considerably longer than those lining the mucous membrane of the uterus : the colummar cells lining the larger ducts of the kidney are considerably longer' 
than those lining the small ducts; the polyherlial cells corering the anterior surface of the colnea are considerably smaller than those on the surface of the lining membrane of the urinary bladrler: the scales lining the ultimate recesses of the bronchial tubes-
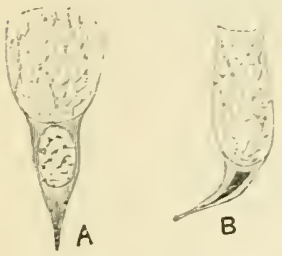

Fig. 24. - Three Mucus-secreting Goblet Cells.

A, From tle -tomach of newt; $B$, from a mucous slanil; $c$, from the - ur face of the inncou: membrane of the intertine.

the air cells-are considerably smaller than those on the sinface of the rnembrane lining the human oral cavity and resophagus (Fig. 2t). 20. As regards

a1-

rangement, the epithelial cells are arranged as a single layer or are stratified, forming several superposed layers; in the former case we have a single-layered, in the latter a stratified epithelium. The simple epitheliun may be composed of squanous cells, simple squamous or simple parement epithelium; or it nay be composed of columnar cells, simple columnar epithelium. The stratitied epithelium may be stratified parement or stratified columnar; in the former case all or the majority of the layers consist of squamous or polyhedral cells; in the latter all cells belong to the columnal kind. Simple squamons epithelium is that which lines the air cells, certain urinary tubules of the kidney (the looped tubes of Henle, the cortical parts of the collecting tubes), the acini of the milk-gland, the inner surface of the iris and choroid membrane of the eyeball. Simple columnar epithelium is that on the inner surface of the stomach, small and large intestine, uterus, small bronchi, ducts and acini of mucous and salivary glands, of some kidney tubules, etc. Stratified parement epithelium is that on the epidermis, the epithelium lining the carity of the mouth, pharynx, 
and asophanus in man and mammals, the anterior surfice of the cornea, etc.

Functionally, epithelium can be classified as: (a) tegmental-o.g. the epiclermis of the skin, the epithelium of mucous membrane; $(b)$ as secretory-e.g. the epithelium lining the alveoli and tubes of secreting glands, the liver, the kidney; etc.; (c) sensory - e.g. the epithelial-like cells forming the terminal organs of nerve fibres-e.g. in the retina, in the organ of hearing (cochlea, restibule, and semicircular canals of the internal ear'), in the taste buds, in the olfactory membrane, and in the skin ; $(d)$ forming special horny organs-e.g. hair's, nails, the horny papillie on the tongue of feline animals : (e) some specific, not well-understood function-e.\%. the epithelium covering the glomeruli of the Malpighian corpuscles of the kidney, the epithelium (or endothelium) forming the wall of bloodcapillaries and lrmph vessels.

21. The epidermis (Fig. 25) consists of the following lavers:-(a) Stratum comenme this is the superficial horny layer, and it consists of several layer's of horny scales, without any nucleus. Its layers are separated from one another by narrow clefts containing air, and they are in process of desquanation. This stratum is thickest on the palm of the hand and finger's and the sole of the foot. (b) The stratum tucidum, composed of sereral dense layers of horny scales, in which traces of an exceedingly flattened nucleus may be perceived. (c) Then follow many layers of nucleated cells, forming the stratum or rete Malpighii or rete mucosum. The most superficial layer or layers of it are flattened scales, which are characterised by the presence around the nucleus of globular or elliptical granules of the nature intermediate between protoplasm and keratin. Their substance is called eleidin by Ranvier, keratohyalin by Waldeyer ; these 
cells form the stratum :ranulosum of Lingerhans. Deeper down, the cells are less tlattened

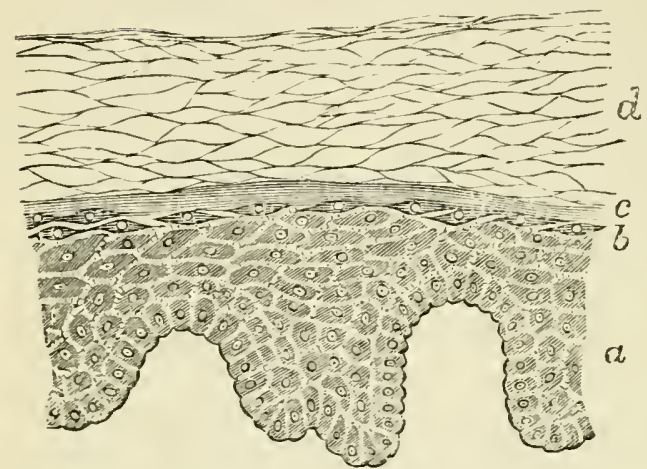

Fig. 25. - From a Vertical Section through the Epidermis. (Atlas.)

$a$, The stratum Malujghii; $b$, the stratum granulo-um; $c$, the stratum lucidum; $d$, the stratum corneum. a $\mathrm{nd}$ more polyhedral, and thedeepest form a layer of more or less columnar cells, placed rertically on the surface of the subjacent corium.

The substance of the hairs, nails, claws, lioofs, consists of

horny scales. (See chapter on Skin.)

2.2. The
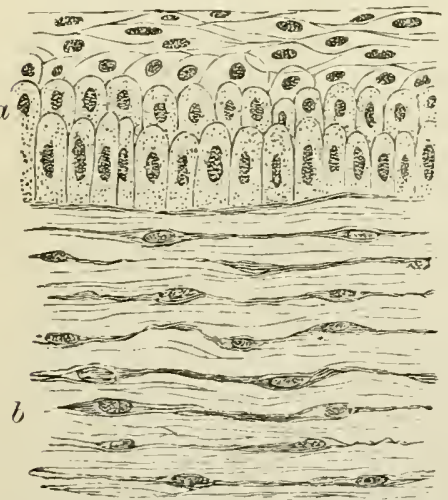

Fig. 26.-From a Vertical Section through the anterior layer's of the Cornea. (Handbook.)

$a$, The stratified pavement epithelium: $b$, the substantia propria, with the cormeal corpuscles between its lamellix.

\section{bavenent}

limun (Fig. the cavity of the mouth, the surface of the tongue, the pharynx and cesophagus of man and mannmals, and the anterior surface of the cornea, etc., is, as regards the style and arrangement of the cells, identical with the stratum Mirpighii of the epiclermis. The cell protoplasm is more transparent in the. former, and the granular cells of the stratum 
granulosum are not always present, but they generally are in the epithelium of the tongue and of the rest of the oral carity. The most superficial scales show more or less liorny transformation.

23. Stratified colmunar epithelium is met with on the lining membrane of the respiratory organs: in the larynx, trachea, and large bronchi. It consists of several layers of columnar cells; a superficial layer of conical or prismatic cells, with a mare or less pointed extremity directed towards the depth; between these are inserted spindle-shaped cells, and finally inverted conical cells.

The epithelium of the ureter and bladder is called transitional epithelinm. It is stratified, and the most superficial layer consists of polyhedral cells. Underneath this is a layer of club-shaped cells, between which extend one or more layers of small spindleshaped cells.

Amongst the columnar epithelial cells occurring in man and mammals the ciliated cells and the goblet cells, and amongst the squamous cells the prickle cells, deserve special notice.

24. Ciliated cells are characterised by possessing a bundle of very fine longer or shorter lairs or cilia on their free surface. These cilia are direct prolongations of the cell protoplasm. More correctly speaking, the cilia are continuous with the filaments or strice of the cell protoplasm. The superficial layer of conical cells of the epithelium in the respiratory organs, the columnar cells lining the uterus and oviduct, and the columnar cells lining the tubes of the epididymis, possess such cilia. In lower vertebrates the ciliated cells are much more frequently observed; in Batrachia the epithelial cells lining the mouth, pharynx, and resophagus are ciliated.

While fresh in contact with the membrane which they line, or even after removal from it, provided the 
cells are still alive, the ciliated cells show a rapid synchronous whip-like movement of their cilia, the cilia of all cells moving in the same direction. The morement ceases on the death of the cell, but may become slower and may cease owing to other causes than death, such as coagulation of mucus on the surface, want of sutficient oxygen, presence of carbonic acid, low temperature, etc. In these circumstances, removal of the impediment, as by dilute alkalies, will generally restore the activity of the cilia. IIoderate electric currents and heat stimulate the morement, strong electric currents and cold retard it. Reagents fatally affecting cell protoplasm also stop permanently the ciliary action.

25. Goblet or chalice cells (Figs. 24, 27) are cells of the shape of a conical cup. The pointed part is directed away from the free surface, and contains a compressed triangular nucleus surrounded by a trace of protoplasm. The body of the

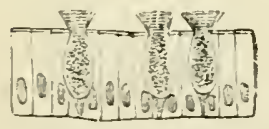

Fig. 27.-From a Tertical section through the Epithelium on the surface of the mucous membrane of the large intes. tine.

Three goblet cells are seen pouring out their mucus. The rest are ordinary columnar cells.

\section{are goblet cells.}

The protoplasm of colummar cells facing a free surface, no matter whether in simple or stratified epithelium, ciliated or non-ciliated, may undergo such alteration as will lead to the transformation of the cell into a mucus-secreting goblet cell. This takes place during life, and corresponds to an important function of columnar epithelial cells-viz. 
the formation of mucus. In mucus-secreting glinds all the epithelial cells have this function permanently, but in ordinary columnar epithelium only a comparatively small number of the cells, as a rule, unclergo this change, and then only temporarily; for a cell subject to it at one time may shortly afterwards resume the original shape and aspect of an ordinary protoplasmic, cylindrical, or conical epithelial cell, and vice versâ. If ciliated celis undergo this change, the cilia are generally first detached.

It can be shown that in this change of an ordinary columnar epithelial cell into a goblet cell the interstitial substance of the cell reticulum swells up and increases in amount, the meshes enlarging and distending the body of the cell. The middle and upper part of the cells then change, first into mucigen, and finally into mucin, which is eventually discharged, leaving in the deeper part the compressed nucleus surrounded by a trace of protoplasm behind (see Fig. 3t).

26. Prickle cells (Fig. 25).-Amongst the middle and deeper layers of the stratified parement epithelium, such as is present in the epidermis and on the surface of the oral carity and pharynx, we meet with a close, more or less distinct and regular striation, extending from the margin of one cell to that of each of its neighbours, by means of fine transverse short fibrils which, passing from protoplasm to protoplasm, connect the surfaces of the cells.

27. Pigmented epithelial cells-i.e. epithelial cells filled with black pigment particles (crystals) - are found on the internal surface of the choroid and iris of the eyeball.

In coloured skins, and in coloured patches of stin and mucous membrane, such as occur in man and animals, pigment in the shape of clark granules is found in the protoplasm of the deeper epithelial cells, as well 
as in branched cells situated between the epithelial cells of the deeper layers. Minute branched nonpigmented nucleated cells are met with in the interstitial or cement substance of various kinds of epithelium, simple and stratified-e.g. epidermis, epithelium of oral cavity, cornea, etc.

2.8. Epithelial cells undergo division, and by this means a constant regeneration takes place. In those parts where the loss of the superficial layers of cells is conspicuous, such as the epidermis, the stratified epithelinm of the tongue and oral carity, the sebaceous follicles of hairs, the regeneration goes on more copiously than at places where no such conspicuous loss occurs-as, for instance, in the stomach and intestines, the secreting glands, or sense organs.

In the stratified pavement epithelimm it is the cells of the deepest layers which chiefly divide. As a rule, this division takes place transversely in the cylindrical cells, but may also occur longitudinally (A. Kollmann). The epithelial cells next to the deepest laser of columnar cells are to a great extent the result of the division of the latter, and as this proceeds there is a gradual shifting of the older cells towards the surface and a simultaneous flattening of the cell protoplasm as well as the nucleus.

29. The interstitial substance between, and the protoplasm of, the epithelial cells being a soft flexible material, the cells can change their shape and arrangement owing to pressure exerted on them by the contraction or distension of the subjacent nembrane. Thus the epithelium lining a middle-sized bronchus at one time appear's composed of thin colummar cells in two layers; at another, as a single layer; or again, as a single layer of short colummar cells: in the first case the bronchus is contracted, in the second in a medium state of distension, in the third much distended. Similar changes may be noticed in the 
epithelium lining the bladder and the stratum Malpighii.

The interstitial substence, being a soft, semi-fluid substance, represents the paths through which granules and formed particles may find their way from the free surface into the membrane beneatl, or vice versî. Also lencocytes pass out in certain localities from the membrane underneath, between and into the substance of epithelial cells, and may finally be discharged on to the free surface-e.g. in the tonsils, in the fances and pharynx and larynx. Epithelial cells may in this way inclucle in their substance various formed particles: granules, fat globules, leucocytes, nuclei of leucocytes, etc. Besides these cell enclosures and the paranuclei and chromatin granules mentioned in a former paragraph, in some localities (e.g. stratum Malpighii of the epidermis, epithelium of the oral cavity, pharynx and asophagus) the epithelial cell substance undergoes a partial or total change into keratinous substance, keratohyalin, forming a mantle around the unchanged cell protoplasm like a capsule. 


\section{CHAPTER IV.}

\section{ENDOTHELIU.I.}

30. The free surfaces of the serous and synovial membranes, and of those of the brain and spinal cord, the posterior surface of the cornea and anterior surface of the iris, the surfaces of tendon and tendonsheaths, the lympli sinuses or lymph sacs of amphibian animals, the carity of the heart, of blood-ressels and of lymphatic ressels, are lined with a continuous

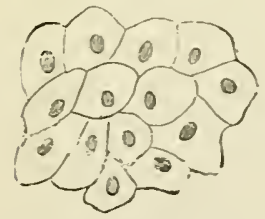

Fig. 2S.-Endothelium of the Mesentery of Cat.

The outlines of the endothelial cells and the nucleus of the latter are well shown.

endothetial membrane, composed of a single layer of flattened transparent squamous cells, called endothetial cells (Fig. 28). Each contains an oval nucleus, situated as a rule excentrically. 'Just as in the case of epithelium, the enclothelial cell plates are joined by a fluid or semi-fluid homogeneous interstitial or cement substance of the nature of globulin. When examining any of the above structures fresh, the endothelial cells are not, as a rule, visible, owing to their great transparency; but by staining the structures with a dilute solution of nitrate of silver, and then exposing them to the influence of the light, the cement substance appears stained black, whereby the shape and size of the cell plates become ericlent. By various dyes also the nucleus of each cell plate may be brought into view.

On careful examination, and with suitable reagents, it can be shown that each endothelial cell 
comsists of a homogeneous ground plate. In it lies the nueleus. and alound it is a substance which appeat's cranular: but which is of a fibrillar nature, the fibrillit being arranged in a network, and extending

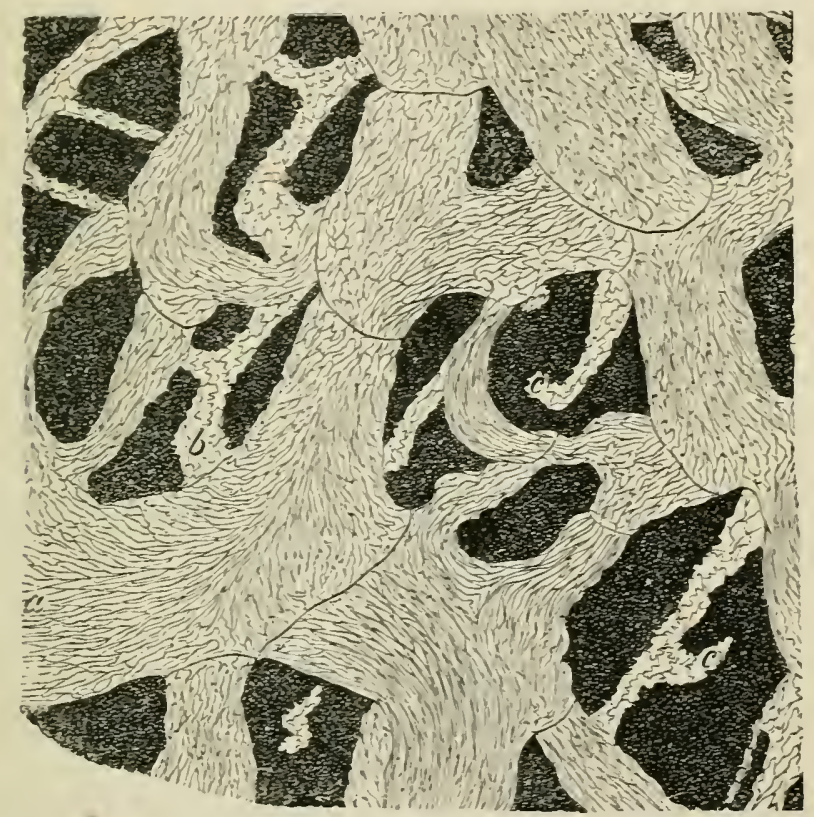

Fig. 20.- Tetwork of Lymplatics in the Central Tendon of the Diaphragm of Rabbit, prejared with nitrate of silver, so as to show the outlines of the Enclothelial Cells forming the wall of the Lymphatics. (Hundbool:) $a$, Iarge lymphatic ressels; $b$, lrmphatic capillaries ; $c$, apparent ends of the capi laries.

in many places up to the margin of the ground plate. The nucleus is limited by a membrane, and contains a well-developed reticulum. The fibrillæe of the cell substance appear to be connected with the nuclear reticulum.

31. As regards shipe, endothelial cells differ considerably. Those of the plenra, pericardium, peritoneum, and endocardium of man and mammals are 
more or less polygonal, or slightly elongated. 'Their' outlines rary; in the lining of the lymph sacs of the frog they are much larger, and of very sinuous outline; while those of the posterior surface of the cornea

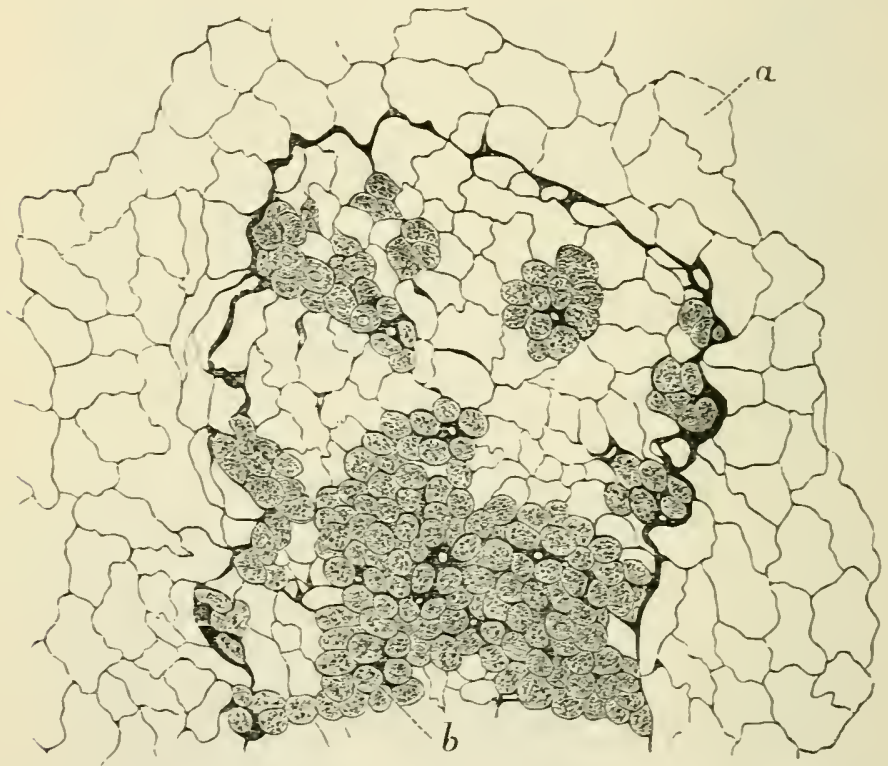

F'ig. 30.-Onentum of Rabbit, stained with Nitrate of Silver. (Atles.) (1. Ordinars flat enduthelial cells; $b$, germinating cells.

are very regular, pentagonal, or hexagonal, having straight outlines in the perfectly normal and well-preserved condition, but serrated and sinuous after they have been prepared with various reagents and in the abnormal state; the endothelial plates lining the bloodressels and lymphatic vessels (Fig. 29) are narrow and elongated, with more or less sinuous outlines. In the lymphatic capillaries the endothelial plates are polygunal, but their outline is serrated.

32. As a rule, the endothelial cells are flattened- 
i.e. scaly-but in some places they are polyliedrat, or even short columnar. Such cells occur isolated or in small groups, or corering large and small patches, nodular, villous, or cord-like structures of the pleura

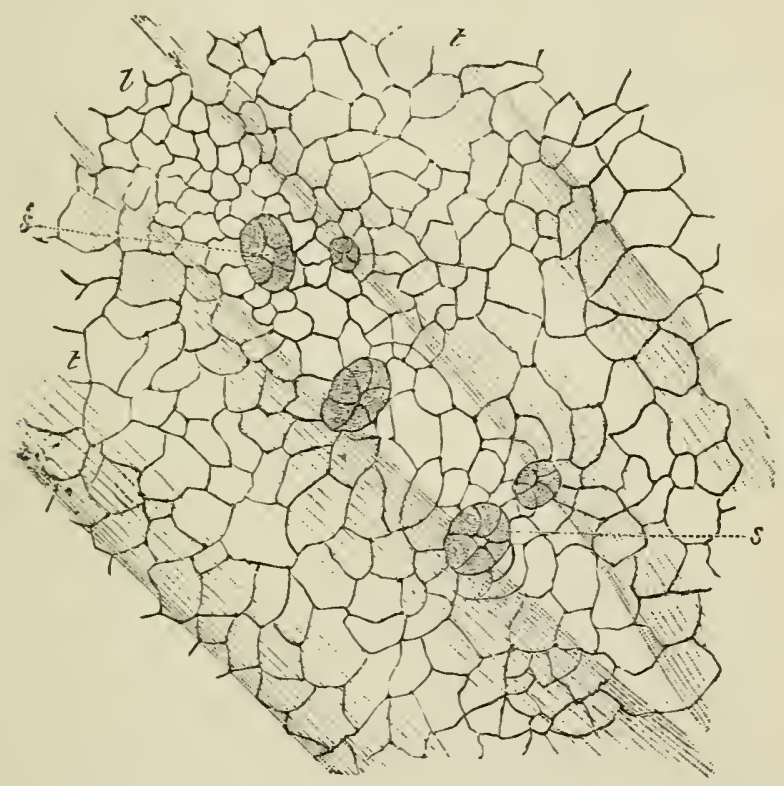

Fig. 31. - Part of Peritoneal Stirface of the Central Tendon of Diaphragm of Rabbit, prepared with Nitrate of Silver. (Handbook.)

$s$, Stomata; $l$, lymph-channels; $t$, tendon hundles. The surface is covered with endothelium. The stomata are surrounded by germinating enduthelial cells.

and omentum, on the synovial membranes, tunica vaginalis, testis, etc. They are especially oluservable in considerable numbers in the pleura and omentum (Fig. 30) of all normal subjects (in man, ape, dog, cat, and rodent animals) ; their number and frequency of occurrence are increased in pathological conditions (chronic inflammations, tuberculosis, cancer; etc.).

These endothelial cells are the germinating endo. thelial cells, and they can be shown to be in an 
active state of division. They thus produce small spherical lymphoid (amœboid) cells, which ultimately are absorbed by the lymphatics, and carried into the blood system as white blood corpuscles. On the

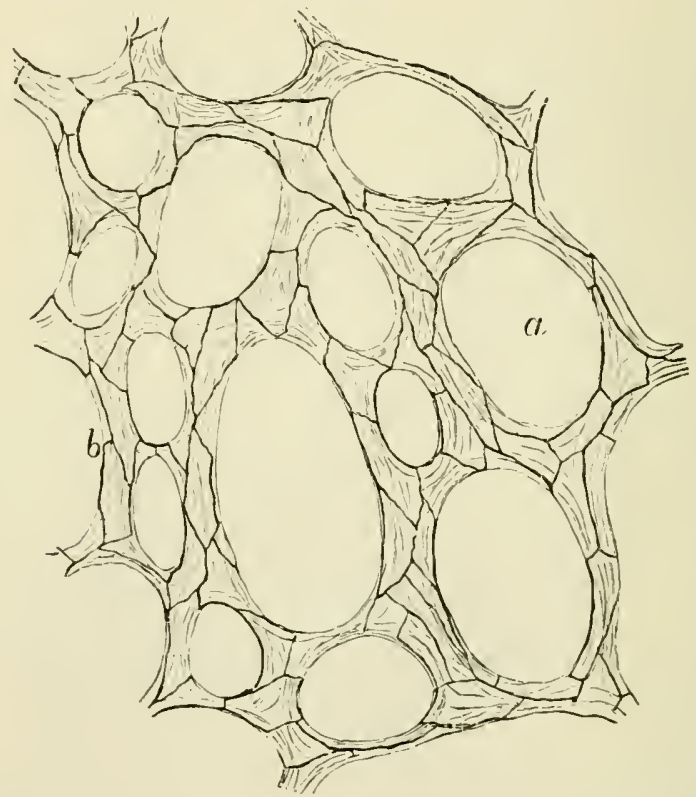

Fig. 32.- Part of Omentum of Cat, stained with Nitrate of Silver.

$a$, Fenestra or holes: $b$, traneetule covered with enchothehum. Onty the outlines (silver lines) of the endothelial cells are shown.

surface of the serous membranes, especially the diaphragm (Fig. 31) and pleura, there exist minute openings, stomata, leading from the serous cavity into a lymphatic vessel of the serous membrane. These stomatir are often lined by germinating cells.

33. In the frog, germinating cells occur in great abundance on the mesogastrium and the part of the peritoneum which separates the peritoneal cavity from the cisterna lymphatica magna. This part of 
the peritonem is ealled the septum cisterne lymphatica magne, and on it ocenr numerous holes or stomata, by which a free communication is established between the two cavities. On the peritoneal surface of this septum the stomata are often bordered by germinating cells. In the female frog, these and other germinating endothelial cells of the peritoneum (mesogastrium, mesenterium, septum cisterna) are ciliated.

34. The omentum and parts of the pleura are, in the adult lruman subject, ape, dog, cat, guinea-pig, rat, etc., of the nature of a fenestrated membrane (Fig. 32), bands of fibrous tissue of various sizes dividing and reuniting, and leaving between them larger or smaller holes, in shape oblong or circular. These holes or fenestrie are not covered with anything, the endothelial cells adhering only to the surfaces of the bands without bridging over the fenestræ. On the peritoneal surface of the diaphragm the endothelial cells possess a different arrangement from that on the pleural side; on the former surface a number of lymph channels (that is, clefts between the bundles of tendon and muscle) radiate towards the middle of the central tendon. The endothelium of the free surface over these lymph channels is composed of much smaller cells than at the places between, so that the endothelium of the peritoneal surface of the diaphragm shows numbers of radiating streaks of sniall endothelial cells. Many of these small cells are not flattened, but polyhedral, and of the nature of germinating cells (Fig. 31). The above-mentioned stomata occur amongst these small endothelial cells. 


\section{CHAPTER V.}

FIBROUS CONXECTIVE TISSUES.

35. Br the name of "connective tissues" we designate a variety of tissues which have in common with one another, that they are dereloped from the same embryonic elements; that they all serve as supporting tissue or connecting substance, for nerrous, muscular, glandular, and vascular tissues; that they are capable of taking one another's place in the different classes of animals; that in the embryo and in the growing normal and morbid condition one may be changed into the other; that in the adult they gradually shade off one into the other ; and that they yield allied chemical products.

Connective tissues are divided into the three great groups of (1) fibrous connective tissue; (2) cartilage; (3) bone, to which may be added dentine. Each of these is subdivided into several varieties, as will appear farther on; but in all instances the ground substance, ol matrix, or intercellular substance, is to be distinguished from the cells. In the fibrous connective tissue the matrix yields collagen or gelatin, and the cells are called connective-tissue cells, or connective-tissue corpuscles. In the cartilage the ground substance yields chondrin, and the cells are called cartilage cells. In the third group the ground substance contains inorganic lime salts, intimately con. nected with a fibrous matrix, and the cells are called bone cells.

36. The fibrous connective tissue, or white fibrous tissue, occur's in the skin and mucous 
membranes, in the serous and synovial membranes, in the membranes of the brain and spinal cord, in tendons and tendon sheaths, in fascie and aponeuroses, in the intermuscular tissue, and in the tissue connecting neighbouring organs, etc. It consists of microscopic band-like or cylindrical bundles or fasciculi of exceedingly fine homogent ous fibrils (Fig. 33), which

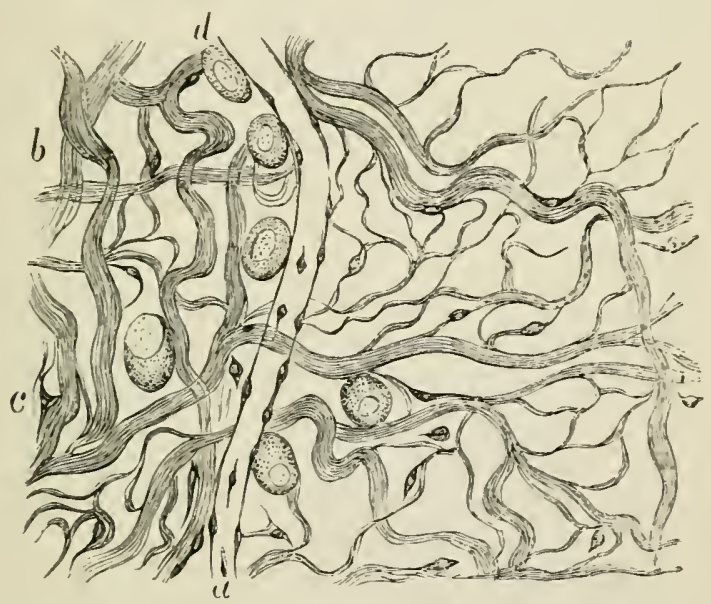

Fig. 33. - Plexus of Bundles of Fibrous Tissue from the Omentum of Rat.

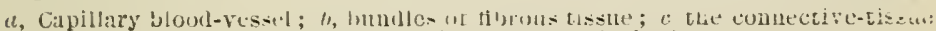

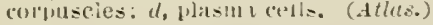

are known as the elementary connective-tissue fibrils. According to the number of these the bundles differ in size. The bundles, and also their constituent fibrils, may he of very great length-several inches. Where the fibrous tissue forms continuous massesas in tendon, fascia, aponeurosis, skin, and mucous membrane- the microscopic bundles are aggregated into smaller or larger groups, the trabeculce, and these are again associated into groups. The fibrils are held together by an albuminous (globulin), semi-fluid, homogeneous cement substance, which is also present between the bundles forming a trabecula. 
The groups of bundles, and even the individual bundles, are in some localities invested with an elastic sheath-e.g. in the trabeculæe of bundles in the subcutaneous tissue.

On adding an acid or an alkali to a bundle of fibrous tissue, it is seen to swell up and to become glassy-looking, homogeneous, and gelatinous. Subjected to boiling in water, or to digestion by dilute acids, the bundles of fibrous tissue rield collagen or gelatin.

37. According to the arrangement of the bundles, the fibrous connective tissue varies in different localities. (1) In tendons and fascire the bundles are arranged parallel to one another. () In the true skin and mucous, serous, and synorial membranes, in the dura mater and tendon sheaths, the trabeculie of bundles divide repeatedly, cross and interlace rery intimately with one another, so that thereby a dense felt-work is prorluced. (3) In the subcutaneous, submucous, or subserous tissue, in the intermuscular tissue, in the tissue connecting with one another different organs or parts of the same organ-i.e. interstitial connective tissue-the texture of the fibrous tissue is more or less loose, the trabecule dividing and reuniting and crossing one another, but learing between them larger or smaller spaces, cellulie or areolie, so that the tissue assumes the character of a loose plexus, which is sometimes called "areolar" or" "cellular tissue." Such tissue can be more or less easily separated into larger or smaller lamellie, or plates of trabeculæ. (4) In the omentum and parts of the pleura of man, ape, dog, cat, and some rodents, and in the subarachnoidal tissue of the spinal cord and brain, the trabeculæ form a fenestrated membrane, with larger or smaller oval or circular holes or fenestre.

38. The commective-tissue cells or corpuscles occurring in white fibrous tissue are of sereral 
valleties. (11) In tendon and fascie the colls are called tendon cells or tendon corpuscles; they are flattened

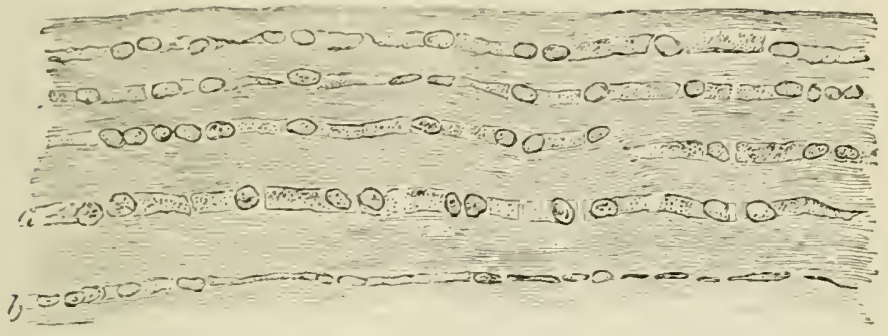

Fig. 34.-Tenton of Jlonse's Tail. (E. A. Schëfer.)

$a$, C'bains of tendon-cells seen broadways; $b$, the same in profile.

nucleated protoplasmic cells of a square or oblong shape (Fig. 34), forming continuous rows (single files), situated on the surface of groups of bundles of fibrous tissue. Between these groups are wider or narrower channels, the interfascicular lymph spaces, running parallel with the long axis of the ten(lon (Fig. 3.5). The cells in each

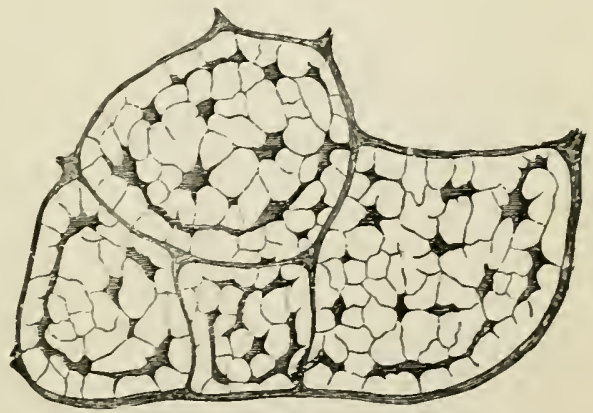

Fig. 35.-From a Transverse Section through the Tendons of the Tail of a Mouse, stained with gold chloride. (Handbook.)

Several fine tendons are shown here. The dark branched corpuscies correspond to albumiluols cement substance stained with gold chloride; they are the channels between the bundles of fibrous tis-ue, constituting the tendon, and seen bere as the clear spaces in cross section. In earh of these cliannels is a row of tendon cells-not discernible here, the long axis of these rows being parallel with the long axis of the tendun.

row are separated from one another by a narrow line of albu-

minous cement substance, and the round nuclens of the cell is generally situated at one end, in such a 
way that in two adjacent cells of the growing tendon the nuclei face each other. This indicates that the individual cells undergo division. Corresponding to

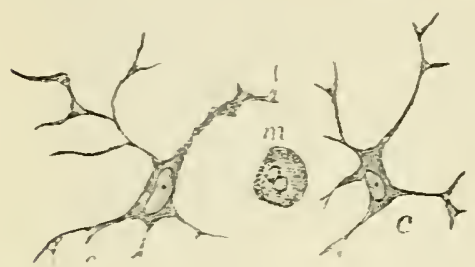

Fig. 3i._-From the Tail of a Tadpole. a migrators cell. (Atlas.) the margin of each row, the cells possess minute processes. The cell plate is not quite Hat, but possessed of one, two, or even three membranous projections br which it is wedged in between the indiviclual bundles of the group to which the row of cells belongs.

39. (b) In the serous menbranes, cornea, subcutaneous tissue, and loose connective tissues, the cells

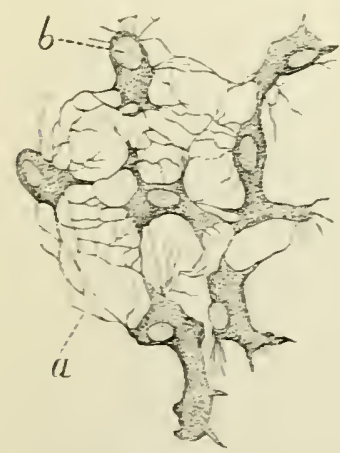

Fig. 37.-From the Cornea of hitten, showing the Networks of the Branched Corneal Corpuscles.

$a$, The network of their pro. ces-es: $b$, nucleus of the corpuscle. (Atlas.) are flattened transparent corpuscles, each with an oblong flattened nucleus, and more or less branched and comnected by their processes. In the cornea they are spoken of as the comeril corpuscles, and are very richly branched (Fig. 3T). They are situated between the lamella of fibrous bundles of which the ground substance of the cornea consists.

These corpuscles are also situated in the interfascicular lymph spaces, or spaces left between the bundles of the fibrous matrix, which are carities in the interstitial cement, cementing the bundles and trabeculie together (ron Recklinghausen). In the cornea and serous membranes these spaces possess the shape of branched 
latcune, each lacuna being the home of the body of the cell, while the branches or canaliculi contain its processes. These canaliculi form the channels by which neighbouring lacunie anastomose with one another (Fig. 38). The cell and its processes do not fill up the lacuna and its canaliculi, but are bathed in the priaplasma or fluid contained in the lymph canal system. In loose connective tissue the lacuna may be of considerable size, and may contain several connective cells, which make as it were a lining for it. These in some places are very little branched, and almost form a continuous endotheloid membrane of flattened cells. Such is the subepithelial endothelium of Debove, occurring underneath the epithelium on the

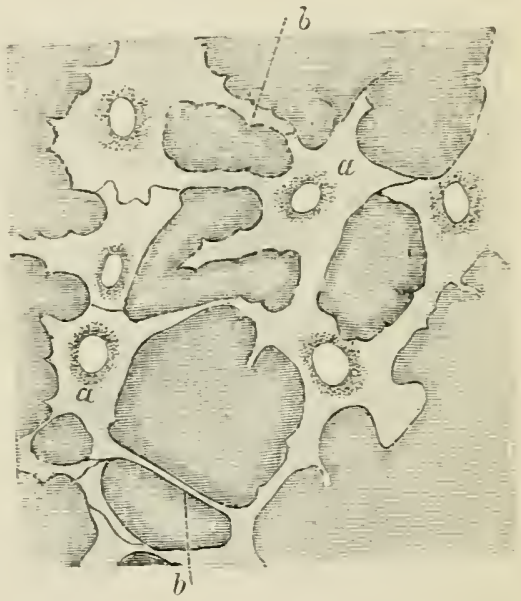

Fig. 38.-Fron the Cornea of Kitten, stained with Nitrate of silver, showing the Lymph-canal System.

$a$, The lacunx, each containing the nucleated cell.body just indicated here: $b$, the canaliculi for the cell proce--es. (Atlas.)

\section{surface of the mucous}

membrane of the bronchi, bladder, and intestines.

40. (c) In the true stin and mucous membranes the comnectire-tissue cells are also branched flattened corpuscles, and by their longer or shorter processes are connecterl into a network (Fig. 36). Each cell has a flattened oblong nucleus. As a rule, some of the processes are membranous prolongations coming off under an angle from the body of the cell, which is then called the chief plate, the processes being the secondary plates. By the latter the cell is 
wedged in between the bundles of the trabecula to which it belongs.

This character of the cells (i.e. possession of secondary plates; is well shown by the cells of the skin and mucous membranes, but only in a very limited degree by those of the comea and serous membranes, and somewhat better by some of those of the subcutaneous and other loose connective tissues.

In the skin and mucous membranes also the cells and their processes are bathed in the paraplasma contained in the interfascicular lymph spaces.

41. The connective-tissue corpuscles hitherto mentioned are fixed corpuscles; they do not show morement. Kiihne and Pollett ascribe to the cormeal corpuscles a certain amount of contractility, inasmuch as they are said to be capable of withdrawing their processes on stimulation. When this ceases they are said again to protrude them. According to Stricker and Norris, they acquire contractility when the corneal tissue is the seat of inflammatory irritation. It can be shown that the connectivetissue cells consist, like the endothelial plates, of a ground plate and a fibrillar reticulated (granularlooking) substance around the nucleus, and extending beyond the ground plate into the processes of the cell.

42. Pigment cells.-In the cold-blooded vertebrates, fishes, reptiles, and ampinibian animals, we find certain branched nucleated comnective-tissue corpuscles, distingruished by their size and by the protoplasm both of the cell-body and processes (but not of the nucleus) being filled with pigment granules. The pigment is either grey or yellow, or more commonly dark brown, or even black. These cells are called pigmented connective-tissue cells, or simply pigment cells. They are very numerous in the skin of fishes, reptiles, and amphibian animals, and also around and between 
the llood-vessels of the serous membranes. They are also present in man and mimmals, but then they are chietly limited to the eye-ball, where they occur in the
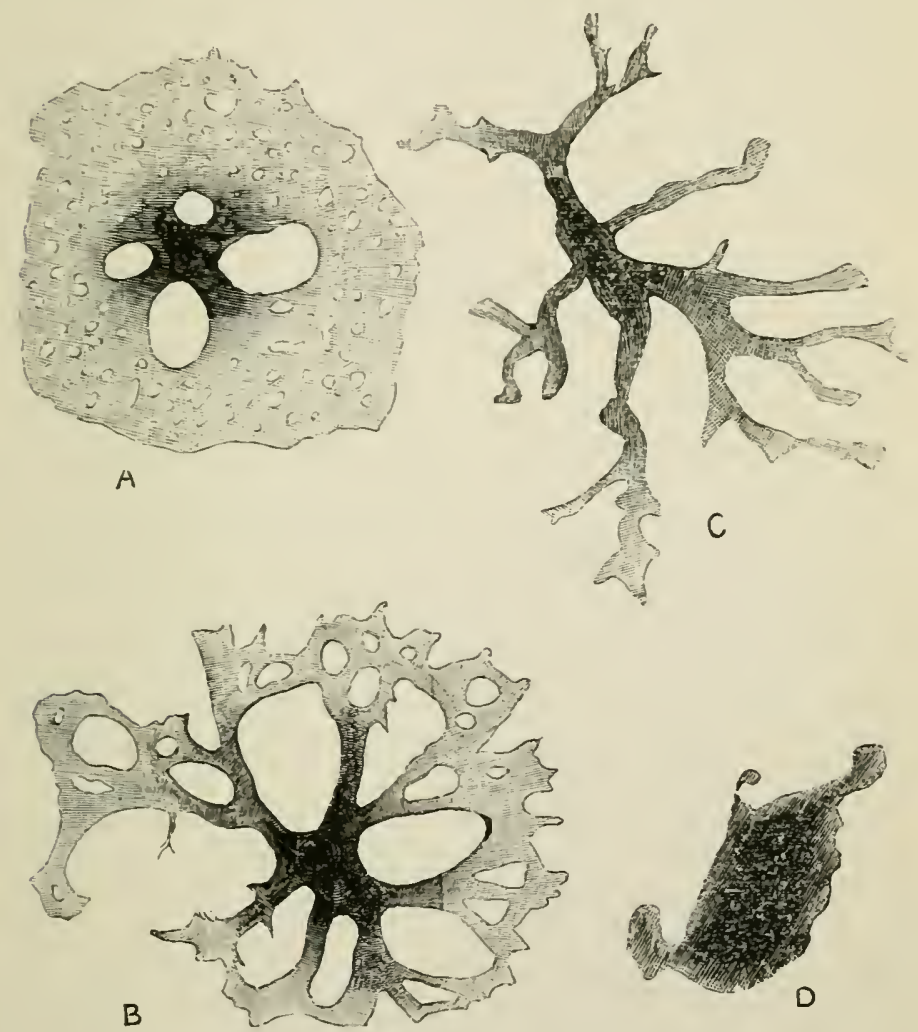

Fig. 39.-Pigment_Cells of the Tail of Tadpole.

$\Delta, B, C, D$ reprcsent various states; A heing a cell in an uncontracted or passive stat.. Din a contracled or active stace.

proper tissue of the iris of all but albino and bright blue eyes, and in the tissue of the choroid membrane. In clark eyes of mammals a large number of these cells are found in the tissue between the sclerotic and choroid, as the lamina fusca, and also, but to a more 
limited degree, in the sclerotic. As a rule, ther appear to be of various kinds: such as are tlattened, large plates perforated ly a number of small and large holes and minute clefts: such as possess a more spindleshaped borly, and long, thin, not very richly branched processes; and intermediate forms between the two. But on careful examination it will be seen that these appearances are due to different states of contraction of the same kind of cells (Fig. 39).

43. In the lower rertebrates the dark pigment cells show marked contractility, inasmuch as they are capable of altogether withdrawing into their body the pigmented processes. In the passive state these are exceedingly mumerous, and form a network so dense that the whole mass of the cells and their paraplasma resembles an extremely close network of pigment. In the maximum of activity the pigmented processes disappear, being withdrawn into the cell-body, which now looks like a spherical or oblong mass of black pigment. Between the states of passireness and maximum activity there are rarions intermediate grades, in which the pigmented processes are of various numbers and lengths.

44. Owing to the great number of the pigment cells in the skin of fishes and amphibians, the state of contraction of these cells materially affects the colour of the skin. If the dark pigment cells of a particular part contract, the skin of this particular part will hecome lighter and brighter, the degree of lightness and brightness depending on the degree of contraction of the pigmented processes by the cells. Briicke has shown that clarkness is a stimulus to the pigmented cells; ther contract and the skin luecomes light. Sunlight leares the pigmented cells in the passive state, their pigmented processes numerous and well branched, and the skin appears therefore of a darker colour. If previously they have been 
contracted by darkness, on being exposed to sunlight they again return to the passive state. 'The contraction of the pigment cells is under the direct influence of the nervous system (Lister). Pouchet proved that the contractility of the pigment cells of the skin of certain fishes is influenced as a reflex action by the stimulation of the retina by light.

45. Fat cells.-Fat cells in the ripe and fully-formed state are spherical, large resicles, each
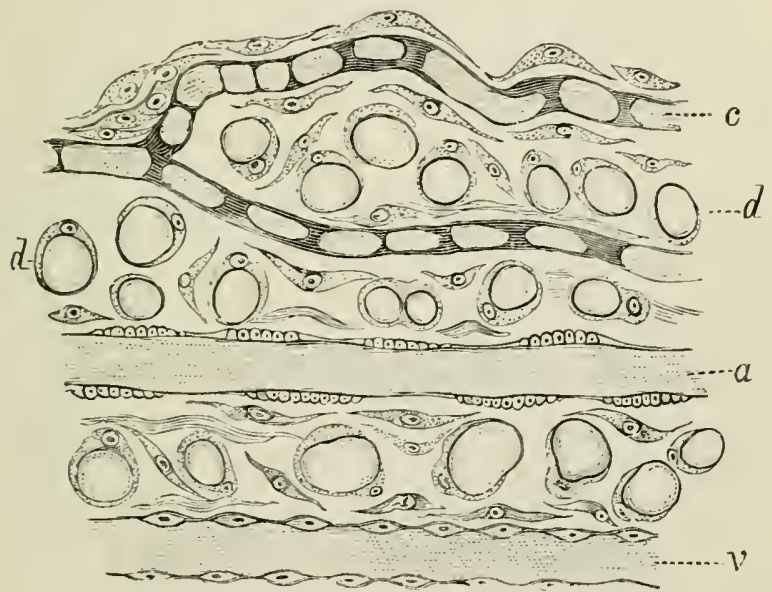

Fig. 40.-Fron a Prepraration of the Omentum of Guinea-pig. (Atlus.)

$a$, Artery ; $v$, vein ; $c$, young capillary blood-vesiel ; $d$, fat cells.

consisting (a) of a thin motoplasmic membrane, which at one point includes an oval nucleus flattened from side to side, and $(b)$ of a substance, which is a fat globule filling the cavity of the vesicle (Fig. 40). These fat cells are collected together by fibrous connective tissue into smaller or larger groups, which in their turn form lobules: these again form by means of thicker masses of fibrous connective-tissue lobes, and these are finally arranged as continuous masses. Each group and lobule has its afferent arteriole, one or two 
efferent reins, and a dense notuorl of crppillaries between; each mesh of the capillary network holding one, two, or three fat cells (see below). Such are the nature and arraugement of fat or adipose tissue in the subcutaneous and subnucous tissue, in the serous

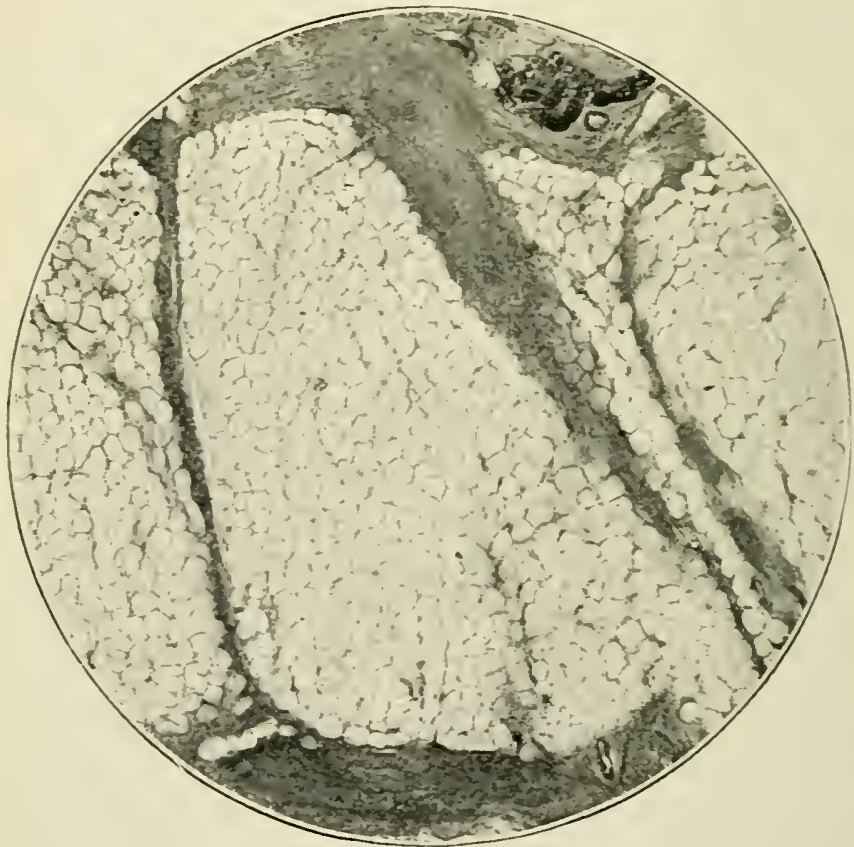

Fis. 41.-From a section thrungh the alipose layer of the skin ; showing Lobules of Fat-cells. Magnifying jower, 40. (From a Photograph by Mr. A. Fringle.)

and synovial membranes, in the intermuscular tissue, in the loose tissue connecting organs or parts of organs.

It can be shown that fat cells are derived from ordinary connective tissue cells. In some placesboth in the embryo and adult - the protoplasm of the comnective-tissue corpuscles, srowing in size, becomes 
filled with small fat globules, which, increasing in number, become fused with one another to larger slobules; as their size thus increases the cell nucleus becomes shifted to the periphery; ultimately one large fat globule fills the cell, and what is left of the

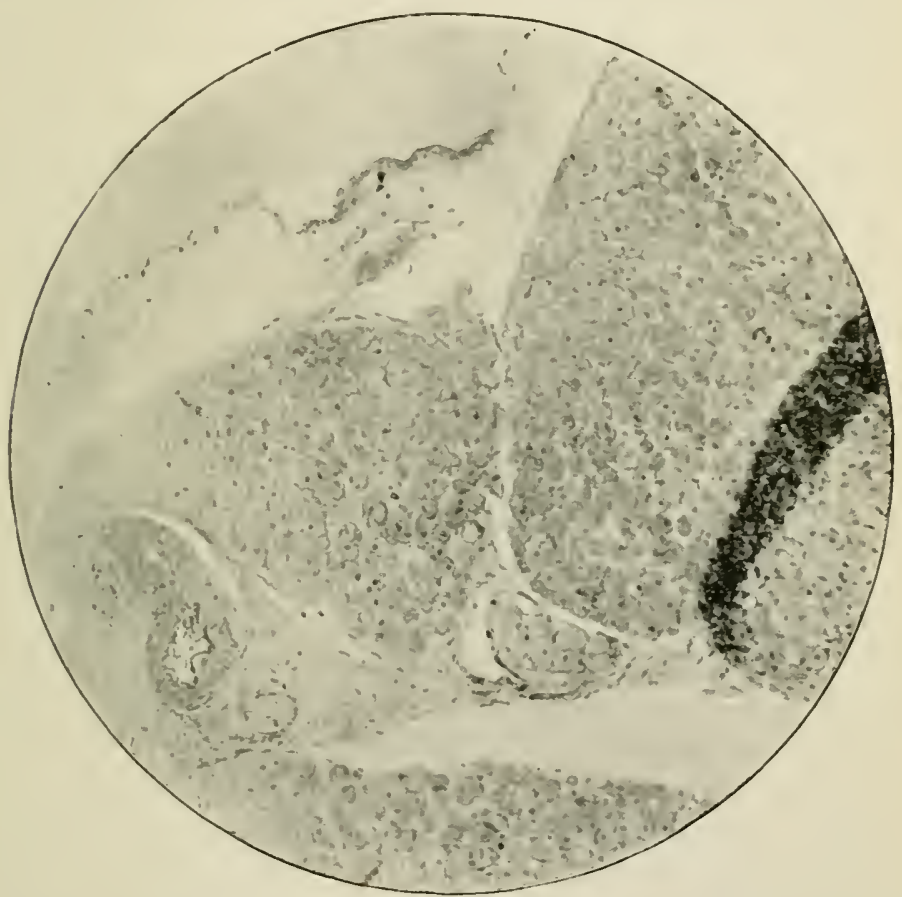

Fig. 4..-Fiom a section of Lobules of Fotal Fat, showing connective-tissue septa with ressels (surrounding the lobules); the spheroidal young cells, many of them containing globules of fat. (Photograph, moderatcly magnifierl.)

cell protoplasm surrounds this fat globule like a membranous envelope. The cell as a whole has become in this process many times its original size (Fig. 4l).

46. It can also be shown that where at one time only few isolated connective-tissue corpuscles are present, at another time, in the natural state of 
growth, and especially under very favourable conditions of nutrition, the counective-tissue cells become increased by cell-multiplication so as to form groups; these groups continue to increase in size and to be gradually furnished with their own srstem of bloodressels; the individual cells constituting the group become then converted into fat cells, and their processes are thereby lost (Fir. 42).

Isolated connective-tissue cells sitmated in the neighbourhood of small blood-ressels are converted into fat cells under farourable conditions of nutrition.

In starration the fat cells lose their fat globule, they become smaller and contain a serous fluid, which may ultimately also disappear. Finally, the fat cell mar be reduced to a small, solid, protoplasmic, slightly branched cell.

4i. In many places the fibrous comnective tissue includes, besides the fixed cells, other's which show amceboid morement, urendering cells. These are of rarious kinds, like those of the blood: (1) A majority are identical with the typical hraline lencocytes of the blood, as regards size, shape, aspect, and seneral nature (Fig. 36, $m$ ). They wander about through the spaces of the fibrous tissue. They contain two or three nuclei. (2) Those of the second variety possess a small amount of protoplasm, and one comparatively large nuclens: they correspond to the lymphocytes mentioned in connection with the white blood corpuscles. The amreboid movement of these cells is not so distinct as in the first variety. Plasma cells of Waldeyer. They are larger than the former, less prone to migrating, being possessed of only slight amoboid movement, which is, however, sutficiently pronounced to be detected. They always contain granules, and correspond to the graviular cells mentioned of the blood; also in regard to their predilection for acid and basic aniline dyes they may be 
distinguished as eosinophile or oxyphile, basophile or neutrophile cells. The "granules" in some of the plasma cells may change into fat globules, and thus the plasmia cell becomes converted into a fat cell.

48. The wandering cells occur almost in all loose fibrous tissues, chiefly around or near blood-ressels; they are not numerously met with in the healthy state, but increase greatly in the state of inflammation of the part. Those of the larger kind-e.y. the granular wandering cells or plasma cells, are met with in certain localities only ; in the sub-lingual gland of the dog and grinea-pig they occur in numbers between the gland tubes or acini. They are also found in the mucous membrane of the intestine, in the trabecula of the lymphatic glands, and in the omentum. The "granules" of these cells under many conditions change into fat glowules. Just like the hyaline leucocytes of the blood so also those of the comnective tissues are capable of swallowing minute particles of extraneous matter-granules of living (bacteria) and non-living matter that accidentally find entrance into the connective tissue. These cells, when acting in this capacity, are called phagocytes.

49. Development of fibrous tissue.-Fibrous connective tissue is dereloped from embryonic connective-tissue cells-i.e. from spindle-shaped or branched nucleated protoplasmic cells of the mesoblast. The spindle-shaped cells are met with isolated or in bundles, as in the umbilical cord or embryonic tendon. The branched cells form a network, as in the fœtal skin and mucous membrane. In both instances the protoplasm of the embryonic connective-tissue cells increases rapidly in amount, and becomes gradually transformed into a bundle of elementary tibrils, with a granular-looking interstitial substance. The nucleus of the original cell finally disappears. A modification 
of this is when only part-generally unilateral-of the cell substance is converted into a bundle of connective tissme fibrils and inter-fibrillar cement substance. A remmant of the protoplasm persists with the nuclens as a connective-tissue cell.

The same modes of formation of connective tissue may be also observed in the adult under normal and pathological conditions.

50. Fibrous comnective tissue is in most places

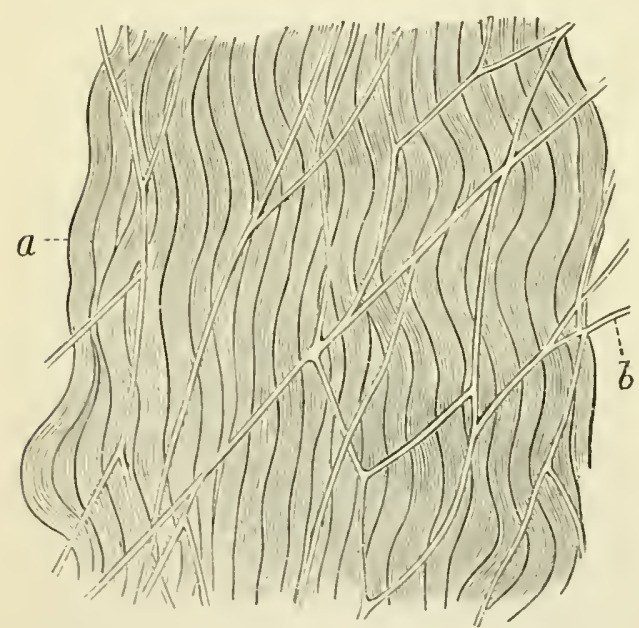

Fig. 43.-From a Prelaration of the Mesentery. a, Bundles of fibrons tissue: $b$, network of elastic fibres. (Atlas. associated with elastic fibres or yellow elastic tissue. These are of bright aspect, of variable thickness and length, blanching and anastomosing so is to form networks (Fig. 43). They are sometimes straight, but more often twisted and coiled. The latter condition nna be observed when the tissue is shrunk, the former when it is stretched. 'They do not swell up in acids or alkalies, nor yield gelatin on boiling, but contain a chemically different substance-riz. elastin. When broken their ends generally curl up.

51. Elastic fibres occur in great numbers as networks extending on and between the bundles of fibrous tissue in the skin and mucous membranes, in the 
serous and synovial membranes, and in the loose interstitial connective tissues. They are not very commonly met with in tendons and fascia ; in the former they are seen as single filmes often twisting round the tendon bundles.

Elastic fibres forming l,undles, but branched and comnected into networks within the bundle, are to be found in large numbers in the walls of the trachea, bronchi, infundibula, and alveoli of the lung, in the ligamenta flara, in the ligamentim nuche of the ox (in which the fibres are exceedingly thick cylinders), ju yellow elastic cartilage (see below), in the membrane lining the carity of the heart, and in the vascular system, particularly the arterial division. In the latter organs the intima, and also to a great extent the medial, consist of elastic fibrils densely connected into a network.

5.2. The following are special morphological modifications of the elastic fibres: (a) elastic fenestrated membranes of Henle, as met with in the intima of the big arteries; these are in reality networks of fibres with rery small meshes, and the fibres unusually broad and flat. (b) Ilomoyeneous elastic membranes, which surround, as a delicate sheath, the connectivetissue trabecula in some localities-e.g. subcutaneous tissue. (c) Homogeneous-looking elastic membranes in the cornea, behind the anterior epithelium as Boxman's anterior elastic membrane, and at the back of the cornea as elastica posterior, or Descemet's membrane; in the latter bundles of minute fibrils have been observed. Between the mucosa and submucosa of the stomach of the cat occur's an elastic membrane of consiclerable thickness. (d) Elastic trabeculie forming a network, as in the ligamentum pectinatum iridis. In the embryonic state the elastic fibres are nucleated, the nuclei being the last remnants of the cells from which the fibres develop, one cell generally giving 
origin to one fibre. These nucleated fibres are called Henle's nucleated fibres.

5.). Special varieties of fibrous connectire tissue are these :-

(1) Adenoid reticulum. This is a network of fine fibrils. or plates, forming the matrix of Irmphatic or adenoid tissue. (See Lymphatic glands.) 'The reticulum is not fibrous connective tissue nor elastic tissue; it contains nuclei in the roung state, and is derised from a network of branched cells; but in the adult state the reticulum itself possesses no nuclei. Those found on it do not form an essential part of it.

(?) The reurogtia of Tirchow is a dense network of rery fine homogeneous fibrils which form the supporting tissue for the nerrous elements in the central nerrous system. These fibrils are supposed to be elastic fibres (Gerlach). Embedded in, and intimately connected with, the network of these fibres are found branched, nucleated, flattened cell plates, which correspond to the fixed connectire-tissue cells.

(3) Gelatinous tissue. This occurs chiefly in the embryo, being the unripe state of fibrous connective tissue (see above). It consists of spindle-shaped or branched connective-tissue cells, separated from one another by a homogeneous transparent mucoid substance. It is met with in the umbilical cord and in the carity of the middle ear of the embryo. and in all places where fibrous comnective tissue is to be rlereloped. After birth it is found in the tissue of the pulp of the teeth, where it persists throurh life: in some places it is the precursor of fat tissue, its cells becoming transformed into fat cells. 


\section{CHAPTER VI.}

CARTILAf:E.

54. Cartilage consists of a firm ground substance which rields chomdrin, and of cells embedded in it. Most cartilages (except on the articulating surface) are corered on their free surface with a membrane of fibrous connective tissue with a few elastic fibrils. This membrane is supplied with blood-ressels, lymphatics, and nerres, and is of essential importance for the life and growth of the cartilage. This is the perichondrium. There are three varieties of cartilage.

5.5. (1) Hyaline cartilage(Fig. 44). -This occurs on the articular surfaces of all bones; on the borders of many short bones; in the sternal part of the ribs, as costal cartilages; at the margin of the sternum, scapula, and os ileum: in the rings of the trachea, the cartilages of the bronchi, the septum and lateral cartilages of the nose: and in the thyroid and cricoid cartilages of the laryux. The ground substance is hyaline-i.e. transparent, like ground glass, and firm. The cells are spherical or oval protoplasmic corpuscles, each with one or two nuclei. They undergo division, and although the two offsprings are at first close together (half moon-like in optical section), they gradually grow wider apart by the deposit of hyaline ground substance between them. The cells are contained in cavities, called the cartilaye lacunce. Each cell generally occupies one lacuna, but, according to the progress of division, a lacuna may contain two, 
four, six, or eight cartilage cells; the latter are those cases in which division proceeds at a more rapid rate than the deposition or formation of hyaline ground substance between the cells.

The part of the cartilage next to the perichondrium shows most active growth; hence the cells are here smaller, closer together, and there is less ground substance.

Each lacuna is lined by a delicate membrane, and, according to the state of the cell, is either completely

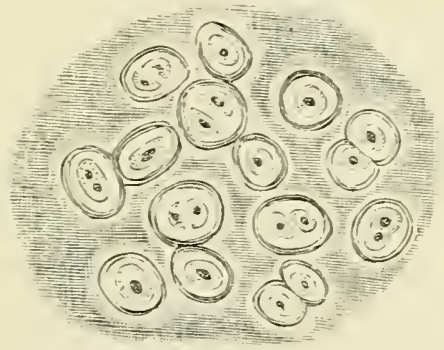

Fig. 44.-Hyaline Cartilage of Human Trachea.

In the hraline rronnd sub-tance are -een the cartilage cells enclosed in (itpsiles.

56. In some places, especially in articular cartilage (Tillmanns Baber), bundles of fine connectiretissue tibrils may be noticed in the lyyaline ground substance.

57 . In some cartilages the protoplasm of the cell becomes filled with fat globules (Fig. 46). This fact may be observed in many normal cartilages; sometimes the fat globules become confluent into one large drop, and then the cell has the appearance of a fat cell. In old age, disease, and deficient nutrition lime salts are deposited in the gromnd substance, beginning from the circumference of the cell. The earthy matter appears in the shape of opaque granules, or irregular 
ol' angular gramules. 'The ground substance therehy loses its transparency, becomes opargue in transmitted, white in reflecter, light, and, of course, very hard and brittle. This process is the calcification of cartilage. It is also met with in cartilage that is to be replaced by hone, loeing the precursor of the formation of bone, as in the embryo (see below), and at the growing ends of

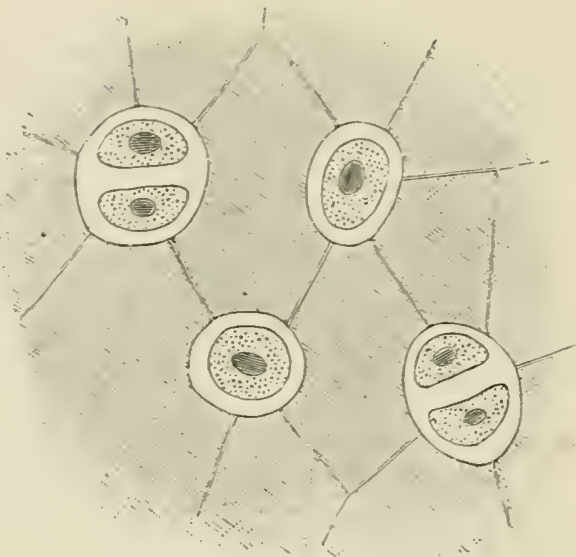

Fig. 45.-From a Preparation of the sterna Cartilage of a Newt.

The lacunæ containing the cartilage cells anastomnse by tine channels. long bones.

58. The division of the nucleus of the cartilage cells has been observed during life by Schleicher and Flemming. It takes place after the mode of karrokinesis. The lacune of the cartilage are not isolated cavities, but are connected with one another by fine channels (Fig. 45), so that the ground substance is easily permeable by the current of nutritive fluid. These channels and lacuna form an intercommunicating srstem, and are connected with the lymphaties of the perichondrium (Budge). Formed matter, as pigrment granules, red and white blood

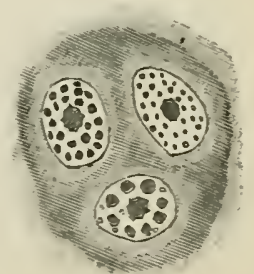

Fig. 413.-Tlıree Cartilage Cells filled with Fat Droplets. From the lyyaline cartilage of the nasal sejtum of Guinea-pig. 
corpuscles, and pus corpuscles, may also find its way into the channels and lacunse of the cartilage from the perichondrium.

At the borders of articular cartilage, where this is joined to the spnotial memlirane and to the capsule of the joint, the cartilare cells are more or less branched, and pass insensibly into the branched connective tissue cells of the membrane. In fotal hyaline cartilage mans of the cells are spindle-shaped or branched.

$5 \%$. In the cartilage separating the bone of the apophrses from the end of the diaphrsis of tubular bones there is a peculiar hraline cartilage, known as the intermediate or osifining cartilage. Its cells are arranged in characteristic vertical rows, owing to the continued division

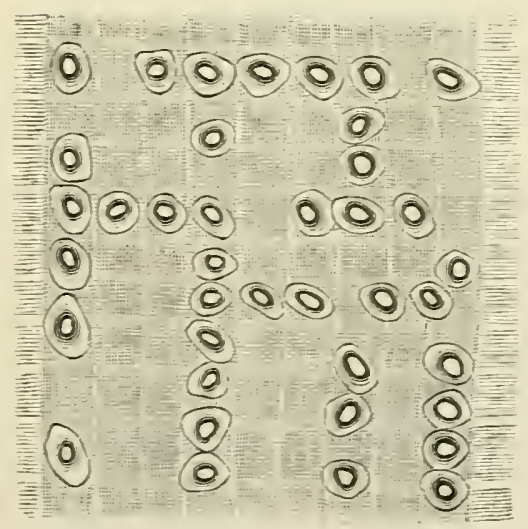

Fig. 47.-Fibrc-Cartilace of an Intervertebral Ligament. (Atlas.)

Showing the bondle- of fibrou-ri--ne and row = of cartilage cell. of the cells in a transverse direction.

Cartilages, or parts of cartilages, in which the cells are very closely placed, owing to the absence, or scanty deposit and formation, of ground substance, are called porienchymatous or cellular cartilage.

\section{0. (2) Fibro-car-}

tilage, or connectivetissue cartilage, occur's as the interrertebral discs, as the interarticular cartilages, sesamoid cartilages, and as the cartilage forming the margin of a fossa glenoidalis. It consists of fibrous connective tissue urrunged in bundles, and these again in lavers. The ground substance of this cartilarge is said to yield chondrin and 
not gelatin. Between the strata of the fibrous bundles are rows of more or less flattened oval protoplasmic nucleated cells, each inrested in a deficate capsule (Fig. 47). They are less flattened than the colls of tendon, and the capsule distinguishes the two. Where fibro-cartilage passes into tendinoms tissue the two kinds of cells pass insensibly into one another.

\section{1. (3) Yellow, or} elastic cartilage. This valiety is also called reticular; it occurs in the epiglottis, in the pinna of the external ear, in the Eustachian tube, in the cartilages of Wrisberg and Santorini in the larynx. In the early stages this kind is hyaline. Gradually

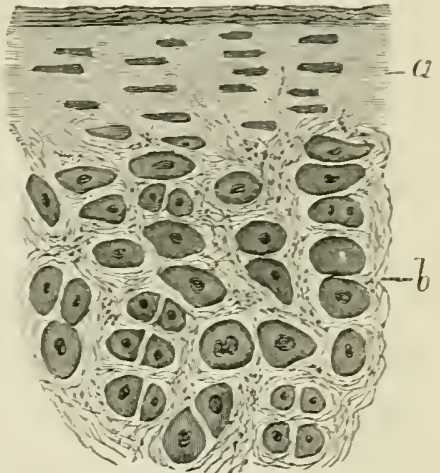

Fig. 45.-From a section through the Epiglottis. (Atlus.)

$a$, Perichondrium; $b$, networks of ela-tic fibrils surrounding the car. tilage cells. numbers of elastic tibrils make their appearance, growing into the cartilage matrix from the perichondrium in a more or less rertical direction, and branching and anastomosing with one another. The tinal stage is reached when the ground substance is permeated by dense netucork's of elastic fibrils (Fig. 48), so arranged that spherical or oblong spaces are left, each of which contains one or two cartilage cells, surrounded by a smaller or larger zone of hyaline ground substance. 


\section{CHAPTER VII.}

BOYE.

62. Boxe, or osseous substance, is associated with several other soft tissues to form a bone in the anatomical sense of the word.

(a) The periosteum. - Except at the articular surfaces, and where bones are joined with one another by ligaments or cartilage, all bones are covered with a rascular membrane of fibrous connective tissue. This is the periosteum. It consists in most instances of an outer fibrous layer, composed of bundles of tibrous tissue densely aggregated, and an inner, or osteogenetic layer, which is of loose texture, consisting of a meshwork of thin bundles of fibious tissue, in which numerous blood-vessels and many protoplasmic cells are contained. The blood-ressels form by their capillaries a network. The cells are spheroidlal or oblong, each with one spherical or oval nucleus. They have to form bone-substance, and are therefore called the osteoblasts (Gegenbaur).

(b) The cartilage is hyaline cartilage, and its distribution on and connection with bone have been mentioned on pp. 63 and 64 .

63. (c) The marrow of bome is a soft vascular tissue, filling up all spaces and carities. It consists of a very small cimount of fibrous tissue as at matrix, and in it are embedded numerous blrod-ressels and cells. The few afferent arterioles break up into a dense network of capillaries, and these are continued as plexuses of reins, characterised by their compara- 
tively large size and exceedingly thin walls. The cells are of the same size, aspect, and shape as the osteoblasts of the osteogenetic tissue, and they are called marrow cells.

In origin and structure, the tissue of the osteogenetic layer of the periosteum and the marrow are identical. In the embryo, the marrow is derived from an ingrowth of the osteogenetic layer of the periosteum (see below), and also in the adult the two tissues remain directly continuous. As will be shown later, the marrow at the growing ends of the bones is concerned in the new formation of osseous substance in the same way as the osteogenetic layer of the periosteum is in that of the surface; and in both tissues the highly vascular condition and the cells (osteoblasts of the osteogenetic layer, and marrow cells of the marrow) are the important elements in this bone formation. Narrow is of two kinds, according to the condition of the cells. If many or most of these are transformed into fat cells, it has a yellowish aspect, and is called yellow marrow; if few or none of them have undergone this change, it looks red, and is called red marrow. In the central, or marrow, eavity of the shaft of tubular bones, and in the spaces of some spongy bones, the marrow is yellow; at the ends of the shaft, in the spongy bone substance in general, and in young growing bones it is red.

Some of the cells, especially those of red marrow, the erythrollasts, are the elements from which normally vast numbers of red blood corpuscles are formed, as has been mentioned on a former page.

In marrow, particularly in red marrow, we meet with large multinucleated cells, called myeloplaxes of Robin. They are derived by overgrowth from ordinary marrow cells, and are of importance both for the absorption as also for the formation of bone (see below). According to Heitzmann, Malassez, and 
others, they also have to do with the formation of blood-vessels and blood corpuscles. Numerous eosinophile cells are present in the marrow.

64. The matuix of osseous substance is dense plexiform fibrous connective tissue, i.e. a tissue yielding gelatin on boiling. The cement substance between the fibrils is petritied, owing to a cleposit of insoluble inorganic lime salts, chiefly carbonates and phosphates. These can be dissolved ont by strong acids (hydrochloric) and are thereby converted into soluble salts. Thus the organic matrix of osseous substance-called ossein-may be obtained as a soft flexible material, easily cut.

In young bone the matrix or ossein is a plexus of trabeculie of fibrous tissue (v. Ebner), and in it are also a few elastic fibres to be noticed.

The bone substance is in the adult state generally lamellated, the lamellæ being of microscopic thinness. Between every two lamella are numbers of isolated, flattened, oblong spaces-the bone lacunce (Fig. 49), which anastomose

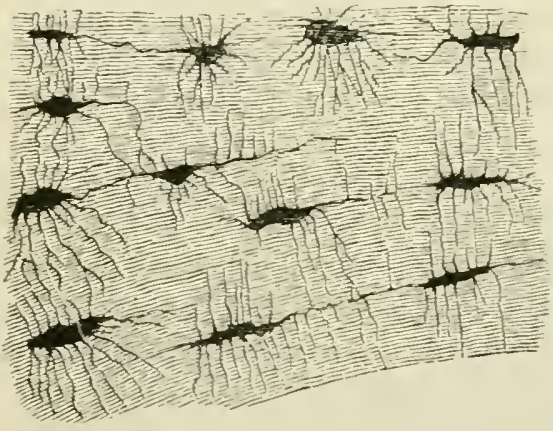

Fig. 49.-Osseous Lamelle; oblong branched bone lacumit and canaliculi between them. (Atlus.)

The bone lacune and their canaliculi are the lymph-canalicular system of osseons substance, for they

by numerous fine canals with one another, and also with those of the next lamella above and below (Fig. 50). The appearances are rery similar to those presented by the lacunze and canaliculi containing the corneal corpuscles as described in Chapter $\mathrm{V}$. 
are in open and free communication with the lymphatic ressels of the marrow spaces and of the Havelsian canals.

65. In the bone matrix, each lacuna contains also a nucleated protoplasmic cell, called the bone celi, which, however, does not fill it completely. In the

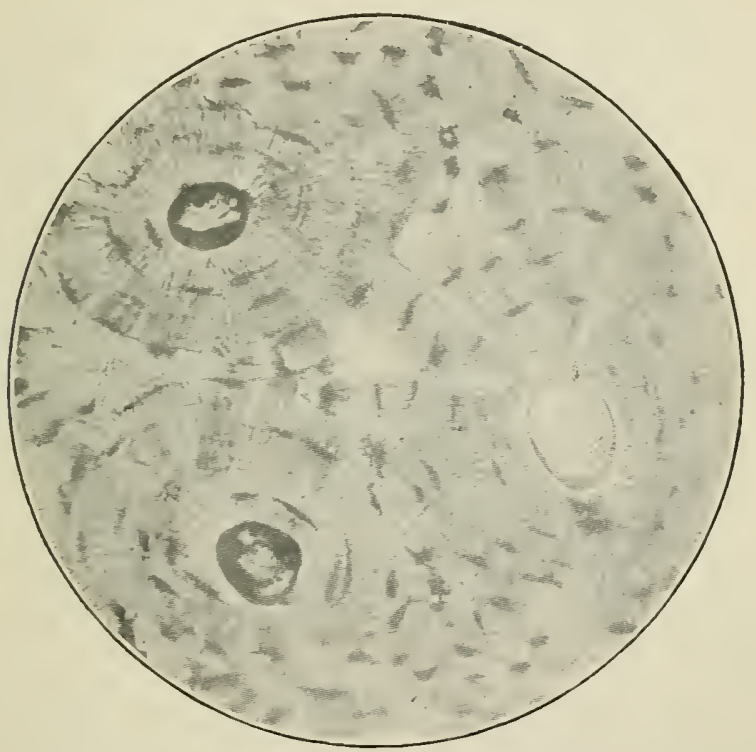

Fig. 50.-From a Transverse Section through Compact Bone, showing systems of concentric lamellæ (with bone corpuscles between) aruund Haversian cauals. (From a photogram by Mr. Pearce.)

young state the cell is branched, the branches passing into the canaliculi of the lacunre; but in the old state only traces of the original nucleated cell and very few processes can be detected; this with its lacuna and canaliculi is called a bone corpuscle.

66. According to the arrangement of the bone substance, we distinguish comprect from spongy substance. The former occurs in the shaft of tubular 
bones and in the onter layer of flat and short bones. Its lamellæ are arranged as : ( 1 ) concentric or Haversian lamella, directly surromnding the Haversian canals (Fig. 51). These are narrow canals of varying lensths pervading the compact substance in a longitudinal

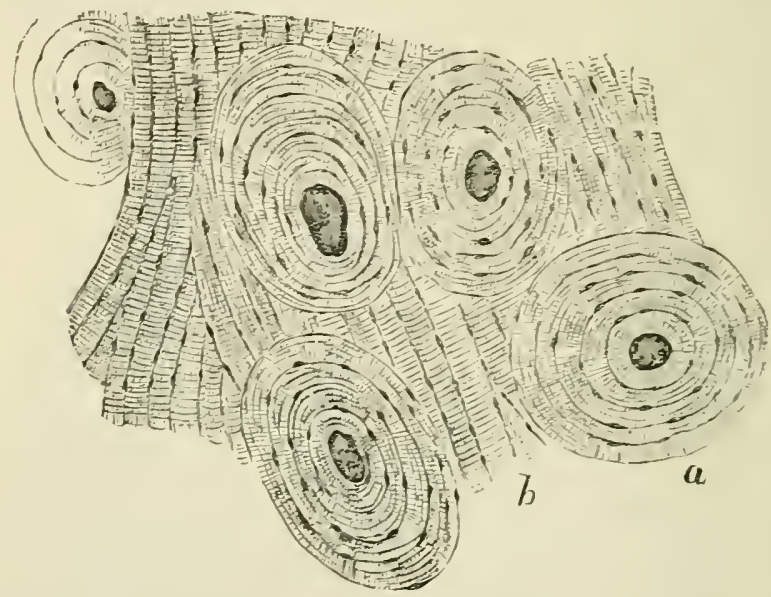

Fig. 5i.-Compact Bone substance in Cross-section. (Atles.)

$a$, Concentric lamelle arranged around the Haversian canals, cut across; $b$, in . termediate or ground lamelli. The bone lacunw are seen between the bone lamellæ.

direction, and anastomosing with one another by transverse or oblique branches. The Haversian canals near the marrow cavity are larger than those near the periosteum. In fact, those next to the marrow cavity become gradually enlarged by absorption of the concentric lamellæ, until finally they are fused with the marrow cavity. Each Haversian canal contains a blood-ressel, one or two lymphatics, and a variable amount of marrow tissue. These canals open both into the marrow cavity and on the onter surface into the osteogenetic layer of the periosteum, and they form the means by which the latter remains in continuity with the marrow. Each canal is surrounded 
by a series of conrenticic bone lamella, with the bone corpuscles betueen them, and this is a system of concentric lamelle. Near the external surface of the compact substince the number of lamellas in each system is smaller than in the deeper parts.

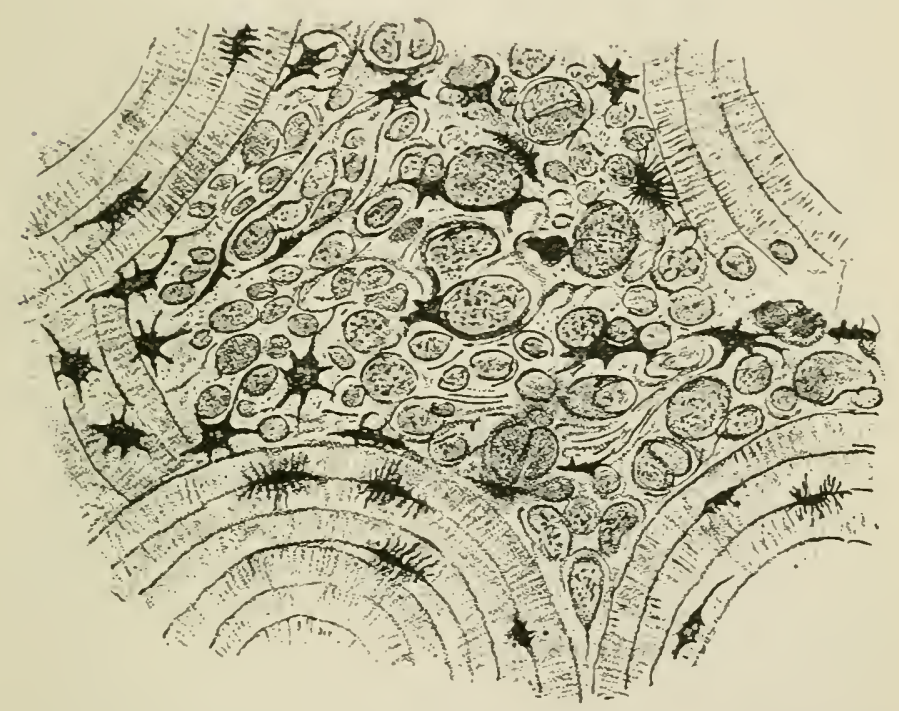

Fig. ild.-Shar ley's filmes amongst the insterstitial lamelle of a transrerse section of the human humerus; the fibres run in a vertical direction, and surround spaces which contain the bone-cells. (After Fölliker, I.)

Between these systems of concentric lamellie are the intermediate or yround lamelle; they run in various directions, and in reality fill the interstices between the systems of the Haversian or concentric lamella. Near the external surface of long bones they have preeminently a direction parallel to the surface. These are the circumferential lamelle of Tomes and de Morgan. The ground lamellae are the earliest to be dereloped, being the matrix of the first-formed spongy bone, and they are the last to disappear where bone is 
melted down in the marrow cavity. The concentric lamellix, on the other hand, are the last to be formed where spongy bone is converted into compact bone, and they are the first to become absorbed where compact bone is reduced again to spongr bone, as near the central marrow cavity. The lamellæ of compact bone are perforated by perpendicular petrified fibres, the perforating fibres of sharper. Ther form a continuity with the fibres of the periosteum, from which they are dereloped, through the lamellie of osseous substance deposited by the osteogenetic layer of the periosteum (Fig. 51A).

67. spongy bone substance occurs in the end of the shaft, in the apophyses, in short bones, and in the diploë of flat bones. The cavities or meshes of the spongy substance are called Harersiru spaces or cancelli; they intelcommunicate with one another, and are filled with marrow, which in the roung and growing state is generally of the red rariety. The firm parts form spicules and septa, called bove tioulseculte, of rarving length and thickness, and are composed of lamellice of bone substance.

According to the arrangement of the trabeculie, the spongy substance is a unitorm honeycombed substance, or appear's longitudinally striated, as in the end of the shaft. In the latter case the marrow spaces are elongated and the trabecula more or less parallel, but anastomosing with one another by transrerse branches.

6ミ. Development of bone.-Bone is dereloped in the embreo, and continues to be formed also after birth as long as bone grows, either in the cartilage or, independently of this, directly from the osteogenetic layer of the periosteum. "The former mode is called endochondral, or intracartilarinons: the lat ter periosteal. or intermembranons formation.

All the bones of the limbs and of the vertebral 
colnmm, the sternum, and the ribs, and the bones forming the base of the skull, are preformed in the early embryo as solid hyaline cartilage, covered with a membrane identical in structure and function with the periosteum, which at a later period it represents. 'This cartilage is eventually replaced by boneendochondral bone. The tegmental bones of the skull, the bones of the face with the lower jaw, except the angle, are not preformed as cartilage at all. Only a membrane identical with the future periosteum is present, and underneath and from it the bone is gratually deposited-periosteal bone. The same cleposit of periosteal bone takes place on all bones, no matter what their origin, and this deposition of layer after layer of bone by the osteogenetic layer of the periosteum represents the grouth of the bone in thickness.

69. Endochondral formation.-The stage next to the one (1) in which we have solid hyaline cartilage covered with periosteum is the following: (2) Starting from the "centre, or point, of ossification," and proceeding in all directions, the cartilage hecomes permeated by numbers of channels (cartilage channels) containing prolongations (periosteal processes of Virchow) of the osteogenetic layer of the periosteum-i.e. ressels and osteoblasts, or marrow cells. This is the stage of the rascularisation of the cartilage. In the next stage (3) the cartilage bordering on these channels grows more transparent, the lacunæ becoming enlarged and the cartilage cells more transparent. 'The latter gradually break down, while the intercellular trabeculæe become calcified; the lacunse, by absorption of the calcitied trabeculie, fusing with the cartilage channels. These latter thereby becone transformed into irregular cavities, which are hordered by trabecula of calcified cartiluge. The cavities are the mimary marrou carities, and 
they are filled with the primary or cartilage marrow

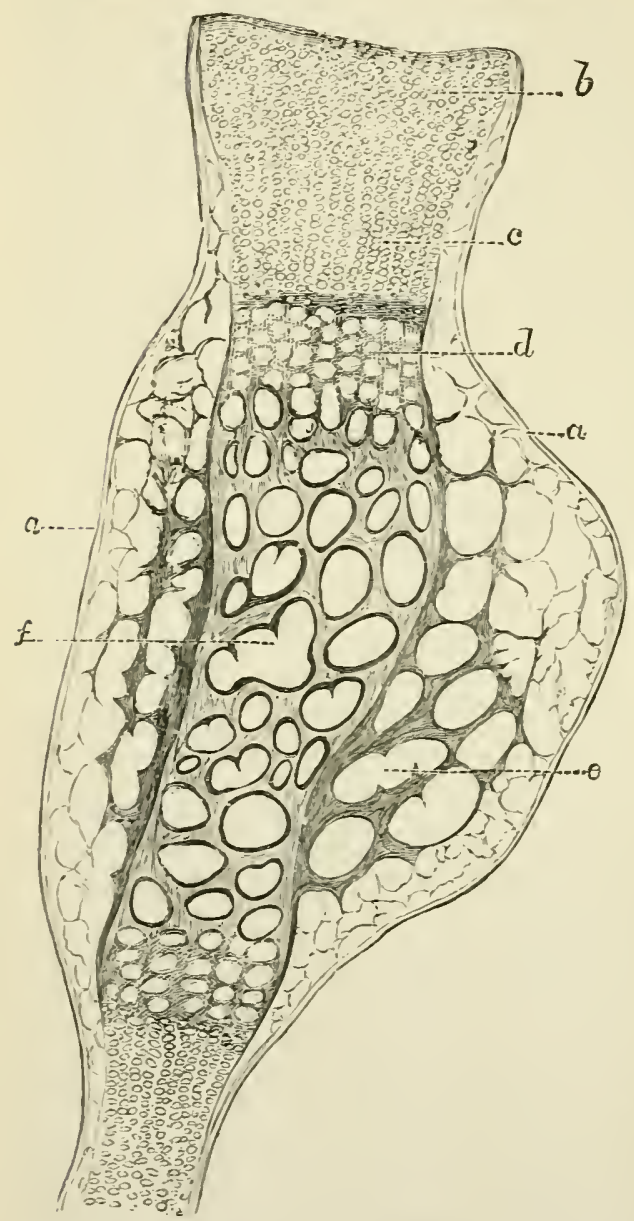

Fig. 5:.-Longitulinal Section through the entire Fotal Humerus of a Guinea-jig.

a, Periosteum ; b, hyaline cartilage of the epiphysis; $c$, interuediate cartilage at the end of the shaft; $d$, zone of calcification : e, leriosteal lone, spongy : $f$, enduchondral lone, spungr. -i.e. blood-ressels and osteoblasts, derived, as stated abore, from the osteogenetic layer of the periosteum. (t) The osteoblasts arrange themselres by actire multiplication in aspecial layer on the surface of the calcified cartilage trabeculae projecting into and bordering the primary marrow cavities. The osteoblasts foim bone sulbstunceosseous matrix and branclied bone corpuscles -and as this proceeds, the calcified cartilage trabecula become gradually ensheathed and covered rith a layer of osseons substance. Thus the original cartilage gradually assumes the appearance of a spongy 
substance, in which the cavities (primary marow cavities) are filled with the primary marrow, and are of considerable size, while the trabecula bordering them are calcitied cartilage covered with lilyers of new bone. 'The marrow cells, or osteoblists, continue to deposit bone substance on the free surface of the trabecule, while the calcified cartilage in the centre of the trabeculie griadually becomes absorbed.

70. The nearer to the centre of ossification, the more adranced is the process-i.e. the more bone and the less calcified cartilage is found constituting the trabeculie, and the thicker the latter. At the "centre, of ossification," i.e. whence it started, the process is farthest advanced; away from it, it is in an earlier stage. At this period of embryo life, between the centre of ossification and a point nearer to the extremity of the shaft of a long bone, all stages described above may be met with-viz. between the solid unaltered hyiline cartilage at the end of the shaft and the spongy bone with the unabsorbed remains of calcified cartilage in the middle of the shaft all intermediate stages occur (Fig. 52).

71. After birth, and as long as bone grows, we find in the end of the shaft, and also in the epiphysis, a continuation of the process of endochondral formation described above. In fact, all bones preformed in the embryo as cartilage grow in length before and after birth by endochondral formation of new bone. The hyaline cartilages at their extremities, the cartilage of the epiphysis, the intermediate cartilage at the end of the shaft, are the cartilages at the expense of which the new bone of the epiphysis and of the end of the shaft respectively are formed by the marrow (blood-ressels and marrow cells or osteoblasts) in contact with the cartilage. As long as this cartilage continues to grow, so long is there new formation of 
bone by the marrow encroaching on it, or, in other words, so long is there growth in length of the shaft. When at a certain period of adult life the growth of the intermediate cartilage lias come to an end, the cartilage is completely replaced by the spongy bone

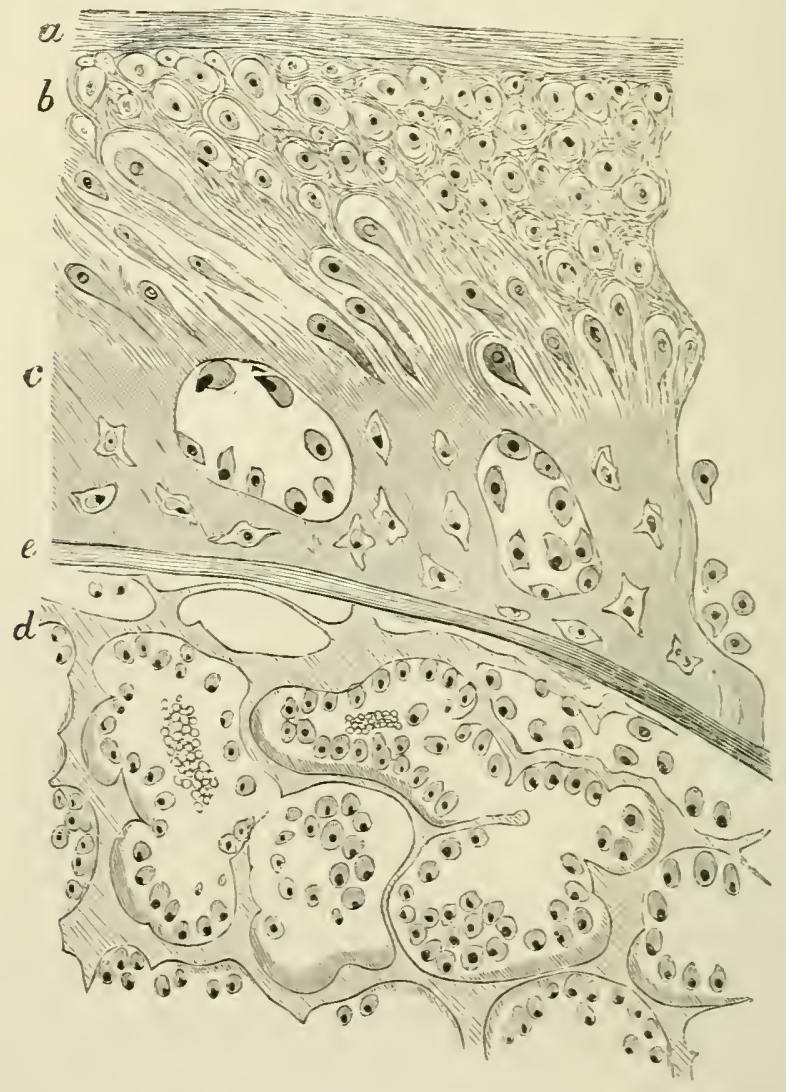

Fig. 53. - From a Transverse Section through the Tibia of Fœtal Kitten. $a$, Fibrous layer of the periosteum; $b$, ostengenetic layer of the periostemin; $c$, periosteal bone; $d$, calcified cartilage not covered yet by bone: below this layer the trateculie of calcified cartilage covered with plates of boneshaded darkly in the ffgure; $\varepsilon$, boundary between periosteal and endochondrai bone. (Atlus.) 
of the end of the shatft, and this is not capable of further lengtliening.

72. Following the development of a tubular bone after the abore mentioned stage 4, we find that the spongry bone once formed is not a permanent structure,

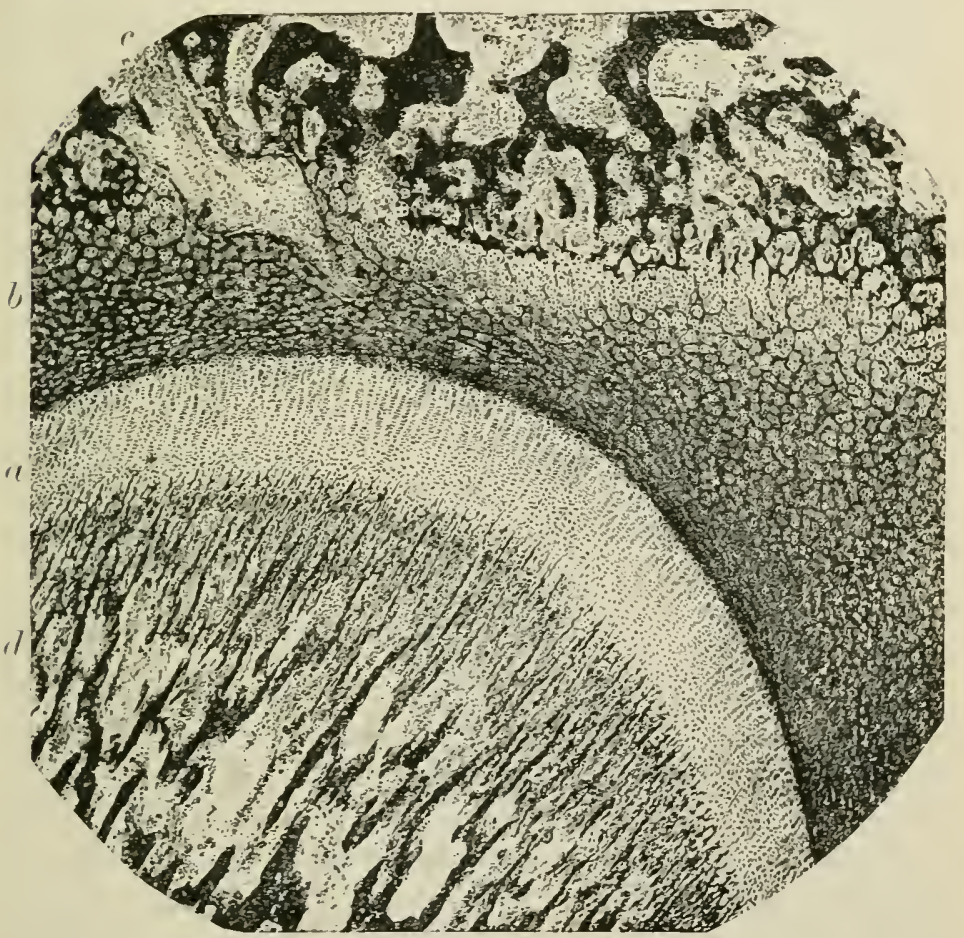

Fig. 54.-From a Section through the Intermediate Cartilage of Fenur of a Fœtus. Low magnifying power. (From a photograph by Mr. A. Pringle.)

$a$, Intermediate cartilage ; $b$, cartilage of the eliphysis; $c$, spongy bone of epiphysis; $d$, spongy bone at the end uf the shaft.

but becomes gradually absorbed altogether, and this process also starts from the points of ossification. Thus a gradual enlargement and ultimate fusion of the marrow cavities of the spongy endochondral bone 
into one continuous cavity takes place. This represents the rudiment of the future central narrow cavity of the shaft. Simultaneously with, or somewhat previous to, this absorption of the endochondral bone, new bone of the nature of spongy lone is deposited directly by the osteogenetic lreyer of the periosteum on the outer surfuce of the endochondial bome. This also comnences at the centre of ossification, and proceeds from here gradually to further points. This is the first rudiment of the periosteul bone of the shaft (Figs. 52, 53). It is formed without the intervention of cartilage directly by the osteoblasts of the osteogenetic layer. And as fresh masses of osteoblasts become developed by division, new layers of spongy bone are formed by the cluange of the former into bone matrix and bone cells, and the old trabeculie become increased in thickness. In the meshes or Haversian spaces of this new spongy periosteal bone the same tissue is to be found that constitutes the osteogenetic layer of the periosteum, the one heing derived from, and continuous with, the other.

In these Harersian spaces concentric lamellie of hone substance become subsequently formed by the osteoblasts, while at the same time the Haversian spaces, being narrowed in by the deposit of the concentric lamellae, are transformed into the Harersian canals. The original spongy bone represents, therefore, the ground substance (primary, or ground lamellae), in which, or rather in the spaces of which, the secondary deposit of the concentric lamellax or Haversian systems of bone lamella takes place, by which deposit the spongy bone becomes transformed into compact bone. This process is farthest adrancerl in the middle of the thickness of the shaft, and least near the periostemm. When this compact bone is again absorbed--e.g. that next the medullary cavity of the 
shaft of a long bone-the concentric lamellie are first absorbed, the $\mathrm{H}_{\mathrm{i}-}$ ressian canal being in this way widened out and again transformed into a Haversian space.

While, then, the lone first deposited by the periosteum is of a spongy character, and gradually becomes transformed into compact, the reverse is going on at the same time near the marrow eavity, inasmuch as compact bone is here changed into spongy bone, and this ultimately disappears and becomes absorbed by the marrow.

73. At birth all the primary endochondral bone has already disappeared by absorption from the centre of the shaft, and the bone present is

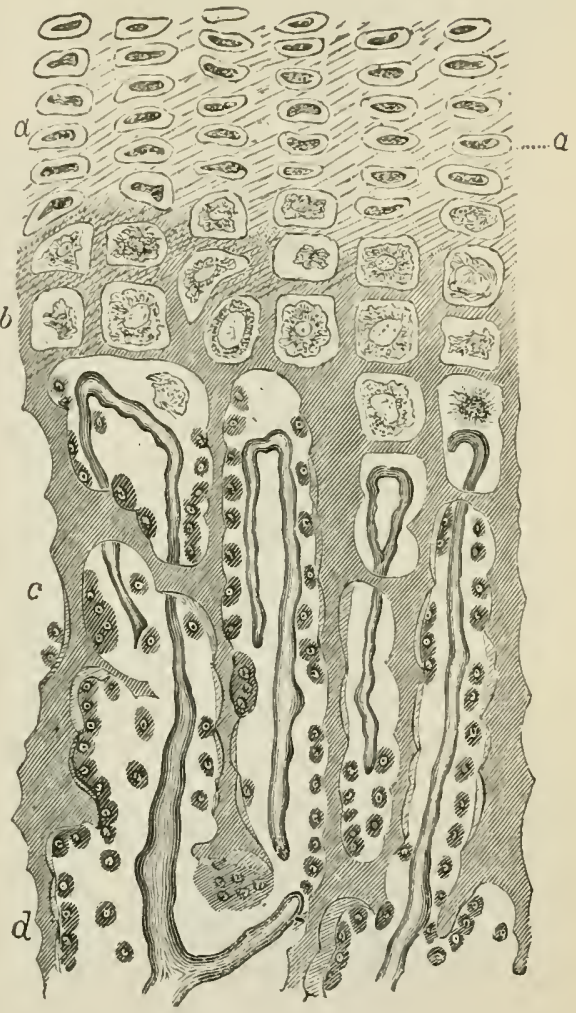

Fig. 55.-From a Longitudinal Section of Femur of Rabbit, through the part in which the intermediate cartilage joins the end of the shaft. (Atlas.)

$a$, Intermediate cartilage; $b$, zone of calcified cartilage; $c$, zone in which the calcified trabecule of cartilage become gradually invested in osseous substance, shaded light in the figure; the spaces between the tralsecule contain marrow, and the capillary blood-ressels are seen here to end in loops: d, in this zone there is more bone formed: the greater amount the further away from this zone.

all of periosteal origin. At the extremity of the shaft, lowever, the spongy bone is all endochondral 
bone, and it continues to grow into the intermediate cartilige as stated abore, so long as the bone grows as a whole (Fig. 55). Of course the parts of this spongy bone nearest to the centre

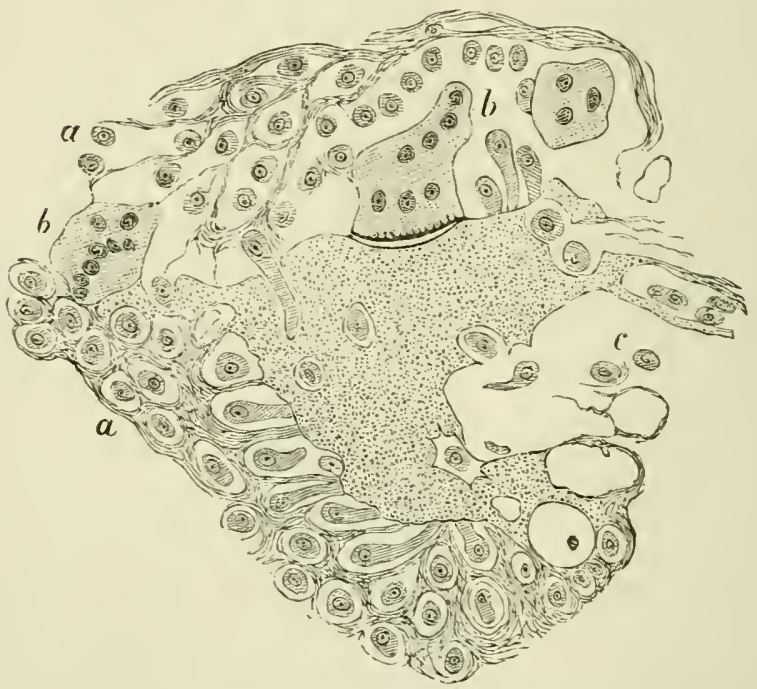

Fig. 56.-Small mass of Bone Substance in the Periostem of the Lower Jaw of a Human Fotus. (Atles.)

$a$, Osteorenetic layer of periosteim ; b. multinucleated glant cells, my eloplaxes. The one in the middle of the upper margin is an ostenclast, whereas the smaller one at the left unner corner appears concerned in the furm'ition of bone. Above $c$ the osteolitist cells become surrounded by usseums sulstance and thus become converted into bone cells.

of the shaft are the oldest, and ultimately disappeat by absorption into the central medullary cavity. In the epiphysis the spongy bone is also endochondral bone, and its formation is connected with the deep lalyer of the articular cartilage, but more so with the hyaline cartilage separating the epiphysial spongy bone from the intermediate cartilage (see $c$ of Fig. 5t).

Underneath the periosteum and on the surface of the spongy endochondral bone at the extremity of the shaft, the periosteal bone is represented only lyy a 
thin liryer, extending as far as the periosteum reaches - e.g. to the margin of the articular cartilage.

\section{Intermcubnamous formation.-All}

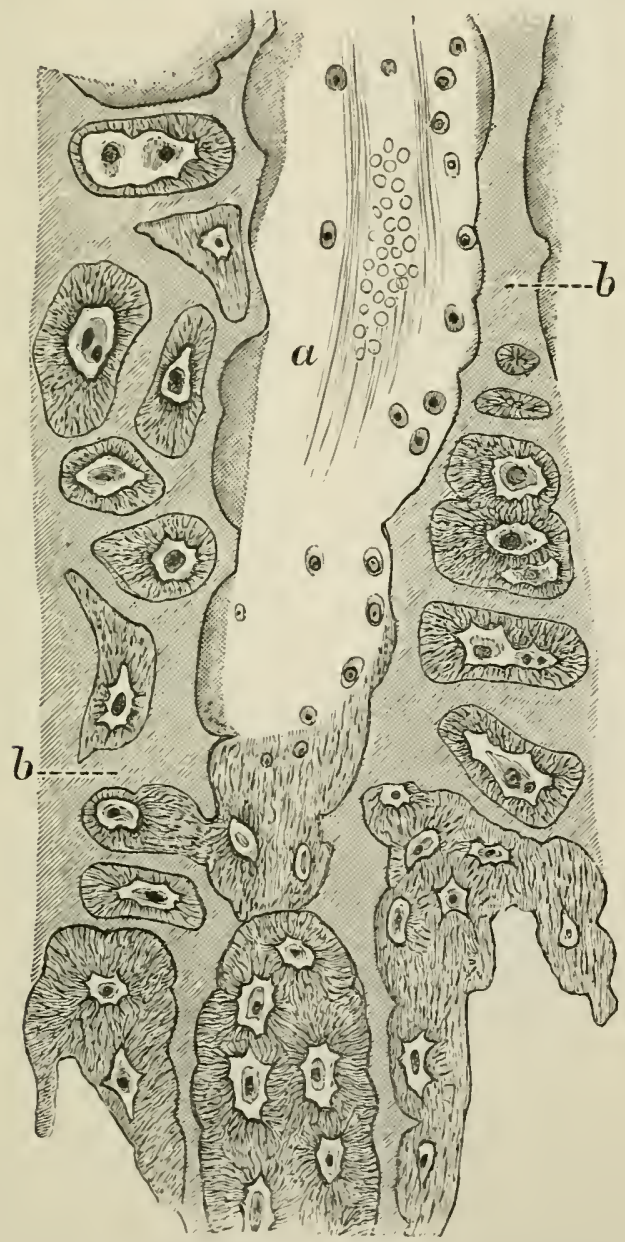

Fig. 57.-From a Longitudinal section through the Spongy Bone of Shaft, near the intermediary cartilage, of Foetal Kitten, showing the formation of osseous substance on the calcified cartilage. (Atlas.)

$a$, Inrrow suace, with bloud-ressel; $b$, calcufied cartilage, corered with isolated or confluent zoues of new osseons substance, consisting of fibrillated bone matrix, hone lacuna, and in it a bone cell. 


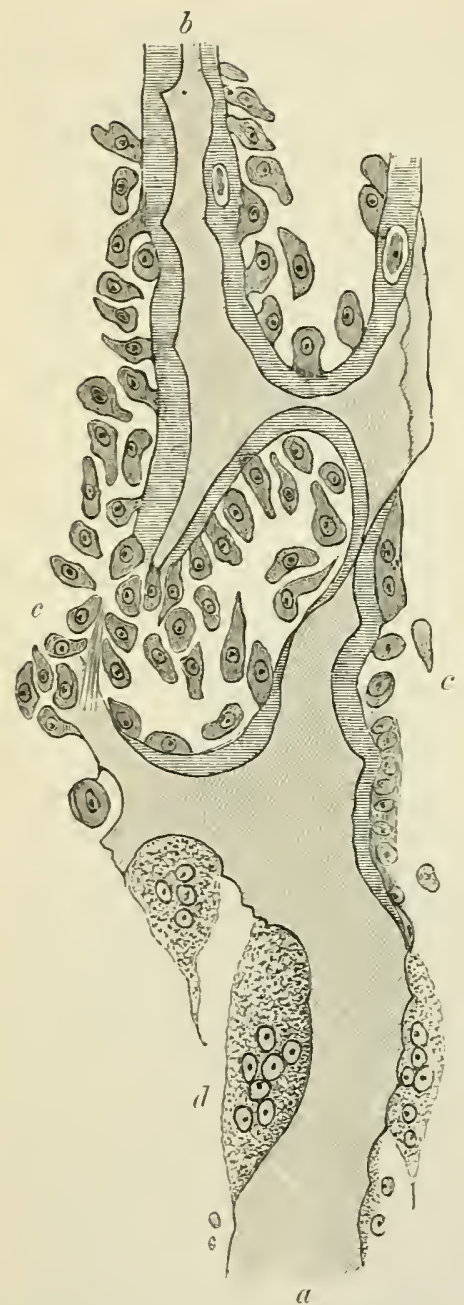

Fig. js.-From a Lonoitudinal Section of Femur of Rabbit, close to the intenneuliate cartilage.

$a$, Calcified cartilage, next to the intermediate cartilage; $b$, calclfied cartilage covered with thin layer of bone; $c$, marrow spaces containing osteublasts, forming bone on the calciticd cartilage; $d$, myeluplaxes (chundroclasts). bones not preformed in the embryo as cartilage are dereloped directly from the osteogenetic layer of the periosteum in the manner of the periosteal bone described on p. 80. Here also the new bone is at first spongy bone, which in its deeper or older layers gradually becomes converted into compact bone.

In all instances during embryonic life and after birth the growth of a bone in thickness takes place after the mamner of periosteal or intermembranous bone; this is at first spongy, but is gradually converted into compact bone.

75. All osseous substance is formed in the embryo and after birth by the osteoblasts, or marrow cells (Gegenbaur, Wal(leyer): each osteoblast giving origin to a zone of osseous matrix, and remaining in the centre of this as a nucleated protoplasmic remnant, which gradually becomes branched and transformed into a bone cell. The 
osseous matrix is at first a soft fibrillar tissue, but is gradually and uniformly impregnated with lime salts. This impregnation always starts from the centre of ossification (Eig. 5\%).

76. Wherever in the embryo or arlult, in health or disease, absorption of calcified cartilage or of osseous substance is going on, we meet with the multinucleated large protoplasmic cells called the myeloplraxes of Robin. Külliker showed them to be important for the absorption of bone matrix, and called them therefore osteoclasts (Fig. 56). For cartilage they may be called chondroclasts (Fig. 58). When concerned in the absorption we find these myeloplaxes situated in smaller or larger pits, which seem to have been produced by them; these absorption pits or lacunæ on the surface of bones are called Howship's lacunce. They invariably contain numbers of osteoclasts. It can, howerer, be shown that myeloplaxes are also concerned in the formation of bone by giving origin to a number of new osseous zones with theil bone cells. In the earliest stages of development of the fotal jaw this process is seen with great distinctness (Fig. 56 ).

$7 \tau$. Dentine forms the chief part of a tooth. It consists of a petrified matrix in which are numbers of perpendicularly arranged canals-the dentinal tubescontaining the dentinal fibres. It is in some respects similar to bone, although differing from it in certain essentials. It is similar inasmuch as it is dereloped in like manner by some peculiarly transformed embryonic connective tissue - viz. by the tissue of the embryonic tooth papilla - and inasmuch as cells are concerned in the production both of the petrified matrix (impregnated with lime salts) and of the processes of the cells contained in its camals-the dentinal fibres. The details of structure and distribution will be described in connection with the teeth. 


\section{CHAPTER VITI.}

NON-STPIPED YUSCULAR TISSUE.

78. Thus tissue consists of nucleated cells, which, unlike ammobid cells, are contractile in one definite direction, becoming shorter and thicker during contraction.

The cells are elongated, spinulle-shaped, or band-like (Fig. 59), and drawn out at each extremity into a longer or shorter, generally single, but occasionally

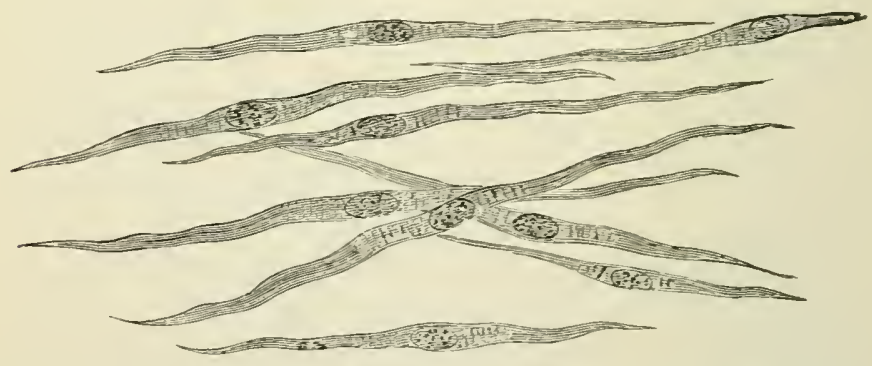

Fig. 59.-Fon-striped Muscular Fibres, isolated. (Atlus.)

The cross-markings indicate colrugations of the elastic she:th of the individual tibres.

branched, tapering process. Each cell includes an oval mucleus, which is flattened if the cell it belongs to is flattened. The cell substance is a pale, homogeneous-looking or longitudinally striated substance.

During extreme contraction the nuclens may become more or less plicated, so that its outline becomes wavy or zig-zag.

It las been shown by Klein in certain preparations 
-e.y. the non striped muscle cells of the mesentery of the newt - that each muscle cell consists of a delicate elastic sheath, inside of which is a bundle of minute filrils which cause the longitudinal striation of the cell. These fibrils are the contractile portion; and they are contractile towards the nucleus, with whose intramuclear reticulum they are intimately connected. When the cell is contracted its sheatl becomes transversely corrugated (Fig. 60).

79. The non-striped muscular cells are aggregated into smaller or larger bundles by an interstitial albu-

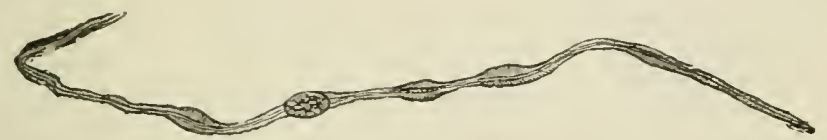

Fig. 60.-Fon-stripel Huscular Cell of Mesentery of Newt. (Atlas.)

Slowing several places where the muscular substance appears contracted, thickened. At thes places the corrugations of the sheath are marked.

minous homogeneous cement substance, the cells being imbricated with their extremities. The bundles may form a plexus, or they may be aggregated by fibrous connective tissue into larger or smaller groups, and these again into continuous masses or membranes. In the muscular coat of the bladder of the frog, in the choroidal portion of the ciliary muscle, in the arrector pili, in the muscular tissue of the scrotum, very well marked plexuses of bundles of non-striped muscular cells may be met with. In the muscularis mucose of the stomach and intestines, in the outer muscular coat of the same organs, in the uterus, bladder, etc., occur continuous membranes of non-striped muscular tissue.

When the muscular cells form larger bundles they are more or less pressed against one another, and therefore in a cross-section appear of a polygonal outline.

S0. Non-striped muscular tissue is found in the 
following places: In the muscularis mucose of the resophagits, stomach, small and large intestine; in the outer muscular coat of the lower two-thirds or half of the human wsophargus : in that of the stomach, small and large intestine; in the tissue of the pelris and outer capsule of the kidney ; in the muscular coat of

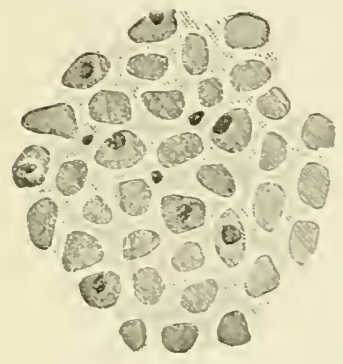

Fig. 61.-From a Transverse section throngh Bumbles of Ton-striped Yuscular Tissue of the Intestine.

The miscular cells being spindle-shaperl are cut at. variou, herghts; the large corpuscle of the figure correspond to the midale, the small unes to the extremities of the muscle cell-. (Atlas.)

fissura orbitalis; in the sphincter and dilator propillie, and the ciliary muscle; in the capsule and trabeculie of the spleen, and the trabeculie of some of the lymphatic glands: in the arrectores pilorum, and sweat glands of the skin, the tunica dartos of the scrotum; in the tissue of the nipple of the breast; in the large ducts of the salivary and pancreatic glands; and in the muscular coat of the gall bladder, the hepatic and cystic duct. The aorta and the arteries have a large amount of non-striped muscular tissue, the reins and lymphatics less.

81. As regards length, the muscular cells vary within considerable limits (from $\frac{1}{5} \overline{0}$ to 0.5 millimeter), those of the intestine, stomach, respiratory, urinary, 
and genital organs being very long as compared with those of the blood-ressels, which are sometimes only twice or thrice as long as they are broad, and at the same time branched at their extremities.

Non-striped muscular tissue is richly supplied with blood-ressels, the capillaries forming oblong meshes, though their number is not so great as in striped muscle. The nerves of non-striped muscle are all clerived from the sympathetic ; their distribution and termination will be described in a future chapter 
90

\section{CHAPTER IX.}

STRIPED MUSCUIAR TISSTE.

8.. THE striped muscular tissue is composed of long cylindical fibres, some measuring in length as

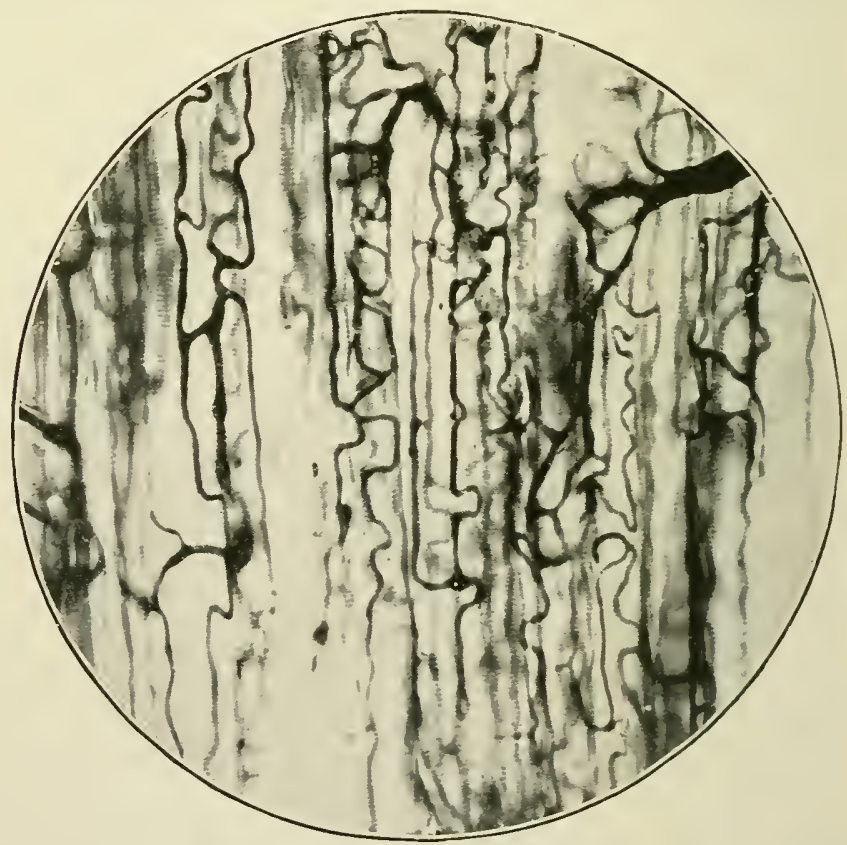

Fig. 62.-Striped IIuscular Fibres of the Tongue of a Gninea-jig, of which the blood-vessels have heen injected with carmine gelatine. Owing to the contracterl state of the muscular filnes the capillaries are much twisted and wayy ; in several places the "safety receptacles" are well shown. (From a microphoto., molerately magnifierl.)

much as $1,2,2$ inches, others are much shorter ; their thickness varies between $\frac{1}{200}$ to $\frac{1}{60} 0^{-}$of an inch. The 
fibres are regularly transversely striated, and are therefore called the striped or striated muscular fibres By fibrous connective tissue they are grouped together so as to form larger or smaller bundles-muscular fasciculi; the connective tissue surrounding the bundles is called the perimysium: while the delicate connective tissue passing from the perimysium into the bundle, and separating the individual muscular fibres from one another, is called the endomysium. The perimysium is the carrier of the larger vascular and nervous branches, while the endomysium contains the capillaries and the terminal nerves. The capillaries form very rich networks with elongated meshes, and are always situated between the individual muscle fibres. The capillaries and veins appear very wavy and twisted in the contracted bundles, and straighter in the uncontracterl bundles (Fig. 62). The small ressels are providerl here and there with peculiar saccular dilatations, which act as a sort of safety receptacle for the blood when, during a sudden intense contraction, it is pressed out from some of the capillaries.

83. Each muscular fibre during contraction becomes shorter and thicker. In the living uninjured muscular fibres, spontaneously or after the application of a stimulus, a contraction starts at one point and passes orer the whole muscular fibre like a wavecontraction ware - the progress of which is noticeable by the thickening rapidly shifting along the fibre, the part behind resuming its previous diameter.

84. A striped muscular tibre consists of (1) a delicate hyaline elastic sheath, the sarcolemma, and (2) the muscular contents. It is the structure of the latter which has given origin to a variety of theories, owing to optical difticulties in examining fresh and living fibres, and owing to the varied changes it is liable to undergo when acted upon by many reagents. 
In the following we shall adopt the riew enunciated by Rollett during recent years; we think that his conclusions are based on extensive observations and study of muscular fibres in rertebrates and invertebrates under the best conditions, and his conclusions harmonise best with the classical observations of Bowman, Briicke, Cohnheim, and Engelmann, and witl observations which can be verified by careful study of fresh muscular fibres.

s.5. The contents of a mus-

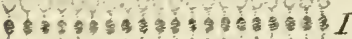

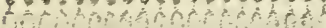

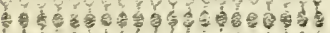

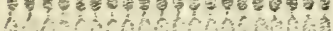
cular fibre consist of two principal parts (Figs. 63, 6t): (a) the fibrille, or rhabdia of Kühne; and (b) the sarco-

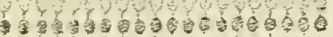
2. plasm or interfilurillar substance, a hyaline or faintly granular substance, having

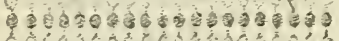
resemblances to protoplasm, and acting as the matrix for

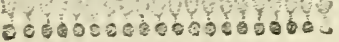
the fibrillie. The fibrillie extend in a longitudinal direction parallel to the long axis of the muscular fibre, and they are grouped together into bands, strands, or tubes, called the muscle columins ; the latter are aggregated into larger groups. The sarcoplasm fills up all interstices between the groups of the muscle columns, between the columns of each group, and between the fibrillie of each column. The amount of salcoplasn between the groups of columns is generally greater than between the columns of each group. During growth and regeneration of muscular fibres in the adult the collections of nucleated sarcoplasm on the surface-i.e. underneath the sarcolemma-become conspicuously increased in vertebrate 
muscular fibres, both in number and size ; and they are the material from which muscular fibrillie are formed. special collections of nucleater sarcoplasm are found at the termination of the motor nerve fibre in the muscular fibre (see below).

On observing a cross section through fresh or well-preserved muscular fibres, the sarcoplasm is seen as transparent lines subdividing the muscular contents, which appear dim like grround glass, into small more or less polyhedral areas, the areas of Cohnheim. These areas are the cross-sections of the muscular columns, and are therefore made up of a number of granules, the optical cross-sections of the constituent fibrillæ. The muscular columns appear aggregated by larger accumulations of sarcoplasm into larger or smaller groups; and between the groups the sarcoplasm is again greater than between the fibrillæ of each column, and in this respect there exists the greatest variety between the different animals. In the perfectly fresh condition the amount of sarcoplasm between the fibrillie of a column is

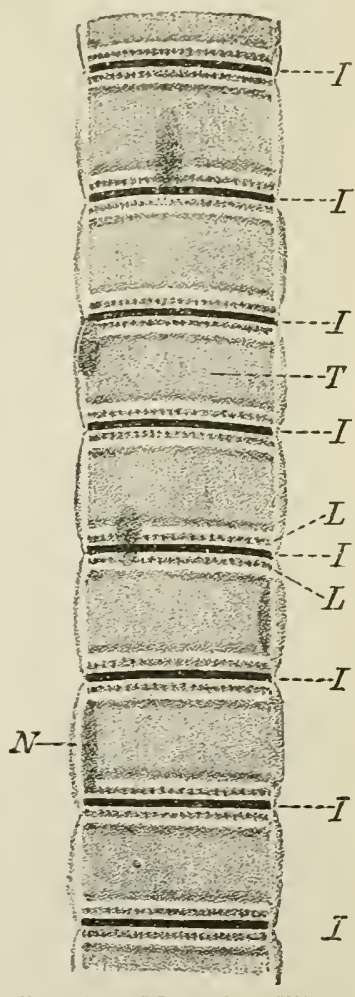

Fig. 64.-MIsculill Fihre, stained with hitmatoxyJin, of staphylinus citsireus. (Rollett.)

I, Intermerliate disc (Kranse's membrane or Dobie's layer): $L$, secondary dise (placed within the lateral dise or Flögel's lisyer); $T$, tranverse disc (sarculs: elements): $x$, nucleus of muscle corpuscle. in some cases insignificant, and almost appears absent from place to place. The sarcoplasm shows also other differences of 
distribution; in the muscular fibres of many insects it generally forms a cylindrical accumulation in the centre of the muscular fibres, containing spherical nuclei ; from it thinner septa pass between the groups of muscular columns. In vertebrate muscular fibres the sarcoplasm forms small plate-like or angular collections on the surface of the muscular contents-i.e. inmediately moler the sarcolemma. These collections include splierical, or more generally oval, nuclei, and are called the muscle corpuscles. The whole sarcoplasm must be considered as a sort of protoplasmic basis, and the muscle corpuscles as the nucleated accumulations of it.

86. Each fibrilla shows along the whole length of the muscular fibre regular alterations, as regards both aspect and thickness of its substance, and accordingly can be considered as consisting of different portions following each other endwise, and repeating themselves uniformly and in regular manner throughout the whole lengtl and thickness of the muscular fibre. These portions are the sarcous elements of Bowman, dim, homogeneous rods or prisms forming the chief parts; between each two successive sarcous elements of the same fibrilla, at equal distance, is a dirk granule, sometimes double, to which the end of each sarcous element is joined by a thin bridge. In the fresh state the sarcous elements are prisms, and those of contiguous fibrille, almost touch each other at their sides, so that little or no sarcoplasm interrenes between them here; but when the sarcous elements shrink - e.g. after death or after hardening reagents, or sometimes even during life and during contractionthey are more or less hourglass-shaped, and are separated by thin layers of sarcoplasm from those of contignous tibrille. The bridge by which each end of a sarcous element is joined to the granule being much thinner than the latter, there is more sarco- 
plasm present in the layer containing the bridge; and since the sarcoplasm is more transparent tham either the sarcous alements or the granules of the fibrillae, the muscular fibre is a whole shows a cons p i c u o u s transparent layer or dise between each layer of the dark granules and each layer of the sarcous elements. This causes the transverse striation. The layer of the dark granules corresponds to the line of Dobie, or the line of Amici, or the inter-
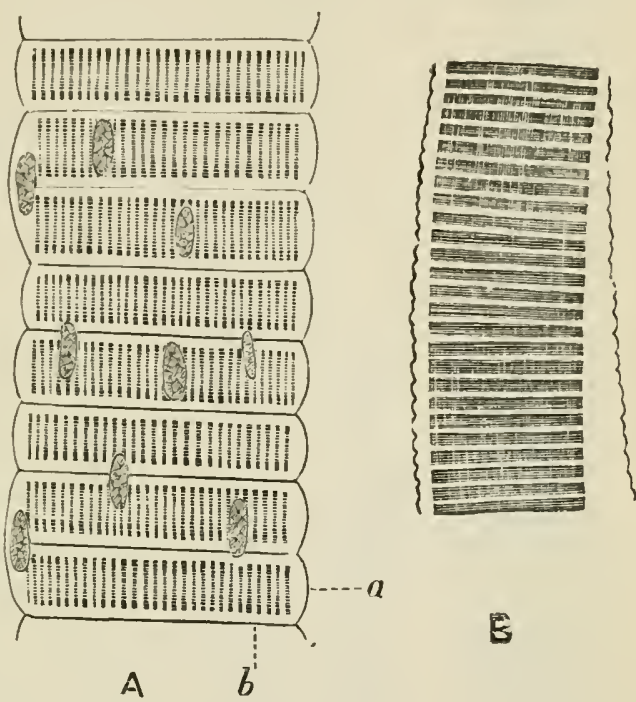

Fig. 65.-Striped Muscular Fibres of the Water Beetle (Hydrophilus). (Atlas.)

$a$, Sarcolemma; $b$, Kranse's memlurane. The sarcous elements are well seen. In A the oblong nuclei of the muscle corpuscles are shown. In is the sarcolemma hat become unuaturally raised from the muscular contents. The contractile dises are well shown; so also are the sarcous elements.

mediate disc of

Engelmann, or the membrane of krause. The layer or disc of sarcoplasm in which the bridges are placed, which join the sarcous elements to the granules of the intermediate disc, is the lateral risc. The layer or disc of sarcons elements corresponds to the trensierse clisc. In many muscular fibres of insects, notably in those of the crab (Rutherford), there occurs in each fibrilla within the lateral disc a short rod-like thickening midway between the sarcous element and the dark granule; the layer or 


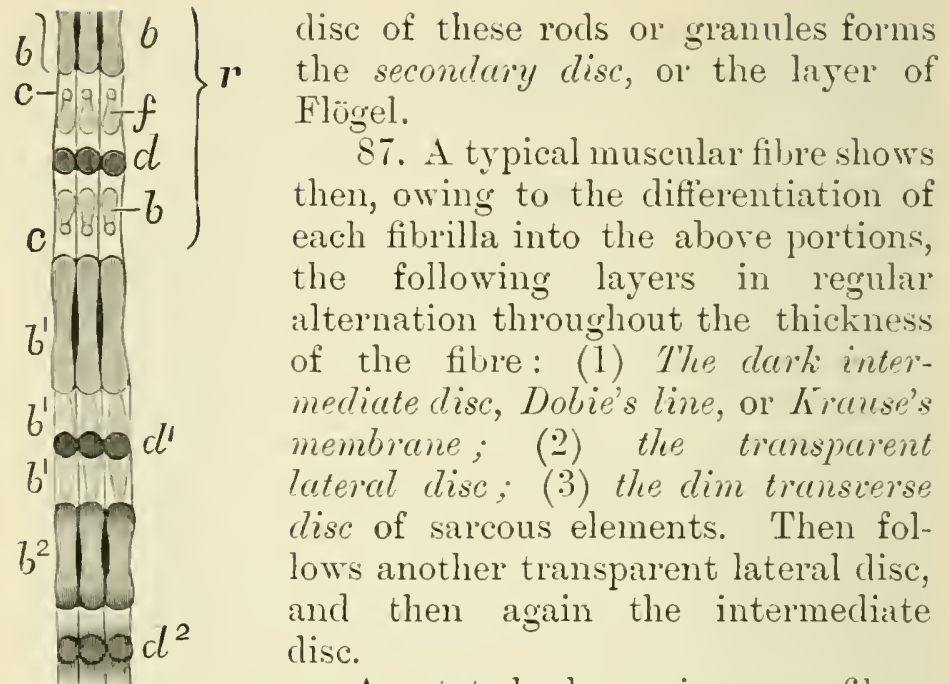

As stated above, in some fibres the line of Dobie is a double row of gramules, and the transparent lateral disc contains a line of granules, Flügel's layer.

The intermediate disc appear's to be intimately connected with the sarcolemma; hence Krause gave it the name of a membrane. When a muscular fibre contracts during life, or when it shrinks after death, the sarcolemma shows regular bulgings between each two Krause's membranes; at these latter the sarco-

Fig. 66. - Three Fibrille of Crab's Muscle, showime the successire stages from complete relaxation $(r)$ to complete contraction $(t)$. (From Rulherforl's "struture and contraction of siriped Huscular Fibre.")

$b-b 10$, The rariuns appearances of the sarcoll- elemeuts: $d-d 9$, the alnearances of Dohie's granules; $f$, Flögel's sranules: $c$, clear laver (lateral disc) letween Flögel's granules and end of sarcons elements. 
lemma is drawn in. The part of a muscular fibre between two neighbouring Krause's nembranes and the corresponding portion of the sarcolemma is
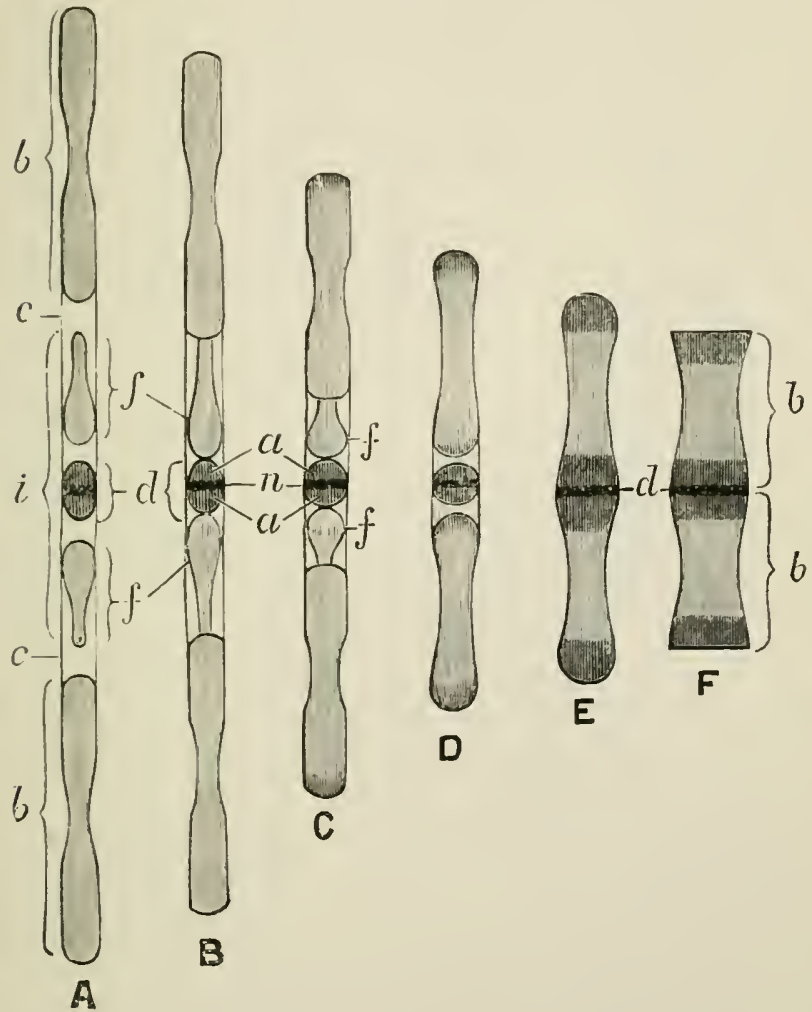

Fin. (iT.-Semi-schenatic representation of portions of Fibrils of Crab's Muscle, showing the appearances of the fibrillar segments in the several stages from complete relaxation at $\mathrm{A}$ to complete contraction at F. (After Rutherforil.)

$A-b$, Bowman's sarcous elements ; $i$, intermediate discs, comprising $d$, granules of Dobie ; $f$, granules of Flögel ; $c$, clear layer between it and end of sarcons element (lateral disc). B, lifit stase of contraction; the clear layer between Dobie's grannles and Flörel's graunles on the one side. and Flögel's granules and the end of the sarcous elements has disappeared. F, complete contraction, showing sarcons elements completely shortened: accunulatiou of cliromatic sulstance at the ends, leaving the intervening shaft clearllensen's median disc. 
spoken of as a muscular compartment of Krause (See Fig. 6.5, A).

The lateral disc contains in some muscular fibres (see above) a layer of granules or rods, the secondary disc. or Flögel's larer; but each of these granules or rods is joined to a granule of the

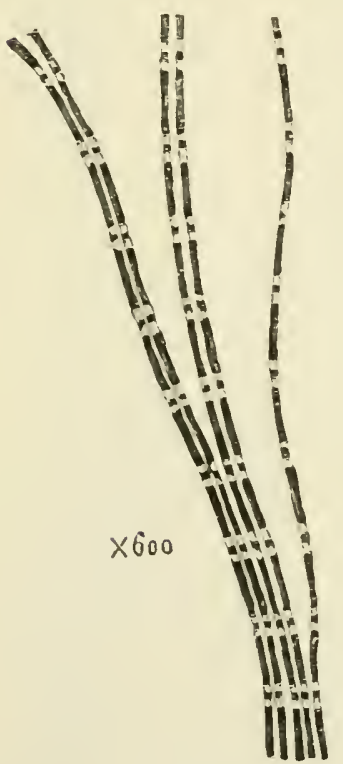

Fig. is.-Primitive Muscular Fibrilla from the Crab's Muscle. (After Rutherford.) intermediate disc, or Dobie's layer, on the one hand, and to the end of a sarcous element on the other; so that in reality it is a thickening of the bridges connecting the ends of a sarcous element to the granule of the intermediate disc.

The transverse disc, or the laver of sarcous elements, shows in muscular fibres during contraction (see below) or after hardening, or after treatment with reagents, a median transverse transparency, due to the substance of the sarcous elements being here thinner, as mentioned above. This corresponds to the median disc of Hensen. Rutherford, however, pointed out that this appearance is due to the stainable or chromatic substance of each sarcous element accumulating at the ends (Figs. 66 and $6 \bar{i}$ ).

In muscular fibres treated with alcohol, the connection between the sarcons elements and the rest of the fibrille is not recognisable; hence the muscular fibre seems split up into discs, apparently not connected with one another (see Fig. 6.5).

The reticulation described by Melland, Marshall, and others is due to coagulation of the sarcoplasma 
brought about by certain hardening reagents; the sarcoplasmia between the gramules of the layer of Dobie or Krause would thus form a reticulated disc extending transversely across the muscular fibre, and to it are joined lines of coagulated sarcoplasma extending longitudinally between the sarcous elements of the tibrillae (Fig. 69).

SE. During contraction the transrerse striation of the tibre becomes much narrower, the different discs becoming thimner in the long, broader in the transverse direction of the fibre. In the naturally contracted portion of a muscular fibre -i.e. at the point of the passage of the contraction wave-tlie stripes alter their character, inasmuch as at the end of the transverse and lateral discs the fibres become darker, while the middle of the discs of sarcous elements becomes lighter. Whether the former change -i.e. of the lateral discs-

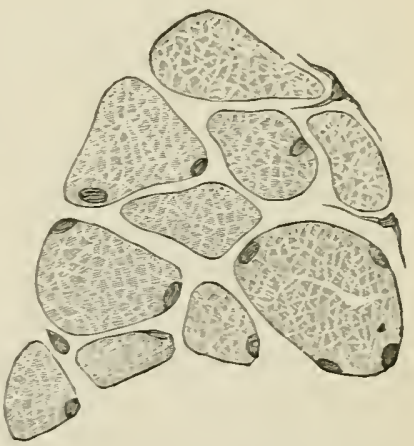

Fig. 192.-_triped Unscular Fibres in Cross-section. (Altas.)

Fach fibre is limited bs the -arco. lemma ; the muscular substance is differentiated into Colunheim's areas. is due to compression, while the latter-i.e. of the sarcous elements - is clue to an imbibition with water squeezed out of the sarcoplasma in the lateral dises, as is maintained by Engelmann, has not been fully established. Rutherford, on the other hand, points out. what appears a good explana tion of this phenomenon-viz. of the so-called reversal of the stripes during contraction - that cluring contraction the chromatic substance of the sarcous elements, together with Flögel's granules and Dobie's granules, forms one shortened mass: hence the darkness of these portions in each fibrilla. We reproduce 
here from Rutherforl drawings illustrating these points (Figs. 66 and 67 ).

Rollett considers, with Briicke, Kölliker, Engelmann, and many others, that the fibrillit are the contractile parts: while Kiihne, Rámón y Cajal, and others, are inclined to think that the sarcoplasmawhich Kühne calls sarcoglia--is the contractile part, while the fibrilla-i.e. the rhabdia of Kïhne-or rather the sarcons elements, are elastic elements.

The differentiation into intermediate, lateral, and transverse discs, possessing the above-named different structure and optical properties, produces the transverse striation of the muscular fibres: but it must be also added that a fibre, thongh homogeneons but moniliform (by shrinking or naturally so), would show a transverse striation (Haycraft).

89. In the embryo the muscular tibres are developed from spindle-shaped nucleated cells (Remak, Weissmann, Külliker). One spindle-shaped cell with

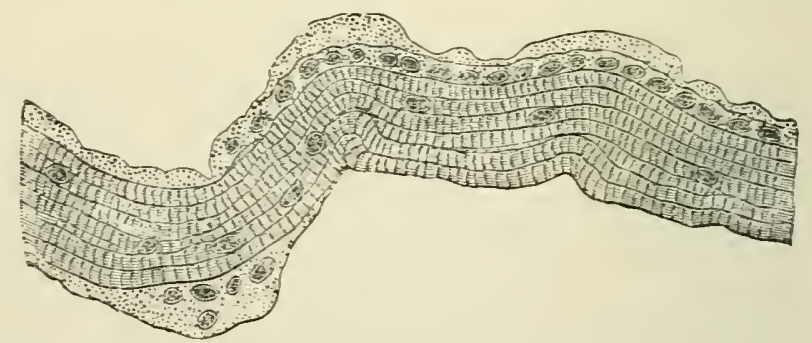

Fig 70. - Striped Muscular Fibre of the Diapiragm of a Guinea-pig. (Atlas.)

The nuscle corpuscles are much increased iu s ze aud numbers; they are probably used here for the new formatiou of inuscular substance.

an oval nucleus grows rapidly in length and thickness, its nucleus divides repeatedly, and the offspring become shifted from one another as the cell continues to grow in length. 'Thus a long spindle-shipped mass of sarcoplasma, with numerons nuclei, is the result. 
This salleopliasma in the mildle of the cell becomes converted into fibrillae, and this formation continues, while the sareoplasma als a whole increases. The muscle corpuscles of the adult fibres are remains of this sarcoplasma (Fig. 70).

At all times in aulult life, when muscular fibres increase in thickness, as, for instance, when muscle is kept at constant work, this increase is due to increase of sarcoplasma, and part-conrersion of this into fibrillix.

Paneth described in tishes, amphibia, birds, and mammals a mode of new formation of muscular fibres which supplements the one above described. While in the embryo the first muscular fibres derelop from spindle-shaped cells in the manner stated above, muscular fibres are also newly formed from spherical or oval cells-sarcoplasts; in the interior of these cells, the protoplasm is converted into contractile substance, which is capable of enlarging and elongating, and becoming converted into striped muscular fibres. According to Kolliker and Weissmann, muscle tibres divide longitudinally also, so that one fibre is capable of giving origin to a bundle of thin fibres each of which continues to increase in thickness (see muscle spindles below).

90. The striped muscular tibres, taken as a whole, are, as a rule, spindle-shaped, becoming gradually thinner towards their ends. They are branched in some exceptional cases-e.y. in the tongue; here the extremities of the nuscular fibres, passing into the mucous membrane, become richly branched previous to their termination amongst the connective-tissue fibres of the mucosa.

91. Muscular fibres terminate in tendons, either by the whole fibre passing into a bundle of connectivetissue fibrils (Fig. 11 ), or by the fibre ending abruptly with a blunt, conical end, and becoming here fixed to 
a bundle of connective-tissue fibrils. 'The iurlividual fibres have only, as has been mentioned alore, a limited length; so that, following an anatomical bundle from one end to the other, we find at many points along the fasciculus some muscle tibres

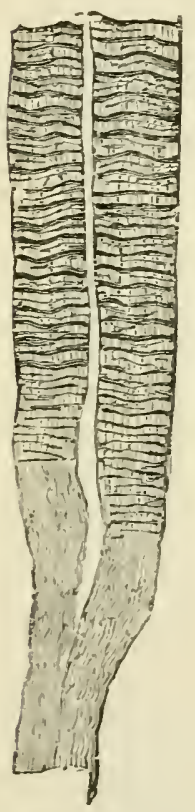

Fig. $71 .-$ Twn striperl Muscular Fibres passing into Bundles of Fibrous Tissue. (Handbooh.)

(Termination in Tendon.) terminating, othel's originating. This takes place in the following way: the contents of a fibre suddenly terminate, while the sarcolemma, as a fine thread, becomes interworen with the fine connective tissue between the muscular fibres. Many muscles contain peculiar spindle-shaped enlargements; these are the muscle buds of Kolliker Ol the muscle spindles of Kühne; rach spindle is a bundle of tine striped muscular fihres formed by length division of a mother fibre, and enclosed within a thickened connective-tissue sheath. which sheath is continuous with the laminated connective - tissue sheatl (Henle's sheath) of nerve tibres-in fact, the spindles occur at the entrance of certain nerves into the muscle bundle (see nelve endings).

9.2. The striped muscular fibres of the lieart (auricles and rentricles) and of the caldiac ends of the large veins (the pulmonary reins inchnded) differ from other striped muscular tilues in the following respects:-(1) They possess no distinct sarcolemma. ( $(2)$ Their muscle corpuscles are in the centre of the fibres, and more numerous than in ordinary tibres. (3) They are very richly branched, each fibre giving off all along its course short branches, or continually dividing into smaller tibres and forming a close 
network (Fig. 72). A transverse section through in bundle of such fibres shows, therefore, their crosssections irregular in shape and size. (4) Each nucleus of a muscle corpuscle occupies the centre of one prismatic portion; each fibre and its branches thus appear composed of a single row of such prismatic portions, and they seem separated from one anotherat any rate in an early stage-by is septum of a transparent substance.

93. Some muscular tibres are either markedly pale or markedly red (Ranvier); in the former (e.g. quadratus lumbor'um, or adductor magnus femoris of rabbit) the transverse striation is more distinct, and the muscular corpuscles less numerous, than in the latter (e.\%. semitendinosus of rabbit, diaphragm). Here

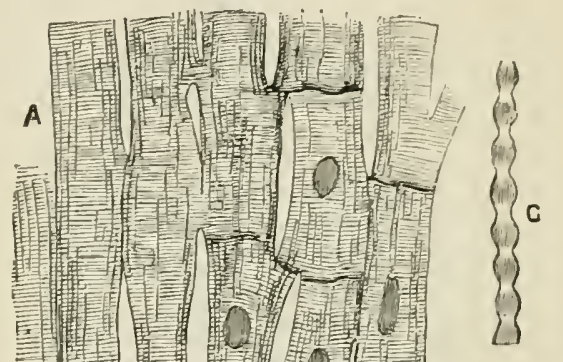
the longitudinal striation appears very distinct, but these differences are not constant in the same fibres of other animals or of man (E. Neyer).

94. Briicke has shown that striped nuuscular fibres are doubly refractive, or anisotropous, like uniaxial positive crystals (rock crystal), the optical axis coinciding with the long axis of the fibres. The 
sarcoplasma is isotropous, the fibrilla alone being anisotropous; of these the sarcous elements were the first recognised by Bricke to be doubly refractive. They are, however, not the ultimate optical elements, but must be considered as composed of disdiaclasts, the real doubly refractive elements (Briicke). 


\section{CHAPTER X.}

TIIE IIEART ANI BLOOD-TESSELS.

95. (A) THE heart consists of an outer serous covering, the iviscral pericardium or exocurd, an inmer lining, the endocardium, and between the two the musculai substance (Fig. T3).

Underneath the pericardium is a thin layer of connective tissue called the subpericardial tissue.

The free surface of both the pericarclium and endocardium has an endothelial covering, like other serous membranes-i.e. a single layer of transparent nucleated cell plates of a more $\mathrm{Or}^{2}$ less polygonal or irregular shape. The groundwork of these two membranes is tibrous connective

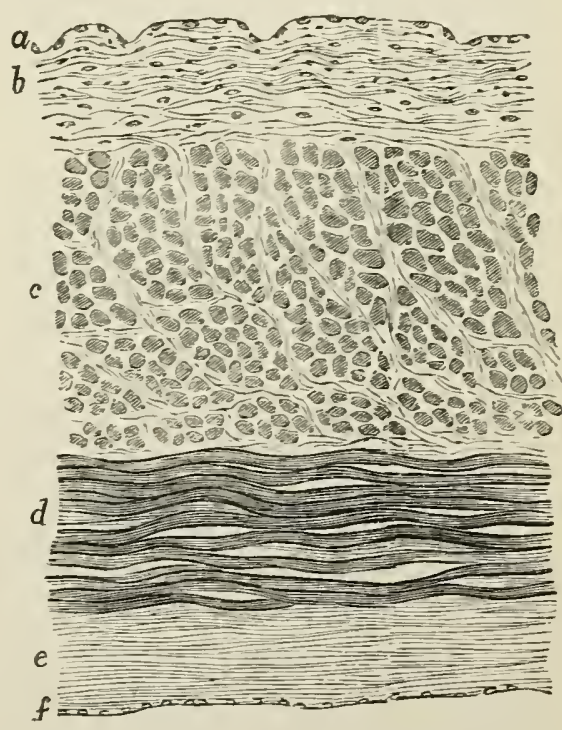

Fig. 73.-Transverse Section througl the Auricle of the Heart of a Child.

$a$, Endothelium lining the endocardium; $b$, endocardium ; $c$, muscular bundles cut tranver-ely ; $d$, mu-cular bundles cut longitudinally; $e_{\text {: }}$ Pericardial covering ; $f$, endotlielium. tissue, forming a dense texture, and in addition there are many elastic tibres arranged as networks. Capillary blood-ressels, 
lymphatic ressels and small branches of nerve tilres are met with in the pericardial layer. The subpericardial tissue consists of trabecule of fibrous connective tissue, which are continuous with the intermuscular connective tissue of the muscular wall of the lieart. The former contains in many places groups of fat cells.

96. On the free surface of the papillary muscles, in some parts of the surface of the trabeculie carnea, and at the insertion of the valres, the endocardium is thickened by tendinous connective tissue. Each valve is covered with a prolongation of the endocard, but the main body of the valve is dense fibrous comnective tissue; on the surface of this connective-tissue matrix is a somewhat looser connective tissue, containing also a few elastic fibres.

All the cordae tendineat and the valves are of course corered on their free surfaces with endothelinm.

special tracts of muscle fibres occur in the subendocardial tissue.

The fibres of Purkinje are peculiar beaded tibres occurring in the subendocardial tissue in some mammals-e.g. the sheep and the horse-and birds (not in man). 'They are thin, trinsversely striped, muscular' tibres possessed of local thickenings; the central part of each thickening is a continuous mass of protoplasm, with nuclei at regular intervals, as is the case with some skeletal muscular fibres of insects. These headed tibres of Purkinje must not be confused with the muscle spinalles of Kühne.

97. The muscular fibres forming the proper wall of the heart, the structure of which has been described in the previous chapter, are grouped in bundles separated by rascular fibrous comnective tissue. In the rentricles the bundles are aggregated into more or less distinct lamellae.

Like other striped muscular tibres, those of the 
wath of the heart atre richly supplied with blood-ressels and lymphatics. The endocardium and valves hive no blood-ressels of their own, but the pericardium possesses its own system of lloodvessels.

The lymphatics form a pericardial and an endocardial network connected with the lymplatics of the muscular tissue of the heart; here there are lymphatic clefts between the muscular bunclles, and also networks of tubular lymphatics.

98. The nerve branches of the

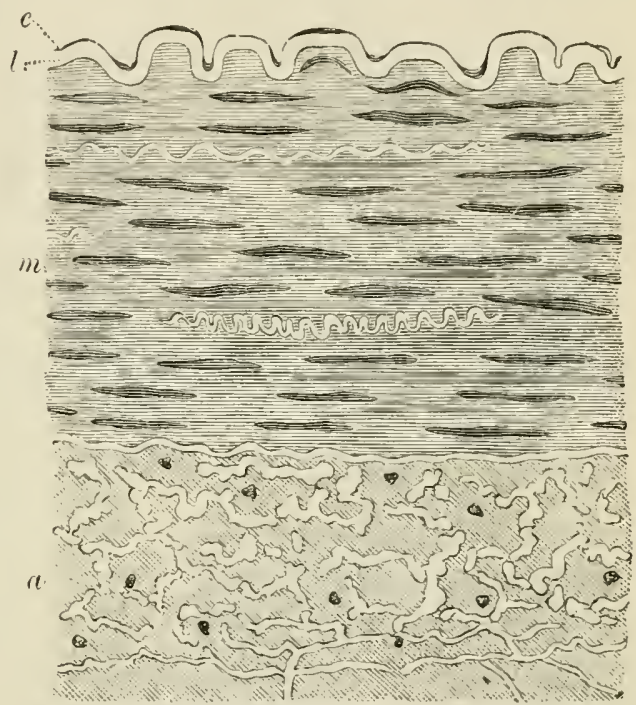

Fis. 74.-From a Transverse section through the Inferior Mesenteric Artery of the Pig.

$e$, Endothelial lining; l, elastic intima; $m$, museular media; $"$, arlventitia with numerous elastic tibrils, cut in transverse section. (.1tas.) plexus cardiacus form rich plexuses. In connection with some of them are found numerous collections of ganglion cells or ganglia. These are very numerous in the nerve plexus of the auricular septum of the frog's heart (Ludwig, Bickler), and in the auriculo-ventricular septum of the frog (Dogiel). In man and mammals numerous ganglia are found on the auricular nerve branches, chiefly at the point of junction of the large veins with the heart, Remak's ganglia, and at the boundary between the amricles and the ventricles, Bidder's ganglia.

9). (B) The arteries (Fig. 74 ) consist of : ( $a$ ) an 
endothelial. layer lining the lumen of the ressel; $(b)$ an intima, consisting of elastic tissue: (c) a media, containing a large proportion of non-striped muscular cells arranged chiefly in a transverse, i.e. circular manner; and $(d)$ an adientitir composed chiefly of fibrous

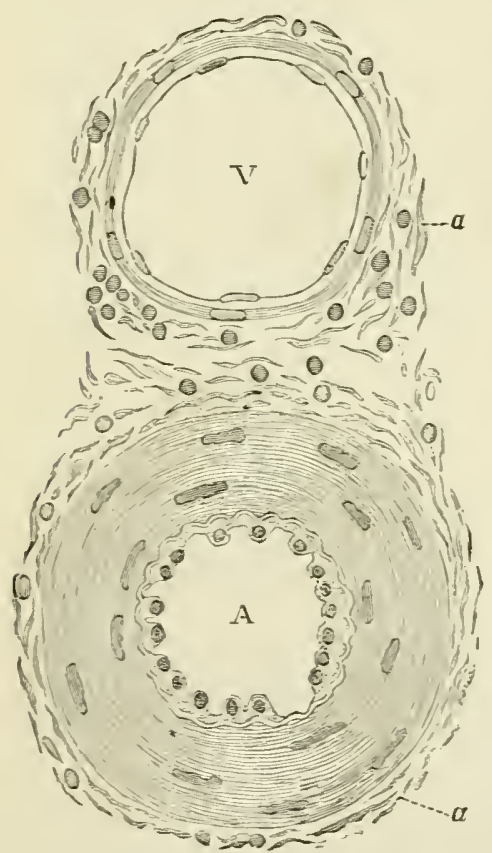

Fig. 75.-Transterse section through a Microscopic Artery and Vein $1 n$ the Epiglottis of a Child. (Atlas.)

$A$, The artery, showing the nucleated endothelium, the circular mu-cular media, aud at $a$ the fibrou-tis:ue adventitia: $r$, the rein, showing the same layer: : the media is rery much thinner than in the artery. connective tissue, with an admixture of networks of elastic fibres.

(a) The enclothelium is a continuous single layer of flattened elongated cell plates.

(b) The intima in the aorta and large arteries is a very complex structure, consisting of an innermost layer of fibrous comnective tissue, which is the "inner longitudinal fibious layer" of Remak, outsicle of which is a more or less longituclinally arranged elastic nembrane. This is laminated, and conposed of fenestrated elastic membianes of Henle. (See page 61.) The larger the artery the thicker the intima. In microscopic arteries the intima is a thin fenestrated membrane, the fibres having distinctly a longitudinal arrangement.

(c) The media is the chief layer of the wall of the arteries (Fig. 75 ). It consists of transversely arranged 
(ristic lamellae (fenestrated membranes and networks of elastic fibres), and between them smaller or larger bundles of circularly arranged muscular cells. The larger the artery the more elastic tissue is there present in the media, the smaller the artery the more muscular tissue. In mieroscopic branches of arteries the media consists almost entirely of circular nonstriped muscle cells with only few elastic fibres.

100. In the last branches of the microscopic arteries the muscular media becomes discontinuous, inasmuch as the (circular) muscular cells are arrangerl not as a continuous membrane, but as groups of small cells (in a single layer) in a more or less alternate fashion.

When the media contracts, the intima is thrown into longitudinal folds.

The aorta has, in the innermost and in the ontermost parts of the media, numbers of longitudinal and oblique numsele cells. According to Bardeleben, all large and middle-sized arteries have an inner longitudinal muscular coat.

101. Between the media and the next outer layer there is, in larger and middle-sized arteries, a special elastic membrane, the elastica externa of Henle. (d) The adventitia is a relatively thin fibrous connective-tissue membrane. In large and middle-sized arteries there are numbers of elastic fibres present, especially in the part next to the media; they form networks, and have chiefly a longitudinal direction.

The larger the artery the more insignificant is the adventitia as compared with the thickness of the media.

In microscopic arteries (Fig. 76 ) the ardventitia is represented by thin bundles of fibrous connective tissue and branched comnective-tissue cells.

Large and middle-sized arteries possess their own 
srstem of blood-ressels (rasa rasorum), situated chiefly in the adrentitia and media; lymphatic ressels and lrmphatic clefts are also present in these coats.

102. (c) The veins difter from the arteries in the greater thinness of their wall. The

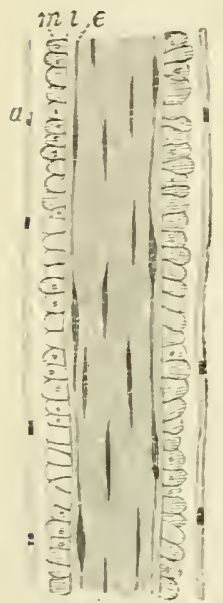

Fir. Tu.-Minute Microscoric Artery. (Atlas.)

e, Endotbelinm: i, intima: $m$, muscular n edia.compo-ed of a single laver of circularly - arranged non-strified muscular cells; $a$, adrentitia. intima and media are similar to those of arteries, only thimmer, both absolutelr and relatively. The media contains in most reins circularly arranged muscular tibres; they form a continuous laser, as in the arteries, and there is between then generally more fibrous commective tissue than elastic. The adrentitia is usually the thickest coat. and it consists chiefly of fibrous connective tissue (Fig. Tì). The smallest reins-i.e. before passing into the capillaries-are composed of a liming endothelium. and outside this are clelicate bundles of comnective tissue forming an adrentitia. The ralres of the reins are folds. consisting of the endothelium lining the surface, of the whole intima, and of part of the muscular media.

103. There are many reins that have no muscular fibres at all-e.g. vena jugularis (interna and externa), the rena subclavia, the reins of the bones and retina, and of the membranes of the brain and cord. Those of the gravid uterus have only longitudinal muscular fibres. The vena cara, azTgos, liepatica, spermatica interna, renalis and axillaris, possess an imner circular and an outer longitudinal coat. The rena iliaca, cruralis, poplitea, mesenterica, and umbilicalis possess an imner and outer longitudinal and a middle circular 
muscular coat. The intima of the rene pulmonales in man is connective tissue containing circular bundles of non-striped muscular cells (Stieda).

104. The trunk of the rena pulmonales and rene care possesses striped muscular fibres, these being continuations of the muscular tissue of the auricles.

105. Hoyer showed that a direct communication exists between arteries and reins without the intervention of capillaries-als in the matrix of the nail, in the tip of the nose and tail of some mammals, in the tip of the fingers and toes of man, in the margin of the ear lobe of dog and cat and rabbit.

In the carernous tissue of the genital organs reins form large irregular sinuses, the wall of which is formed by fibrous and non-striped muscular tissue.

106. (D) The capillary blood-vessels are minute tubes of about $\frac{1}{200 \overline{0}}$ to $\frac{1}{3000}$ of an inch in diameter. Their wall is a single layer of transparent elongated endothelial plates, united by thin lines of cement substance (Fig. 77 ). Each cell has an oval nucleus ; in fact, the wall of the capillaries is merely a continuation of the endothelial membrane lining the arteries and reins.

In some places the capillaries possess a special adrentitic made up of branched nucleated connectivetissue cells (hyaloidea of frog, choroidea of mammals), or of an enclothelial membrane (pia mater of brain and cord, retina and serous membranes), or of actenoid reticulum (lymphatic glands, His).

The smallest capillaries are found in the central nerrous system, the largest in the marrow of bone. The capillaries form networks, the richness and arrangement of which vary in the different organs, according to the nature and arrangement of the elements of the tissue (Fig. 78). 
107. If capillaries are abmormally distended, as in inflammation, or otherwise injured, the cement

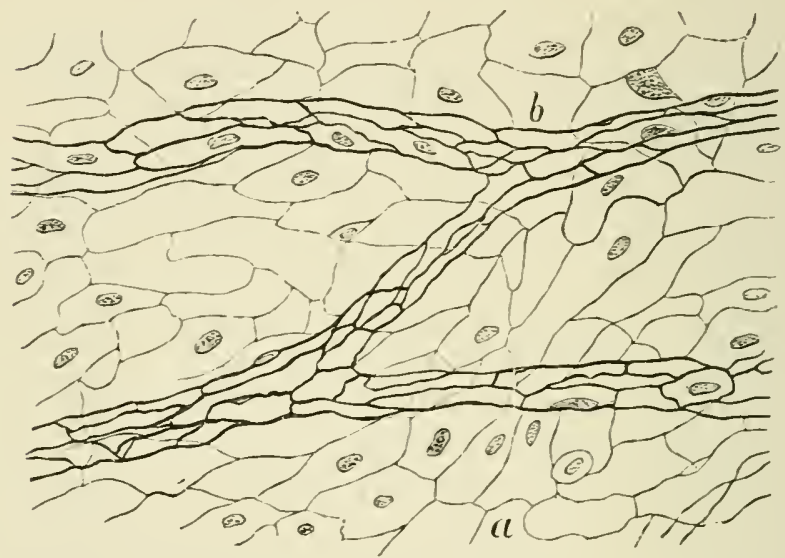

Firg. 7\%. From a Preparation of the Peritonem, stained with Nitrate of Silver. (Hondbooli.)

a, Entuthelim on the free surface of the membrane; $b$, capillary blood vessels in the nembrane; their wall is a lajer of endothelium.

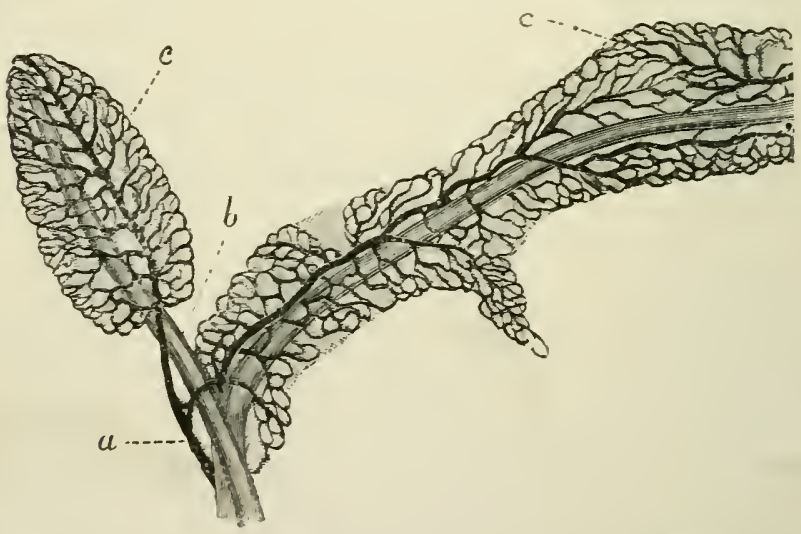

Fis. is.- Young Fat Tissue of the Omentum, its Bloorl-vessels injected. ", Artery ; $b$, vein; $c$, network of capillaries. (II (undbook.)

sulustance between the endothelial plates is liable to give way in the shape of minute holes, or stigmata, 
which may hecome larger holes, or stomutu. 'The parssige of red blood corpuscles (diapsesis) and the migration of white corpuscles in inflammation through the unbroken eapillaries and small veins occur through these stignati and stomati.

108. Young and growing rapillaries, both of normal and pathological tissues, possess solid threadlike shorter or longer nucleated protoplasmic processes (Fig. 79), into which the canal of the capillary is

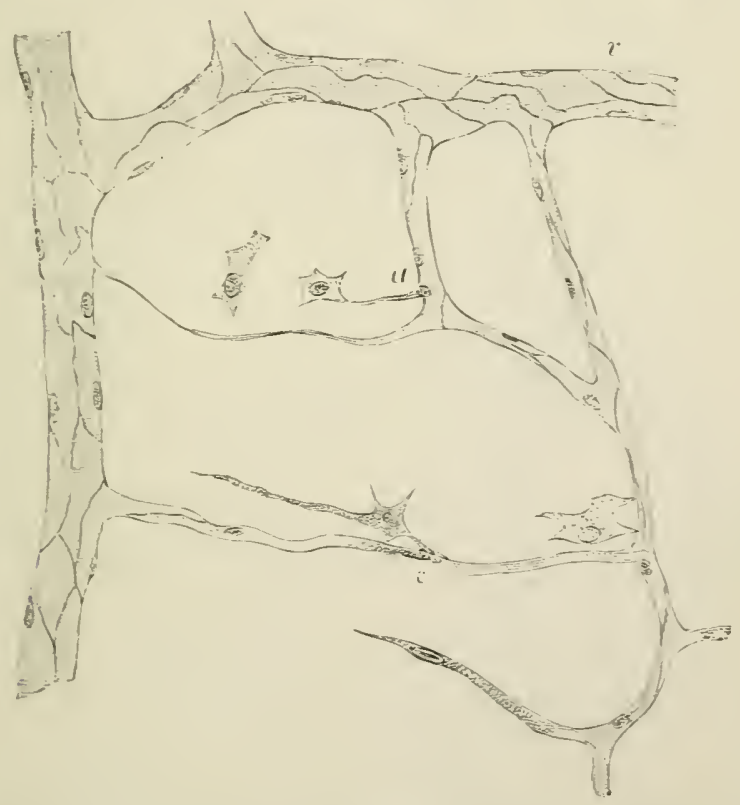

Fig. 79. -From a Preparation of Omentum of Rablit, after staining with Nitrate of silver. (Atlis.)

$v$, Minute rein ; $a$, solid protoptasmic prolongations of the wall of a capillary, connected with connective-tissue corpuscles; $c$, solid young bud.

gradually prolonged, so that the thread becomes con. verted into a new eapillary branch. Such growing eapillaries are capable of contraction (Stricker).

All blood-ressels, arteries, reins, and capillaries, 
in their early stages, both in embryonal and adult life, are of the nature of minute tubes, the wall of which consists of a simple endothelial nembrane. In the case of the vessel becoming an artery or vein, cells are added to the outside of the endothelium, thus forming the material for the development of the elastic, muscular, and fibrons connective-tissue elements of the wall.

109. In the first stage, both in the embryo and in the adult, the ressel is representer by solid nucleated protoplasmic cells, spherical, elongated, spindle-

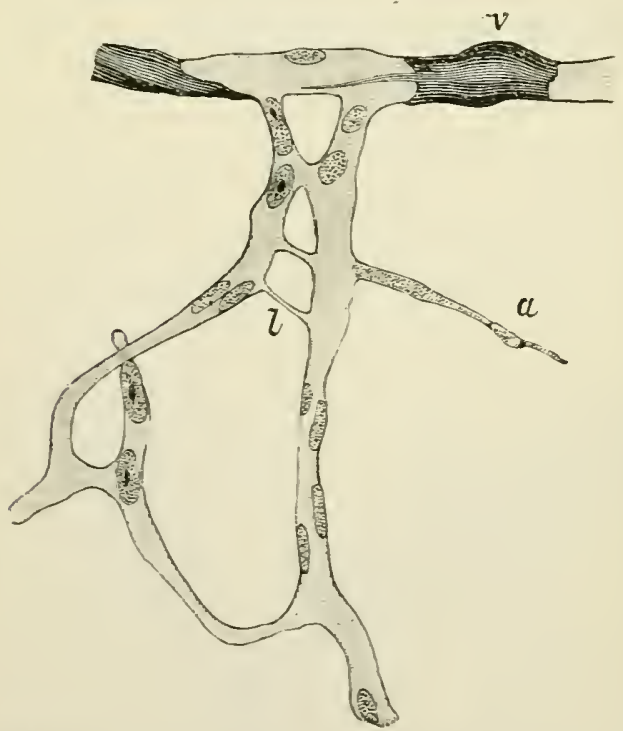

Fis. s0.-Developing Capillary Bluod-ressels from the Tail of Tadpole. (Atlos.)

r, Capillary vein with clumps of pirment in the wall; $i$, nucleated protoplasmic sprout; $l$, snlid anastomosis between two neighbouring capillaries.

fluent, and thus a romng vessel is formed, at first very irregular in outline, lut sradually acquiring more and more of a tubular form. In the case of ched - icrsofiormative cells. Such cells may be isolated and independent of any pre-existing ressel, or ther may be solid protoplasmic outgrowths of the endothelial wall of existing capillary ressels (Fig. sio). In both cases they become liollowed out by a process of vacuolation; isolated vicuoles appear at first, but they gradually become con-

shaped, or bran- \\ I If} II

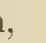
t 
an isolated cell, its protoplasmic processes grow by degrees to the nearest capillary, to the wall of which they become fixed, and the carity of the cell finally opens through such processes into that of the capillary ressel.

'The islets or eysts of blood that appear early in the areat rasculosa of the embryo are due to vacuolation of

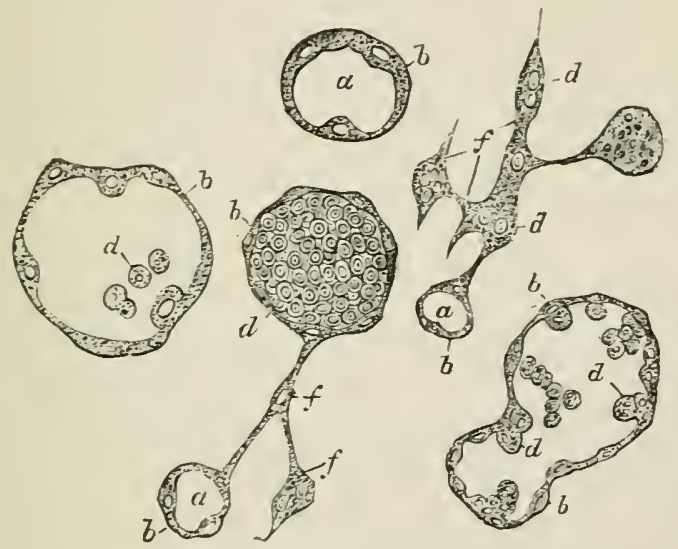

Fig. S1.-Cells from mesoblast of chich's blastoderm undergoing development into blood-ressels in the area vasculosa. (Hendbool:)

", civity" of cell; $b$, cell wall; $f$, cells not yet hollowed out; $d$, bloud corpusch:

spherical or elongated vasoformative cells of the mesoblast, the islets or cysts being composed of a central portion which are blood corpuscles, at first white, then led, and a peripheral protoplasmic nucleated envelope, the future rascular' wall. 'The central nucleated blood cells develop by a process of endogenous division from the original cell protoplasm. The blood cysts, at first isolated, afterwards become connected by protoplasmic processes with other cysts or other vasoformative cells, ultimately forming a network of ressels (Fig. S1).

The wall of young capillaries is granular-looking protoplasm (the original cell substance), and in it 
are disposed, in more ol less regular fashion, oblong nuclei, derised by multiplication from the nucleus of the original cell. In a later stage, a differentiation takes place in the protoplasmic wall of the capillary into cell plates and cement substance, in such a way that each of the abore nuclei appertains to one cell plate, which now represents the final stage in the formation of the capillary. Both in the embryo and in the adult a few isolated nucleated protoplasmic cells, or a few protoplasmic solid processes of an existing capillary, may by actire and continued growth gire origin to a whole set of new capillaries (Stricker, Aftanasieff. Arnold, Klein, Balfour, Panvier, Leboucq). 


\section{CHAPTER XI.}

THE LYMPHATIC VESSELS.

110. 'THE large lymphatic trunks, such as the thoracic duct, and the lymphatic ressels passing to and from the lymphatic glands, are thin-walled vessels,

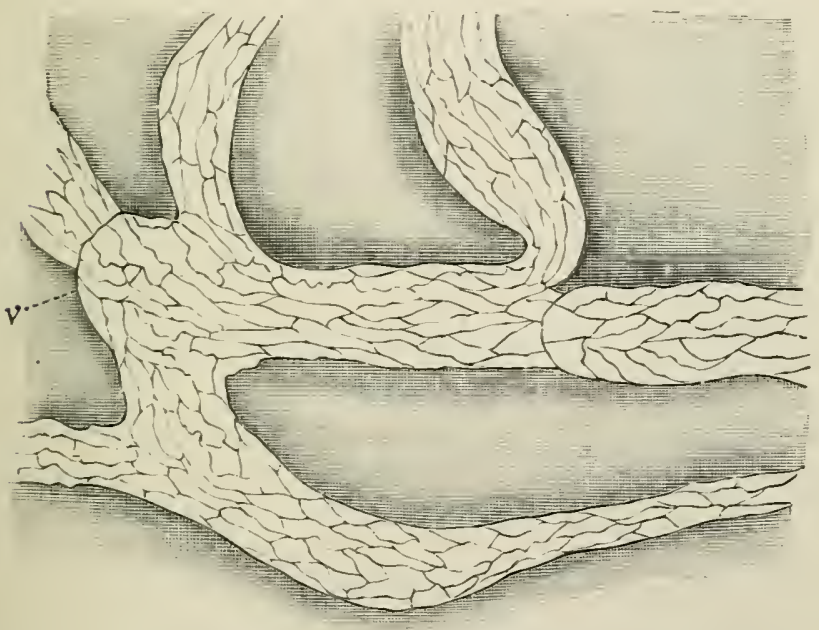

Fig. s...-Lymphatic Vessels of the Diapluragu of the Dog, stained witl Nitrate of silver. (Atlos.)

The cndothelium forming the wall of the lymphatics is well shown ; $v$, valves.

similar in structure to arteries. Their lining endothelium is of the same character as that of an artery, and so are the elastic intima and the media with its circular muscular tissue ; but these latter are very much thinner than in an artery of the same calibre. 
The adrentitia is an exceedingly thin connectivetissue membrane with a few elastic fitres. The ralres are semi-lunar folds of the entlothelium and intima.

111. The Irmphatics in the tissues and organs form rich plexuses. They are tubular ressels, the wall of which is, like that of a capillary blood-ressel,

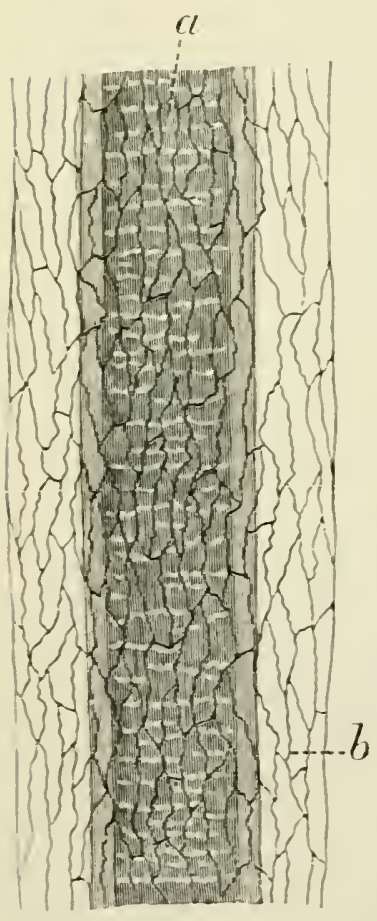

Fi-. 83.-Fron silver-stainerl specimen of the mesentery of the frog.

(1, Arters: $b$, Terivascular limplitic ressel, thowing its endotbelial wall.

The ressel appears slightly dilated immediately berond the valve-that is, on the sicle farthest from plates (Fig. S.). The lympluatic is often many times wider than a blood capillary. The endothelial plates are elongated, but not so long as in a blood capillary; with more or less sinuous outlines: but this depends on the amomnt of shrinking of the tissue in which the ressel is embedded: when there is no shrinking in the tissue or in the ressel. the ontlines of the cells are more or less straight.

The lymphatics are supported by the fibrous connective tissue of the surrounding tissue. which does not, lowerer, form part of their wall.

112. The outline of the ressel is not straight, but more or less moniliform, owing to the slight dilatations present below and at the semi-lman valies: these are folds of the enclothelial wall, and they are met with in great numbers. a single laver of endothelial 
the periphery, or rootlet, whence the current of lymph starts.

113. Tracing the lymphatic ressels in the tissues and organs towards their rootlets, we come to more or less irregularly-shaped ressels, the wall of which also consists of a single layer of polygonal enclothelial plates: the outlines are rery sinuons. These are the lymplutic copillaries; in some places they are mere clefts and irregular sinuses, in others they have more the character of a tube, but in all instances they have a complete endothelial lining, and no valves.

Sometimes a blood-ressel, generally arterial, is ensheathed for a shorter or longer distance in a lymphatic tube, which has the character of a lymphatic capillary; these are the perivascular lymplatics of His, Stricker, and others (Fig. 83).

114. The rootlets of the Iymphatics are situated in the connective tissue of the different organs in the shape of an intercommunicating system of crevices, clefts, spaces, or canals, existing between the bundles, or groups of bundles, of the connective tissue. These rootlets are generally without a complete endothelial lining, but are identical with the spaces in which the comnectire-tissue corpuscles are situated; where these are branched cells anastomosing by their processes into a network-such as the cornea, or serous membranes - we find that the rootlets of the lymphatics are the lacune and canaliculi of these cells - the typicai lymple-cenalicular system of von Recklinghansen (Fig. 8t). The endothelial cells forming the wall of the lymphatic capillaries are directly continuous with the connective cells situated in the rootlets. In tendons and fascie the minute lymphatics lie between the bundles, and have the shape of continuous long clefts or channels; in striped muscular tissue they lave the same cluaracter, being situated between the muscular fibres. 
The passage of plasma from the minute arteries and capillary blood-ressels into the lrmph-rootlets situated in the tissues, and thence into the lymphatic

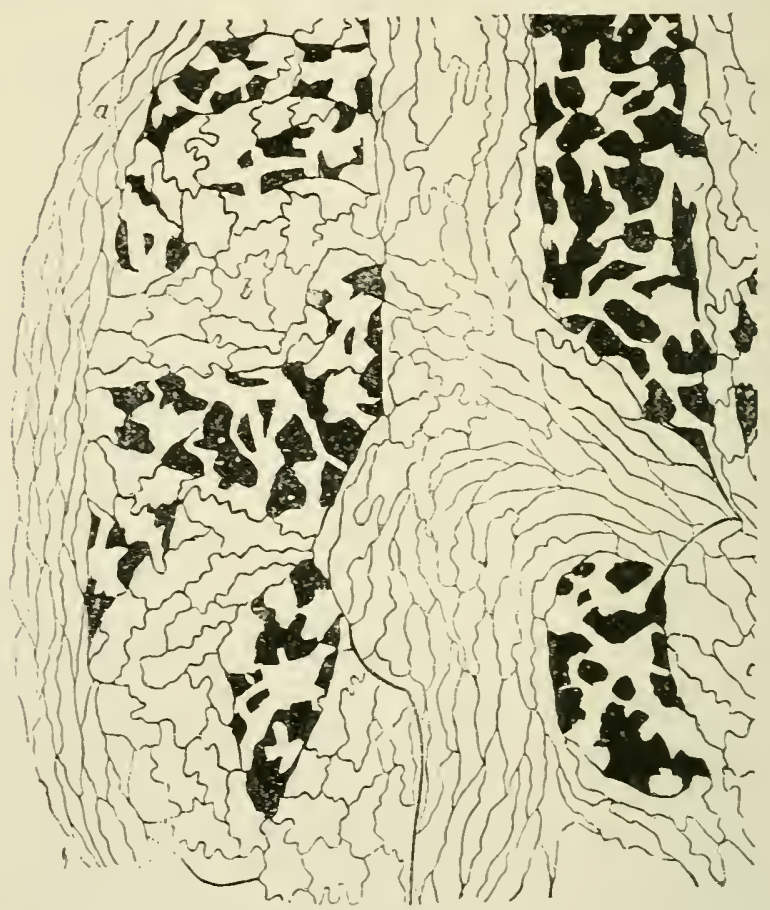

Fig. st.- From silver-stainel preparation of the Central Tenclon of the Rabit's Diapluragm, showing the direct connection of the Lymplucanalicular System of the Tissue with the Lymphatic Capillaries.

a. Lymplic vessel : $b$, lymphatic capillary lined with "sinuous" endothelium. (Handbook:)

capillaries and lymphatic ressels, represents the natural current of lymph irrigating the tissues.

115. Lymph cavitics.-In some cases the lymphatic ressels of a tissue or organ are possessed of, or connected with, irregularly-shaped large sinuses, much wicler than the ressel itself: these cavities are the lympl sinuses, and their wall is also composed of a 
single layer of more or less polygonal endothelial plates with rery sinuous outlines. Such sinuses are found in connection with the subcutaneous and submucous lymphatics, in the diaphragm, mesentery, liver, lungs, etc. On the same footing-i.e. as lymph sinuses-stand the comparatively large lymph cavities in the body, such as the subdural and subarachnoidal spaces of the central nerrous system, the synovial cavities, the cavities of the tendon-sheaths, the cavity of the tunica vaginalis testis, the pleural, pericardial, and peritoneal cavities. In batrachian animals-e.g. frogs-the skin all over the trunk and extremities is separated from the subjacent fascire and muscles by large bags or sinuses-the subcutaneous lymple sacs. These sinuses are shut off from one another by septa. Between the trunk and the extremities, and on the latter, the septa generally occur in the region of the joints. In female frogrs in the mesogastrium smaller or larger cysts lined with ciliated endothelium are sometimes found. Behind the peritoneal cavity of the frog, on each side of the vertebral column, exists a similar large lymph sinus, called the cisterna

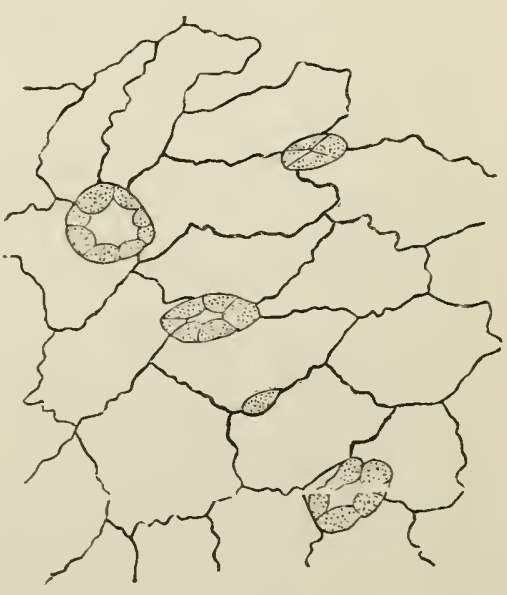

Fis. S.j.-Stomata, lined with Germinating Endothelial Cells, as seen from the Cisternal Surface of the Septum Cisterna Lymphaticie Magnie of the Frog. (Itanelbool:) lymphatica magna.

116. The lymph cavities are in all instances in direct communication with the lymphatics of the surrounding parts by lioles or open mouths (stomata), often 
surrounded by a special laver of polyluedral endothelial cells-germinating cells (Figs. 5.5, 86). Such stomata are numerous on the peritoneal surface of the central tendon of the diaphragm, in which are found straight lrmpli channels between the tendon bundles, and these channels communicate br nu-

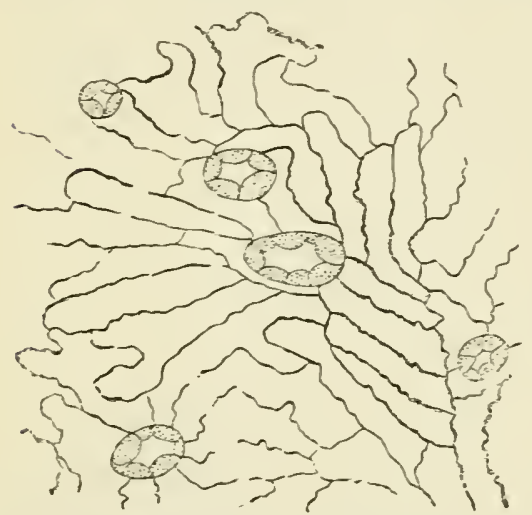

Figr. S6..-Endothelimm and stomata of the Peritoneal Surface of the septum Cisternat Lrmphatica Magne of the Fro: (Hondlionk.) merous stomata with the free surface. A similar arrangement exists on the costal pleura, the omentum, and the cisterna lympliatica magna of the frog. (See Chapter. IT.)

117. The serous numbinars consist of endothelium upon a laver of fibrous tissue witl networks of fine elastic fibres: they contain networks of blood capillaries and numerous lrmphatic ressels arranged in (superficial and deep) plexuses. Plexuses of lymphatics are very numerous in the pleura costalis -or rather, intercostalis - in the diaphragm and pleura pulmonalis. They are important in the process of absorption from the plenral and peritoneal cavity respectively. Lymph and lrmph corpuscles, and other solid particles, are readily taken up by the stomata (see Fig. 31) and brought into the lrmphatics. Here the respiratory movements of the intercostal muscles, of the diaphragm, and of the lungs respectivels, pro. duce the result of the action of a pump.

118. There exists a clefinite relation between the lymphatics on the one hand and the epithelium on the 
other, which covers the mucons membranes and lines the various glands, and also between the endothelium covering serous membranes and that lining their vessels and lymph cavities - namely this: the albuminous semifluid cement substance (see former chapters) between the epithelial or endothelial cells is the path by which Huid and formed matter passes between the surfaces and the lymph-canalicular system-i.e. the rootlets of the lymphatics.

119. Lymph taken from the lymphatics of different regions differs in composition and structure. That from the thoracic duct contains a large number of colomless or white corpuscles (lymph corpuscles), each of which is a protoplasmic nucleated cell similar in structure to a white blood corpusele. They are of various sizes, according to the stage of ripeness. The smaller lymphocy tes contain one, some of the larger contain two and three nuclei corresponding to the typical leucocytes. The latter show more pronounced amoboid morement than the former. Also "granular" oxyphile, basophile, and amphophile cells are met with amongst the lencocytes. A few red corpuscles are also met with. Granular and fatty matter is present in large quantities during and immediately after digestion.

In the frog (and also in other lower vertebratese.g. reptiles) there exist certain small vesicular lymph carities, about an eighth of an inch in diameter, which show rhythmic pulsation; they are called lymph hearts. On each side of the os coccygis and underneath the skin is a pulsating posterior lymph heart. The anterior lymph heart is oral, and is situated on each side of the processus transversus of the third and fourth vertebræ; it is rather smaller than the posterior one. Each lymph heart has afferent lymphatics, by which it is in open communication with the lymphatics of the periphery, and from it passes out an efferent ressel which opens into a large vein (a branch of the 
sciatic and jugular veins respectively). A valve allows lymph to flow out of the lymph heart into the rein, but prevents regurgitation of blood from

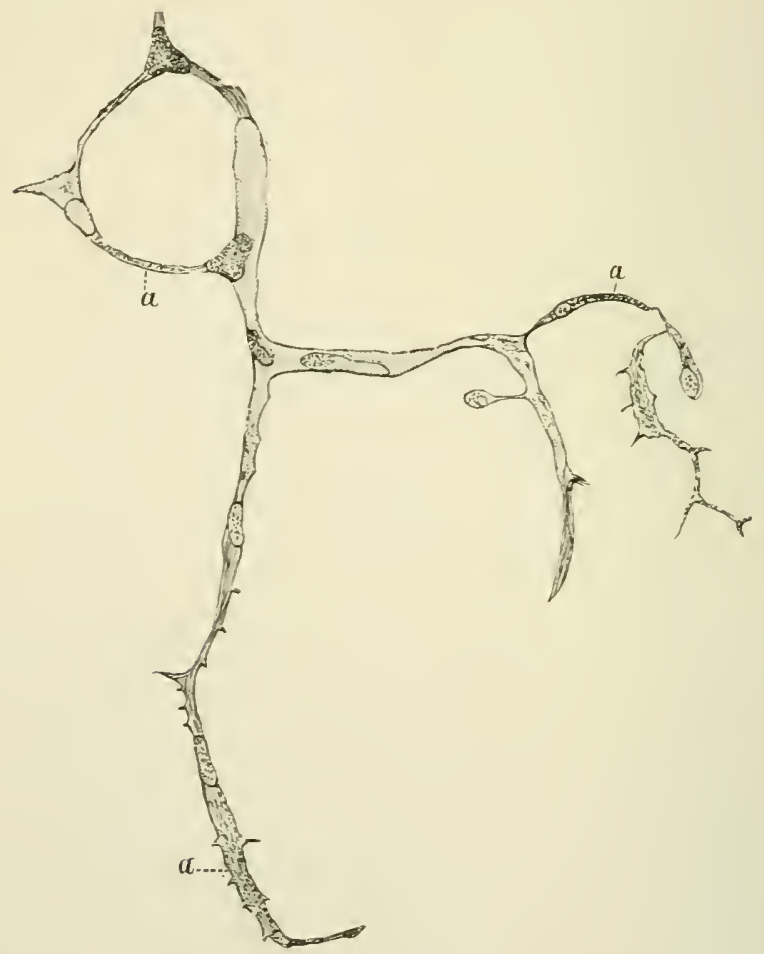

Fis. si.-Developing Lympli-capillaries in the Tail of Tadpole. (Atles.)

a, Solid nucleated protoplas nic branches not yet hollowed out.

the vein. The internal surface of the lymph hearts is lined with an endothelinm like the lrmph sacs, and in their wall they possess plexuses of striped, branched, muscular fibres. The nerve fibres terminate in these striped muscular fibres in the same manner as in those of other localities. (Rianvier.) 
120. Lymphatic ressels are dereloped and newly formed under normal and pathological conditions in precisely the same way as blood-ressels. The accompanying woodcut (Fig. 8T) shows this very well. The have also here to do with the hollowing out of (connective tissue) cells and their processes previously solid and protoplasmic. 


\section{C'HAPTEP XII.}

FOLLICLES OP SIMPLE LYMPH FLANDS.

121 . UYDER this name we include the blood glands, or the conglobate gland substance of Hewson, His, and Henle, or the lrmph follicles (Kolliker, Huxler, Luschka). The ground substance of all lymph glands, simple as well as compound (see below), is the lymphatic or adenoid tissue, or leucocytogenous tissue. Like all other gland tissue, it is supplied with a rich network of capillaries derived from an afferent artery, and leading into efferent reins.

12.2 . The elements constituting this tissue are :-

(a) The adenoid reticulum (Fig. 8s), a network of tine homogeneous fibrils, with numerous plate-like enlargement.s.

(b) Smull, trarsparent. flut, endotheloir cell plates, each with an oral nucleus. These cell plates are fixed on the reticulum, of which at first sight ther seem to form part. Their oral nucleus especially appears to belong to a nodal point-i.e. to one of the enlargements of the reticulum; but by continued shaking of a section of any lymphatic tissue, the oral nuclei and their cell plates can be got rid of, so that only the reticulum is left, without any trace of a nucleus.

(c) Lympilc corpuscles completely till the meshes of the adenoid reticulum. These can, however, be easily shaken out. They are of different sizes; some-the young ones-are small cells, with a comparatively large nucleus; others-the ripe ones-are larger, have a distinct protoplasmic cell body, with one or 
two muclei. In all lymphatic tissues, lee they part of it simple or of a compound lymph sland, certain parts are of greater transparency than other's, rlue to the lyomph cells being larger and in a state of clivision, as indicated by the various phasesofmitotic division of their nucleus (Flemming, Heilbrumm). These parts form, therefore, centres of germination, and constitute what are spoken of as germ centres, or germ nodules (Flemming). The gern centres are not permanent structures.

12:3. The adenoid tissue occurs as:

(1) Difficse adenoid tissue, without any detinite arrangement. This occur's in the subepithelial layer of the mucous membrane of the nasal fosse and trachea, in the mucous membrane of the ficlse vocal cords and the ventricle of the larynx, in the posterior part of the epiglottis, in the soft palate and tonsils, at the root of the tongne, in the pharynx, in the mucosa of the small and large intestine, including the villi of the former; and in the mucous membrane of the nasal cavity and vaginil.

(-̈) Corrts, cyliuders, or patches of adenoid tissue; 
in the omentum and pleura, and in the spleen (Malpighian corpuscles).

(3) Lymple follicles, i.e. oval or spherical masses more or less well defined; in the tonsils, at the root of the tongue, in the upper part of the plarynx (pharyux tonsil), in the stomach, small and large
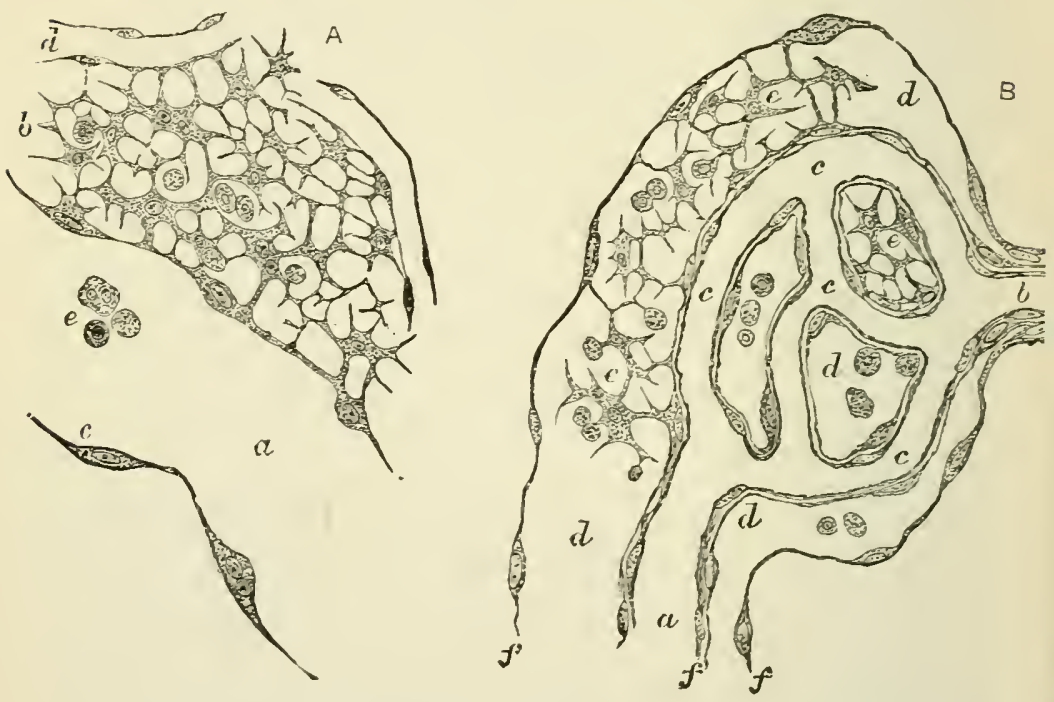

Fig. S9. - Lymphangial Norlules, in the Oment um of a Guinea-pig, develnyiıs: in connection with lymph ressels. (Klein's "Lympluatic system.")

A, Perilymphangial nodule: $a$, lymph resoel ; $b$, lymphoid tissue: $c$, its endu. thelial wall; $i$, hlood capillaries: $\mathrm{B}$ : endolymlhangial structure: $a$, vein : $b$, artery ; $c$, capillaries ; $d$, peri rascular $l y^{\circ} m \mathrm{ph}$ vessel ; $e$, lymphatic tissue : $t$, endothelial wall of the lymph ressel.

intestine; in the nasal mucous membrane, in the large and small bronchi; and in the spleen (Malpighian corpuscles).

Nost of these masses of arlenoid tissue mentioned hitherto are dereloped in the wall or even in the eavity of a lymph ressel or lymph sinus as peri-and endo-lymplangial rodules; in the former case the lymph tissue remains surrounded for a smaller or 
larger part of its periphery by a lymph sinus forming part of a network of lymph tulses (Fig. $\$ 9, A$ and $\mathrm{B}$ ).

124. The 1onsils (Eig. 90) are masses of lymph follicles and diffuse allenoid tissue corered with a thin mucous membrane, which penetrates in the shape of

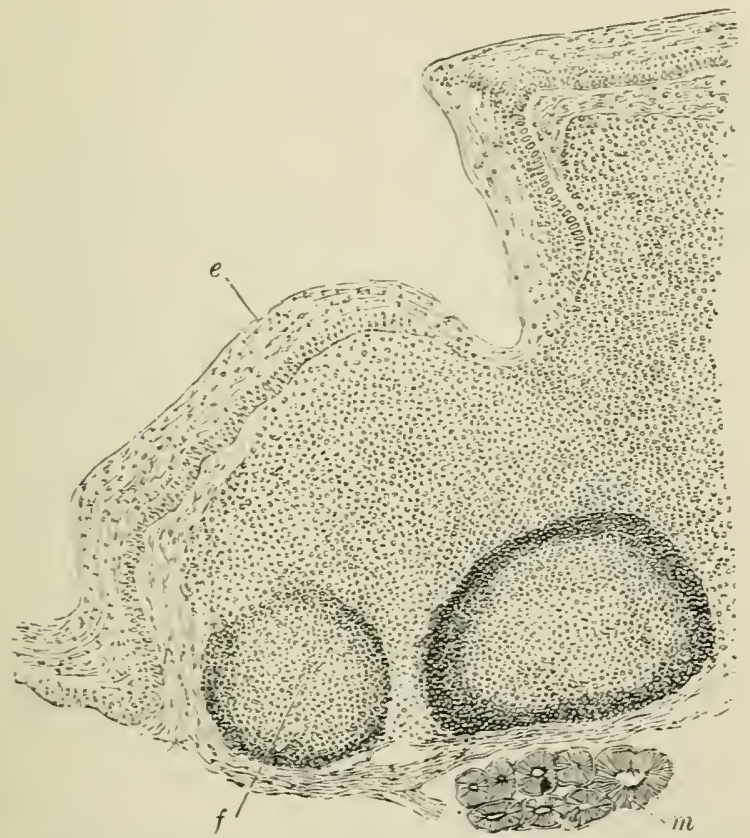

Fig. 90.-Fertical Section throngli part of the Tonsil of Dog. (Atlas.)

e, stratified pavement epithelim covering the free surface of the mucous membrane. The tisste of the mucous membrane is infiltrated with adenoil tissue, $f$, lgmph follicles; $m$, mucous gland of the submucous tissue.

longer or shorter folds into the substance within. Numbers of mucus-secreting glands situated outside the layer of lymph follicles discharge their secretion into the pits (the crypts) between the folds. The free surface of the tonsils and the crypts is covered or lined with similar stratified epithelium to that which lines the oral cavity. Numbers of $1 y \mathrm{mph}$ corpuscles 
constantly, in the perfectly normal condition, migrate through the epithelium on to the free surface, and are mixed with the secretions (mucus and saliva) of the oral cavity. 'The so-called mucous or salivary corpuscles of the saliva, taken from the oral cavity, are such discharged lymph corpuscles (Stöhr). 'They become swollen up by the water of the saliva, and assume a spherical shape. They finally disintegrate.

Similar relations, only on a smaller scale, obtain at the root of the tongue.

The pharynx tonsil of Luschka, occuring in the upper part of the pharynx, is in all essential respects similar to the palatine tonsil. Owing to large parts of the mucous membrane of the upper portion of the pharyux being corered with ciliated columnar epithelium, some of the crypts in the pharynx tonsil are also lined with it.

125. The Ienticular glands of the stomach are single lymph follicles.

The solitary glands of the small and large intestine are single lymph follicles.

The agminated glamds of the ileum are groups of lymph follicles. The mucous membrane containing them is much thickened by their presence. These groups of follicles are called a Peyer's patch or a Peyer's gland (see Intestine).

126. In most instances the capillar'y blood-ressels form in the lymph follicles meshes, arranged in a more or less radiating manner from the periphery towards the centre; around the periphery there is a network of small veins. A larger or smaller portion of the circumference of the follicles of the tonsils, pharyux, intestine, bronchi, etc., is surrounded by a lymph sinus leading into a lymphatic ressel. (See above.) The lymphatic ressels and lymph sinuses in the neighbourhood of lymphatic follicles or of diffuse adenoid tissue are almost always found to contain 


\section{SIMPLE LYMPHATIC GLANDS.}

numerous lymph corpuscles, thus indicating that these are produced by the adenoid tissue and absorbed by the lymphatics.

127. The thymus gland consists of a frame-

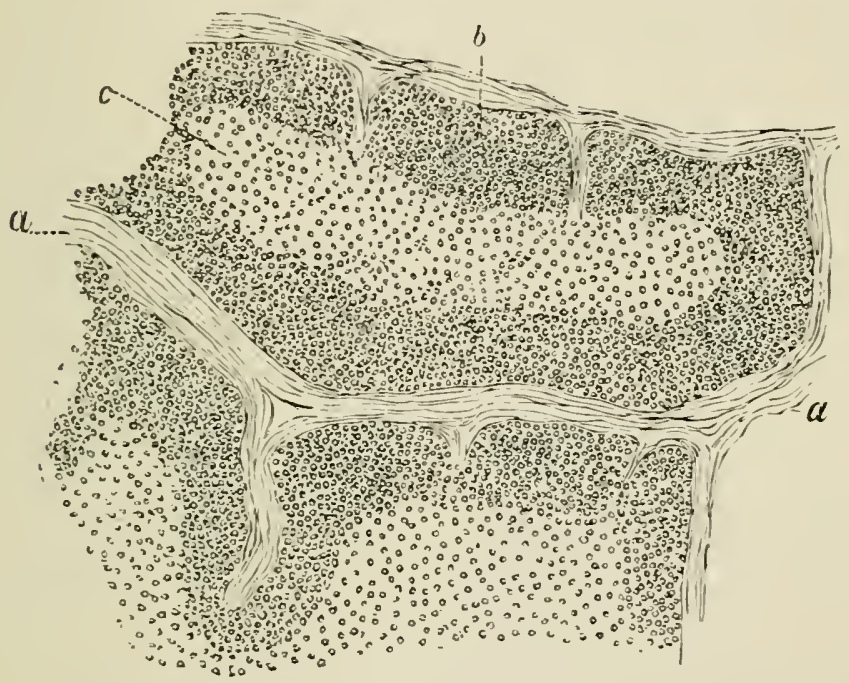

Fig. 91.-Section through the Thymus Gland of a Fotus.

$a$, Fibrous tissue between the follicles; $b$, cortical portion of the follicles $c$, medullary portion.

work and the gland substance. The former is fibrous connective tissue arranged as an outer capsule, and in connection with it are septa and trabecula passing into the gland and subdividing it into lobes and lobules, which latter are again subdivided into the follicles (Fig. 91). The follicles are very irregular in shaje, most of them being oblong or cylindrical streaks of adenoid tissue. Near the capsule they are well defined from one another, and present a polygonal outline; farther inwards they are nore or less fused. Each shows a central transparent medulla (germ centre) and a peripheral less transparent cortex (Watney). 
At the places where two follicles are fused with one another the medulla of both is continuous. The matrix is adenoid reticulum, the fibres of the medullary part being coarser and shorter, those of the cortical portion of the follicle finer and longer. The meshes of the alenoid reticulum in the cortical part of the follicles are tilled with lymph corpuscles like those occurring in the adenoid tissue of other organs, but in the medullary part they are fewer, and the meshes are more or less completely occupied by the enlarged but more transparent cells; in many of these mitotic dirision of the nucleus occurs. These conditions canse the greater' transparency of the medullia and represent the germ centres above mentioned. Amongst the large cells of
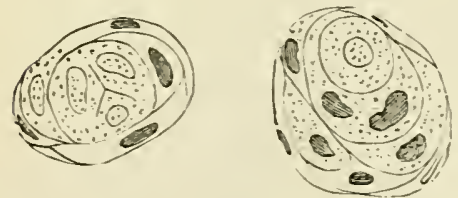

Fig. 92.-Twn Concentric or Hassall's

Corpuscles of the Tllymus. Fotal Gland. the medullary portion, some are coarsely granular and include more than one nucleus; some are even multinucleated giant cells.

128. Amongst the cells of the medulla occur also larger or smaller, more or less concentrically arranged nucleated protoplasmic masses, which are the concentric bodies of Hassall. (Fig. 92). They are met with even in the early stages of the life of the thymus, and cannot therefore be connected with the involution of the gland, as maintained by Afanassief, according to whom the concentric corpuscles are formed in blood-ressels which thereby become obliterated. According to Watney they are concerned in the formation of bloodressels and connective tissue.

The lymphatics of the interfollicular septa and trabeculie always contain numbers of lymph corpuscles. The blood capillaries of the follicles are more richly distributed in the cortex than in the medulla, and 
they radiate from the periphery towards the central parts.

129. After birth the thymus begins to undergo involution, leading to the gradual disappearance of the greater portion of the gland, its place being taken by connective tissue and fat. But the time when the involution is completed varies within very wide limits.

It is not unusual to find in persons of fifteen to twenty years of age an appreciable amount of thymus tissue. According to Waldeyer, about 60 per cent. of adults examined had still a portion of thymus gland left. In some animals-e.g. guinea-pig-the involution of the gland even in the adult has not made much progress. In the thymus of the dog Watney found cysts lined with ciliated epithelial cells. 


\section{CHAPTER XIII.}

COIPOUND LYIPIHTIC GLAYDS.

130. The compound or true lymphatic glands are nodules, generally of an oblong shape, directly interpolated in the course of lymphatic vessels. Such are the mesenteric, portal, bronchial, splenic, sternal, cervical, cubital, popliteal, inguinal, lumbar glands. Afferent lymphatic vessels anastomosing into a plexus open at one side (in the outer capsule) into the lymphatic gland, and at the other (the hilum) emerge from it as a plexus of efferent lymphatic tubes.

131. Each true lymphatic gland is enveloped in a fibrous capsuie which is connected with the interior and the hilum by trabeculce and septa of connective tissue. The trabecule having advanced a certain distance, about one-third or one-fourth, towards the centre, branch into minor trabeculæe, which in the gland anastomose with one another so as to form a plexus with small meshes. 'Thus the peripheral third or fourth of the gland is subdivided by the septa and trabeculie into relatively large spherical or oblong compartments, while the middle portion is made up of relatively small cylindrical or irregularly-shaped compartments (Fig. 93). The former region is the cortex, the latter the medulla of the glind. The compartments of the cortex anastomose with one another and with those of the medulla, and these latter also form one intercommunicating system.

The fibrous capsule, the septa and trabecula are the carriers of the vascular trunks; the trabeculæ consist of fibrous connective tissue and of a certain 
amount of non-striped muscular tissue, which is conspicuous in some animals-e.\%. pig, calf, rabbit, guinea-pig-lut is scanty in man.

Sometimes coarsely granular connective-tissue cells (plasma cells) are present in considerable numbers in the trabeculie.

132. The compartments contain masses of adenoid

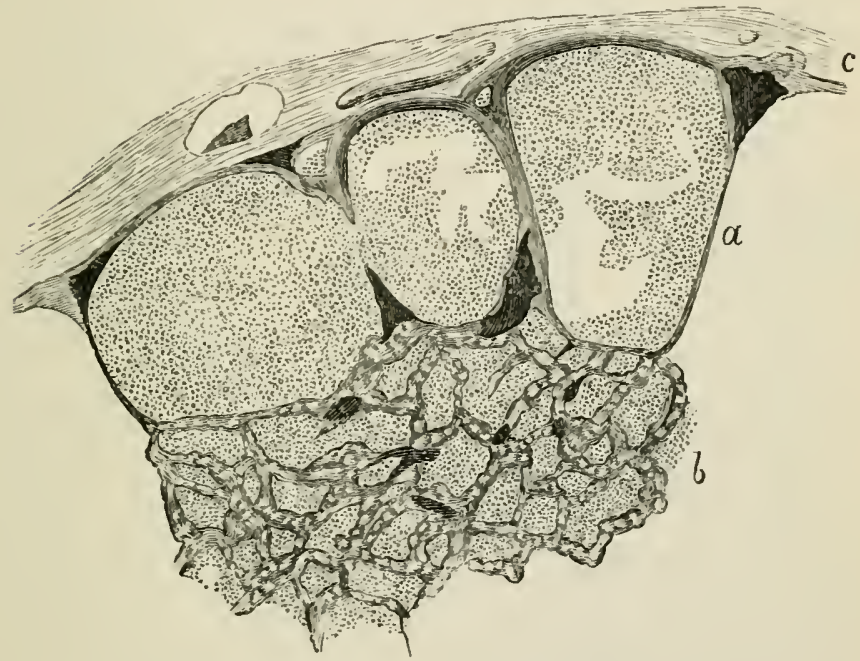

Fig. 93. - From a Vertical Section through a Lymphatic Gland, the

Lymphaties of which had been injected. (Atlas.)

c, Outer capsule, with lymphatic vessels in section ; $a$, cortical lymph follicles; around them are the cortical lymph sinuses; $b$, medulla; injected lymph sinuses between the masses of adenoid tistue.

tissue, without being completely filled with it. Those of the cortex contain oval or spherical masses-the lymph follicles of the cortex; those of the medulla cylindrical or irregularly-shaped masses-the medullary cylinders. The former anastomose with one another and with the latter, and the latter amongst themselves, a condition easily understoor from what has been said above of the nature of the compartments containing these lymphatic structures. The follicles 
and medullary cylinders consist of adenoid tissue with germ centres of exactly similar character to that described in the previous chapter. And this tissue also contains the last ramifications of the bloodvessels-i.e. the last branches of the arteries, a rich network of capillary blood-vessels, and the first or smaller branches of the veins. The capillaries and other vessels receive also here an adventitious envelope fiom the adenoid reticulum.

133. The cortical follicles and the medullary

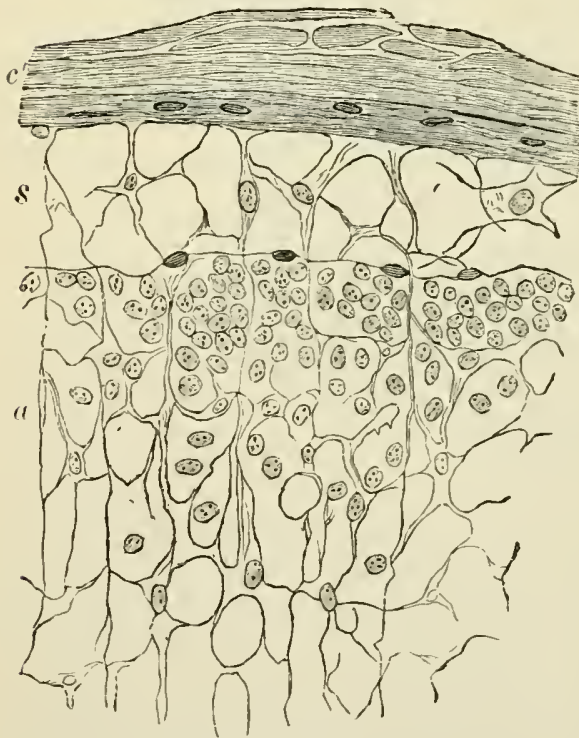

Fig. 94.-From a Section through a Lymphatic Gland. (Atles.) cylinders do not completely fill out the compartments made for them by the capsule and trabecula respectively, but a narrow peripheral zone in each compartment is left free; these are the lymplatic sinuses. In the cortex they are spoken of as the cortical (Fig. $94)$, in the medulla as the medullary, lymph simuses (Fig. 95). The former is a space between the outer

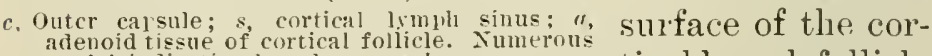
nnclei, indicating lymulu corpuscles.

tical lymph follicle and the corresponding part of the capsule or cortical septum, the latter between the surface of a medullary cylinder and the trabecula. From what lats been said of the 
relation of the compartments, it follows that the cortical and merlullary lymph sinuses form one intercommunicating system. These are not empty free spaces, but are filled with a coarse reticulum of fibres, much coarser than the adenoid reticulum ; to it are attached large transparent cell plates-endotheloid

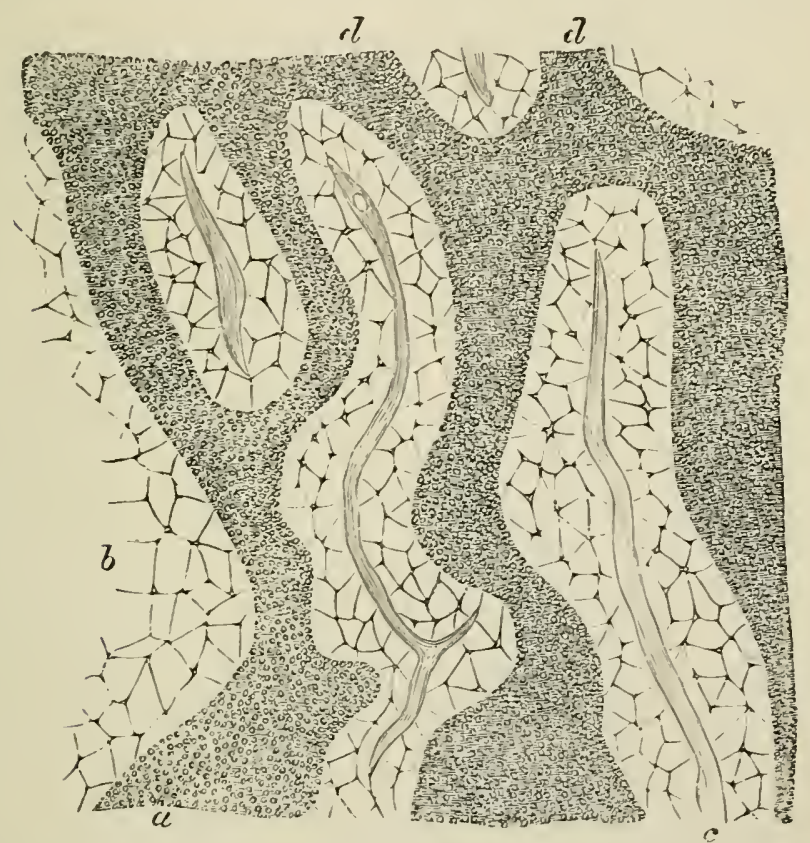

Fig. 95.-From a Section through the Medulla of a Lymphatic Gland.

$a$, Transition of the medullary cylinders of adenoid tissue into the cortical follicles; $b$, lymph sinuses occupied by a reticulum ; $c$, fibrous tissue trabeculie ; $d$, medullary cylinders.

plates. In some instances (as in the calf) these cell plates of the medullary sinuses contain brownish pigment granules, which give to the medulla of the gland a dark brown aspect. In the meshes of the reticulum of the sinuses are contained lymph corpuscles, the majority of which consist of a comparatively large protoplasmic body and one or two nuclei; 
they show lively amœboid movement; a few small lymphocytes are also amongst them.

The surface of the trabecula facing the lymph sinuses is covered with a continuous layer of endothelium (ron Recklinghausen), and a similar endothelial membrane, but not so complete, can be made out on the surface of the cortical follicles and the medullary cylinders. The endotheloid plates, applied to the reticulum of the sinuses, are stretched ont, as it were, between the endothelial membrane covering the surface of the trabeculie on the one hand and that covering the surface of the follicles and cylinders on the other.

In the mesenteric glands of the pig the distribution of cortical follicles and medullary cylinders is almost the reverse from that of other glands and in other animals: the cortical part having the arrangement of cylinders of adenoid tissue and trabecula, while the medulla shows lymph follicles and longer septa between them.

134. The afferent lymphatic ressels having entered the outer capsule of the gland, and having formed within the capsule a dense plexus, open directly into the cortical lymph sinuses. The medullary lymph sinuses, on the other hand, lead into lymphatic vessels, which leave the gland at the hilum as the efferent vessels.

Both afferent and efferent vessels are supplied with valves.

135. The course of the lymph through a lymphatic gland is this: From the afferent vessels, situated in the capsule, the lymph flows into the cortical lymph sinuses, from these into the medullary sinuses, and from these into the efferent lymphatics. Owing to the presence of the reticulum in the lymph sinuses the current of the lymph will flow very slowly and with ditticulty, as if through a spongy filter. Hence a 
large number of formed corpuscles, pigment, inflammatory or other elements, passing into the gland from the afferent ressels are easily arrested and deposited in the sinuses, and are there rearlily swallowed by the amoboid corpuscles lying in the meshes of, or deposited on the reticulum.

Passing a stream of water by way of the afferent lympli vessels through the gland, the contents of the meshes of the reticulum of the sinuses-i.e. the lymph corpuscles-are of course the first things washed out (von Recklinghausen), and on continuing the stream some of the lymph corpuscles of the follicles and cylinders are also washed ont. Probably also by the normal lymph-stream passing from the minute arteries and capillary blood-vessels of the arlenoid tissue (follicles and medullary lymph cylinders) into the lymph sinuses, lymph cells are drained, as it were, from the follicles and cylinders into the sinuses. The amceboid movement of these cells will greatly assist their passage into the sinuses. From here the cells are carried away by the lymph current into the efferent lymph vessels, and are ultimately carried into the big lymph-trunks discharging into the big veins-i.e. into the circulating blood-as white blood corpuscles. 


\section{CHAPTER XIT.}

NERVE FIBRES.

136. Thк nerve fibres conduct impulses to or from the tissues and organs on the one hand, and the nerve centres on the other, and accordingly we have to consider in each nerve fibre the peripheral and

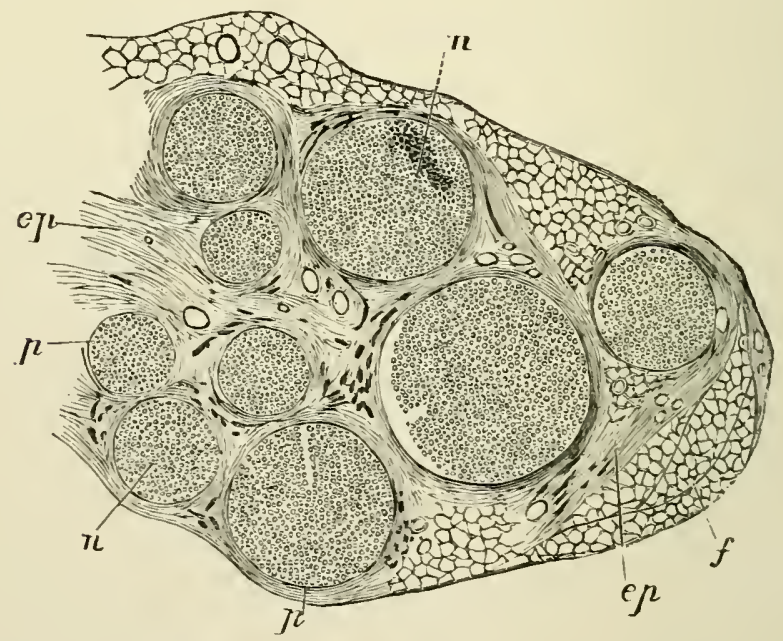

Fig. 96.-From a Transverse Section through the Sciatic Nerre of Dog. $e p$, Epineurium; $p$, perineurium : $n$, nerve fibres constituting a nerve bundle in cross-section; $f$, fat tissue surrounding the nerve. (dtlus.)

central termination and the conducting part. The latter, i.e. the nerve fibres proper, in the cerebrospinal nerves are grouped into bundles, and these again into anatomical nerve branches and nerve trunks. Each anatomical cerebro-spinal nerre con- 
sists, therefore, of bundles of nerve fibres (Fig. 96). The general strona by which these bundles are held together is fibrous connective tissue called the epineurium (Key and Retzins); this epineurium is the carrier of the larger and smaller blood-vessels with which the nerve trunk is supplied, of a plexus of lymphatics, of groups of fat cells, and sometimes of numerous plasma cells.

137. The nerve bundles or funiculi (Fig. 97) vary in size according to the number and size of the nerve fibres they contain. They are well defined by a sheath of their own, called perineurium (Key and Retzius). This perineurium consists of bundles of fibrous connective tissue arranged in lamellæ, every two lamella being separated from one another by smaller or larger lymph spaces, which form an intercommunicating system, and anastomose with the lymphatics of the epineurium whence they can be injected. Between the lamella, and in the spaces, are situated flattened endotheloid connective-tissue corpuscles.

The nerve bundles are either simple or compound. In the former the nerve fibres are not subdivided into groups within the bundle, in the latter the bundles are subdivided by thicker and thinner septat of fibrous connectire tissue connected with the perineurium. When a nerve bundle divides - as when a trunk repeatedly branches, or when it enters on its peripheral distribution-each branch of the bundle receives a continuation of the lamellar perineurium. The more branches the perineurium has to supply, the more reduced it becomes in thickness. In some of these minute branches the perineurium is reduced to a single layer of enclothelial cells. When one of these small bundles breaks up into single nerve fibres, or into small groups of them, each of these has also a continuation of the fibrous tissue of the 
perinemrium. In some places this perinemral continuation is only a rery delicate endothelial membrane as just mentioned, in others it is of considerable thickness, and still shows its lamellated nature. Such

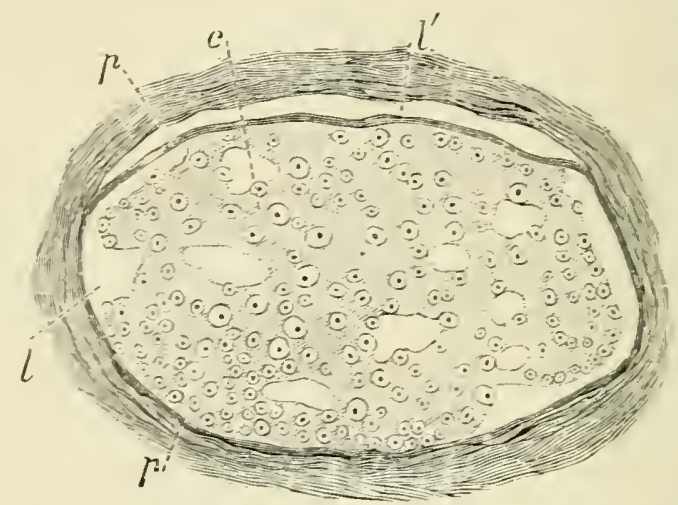

Fig. 9.- Transverse Section through a NerTe Bundle in the Tail of Mouse. (Atlos.)

$p$, Perinenrium; $c$, endoneurium separating the medullated nerve fibres seen in cross-section; $l$; $15 \mathrm{mph}$ =race- in the perineurium; $l, 15 \mathrm{mph}$-paces in the endonearium.

a lamellated sheath of single nerve fibres, or o a small group of them, represents what is called a Henle's sheath.

138. The nerve fibres are held together or'separated respectively within the bundle by connective tissue, called the endonentium (Fig. 9\%). This is a homogeneous sround substance in which are embedded tine bundles of fibrous connective tissue, and connectire-tissue corpuscles, and capillary blood-vessels arranged so as to form a network with elongated meshes. Between the perineurium and the nerve fibres are found here and there $15 \mathrm{mph}$ spaces: similar spaces separate the individual nerve fibres, and have been injected 1,5 Key and Retzius. The endoneural lymph spaces communicate with those of the perineural sheath. 
When nerve trunks anastomose so as to form a plexus-e.g. in the brachial or sacral plexus-there occurs a division, an exchange and re-arrangement of nerve bundles in the branches. A similar condition obtains in the ganglia of the cerebro-spinal nerres. Nerve trunks and nerve branches passing through a lymph cavity, such as the subdural spaces, or the subcutaneous lymph sacs, or the cisterna lymphatica magna in the frog, receive from the serous membrane an outer endothelial corering.

139. Nost of the nerve fibres in the bundles of the cerebro-spinal nerves, with the exception of the olfactory nerve, are medullated neve fibres. These are doubly-contoured smooth cylindrical filres, varying in diameter between $\frac{1}{\square 00}$ or more and $\frac{1}{100 \overline{0}}$ of an inch. Within the same nerre, and eren within the same nerve bundle, there occur fibres which are several times thicker than others, and it is probable that they are derived from different sources; this, for instance, is rery conspicuous in the vagus nerve (Gaskell, Fig. 98). Schwalbe has shown that the thickness of the nerve fibre stands in a certain relation to the distance of its periphery from the nerve centre and to its functional activity.

A medullated nerve fibre in the fresh condition is a bright glistening cyliniler, showing a dark double contour. Either spontaneously after death, or after. reagents-as water, sait solution, dilute acids-or after pressure and mechanical injury, the outline of the nerve fibre becomes irregular; smaller or larger glistening dark-bordered droplets and masses appear, and gradually become detached. These droplets and masses are called myeline droplets, and are derived from the fatty substance or myelin constituting the medullary sheath or white substance of Schwann (see below). When a nerve fibre within the bundle undergoes degeneration during life, either after section of 
the nerve or after other pathological changes, or in the natural course of its existence (S. Mayer), the medullary sheath is the first to undergo change; it breaks up into similar smaller or larger globules or

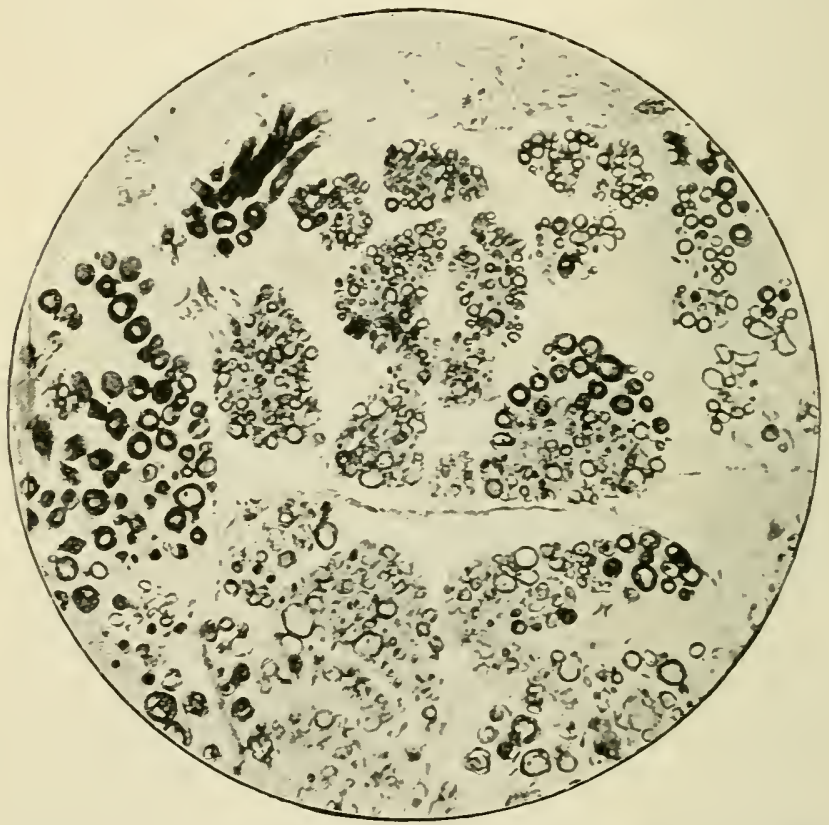

Fig. 95.-From a Transverse Section throngh the Vagus Nerve, showing in the nerve bundles nerve fibres (in cross-section) which differ markedly in size, some being much larger than others. (Photo., highly magnified.)

particles, which gradually besome granular and absorbed. Later also the axis cylinder dwindles away, and only the neurilemma with the nucleated corpuscles persist.

140. Eich medullated nerve fibre (Figs. 99, 101) consists of the following parts: $(a)$ the central axis cylinder, raon or newrain. This is the essential part of the fibre, and is a cylindrical or band-like, 
pale, transparent structure, which in certain localities (near the terminal distribution, in the olfactory nerves, in the central nervous system), and especially after certain reagents, show's itself composed of rery fine homogeneous or more or less beaded fibrillie-the elementriy or primitive fibrille: (Hax Schultze)-held together by a small amount of a faintly granular interstitial substance The longiturlinal striation of the axis cylinder is due to its being composed of primitive fibrille. The thickness of the axis cylinder is in direct proportion to the thickness of the whole nerve tibre. The axis cylinder itself is enveloped in its own hyaline more or less elastic sheath-the axilemma (Kühne), composed of neurokeratin.

141. (b) The medullary sheath, or myeline sheath, or white substance of Schwann, is also called the medulla of the nerve fibre. This is a glistening bright fatty substance surrounding the axis cylinder, as an insulating hollow cylinder surrounds an electric wire. The medullary sheath gives to the nerve fibre its double or dark contour. Between the axis cylinder and the medullary sheath there is a small amount of albuminous fluid, which appears greatly increased when the former, owing to shrinking, stands farther apart from the latter.

142. (c) The sheath of Schucann, or the neurilemma, closely surrounds the medullary sheath, and forms the outer boundary of the nerve tibre. It is a delicate structureless nembiane. Here and there between the neurilemma and the medullary sheath, and situated in a depression of the latter, is an oblong nucleus, surrounded by a thin zone of protoplasm. These nucleated corpuscles are the nerre corpuscles (Fig. 99), and are analogous to the muscle corpuscles, situated between the sarcolemma and the striated muscular substance. They are not nearly so numerous as the muscle corpuscles. 
143. The neurilemma presents at certain definite intervals annular constrictions - the nodes or constrictions of Ranvier (Figs. 99, 100, 101)-and at these

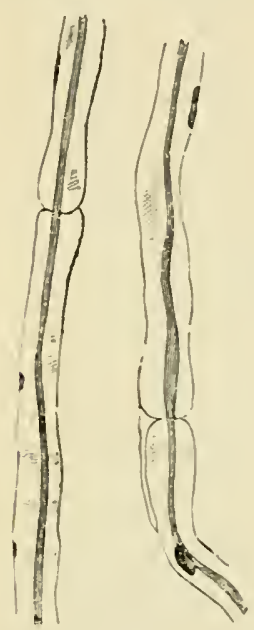

Fig. 99. - Two Nerve Fibres, showing the modes or constrictions of Ranvier and the axis cy. lincler. The medullary sheath has been dissolved away. The deeplystained oblong nuclei inaicate the nerve corpuseles within the neurilemma. (Atlas.) nodes of Ranvier the medullary sheath, but not the axis cylinder and its special sheath, is suddenly interrupted, and sharply terminates at the constriction. The neurilemna is at the same time thickened by annular permanent folds (see $\mathrm{B}$ in Fig. 101). The portion of the nerve fibre situated between two nodes is the internodal segment. Each internodal segment has generally one, occasionally more than one, nerve corpuscle. The medullary cylinder of each internodal segment is made up of a number of conical sections (Fig. 101, A) imbricated at their ends (Schmidt, Lantermann; and each such section is again made up of a large number of rod-like structures (Fig. 10\%) placed vertically on the axis cylinder (MacCarthy).

These rods are, however, connected into a network. The network itself is very likely the neurokeratin of Ewald and Kühne, whereas the interstitial substance of the network is probably the fatty substance leaving the nerve fibre in the shape of myeline droplets, when pressure or reagents are applied to the fresh nerve fibre.

144. Medullated nerve fibres without any neurilemma, and consequently without any nodes of Ranvier, with a thick more or less distinctly laminated medullary sheath, form the entire white substance of 
the brain and spinal cord. In these organs, in the hardened and fresh state, numerous nerve fibres may be noticed, which shuw more or less regular varicosities, owing to local accumulations of fluid between the axis cylinder and medullary sheath. These are called varicose nerve

A

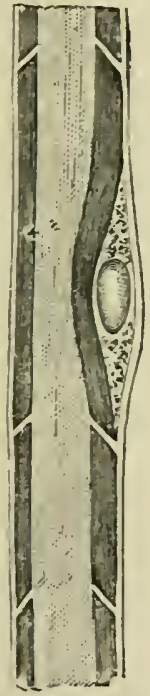

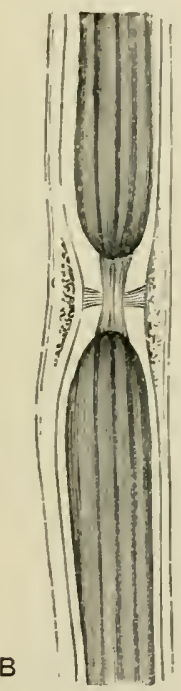

Firg. 101.-Medullated Nerve Fibres.

A, Medullated nerve fil re, showing the subdivision of the medullars sheath into cylindrical sections imbricated with their ends ; a nerve corpu=cle with an oval nucleus is seen between the neurilemma and the medullary sheath. $\mathrm{B}$, nedullated nerve fibre at a node or constriction of lianvier ; the axis cylinder passes uninterruptedly from one serment into the other, but the medullary sheatls is iuterrujted. (hey.and Retzins.)

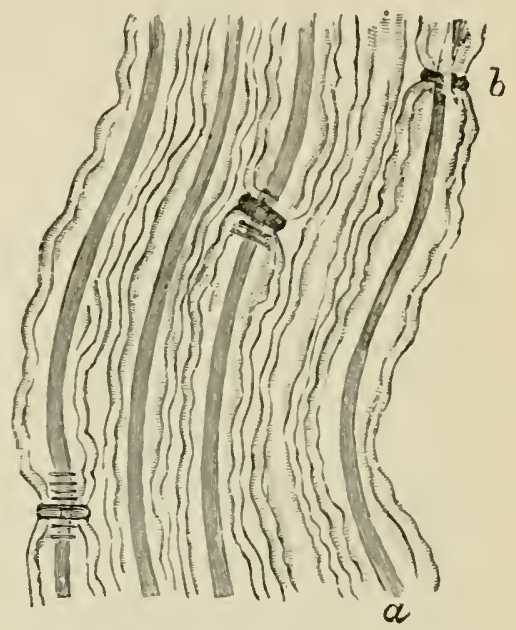

Fig. 100._-Melullater Nerve Fibres, after staining with nitrate of silver. (Key and Retzius.)

$a, A x i=c y l i n d e r ; b$, Ranvier's constriction.

fibres. They occur also in the branches of the sympathetic nerve.

The nerve fibres of the optic and acoustic nerve are medullated, but without any neurilemma; they are therefore without any nodes of Ranvier. Varicose fibres are common in them.

145. Medullated nerve fibres occasionally in their course divide into two medullated fibres. Such division is very common in 
medullated nerve fibres supplying striped muscular tissue, especially at or near the point of entrance into the muscular fibres. (See below.) But also in other localities division of nerve tibres may be met with. The electric nerve of the electric fishes

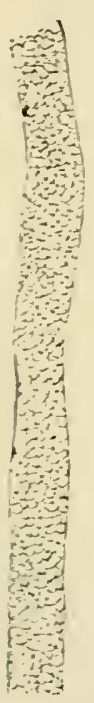

A

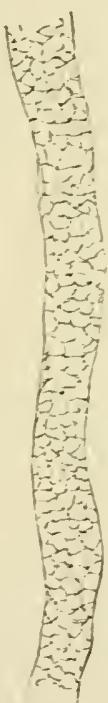

B
C

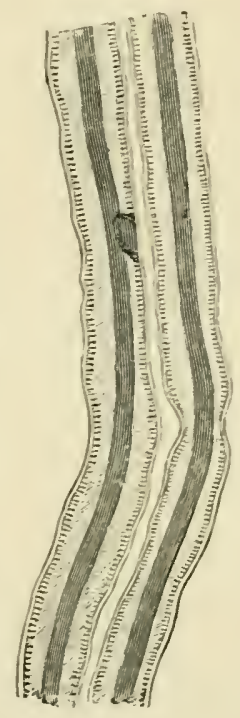

Fig. 102.--Medullated Ferve Fibres.

$A, B$, Showing on a surface view the retuculated nature of the mednllary sheath: c, two nerve fibres -howini the axis crlinder, the medallary sbeath with their vertically-arranged minute rods. and the delicate neuri. lemna or outer byaline sheatb. (Atlas.)

- e.g. malapterurus, grymnotus, silurus - shows such divisions to an extraordinary degree, one huge nerse fibre dividing at once into a bundle of minute fibres. Division of a medullated fibre takes place generally at a node of Ranvier. The branches taken together are generally thicker than the undivided part of the fibre, but in structure they are identical with the latter.

146. When medullated nerve fibres approach their peripheral termination, they change sooner or later, inasmuch as their medullary sheath suddenly ceases; and now we have a non-medullated or grey (transparent) nerve fibre of Remak. Each of these consists of an axis cylincler, a neurilemma, and between the two a nucleated nerve corpuscle from place to place. Non-medullated nerve fibres alwars show the fibrillar nature of their axis cylinder. The olfactory nerve branches are entirely made up of non-medullated nerve fibres. In the branches of the sympathetic 
most fibres are non-medullated. Non-medullated fibres do not show Ranvier's constrictions. Bundles of non-medullated fibres are grey, bundles of medullated filnes are white, when viewed in reflected light; the former being without medullary sheath allow light to

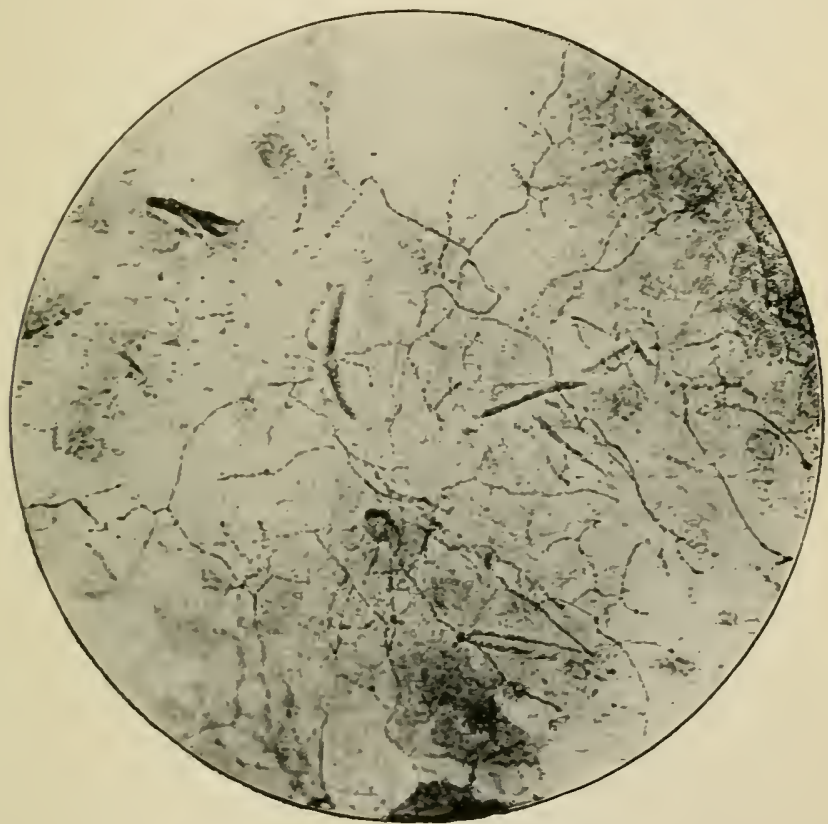

Fig. 103. - View of the anterior surfuce of Gold-stained Cornea of Guineapig, showing the rich distribstion of the terminal nerve fibrille and their ramifications in the anterior epithelium of the cornea. (Photo., highly inagnified.)

pass through them, while the latter owing to their medullary (fatty) sheath reflect light strongly.

In the extra-vertebral course of many branches of the cerebro-spinal nerves-e.y. those supplying the limbs, the wall of the chest and abdomen-there occur non-medullated tibres generally in small groups; 
these fibres are considered to be derived from the sympathetic system, having joined the cerebrospinal nerves by the grey portions of the rami communicantes (Gaskell). The non medullated fibres near their terminal distribution always undergo repeated divisions. They form plexuses, large fibres branching into smaller ones, and these again joining. Gener-

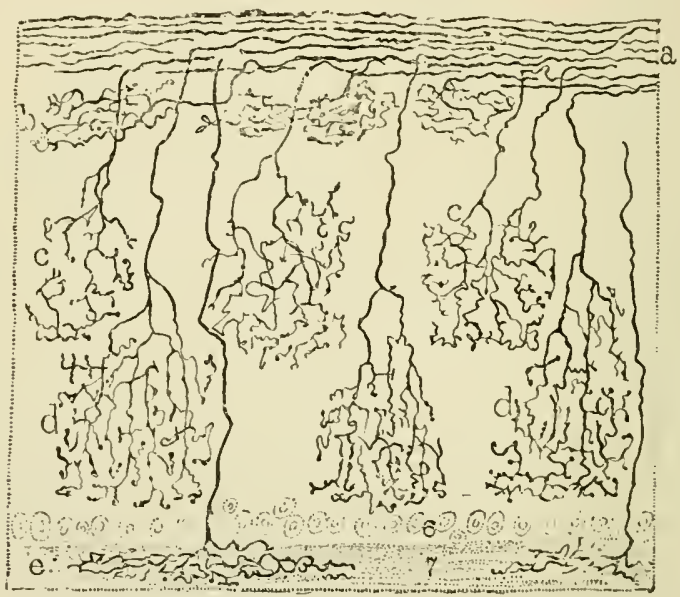

Fig. 104.-Dendritic terminations-Dendrons of Nerve Fibres. Transverse section of the optic lobe of a birl prepared by Golgi's metiod. (R. $y$ Cajal: from (iuain.)

$a$, Optic flbres: $b, c, d, e$, dendrons of same in the different layers of the optic lobe; 6 and $i$ are the sixth and seventh layers respectively of the organ.

ally at the nodal points of these plexuses there are triangular nuclei, indicating the corpuscles of the neurilemma.

147. Finally the non-medullated nerve fibres leaving the plexuses ultimately lose their neurilemma and break up into their constituent small bundles and even single primitive nerve fibrille, which occasionally show regular varicosities (Fig. 105). Of course, of a neurilemma or the nuclei of the nerve corpuscles there is nothing left. The bundles of primitive fibrils 
and also single fibrils branch and interlace, whereby a more or less dense dendritic ramitication-arborisation or dendron - is produced (Fig. 104). The indivi-

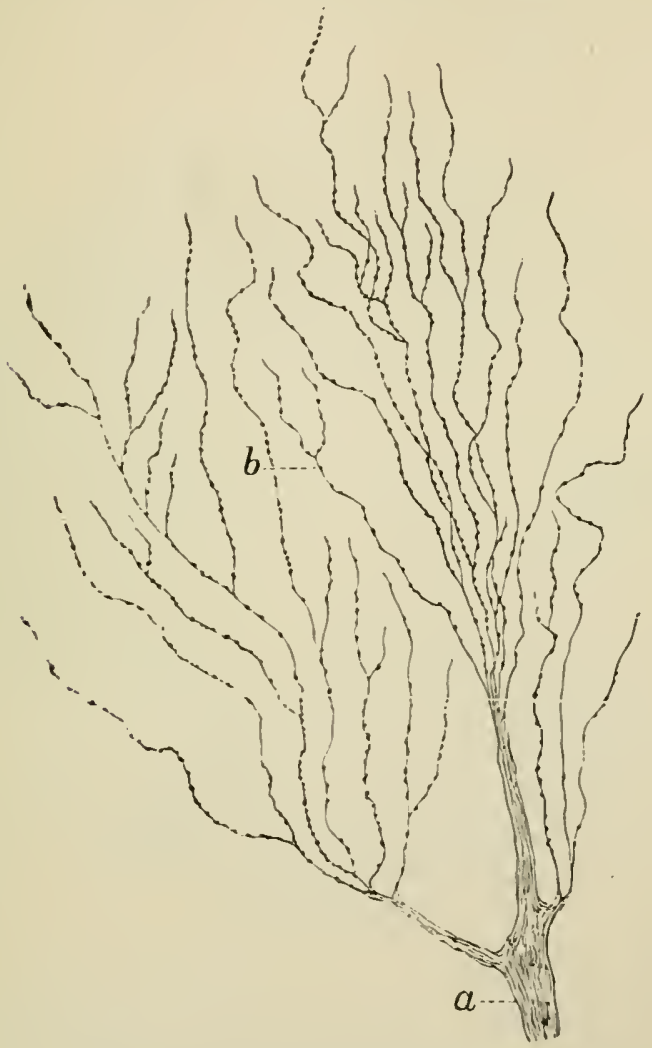

Fig. 105.-Nerve Fibres of the Cornea.

$a$, Axis crlinder near the anterior epithelium of the cornea splitting up into its constituent primitive fibrilla : $b$, primitive fibrille.

dual fibrils of the dendron are straight or twisted, and often provided with smaller or larger terminal knobs. In some localities-e.g. in the grey matter of the central nervous system-the number of fibrils con- 
stituting a dendron is large, and hence the dendron is conspicuous, in other localities the number of fibrils is relatively scanty-e.g. in the anterior epithelium of the cornea-and hence the arborising character of the dendron is not rery conspicuous (Fig. 103).

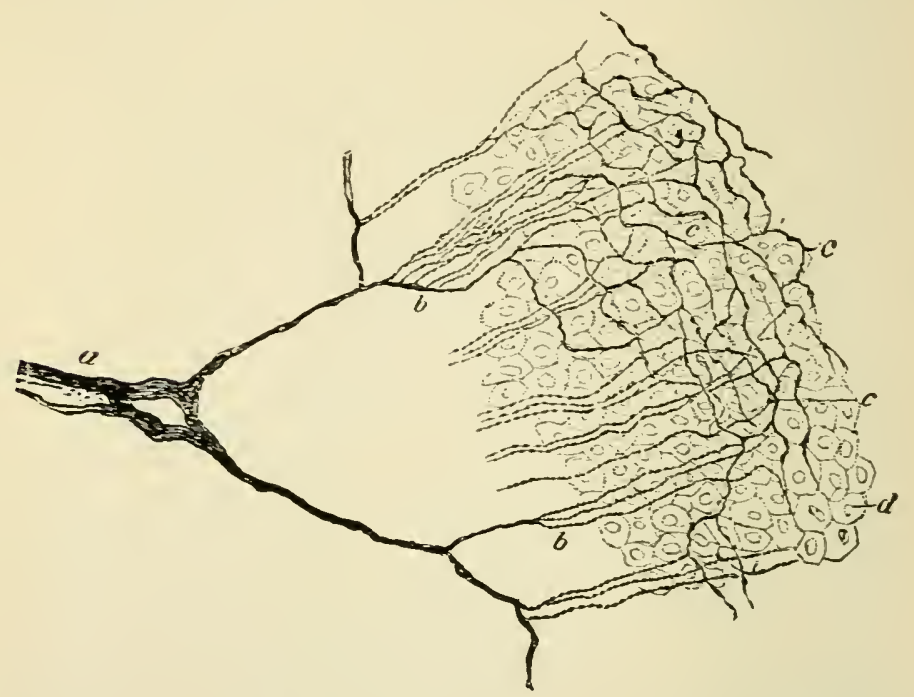

Fig. 100.-Intra-epithelial Nerve-termination in the Anterior Epithelium of the Cornea, as seen in an oblique section. (Handbook.)

$a$, Axis cylinder ; $b$, sub-epithelial nerve filvilla ; $c$, intra-epithelial ranification ; d, epithelial cells.

Pronounced dendrons are found in the nerve termination in muscle and tendon (the endplates) in the branched processes (dendrites) of the ganglion cells in the central nervous system, as will be described and illustrated later.

In the skin, cornea and mucous membranes, the peripheral termination - i.e. the primitive fibrils and their ramitications, are intra-epithelial (Fig. 106). i.e. they are situated in the stratum Malpighii of the epidermis, in the epithelial parts of 
the hair follicle, in the anterior epithelium of the cornea, or in the epithelium of the mucous menbranes. The primitive nerve tibrils lie in the interstitial substance between the epithelial cells, and some of them have been observed to end with minute

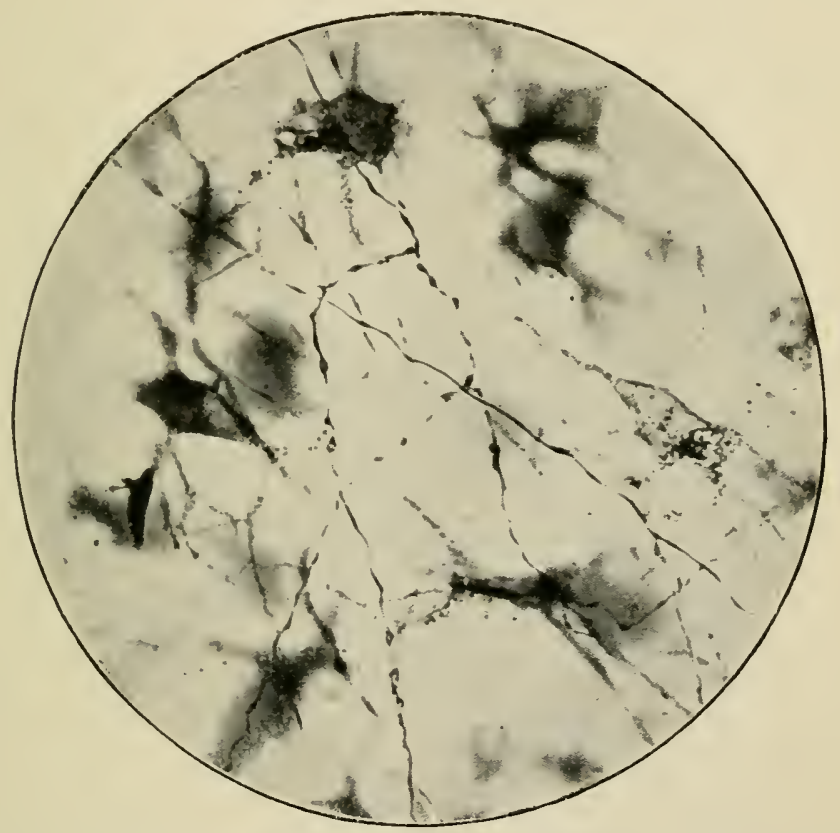

Fig. 107.-From goll-stained cornea of frog, showing the numerous bearled tine nerve fibrils and the branched corneal corpuscles. (Photo., highly magnified.)

kuobs in the cell substance itself close to the nucleus (Pfitzner, Macallum).

148. Tracing then a nerve fibre, say one of common sensation, from the periphery towards the centre, we have isolated primitive fibrils or their ramifications; they form by aggregation simple axis cylinders, which vary in thickness according to the number of their 
constituent primitive fibrils. These axis cylinders then become invested by neurilemma and nuclei, and form plexuses. By association they form larger axis cylinters, and these form typical nom-medullated nerve fibres with neurilemma, and with the nuclei of nerve corpuscles (Fig. 106). Lastly, if a medullary sheath makes its appearance between the neurilemma and the axis cylinder of each tibre we get a medullated nerve tibre. 


\section{CHAPTER XV.}

PERIPIIERAI YERVE-ENDINGS.

149. In the preceding chapter we referred to the termination of the nerves of common sensation, as isolated primitive fibrillie, and as ramifications and dendrons of these in the epithelium of the skin and mucous membranes, in the anterior epithelium of the comea, and in the grey matter of the central nervous system. Besides these there are other special terminal organs of sensory nerves, probably concerned in the perception of some special quality or quantity of sensory impulses. These are all comnected with a medullated. nerve fibre, and are situated not in the epithelium of the surface but in the tissue, at greater or lesser depth. Such are the corpuscles of Pacini and Herbst, the end-bulbs of Krause in the tongue and conjunctiva, the genital end-corpuscles or end-bulbs in the external genital organs, the corpuscles of Meissner or tactile corpuscles, in the papillæ of the skin of the volar side of the fingers, the touch-cells of Merkel, the end-corpuscles of Grandry, in the beak and tongue of the duck.

150. The Pacimian corpuscles.-These are also called Vater's corpuscles. They occur in large numbers on the subcutaneous nerve fibres of the palm of the hand and foot of man, in the mesentery of the cat, along the tibia of the rabbit, in the genital organs of man (corpora cavernosa, prostate). Each corpuscle is oval, more or less pointed, and in some places (palm of the human hand, mesentery of the cat) easily perceptible to the unaided eye, the largest 
being about $\frac{1}{0}$ th of an inch long and $\frac{1}{30}$ th of an inch broad ; in other places they are of microscopic size. Each possesses a stalk, to which it is attachfd, and which consists of a single medullated nerve fitre (Fig. 10S), differing from an ordinary medullated

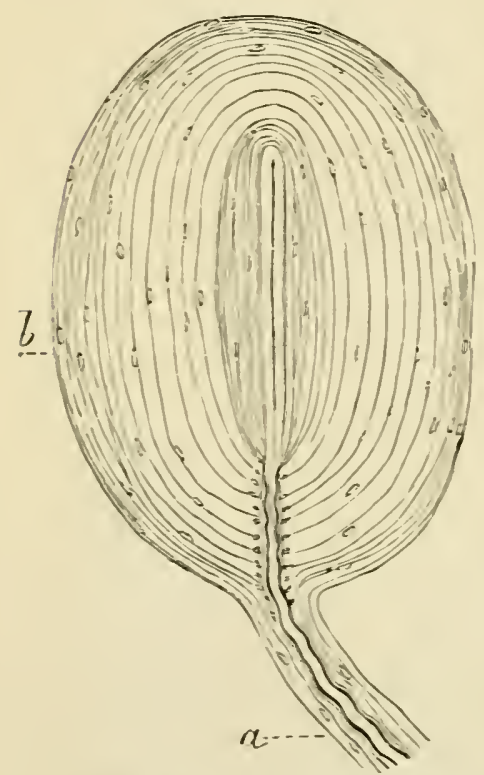

Fig. 105.-Pacinian Corpuscle, from the Mesentery of Cat.

$a$, Medullated nerve firre: $b$; concentric calsules. nerve fibre merely in the fact that outside its neurilemma there is present a thick laminated comnective-tissue sheath. This is the slieatl of Henle -continuous with the perineural sheath of the nerre branch with which the nerve fibre is in connection. This medullated nerve tibre within its sheath possesses generally a very wars outline. The corpuscle itself is composed of a large number of lamellie, or capsules, more or less concentrically arranged around a central elongated or cylindrical clear space. 'This space contains in its axis, from the proximal endi.e. the one nearest to the stalk-to near the opposite or distal end, a continuation of the nerve fibre in the shape of a simple aris cylinder. But this axis cylinder does not fill out the central space, since there is all round it a space left filled with a transparent substance, in which, in some instances, rows of spherical nuclei may be perceived along the margin of the axis cylinder. At or near the distal end of the central space the a.is cylinder divides in tuo or 
more branches, and these terminate in pear-shaped; oblong, spherical, or irregularly-shaped granularlooking enlargements.

151. The concentric capsules forming the corpuscle itself are disposed in a different manner at the periphery and near the central space from that in which they are disposed in the middle parts, in the former localities being much closer together and thinner than in the latter. On looking, therefore, at a Pacinian corpuscle in its longitudinal axis, or in cross-section, we always notice the striation (indicating the capsules) to be closer in the former than in the latter places. Each eapsule consists of-- $(a)$ a hyaline, probably elastic, ground substance, in which are embedded here and there $(b)$ fine bundles of connective-tissue fibres; $(c)$ on the inner surface of each capsule, i.e. the one directed to the central axis of the Pacinian corpuscle, is a single layer of nucleated endothelial plates. The oblong nuclei risible on the capsules at ordinary inspection are the nuclei of these endothelial

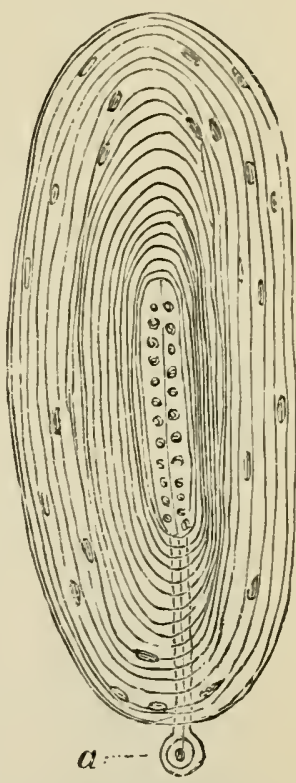

Fig. 109.-Herhst's Corpuscle, from the Tongue of Duck.

$a$, Medullated nerve fibre cut away. plates. There is no fluid between the capsules, but these are in contact with one another (Huxley). Neighbouring capsules are occasionally connected with one another by thin fibres.

152. In order to reach the central space of the corpuscle, the medullated nerve fibre has to perforate the capsules at one pole; thus a canal is formed in which is situated the medullated nerve fibre, and 
as such, and in a very wavy condition, it reaches the proximal end of the central space. This part of the nerve fibre may be called the intermediate part. The lamellie of the sheath of Henle pass directly into the peripheral capsules of the corpuscle.

Immediately before entering the central space, the nerve fibre divests itself of all parts except the axis cylinder, which, as stated above, passes into the central space of the Pacinian corpuscle. In some cases a minute artery enters the corpuscle at the pole, opposite to the nerve fibre; it penetrates the peripheral capsules, and supplies them with a few capillary ressels.

153. The corpuscles of Irerbst are similar to the Pacinian corpuscles, with this difference, that they are smaller and more elongated, that the axis cylinder

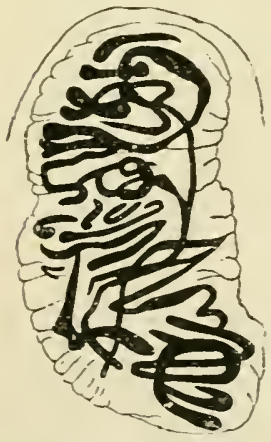

Ficr. 110.-Tactile Corpuscle of Meissner from the skin of the Human Hand. (E. Fischer and W. Flemming.)

showing the convolutions of the nerre fibre.

in man and in apes; they are oblong, straight, or slightly folded. In man they are about $\frac{1}{50}$ to $\overline{3}_{0}^{1} \overline{0}$ of an inch long, and $\overline{5} \frac{1}{0}$ to $\frac{1}{200}$ of an inch broad. 
They are connected with a medullated nerve fibregenerally one, occasionally, but rarely, two-with a sheath of Henle. The nerve fibre enters the corpuscle, but usually before doing so it winds round the corpuscle as a medullated fibre once or twice or oftener, and its Henle's sheath becomes fused with the fibrous capsule or sheath of the tactile corpuscle. The nerve fibre ultimately loses its medullary sheath and penetrates into the interior of the corpuscle, where the axis cylinder branches; its branches retain a coiled course all along the tactile corpusclé (Fig. 110), anastomose with one another, and terminate in slight enlargements, shaped or cylindrical. These enlargements, according to Merkel, are touch-cells. The matrix; or main part of the tactile corpuscle consists, besicles the fibrous sheath with nuclei

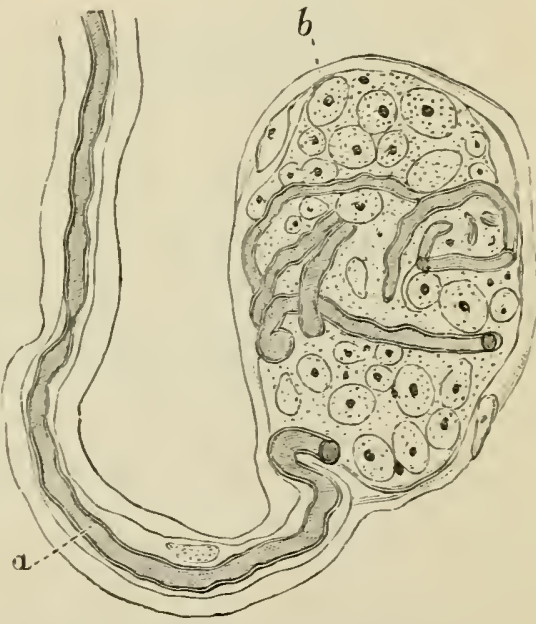

Fig. 111.-End-hulh of Krause. and numerous elastic fibres, of fine bundles of comnective tissue, and of a number of nucleated small cells.

155. The end-bulbs of Krause.-. These occur in the conjunctiva of the calf and of man, and are oblong or cylindrical minute corpuscles situated in the deeper layers of the conjunctira, near the corneal margin. A medullated nerve fibre, with Henle's sheath, enters the corpuscle (Fig. 11l). This possesses a nucleated capsule, and is a more or less laminated 
(in man more granular-looking) structure, numerous nuclei being scattered between the lamina. Of the nerve fibre, as a rule, only the axis cylinder is prolonged into the interior of the corpuscle. Ocrasionally the medullated nerve fibre passes, as such, into the corpuscle, being at the same time more ol less convoluted. Haring passed to near the distal extremity, it branches, and terminates with small enlargements (Krause, I.ongworth, Merkel, Key and Rietzius).

The end-bulbs in the genital organs, or the genital corpuscles of lirause, are similar in structure to the simple end-bulbs. They occur in the tissue of the cutis and mucous membrane of the penis, clitoris, and ragina.

156. The corpuscles of Grandry, or touch corpuscles of Merkel, in the tissue of the papille in the beak and tongue of birds, are oral or spherical corpuscles of minute size, possessed of a rery delicate nucleated membrane as a capsule, and consisting of a series (two, three, four, or more) of large, slightlyflattened, granular-looking, transparent cells, each with a spherical nucleus, and arranged in a rertical
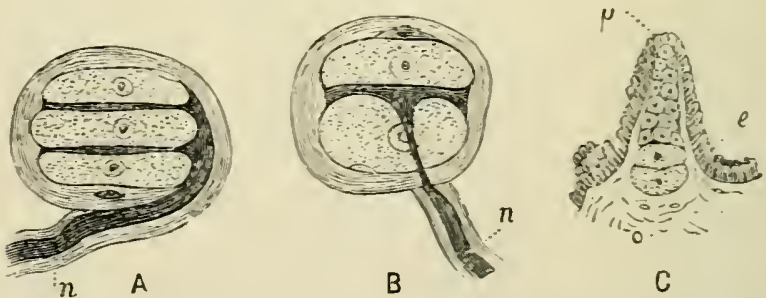

Fig. 112.-Corpuscles of Grandry in the Tongue of Duck. (Iz'luierdo.)

A, Composed of three cells: B. composed of two cells: $\mathrm{c}$, showing the derelopment of a Grandry's corpuscle from _the epithelium corering the papilia, $p$; $e$, epithelinm: $n$, nerve fibre.

row (Fig. 112). A medullated nerve fibre enters the corpuscle from one side, and losing its medullary 
sheath, the axis cylinder branches, and its branchlets terminate, according to some (Merkel, Henle), in the cells of the corpuscle (tonch cells of Merkel); according to other's (Key and Retzius, Ranvier, Hesse, Izquierdo), in the transparent substance between the touch cells, thus forming the "dise tactil" of Ranvier or the "Tastplatte" of Hesse. Neither theory seems to us to answer to the facts of the case, since we find

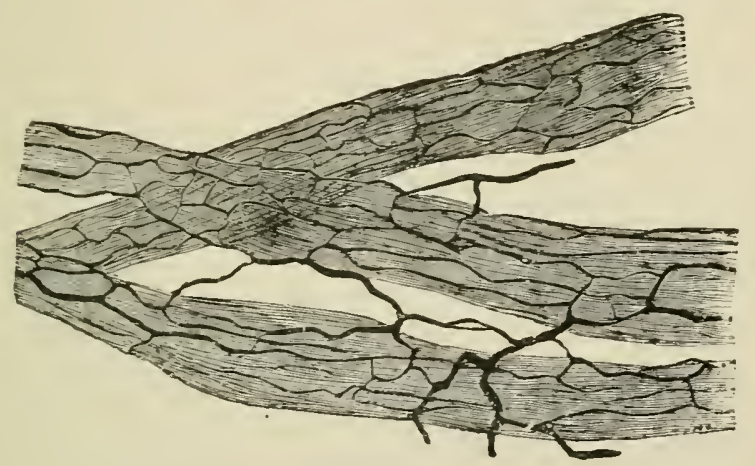

Fig. 113.-Bundles of Non-striped Mnscnlar Tissue stirrounded by Plexisses of Fine Nerve Fibres. (Handbooli.)

that the branchlets of the axis cylinder terminate, not in the touch cells, nor as the dise tactil, but with minute swellings in the interstitial substance between the touch cells, in a manner very similar to what is the case in the conjunctival end-bulbs. According to Merkel, single or small groups of touch cells occur in the tissue of the papillie, and also in the epithelium, in the skin of man and mammals.

15\%. In articulations-e.g. the knee-joint of the rabbit - Nicoladoni described numerous nerve branches, from which fine nerve tibres are given off. Some of these terminate in a network, others on blood-ressels, and a third group enter Pacinian corpuscles. Krause described in the synorial membranes 
of the joints of the human fingers medullated nerve tibres which end in peculiar tactile corpuscles, called by him "articular" nerve corpuscles."

\section{The nerve branches supplying nou-}

striped muscular tissue are derived from the srmpathetic srstem. They are composed of nonmedullated fibres, and the branches are invested

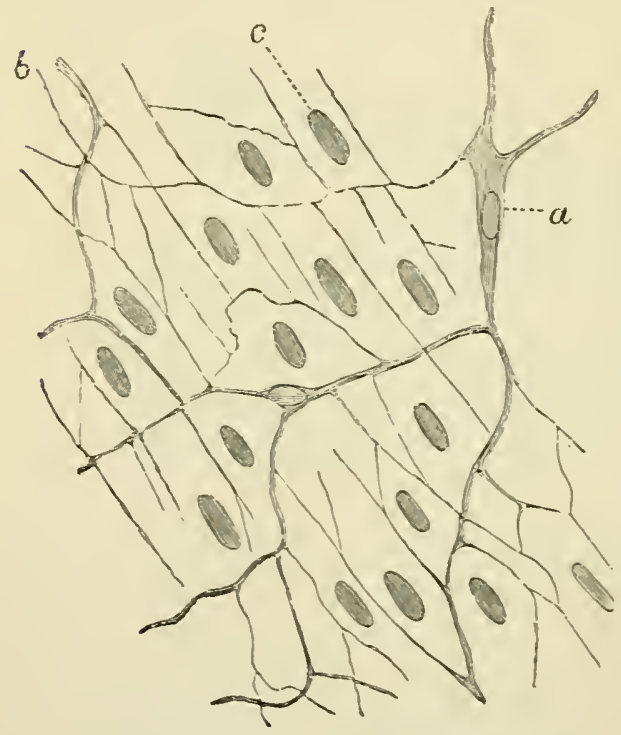

Fig. 114.-Termination of Jerves in Non-striped Muscular Tissue. (Atlas.)

a, Yon-medullated firre of the intermediary plexus; 7. fine intermuscular fibrils; $c$, nuclei of mus: culill cells. in an endothelial sheath (perineuri u 11 ).

The branches divide into single or small groups of axis cylinders, which reunite into a plexusthe ground plexus of $A r$ nold. S mall filses coming off from the plexus supply the individual bundles of non-striped muscle cells, and they form a plexus called the intermediary plears (Figr. 113). The fibres joining this plexus are smaller or larger bundles of primitive fibrillie; in the nodes or the points of meeting of these fibres are found angular nuclei. From the intermediate plexus pass off isolated or small groups of primitive fibrilla, which pursue their course in the interstitial substance between the muscle cells; these are the intermuscular 
fibrils (Fig. 114). Accorting to Frankenhatiiser and Armold, they give ofl tiner tilnils, enting in the nucleus (or nucleolus). According to Elischer, the primitive fibrils terminate on the surface of the nucleus with a minute swelling.

In many localities there are isolated ganglion cells in connection with the intermuscular fibres.

159. The nerres of blood-vessels are derived from the sympathetic, and they terminate in arteries and reins in essentially the same way as in nonstriped muscular tissue, being chiefly present in those

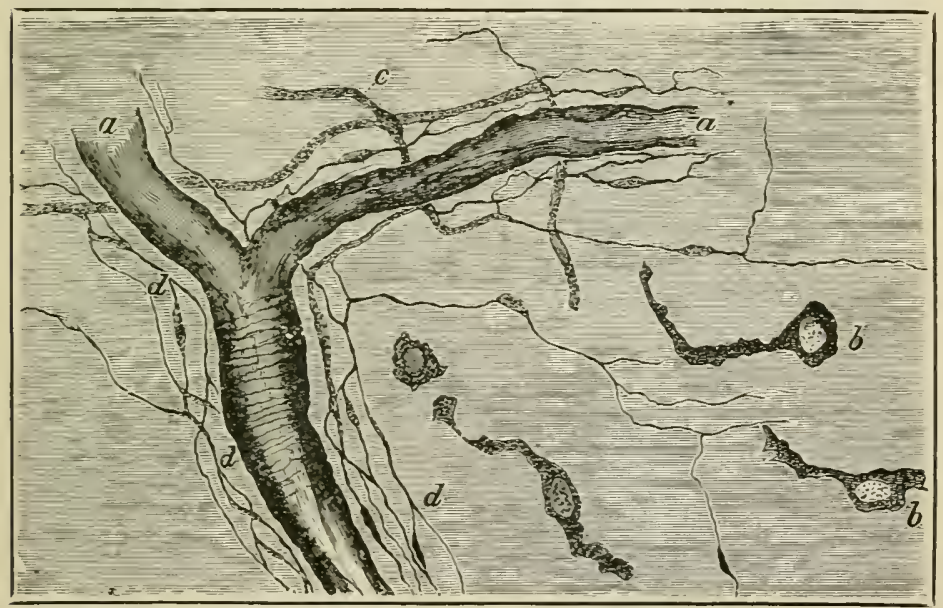

Fig. 115.-Plexus of Fine Non-medullated Nerve Fibres surrounding Capillary Arteries in the Tongne of Frng, after staining with chloride of gold. (Hemilbook:)

$a$, Blood-re--el; $b$, connective tissue corpuscles; $c$, thick non-medulated fibres $d$, plexus of fine nerve fibres.

parts (media) which contain the non-striped muscular tissue. But there are also fine non-medullated nerve tibres, which accompany capillary ressels-capillary arteries and capillary veins - and in some places they give off elementary fibrils, which form a plexus around the ressel (Fig. 11.5). In some localities the 
vascular nerve branches are provided with small groups of ganglion cells.

160. In striped ursicle of man and mammals, reptiles and insects, the termination of nerve fibres
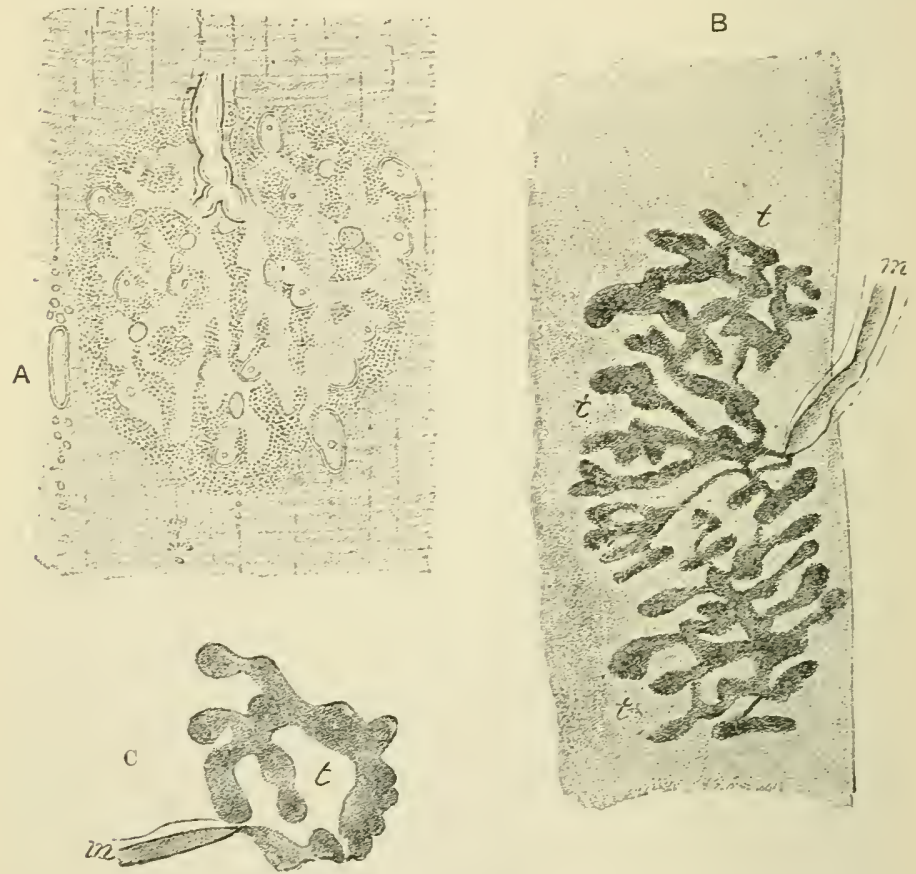

Firg. 116.-Nerve-endings in Striped Muscular Fibres. (Kimlly lent by Professor Kü̈hne.)

A, In fresh muscular fibre of Lacerta, $\times \frac{600}{10} ; \mathbf{B}$, in gold-stainerl muscular fibre of lacerta, $\times \frac{550}{1} ; C$, in gold-stained muscular fibre of don, $\times$ 1inn; $m$, medullated nerve fibre; $t$, termination of axis cylinder underneath the sarcolemma of the muscular fibre.

takes place, according to the commonly accepted view of Kirhne, in the following manner (Fig. 116):-A medullated nerve fibre, enclosed within a lamellated sheath (Henle's sheath) divides at a node of Ranvier, each branch - a medullated nerve fibre-enters under a variable angle a striped muscular fibre, the neurilemma 
becoming fused with the sarcolemma, and the nerve fibre, either at the point of entrance or immediately afterwards, loses its medullary sheath, so that only the axis cylinder, with its axilemma, passes on, and then forms on the surface of the muscular substance a terminal arborisation or dendron, which is called the nerve endplate. Each axon, on entering, gives off by division several branches like antlers; in amphibia these branches are rodlike, long, and of the form of bayonets; in mammals they are crooked, hook-like. In all instances, however, the divisions are unsymmetrical. In many cases the arborisation of the endplate is embedded in a gramular mass of protoplasm containing oblong nuclei. This nucleated protoplasm is identical with the substance of the sarcoglia, or the sarcoplasm mentioned on a former page. When the muscular fibre contracts, this endplate naturally assumes the shape of a piominence - Doyère's nerve mount. Each muscular

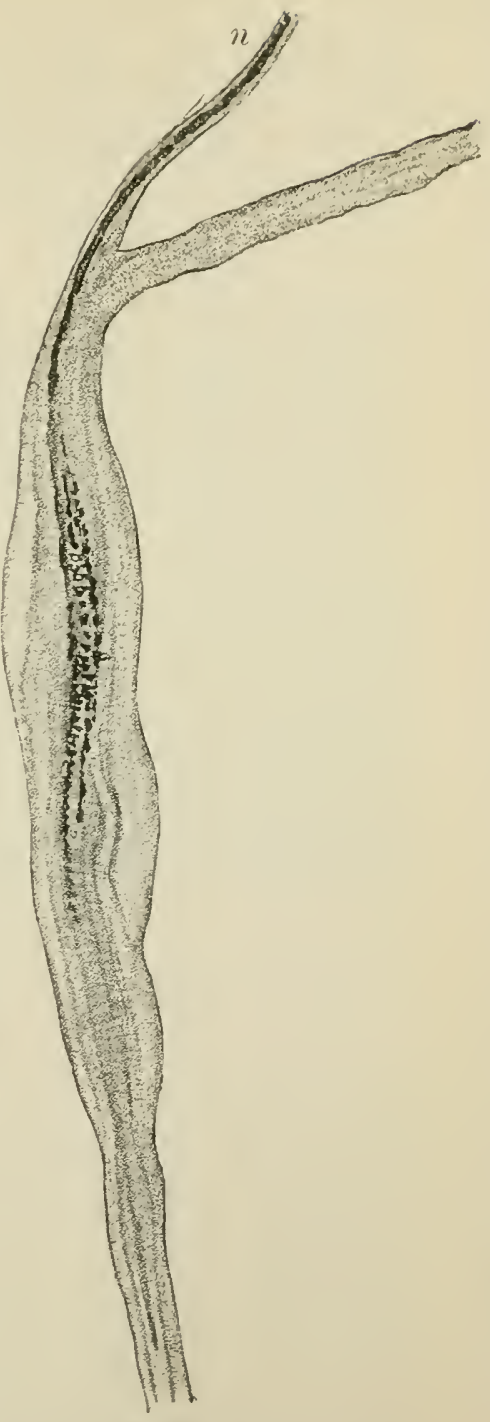

Fig. 117.-Muscle spindle of the raubit treated with gold chlo. lide. (Kölliker, II.)

$n$, Terve fibre, terminatina in the midale part of the spindle as a spiral ending of fine fibrils. 
tibre has at least one nerve endplate, but occasionally has sereral in near proximity. Each endplate is generally supplied by one nerve fibre, sometimes, howerel, by two. "The contraction wave generally starts from the endplate. The muscle

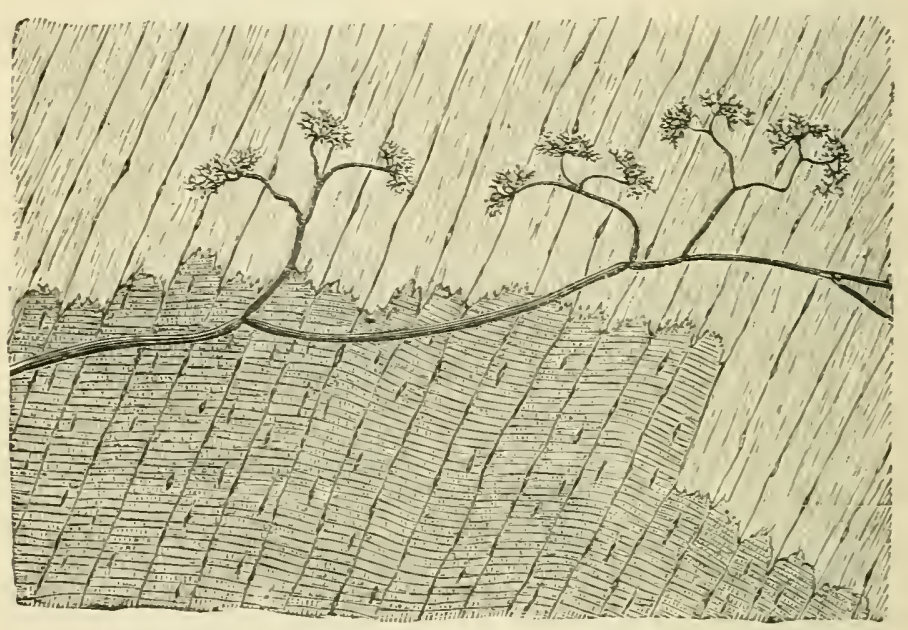

Fig. 11s.-Termination of Medullated Nerre Fibres in Tendon, near the Insertion of the striped Muscular Fibres. (Golgi.)

The nerve fibres terminate in peculiar arborising endrlates of primitre fibrillæ.

bucts of Kölliker or muscle spindles of Kühne (mentioned on a former page) contain numerous medullated nerve fibres with lamellated Henle's sheath, and these nerve fibres terminate in the same manner, namely, by neans of nerve endplates (Fig. 117). In these endplates the fine nerre fibres have a spiral arrangement (Ruftini). These are considered to be sensory end-organs. According to Kölliker, from the primary nerve ending of the mother fibre-i.e. of the undivided portion of the spindlegrow out the nerve endings for the thin daughter tibres. 
Besides this intra-muscular termination, there is a plexus of tine nerve fibres, many of them said to terminate with free ends, situated outside the sarcolemma-i.e. intermuscular; such free ends are described by Beale, Kölliker, Krause, and other's. Kölliker and Arudt consider these intermuscular fibres as sellsory nerves.

\section{Ten-}

donsalesupplied with special nerve e $n d$ i n g s, studied by Sachs, Rollett, Gempt, Rauber, and particularly Golgi, whose work on this subject is ex-

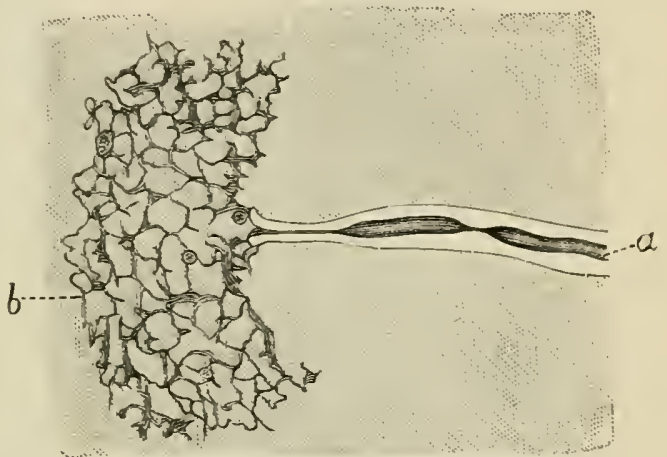

Fig. 119.-One of the Terminal Ramilications of the previous figure, more lighly magnified.

$a$, Medullated nerve fibre; $b$, apparently reticulated endplate. (Golyi.)

tensive. These terminations are most numerous near the muscular insertion. They are of the following kinds:- $-(a)$ A medullated nerve tibre branches repeatedly, and the axis cylinder, after having lost the medullary sheath, breaks up into a small plate composed of a dendritic ramitication of fine primitive nerve fibrils (Fig. 118). Owing to the number of the fibrillie and their repeated crossing, it is difficult to say whether the appearances as shown in Fig. 119 correspond to a real network or to a dendron. This endplate is occasionally embedded in a granular-looking material, and thereby a similar organ as the nerve enclplate in muscular fibres is produced (Fig. 119). (b) In the tendons of man and many mammals Golgi has shown that nerve fibres terminate in peculiar spincile-shaped 


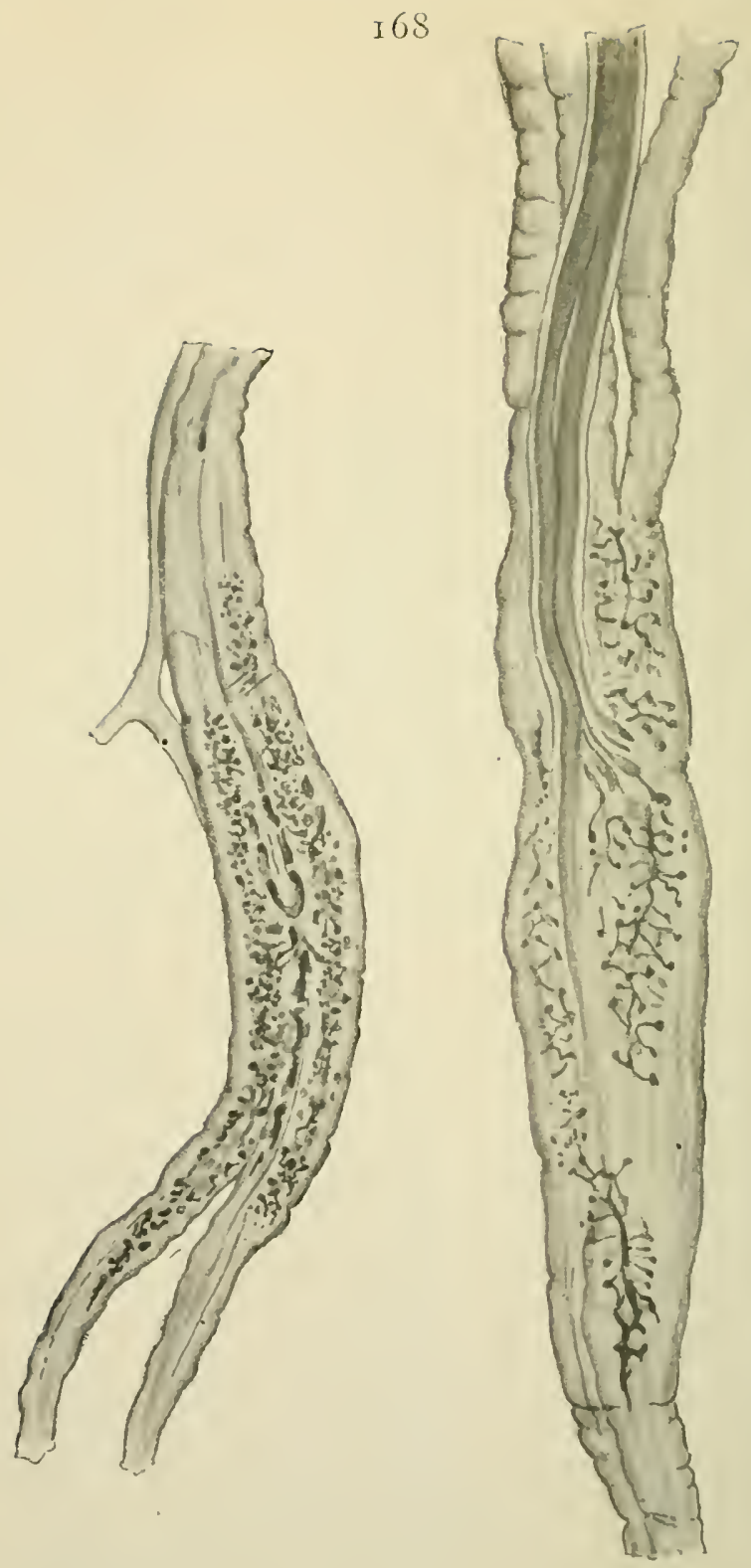

Fig. 120.-Two Tendon spindles of Golgi in the rablit, showing the distribution and spiral termination of the nerre fibres on the spindles. (After Köllilier.) 
enlargements of tendon bundles (Fig. 120). 'These temlon spindles of Golgi consist each of two, three, or more tendon bundles within a common sheath; a bundle of tine medullated nerve fibres enters the

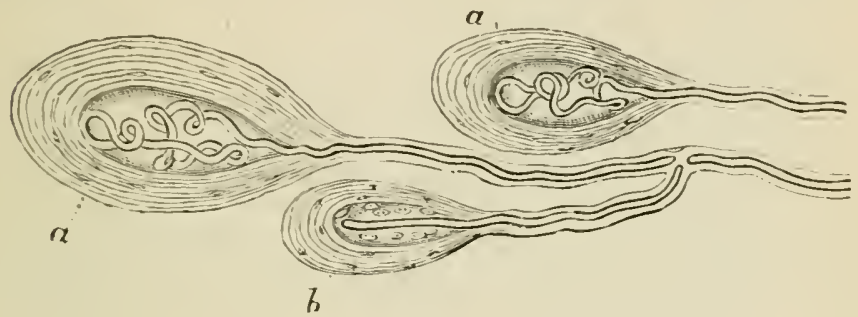

Fig. 121.-Termination of Merlullated Nerve Fibres in Tendon. (Golgi.) $a$, End-bulb. with conroluted medullated nerve filse ; $b$, end-bulb similar to a Herlost's corpuscle.

spindle, their axis cylinders break up into primitive fibrillae, which are arranged as a network and as spiral fibrille. (c) A medullated nerve fibre terminates in an end-bulb (Fig. 121), similar to those of the conjunctivil, or of a Herbst's corpuscle. 


\section{CHAPTER XVT.}

THE SPINAL COPD.

162. Tre spinal cord is enveloped in three distinct membranes. The outermost one is the dura mater. This is composed of more or less distinct lamelle of fibrous comnective tissue with the flattened connectivetissue cells and networks of elastic fibres. 'The outer and inner surface of the dura mater is covered with a layer of endothelial plates.

163. Next to the dura mater is the extremely delicate arachnoid membrane. This also consists of bundles of fibrous connective tissue. The outer surface is smooth and covered with an enclothelial membrane facing the space existing between it and the inner surface of the dura mater; this space is the subdural lymph space. The inner surface of the arachnoidea is a fenestrated membrane of trabeculie of fibrous connective tissue, covered on its free surface-i.e. the one facing the sub-arachnoidal lymphl space - with an endothelium.

164. The innermost membrane is the pia mater. Its matrix is fibrous comnective tissue, and it is lined on its outer surface with an endothelial membrane. Also the inner surface facing the cord proper has an endothelial lining, but this is not as complete and continuous as that of its outer surface. Between the arachnoid and pia mater extends, from the fenestrated portion of the former, a spongy plexus of trabeculae of fibrous tissue, the surfaces of the trabecula being covered with endothelium. By this 
spongy tissue-the sub-urachnoidul tissue (Key and Retzius) - the sub-arachnoidal space is subdivided into a labyrinth of areolie. On each side of the cord, between the anterior and posterior nerve roots,

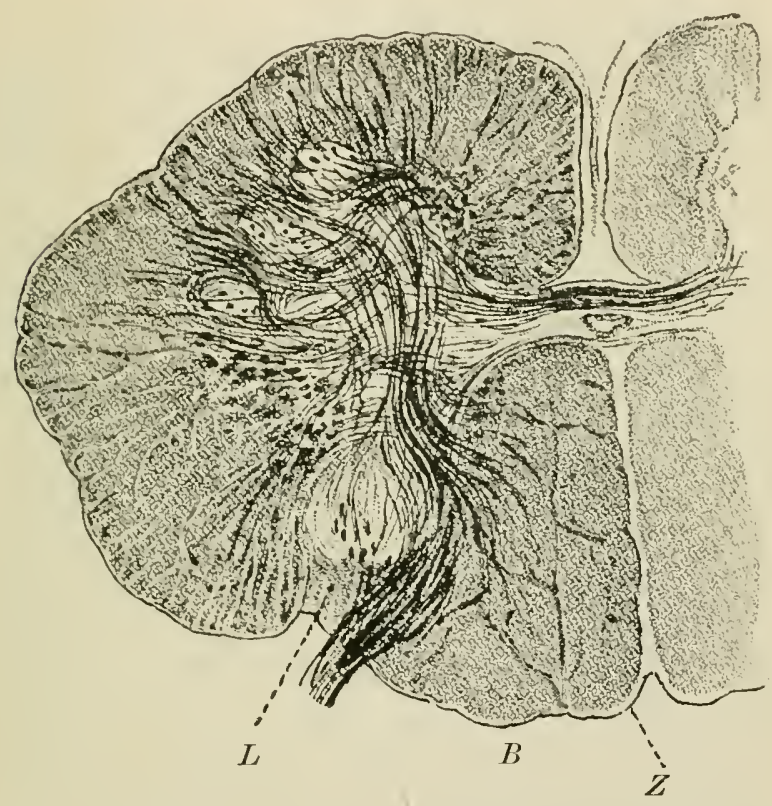

Fis. 122. - Transverse section through the Cervical Cord of a child, 2 years old, slowing well the anterior white commissure and the numerous medullated tibres passing horizontally throngl the grey matter (collaterals) from and to the white columns. (IVeigert.)

z, Tract of Goll; B, tract of Burdach ; L, tract of Lissauer.

extends a spongy fibrous tissue, called ligamentum denticulatum, between the arachnoidea and pia. By it the sub-arachnoidal space is subdivided into an anterior and posterior livision.

165. The subdural and sub-arachnoidal spaces do not communicate with one another (Luschka, Key and Retzius). 
The dura mater, as well as the arachnoid, sends prolongations on to the nerve roots; and the subdural and sub-arachnoidal spaces are continued into the lymphatics of the peripheral nerves.

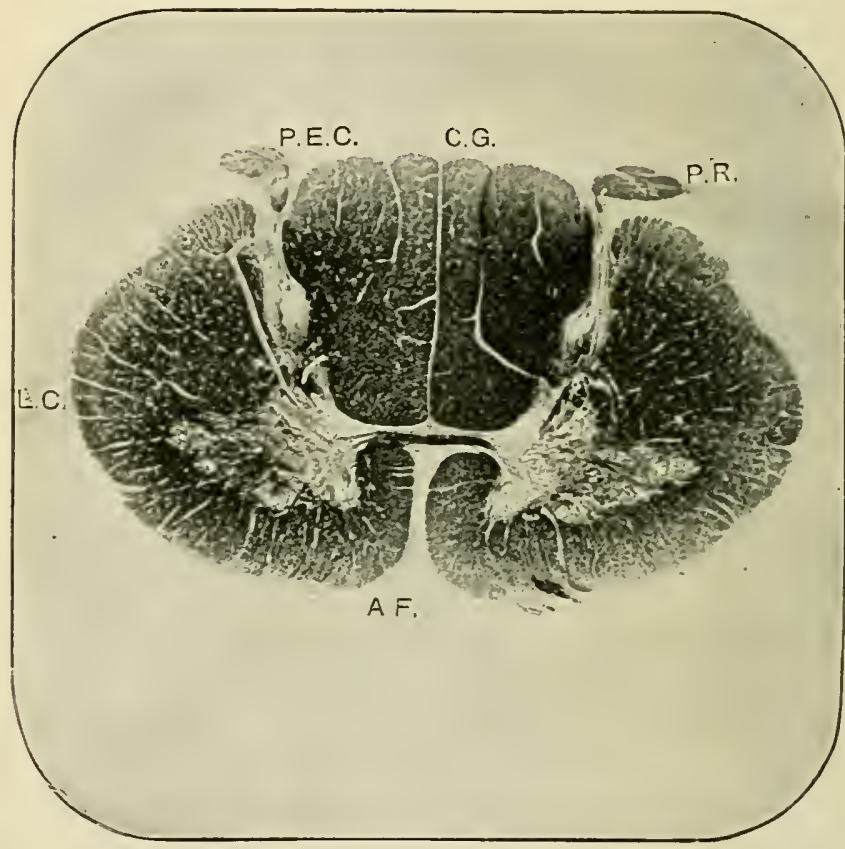

Fig. 123A.-Transverse section of the Spinal Cord in the Cervical region. (Wicrophotogreph of Weigert-Pal specimen.)

P. E. c. l'ostero-extermal column ; c. G., postelo-median colmmn or column of foll ; P. R., the issuing posterior root; L. C., latelal colmmm : A. F., anterior"or ventral fissure. The white matter is more deeply stained than the more central gres.

All three membranes contain their own system of blood-vessels and nerve fibres.

166. The cord itself (Fig. 122) consists of an outer or cortical part composed of medullated nerve fibres: the white matter, and an inner core of grey matter. On a transverse section through the cord the 
contrast of colour between the white mantle and the grey core is very conspicuous. The relation between the white and grey matter differs in different parts; it gradually increases in farour of the former as we

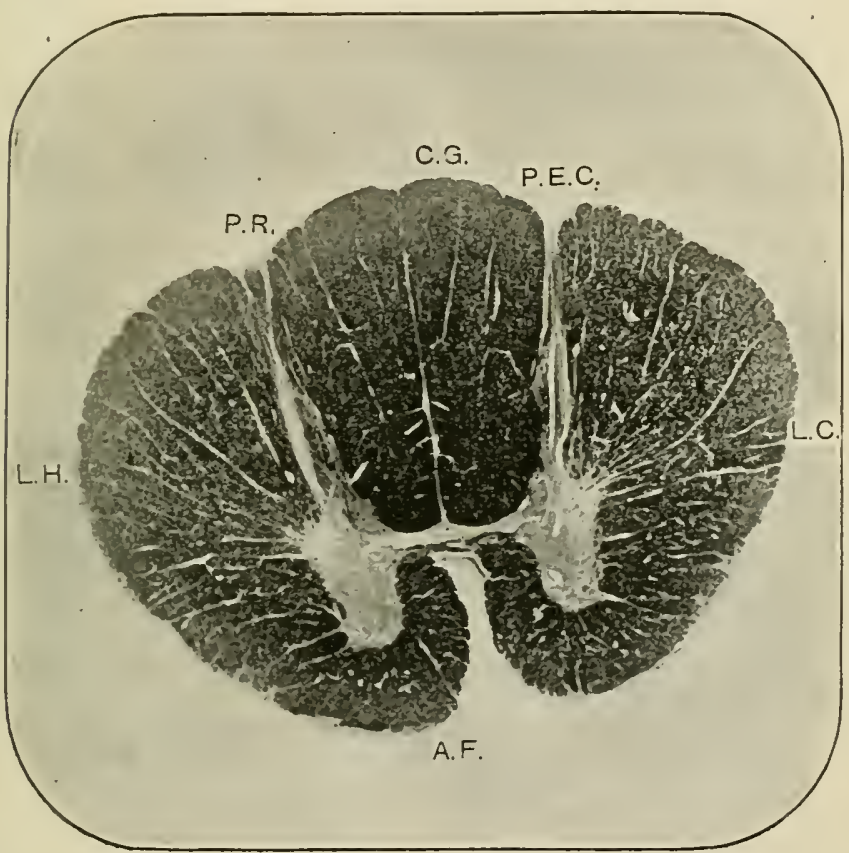

Fig. 123в.- Section of the Spinal Cord in the Dorsal region. (Wicrophotograph of a IVeigert-Pal specimen.)

Yote the small amount of grey matter which projert; laterally at level L. 11. to form a lateral linrn. Tote, ton. at the same level on the median side of the posterior horn a definite mass, forming Clarke's colmmus. The lettering is as in the section through cervical region.

ascend from the lumbar to the upper cervical portion (Figs. 123A, 123 $\mathrm{B}, 123 \mathrm{C}$ ). The grey matter presents in every transverse section through the cord more or less the shape of a capital $\mathrm{H}$; the projections being the anterior and posterior horns or cornua of grey matter, and the cross-stroke being the grey commissure. 
In the centre of this grey commissure is a cylindrical canal lined with a layer of columnar epithelial cells; this is the central canal; the part of the grey commissure in front of this canal is the anterior, the rest the posterior, grey commissure. The shape of the whole figure of the grey matter differs in the different regions, and this difference is brought about by the breadth and thickness of the grey commissure as also of the grey horns themselves. In a section through the cervical region the grey commissure is long and thin; in the dorsal region it becomes shorter and thicker ; and in the lumbar region it is comparatively very short and thick. Besides this, of course, the relative proportions of grey and white matter, as mentioned before, indicate the region from which the particular part of the cord has been obtained. In the lower cervical and lumbar regions where the nerves of the brachial and sacral plexus leave or join the cord respectively, this latter possesses a swelling, and the grey matter is there increased in amount, the swelling being in fact clue to an accumulation of grey matter, with which additional numbers of nerve fibres become comnected; but the general shape of the grey matter is retained.

167. The cornua of the grey matter are generally thickest in the line of the grey commissure: they become thinned out into anterior and posterior edges respectively, which are so placed that they point towards the antero-lateral and postero-lateral fissures. The anterior horns are in all parts thicker and project less than the posterior, and therefore the latter reach nearer to the surface, becoming attenuated and passing into the posterior nerve roots.

There is generally a third projection of grey matter-the lateral horn (see Fig. 123 B). This is, however, conspicnous only in the upper two-thirds of the thoracic cord. 
168. The white matter is composed chiefly of nedullated nerve filores rumning a longitudinal course, and therefore, in a transverse section through the cord, appear in cross-section. 'They are arranged into

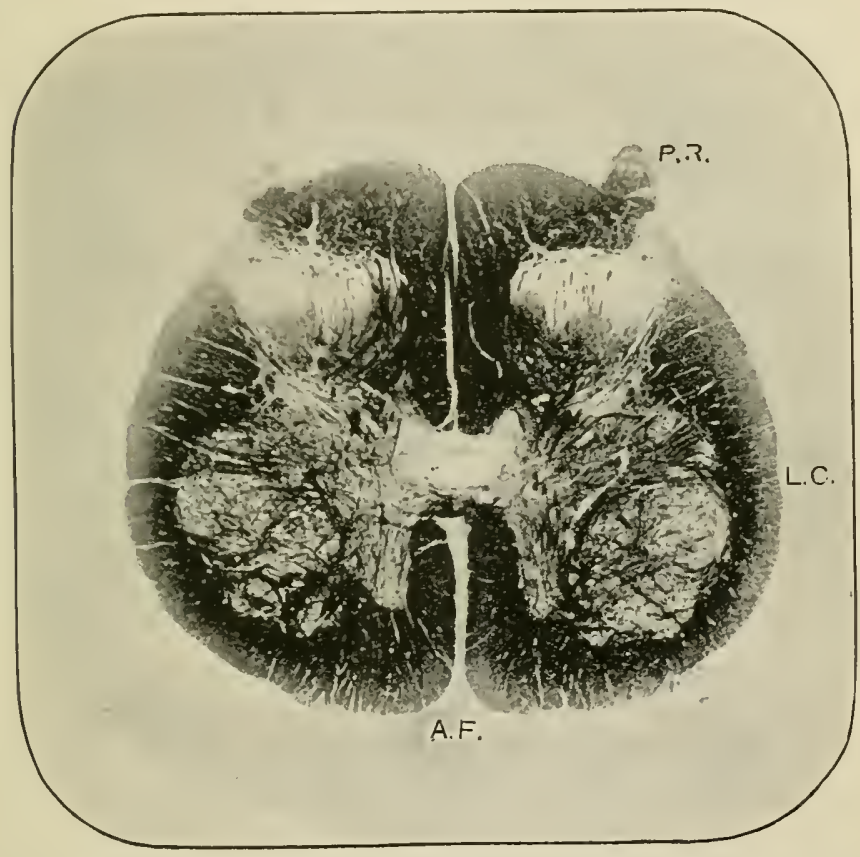

Fig. 123c.-Section through the Spinal Corl in the Sacral region. (Wicrophotogruph of a Weigert-Pal spiccimen.)

The ligliter stained grey matter is large in amount eompared with the darker white matter. The tils of the posterior horns and around the central canal are very lightly stained owing to the presence of much substantia gelatinosa. Iany nedullated fibres are seen traversing the anterior lorns.

columns, one anterior, one lateral, and one posterior column for each lateral half of the cord, the two halves being separated by the anterior and posterior. median longitudinal fissure. 'The anterior median fissure is a real fissure extending in a horizontal 
direction from the surface of the cord to neai the anterior grey commissure. It contains a prolongation of the pia mater and in it large vascular trunks. The posterior fissure is not in realicy a space, but is filled up by neuroglia. It extends as a continuous mass of neuroglia in a horizontal direction from the posterior surface of the cord to the posterior grey commissure. The exit of the anterior or motor nerve roots and the entrance of the posterior or sensitive nerve roots are indicated by the anterior lateral and posterior lateral fissures respectively. These are notreal fissures in the same sense as the anterior median fissure, but correspond more to the posterior median fissure, being in reality filled up with neuroglia tissue, into which extends a continuation from the pia mater with large vascular trunks. The white matter between the anterior median and anterior lateral fissure is the anterior colrmm, that between the anterior lateral and posterior lateral fissure is the lateral column, and that between the posterior lateral and posterior median fissure is the posterior column.

169. Besicles the septa situated in the two lateral fissures respectively, there are other smaller septa, neuroglia and prolongations of the pia mater, which pass in a horizontal and radiating direction into the white matter of the columns, and these are thus subdivided into a number of smaller portions; one such big septum is sometimes found corresponding to the middle of the circumference of one lialf of the cord. This is the median lateral fissure, and the lateral column is subdivided by it into an anterior and posterior division.

Similarly, the anterior and posterior columns may be subdivicled into a median and lateral division (Figs. 123 $\mathrm{A}$ and 125).

170. Some of these various subdivisions bear 
definite names ('Türk, C'harcot, Goll, Flechsig, Gowers) :-

(a) 'The median division of the anterior column is called the direct or uncrossed pyramidal tract, being

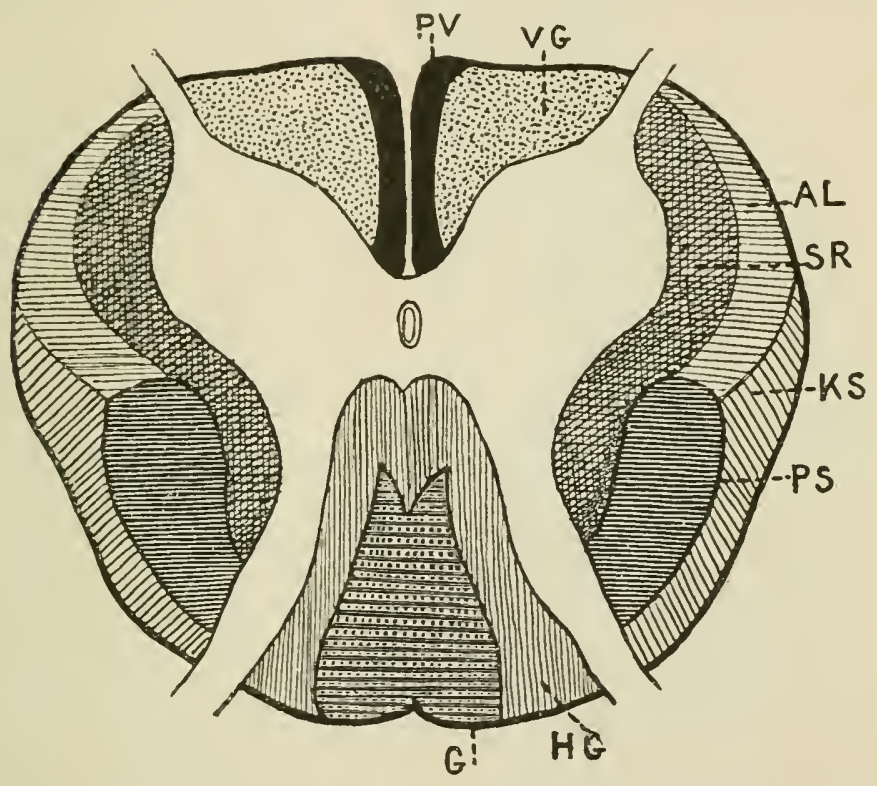

Fig. 124.-Scheme of the sululivision of the White Columns. (After Fleschsig and Kuhler, from hölliker, II.)

$\mathrm{P} \mathrm{F}$, Direct pyramidal tract of anterior white column ; $\Gamma \mathrm{G}$, rentral ground tract of anterlor white column ; A L, antero-lateral tract of lateral column. Gowers's tract; s $\mathrm{r}$, remainder of antero-lateral part of lateral column ; $\mathrm{K} \mathrm{s}$, direct cerebellar tract of lateral column; P s, crossed pyramidal tract of lateral colımn; H G, tract of Burdach of posterior white column; $\mathrm{G}$, tract of Goll in posterior column. Grey matter, grey commissure around central canal, anterior and posterior roots left unshaded.

a continuation of that part of the anterior pyramiclal tract of the medulla oblongata (see below) that does not decussate in the medulla.

(b) The lateral division of the anterior column is the ventral or anterior ground tract.

(c) The direct cerebellar frisciculus or tract is the superticial portion of the postero-lateral columm; it is 
a direct continuation of the white matter of the cerebellum.

(d) The posterion division of the lateral column inside the cerebellar fasciculus is called the crossed

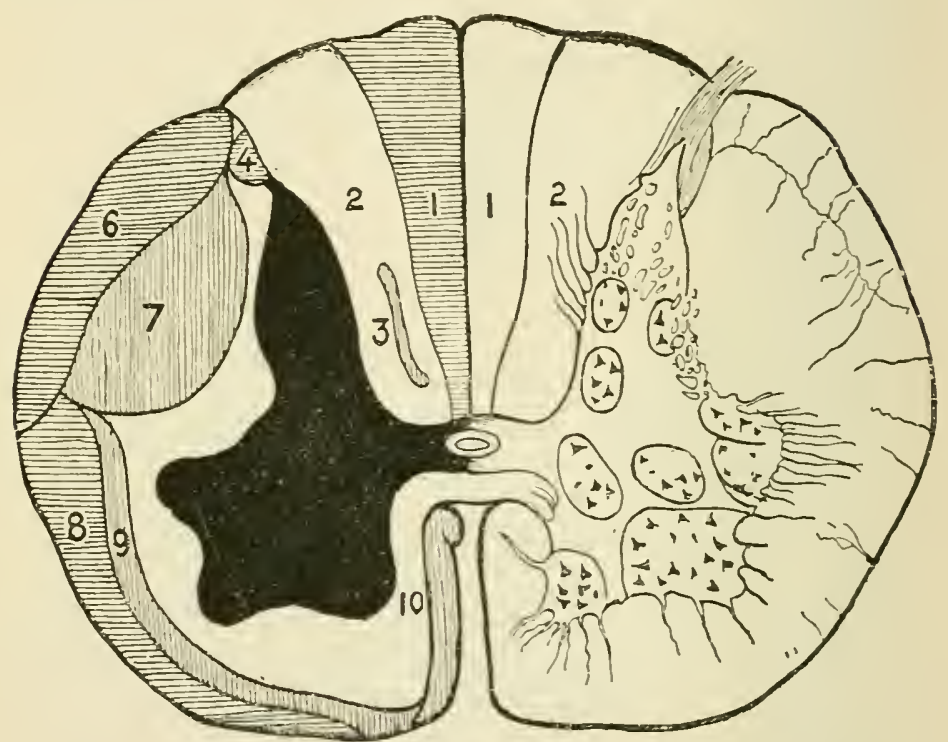

Fig. 125--. Section of spinal Cord, one half of which (left) shows the tracts of the white natter; and the other half (right) shows the grouping of the ganglion cells in the grey matter (semilliagrammatic). (After Sherrington, from Kirlie's "Physiology.")

$7,10,9$, and 3 are tracts of descending degeneration; $1,4,6$, and 8 of ascending degeneration: 1 , tract of Goll; $:-$ tract of Burdach: 3 , comma tract ; 4 , tract of Lissauer ; all these belong to the posterior whire column; 6 , direct cereheliar tract; $\vec{i}$, crossed psramidal tract ; $s$, tract of Gowers; $y$, descending antero-lateral tract; 10 , direct prramidal tract.

myramidul fasciculus or tract, being a continuation of the decussated part of the anterior pyramidal tract of the medulla oblongata.

(e) The lateral division of the posterior column, with the exception of a small peripheral zone, is the cuneiform or cuneate fusciculus, or the tract of Burelach. 
This part is connected directly with the median bundle of the posterior nerve roots, or rather by the numerous collaterils passing off from the posterior root fibres.

$\left(f^{*}\right)$ 'The median division of the posterion' column is called the fisciculus or tract of Goll.

(g) The tract or fasciculus of Lissauer (Fig. 125) is a small mass of white fibres situated between the outer superficial portion of the tract of Burdach and of the direct cerebellar tract, and close to the posterior lateral fissure.

In addition to these, a narrow mass of fibres in the depth of the tract of Burdach, near the grey commissure, represents

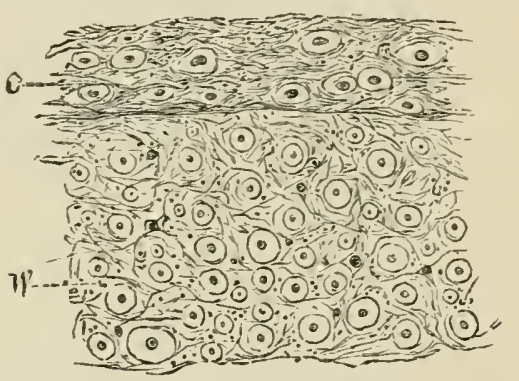

Fig. 126.-From a transierse section through a most peripheral part of the White Matter of the Cord. (Atlas.)

c, Special peripheral collection of neuloglia ; $\iota$, white matter with the medullated nerve fibres shown in cross section, and neuroglia betwecn them. a separate group, called the comma-shaped tract : and the superficial mass of white matter in the anterior half of the lateral column, which is called the anterolateral ascending tract of Goucers (see Fig. 124).

These various divisions can be traced from the medullata oblongata into the cervical, and more or less into the dorsal part of the cord; but further down many of them, like the direct cerebellar tract and the tract of Goll, are lost as separate tracts, except the crossed pyramidal fasciculus.

Experiments have been made which demonstrate that these different tracts are physiologically of very different character. According to a well-established law-the Wallerian law-each nerve fibre has its 
nutritive centre in the ganglion cell with which it is connected, and if a nerve fibre is cut, tlat part which remains connected with the nutritive centre does not degenerate, while that part severed from the centre degenerates. Consequently, if by cutting the cord at

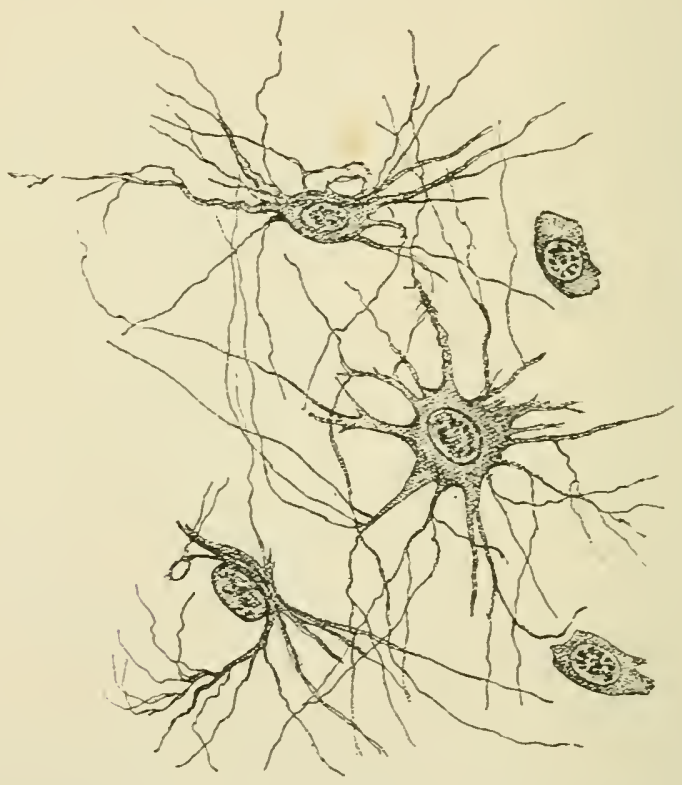

Fig. 127.-Stellate Neuroglia Cells of Golgi, with numerous ramifying processes ; from the cord of ox. (Köllitier, II.)

a particular level some fibres remain intact above the section but degenerate below, they show descending degeneration; they have their nutritive centre above the section and are probably efferent fibres. On the other hand, those fibres which degenerate above, but remain intact below the section, show ascencting degeneration; they have their nutritire centre below the section and are probably afferent tibres.

By means of Weigert's method it has been 
possible to show (Weigrert) not only that the nerve fibres constituting the white columns are grouped in different tracts but that in the embryo they obtain their medullary sheath at different but definite periorls.

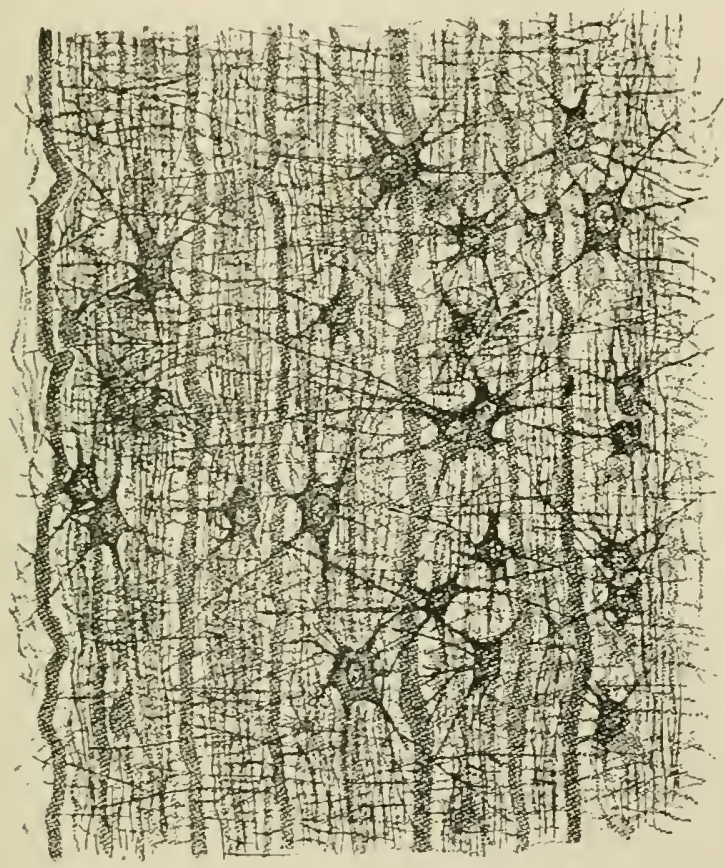

Fig. 12S.-Longitulinal section through the Lateral White Column of the Cord of the Ox, showing the axis cylinders of the medullated nerve fibres, ntmerous fine longitudinal and transverse fibrils of the neuroglia, anıl the stellate neuroglia cells of Golgi. (After Kölliker, II. Highly magnified.)

Now in this way it has been made probable that the tracts marked in the firgures in the above-named divisions of the anterior and lateral columns contain partly efferent, partly afferent tibres, while almost the whole of the fibres of the posterior columns are afferent; see explanation of figures. 
171. Structure of the cord.-The most inportant and fundamental facts which have been brought to light within recent years concening the intimate structure of the white and grey matter and of the mutual relations of the different parts and the different elements of the cord, the brain, the medulla, and the sympathetic system, are due to various new methods of histological examination, as also to the experimental methods of section of the cord and nerve roots in the living, and observing the after-effects as exhibited by degeneration of nerve tracts. As regards the histological methods, Weigert and Pal's method of staining medullated nerve fibres of the cord, Marchi's method of distinguishing between degenerated and healthy medullated fibres, and, above all, Golgi's silver method, by which nerve fibres and ganglion cells can be easily traced in their finest ramifications, hare been the means of opening up an almost new field of accurate inquiry concerning all parts of the central nervous system as well as of the special senses. Golgi's silver method has enabled himself, and, to a very conspicuous degree, Rámón y Cajal and Kölliker, to bring to light facts concerning the intimate structure of the central nerrous system, the ganglia, and the sense organs, which stand out in respect of clearness and trustworthiness. Other histologists, Lenhossek, Retzius, and others, have hy this method also been enabled to contribute important facts.

172. The ground substance (Fig. 126) of both the white and grey matter-i.e. the stroma in which nerve fibres, nerve cells, and blood-ressels are embedded-is a peculiar kind of connective tissue, which is called by Virchow neuroglia and by Kölliker supporting tissue. It consists of three different kinds of elements: $(a)$ a homogeneous transparent semi-fluid matrix, which in hardened sections appears more or less granular; (b) a network of very 
delicate tibrils-nenroglia filmils-which are similar. in some respects, but not quite identical with elastic filres. In the columms of the white matter the

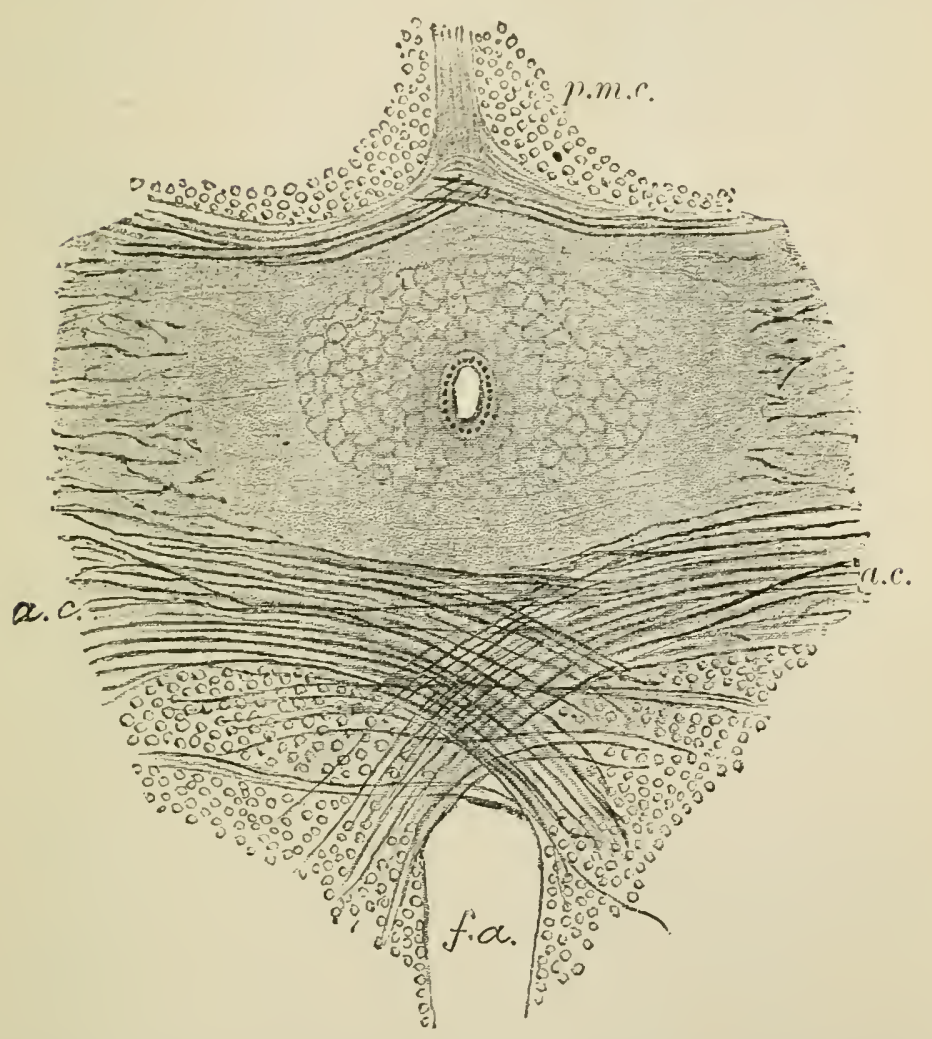

Fig. 129.-Cross-section of the central part of the Spinal Cord from the Lumbar region of an Alult, showing the central canal, its lining epithelimm surrounded by nemroglia, forning the central grey nucleus. (After Sichöfer.)

f. a., Anterior median fissure; p.m.c., posterior white column: a.c., anterior white commissure.

fibrils extend chiefly in a longitudinal direction, in the grey matter they extend uniformly in all directions, and in the septa between the columns 
they extend for the most part radially. (c) Richly branched nucleated cells intimately woren into the network of neuroglia fibrils. These cells are the nevioglice cells or glia cells. Golgi was the first to show that though richly branched they do not anastomose with one another. The greater the amount of

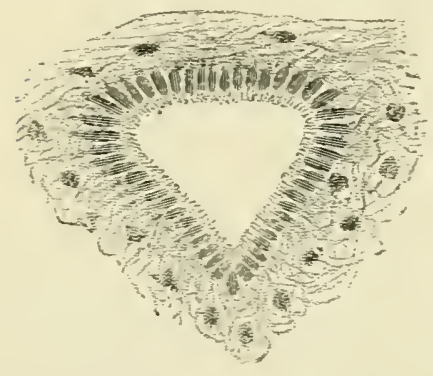

Fig. 130. - Cross-section through central canal of the coril, sluwing the lining epithelinin. from a child of six. (After sicherfo)

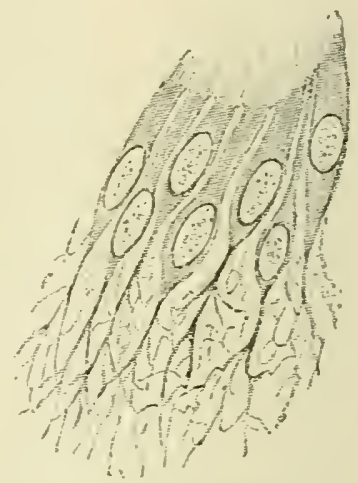

Fig. 130B.-Ciliated Epithelium lining the central canal of the cord in a child of six, more highly magnitied than in Fis. 130A. (After schäfer.)

nemroglia in a particular part of the white or grey matter, the more numerous are these three elements (Figs. 127 and $12 s$ ).

In both the white and grey matter the neuroglia has a very unequal distribution; but there are certain definite places in which there is always a considerable amount-a collection, as it were, of neuroglia tissue. These places are: ( $a$ ) underneath the pia materi.e. On the outer surface of the white matter: here most of the nemroglia tibrils have a horizontal direction; near the grey matter there is a greater amount of neuroglia between the nerve tibres of the white matter than in the middle parts of this latter; in the septa between the columns and between the 
divisions of columns of white matter; at the exit of the anterior and the entrance of the posterior nerve roots.

(b) A considerable accumulation of neuroglia is present immediately around the epithelium lining the

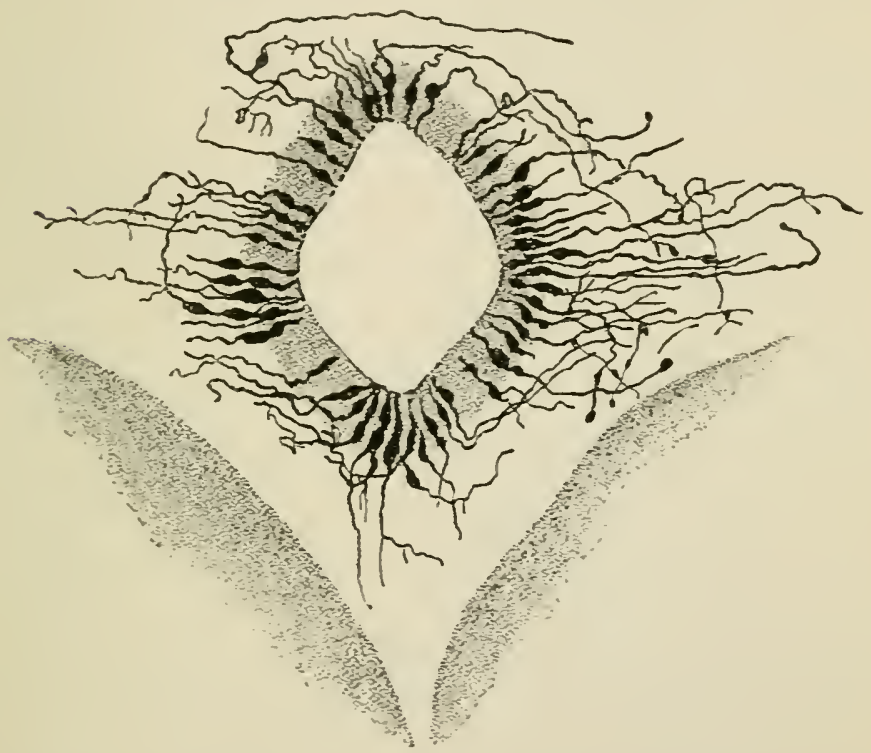

Fig. 131.-Central Canal of the Corl of a Child, 1 a year old ; the cells of efrendyma are well shown, with their long filamentous processes. (

central canal; this mass is cylindrica?, and is called the cential grey nucleus of Kölliker (Fig. 129). The epithelial cells lining the central canal are conical, their bases facing the canal, their pointed extremity being drawn out into a fine tilament intimately interwoven with the network of neuroglia fibrils. In the embryo and young state (Figs. $130 \mathrm{~A}$ and $130 \mathrm{~B}$ ), the free base of the epithelial cells has a bundle of cilia, but in the adult they are lost amongst the epithelial cells 
lining the central canal: some show in preparations stained after Golgi's method processes of extreme length (Fig. 131).

(c) Another considerable accumulation of neuroglia exists near the dorsal end of the posterior grey horns, as the substrntia gelatinose of Rolando.

173. The white matter (Fig. 132) is composed, besides neuroglia, of medullated nerre fil,res varring rerr much in diameter, and forming the essential and chief part of it. They

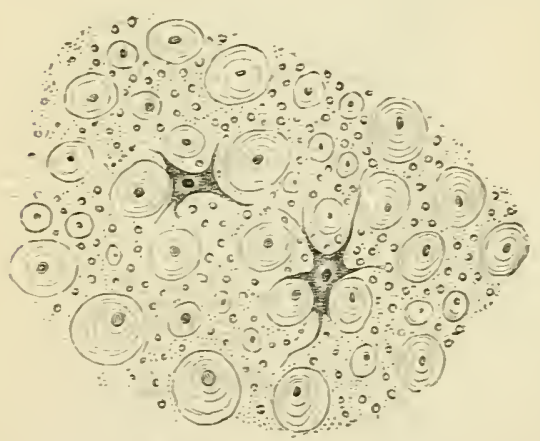

Fig. 132.-From a transterse section through the White Matter of the Cord.

Showing the transtersely-cut medullated nerve fibres, the neuroglia hetween them with two hranched neuroglia cells. (.1tlns.) possess an axis cylinder and a thick medullary sheath more or less laminated, but are deroid of a neurilemma and its corpuscles. Of course, no nodes of Ranvier are obsertable. In specimens of white matter of the posterior columms, where the nerve fihres have been isolated by teasing after hardening, manr fine medullated tibres are met with which show the varicoseappearance mentioned in a former chapter. The medullated nerve fibres, or rather the matrix of their medullary sheath, contains neurokeratin. The nelve fibres of the white matter run chiefly in a longitudinal direction, and they are separated from one another by the neuroglia. Here and there in the columms of white matter are seen connectire-tissue septa with ressels, by which the nerve fibres are grouped more or less distinctly in divisions.

17t. Although most of the nerve fibres con- 
stituting the columms of white matter are of a longitudinal direction-i.e. passing upwards or downwards between the grey matter of the cord on the one hand and the brain and medulla oblongata on the other-there are nevertheless a good many medullated nerve fibres and groups of nerve fibres which have an oblique or even horizontal course.

Thus : (1) The anterior median fissure does not reach the anterior grey commissure, for between its bottom and the latter there is the white commissure (see Fig. 129). 'This consists of bundles of medullated nervefibres passing in a horizontal or slightly oblique manner chiefly between the grey matter of the anterior horn of one side and the anterior white column, including the direct pyramidal tract, of the opposite side.

This anterior white commissure is in respect of position a continuation of the clecussation of the pyramidal tract in the lower part of the medulla oblongata. As mentioned above, this latter passes down the cord as the crossed pyramidal tract in the inner part of the postero-lateral column. From this it follows that the fibres of the pyramiclal tract of the medulla ultimately all cross over to the opposite side of the cord. The majority do this in the pyramidal decussation of the medulla, the minority descend in the cord as the direct pyramidal tract, but its fibres gradually along the cord cross over by the anterior white commissure.

(2) The medullated nerve fibres constituting the anterior roots of the spinal nerves leave the cord at and about the antero-lateral fissure; the fibres pass mostly in a somewhat oblique, some also in a horizontal direction through the white matter of the cord, and each of them originates, some sooner, some later, as the axon or axis cylinder process of a ganglion cell of the anterior grey horn. This is the fate of most of the anterior root fibres-that is to say, they are 
primarily the axons of ganglion cells of the anterior grey horn of the same side; this axon becomes invested with a medullary sheath, and as an efferent medullated nerve fibre passes out through the anterior nerve roots. It is, howerer, probable that some of these tibres are axis-cylinder processes or axons of ganglion cells of the anterior horn of the opposite side, and as such pass through the anterior commissure, while a small number of anterior root fibres can be traced into the posterior grey horn, where they are evolved as the axis cylinder or axon of a ganglion cell of this part of the grey matter.

As will be mentioned presently, the grey matter of the cord contains, in the dorsal or thoracic portion (between the serenth cervical and second or third lumbar nerve), a special column of ganglion cellsClarke's column; the axon of some of these cells appears to pass through the anterior grey horn to join the anterior root fibres.

But according to Flechsig, with whon Külliker agrees, the axous of most of the ganglion cells of Clarke's column pass in a horizontal direction from the grey matter into the lateral white column, where they pursue their comse as longitudinal fibres towards the cerebellum, thus forming the tibres of the direct cerebellar tract.

(3) The posterior roots. The medullated nerre fibres constituting the posterior roots are branches of the axis-cylinder process of the ganglionic cells of the spinal ganglion; they enter the cord as small bundles hy the postero-lateral fissure, between the lateral and posterior columms of white matter, in a slightly slanting direction, and at the same time turned more towards the posterior column of white matter. Now the tibres of the posterior roots may be roughly grouped into a lateral and median bunale, the former. containing predominantly fine medullated fibres, the 
latter predominantly larger medullated fibres; the former as well as the latter, after their entry into the cord, sooner or later divide, each into an ascendiny and a descending medullated fibre. The ascending and descending fibres resulting from the division of the tibres of the lateral bundle form part of and pursue their longitudinal course in that portion of the posterior white column which lies next to the posterior grey hom and the lateral white column, and which is known as Lissauer's tract or Lissauer's bundle (see Fig. 122). The ascending and descending medullated fibres resulting from the division of the fibres of the median bundle also following a longitudinal course are distributed principally over, and form part of, the white matter of the posterior columns (Burdach's and Goll's tract). Some of these fibres are said, however, to enter directly into the grey matter of the posterior horn and to terminate there.

(4) All medullated fibres constituting the clifferent columns of white matter and descending or ascending respectively in the cord send out at numerous levels horizontal fibres which enter or pass out from the grey matter. The discovery of these fibres by Golgi and Rámón y Cajal by means of the silver method constitutes a fundamental advance in our knowledge of the minute anatomy and physiology of the cord. These horizontal fibres which branch off from, or join respectively, the fibres constituting the different tracts of the white matter are called collaterals (see Figs. 122 and $123 \mathrm{c})$. The collaterals give off branches themselves. By means of the collaterals and their hranches numerous connections are formed between the longitudinal fibres of the white columns on the one hand and the grey matter on the other. The collaterals terminate, or originate respectively, nec and around nerve cells in all parts of the grey matter. by means of arborisations or dendrons (Fig. 133). 
175. As mentioned just now, collaterals are not limited to any one tract of the white columns, and are not limited to any particular level, but are griven off

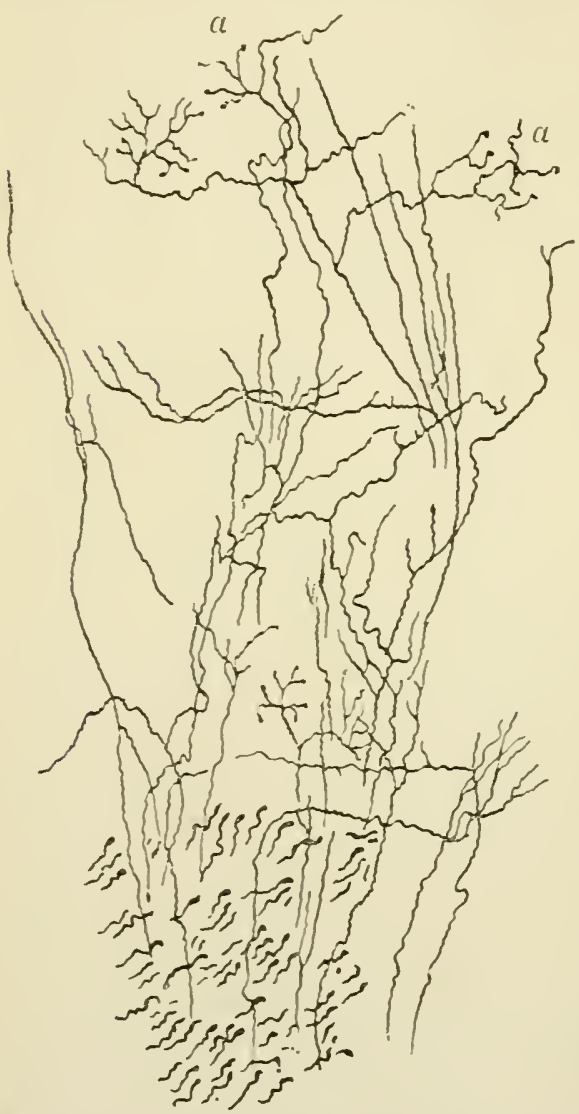

Fig. 133.-Collaterals passing frum fibres of posterior column into the gres matter, aml teminating at a by dendrons. From the cord of a newly-born clild. (After Kölliker, II.) or pass into respectively the longitudinal fibres constituting the white columns in general and at everr level through which sections of the cord are made. Figs. 12:2 and 1230 give a good representation of these facts.

Following, then, the longitudinal medullated fibres constituting those tracts of white matter, which were described ahore as clescend. ing fibres (showing descending degeneration) - e.g. the direct pyramidal tract, the crossed priamidal tract, the inner portion of the anterior part of the lateral column-it is seen that at many points each sends out horizontal collaterals which enter the grey matter and terminate 
there as arborisations or dendrons close to, or around, ganglion cells; and similarly the longitudinal medullated fibres constituting those tracts of white matter spoken of above as ascending tracts - e.g. the tract of Goll, of Burdach, of Lissauer, the direct cerebellar tract and the superficial parts of the anterior portion of the lateral column (Gowers's tract) - are connected, brought into relation, by means of collaterals and their dendrons, with the grey matter and with the ganglion cells situated in the latter. The bundles of fine nerve fibres, so conspicuous in every horizontal section, patssing in a horizontal mamner from the posterior colmmns through and around the substantia gelatinosa of Rolando of the posterior grey horn, are bundles of collaterals given off by the longitudinal fibres of the posterior columns.

176. The grey matter of the cord contains the same kind of neuroglia as the white matter--viz. neuroglia fibres and neuroglia cells; the fibres do not, however, form longitudinal networks as in the white matter-due to the peculiar (longitudinal) arrangement of the nerve fibres-but are distributed more or less as a uniform network; every section, therefore, be it longitudinal or transverse, shows the glia fibrils cut transversely, obliquely and longitudinally. The glia cells are the same in size and in their numerous branched processes as in the white matter.

In this matrix of neuroglia are embedded nerve cells or ganglion cells and nerve fibres and their ramitications. The ganglion cells are all possessed of several processes, and are therefore multipolar; they differ in respect $(a)$ of position, $(b)$ of size, $(c)$ of the structure, distribution and comnections of their processes.

177. (a) in respect of position, the nerve cells form groups and aggregations which, in the longitudinal axis of the grey matter, are more or less 
discontinuous, so that to each particular spinal nerve or segment corresponds a more or less separate mass. The following groups can be distinguished on each sicle (Fig. 125) :

(1) The centro-lateral group, situated in that part of the anterior cornu which is in contact with the rentral portion of the lateral column;

(2) 'The dorso-lateral group, also situated laterally in the anterior cornu immediately behind or dorsally to the first-named group;

(3) The ventro-median group, situated in the foremost portion of the anterior cornu where this is in contact with the anterior column;

(4) The dorso-mertian group, immediately behind the former-i.e. next the anterior white commissure.

(5) As mentioned above, that portion of the grey matter which projects laterally between the anterior and posterior cornu of each side and about midway (Figs. 122 and 125) - i.e. the lateral cornu-contains in the upper two-thirds of the thoracic cord groups of ganglion cells which represent the cells of the lateral horn, but they are present only as scattered ganglion cells in the corresponding portion of the grey matter above and below the proper lateral horn (Waldeyer).

(6) Thronghout the thoracic cord there is present a conspicuous group of ganglion cells, which group is in cross-section of a rounded or oval shape; this is the posterior vesicular column of Clarke or Stilling's group, and is situated at about the same level as the group of cells in the lateral horn; but while this latter is lateral, the column of Clarke is situated medially, and it has to be added that it really belongs more to the base of the posterior cornu. These two groups 5 and 6 belong therefore to the middle region of the grey matter.

(7) The posterior cornu contains in all parts only scattered cells not definitely grouped, like those 
mentioned in the anterior cornu and the middle region of the grey matter. Also in the substantia gelatinosa of Rolando occur solitary ganglion cells. Amongst the cells of the posterior cornu the socalled maiginal cells of Waldeyer and Lissaner deserve special mention; they are situated at the margin of the posterior horn, or rather of the substantia gelatinosa, where this is in contact with the dorsal and lateral columns of white matter. The marginal cells are long and spindle-shaped and different from most other cells of the posterior comu in their being possessed of a distinct axon or axiscylinder process.

178. (b) In respect of size the ganglion cells show considerable differences; the biggest cells are those of the anterior cornu mentioned as groups 1 , 2 , and 3 ; the cells of these groups measure about $70-130 \mu$ in diameter; while those of group 4, dorsomedian group of the anterior horn, are considerably smaller, $30-80 \mu$; between these two sizes are the cells of the lateral horn and of Clarke's column, while those of the posterior cornu, with few exceptions, are comparatively small cells.

179. (c) In respect of structure each ganglion cell possesses a vesicular nucleus with a prominent nucleolus, and the substance of the cell is in all cases, when examined in the fresh state or in suitably prepared specimens, of the nature of a more or less fibrillated substance, between which a finely granular matrix can be recognised (M. Schultze). The fibrillæ are gromped in bundles, and appear continuous and radiating from around the nucleus towards and into the fibrillated processes; around the nucleus the fibrillæ appear more or less concentrically arranged. In the anterior cornu the ganglion cells contain normally pigment granules grouped near and around the nucleus (Klönne and Miuller) (see Fig. 134). 
Between the fibrille constituting the substance of the ganglion cells are found masses of granules (distinct from the just-mentioned pigment) which take the stains well : these are the chromatic granules of Nissl. In some ganglion cells they are distinct

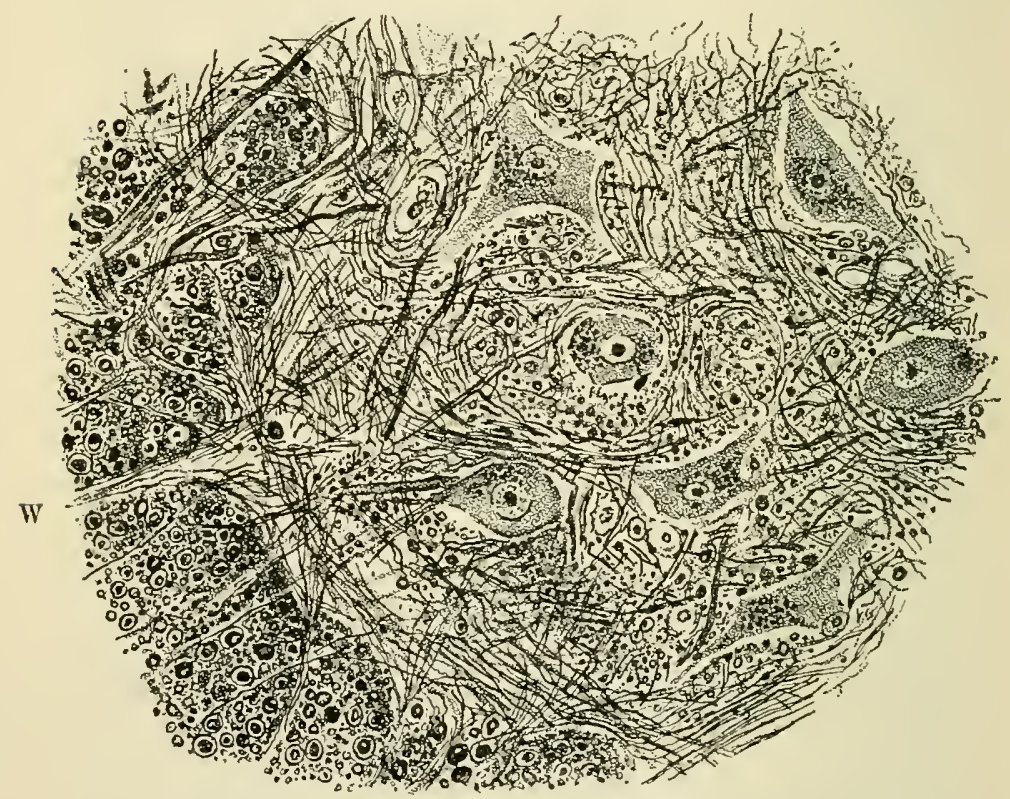

Fig 134.- Section through the Lower Lumbar Cord of Man. After a preparation of Klönne and Mïller in Berlin. (Kölliker, II.)

w, White lateral column in cross-section; G, grey matter of anterior horn, showing ganglion cells with pigment granules, and many medulated nerre fibres.

and conspicuous, in others less so. The presence of these chromatic granules indicates, it is suggested, a phase or phases of normal activity of the ganglion cells, whereas their disappearance and absence corresponds to a pathological state of diminished or abnormal function.

180. The most important differences, however, 
are noticed on the ganglion cells with regard to the mature and conncetions of their processes.

As mentioned on a previous page, all ganglion cells of the cord are multipolar ; amongst the processes

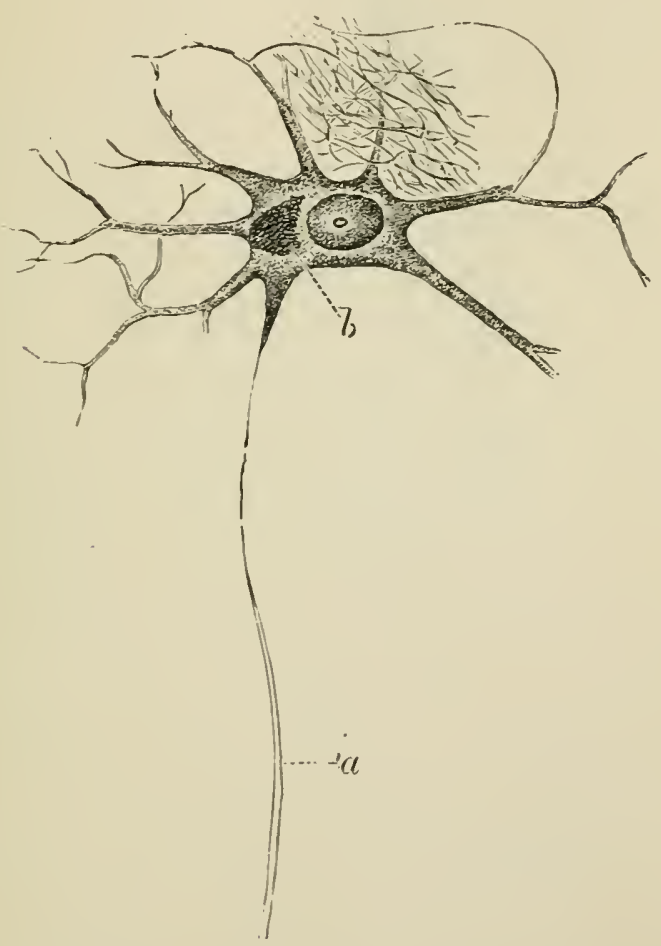

Fig. 135.-Isolated Ganglion Cell of the Anterior Horn of the Human Cord. (Gerlach, in stricher's ". Yrunuel of Histology.")

$a, A x$ is cylinder process : $b$, limment. The branched dendrites of the ganglion cell break up into the fine arborisation shown iu the upler lart of the figure.

into which the substance of the cells is continued there is one, occasionally two, which become sooner or later the axis cylincler of a medullated nerve fibre; this is the axon or neuraxon of the ganglion 
cell (Fig. 135). Such an axon is seen to come oft from each of the ganglion cells of the anterior cormu

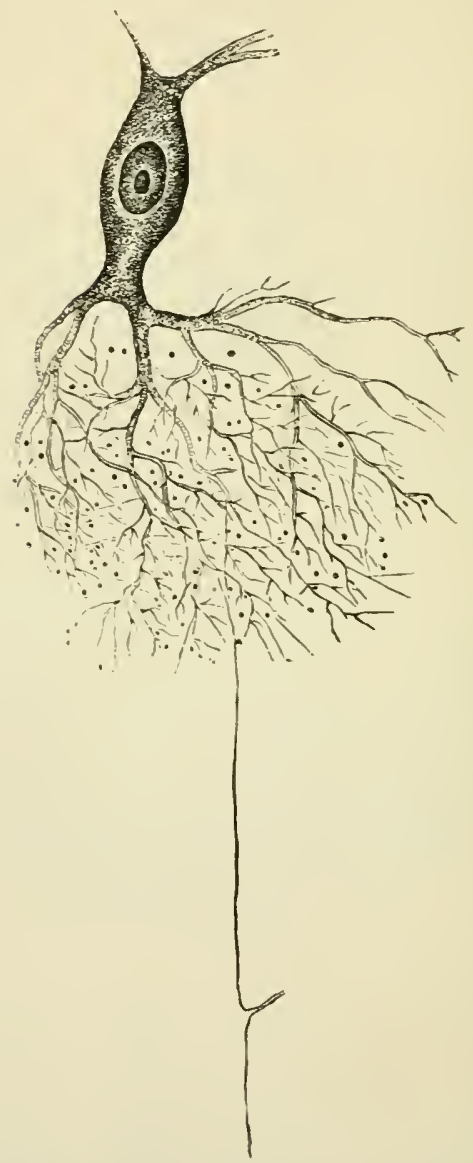

Fig. 136. - Isolated Multipolar Ganglion Cell of the Grey Matter of the Corl. (Gertach, in Strictier's IIanual.)

The dendritically-branched processes (dendrites) break up into the fine arborisation into which is seen to pass a fine nerve fibre and its ramification derived from $a$ posterior nerve root fibre.

and of Clarke's column, and of some cells in the posterior cornu. The axon of most of the anterior 
cells is continued as the axis-cylinder process of a medullated nerve fibre passing out as an anterior root fibre. 'The axon of other cells in the anterior cornu, as also to a lesser extent of the posterior colnu (including those of the substantia gelatinosa), does not, however, pass into anterior root fibres, but becomes the axon of longitudinal medullated nerve fibres forming part of the lateral, and to a lesser extent the anterior, columns of white matter.

These important facts were discovered by Golgi and Rámón y Cajal, and were confirmed by Kölliker. According to Golgi and Rámón y Cajal, axis-cylinder processes or axons of ganglion cells from all jarts of the grey matter may pass into the anterior commissure.

Cells of this character-i.e. possessing axons which pass as longitudinal medullated fibres into the white columns--are Kölliker's "Tract cells."

181. Another very striking fact discovered by Golgi and by Ramón y Cajal is this: that the axon of the ganglion cells ramifies. In some, like those cells of the anterior cornu, whose axon passes into an anterior root fibre, the axon for some distance gives off few or no branches (Golgi's group A). In other cells, like those of the posterior cornu, the axon is much branched and its fibres are lost in the grey matter (Group в). The former are considered by Golgi as motor, the latter as sensory cells.

Besides the axon, all ganglion cells in all parts of the grey matter possess more or less numerous processes which, owing to their rich and dendritic branching and their distinctly fibrillated nature, are the protoplasmic or branched processes, or the dendrites (Fig. 136). In the cells of the anterior cornu, in those of Clarke's columm and of the lateral horn, the dendirites are numerons and distinctly arborescent; they are less numerous in the cells of the posterior cornu; thicker branches give off laterally smaller branches, 
which by continued ramitication become greatly attenuated and ultimately resolve themselves into arborescent terminations or dendions (Fig. 136).

While the dendrites and their terminal dendrons of most of the ganglion cells are distributed in the grey matter, Golgi has proved that of some cells some of the dendrites pass into and are distributed amongst the nerve fibres of the white columns. a

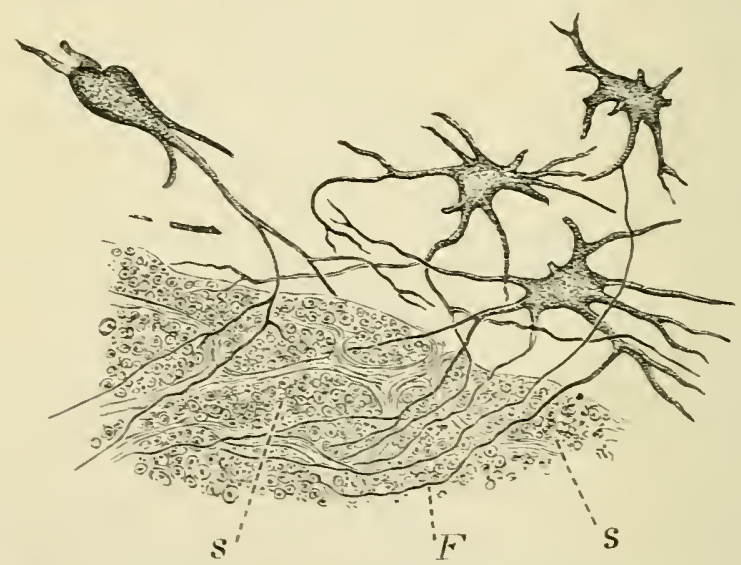

Fig. 137.-From the Lateral Horn of the Cerrical Corl of the Ox. Highly magnified. (Kölliker, II.)

$s$ Iateral column of whire matter in cross-section: $F$, fine dendrites of the sanglion cells peuetrating in to the white column.

fact which Kölliker has emphasised, and which particularly holds good for the cells of the lateral horn in the cerrical cord of the ox. (Fig. 13i.)

182. Besides the ganglion cells, their axons, clendrites and dendrons, the grey matter contains nerre fibres of a difterent origin and comnection. As mentioned cn a former page collaterals of longitudinal fibres of all white tracts enter, or pass out respectively from the gres matter; here they ramify and terminate log arborisations or dendrons, which 
are either intermingling with, or surrounding the arborising dendrons of the dendrites of ganglion cells or surround the body of the ganglion cells. Owing to the great number of such collaterals, as mentioner on a former page, their arborisations or dendrons forni a considerable portion of the grey matter:

Sherringtonsuggests the term of symapsis (oúv and $\ddot{i} \pi-\omega)$ as indicating the contignous but not continuous relation of the arborising terminations of axons surrounding the arborising dendrites or the body of a ganglion $\mathrm{mw}$ cell. Such synapsis would then occur everywhere in the central nervous system (cord, brain,

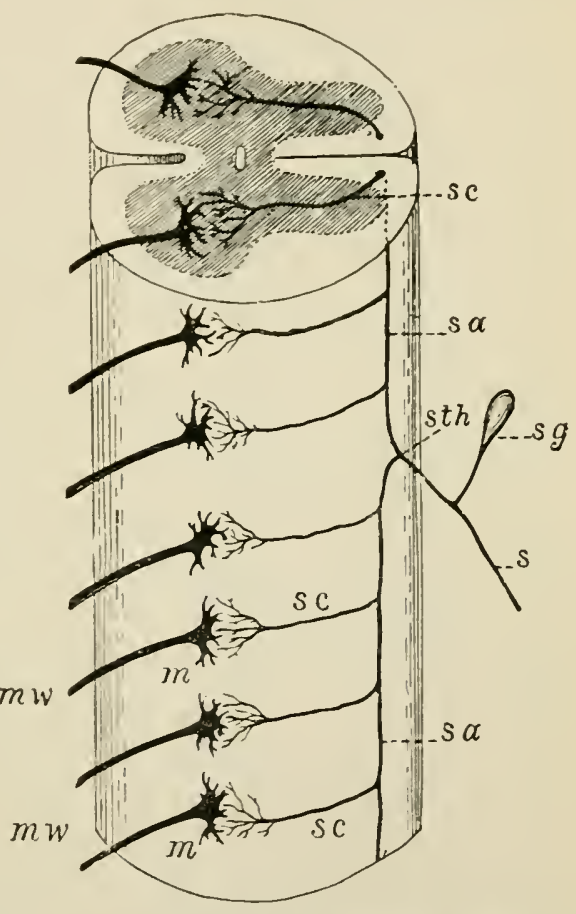
medulla,

Sympa- Fig. 13-A.-Scheme of the Elements of the Cord thetic concernerl in Reflex Actions. Longitudinal thetic ganglia, re- view. (Kölliker, II.)

tina, etc.) where $s g$, Ganglion cell of a spinal ganglion: $s$, senneuraxons and their. collaterals of a near or distant ganglion sory thre coming from the periphery; sth, division of a posterior root fibre into $s a$, an ascending and descending tibre; $s c$, collaterals of same passing to motor ganglion cells, $m$; $m u$, motor (anterior) root fibres being a xon of anterior nerve cells.

cell arborise (ter-

minate) around dendrites or the cell body of a ganglion cell.

A second, also consiclerable, portion of the grey 
matter is made up of dendrons, the developing fibres of which are not collaterals but are direct continuations of longitudinal fibres of the white columns; thus the descending branches of posterior root fibres terminate in this way in the grey matter, many of the main fibres of the

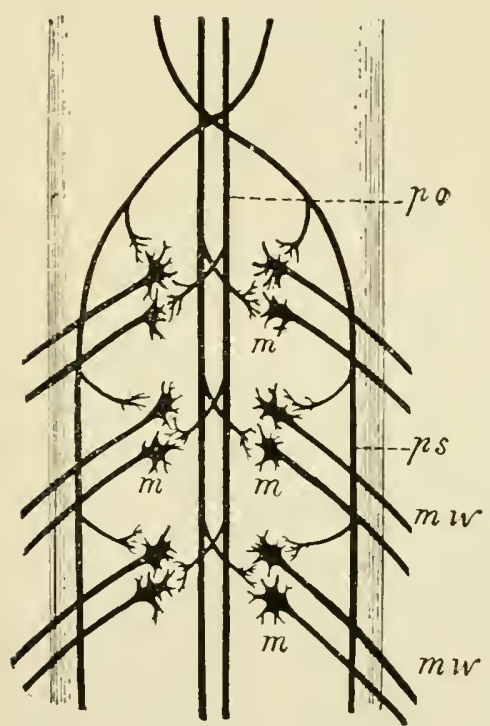

Fig. 137. - Scheme of the Conduction of Impulses in Volmtary Movement. (Kölliker, II.)

$p s$, Fibres of the crossed pyramidal tract in the cord: these fibres had crossed (pyramidal crossing) in the medulla: collaterals of these fibres pass into and terminate in the grey matter of the cord : $p o$, tibres if the direct pyramidal tract in the cord, collaterals cross in the cord; $m$, nerve cells in the anteriol grey horns: $m u$, axons of same forming the fibres of the motor (anterior) roots.

anterior and particularly the lateral columns pass into $\mathrm{Ol}^{\circ}$ pass from the grey matter, and after a shorter or longer course, either on the same side or after crossing through the anterior or posterior commissure terminate as dendrons around ganglion cells or intermingle with the arborisations of clendrites of ganglion cells. The manner of the most probable connections and actions of the grey matter of the cord are illustrated by the accompanying diagrams (Figs. $137 \mathrm{~A}$ and $137 \mathrm{~B})$, copied from Kölliker.

Before the introduction of the method of Weigert, and its modification by Pal (by which the medullary sheath of nerve fibres is stained), it was unknown that the grey matter of the cord contains medullated nerve fibres to any large extent. By the above methods, if successfully applied to the examination of suitably stained sections of the cord, 
it is shown that the grey matter contains a really astonishing number of medullated nerve fibres, running singly or in small bundles, horizontally and obliquely. All the above collaterals, as also the continuations of the fibres passing from the white columns into the grey matter, or vice versth, are medullated fibres (see Figs. 122 and 123A).

183. The large vascular branches enter the white matter of the cord from, or pass out by way of the pia mater, being invested in neuroglia continuous with the tissue of the pia mater. By continued division they resolve themselves into fine branches, which pass into, or pass from, the network of capillaries.

The capillaries are more abundant and form a more uniform network in the grey than in the white matter. In the latter most of them have a course parallel to the nerve fibres, i.e. longitudinally. The blood-ressels and the ganglion cells are ensheathed in lymph spaces (perivascular and pericellular spaces). 


\section{CHAPTER NVII.}

THE MEDULLA OBLONGATA OR SPINAL BULB,

184. As the cervical portion of the spinal cord passes into the medulla oblongata its parts alter in position and relation. It is possible, to a large extent, to recognise in the bulb, regions which correspond to different areas of the cord. Many of the cord areas are, howerer, lost in the bulb, and on the other hand, many new areas appear.

185. The anterior or ventral fissure is continued as far as the bulb extends. The posterior or dorsal fissure of the cord is also continued for a certain distance along the medulla, but this widens out in the upper part of the bulb into the lower end of the fourth rentricle. The line of origin of the anterior roots of the spinal cord is continued into the medulla, being marked out by the exit of the roots of the hypoglossal nerve. In the upper portion of the medulla this line of origin develops into a marked fissure. The shallow groove existing dorsally between the postero-median ancl postero-external columns of the cord is even better marked in the bulb, and divides the funiculus gracilis (median) from the funiculus cuneatus (external). The postero-lateral groove into which the posterior roots pass to the cord is continued up as the external boundary of the funiculus cuneatus and the internal boundary of ret another longitudinal projection, leading up to a prominence, the tubercle of Rolando. In the upper portion of the cervical cord there project from the lateral columus the roots of the spinal 
accessory nerve. The line of origin of these roots is continued up along the lateral surface of the bulb and there arise successively along this line the roots of

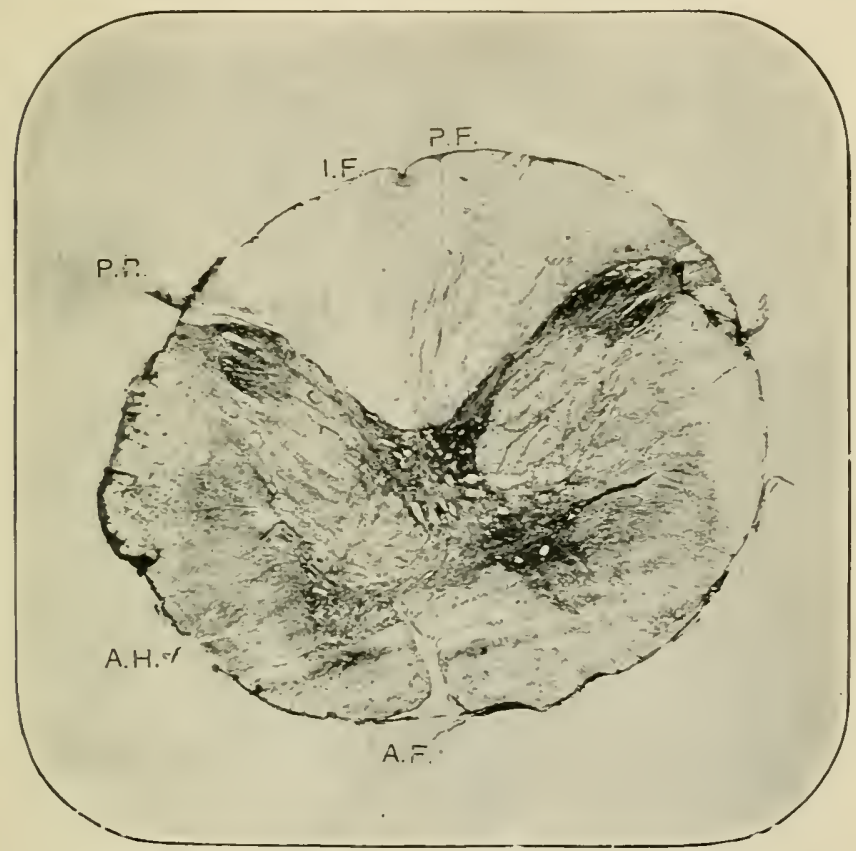

Fig. 135.-Section through the Lower End of the Pyramidal Decussation. The section is slightly distorted. (Microphotograph of section stainerl with aniline blue-blacli.)

A. F., Anterior or ventral fissure lying obliquely on accountiof fibres passing from crossed pyramidal tract on left side to anterior column ou right; $P$. $F$., posterior fissure ; I. F., corresponds to septum between Goll's column and losteroexternal column; P. k., no-teriol rout of first cervical nerve; on the left side at level A. H, the anterior horn is separated from rest of gres matter. Th. substantia gelitimosi at tip of posterior horn is increased, and the angle between the posterior horns is greater than below.

the spinal accessory, the ragus, and the glossopharyngeal. At the junction of the bulb with the pons the seventh nerre passes out in the same line, and passing through the substances of the pons the fifth nerve possesses a corresponding origin. 
186. It will be found most convenient in order to determine the relation of the different regions in the bulb with those of the cord, to examine the appearances presented by successive sections of the

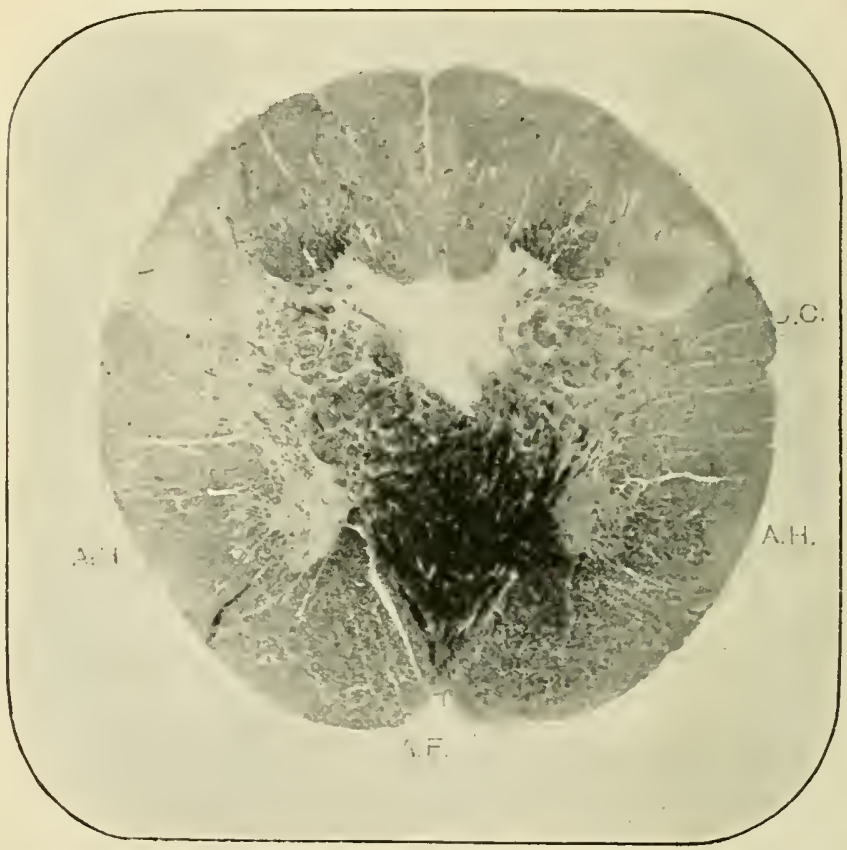

Fig. 139.-Section through the Upper Part of the Pyramirlal Decussation in the Melulla Oblongata. (Microphotograph of a Weigert-Pril specimen.)

A, F. Remains of anterior fissure; the dark mass immediately above consists of the decussating pyramidal fibles; at the level A. II. is a light mass on either side representing the remains of anterior horn; at the level c. c. in the midile line is the grey matter round the central canal; the posterior nuclei are not clearly distinguishable.

bulb, cut in a dorso-ventral direction, and commencing at a level immediately above the cervical spinal cord.

187. 'The region of the pyramidal decussation (Figs. 138 and 139).-- In this region the fibres 
of the crossed pyramidal tract, lying in the dorso-lateral portion of the cord, take on an oblique course and, passing across the middle line, again resume their direct, course in what would correspond in the cord to the

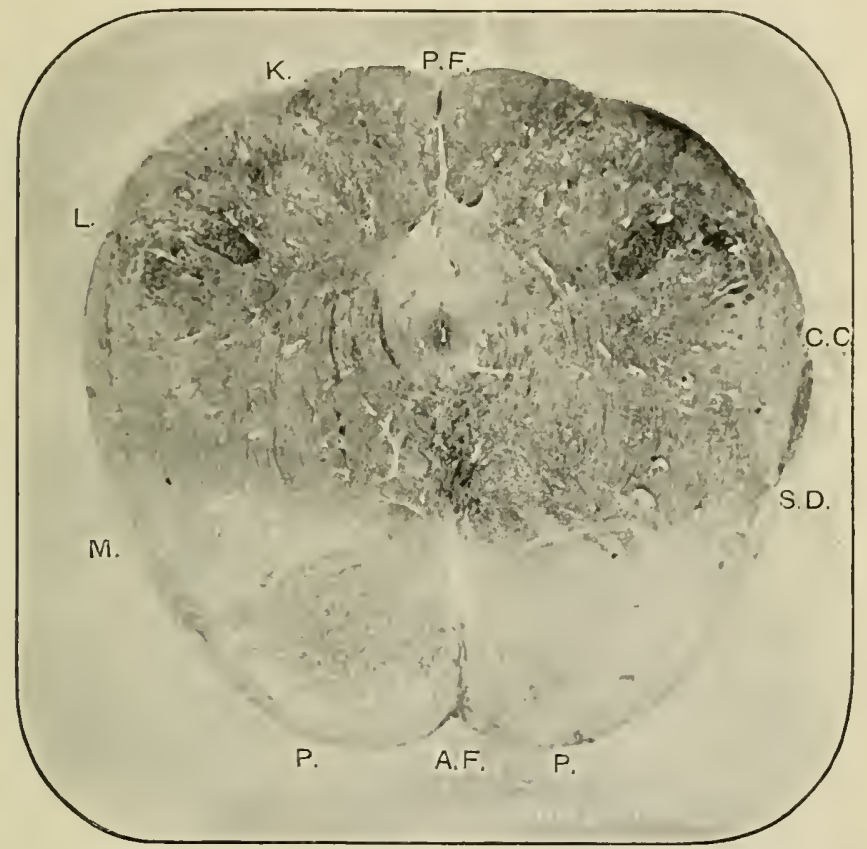

Fis. 140.-Section through the Medulla Oblongata at the level of the Sensory Decussation. (Photograph of a Weigert-Pal specimen.)

The section has not involved the olives; the pramids are completely formed and project at $\mathrm{P}$, and extend inwards as far as the level $3 \mathrm{r}$, meeting in the middle line. At level of c.c. on middle line is the central canal, and at a short distance from this are seen numerous fibres arching round and decussating on middle line at level s. D.; K, lies between funiculi gracilis and cuneatus.

anterior or ventral column. In their passage across to the other side of the medulla these fibres separate off the head of the anterior horn so that the grey matter of the caput lies in the anterior area disconnected from the main mass of the grey matter. The angle formed by the median boundaries of the two posterior 
horns increases very considerably, so that these horns come to lie more transversely across each half of the medulla than was the case in the cord. There develop also from this inner margin of the posterior horss, in the upper part of the pyramidal decussation, certain protuberances of grey matter; a median mass projecting into the funiculus gracilis and known as the nucleus of the funiculus gracilis and a more externally situated mass, projecting into the funiculus cuneatus, and known as the nucleus of the funiculus cuneatus. The substantia gelatinosa at the tip of the posterior hor'n also becomes more conspicuous and causes the medulla to project in this region, forming the funiculus of Rolando. Higher up this projection becomes even more conspicuous and is known as the tubercle of Rolando. In the region of the pyramiclal decussation the substantia gelatimosa of Rolando is separated from the surface by a longitudinal mass of medullated fibres which pass to the origin of the fifth nerve. This mass of fibres is spoken of as the ascending root of the fifth nerve.

188. The region between the upper end of the pyramidal decussation and the commencenent of the olives (Fig. 140).- In this region the central canal is seen to lie more posteriorly corresponding to its gradual approach towards the posterior surface. The pyramids occupy well defined positions on the ventral side of the bulb immediately abutting on the anterior fissure and bounded laterally by the fibres of the hypogiossal nerve coursing from the nucleus of the twelfth, across the medulla. There is to be seen lying in the lateral region between the substantia gelatinosa of Rolando and the fibres of the twelfth, a mass of cells, which correspond to some extent to the more dorsal portion of the separated anterior horn, but which in part is to be regarded as a new formation. 


\section{MEDULLA OBLONGATA.}

This mass of cells is spoken of as the lateral muclens. It is to be noticed that the posterior white matter is gradually undergoing absorption, being invaded by the grey matter of the corresponding nuclei. The grey matter of these nuclei gradually becomes more marked, the nucleus of the funiculus gracilis early absorbing the white matter of the column and lying quite close to the surface. The nucleus of the funiculus cuncatus lies rather more deeply, but is gradually invading the white substance. The central portion of the medulla becomes broken up, and fibres are seen passing in an arched manner from the nucleus gracilis mainly, and, to some extent, from the nucleus cuneatus towards the middle line. These arched fibres on reaching the micldle line, for the most part bend longitudinally, and thus form a mass of fibres lying dorsal to the pyramids, and spoken of, higher up, as the inter-olivary layer. This decussation of tibres passing from the gracile and cuneate nuclei is sometimes referred to as the superior or sensory decussation.

\section{The region of the lower portion of} the olives (Fig. 141). - A few millimetres higher up than the last section the olires are seen to be distinctly formed, though they have not reached their greatest size and though the central canal is still closed. The central canal has at this level approached yet more closely to the posterior surface. Each lateral half of the bult, may be more or less distinctly marked off into three areas: a median area lying between the middle line and the roots of the twelfth nerve as they course across the bulb from the hypoglossal nucleus; a lateral area, lying between the roots of the twelfth and those of the elerenth, which issue more laterally; and an area, posterior to the eleventh roots, which may be called the posterior area. The lateral nucleus lies in the dorsal portion of the lateral area. The main 
mass of the olive lies in the ventral portion of the lateral area. hut two additional masses,

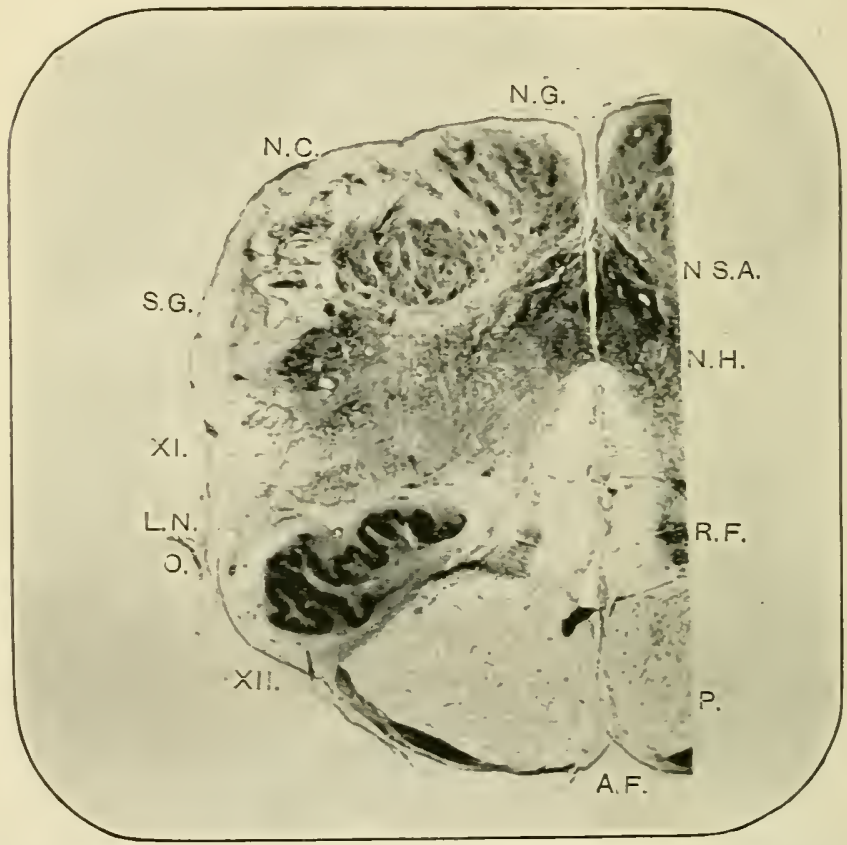

Fig. 141. - Section through the Medulla Oblongata at level of commencement of Olives. (Microphotograph of a specimen stuined $u$ ith aniline blue-liack:)

The central caual is not yet opened our, and is at level of x.s. A, the posterior grer matter is arranged in thrce masses,. . G., nucleus gracilis.. . C., nuclens cuneatus, and 5 . G.. the substantia gelatinosa of Rolaudo: with respect to grey matter round central canal, that at level r.s.A, has cells forming nuclei of the XI, that at level $x$. H. forming nuclei of XII : XI is placed against the line of issue of the spinal accessors, xII a rain-t hypoglosial: the grey matier lring slights leneath surface at Jevel L. x. is the lateral nucleus: 0 , is at level of the twisted dark band, the olive : the large light mreas at level of $\mathrm{P}$ are the prramids: the area more dorsal at lerel $\mathrm{m}, \mathrm{F}$, is the reticular formation, in the middle line of which is the raphe (abore A. F. .

similar in structure to the olive, may also be seen, one lying in the lateral area, dorsal to the main olive, known as the dorsal accessory olive, and the other lying in the median area, separated 
from the main olive by the roots of the hypoglossal nerve and known as the mesial accessory olive. The more central portion of the section is seen to be broken up by fibres passing lorizontally, separating others which are proceeding longitudinally; and yet other strands are to be noticed intersecting both of these. Nerre cells are scattered through this area, and more conspicuously in its lateral portions, and these nerve cells with attendant neuroglia may be regarded as representing the much diffused grey matter of the rentral horn which was separated by the decussation of the pyramidal tibres. This brokeri tissue is spoken of as the reticular formation, the more lateral portion, which appears clarker on account of the nerve cells being more numerous, being referred to as the grey reticular formation, and the central part as the white reticular formation. In the middle line, where the reticular formations of either side are continuous, the decussation of the fibres coursing transversely, and the presence of many fibres running in a dorso-rentral direction, give a somewhat peculiar appearance to the reticular region. The narrow intermediate band is called the raphe, and it contains a larger proportion of nerve cells than the remainder of the median reticular formation. The lateral nucleus is still prominent at this level, the substantia gelatinosa of Rolando and the ascending root of the fifth are also seen. This latter is gradually becoming separated from the surface by a band of fibres rumning longitudinally but somewhat obliquely which represents the commencement of the restiform body or inferior perluncle of the cerebellum. The longitudinal fibres lying outside the lateral nucleus represent the upward continuation of the direct cerebellar tract and these fibres gradually pass into the restifor'm body. Fibres are seen proceeding in a ventral direction from the raphe, originating in part from cells of the raphe 
but having some connection probably with the nuclei gracilis and cuneatus, and these fibres passing from the anterior fissure encircle the pyramids and olives and pass towards the commencing restiform bodies. These fibres are spoken of as external arcuate fibres. There is to be seen at about this level for the first time a somewhat compact bundle of longitudinal fibres lying between the central canal and the substantia gelatinosa, though considerably nearer the former. This bundle is surrounded by grey matter, with the cells of which the tibres are connected. The fibres of the bundle mainly jass ont with the roots of the glossopharyngeal nerre and it therefore has been called the ascending root of the glossopharyngeal: the names fasciculus solitarius and respiratory bundle are sometimes applied to the same tract. In addition to the nerve cells already referred to other important masses of cells are now to be seen clistinctly. (a) The nucleus of the twelfth nerve. This consists of at aroup of nerve cells representing, probably, the most dorsal portion of the separated anterior horn, lying slightly ventral to the central canal. The cells are multipolar and vary in size from $40-i 0 \mu$, and the neuraxons of these cells, after a somewhat irregular course, become the tibres of the hypoglossal nerve. The fibres on each side pass in a ventro-lateral direction across each half of the medulla and issue from the groore lying immediately lateral to the prramids. (b) The nucleus of the eleventh nerre. It must be noted that the eleventh, tenth, and ninth nerves pass off' at different levels from a group of cells longitudinally continuous. This group of cells can be spoken of as the combined nucleus of the spinal accessory (more correctly the bulbar accessory), the ragus and the glossopharyngeal. It is not possible to detine precisely the divisions of the nucleus corresponding to each nerre. In the region of the medulla we are now describing, 
lowever, the roots belong to the spinal accessory nerve. Here the nucleus, consisting of a mass of somewhat spindle-shaped cells, $30-40 \mu$ long and $12-20 \mu$ wide, occupies a position dorsal to the twelfth nucleus and adjacent to the central canal. From this nucleus tibres may be traced passing laterally across each half of the medulla, and emerging from the bulb between the restiform body and the olive. (c) 'The nucleus of the funiculus gracitis. (d) The nucleus of the funiculus cuneatus. There may be seen external to this nucleus an isolated mass of cells, this is to be regarded as an accessory cuneate nucleus. nucleus.

\section{The region of the middle of the lower} half of the fomth ventricle (Fig. 142). - At this level the central canal has opened out into the fourth rentricle. This fourth rentricle is furnished with a lining membrane, consisting of colummar cells (which may be ciliated), resting upon neuroghia. This lining membrane is spoken of as the ependyma. With the opening out of the central canal the gracile and cuneate nuclei have retreated from their median position and come to lie in the dorso-lateral region. The two gracile nuclei therefore are separated from one another by the width of the fourth ventricle. The nucleus of the twelfth nerve lies now in the median position at the dorsal surface, and in this locality a slight bulging into the ventricle exists which corresponds to the funiculus teres. Lateral to the nucleus of the twelfth lies the combined nucleus of the eleventh, tenth and ninth, here corresponding to the vagus nerve. The restiform body has increased in size and has now largely absorbed the direct cerebellar tract. The olives are also much more prominent, and have here reached their full development. These bodies each consist of a lamina of grey matter folded back upon itself, enclosing a space filled with white 
matter. The convex portion of the fold corresponds to the external protuberance. This lamina has, in addition to the main fold, numerous seconclary longitudinal

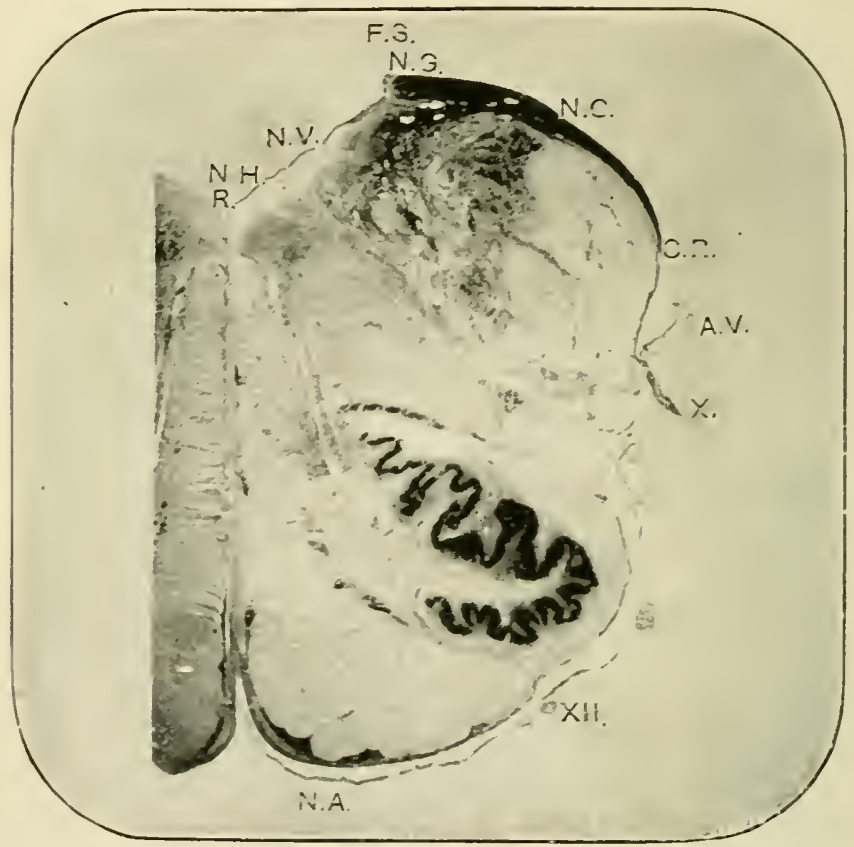

Fig. 142.-Section through the Medulla Oblongata at level of middle of Olives. (Microphotograph of a specimen stained with aniline blue-black.)

P lies orer the raphe; a mas of grey matter just beneath $\mathbf{s}$. H. is nucleus of the XIth, beneath $\mathbf{Y}$.. . is nucleus of the Xth; beneath $\mathbf{X} . \mathrm{G}$. and $\mathbf{S}$. are the nuclei of the fasciculi gracilis and cuneatus; c. R. lies against the light mass of the restiform bods, slightly deeper at lerel A. F. is the ascending rth; $x$ is placed against the jssuing $x$., and runuing down towards $x I I$, from nucleus of the $\mathrm{x} 1 \mathrm{th}$ are the fibres of the xilth ; $\mathrm{X}$. A. is against grey inatter forming the nuclei of the external arciform fibres ; the olive is seen latera] to the roots of XIJth as a deepls stained undulating band; a part is separated on the dorsal side (the dorsal olive) and a small part lies on median side of roots of XIIth (the median accessory olive); at level of C. R. and immediately beneath F.S. is a lisht circular area, the fasciculus solitarius; the grey matter lyng at level of $\mathrm{x}$ and a little below the surface is the lateral nuclens.

folds, so that in transverse section it presents the appearance of a wary band of grey matter passing from the formatio reticularis towards the surface, 
and then alching back it continues its wavy course towards the region from which it started. Internally there pass into the interior of the olive tracts of white fibres which radiate outwards towards the concave surface of the lamina. The lamina itself is composed largely of nemoglia, broken by nerve fibres passing across, there are also present many multipolar nerve cells. These cells possess axis-cylinder processes which possibly pass down into lateral columns of the cord and become connected with motor cells in the grey matter. They are themselves connected with nerve fibres which, springing originally from the cells of Purkinje in the cerebellum, course through the restiform body and, becoming cerebelloolivary fibres in the medulla, pass across the opposite olive. It may also be that the olives are connected by longitudinal fibres with the cerebral hemispheres.

It is possible to classify to some extent the numerous fibres passing transversely across the medulla in this region.

Somewhat lower than the transverse section we are at present considering were decussating fibres from the gracile and cuneate nuclei, called internal arcuate fibres, forming the inter-olivary layer. With the development of the restiform body and the olives, other fibres proceeding transversely become prominent. The external arcuate fibres may be held to comprise three minor groups. (a) Those passing from the raphe and encircling the pyramids and olives. Amongst these fibres in the upper part of the bulb are a mass of nerve cells known as the nucleus arciformis. (b) Fibres passing from the lateral tract into the restiform body. These are largely the more superficial of the fibres of the direct cerebellar tract. (c) Fibres passing dorsally from the gracile and cuneate nuclei to the restiform body of the same side. These tibres are also spoken 
of as superficial dorsal arcuate fibres. In aulition to the so-called arcuate fibres there are other fibres which have a somewhat arched course, but which are best separated into a distinct class, and spoken of as cerebello-olivary fibres. These include a majority of the fibres forming the restiform body. They pass from the restiform body either laterally to the ascend. ing root of the fifth, or to some extent intersecting it, and proceed towards the dorsal lamina of the olive. Most of the fibres then penetrate the grey matter (a few perhaps becoming lost therein), and passing into the white core of the olive emerge at the olivary peduncle and proceed to the raphe. The more dorsal of these fibres passing from the restiform body do not intersect the olive; the more ventral pass round the olive (and are hence regarded by some as external arcuate fibres), and entering between the olive and pyramid pass to the raphe. Having crossed the raphe these fibres either bend longitudinally or pass to the olivary grey matter. The longitudinal fibres lying between the olives in the rentral portion of the formatio reticnlaris are known as the inter-olivary layer. This diffuse column of tibres becomes more distinct higher up, and is then known as the fillet or lemniscus. In the posterior part of the formatio reticularis near the raphe, a fasciculus of longitudinal fibres is gradually becoming more distinct. This is known as the posterior longitudinal bundle, and is to be regarded as representing a part of the anterior or ventral column of the cord. The hypoglossal nucleus lies now on the floor of the ventricle, and external to it lies the nucleus of the vagus. The cells forming this nucleus may be divided into two groups, a more median and a more lateral. The median group consists of the larger cells. In addition to this superficial nucleus there lies in the formatio reticularis, midway between the fibres 
of the twelfth and eleventh nerves, in second nucleus known as the nuclens ambigures or motor nucleus of the tenth. Fibres from this nucleus pass dorsally towards the main vagus nucleus, and issue with the vagus roots. Fibres from the fasciculus solitarius also pass out with the vagus. The vagus fibres thus have three centres of origin.

A section taken somewhat higher than that just considered would show the issue of the glossopharyngeal nerve. A majority of the fibres of the fasciculus solitarius pass out with the glossopharyngeal, running first towards the main nucleus, and then turning lack and coursing with the fibres of the ninth nerve. There are also to be seen at this level, rather more distinctly than in the lower section, lying somewhat external to the fasciculus solitarius, and near to the grey matter corresponding to the nucleus gracilis, some scattered longitudinal bundles of fibres, which are connected with the auditory nerve, and are known as the ascendiny root of the eiglith. 


\section{CHAPTER XVIII.}

CONTINUATION OF THE MEDULLA OBLONGATA THROUGII THE PONS VAROLII AND THE REGION OF THE CRURA.

\section{The region of the middle of the fourth} ventricle (Fig. 1 43). - A dorso-rentral section passing through that part of the fourth ventricle across which the strix acustice course would be somewhat below the precise middle of the ventricle, but may be conveniently considered first. Such a section would not involve the pons varolii and would probably just miss the exit of the sirth nerve. In such a section the upper part of the diminishing olive would be scen still. The formatio reticularis occupies the median portion of each half, and, laterally, the restiform body is here at its maximal size. Coursing ventro-laterally with respect to the restiform body are seen the bigher roots of the ninth nerve; on the median side of this there appears the ascending root of the fifth. On the median side of the dorsal portion of the restiform body are seen longitudinal fibres belonging to the ascending root of the eighth nerve, and lying somewhat dorsal to this are nerve cells belonging to the same nerve. The dorsal edge of the section appears to be composed of transverse tibres coursing from the raphe round the restiform body and directed towards the exit of the eighth nerve. These are the strice acustico.

Lying on the ventro-lateral side of the restiform 
body is a mass of nerve cells connected with the fibres of the acoustic nerve and called the ventral ganglion of the eighth. A section taken slightly higher would involve the pons and show some slight

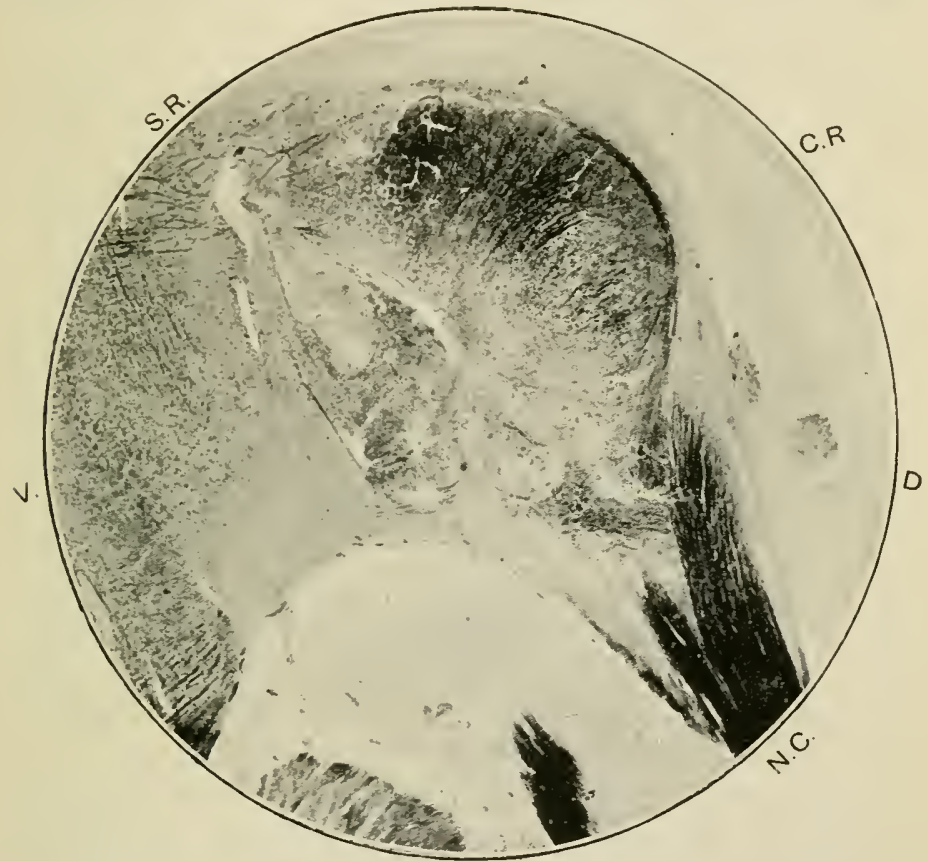

Fir. 143. - Part of a transverse section of the Melulla Oblongata through the exit of the Auditory Nerve. (Microphotograph of a Weigert-Pal speeimen.)

The section is slightly oblique, and hence at the level $\mathrm{D}$ the cochlear nerve (x.c.) is seen dividing into ascending (the more median) and descending (the more lateral) divisions. The half-moon-sliaped mas, (lark in colour at level c. R., is the restiform body. The dark mass lying in centre of the photograph at level of $\mathrm{v}$ is the ascending root of the fifth nerve. The lighters substance at level of $\mathbf{b}$ lying mainly on inner side of the cochlearnerve is the ventral ganglion, the cells of the tuherculum acnsticum are in the lighter substance. rather above the level of $\mathrm{D}$, and lateral to the cochlear nerve. s, R:, lateral portion of striæacustica.

changes when compared with the section just described. The most conspicuous difference in the higher section consists in the presence of a prominent mass of transverse fibres passing across on the rentral aspect 
and breaking up the prramids into smaller bundles. The auditory nerve is to be seen issuing as before, and on the median side of the eighth a second nerve, the serenth, passes out. It must be remembered that neither the sixth nor the serenth nerres pass by direct dorso-ventral courses outwards. The seventh nerve originates from a nucleus lying in the formatio reticularis midway between the rentral acoustic nucleus and the raphe, and at about the same level as the nucleus. The fibres from the facial nucleus at first pass dorsally and then turn longitudinally and pass for a short distance upwards, becoming involved in the nucleus of the sixth. After a short upward course they turn back again towards the lower region of the bulb, and, taking gradually a more ventral direction, finally emerge near the exit of the eighth nerve. There also pass out with the facial nerve fibres derived from the hinder portion of the nucleus of the third nerve. These fibres supply the orbicularis palpebrarum and frontalis muscles. The nerve cells composing the nucleus of the serenth are about t0-60 $\mu$ in size, their neuraxons are directed dorsally to form the nerve fibres of the facial nerve.

A mass of grey matter is also seen lying slightly median, and rentral to the serenth nucleus. This mass of grey matter contains nerve cells, and is known as the superior or little olive. This, in adults, is about $4-5 \mathrm{~mm}$. in length, but is better dereloped in lower animals. The cells are similar to those of the olive, about $30-40 \mu$ in dianeter, with nemraxons and muchbranching dendrites. Another mass of cells is to be made out on the rentro-median aspect of the superior olive. This is known as the trapezoid mucleus. Fibres may be seen proceeding from the ventral nucleus of the eighth, and passing on the ventral side of the superior olive and the trapezoid mucleus. These tibres constitute the trapezium, 
and form the most dorsal portion of the transverse fibres of the pons.

The connection of the auditory nerve with its different origins is now to be described. There are three main nuclei from which origin takes place:(a) the ventral or accessory mucleus lying near the place of exit of the nerve, and, from its resemblance to a spinal ganglion, sometimes called the acoustic yanglion: (b) a mass of cells lying on the floor of the fourth ventricle, midway between the restiform body and the median furrow, called the dorsal median mucleus; and $(c)$ a mass of cells lying near the ascending root of the eighth, between the median nucleus and the restiform body, but somewhat deeper than the former, called the dorso-lateral nucleus or mucleus of Deiters. The ventral nucleus is really divisible into two; a more lateral portion and the main ventral nucleus. The lateral portion forms the tuberculum acusticum. The eighth nerve can be seen to consist of two parts, one part passes to the median side of the restiform body, the other to the lateral aspect. The former is called the restibular' nerve, and the latter the cochlear nerve, corresponding to the destination of these two divisions. The cochlear nerve has finer fibres than the vestibular, the fibres of the former being $1-2 \cdot 5 \mu$, those of the latter $2-4 \mu$. The fibres of both nerves divide, like a spinal posterior root fibre, into an ascending and descending branch after entering the medulla. The ascending branches of the cochlear nerve pass to the ventral nucleus, the descending branches to both the tuberculum acusticum and the ventral nucleus. From the ventral nucleus fibres pass as already stated into the trapezium and become connected in part with the cells of the superior olive and the nucleus trapezoides. The cells of the tuberculum acusticum, and partly also those of the ventral nucleus, 
originate the fibres composing the strice acusticce. (Fig. 152.) The fibres, therefore, coursing round the

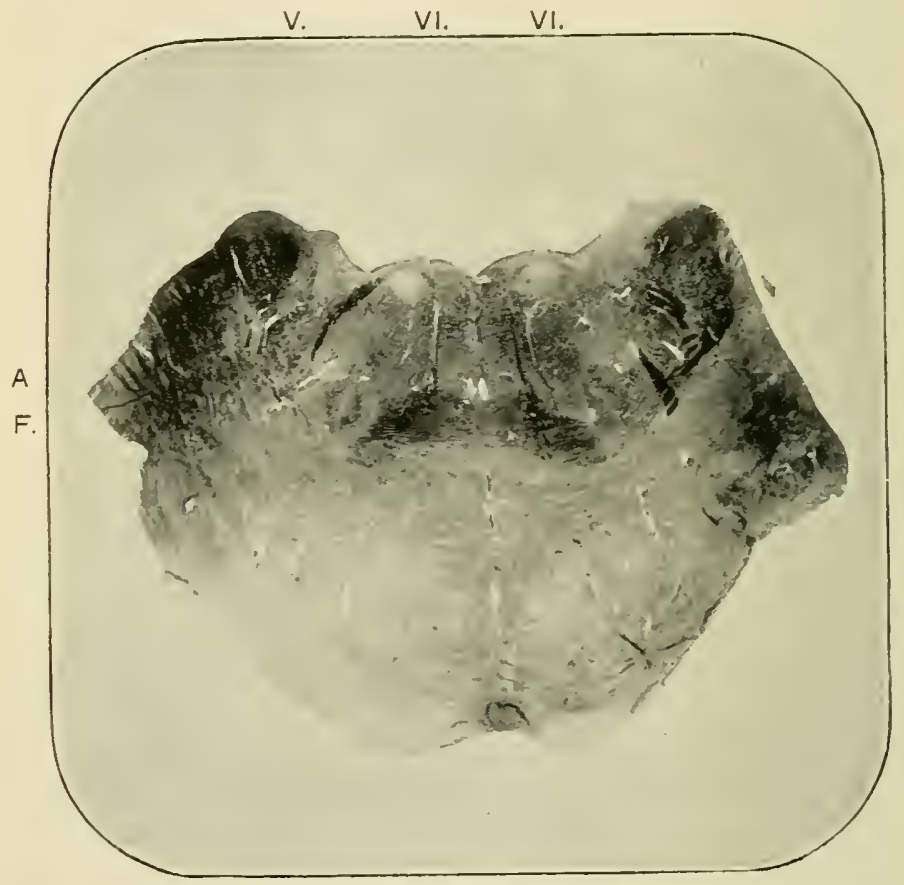

Fig. 144.- Section through the sixth Nucleus and Genu of serenth. (Photograph of a Weigert-Pal preparation.)

The lower half constitutes the bulk of the pons proper, with laterally the middle peduncles; the two symmetrical dark nasses at level $\mathrm{F}$ are the longitudinal fibres of the fillet; on the left side and lateral to the fillet is seen a darkish mass with a lighter centre, the -uperior olive. The floor of the fourth ven. tricle forms the median part of the upper edge.two symmetrical light masses heneath vi are the rith nuclei. Fibres from the inner side are seen passing downwards near the middle line, these are the fibre, of the vith, The fibres of the vith are seen passing apparently from the outer side of the vith nucleus on the left side. The nucleus of the rith lies on dorsal side of the olive. The darkest tissue lying beneath $r$ and at level A constitutes the solnewhat seattered fibles of the ascending root of tith. The genu of the vith is between the nucleus of vith and the median sulcus and is better seen in the enlargement of this legion. (Fig. 115).

restiform body, though apparently the continuation of the cochlear nerve, are really the nenraxons of cells of 
the tubereulum acusticum and ventral nucleus, which are connected with the terminal arborescences of fibres composing the cochlear nerve. The vestibular.

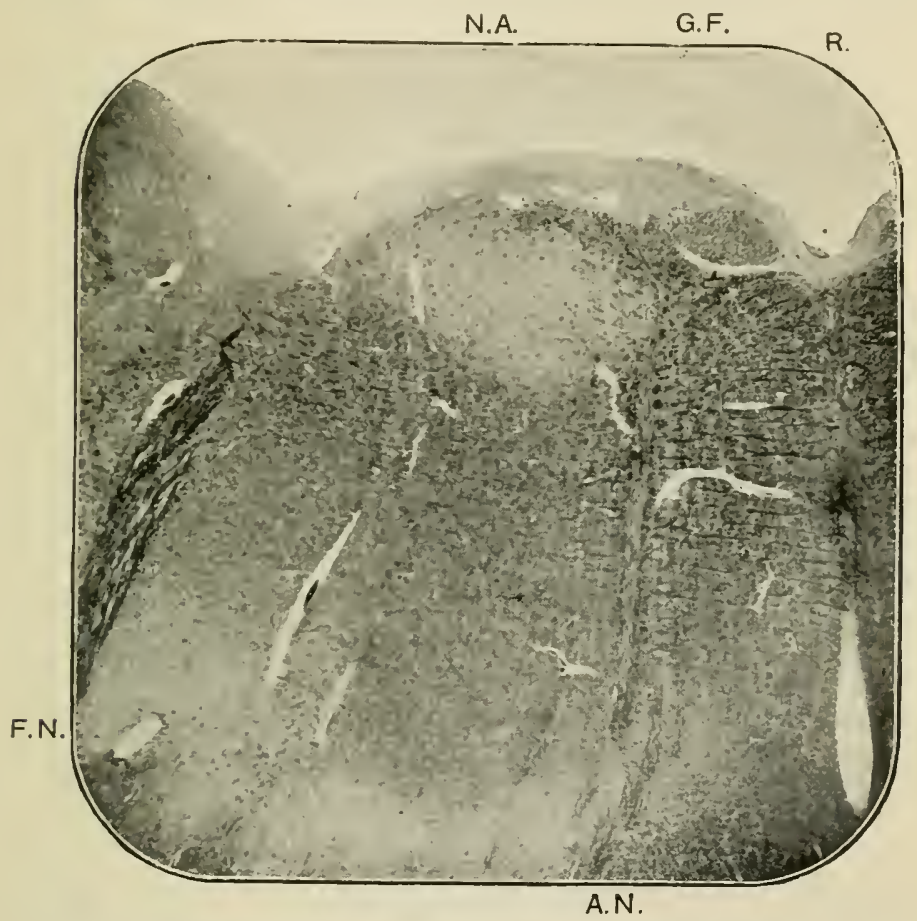

Fig. 145.-Section through the Nucleus of the Sixtl, being a part more highly magnified of Fig. 144. (Microphotograph of a Weigert-Pal specimen.)

The letters x.A., G.F. and R. lie over the cavity of the fourth ventricle. $\mathbf{R}$ lies above the raphe. A dark circular patch a little below $G$. F. corresponds to the genu of the vilh nerve. $x$. A. lies above a circular light area which is the nucleus of the $\mathbf{Y}$ th. F. $\mathbf{x}$. lies against the lower end of a darkly stained mass of fibres which can be dimly traced round the nucleus of the vitli towards the outer side of the genu of VII. This corresponds to the facial nerve just before it issues from the medulla. Fibres ale seen passing from inner side of vith nucleus towards A. $\mathbf{x}$, the fibres of the vith nerve.

nerve fibres also divide, on entering the bulb, into ascending and descending branches. These different branches become connected with the cells of the 
dorso-median nucleus, Deiter's's nucleus, and the cells around the ascending root of the eighth. As regards the further course of the strie acustica, these bundles show many fibres passing vertically into the central mass of the bulb or the tegmentum, as it is termed; other fibres of the striæ acustica decussate at the raphe, some pass thence towards the superior olive and turn longitudinally, other's pass towards the restiform body.

\section{Region of nucleus of seventh nerve.}

The nucleus of the serenth extends towards the midbrain, almost to the upper limit of the nucleus of the sixth. A section taken through the junction of the upper and middle thirds of the fourth ventricle would pass through both these nuclei, showing the appearance seen in Fig. 14t. The fibres here are seen passing from the nucleus of the seventh towards that of the sixth, which is seen on the floor of the fourth ventricle. Towards the inner side of this a more or less prominent mass of tibres of the seventh turn longitudinally, forming the genu of the serenth (Fig. 145), and there are seen laterally fibres about to pass out of the bulb, belonging to this same nerve.

The nucleus of the sixth or abducens nerve consists of multipolar cells, about $40-50 \mu$ in diameter. The neuraxons of these cells pass from the median side rentrally towards the pons and run through this with an oblique backward course so as to issue at the lower edge of the pons in line with the roots of the twelfth. The nucleus is connected with the superior olive by a bundle of fibres, which is called the pericle of the superior olive. Other connections exist with the pyramidal bundles and the posterior longitudinal bundle.

193. The region of the upper end of the fourth ventricle. (Fig. 116.)-A section through the nuclei of the fifth nerve would show the 
characters of a transverse section in this region. 'The origins of the fifth seen in this section consist of two more or less listinct masses of cells, the outer being described as the sensoly nucleus, the inner

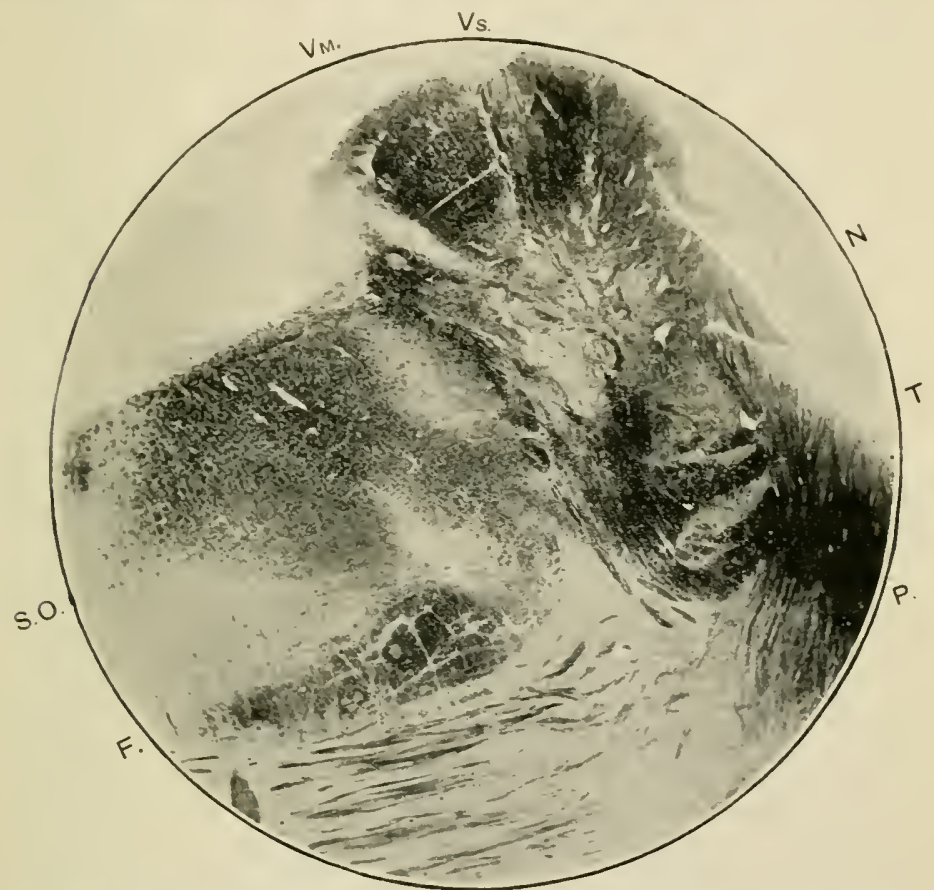

Fig. 146.-Section through the Nucleus of the Fifth Nerve. (Micropltotograph of a Weigert-Pal preparation.)

Below is seen a small part of the pons proper, and at $P$ are fibres passing circumferentialls towards the pons. At level $\mathrm{F}$ is a dark niass on left side of middle line of section, the fllet (above this and near the centre of the microphotograph) at level S.o. is the superior olive. At level $\mathbf{x}$. and beneath ru. and $r$ s. are the twonnclei of the rth; from these and hetween these. at level T, are seen fibres lassing downwards towalds the pons fibres-these form the vth nerve.

as the motor nucleus. From these masses of cells nerve fibres are seen to pass in a ventro-lateral direction to the fifth nerve. The more exact origin of this nerve may be now referred to. In the tirst 
place the nerve consists of two parts, the motor and the sensory divisions. The sensory division proceeds from the Gasserian ganglion, and, on reaching the deeper layers of the pons, the different tibres divide into ascending and clescending portions, like an ordinary sensory nerve. The descending portions form a bundle of fibres, the so-called ascending root of the fifth, which has been referred to in most of the regions already described. This can be traced down distinctly as fir as the pyramidal decussation. The bundle diminishes in amount on tracing it downwards, and is always associated with a mass of grey matter lying on the median side, the substantia gelatinosa. In this substantia gelatinosa are cells round which the tibres of the "ascending" root form arborescences. At the level of the exit of the fifth these cells of the substantia gelatinosa are more evident, and are referred to as the chief sensory nucleus. The ascending branches of the bifurcating sensory root become comnected with the cells of the chief nucleus. From the cells lying in the substantia gelatinosa against the "ascending" fifth along its whole length there pass, towards the middle line, arched fibres, which cross the raphe, then become longitudinal in their course and enter the fillet. On their way towards the upper part of the brain these fillet fibres of the fifth give off numerous collaterals which are connected with cells in the reticular formation. The motor root springs from the motor nucleus. This occupies the position somewhat of an upward continuation of the seventh nucleus. It consists of large multipolar cells $(50-70 \mu)$ having, however, blunt, unbranched processes. The fibres forming the motor root are partially decussated, so that the root on one side is composed of fibres derived from the motor nuclei of both sides. There are connections between the motor and sensory nuclei which may furnish the 
path for reflex masticatory action. There must also exist connections with fibres of the pyramidal system. Passing dorsally between the two nuclei are seen fibres which tim longitudinally and form a small tract traceable, upwards, about as far as the anterior corpora quadrigemina. This is known as the "clescending" or cerebral root of the fifth. It will perhaps be well to describe its course here. In the region of the posterior corpora quadrigemina it lies near the dorsal angle of the superior cerebellar peduncle and dorso-lateral to the outer angle of the posterior longitudiual bundle. It is separated from this bundle by a mass of pigmented cells, known as the substantia fermginea (Fig. 14i). The "descending" root can be traced upwards as a bundle of large fibres against which lies scattered round or spindle-shaped nerve cells, less deeply pigmented than those of the substantia ferruginea. Passing to the level of the anterior corpora quadrigemina, the root can be seen for some distance, lying at the edge of the grey matter surrounding the Sylvian aqueduct and near the upper end of the anterior corpora quadrigemina it becomes lost. Returning to other structures seen at the level of the exit of the fifth nerve, it will be well to refer to the appearance now presented by the fillet.

In the niddle of the fourth ventricle the fillet consists of a mass of longitudinal fibres lying on either side near the middle line and separating the formatio reticularis from the transverse fibres of the pons. In the sub-pontine region the fillet fibres lie between the olives, forming the inter olivary layer. In the upper portion of the fourth rentricle the fillet on either side divides into two masses, one part lying between the superior olive and the middle line, forming the median fillet, the other lying dorsal to the superior olive and known as the lateral fillet. 
The fibres of the median tillet are derived originally from the nuclei of the funiculi gracilis and cuneatus as well as from the nuclei of the ragus, glassopharrngeal, and restilular nerve. The lateral fillet probably originates (1) from fibres of the trapezium, passing from the rentral acoustic ganglion of the opposite side and, therefore, connected with the coclilear root of the eighth; (2) from the superior olires on both sides and, higher ul', from a collection of cells in the course of the lateral fillet, known as the nucleus of the lateral fillet; (3) from longitudinal tibres lying against the superior olive, which increase in number on proceeding upxarcls; (4) possibly, from fibres derived from the strix acusticx, which have passed rentrally into the tegmentum and turned into the tract of the fillet.

The poins proper is made up of numbers of transverse fibres passing laterally from the middle pedmeles of the cereluellum on one sicie to that on the other. In crossing rentrally upon what is the continuation of the substance of the bulb these fibres divide the prramids into groups of longitudinal fibres. The more dorsal of these transverse fibres (those lying immediately adjacent to the upward continuation of the formatio reticularis) are known by the special name of the trajezium. Amongst the transterse fibres of the pons are numerous scattered masses of grey matter with which many of the longitudinal fibres become connected.

\section{The region of the posterior corpora} quadrigemina and upper part of the pons. -The first section taken is immediately below (distal) the posterior corpora quadrigemina. The fourth ventricle has here narrowed to form the commencement of the aqueduct of Sylvius. Surrounding the chamel is the ependyma enveloped on all sides by a considerable thickness of grey matter. In that 
portion lying on the ventral side may be seen masses of cells forming the commencement of the nuclei of

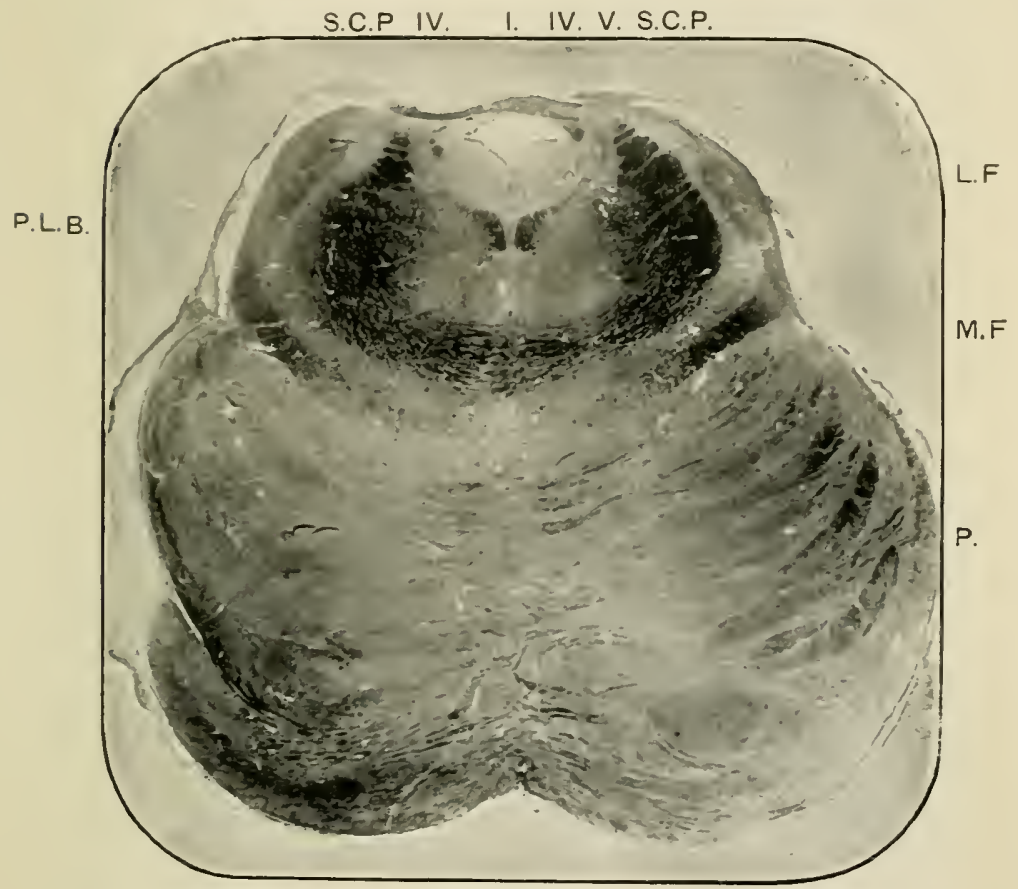

Fig. 147.- Section throush the Pons Varolii immediately helow the Posterior Curlora Quadrigemina. (Hhotograph of a Heigert-Pal specimen.)

The main mass of the section forms the fibres of the pons (P). The two large dark ma-ses in the nuper part (under s. C. P.l, the lower end. meeting in midrle line, are the superior cerebellar peduncles or brachia conjunctiva. The area included between their lower halres forms the tesmentum. The yuadrangular space helow $I$ is the sylvian ayueduct. Decussating in the valve of Vieussens above are seen fibres of the ivth nerve, the two small dark masses below iv being the main trunks lying oblinnely. Lring a short distance below the aulueduct at $P$. L. B. are two dark comma-sbaped nasses, the posterior longitudinal bundles. The two elongated dark unasses one lying asainst l. F.. the other passing hetween the pons fibres and the superior cerebellar peduncles opposite $\mathbf{3 .} \mathbf{F}$. are the lateral and median fillets. The darkish mass lying below $v$, just on the median ide of the upuer nart of the peluncle is the descending ront of rth.

the fourth nerve. Lying again rentral to this grey matter are two prominent longitudinal bundles on 
either side of the middle line, tapering towards the lateral region. These are the posterior longitudinal bundles. Near the lateral tapering end of these bundles may be seen the descerding root of the fifth nerve, separated by a mass of cells forming the substantir fermuginea or locus comulens. Lying to the median side of the root of the fifth may be seen bundles of white fibres passing into the superior. medullary velum or valve of Vienssens, decussating here (Fig. 1 17 ) and issuing literally as the fourth nerve. Lying again ventrally and laterally to the posterior longitudinal bundles, and separated from them by what is an upwarl continuation of the reticular formation, are the upward prolongations of the superior cerebellur peduncles or brachia conjunctiva. There at the level of the nuclei of the fifth nerve, in section, two semicircular masses lie immediately lateral to the side of the fourth ventricle. Passing upwards, they gradually take a more ventral position till, as in the present section, they commence to fuse in the middle line. At a short distance externally and rentrally to the superior cerebellar peduncle is seen another band of longitudinal fibres. This band is of considerable thickness between the peduncle and the lateral surface, then passing ventrally it narrows somewhat, and widens again to a fairly broad band lying on the dorsal side of the pons proper. This is the fillet or lemniscus, the lateral portion with nerve cells forming its nucleus being the lateral fillet, that portion lying adjacent to the pons being the median fillet. Ventrally to this again is the substance of the pons proper, having the characters described in $\$ 193$.

A section slightly higher would pass through the posterior corpora quadrigemina. Here, there would appear two protuberances, dorso-laterally to the aqueduct. The lateral fillet forms connections with 
these borlies. The pons proper is here somewhat smaller, the upper limit being approached. The two superior cerebellar peduncles gradually lessen in width, their lateral extensions disappearing by degrees. The nucleus of the fourth nerve consists of a mass of large multipolar cells lying in the grey matter on the ventral side of the aqueduct and near the midlle line, and reaching from the upper to almost the lower extremity of the posterior corpora quadrigemina. The fibres from these cells take a somewhat oblique backward course to the lower limit of the posterior corpora quadrigemina where they decussate, as already described. In the region of the posterior corpora quadrigemina the posterior longitudinal bundle is very prominent. The basal ends of the ependyma lining the aqueduct are frequently continued into a set of fine fibres which pass through the grey matter (and even beyond) and give a radially striated appearance to the region adjacent to the aqueduct.

\section{The region of ilse anterior corpora quadrigemina and the cruar cerelbi.} At this level (Fig. 148) the pons lias disappeared, and its position is occupied by two well-markeci protuberances on the ventral side, spoken of as the crura cerebri. Lying dorsally to the crus on each side is a broad band of black pigmented cells, forming the substantia nigra. The grey matter around the aqueduct is considerable, the posterior longitudinal bundle is somewhat less conspicuous than below and forms a narrow band lying at the ventral edge of the central grey matter. Large nerve cells lie in the ventral portion of this grey matter, forming the nuclei of the third nerve, the fibres of which can be seen passing ventrally in many bundles. In the middle line between these roots a well-marked raphe is visible. Lying midway between the central grey matter and the substantia 
nigra is a large mass of cells, known as the red nuclens. In man this nucleus consists of cells varying ir size from $20-75 \mu$. These nuclei have some

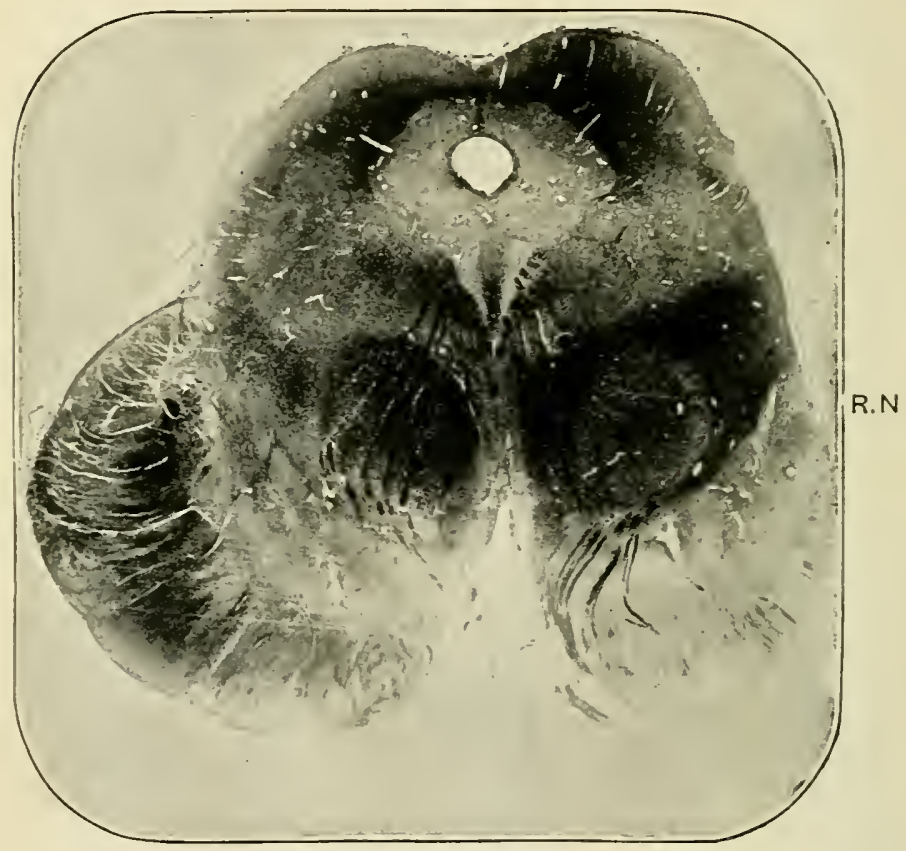

Fig. 148. - Section througl the Anterior Corpora Qtadrigemina. (Photograph of a Weigert-l'al pieparation.)

The section is somewhat oblique, leing slighty higher on the right side than the left. The symmetrical projections alove are the anterior corpori qualrigemina. The opening between them is the sylvian aquednct. The lighter -ub-tance around this is the grey matter suriounding the iter. The darker masses formiug the lower boundary of this grey matter arranged in discrete areas on right side are the posterior longitudinal bundles, lying in which are cells forming the nucleus of the third nerve. The hundes of fibres passing in an arebell manne downwards from the third melens are the fibres of the third nerve. At level $\mathrm{R}$. x. on right -ide is a large ditk mass lying in a still darker latch, luaving the tibres of the third yasing thromoh its median region. This is the commeneenent of the red nucleus, which is not yet evident on the left side, where a colre-ponding dark mass consists of the decussated filmes of the superior eerebellar pedumcle. Ou the left side lying helow and laterally to this mass and liglit in shide is the substantia nigra, this forms the base of a projection (the crus eerelri), in which the tibres of thepgramids and other fibres pass lougitudinally. "The dark band somewliat arched passing upwards to the anterior corpus quatrigeminm from the dark miss of the superior cereluellar peduncle is the tillet. 
connection with the superior cerebellar pednncles, which terminate here in their upward course. Laterally, the fillet is seen passing dorsally towards the prominent anterior corpms quadrigeminum. A small portion of the brachium of the latter may also be seen. The upward continuation of the reticular formation corresponds to the mass between the ventral aspect of the central grey matter and the substantia nigra, and is called the tegmentum. The locus curruleus is no longer seen, but the descending fifth is still apparent.

Structure of the anterior corpus quadrigeminum. Externally there is a thin layer of white matter about $30-40 \mu$ in thickness. This is known as (a) the stratum zonale. The white fibres in this layer pass through the superior brachium from the optic tracts. From the layer many fibres enter the inner layers, and in them form dendritic ramifications. (b) The stratum cinereum. In this layer are numerous cells, whose neuraxons pass inwards. (c) The stratum albocinereum externum. This layer contains numerous small and large cells and nerve fibres. The nerve fibres enter the layer largely from the optic tract by the superior brachium. A considerable amount of decussation of these fibres occurs on the median side with those of the opposite corpus quadrigeminum anterius. (d) The stratum albo-cinereum internum.

(Stratum lemnisci.) This layer is subdivided into three minor layers: (a) the fillet layer, formed from a continuation of the dorsal part of the median fillet and from the lateral fillet; $(\beta)$ a layer of grey matter; $(\gamma)$ a layer of arched fibres bordering the central grey matter and decussating in the middle line. All these layers are pervaded by radial fibres passing from the central grey matter:

The optic lobes of birds have been more fully examined as regards the various layers and their 
connections. Different authors divide these structures in rarious different layers. Adopting Kölliker's description, a rertical section may be regarded as showing-(1) a superficial layer of fibres from the optic tract; (2) and (3) layers of grey matter or molecular layers: in (2) the optic nerve fibres form their dendritic ramifications; (4) a layer of white fibres arranged in a kind of lattice work; (5) an inner layer of white fibres in which course the cerebral visual fibres; (6) a layer of grey matter lying against the ependyma of the rentricle of the optic lobes. The connections of the cells and fibres of this layer have been established by Golgi's method by Rámón y Cajal and $v$. Gehuchten.

In the corpora quadrigemina important connections are made by the fillet fibres. Some of these connections have already been referred to $(\$ 193)$. The fillet fibres in their upward course give off collaterals which ramify or actually terminate themselves in the cells of the nucleus of the lateral fillet. Many of the fillet fibres terminate in dendritic ramifications in the cells of the posterior corpora quadrigemina, many others pass into the anterior. The cells of the lateral nucleus originate fibres which pass possibly towards the cerebrum; some, howerer, descend towards the superior olive. Some of the fibres entering botl corpora quadrigemina decussate dorsally and pass to the opposite corpora. There may also be some connection amongst the fillet fibres with those of the superior cerebellar peduncle.

The mucleus of the third nerve has been described as consisting of many various groups of cells. It is to be regarded as mainly one nucleus, extending through the whole length of the anterior corpus quadrigeminum and somewhat above it. It consists of a main mass with two less distinct masses: a dorsolateral with large cells, and a dorso-median with 
smaller cells. At its cerebral end there is a central mass having large cells. It has been suggested that the dorso-median group of small cells supplies the internal muscles of the eye (sphincter, ciliary). The nucleus is presumably connected with the pyramidal tracts. Arborescences around cells of the third nucleus are to be seen in new-born animals, and the fibres forming them may be followed to the raphe, crossing here and coursing ventrally. Connections also exist with the posterior longitudinal bundle. This bundle is to be regirded as the upward continuation of part of the anterior column of the cord, forming short longitudinal commissures It is associated with the hypoglossal nuclens, those of the vago-accessory, the fifth and the acoustic (vestibular branch). Connections also exist with the sixth, fourth, and third nuclei. The posterior longitudinil bundle furnishes, therefore, commissural connestions between the different eye muscles. Connections of the third nuclens a!so exist with the optic nerves.

The bractic passing to the corporir quadrigemina are spoken of as the superior or anterior and the inferior or posterior. The fibres of the superior pass to the lateral corpus geniculatum and to the occipital tract. The fibres of the inferior brachium are connected with the median corpus geniculatum and possibly may pass through the tegmentum by the internal capsule to the temporal region.

That portion of a transverse section through the region of the corpora quidrigemina which projects ventrally into the two crura is sometimes spoken of as the crusta, being separated from the remainder (tegmentum) of the region ventral to the aqueduct by the substantia nigra. The crusta contains, in addition to the fibres derived from the pyramids which occupy a central portion in each crus, other fibres derived 
from the pons. Those on the median side pass to the frontal region, those on the lateral portion to the temporal and occipital regions. Some fibres on the median side are derived from the median fillet. 


\section{CH A PTER XIX.}

TIE CEREBRUM AND CEREBELLUM.

196. THE structure of the dura mater, arachnoidea, and pia mater of the brain is similar to that of the same membranes of the cord.

As has been shown by Boehm, Key and Retzius, and others, the deeper part of the dura contains peculiar anpullated dilatations connected with the capillary blood-vessels, and forming in fact the roots of the veins.

The glandula Pacchioni, or arachnoidal villi of Luschka, are composed of a spongy connective tissue, prolonged from the sub-arachnoidal tissue and covered with the arachnoidal membrane. These prolongations are pear-shaped or spindle-shaped, with a thin stalk. They are pushed through holes of the inner part of the dura mater into the venous sinuses of this latter, but are covered with endothelium. Injected material passes from the sub-arachnoidal spaces through these stalks into the villi. The spaces of their spongy substance become thereby filled and enlarged, and finally the injection matter enters the venous sinns itself. The pia cerebralis is very rich in blood-vessels, like that of the cord, which pass to and from the brain substance. The capillaries of the pia mater' possess an outer endothelial sheath. The plexus choroideus is covered with a layer of polyhedral epithelial cells, which are ciliated in the embryo and in the young subject.

197. As was mentioned of the cord, so also in the 
brain the subdural lymph space does not communicate with the sub-arachnoidal spaces or with the ventricles (Luschka, Key and Retzius). Nor does there exist a communication between the subarachnoidal space and a space described by $\mathrm{His}$ to exist between pia mater and brain surface, but donl,ted by others. The relations hetween the cerebral nerres and the membranes of the brain and the lymph spaces of both, are the same as those previously described in the case of the cord and the spinal nerves.

The pia mater passes with the larger blood-vessels into the brain substance by the sulci of the cerebrum and cerebellım.

In the white and grey matter of the brain we find the same kinr of smpporting tissue that we described in the cord as neuroglin. In the brain also it is composed of a homoreneous matrir, of a network of neuroglin fibrits, and of hranched, flattened neuroglia cells, called Deitor's's cells.

In the white matter of the brain the nenroglia contains between the bundles of the nerve fibres rows of small nucleated cells; these form special accumulations in the bulbi olfactorii, and in the cerebellum. Lymph corpuscles may be met with in the neuroglia, especially around the blood-ressels and ganglion cells.

All the ventricles, including the aqueductus Sylvii, are lined with a layer of neuroglia, being a direct continuation of that lining the fourth ventricle, and this agdin being a direct continuation of the central grey nucleus of the cord. Like the central canal of the cord, also, the ventricles are lined with a layer of ciliated columnar, or short columnar epithelial cells.

The blood-ressels form a clenser capillary network in the grey than in the white matter; in the 
latter the network is pre-eminently of a longiturinal arrangement, i.e. parallel to the long axis of the bundles of the nerve fibres. In the grey cortex of the hemispheres of the cerebrum and cerebellum, many of the capillary blood-ressels have an arangement vertical to the surface, but are coinnected with one another by numerous transverse branches.

The blood-vessels of the brain are situated in spaces, perivascular lymple spaces, traversed by fibres passing between the adventitia of the vessels, and the neuroglia forming the boundary of the space. There are no separate lymphatic vessels in the grey or white substance.

198. The white matter consists of medullated nerve fibres, which like those of the cord possess no neurilemma or nuclei of nerre corpuscles, and no constrictions of Ranvier. The nerve fibres are of very various sizes, according to the locality. Divisions occur very often. When isolated the fibres show the varicosities mentioned in the cord.

The grey matter consists, like that of the cord and medulla, of a basis of neuroglia in which are embedded nerve cells. The dendritic ramifications from the nerve cells, with medullated and nonmedullated nerve fibres, form a large proportion also of the grey matter.

With regard to the structure of the ganglion cells of the brain and medulla, what has been mentioned of the ganglion cells of the cord holds good as to them. Like the former, those of the medulla and brain are situated in pericellular lymph spaces (Obersteiner).

199. We now proceed to consider in detail the structure of the different parts of the cerebellum and cerebrum.

The cerebellum is composed of laminated folds, or conrolutions, and these again are composed of 
secondary folds, each of which consists of a central tract of white matter covered with grey matter. The tracts of white matter of neighbouring convolutions of one lobe or division join, and thus form the principal tracts of white matter.

The white matter of the cerebellar hemisphere is

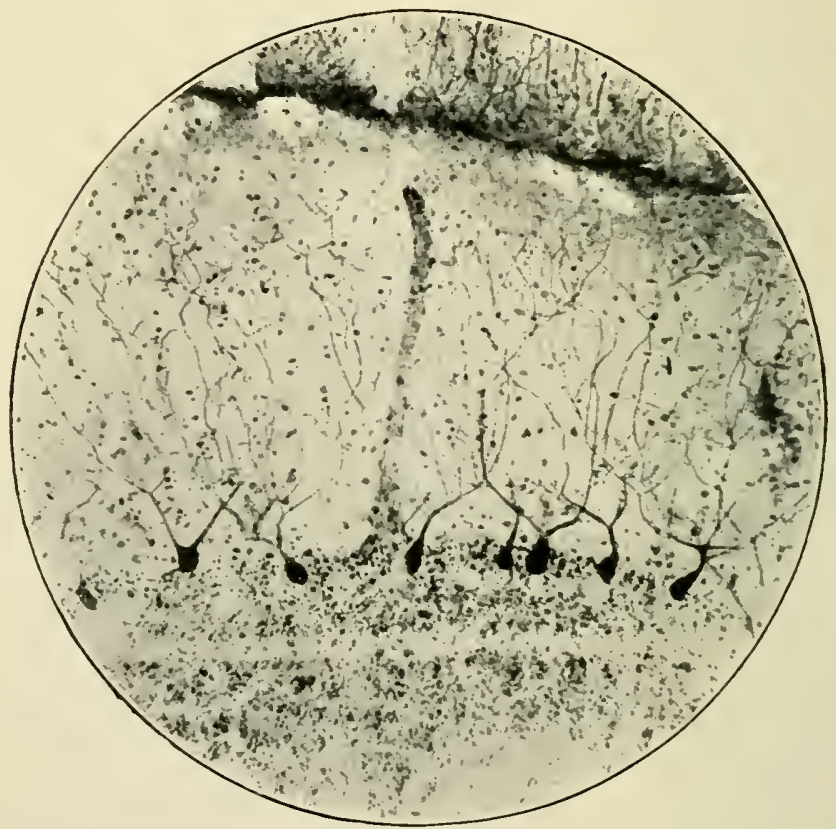

Fig. 149.-Photogram through the grey matter of the cerebellum of the dog, showing the layer of Purkinje's ganglion cells with their clendrites ranifying in the grey cortex. (Low magnificution.)

connected (a) with the medulla oblongata by the corpus restiforme, this forming the inferior peduncle of the cerebellum; $(b)$ with the cerebrum by the processus cerebelli ad cerebrum, this forming the superior peduncle; and (c) with the other cerebellar hemisphere by the tracts connecting with the pons 
varolii; these are the pedunculi cerehelli ad pontem, or the midalle peduncles.

200. On a vertical section through a lamina of the cerebellum (Fig. 149), the following layers are seen: $(a)$ the pia mater covering the general surface, and penetrating with the larger blood-vessels into the superficial substance of the lamina; (b) a thick layer of cortical grey matter; $(c)$ the layer of Purkinje's ganglion cells; $(d)$ the nuclear layer ; and $(e)$ the central white matter.

201. The layer of ganglion cells of Purkinje is the most interesting layer ; it consists of a single row of large multipolar ganglion cells, euch with a large vesicular nucleus. Each possesses also a thin axiscylinder process, directed towards the depth, the cell sending out in the opposite direction-i.e. towards the surface-a thick process which soon branches like the antlers of a deer, the processes being all very long-branched and pursuing a vertical course towards the surface; sooner or later they all break up into the fine nervous network of the grey cortex. The longest processes reach near to the surface. The layer (b) above mentioned-i.e. the cortical grey matter-is in reality the terminal nerve network for the branched processes of the ganglion cells of Purkinje. Sankey maintained, before the adoption of more modern methods of research, that in the human cerebellum there are also small nultipolar ganglion cells connected with the processes of Purkinje's cells.

202. The connections and distributions of the different cells of the cerebellum have been exhibited to a considerable extent by the labours of observers who have followed the methods of Golgi. A scheme of the main points on these results is shown in Figs. 150 and 151. Fig. 150 indicates the appearance represented in a section across a lamina, Fig. 151 corresponds to a section taken in 
the direction of a lamina. Considering the cells of Purkinje first, they are seen to possess a very extensive dendritic ramification, viewed transversely,

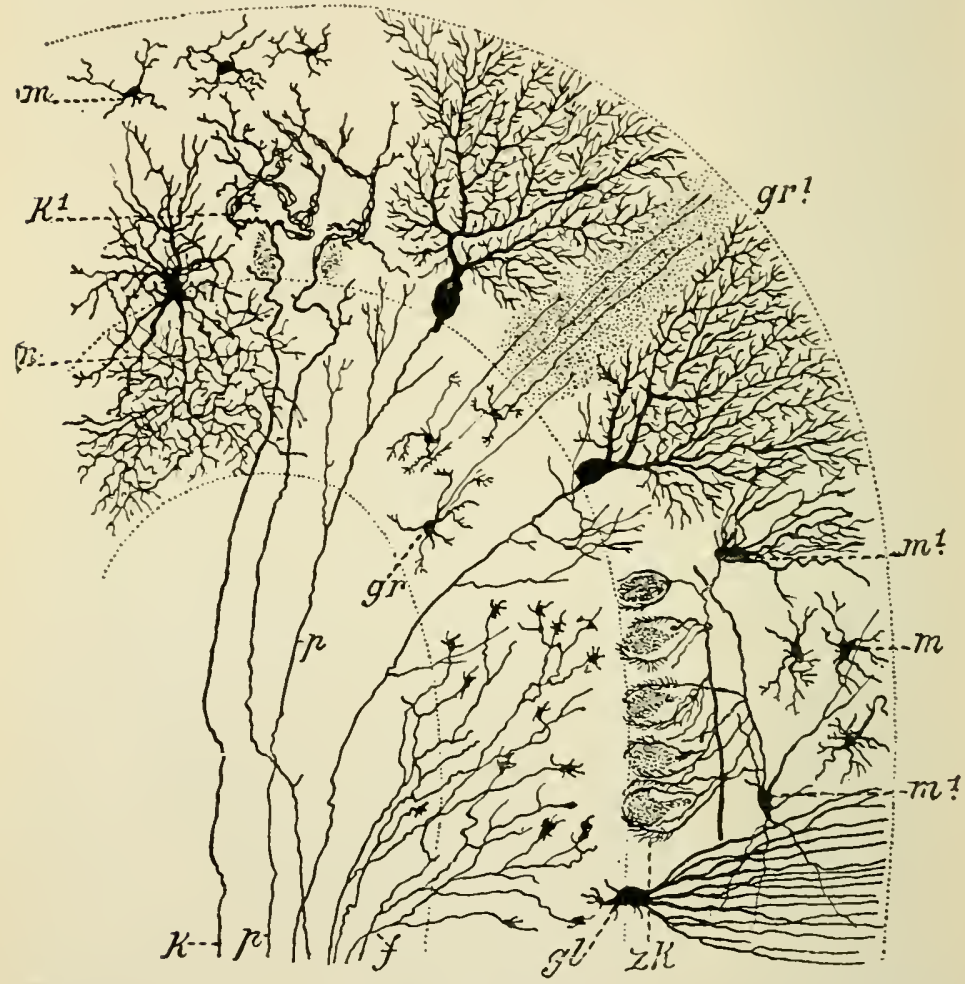

Fig. 150.-Scheme of the Connection of the Cells in the Superficial Grey substance of the Cerebellum. (After Kölliker.)

$p$, Neuraxons of Purkinje's cells with collaterals : $k$, tendril-like fibres witb $k^{-1}$ their terminations : $g l$, glia cells : $f$, moss fibres: $m$, sluall cells of the molecular layer: $m^{1}$, large cells of the same layer (basket cells) forming syuapses round Purkinjes cells, $z k ; g r$, cells of the uuclear larer with neuraxons passing into molecular layers, here turning borizontally and giving a punctated appearance in cross-section; $n$, the luxuriant branching of a Golgi's cell of the second type.

passing through the whole thickness of the molecular layer, as the cortical grey matter is sometimes called. This ramification is less extensive viewed in the longitudinal section of a lamina (Fig. 150). The neuraxon 
passes through the nuclear layer obliquely, giving off collaterals which to some extent re-enter the molecular layer, then the axon passing from the nuclear layer enters the central white matter. 'There are also seen in the molecular layer other faily conspicuous

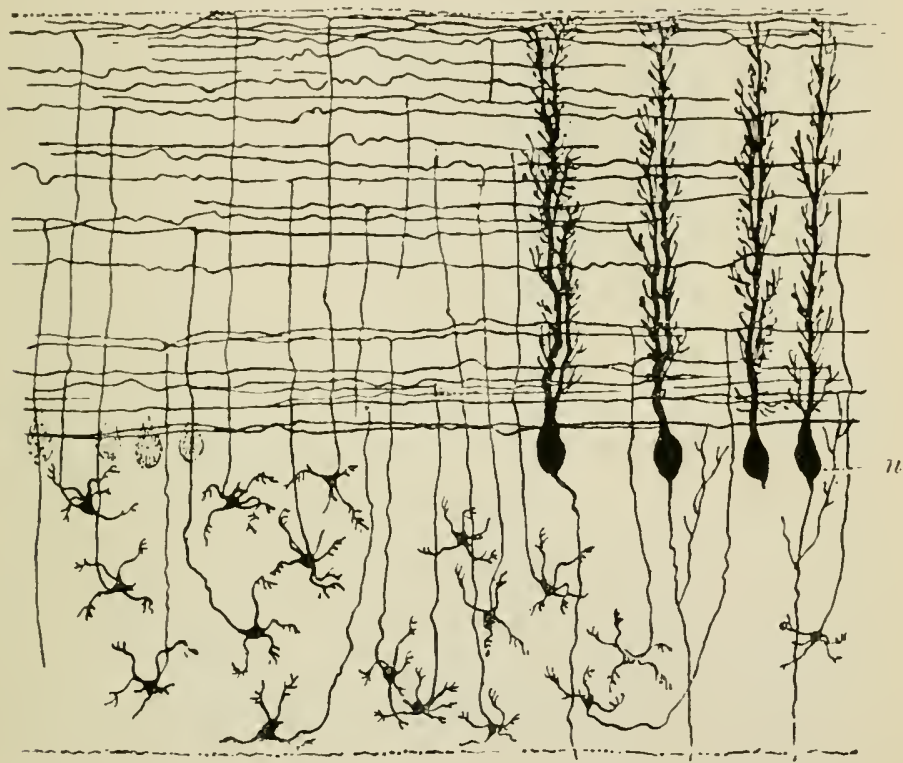

Fig. 151.-Longitudinal Section of the Grey Substance of the Cerebellum. (After Köllilier.)

The restricted branching of the cells of Purkinje $(n)$ is seen. The nuclear cells below are seen sending axons upwards into the molecular layer which divide dichotomously, and run longitudinally.

cells $\left(m^{\prime}\right)$, which are termed backet cells. These cells have dendrites which ramify amongst those of the Purkinje's cells, and a neuraxon which gives off collaterals, and these again form arborescences around the Purkinje cells. Other smaller cells (m) have processes all of which lamify in the neighbourhood of the cell. On the border line between the nuclear and molecular layer's may be seen large multipolar cells 
(sometimes spoken of as Golgi's * cells), which exhibit a dendritic ramification in the nuclear layer, and in which the neuraxon, on entering the molecular layer,

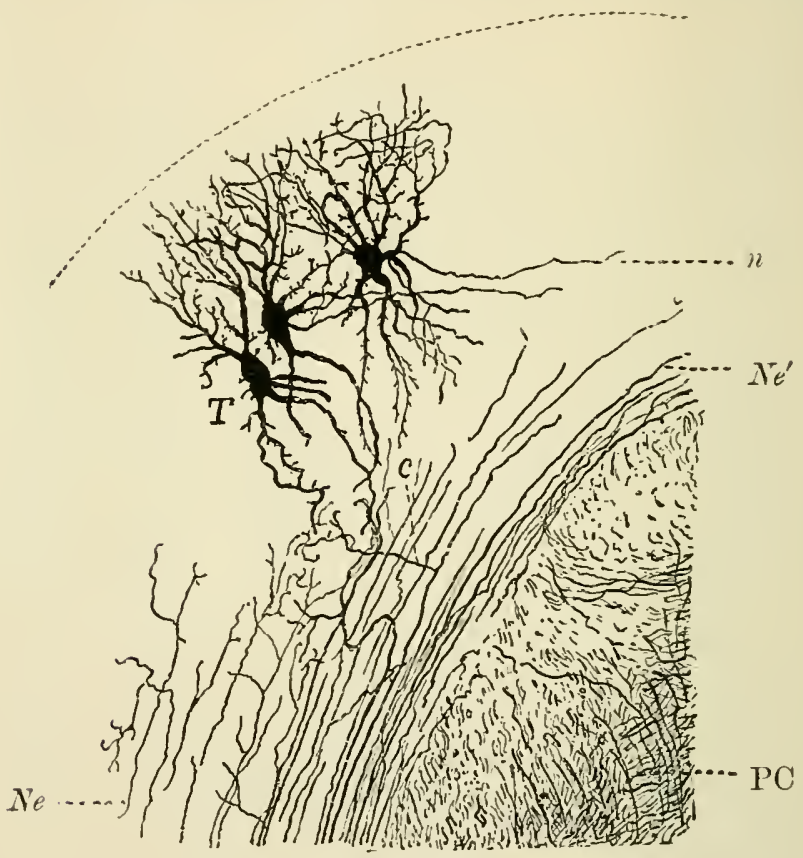

Fig. 152.-From a Transrerse Section through the Edge of the Restiform Borly, PC, and the Tubereulum Acusticum of the new-born Cat. (rolyi. Kölliker, II.)

Te, Yerve filmes of the cochlear nerve: $e^{\prime}$, the same fibres passing round the peduncle; $c$, collaterals : ' $T$, large vanglion cells of the tuberculim; $n$, their axous becoming fildres of the stria acustice.

divides up not far from the main cell. In the nuclear layer are numerous small cells $\left(y r^{\circ}\right)$, the dendrites dividing very near to the cells, the neuraxons,

* Though referred to frequently as "cells of Golgi," these are more correctly described as "cclls of the. secmil type of Golgi." Some authors use the term "cells of Golgi" to refer to neu. roglia cells. 
however, pass into the molecular layer and bifurcate longitudinally (Fig. 150) at various levels. The socalled "molecular" condition of the cortical grey matter is largely due to the appearance of these fibres being cut across as well as to the sections of the processes of the cells of Purkinje. The central white matter shows other fibres than those representing the neuraxons of the Purkinje cells (Fig. 151). One set of these terminate in arborescent tufts in the nuclear layer, and are referred to as moss fibres $\left(f^{\circ}\right)$. Another set pass into the molecular layer and break up on connection with the dendrons of the cells of Purkinje. These are spoken of as tendril fibres. These two sets of fibres are to be regarded as conducting to the grey matter of the cerebellum. In addition to the proper nerve cells already described, may be seen neuroglic cells $(g l)$. These are also present in the central white matter (Fig. 152).

\section{The structure of the cerebral con-} volutions in gencial.- In a vertical section through a cerebral convolution one is able to see with the naked eye a central core of white matter surrounded by a cap of grey or reddish-grey matter, which again, on careful observation, can be seen to consist of several alternate strata of lighter or darker substance. The exact appearance of these different layers varies in different parts of the cerebral hemispheres.

In general, a vertical section of a convolution shows three main layers: (1) a superficial molecular. layer, (2) a layer of pyramidal cells, (3) a layer of polymory,hous cells. These layers are subdivisible into several others in different parts of the hemispheres (Fig. 153).

\section{Structure of the cerebral convolu-} tions in the region of the Rolandic fissure.In this region one can distinguish six layers, showing 


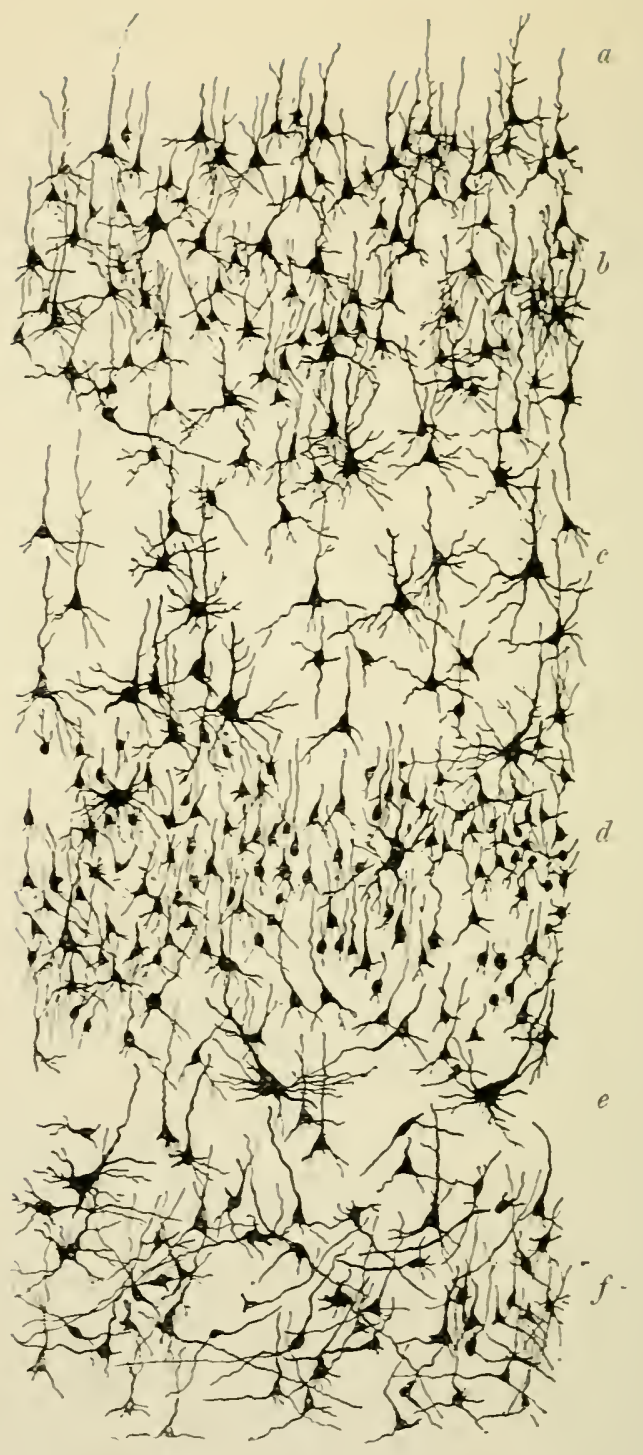

Fig. 153.-Tertical section through the Grey Cerebral Cortex in the Parietal Region. (Köllikièr, II.)

$a$, superficial whice layer: $b$, outer laser of small prramidal cells: $c$, outer laver of large yramidal cells; $d$, inner laser of -mall lirramidal cells; $t$, inner layer of large 1 ramidal cells : $f$, polymorphous cells. 


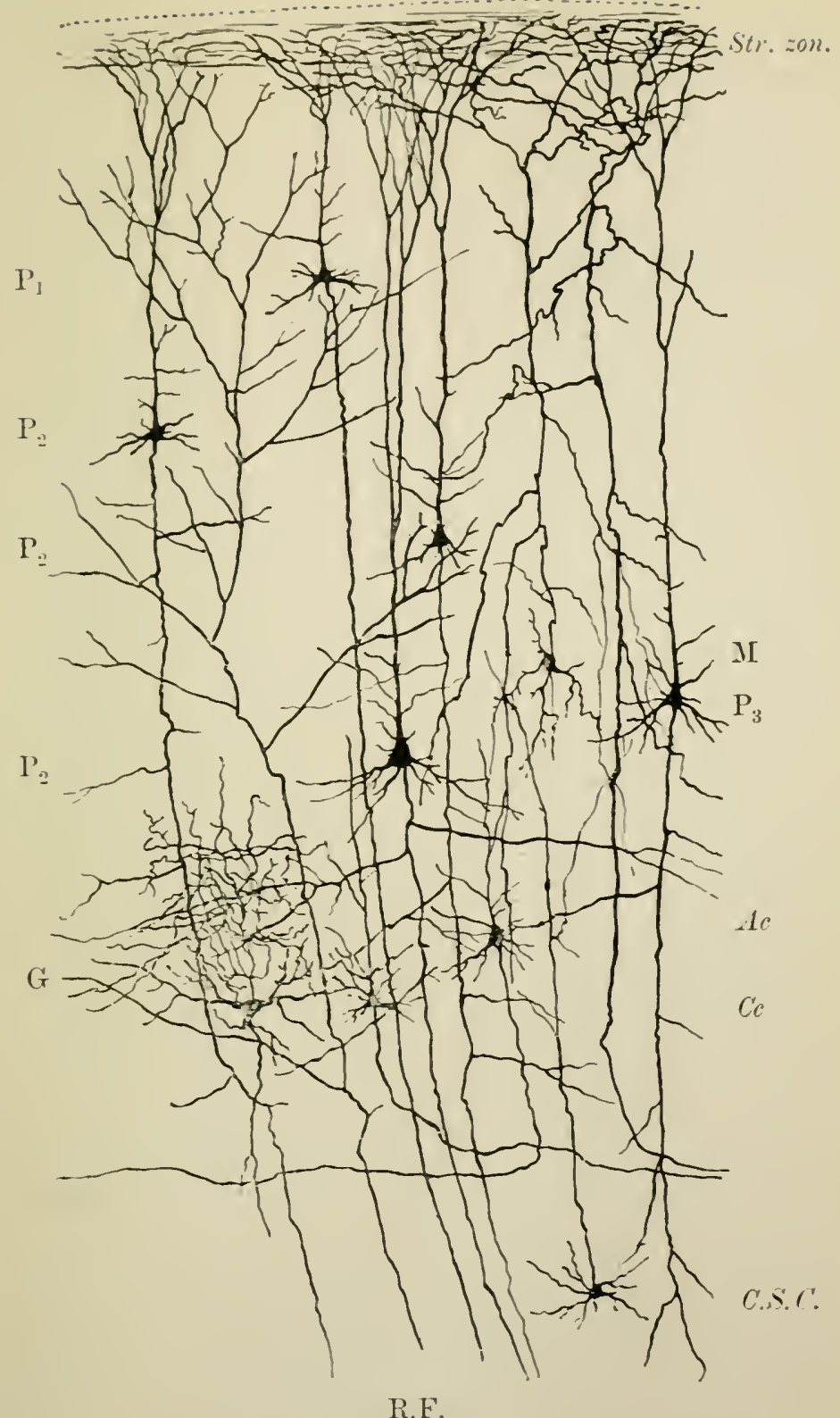

Fig. 154.-For deseription see next jage. 
different characters. Superficially is the stratum sonale or molecular layer $(a)$, then the outer layer of small myamidal cells (b), then (c) the outer layer of large myramidal cells, followed by $(d)$ the inner layer. of small pyramidal cells, then (e) the inner layer of large pyramidal cells, and, adjacent to the white matter $(f)$, the layer of polymorphous cells. These cells are, to some extent, separated into rertical columns by intercolumnar bundles of nerve fibres. There are also, ruming horizontally, following the contour of the grrus, other more or less defined bundles of tibres. Some of these run in the superficial molecular layer; two other bands are disposed tangentially, in the pyramidal cell layer, the more superficial being the band of I'icq d'Azyr or Gennari, the deeper that of Baillarger. In general, the neuraxons of the cells descend towards, and finally, pass into the white matter (Fig. 15t). There are some cells in the cortex which do not conform to this rule. Amongst the pyramidal cells may be found cells known as Martinottis cells, from which the neuraxons ascend towards the superficial molecular layer. Cells known as Golgi's cells are also to be found, with neuraxons passing towards the surface and dividing up not far from the cell. The general relation of the different cells and fibres is shown in the accompansing scheme (Fig, 154)

Description of Fig. $15+(1.245)$.

Fig. 15t.-Scheme of the Connection of the Cells of the Cerebral Curtex. (After hölliker.)

$\mathrm{P}_{1}, \mathrm{P}_{2}$, Smaller and larger pramidal celis, the neuraxons nassing downwards on their was to the inner caysule: $\mathrm{P}_{3}$. wramidal cells forming a termination in the corpus striatum; at level if a cell of Ifartinotti witl neuraxon passing upwards and terninating in stratum zonale: at le rel $G$ a Golgicell (2nd order) with much-branched neuraxon immediately abore it ; Ac, aszociation cell, on inner side of $G$ is a cell $\left(C c^{c}\right)$ with neuraxon passing into corpus callosum : C....., a cell of corpus striatum with neuraxon passing into cortex : li.F. a tibre from the fillet passing up into the cortex, one of Ramon $y$ Cajal's fibres ; str. zon., stratum zonale, or superficial white layer. 


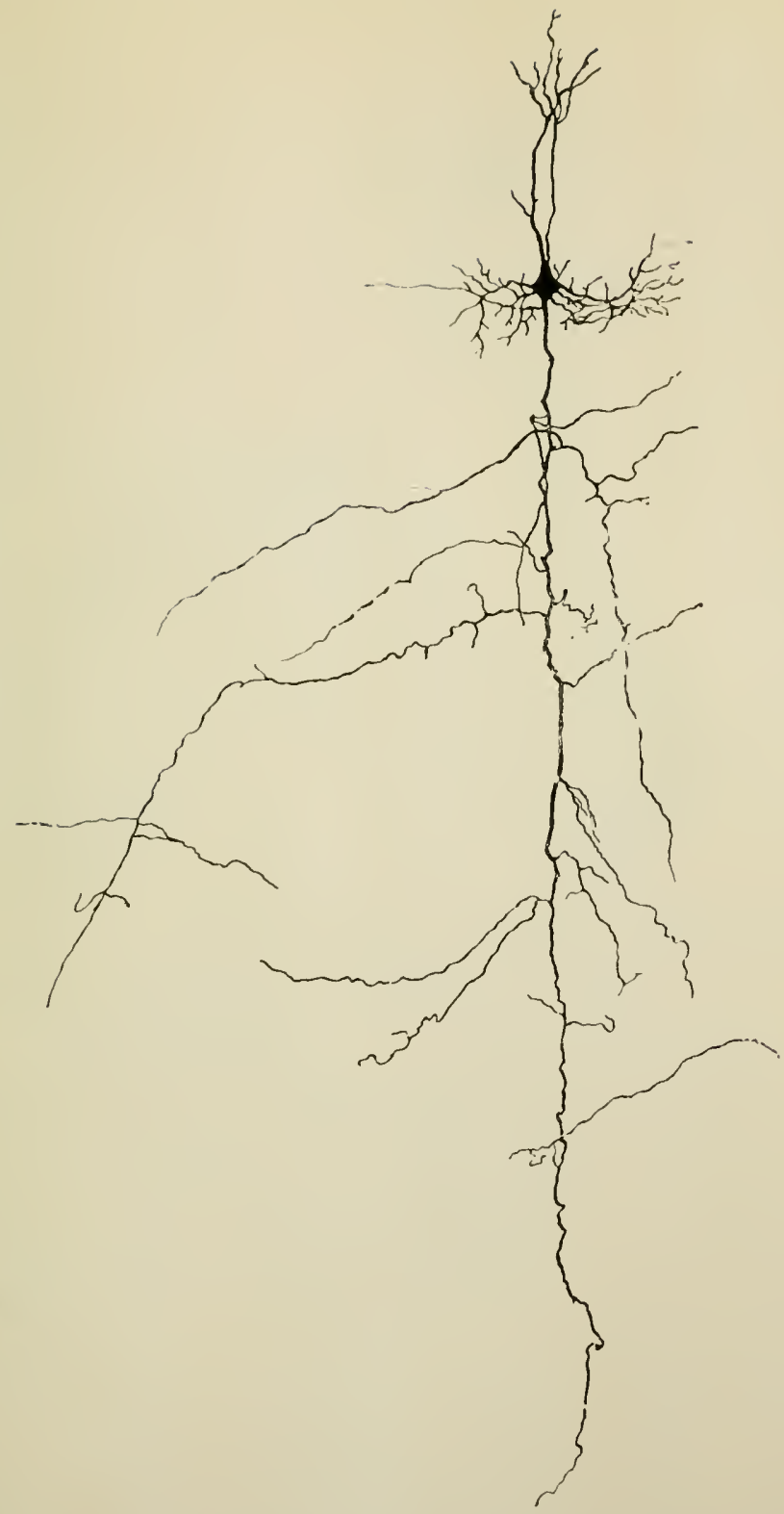

Fig. 155.-Pyramidal Cell of the Cortex of the Brain, its axon giving off numerous collaterals. (Kölliker, $I I$, ) 


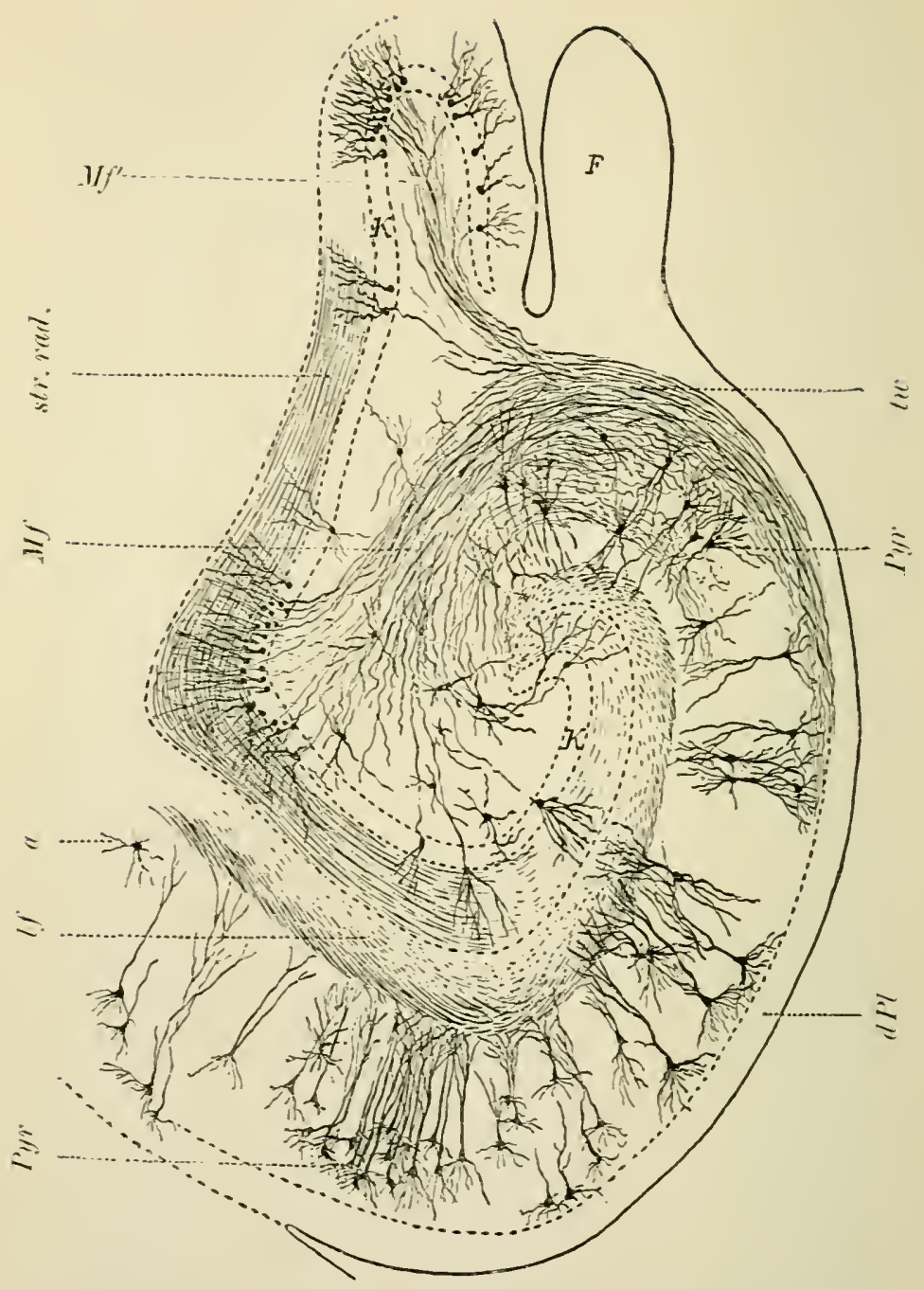

Fig. 150.-Fascia Dentata and arljoining part of Cornu Ammonis of Human Embryo. (After hölliker.)

Mf., Mos fibres (main bundle, an acce-sory bumdle pas-ine ont to the right); str. rud, stratmu radiatum of fascia dentata: $a$, cell with ascendiug axon (cell of Martimotic): Pyr. nyramidal cells: $\dot{F}$, timbria: $h$, nuclear layer

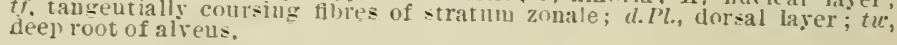


from Kölliker. The pyramidal cells have a conspicuous apical process, which passes vertically, giving off lateral processes, and forms a system of dendrites in the superficial molecular layer. Other dendritic ramifications occur closer to the cell and the neuraxon passes towards the white matter, giving off collaterals as it traverses the grey substance (Fig. 15.5). Some of the pyramidal cells $\left(C_{C}\right)$ have neuraxons which pass to the opposite hemisphere in the corpus callosum, and not towards the inner capsule, through which a large number of the neuraxons course. Some pyramidal cells again probably have their neuraxons terminating in connection with cells of the corpus striatum $\left(\mathrm{P}^{3}\right)$. The connections of a cell of Martinotti are seen (M), and those of a Golgi cell (G). Fibres conducting towards the cortex are represented by (1) Rámón y Cajal's fibres (R.F.), passing from the fillet and subdividing in the cortex; (2) fibres from cells of the corpus striatum (C.S.C.) passing up into the grey matter of the cortex in a similar manner.

205. Structure of the hippocampus major and the fascia dentata (Fig. 156).

The hippocampus as it projects into the ventricle is invested beneath the ependyma with a layer of white fibres called the alvers. Lying against the alveus are pyramidal cells, the neuraxons of which pass into it; the conspicuous apical process passes through a large portion of the thickness of the hippocampus, giving it a radiate appearance (the stratum radiatum), and forming a dendritic ramification above this in the stratum lacunosum. Tracing the substance of the hippocampus towards the fascia dentata, these pyramidal cells become less conspicuous and are not to be regarded as forming any definite layer in this region. The fascia dentata has externally a superficial layer or stratum zonale into which pass the 
dendritic ramifications of a layer of small cells, the stratum granulosum. From these small cells neuraxons pass to the central substance of the fascia

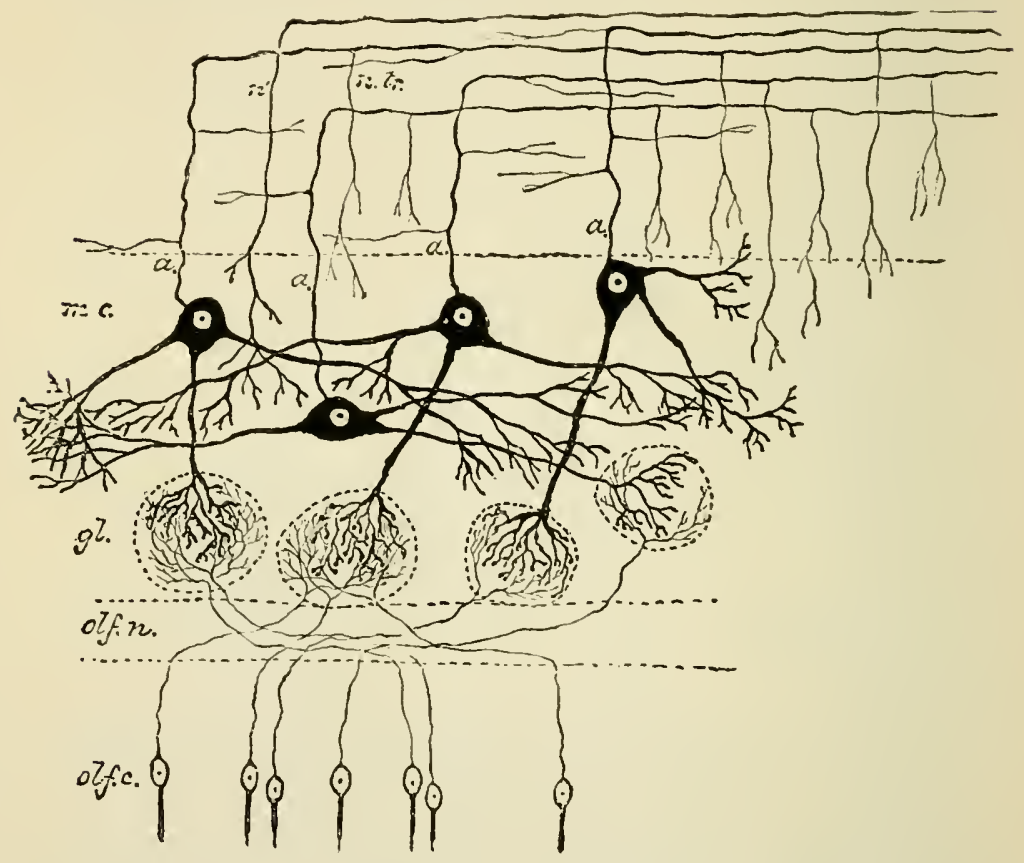

Fig. 15\%.-Diagram of the Probable Connections of Cells and Fibres in the Olfactory Bulb. (After Schiifer.)

olf.c. Sensory cells of the olfactory epithelinm; olf.n., dieenest layer of the hnlb composed of the olfactory nerie fibres which are prolonged from the olfactory cells: $g l$, olfactory glomeruli, containing dendrons of both the olfactory nerve fibres and the mitra! cells; me, mitral cells; $a$, their axons: n.tr., nerve fibres of :he bulb liecoming continnous with the olfactory tract.

dentata, and from this also many so called "moss fibres" issue, passing to the granular layer ( $M f^{\circ}$ and $\left.I S f^{\prime \prime}\right)$.

206. Structure of the olfactory bulb (Figs. 157 and 158).-A vertical section through the olfactory bulb indicates considerably more derelopment on the side lying against the cribriform plate than 
on the dorsal side. Passing from the surface lying on the ethmoid bone, one can make out the following layers: (1) Bundles of olfactory nerve fibres; (2) the zone of olfactory glomeruli; (3) a layer pervaded

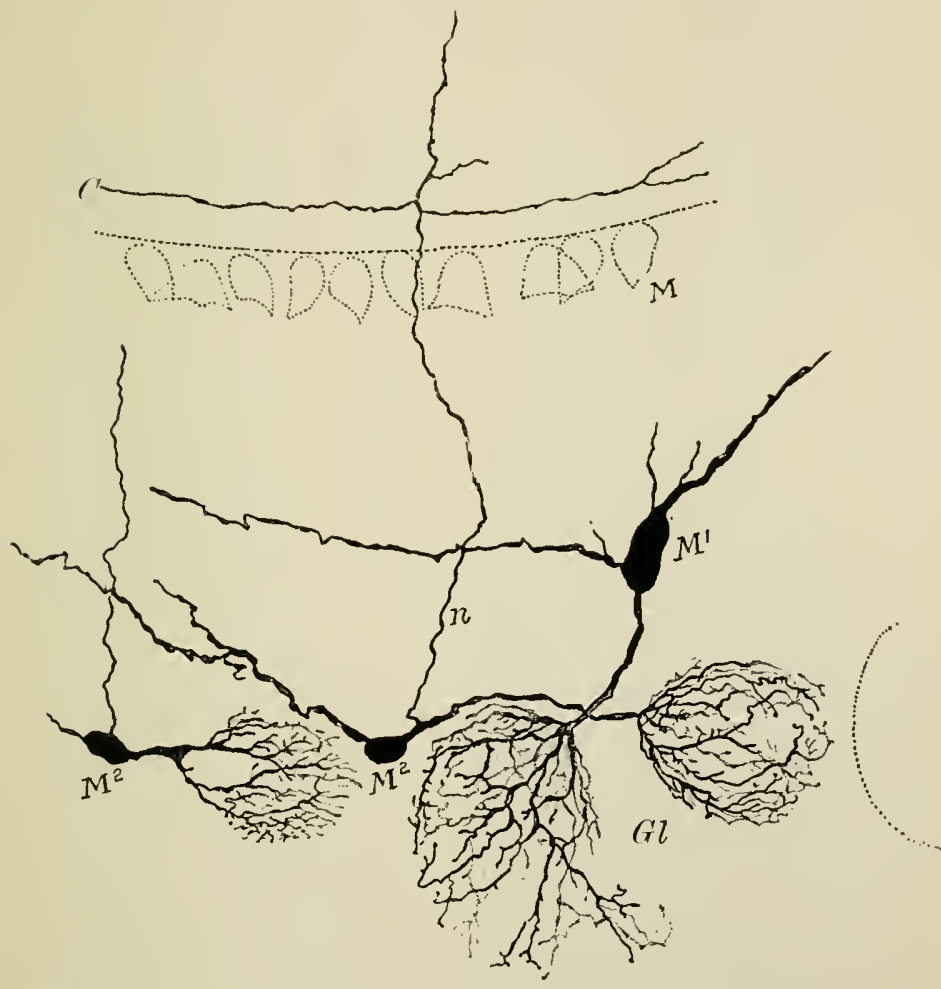

Fig. 158.-From the Olfactory Bulb of a Mouse 24 days old. (Highly magnified. (łolgi. Kölliker, II.)

$C$, Collaterals ; $G l$, glomeruli ; $M$, mitral cells ; $\boldsymbol{M}^{\prime}$, large brush cell ; $\boldsymbol{M}^{2}$, small ditto;n, neuraxon.

by many irregular fibres, giving it the character of a molecular layer, and containing the so-called mitial nerve cells; (4) a nuclear layer composed of small cells; (5) a layer of longitudinal nerve fibres; (6) the neuroglia forming the central substance. The 
connection of these mitral cells is indicated in Figs. 157 and 15. One or two processes pass horizontally and an axis-cylinder process passes through the nuclear layer towards the layer of longitudinal nerve fibres. One conspicuous process passes towards the glomeruli and, entering one of the masses, forms a dendritic clump. Similarly axons from the olfactory cells in the nose pass to these glomeruli and form dendritic clumps. These glomeruli are definite localities where connections are established between cells of the olfactory bulb and the olfactory mucous membrane. 


\section{CHAPTER XX.}

THE CERERRO SPINAL GANGLIA.

207. Tur ganglia commected with the posterior roots of the spinal nerves, and with some of the roots of the cerebral nerves - Gasserian, otic, genic- $R a$ ul a te, ciliary, Mecliel's ganglion, the ganglia of the branches of the acoustic nerve, the submaxillary ganglion, etc.-possess a capsule of fibrous comnective tissue continuous with the epinemrium of the afferent and efferent nerve trunks (Fig. 159). The interior of the ganglion is subdivided into smaller or larger divisions, containing nerve bundles with their perineurium, or larger and smaller groups of

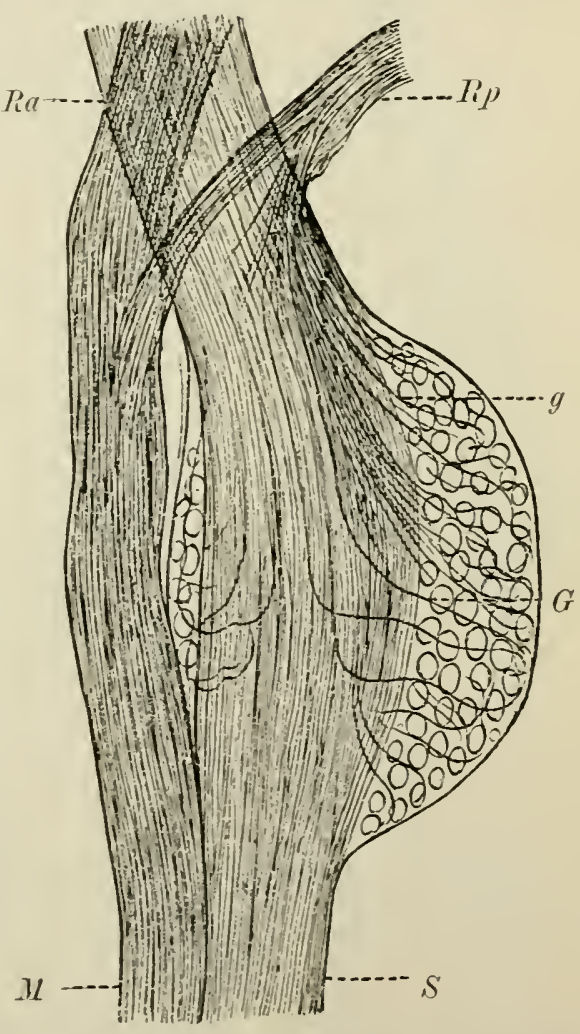
ganglion cells. In Fig. 159.-Spinal Ganglion of the Lumbar the spinal ganglia these latter are

$G$, Ganglion with its cells and their asuns; $R p$, nosterior ; Ra, anterior branch ; $M$, motur ; $s$, sensory root. 
generally disposed about the cortical part, whereas the centre of the ganglia is chiefly occupied by bundles of nerve fibres.

20s. The ganglion cells differ very greatly in size-

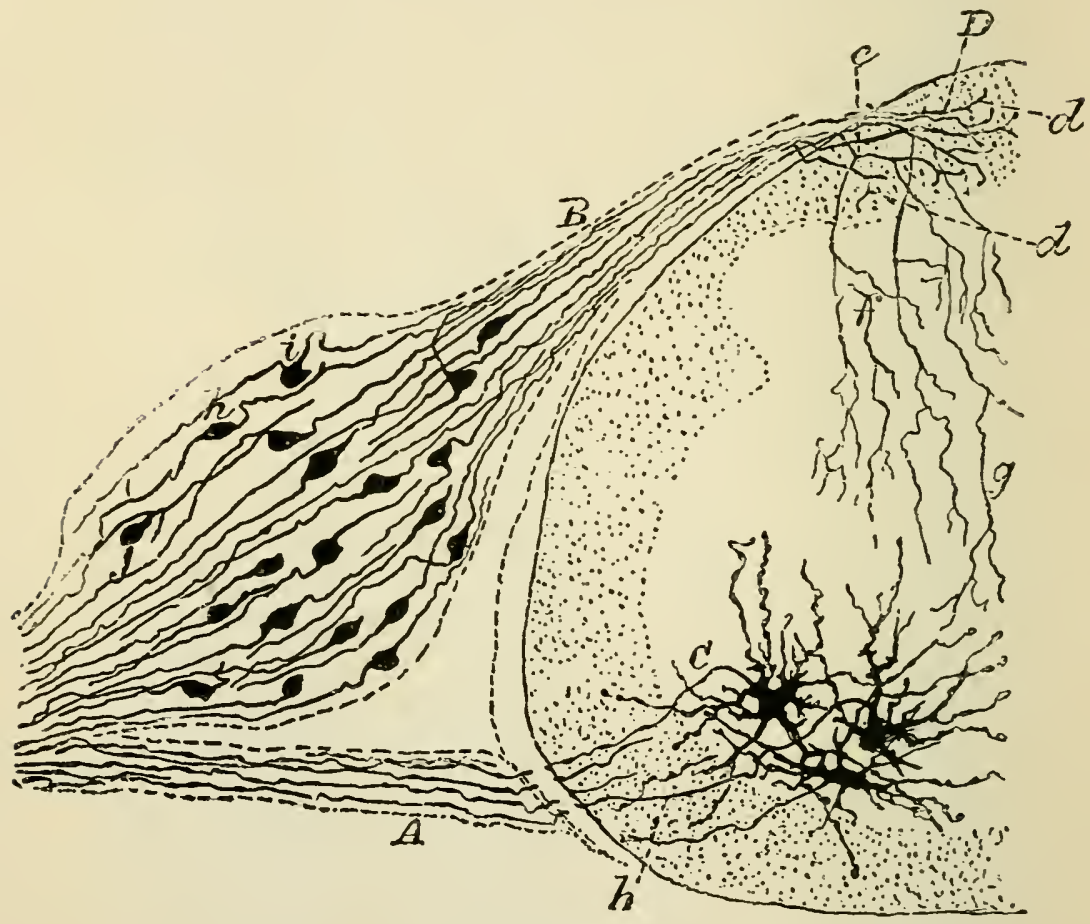

Fis. 160.-Transverse section of the Spinal Cord of a Click of the 9th tay cf incubation. (After Rámón y Cajal, from Quain's "Anatomy.")

A. Axons-anterior ront fibres-issuing from large ganglion cells of anterior horll. $C: B$, wosterior root fibres passing from the blpolar ganglion cells $(h, i)$ of the spinal sanglion into the poserior white column $D$, where they bifurate to hecome longitndiual; $e, f, g$, collatelals foum these fibles $b$, thibres of anterior white column in cross-section.

some being as big, and bigger, thitn a large multipolar ganglion cell of the anterior horn of the cord, other's much smaller (Fig. 162). Each cell has a large oval nucleus, including a network with one or two large nucleoli. 
Tts substance shows a distinct fibrillation. Eiach cell of the spinal ganglia in man and mammals is unipolar (Fig. 162), thask-or pear-shaped, and invested in a hyaline crapsule, lineal with a more or less continuous

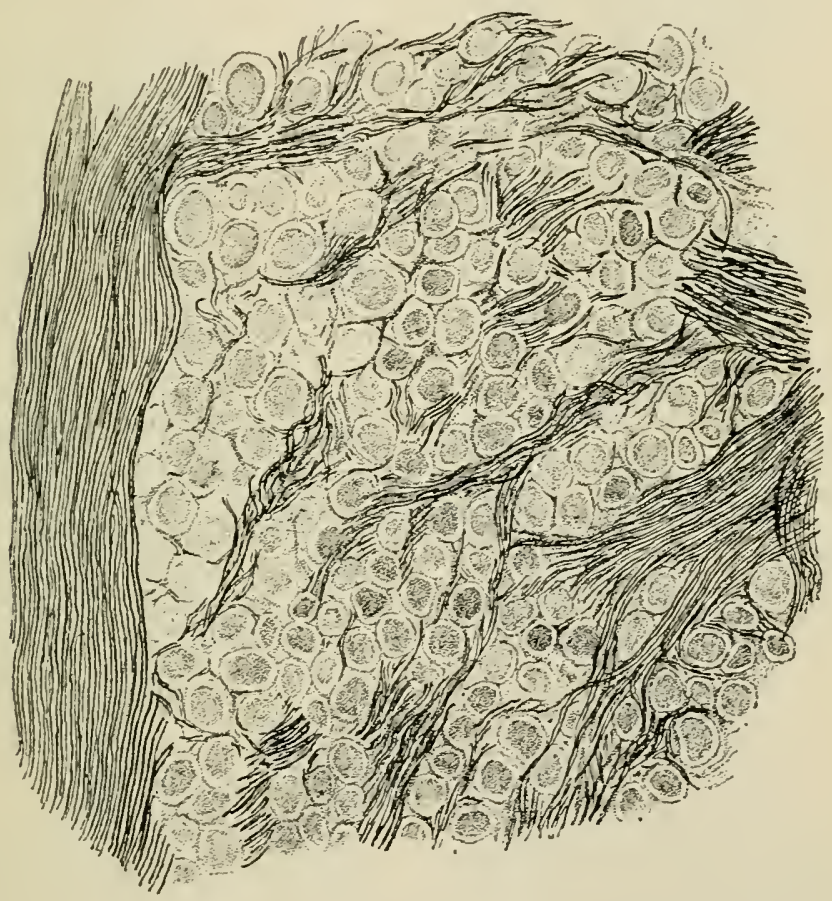

Fig. 161.-From a Longitudinal Section through the Gasserian Ganglion of the Calf. (Köllitier, II.)

layer of nucleated endothelial cell plates. The single process of the ganglion cell is finely and longitudinally striated, and is an axis-cylinder process. Immediately after leaving the cell body it is much convoluted (Retzius); it is then covered with a medullary sheath, and so becomes a medullated nerve fibre. The capsule of the ganglion cell is continued on the axis cylinder process, and, farther on, on the 
medullated nerve fibre, as the neurilemma: the endothelial plates of the capsule pass into the nerve

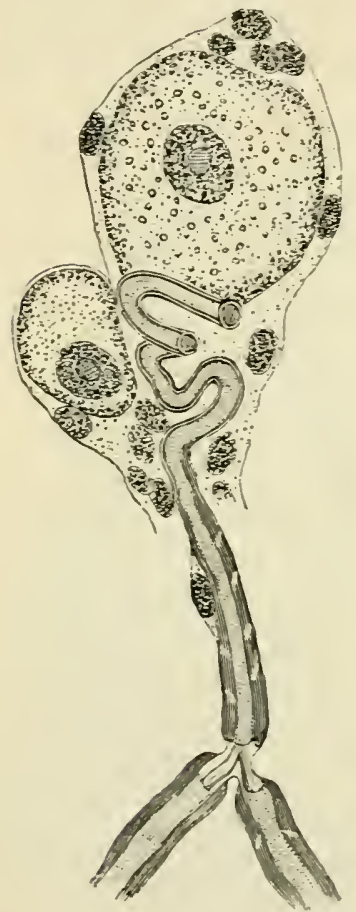

Fig. 162. - Large and small Ganglion Cell of the Ganglion Gasseri of Rablit. (Key and Retzius.)

The aris crlinder, after leaving the cell, becomes rouvoluted and tran-formed into a melullated nerve fihre. which divides into two medullated fibres.

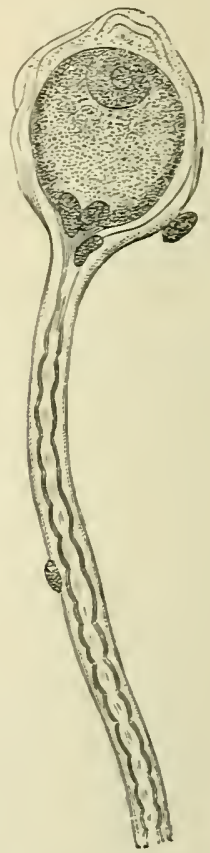

Fig. 163.-Isolated Ganglion Cell of sipinal Ganglion of Toad. (hey and Petzius.)

The axi- cylinder proces: becomes transformed into a medullated nerrefibre. The capsule of the cell 1s prolunged as the neurilemma of the nerve flbre.

corpuscles lining the neurilemma, their number greatly diminishing (Fig. 162).

209. In the rabbit this medullated nerre fibre at its first node of Ranvier, which is not at a great distance from the ganglion cell, divides into two medullated nerve fibres in the shape of $\mathrm{T}$; one branch 
passes to the cord as a posterior root fibre, the other to the periphery (Fig. 163). In man, this T-shaped division has also been observed by Retzius, but, though highly probable, it camnot be said to have been actually proved that in rabbit $\mathrm{Or}^{\circ}$ man every axis-cylinder process shows this $\mathrm{T}$-shaped division. Retzius observed this $\mathrm{T}$-shaped division also in the Gasserian, geniculate, and ragus ganglia in man.

The ganglion cells are not unipolar in all cerebral ganglia; in the ciliary and optic ganglia there are ganglion cells which are multipolar.

210. Numerous ganglia of microscopic size are to be found in the submaxillary (salivary) gland; they are of different sizes, and are in reality ganglionic enlargements of larger or smaller nerre bundles. Each ganglion is invested in connective tissue continuous with the perineurium, and the ganglion cells are unipolar, and of the same nature as those described above, each cell being possessed of an axis-cylinder process, which becomes soon a nerve fibre. At the back of the tongue there are similar small microscopic ganglia. 


\section{CHAPTER XXI.}

THE SYMPATHETIC SYSTEM.

211. Tre sympathetic nerve branches exactly resemble the cerebro-spinal nerves in their connectivetissue investments (epi-, peri-, and endoneurium), and

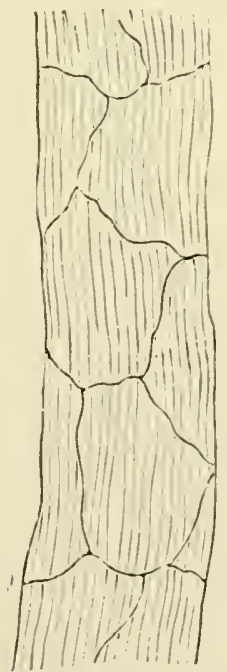

- A

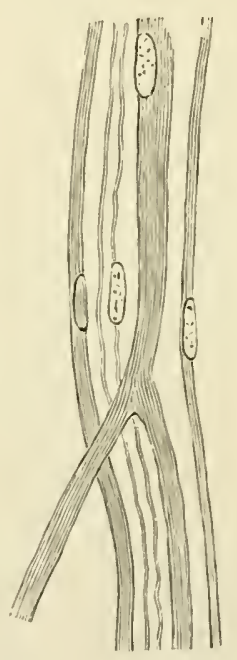

B

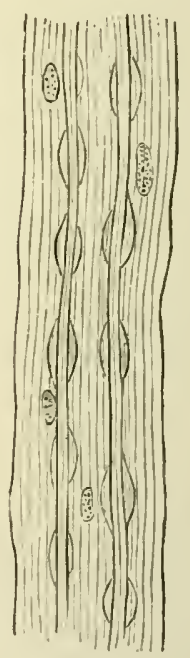

$\mathfrak{c}$

Fig. 164.-Sympathetic Nerves. (Atlos.)

A, Small bumlle inrested in an endothelial sheath, perineurium: B, one medullated and three non-medullated nerve fibres of various sizes; the largest shows division; $c$, two varicose nerve fibres.

in the arrangement of the fibres in bundles (Fig. 16t, A). Most of the nerve fibres in the bundles are monmedullated or Remak's fibres (Fig. 16+A), each being an axis cylinder invested in a neurilemma, with 
oblong nuclei indicative of nerve corpuscles (Fig. $164, \mathrm{~B})$. But there are some melullated nerve filmes to be met with in each bundle, at least, of the larger nerre trunks. These in some cases show the medullary sheath more or less discontinuous, and with a raricose ontline (Fig. $164, \mathrm{c})$, owing to a uniform local accumulation of fluid between it and the axis crlinder. The small or micloscopic bundles of nerve tibres possess an endothelial (perineural) sheath. The small and large branches a 1 ways form plexuses.

212. The ganglia of the sympathetic chain (Fig. 165)-lateral ganglia, as also the further srmpathetic sanglia -the collateral ganglia like the

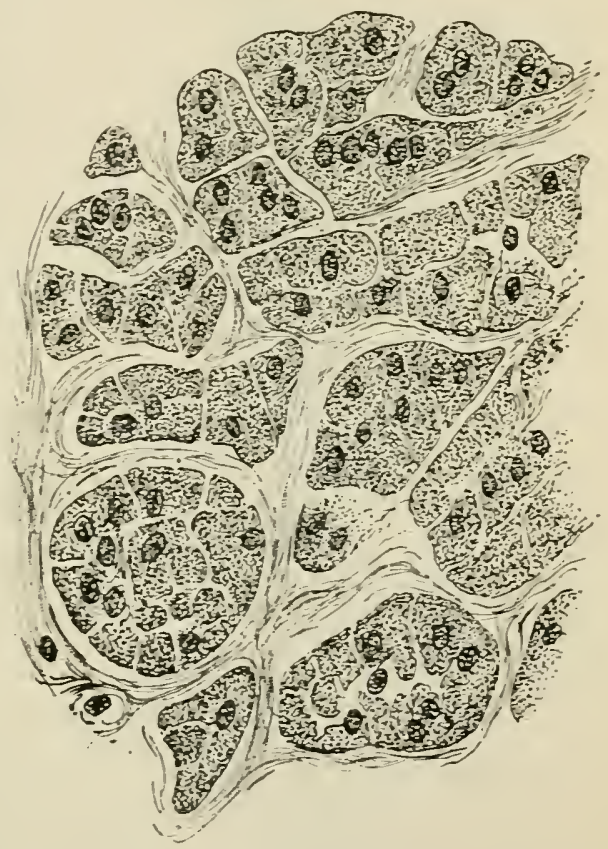

Fig. 164A.-Cross-Section through part of Branch of the splenic Nerre of the Ox, showing bundles of non-medullated or Remak's fibres in cross-section; the nerve fibres being com. posed of fibrillie appear granular in cross. section; the nuclei liere shown belong to the neurilemma of the filres. (Kolliker, II.) semilunar and the cardiac ganglia, and the peripheral ganglia, like those on and in the abdominal viscera, are microscopic in size, but possess in a general way the same structure as the cerebro-spinal ganglia. The ganglion cells are bipolar, or more commonly multipolar. Such are the 
microscopic ganglionic enlargements on many of the sympathetic nerve branches in the thoracic and abdominal organs.

They occur in some organs rery numerously-e.g.

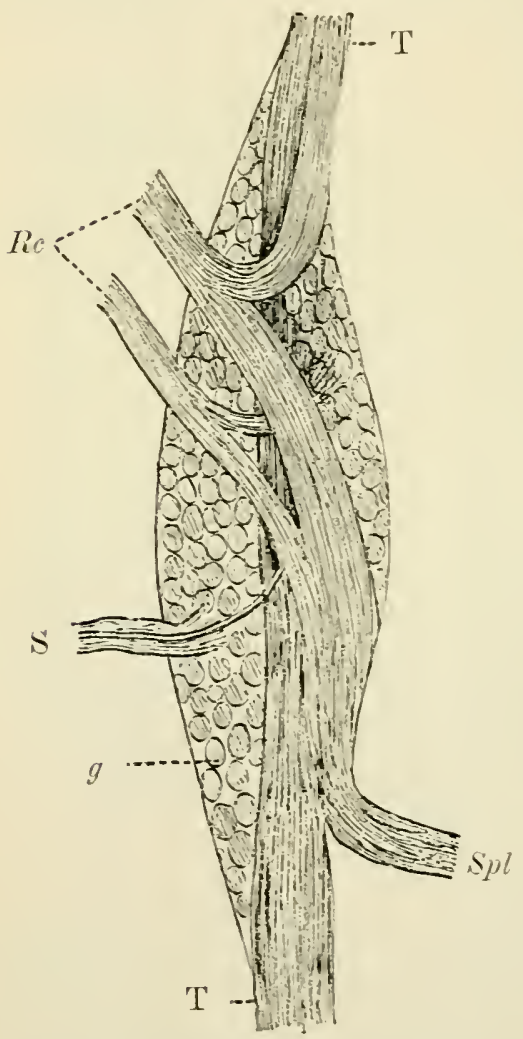

Fig. 165.-Sixth Ganglion Thoracicum of the Left sympathetic of the Rabbit.

Rc, Pami communicantes; $s$, tranch of Eanglion containing two coarser and several finer fibres: $;$, sllanchnicus:; T. smlathetic trunk; g, ganglion cell. (Kolliker, II.)

alimentary canal, urinary bladder (Fig. 166 and Fig. 167), respiratory organs, salivary glands-and are of all sizes, from a few ganglion cells placed between, or laterally to, the nerve fibres of a small bundle, to oval, spherical, or irregularly-shaped masses of ganglion cells placed in the course of a large nerve bundle, or situated at the point of anastomosis of two or more nerve branches (Fig. $167)$.

213. The ganglia in connection with the plexuses of nerve branches of the heart, the ganglia in the plexus of non-medullated nerve fibres existing between the longitudinal and circular coat of the external muscular coat in the alimentary canal, known as the plexus myentericus of Auerbach, the ganglia in the plexus of 
nerve lnanches of the submucous tissue in the alimentary canal, known as Meissner's plexus (Fig. $172)$, the ganglia in the nerrous plexuses in the

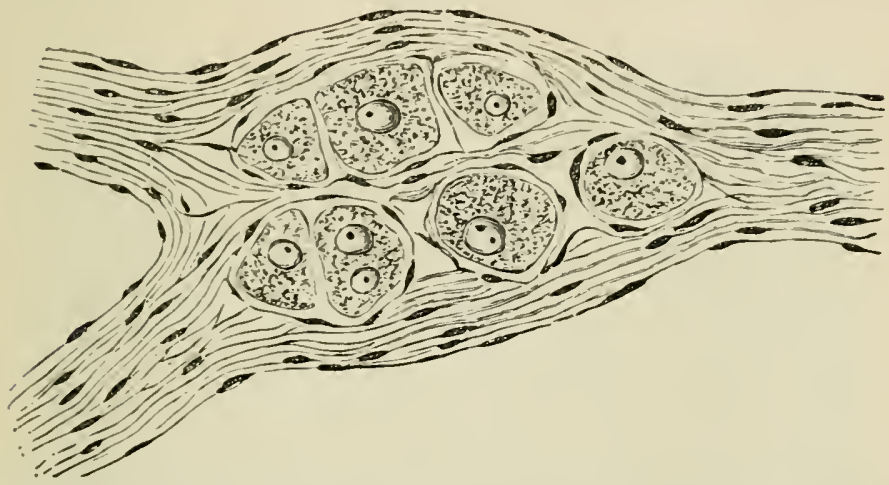

Fig. 166.-Group of Ganglion Cells interposed in a Bundle of Sympathetic Nerve Fibres; from the Blarliler of Rabbit. (Handbook.)

outer wall of the bladder, in the bronchial wall, and in the trachea, and lastly the ganglia in connection

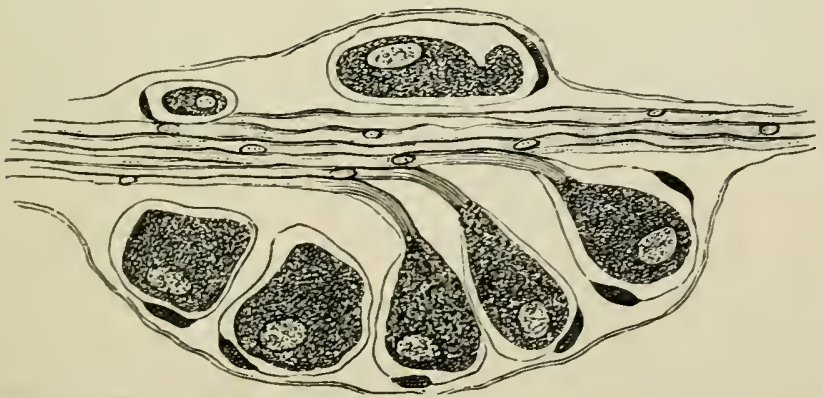

Fig. 167.-Small Collection of Ganglion Cells along a small Bundle of Sympathetic Nerve Fibres in the Bladder of Rabbit. (Atlas.)

Each ganglion cell possesses a capsule. The substance of the ganglion cell is prolonged as the axis cylinder of a nerve fibre.

with the nerves supplying the ciliary muscle of the eye, all belong to the sympathetic system. 
The ganglion cells (Fig. 170) are of very different sizes, each possessing a large oval or spherical nucleus with one or two nucleoli. Their shape is spherical or oval, flask-shaped, club-shaped, or pear-shaped; they

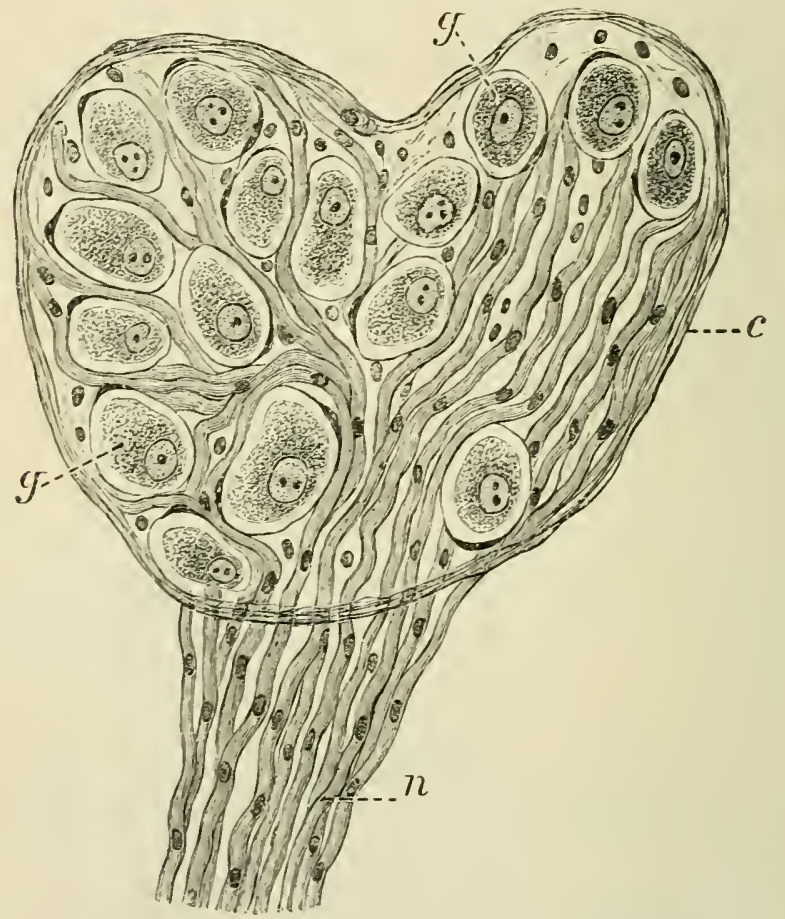

Fig. 16s.-Microscopic Ganglion in the Submaxillary Gland of Dog. (Atlas.) $c$, Connective tissue surrounding the ganglion : $g$, the ganglion cells with their calsule; $n$, nerve tibre.

possess either one, two, or more processes, leing uni-, bi-, or multipolar. The cell is invested in a capsule lined with nucleated cells, both being continuerl on the processes as neurilemma and nerve corpuscles respectively.

214. By the aid of Golgi's method it has been definitely established (Golgi, Rámón y Cajal, Retzius) 
that, like the ganglion cells in the cord, the cells in the ganglia of the sympathetic system possess one axis-cylinder process, axon or neuraxon, which remains unramified (Rámón y Cajal, Van Gehuchten,

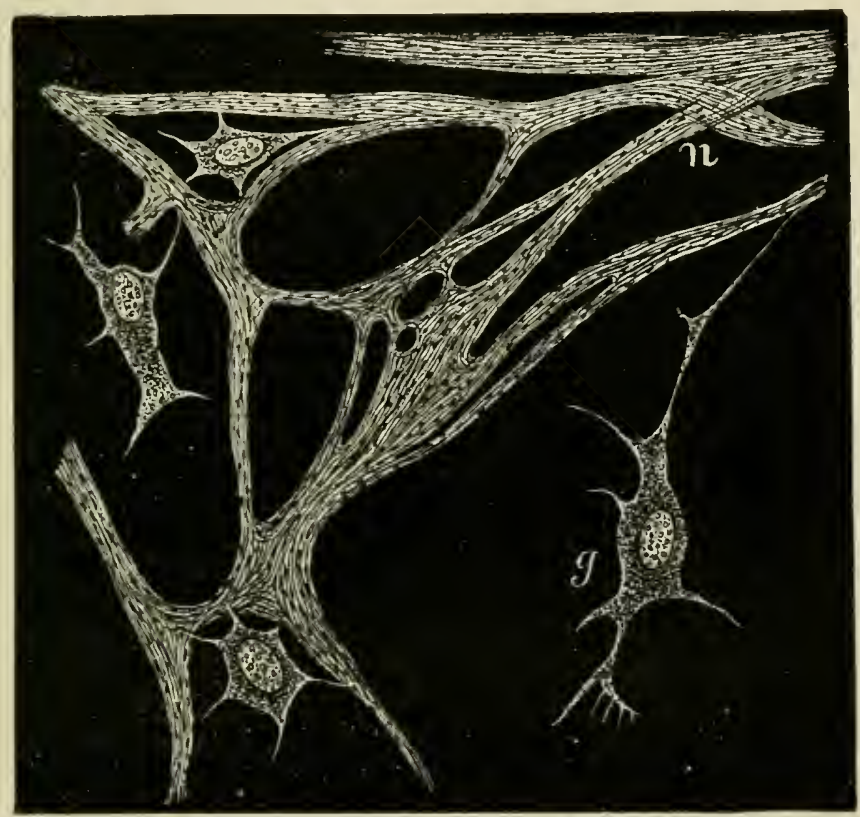

Fig. 16?.-Plexus of Auerbach in Rectum of Toad. (Atlus.) $n$. Verve branches; $g$, ganglion cell.

L. Sala. Von Lenhossek, Kölliker), though sometimes it is possessed of nodose swellings (Fig. 171). It passes into the periphery as a non-medullated fibre (as, for instance, the non-medullated fibres passing from the lateral ganglia of the sympathetic back to the spinal nerves as the grey ramus communicans); or as a medullated fibre (as for instance, the medullated fibres passing from the ciliary ganglion into the ciliary nerves). The 
post-ganglionic fibres of Langley are tibres which originate as the neuraxon of a sympathetic ganglion cell (in the lateral, collateral or peripheral ganglia, as the case may be), and hence pass into muscle (wall of

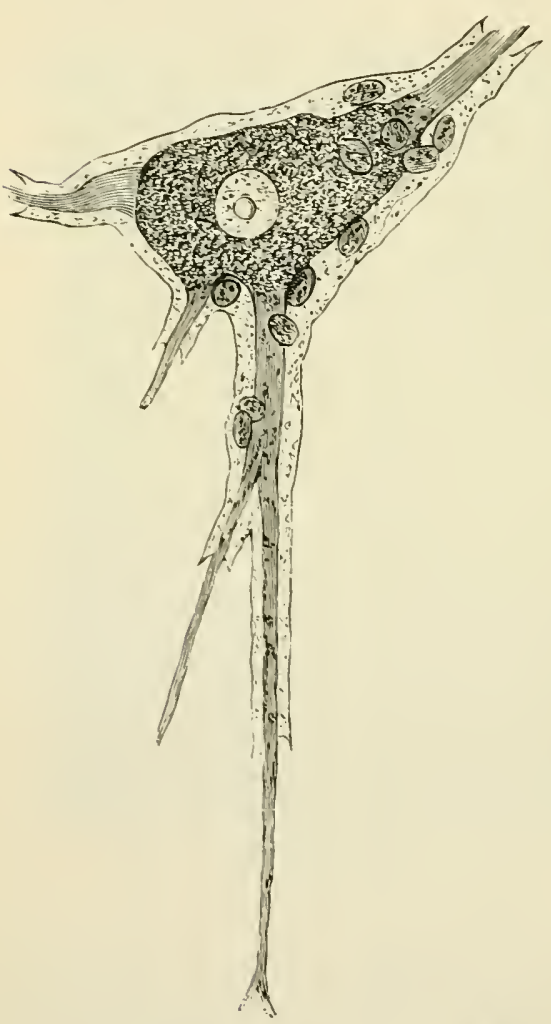

Fig. 170.-Srmpathetic Ganglion Cell of Man. (Key and lict-ius.)

The ganglion cell is multipolar: each process receiving a neurileuma from the capsule of the cell becomes a nom-medullated nerve fibre. intestine, bloodressels, the viscera). The ganglion cells in the microscopic peripheral ganglia are also multipolar, although there occur amongst them bi- and unipolar cells (Rámón y Cajal, Dogiel, Köl. liker).

Besides the neuraxon or axon the sympathetic ganglion cells possess ramifying processes - dendrites, which resolve themselves like those of the cells of the grey matter of the central nervous system into fine fibres, some of them forming more or less distinct arborisittions or dendrons (Fig. 171). An interesting relation exists between the medullated nerve fibres which pass into a sympathetic ganglion from a spinal nerve [motor fibres passing from 
anterior roots, as also sensory fibres from the posterior roots and spinal ganglia], as, for instance, those passing from the motor roots by the white rami com. municantes into the latelal and farther into the collateral ganglia, i.e. the prov-yanylionic fibres of Langley; these fibres termi na te ( $\mathrm{V}$ a n Gehuchten, $\mathrm{L}$. Sala, Dogiel, Yon Lenlıssek) as fine ramifications between and around the ganglion cells, or they form curious, more or less dense, convolutions and plexus surrounding the body of the ganglion cell circumcellula, plexus, as is shown in Fig. 17:3 (Kölliker).

215. By the observations of Beale, Arnold, Axel, Key and Retzius, it

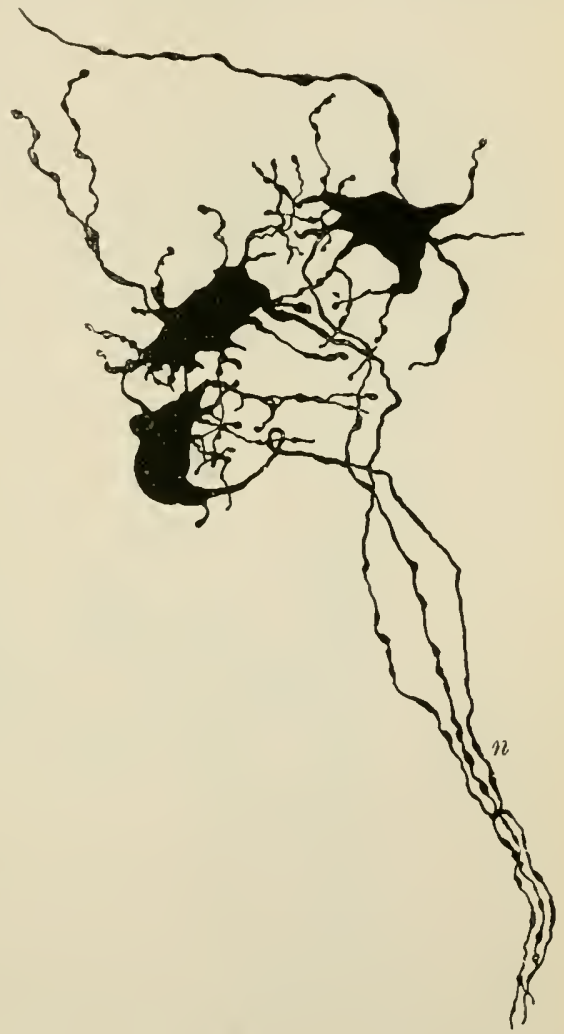

Fig. 171.-Three Multipolar Ganglion Cells with their Axon, n. From the Ganglion Semilunare of Dog one clay old. (Kölliker, II.) was known that in the ganglion cells of the sympathetic nerves of the frog, the ganglion cell substance passes on as a straight neuraxon which continues its course peripherally as a non-medullated nerve fibre surrounded by a nucleated sheath or neurilemma-continued from the capsule of 
the ganglion cell. This straight process is entwined by a thin spiral fibre which, farther away from the body of the ganglion cell, is a medullated fibre; it ramifies on the substance of the ganglion cell (Fig. 17t).

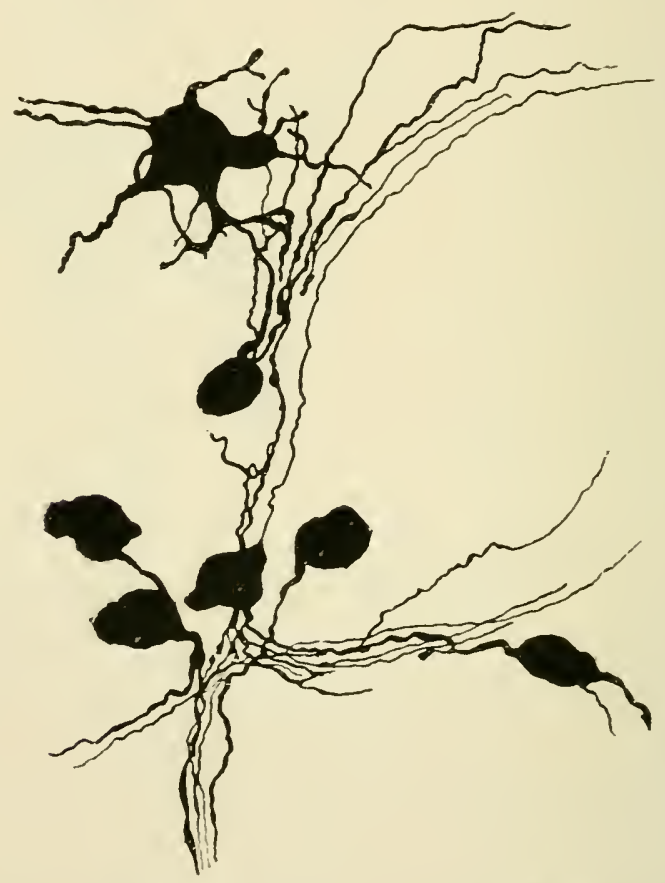

Fig. 172.-Groul of Gangliom Cells from the Plexus of Meissner of a Pulpy ; amongst them a Multipolar anil several Unipolar Cells. (Kulliker, II.)

Arnold, then Ehrlich and further Retzius (the last two by injection of methylene blue into the bloodvessels of the living frog) liave shown this spiral fibre (stained blue) to terminate on and around the substance of the ganglion cell as an arborisation; a condition which occurs in many parts of the central nervous system (anterior grey cornu, cerebellum, sympathetic ganglion cells, previously mentioned, 


\section{SHMP.HTHETIC Siste.M.}

etc.), that is to say, the body of a ganglion cell hecomes surrounded and ensheathed as it were by at dendron of an afferent nerve fibre, the difference being

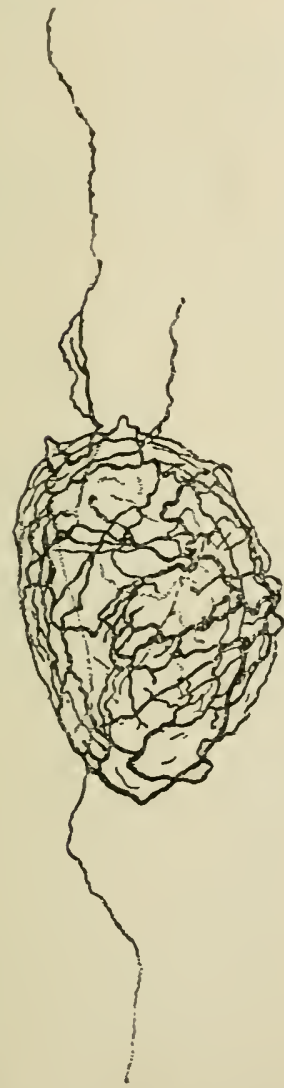

Fig. 173.-Circumcellular Plexus from the Ganglion Cervicale supremum of Calf. (Köllilier, II.)

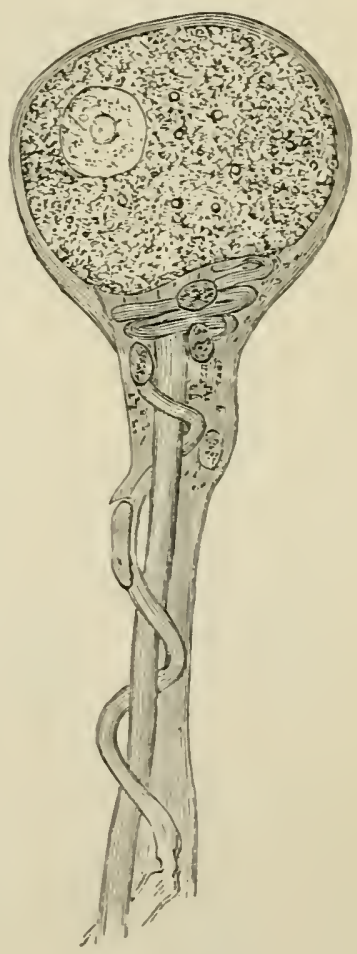

Fig. 174.-Sympathetic Gauglion Cell of Frog, showing the straight process and the spiral tibre; the latter becomes a medullated fibre. (Key and Retzius.)

that in the sympathetic cells of the frog this afferent (medullated) tibre entwines as the spiral fibre the efferent axon (non-medullated) of the ganglion cell. 


\section{CHAPTER XXII.}

GENERAL CONSIDEPATIONS AS TO THE AYATOMICAL CONSTITUTION AND NATURE OF THE FERTOLS SISTEM.

216. WE are now in a position to summarise the general structure and relation of the constituent parts of the nerrous system.

The nerrous srstem consists of nerve cells or ganglion cells and of nerve fibres - the cells forming the centres, the fibres the conducting paths. The ganglion cells form an integral part of the central nerrous srstem-brain, medulla, and cord-as also of the ganglia of the smmpathetic and of the peripheral collections and special nerre end-corpuscles in the various viscera and in the sense organs. The nerre fibres, on the other hand, are all, as far as at present known, axons or neuraxons-that is to say, prolongations of the substance of the ganglion cells; $\mathrm{by}$ these axons near and distant centres, or ganglion cells, are brought in relation to one another, as also by the peripheral terminations of the axons with muscles, skin, mucons membranes, glands, etc. The whole nerrous srstem may be considered as consisting of a collection of units (Rúmón y Cajal), each such unit being called a nenion (Talderer). A neuron, then, is a ganglion cell with all its processes, axon or axons, and dendrites - be they short or long-as well as all the ramifications and terminations of such axons and dendrites. While of many parts of the nerrous 


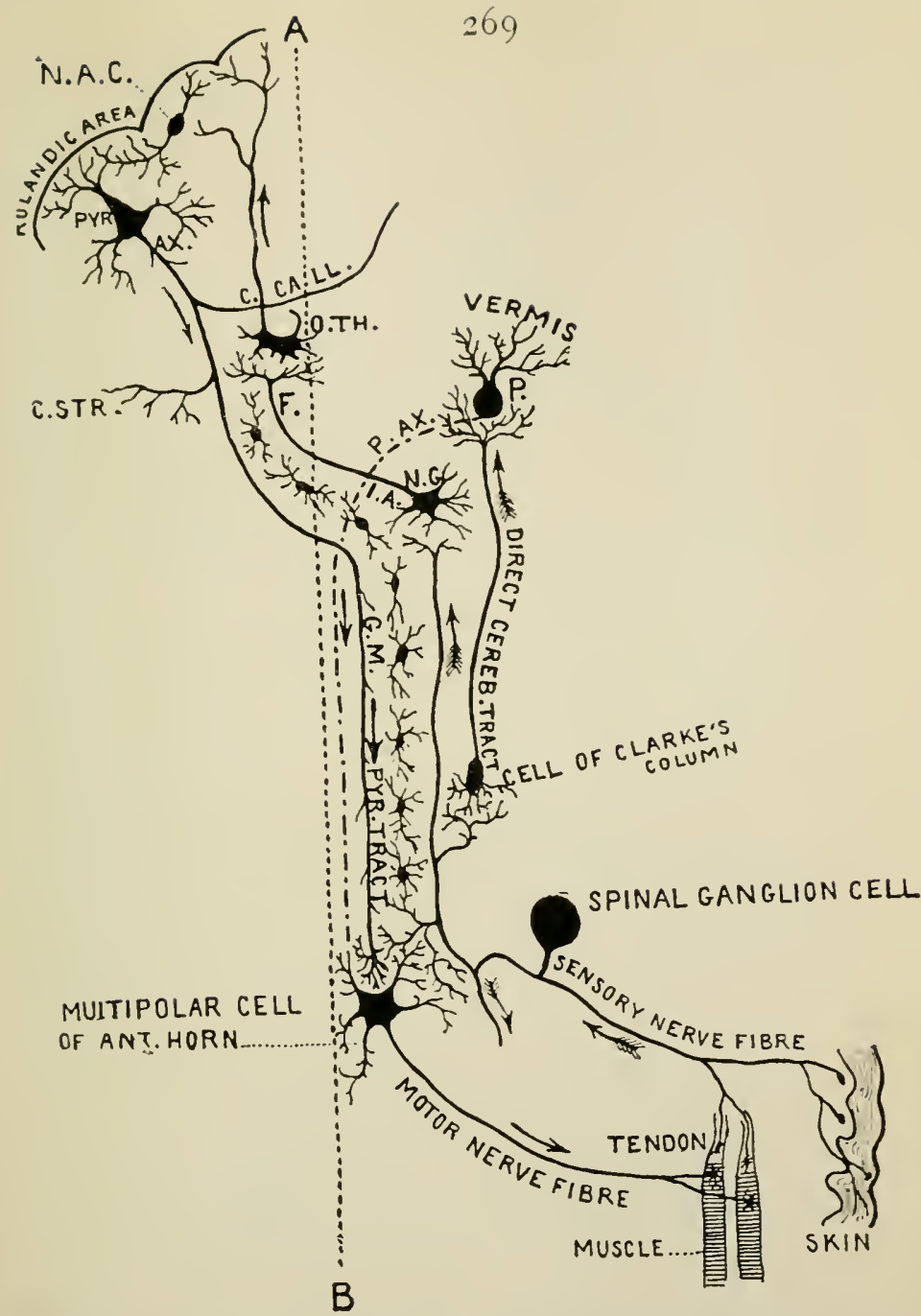

Fig. 175.- Scheme of Relationsluip of Cells and Fibres of Brain and Cord, frepared by Halliburton and Mott. (From Kirke's "Physiology.")

AB, Mitdle line through brain medulla and rord; PYR, lyramidal gauglion cell of the cerebral cortex in the Polandic area: $A x$, axon of this same ganglion cell, a collareral of this axon passes in the corpus callosum (C. CALL.) to terminate in the cortex of the other cerehral hemispliere: c.sTk., is the corpus striatum: s.A.c. ganglinm cell in the cerebral cortex (nerve unit of association of (ajal, around which arborises an axon coming from a gauglion cell of the optic thalamus : $O$. TH., thalamus opticus; F, mesial fillet; $x$. G., nucleus gracilis of the medulli: I.A., axon of a ganglion cell in the nueleus grarilis pissing to the other side as an internal arcuate fibre; $P$, ganglion cell of Purkinje in tbe cortex of cerebellum; P.Ax., its axon; (i.M... succession of cell stations (units) in the grey matter of the cord to the optic thalanti. 


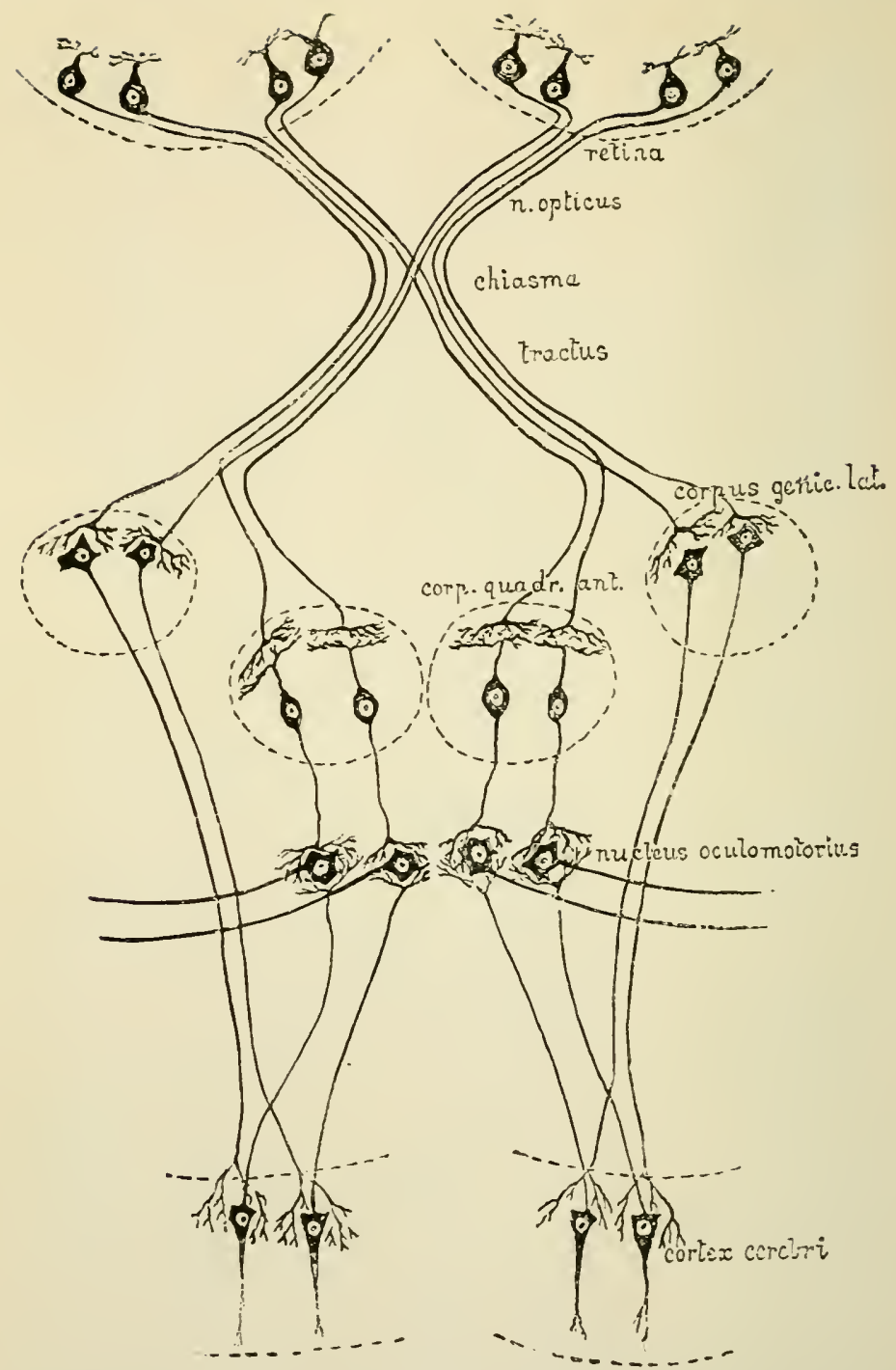

Fig. 176.-Diagram of the probable Connections and Relations of the Optic Nerve Fibres between the Ganglion Cells of the Retina and the Cortex Cerebri. (After Schäfer.)

Between the ganclion cells of the retina and the lateral corpus geniculatum or anterior corpus quadrigeminum respectively is the first nemron ; between the corpus quadrigemimum anterius and the nucleus oculomotorius is a the corpus quadrigeminum anterius and the nucleus octomotorus is a cerebri; between the nucleus oculonutorius and the cortex cerebri on the cerebri; between tue nucleus oculomotols of the nucleus oculomotorius by the nerve fibres constituting the oculomotor nerve terminating in the muscles supllied by this on the other hand is a third neuron. 
system the constituent units or neurons are understood and traced out, there are other parts in which the constituent neurons have not been as yet fully worked out. Of the former it has been established hy the new methods that the older theory as to anatomical continuity between different parts of the nervous system-i.e. the units or neurons-is not correct; but, on the contrary, that the processes (axons as well as dendlites) of one ganglion cell form only contact with those of others, as also with peripheral organs, withont rivect continuity (Fig. 175). 'Thus, for instance, it has been shown that there exists no direct or uninterrupted continuity between a motor (pyramidal) ganglion cell, say of the limb centres in the grey cortex of the brain, and the nerve fibres which terminate as motor end-plates or dendrons in the muscles of the limbs, but that the whole of this path is made up of a succession or chain of neurons or units; and similarly beginning with a dendritic nerve termination in the epithelium of the skin of the limbs up to the arborising termination of nerve fibres in the sensory centres of the grey cortex of the brain, we have no anatomical continuity, but a succession or chain of units or neurons.

In each case, a ganglion cell with its axon, inclusive of its collaterals, and its dendrites, is possessed of arborisations or dendrons which do not form continuity with, but are only in close contiguity to, the arborising axons, or dendrites respectively of another unit or neuron (synapsis). A further point that has been established is this, namely, all nelve fibres, be they medullated or non-medullated, afferent or efferent fibres, be they of a relatively short course -e.g. those beginning and ending within the central nervous system-or do they extend over long distances like those passing out from, or passing into, the cord, medulla, and brain as spinal and cranial 
nerves respectively, are, in reality, axons or direct prolongations of the substance of ganglion cells, which, after a longer or shorter course, terminate as arborisations or dendrons in the periphery or in the central nervous system, as the case may be.

217. We will illustrate, by selecting a few from the many known examples, the nature and extent of such lieurons:

(1) A motor neuron of the grey cortex cerebri consists of the following parts (Fig. 175) : ( $a$ ) the cell body of a pyramidal ganglion cell ; $(b)$ its dendrites, with their arborisations in the grey cortex; (c) the axon given off as the median basilar process and its collaterals becoming medullated nerve firres of the white substance of the cortex, passing further through the internal capsule, the pons, the anterior pyramidal tract of the medulla, the direct or crossed pyramidal tract of the cord, and forming the tinal arborisations or dendrons of them and their collaterals in the anterior cor'nu around the body and dendrites of the ganglion cells in the grey matter of the cord.

(2) A motor neuron of the grey anterior cormu of the cord consists of : ( $($ ) a ganglion cell in the anterior grey cormu of the cord; $(b)$ its dendrites terminating in situ as arborisations or dendrons; (c) the axon passing out as a medullated nerve fibre through the anterior root, and further through a spinal nerve, and terminating finally in the periphery in a striped muscle fibre as a dendron-i.e. the nerve end-plate.

(3) A sensory neuron: ( $a$ ) a ganglion cell of the spinal ganglia ; (b) the afferent nerve tibre-i.e. the distal portion of the $\mathrm{T}$-shaped division of the axon, coming from the periphery-e.g. the skin-by way of a medullated nerve fibre of a spinal nerve; in the skin it terminates or originates either in or around special nerve end-corpuscles or as ramifying fibrilla in the 
epithelium of the surface; (c) the efferent fibrei.e. the proximit branch of the axon of the spinal
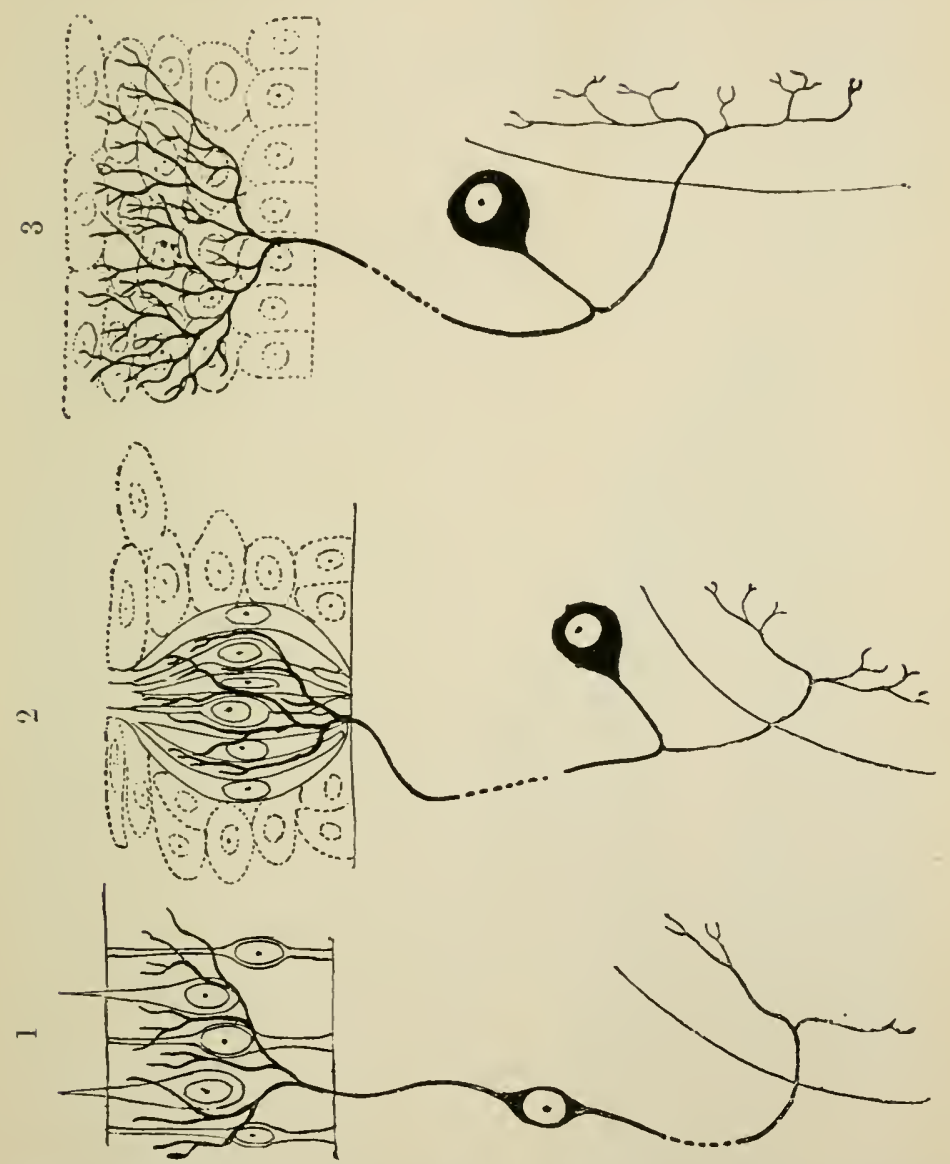

Fig. 17\%.-Diagram showing the Mode of Termination of Sensory Nerve Fibres in 1, the aliditory, 2, the gnstatory, and 3, the tactile sense organs of vertebrata. Each of these rejresents one sensory neuron. (After Retzius, from (uucin.)

ganglion cell passes into the cord as a medullated fibre by way of a posterior root and farther into the 
posterior white column ; it or its collaterals finally enter into the grey matter of the cord or pass on into

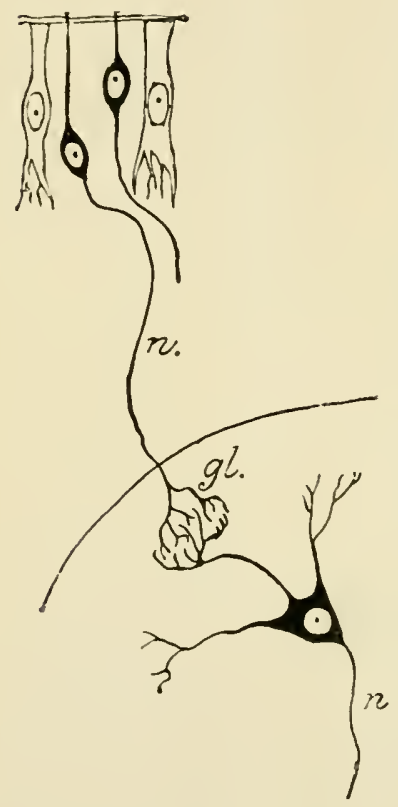

Fig. 175.-Diagram of the $\mathrm{Ar}$ rangement of the Sensory Nerve Fibres in the Olfactory Organ and Bulb. (After lictzius, from Quain.)

$n$, Neuraxon ; $g l$, glomerulus in the olfactory bulb. This represents two consecutive neurons. the nucleus gracilis of the bulb, terminating as denrlrons around or close to a ganglion cell (hody or dendrites) in such grey matter (Fig. 175).

(4) A neuron of a special sense (Figs. 177, 178): (a) the ganglion cell in the ganglion cell layer of the retina; (l) its dendrites terminating as arborisatiuns or dendrons in the imner molecular layer; (c) the axon passing ont in the opposite direction and forming a fibre of the nerve fibre layer and further passing into the optic disc and optic nerve as a medullated fibre, pursuing its course as such through the chiasma and optic tract, and teminating, finally, in an arborisation around cells in the corpus geniculatum or the anterior corpus quadrigeminum (Fig. 176). 


\section{CHAP'TER XXTII.}

THE TEETH.

218. A IIUMax tooth, adult and milk-tooth, consists (Fig. 179) of (a) the encmel covering the crown, (b) the dentine forming the bulk of the whole tooth, and surrounding the pulp cavity both of the crown and fangs, (c) the pulp cavity, and (d) the cement, or crusta petrosa. The cement covers the outside of the dentine of the fang or fangs, the enamel covers the dentine of the crown. The cement is covered on its outside by dense fibrous tissue acting as a periosteum to it, and is fixed by it to the inner surface of the bone forming the wall of the alveolar cavity.

\section{The emamel} (Fig. 180) consists of thin microscopic prismatic elements, the enamel prisms placed closely, and extending in a vertical direction

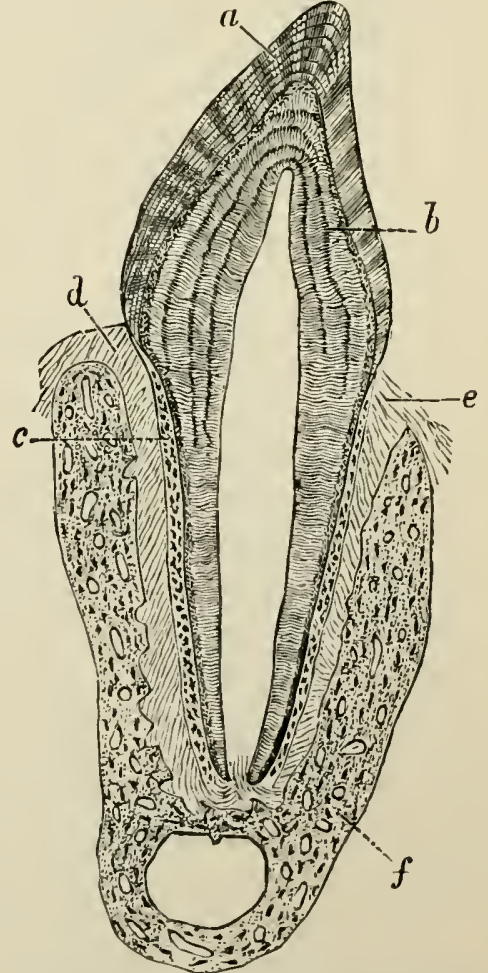

Fig. 179.-Lougitudinal Section through the Præmolar Tooth of Cat. (Waldeyer, in Stricler's Manual.)

$a$, Enamel ; $b$, dentine ; $c$, crusta petrosa ; $d$ and $e$, periosteum; $f$, bone of alveolus. 
from the surface to the dentine. When riewed in transverse section, the enamel prisms appear of a hexagonal outline, and are separated by a very fine interstitial cement substance. The outline of the enamel prisms is not straight, but wary, so that the prisms appear varicose. The prisms are aggregated
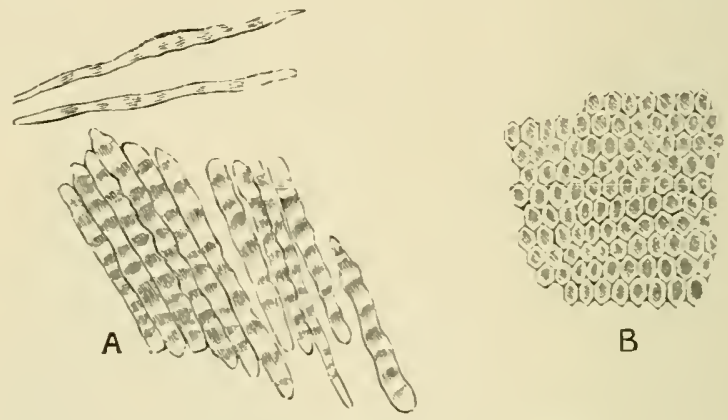

Fig. 1s0.-Enamel Prisms. (Tiöllitict.)

$A$, In longitudinal view; $\mathrm{B}$, sn cross-section.

into bundles, which are not quite paraliel, but more or Jess slightly orerlap one another. On a longitudinal section through a tooth, the appearance of alternate light and dark stripes in the enamel is thus produced. Besides this there are seen in the enamel dark horizontal curved lines, the brown parallel stripes of Retzius, probably due to inequalities in the density of the enamel prisms produced by the successire formation of layers of the enamel. The enamel consists of lime salts-phosphate, carbonate, and fluoride of calcium-with corresponding magnesium salts.

In young teeth the free surface of the enamel is covered with a delicate cuticle (the cuticle of Nasmyth), a single layer of non-nucleated scales. In adult teeth this cuticle is wanting, having been rubbed off? 
2.20. 'The alemtime is the principal part of the hard substances of the tooth. It forms a complete investment of the pulp eavity of the crown and fang, being slightly thicker in the former than in the latter region. The dentine is composed of (Fig. 181): (1) a homogeneous matrix: this is a reticular tissue of fine tibrils impregnated with lime salts, and thus resembling the matrix of bone; (2) long fine canals, the dentinal conals or tubes, passing in a more or less spiral manner, and vertically from the inner to the outer surface of the dentine. These tubes are branched; they open in the pulp cavity with their broadest part, and become smaller as they approach the outer surface of the dentine. Each canal is lined with a delicate sheath-the dentinal sheath. Inside the tube is a fibre, the dentinal fibre, a solid

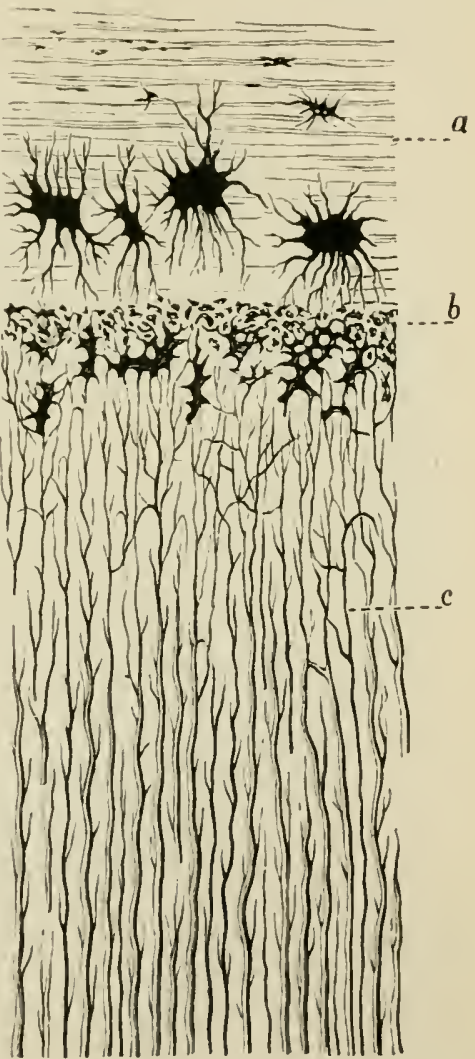

ig. 181.-From a Section through a Canine Tooth of Man. (Waldeyer, in Striclier's Manual.)

u, Crusta petrosa, with large bone corpuscles ; $b$, interglobular suhstance; $c$, dentinal tubules. elastic fibre originating with its thickest part at the pulp sicle of the dentine fiom colls lining the outer-surface of the pulp, and called odontoblasts. 
On the outer surface of the dentine, both in the region of the enamel and crusta petrosa, the dentinal tubes pass into a layer of intercommunicating irregular branched spaces, the interglobular spaces of Czermak.

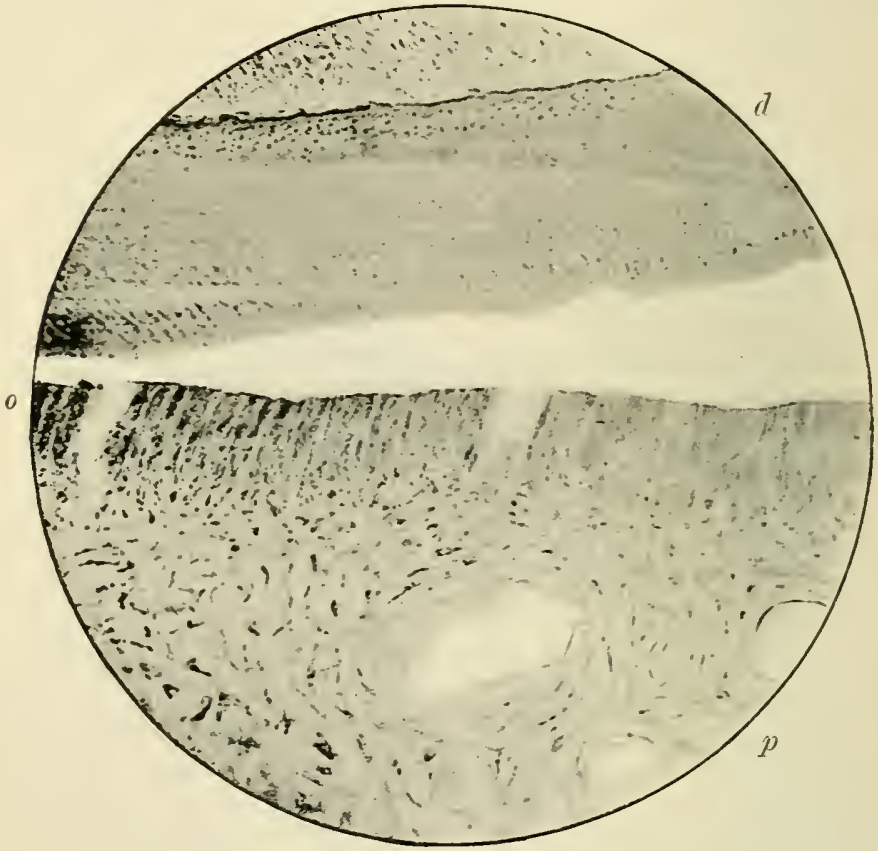

Fig. 152.-From Section through the Pulp and Dentine of Tooth of Guineapig. (Photograph, highly magnified.)

Puip tissue with ressels in cross-section : o, oduntoblasts; $d$, dentine accidentally detached from indontublasts.

or the gramular layer of Purkinje. These communicate with spaces existing between the bundles of enamel prisms of the crown, as well as with the bone laminæ of the crusta petrosa of the fang. The interglobular spaces contain each a branched nucleated cell. The dentinal fibres anastomose with the processes of these cells. The incremental lines of Salter are lines more or less parallel to the surface, and are clue to 
imperfectly calcitied clentine-the interglubular substunce of $C^{\prime}$ ismuak. The lines of bicheger are curved lines parallel to the surface, and are due to the optical effect of simultaneous curvatures of dentinal fibres.

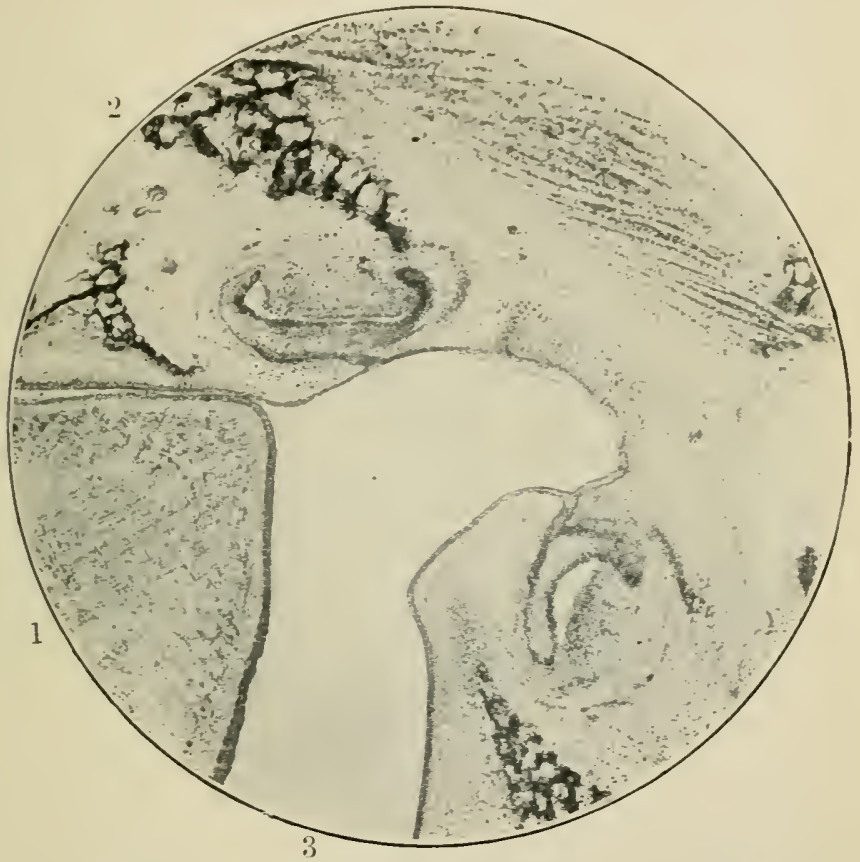

Fig. 183.-Early Derelolment of Tooth. (Photograph by Mr. A. Pringle.) 1, Tungue in cross-section : 2. lwne of jaws: 3, rudiment of ewamel organ and touth lapilla, the former still connected with the -urface epithelimm.

2-21. The cement is osseous substance, leing lamellated bone matrix with bone corpuscles. There are no Haversian canals.

2.2.2. The pulp is richly supplied with bloodressels, forming networks, and extending chiefy in a direction parallel to the long axis of the tooth. Numerous medullated nerve fibres forming plexuses are met with in the pulp tissue; on the outer surface 
of the pulp they become non-medullated fibres, and probably ascend in the dentinal tubes. The matrix of the pulp is formed by a transparent network of richly branched cells, similar to the network of cells forming the matrix of gelatinous comnective tissue.

2.23. On the outer surface of the pulp-i.e. the one in contact with the inner surface of the dentine-is a layer of nucleated cells, which are elongated, more or less columnar. These are the odontoblasts proper (Fig. 182). Between then are wedged in more or less spindle-shaped nucleated cells, the outer or distal process of which passes into a dentinal fibre. The odontoblasts proper are concerned in the production of the dentinal matrix, according to some by a continuous growth of the distal or outer part of the cell and a petrification of this increment, according to others by a secretion by the cell of the dentinal matrix. Waldeyer, Tomes, and others consider the odontoblasts proper concerned in the production both of the dentinal matrix and dentinal fibres. The odontoblasts proper and the spindle-shaped cells are continuous with the branched cells of the pulp matrix.

2. 4. Development of tecth.-The first rudiment of a tooth in the embryo appears as early as the second month. It is a solid cylindrical prolongation of the stratified epithelium of the surface into the depth of the embryonic mucous membrane. Along the border of the jaws the epithelium appears thickened, and the subjacent mucous membrane forms there a depression-the mimitive dental groove. Into this groove the solid cylindrical prolongation of the surface epithelium takes place. This prolongation is the rudiment of the enamel organ. While continuing to grow towards the depth, it soon broadens at its deepest part, and the surrounding vascular mucous membrane condenses at the bottom of the prolongation as the rudiment of the tooth papilla. While the distal part 
of the enamel organ continues to grow towards the depth, it gradually embraces the tooth papilla in the shape of a calp--the encmel. crlp) (Fig 183). During this time the comnection between the surface epithe-

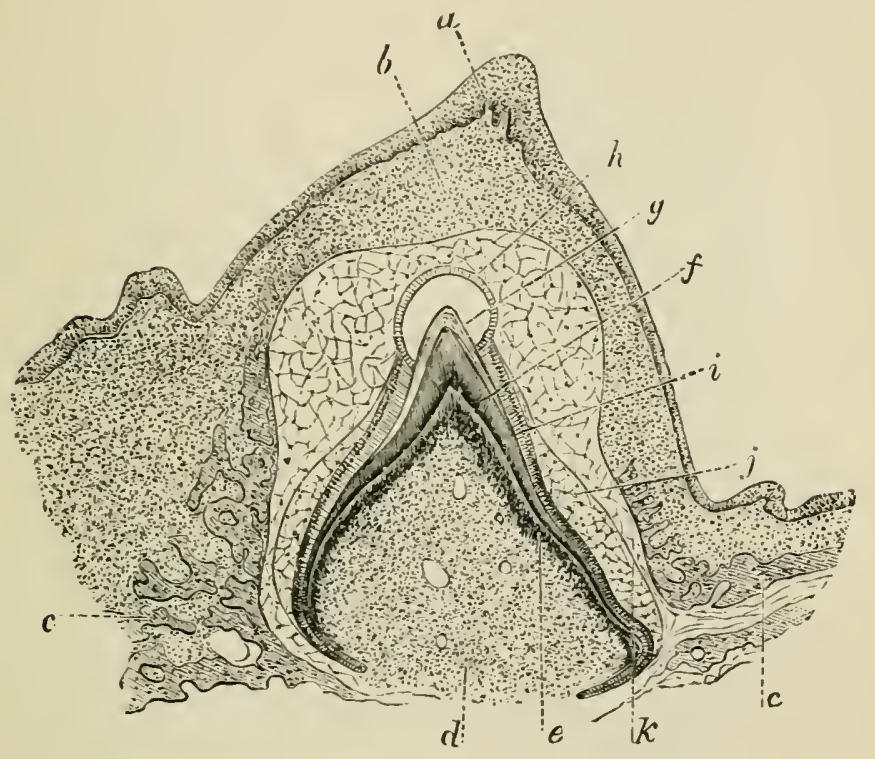

Fig. 1st.-From a section through the Tooth and Lower Jaw of Fœal Kitten.

$a$, Epithelium of the free surface of the gum $\vdots b$, the mucous membrane of same; $c$, spongr bone of ja $w: d$, papila of tooth: $e$, odontoblasts $: f$, dentine; $g$, enamel $; h$, membrane of Namyth : $i$, enamel cells; $j$, iniddle layer of enamel organ; $k$, outer layer of enamel organ.

lium and the enamel cap becomes greatly thimed out and pushed on one side, owing to the growth of the enamel cap and papilla taking place chiefly to one side of the original dental groove.

225. The enamel cap (Fig. 18t) is composed of three strati-an inner, middle, and outer stratum. The inner stratum is a layer of beatiful columnar epithelial cells-the encumel cells; they were originally 
continuous with the deep layer or the columnar cells of the surface epithelium. The middle stratum is the thickest, and is of great transparency, owing to a

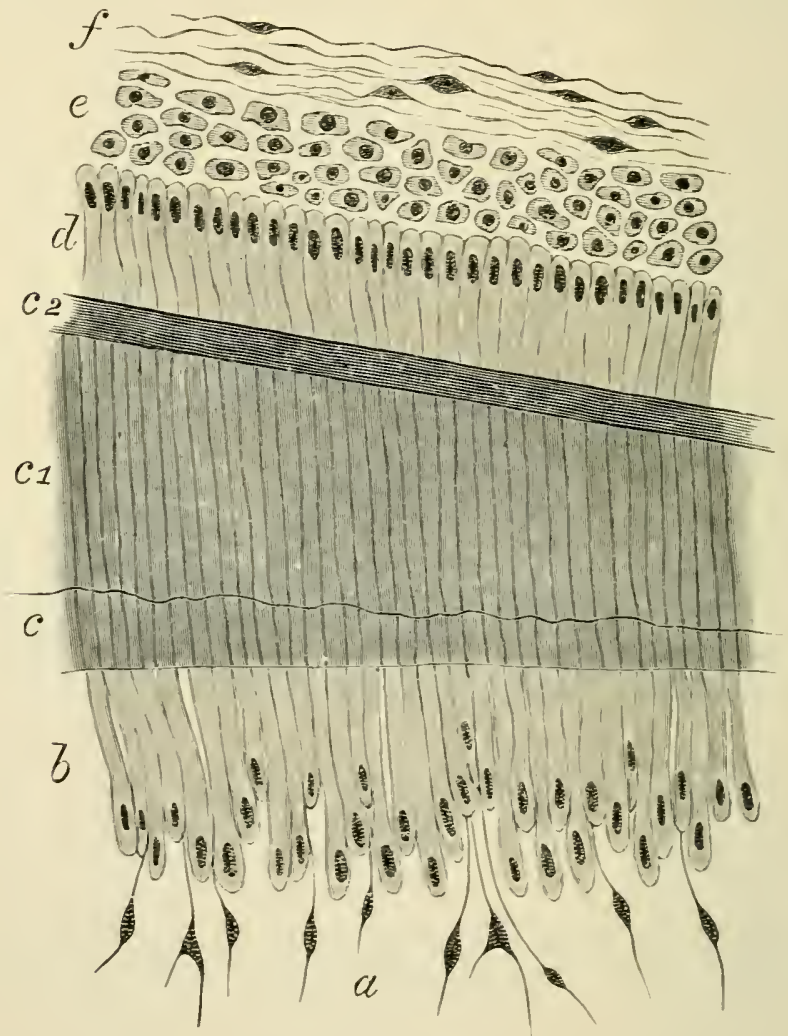

Fig. 185.-From a Vertical section through Fetal Tuoth of Dug. (Atlus.)

$a$. Findle-shaped cells of the tootli foulp: $b$, the layer of obontoblasts: $c$, the miser recenty formed laver of dentine: $c$ l, older dentine: $d$, the laver of enamel cells; $c$, the enamel; $e$, outer cell- of enamel organ $; f$, tissue of the toutb sac.

transformation of the middle layer of the epithelial cells into a spongy gelatinous tissue, due to accunulation of fluid between the epithelial cells of this 
liser, and to a reduction of their substance to thin nucleated plates, apparently branched. The outer' stratum consists of one or more layers of polyhedral cells, continuous on the one hand with the surface epithelium by the bridge of the rudiment of the enamel oruan, and on the other with the enamel cells.

2.26. The foetal tooth papilla is a vaseular enbryonic or gelatinous tissue; on its outer surface a condensation of its cells is soon noticeable into a more or less continuous stratum of elongated or columnar cells, the orlontoblasts.

2.27. Both the dentine and enamel are developed in connection with the odontoblasts and the enamel cells (Fig. 185); the former produce the dentine on their outer surface, while the latter, i.e. the enamel cells, deposit the enamel on their inner surface; thus it happens that the enamel is in close contact with, and on the outside of, the dentine. The dentine and enamel are deposited gradually and in layers. At first they are soft tissues, showing a rertical differentiation corresponding to the individual cells of the enamel cells and odontoblasts respectively. Soon lime silts are deposited in them, at first imperfectly, but afterwards a perfect petrification takes place. The layer of most recently formed enamel and dentine is nore or less clistinctly marked off from the more advanced layer, the most recently formed layer of the enamel being situated next to the enamel cells, that of the dentine next to the odontoblasts (Fig. 186). The amount of enamel and dentine formed is always greatest in the upper part, i.e. that corresponding to the future crown. The milk teeth, while continuing to grow, remain huried in the mucous membrane of the gum, till after birth their proper time arrives, when by active growth and enlargement they break through the gum. During this process 
the enamel of the crown remains covered, i.e. carries with it the inner stratmm of the enamel organ only, i.e. the enamel cells (Fig. $1 s i j, e c$ ); these, at the same time as the surface of the enamel increases,

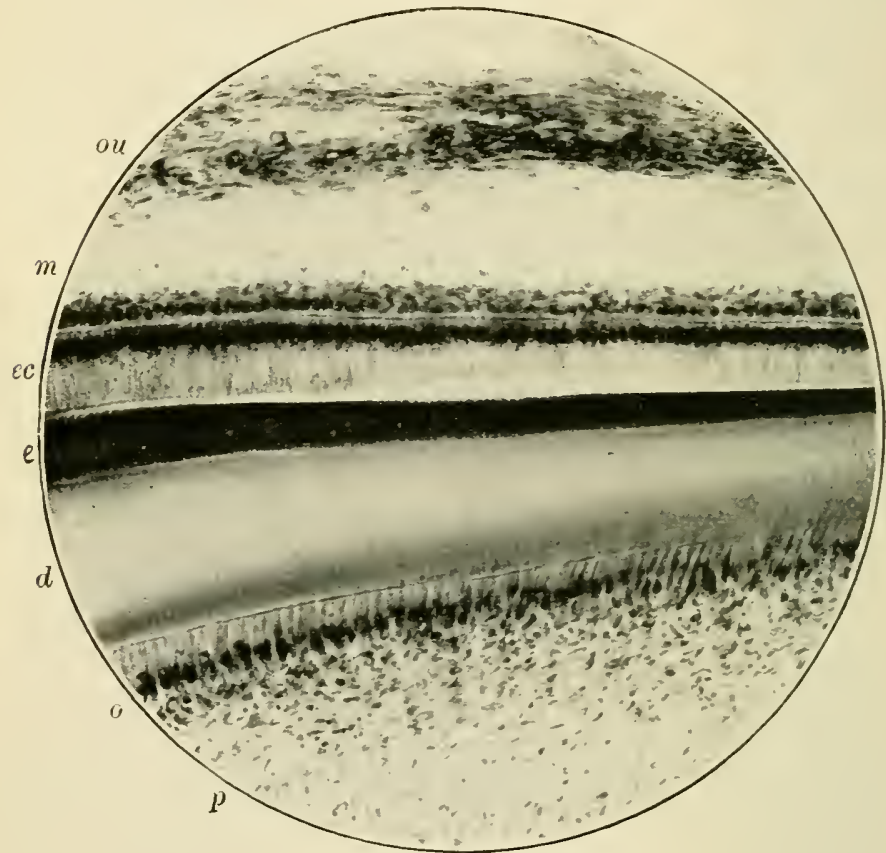

Fig. 1S6.-From a Section through the developing Toctll of Kitten. (Photograph, highly magnified.)

$p$, Puln of the tooth papilla; $o$, laser of odontoblast $;$, dentine ; $f$, enamel : $e c$, enamel cells; m, midule layer of enamel organ; ou, outer liger of enamel organ.

become much flattened, and, finally losing their nuclei, are converted into a laver of transparent scales, the membrane or cuticle of Tasmyth (Fig. 18t, l).

228. Long before the milk tooth breaks through the gum, there appears a solid cylindrical mass of epithelial cells extending into the depth from the original connection between the enamel organ and the 
epithelimm of the surface of the gum mentioned above. This new epithelial outgrow the represents the germ for the enamel organ of the permanent tooth; but it remains stationary in its growth till the time arrives for the milk tooth to be supplanted by a permanent tooth. Then that rudiment undergoes exactly the same changes of growth as the enamel organ of the milk tooth did in the first period of fotal life. A new tooth is thus formed in the depth of the alveolar cavity of a milk tooth, and the growth of the former in size and towards the surface gradually lifts the latter out of its socket.

Nummery has shown that the dentine contains petrified fibres and trabeculie, which are direct continuations of the pulp tissue, and are comparable to the fibres of Sharpey in bone. 


\section{CHAPTER XXIV.}

\section{THE SALIVARY GLANDS.}

229. The salizary glands, according to their structure and secretion, are of the following kinds:(1) True salivary (Fig. 18T), serous, or albuminons

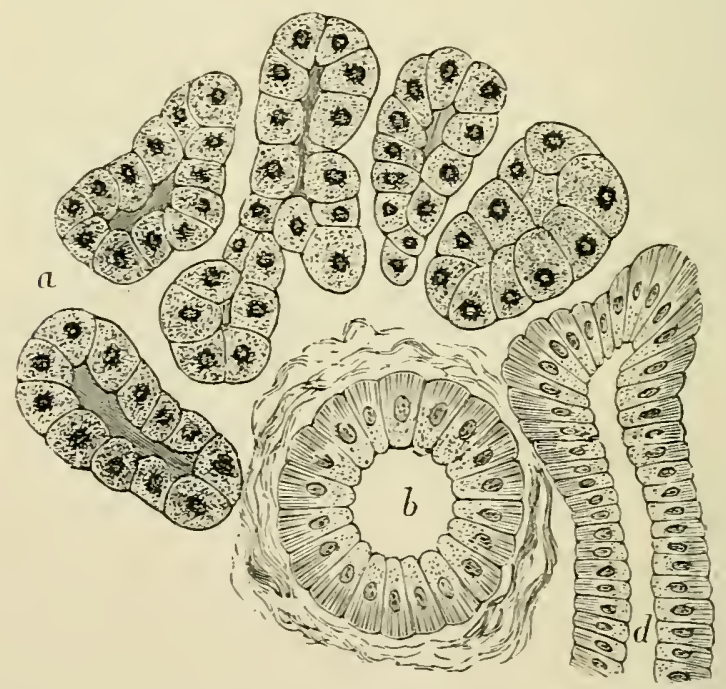

Fig. 187.-From a Section through a Serous or True Salivary Gland; part of the Human submaxillary. (Atlas.)

$a$, The gland alveoli, lined with the albuminous "salivary cells"; $b$, intralobular duct cut transier-ely.

glands, such as the parotid of man and mammals, the submaxillary and orbital of the rabbit, the submaxillary of the guinea-pig. They secrete true, thin, watery saliva. 
230. (2) Mucous ylunds. Of these there are several varieties. In the first place, there is the pure mucous glund (Fig. 1SS), represented by the sublingual grland of the guinea-pig and many of the simple buecal glands of the month. In the next place, the secreting

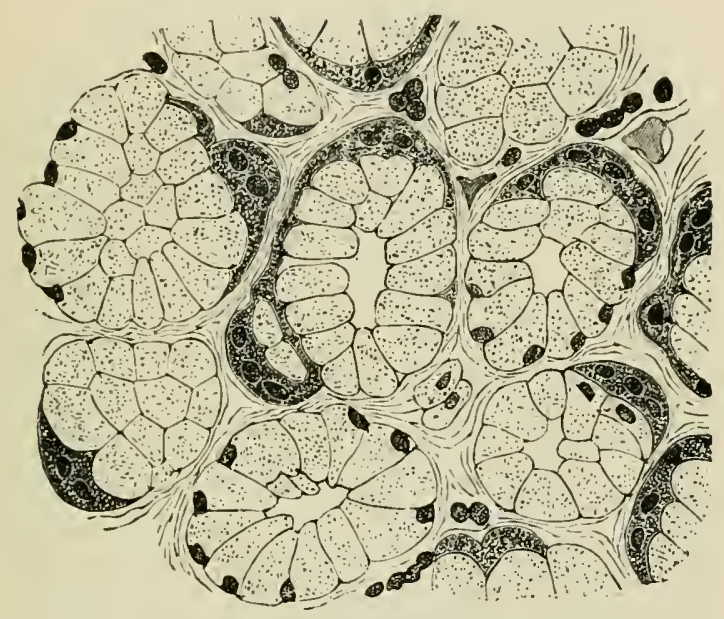

Fig. 188.-From a Section through the Orbital (mucous) Gland of Dog. Quiescent State. (Heidenhain.)

The alveoli are lined with transparent "mucons cells," and outside these are the demilunes of Heidenhain.

alreolus may contain other cells than true mucous cells (mucous ylands with demilunes). There may be comparatively few of this second variety of cell in the alveolus, and such cells may have an entirely peripheral position in the alveolus, and, being thusadapted in shape to the globular character of the alveolus, may become flattened between the basement membrane and more centrally disposed mucous cells, so that in section they have the appearance of half-moon-shaped masses, and are hence called ciemilune cells. The alveolus may contain few of these demilune cells, as in the orbital or submaxillary gland of the dog (Fig. 188), or 
a more or less complete ring of such cells may exist, as in the submaxillary gland of the cat (Fig. 190). Finally, this second variety of cell may be so largely

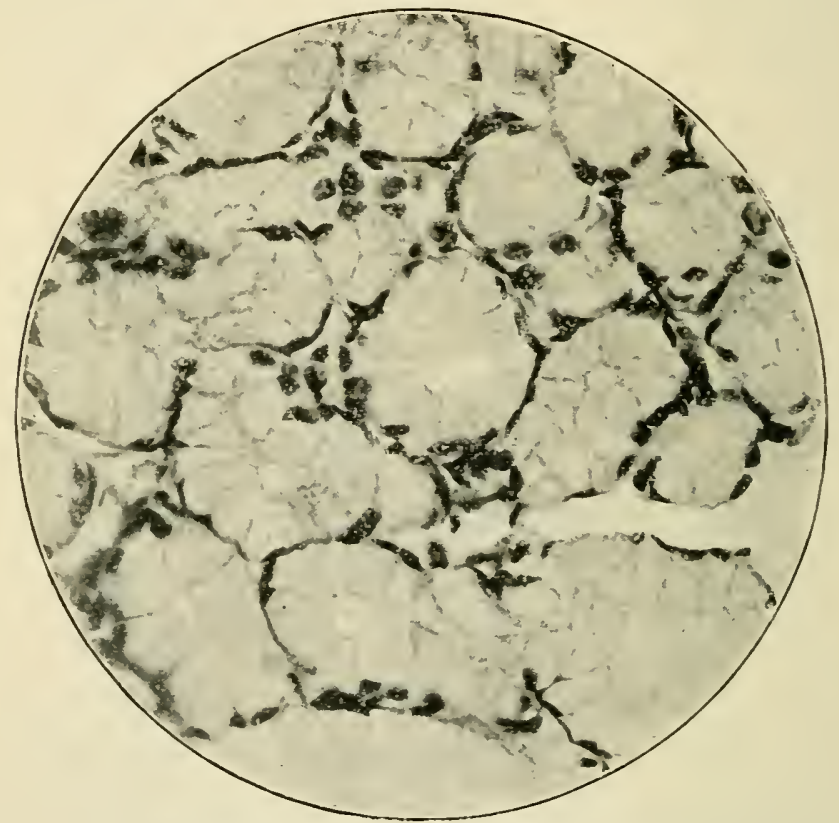

Fig. 159.-Section through a Pure Mucous Gland in the Resting State. The nuclei are seen flattenel at the periphery of the alveoli. The cells are not deeply stainel. There are no (lemilume cells. (Microphotograph.)

represented as to cause the gland to be described as belonging to a separate variety-mixed glands.

231. (3) Hixed salivary, muco-salivary, or seromucous glands. Here some alveoli may be entirely serous, some may belong to one of the varieties of so-called mucous glands. Sometimes the alreoli may contain both serous and mucous cells similarly situated around the lumen, so that we may have actually a mixed salivary alreolus (Fig. 191). It is justitiable to assume that demilune cells really 
represent occisional serous cells present in a mucous alveolus, and these cells occupy a peripheral position.

In arldition to the three salivary glands-parotid, submaxillary, and sublingual-there are in some

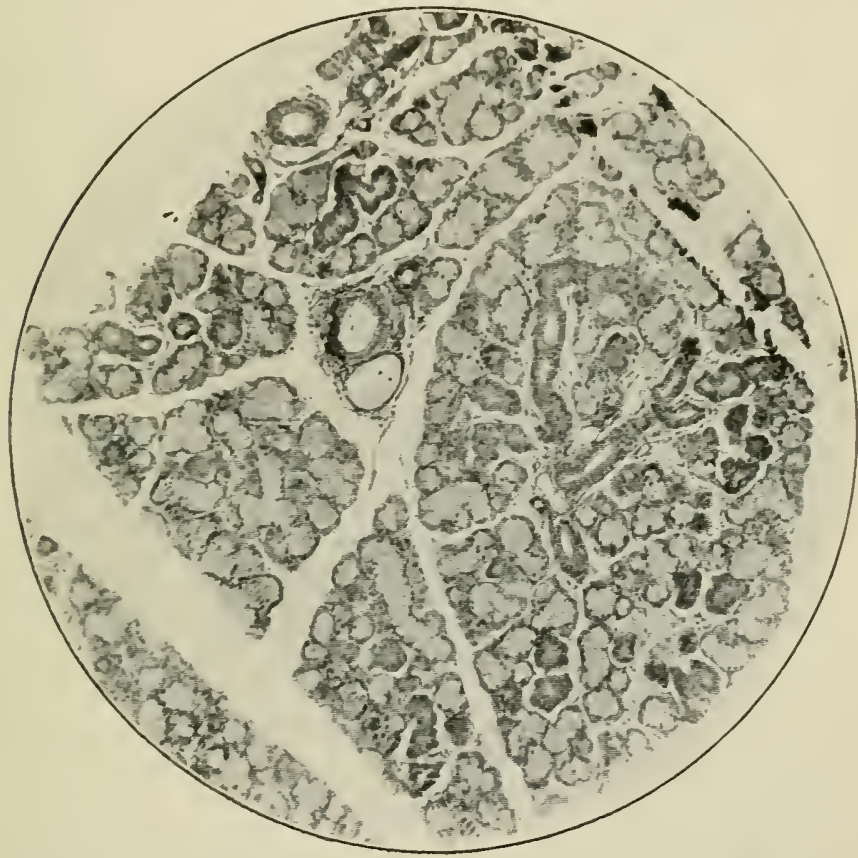

Fig. 190. Section througl the Submaxillary Gland of Cat. The alveoii are in nearly all cases surrounderl by a dark rim, composed of demilune cells. More deeply-stained masses consisting of ducts are also seen. (Microphotograph.)

cases, as in the rabbit and the guinea-pig, two minute additional glands, one intimately joined to the parotid and the other to the submaxillary, and both of the nature of a mucous gland. 'These are the superior and inferior admaxillary glands.

232. The framework.-Each salivary gland is enreloped in a fibrous connective-tissue capsule, in connection with which are fibrous trabecula and 
septa in the interior of the gland, by which the sulystance of the latter is subdivided into lobes, these again into lobules, and these finally into the alreoli or acini. The duct, large ressels and nerres pass

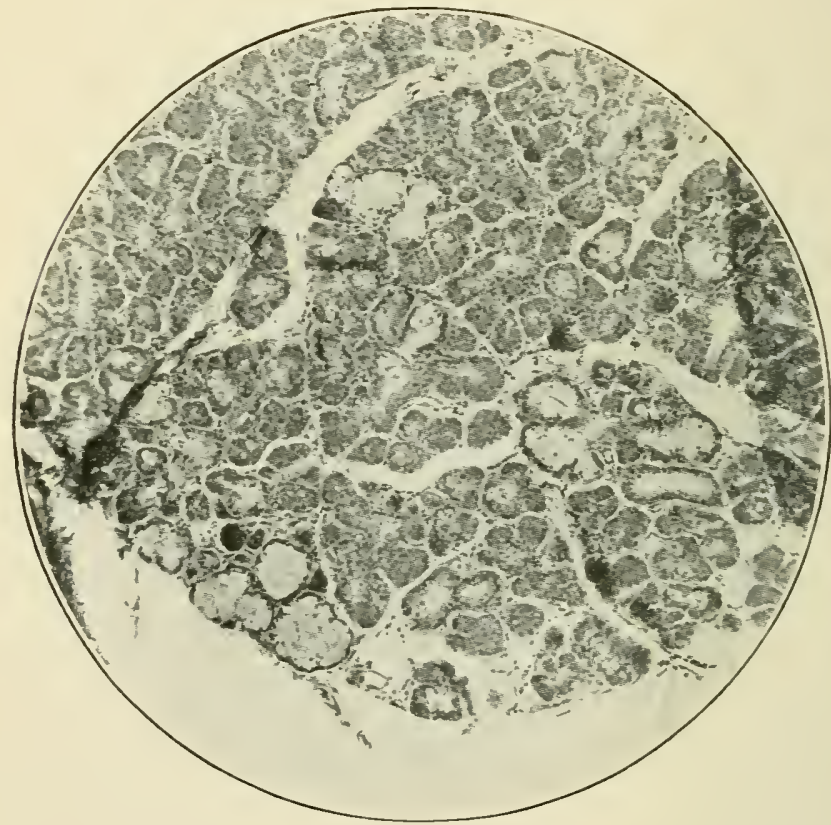

Fig. 101.-Section througln a Human Submaxillary Gland. Nearly all the alveoli consist of albuminous cells. There js also to be seen a fairly large mumber of somewhat larger and less deeply-staijed alveoli which consist largely of mucous cells. (Microphotogreph.)

to and from the gland by the hilum. The connective tissue is of loose texture, contains elastic fibres, and, in some instances more, in other's less, numerous lymplioid cells. In the sublingual gland they are so numerous that they form continuous rows between the alveoli. The connectire-tissue matrix between the alveoli is chietly represented by fine bundles of fibrous tissue and branched connective-tissue corpuscles. 


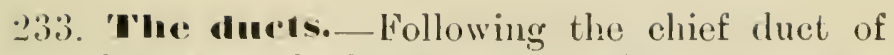
the grand through the hilum into the interior, we see that it divides into several large branches, according to the number of lohes; each of these takes up several branches, one for each lobule. Following it into the lobule, the branch is very minute, and is seen to take up several more minute tubes; all these tubes within the lobule are the intralobular ducts or the sulivary tubes of Pfliger; the bigger duets being the interlobular, and, further, the interlobar ducts. Eilch of the latter consists of a limiting memlnana propria, strengthened, according to the size of the duet, by thicker or thinner trabeculae of comncetive tissue. In the chicf branches there is present in addition nonstriped muscular tissue. 'The interior of the duet is a cavity lined with a layer of columnar epithelial cells. In the largest branches there is, outside this layer and inside the membrana propria, a layer of small polyliedral cells.

234. 'The intualobular ducts, or the salivary tubes of Pflüger, have each a distinct lumen or cavity, which is lined with a single layer of columnir epithelium, and outside this is a limiting membrana propria. Each of the lining epithelial cells lias a spherical nucleus in about the middle; the outer half of the cell substance shows very marked longitudinal striation, due to more or less coarse fibrilla (see Fig. 187). The inner half-i.e. the one bordering the lumen-is granular, or only very faintly striated. The outline of these salivary tubes is never smooth, but irregulari.e. the diameter of the tube varies from pliae to place.

Not in all salivary glands do the epithelial cells of the intralobular ducts show this coarse flbrillation in the outer part of their substance-e.g. it is not present in the sublingual gland of the dog or the guinea-pig.

235. The ends of the branches of the salivary 
tubes are comnected with the secreting parts of the lobule-i.e. the acini or alveoli. These always very conspicuously differ in structure from the salivary tubes.

The last part of the duct which is in immediate comnection with the alreoli is the intermediate part, this being interposed, as it were, between the alreoli and the salivary tube with fibrillated epithelium. The intermediate part is much narrower than the salivary tube, and is lined with a single laver of rery flattened epithelial cells, each with a single oral nucleus; the boundary is formed by the membrana propria, continued from the salivary tube. The lumen of the intermediate part is much smaller than that of the salivary tube, and is generally lined with a fine hyaline membrane, with here and there an oblong nucleus in it.

At the point of transition of the salirary tube into the intermediate part there is generally a sudden diminution in size of the former, and the columnar cells of the salivars tube are replaced by polyhedral cells; this is the neck of the intermediate part. In some salivary glands, especially in the mucous, this neck is the only portion of the intermediate part present-e.g. in the submaxillary and orbital glands of the $\log$ and cat, and in the sublingual of the rabbit. In others, especially in the serous salivary glands, as the parotid of man and mammals, the submaxillary of the rabbit and guinea-pig, and in the mixed salivary-as the submaxillary and sublingual of man-there exists after the neck a long intermediate part, which gives off several shorter or longer branches of the same kind, all ending in alveoli.

236. The aIveoli or aciui are the essential or secreting portion of the gland; they are flask-shaped, club-shaped, shorter or longer cylindrical tubes, more or less wary or, if long, more or less convoluted; many 
of them are branched. Generally sereral open into the same intermediate part of a salivary tuise. The acini are much larger in diameter than the intermediate part, and slightly larger, or about as large as the intralobular ducts. But there is a diflerence in this respect between the acini of a serous and of a mucous salivary gland; in the former the acini are smaller than in the latter.

The menbrana propria of the intermediate duct is continuous with the membrana propria of the acini. This is a reticulated structure, being in reality a basket-shajed network of hyaline branched nucleated cells (Boll). The lumen of the acini is minute in the serous, but is larger in the mucous glands; it is in both glands smaller during secretion than during rest.

237. The epithelial cells lining the acini are called the sulivary cells - they are of different characters in the different salivary glands, and chiefly determine the nature of the gland. 'The cells are separated from one another by a fluid albuminous cement substance. (i.) In the serous or true salivary glands, as parotid of man and mammals, submaxillary of rabbit and gruineapig, the salivary celis form a single layer of shorter or longer columnar or prramidal albuminous cells, composed of a reticulated protoplasm, and containing a spherical nucleus in the outer part of the cell. (ii.) In the mucous glands, such as the sublingual of the guinea-pig, or the admaxillary of the same animal, the cells lining the acini form a single layer of gobletshaped mucous cells, such as have been described above. Each cell consists of an inner principal part, composed of a transparent mucoid substance (contained in a wide-meshed reticulum of the protoplasm), and of an unter small, more opaque part, containing a compressed and flattened nucleus. This part is drawn out in a fine extremity, which, being curved in a direction parallel to the surface of the acinus, is 
imbricated on its neighbours. In the case of the submaxillary and ortbital glands of the $\log$ and the sublingual of the rabbit, there exist, in addition to and outside of the mucous cells lining the acini, but within the membrana

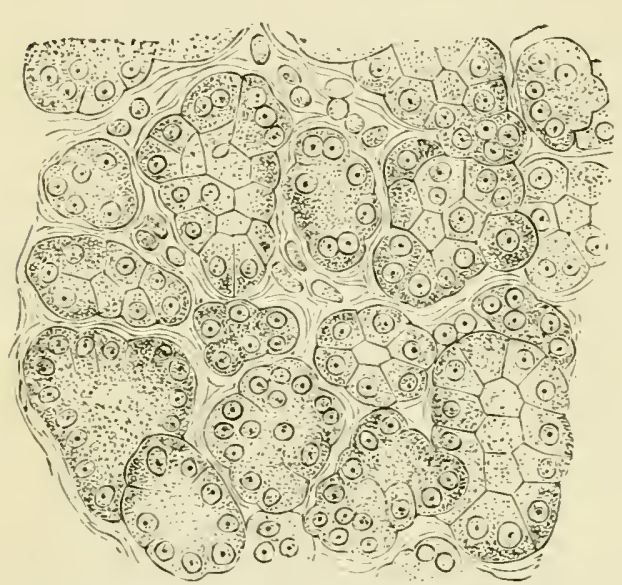

Fig. 192.-From a Section through the Orbital Gland of Dog, after prolonged electrical stimulation. The acini are lined with small granular' cells. (Lurclorslit.) propria, from place to place c $\mathrm{l}^{\circ}$ e s c e n t i c masses, being the demilunes of Heidenhain, or the crescents of Gianuz i (see Fig. 188). Each is composed of several polyhedral gramularlooking cells, each with a spherical nucleus; the cells at the margin of the crescent are, of course, thimner than those forming the middle. Heidenhain and his pupils, Lavdovski and others, have shown that, during prolonged exhausting stimulation of the submaxillary and orbital of the dog, all the lining cylindrical mucous cells become replaced by small polyhedral cells, similar to those constituting the crescents, while at the same time the acini become smaller (Fig. 192). These observers maintain that this change is due to a total destruction of the mucous cells, and a replacement of them by new ones, derived by multiplication from the crescent cells. 'This is improbable, since during ordinary conditions of secretions there is no disappearance of the mucous cells as such; they change in size, becoming larger during 
secretion, and their contents are converted into perfect mucus. It is probable that, on prolonged exhaustive stimulation, the mucous cells collapse into the small cells, seen hy Heidenhiain and his pupils.

238. (iii.) The acini of the sublingual of the $\log$ are again different in structure both from those of the submixillary of the dog and of the sublingual of the grinea-pig, for the acini are there lined either with mucous cells or with colummar albuminous cells, or the two kinds of cells follow one mother in the same alveolus.

'This gland is a sort of intermediate form between the sublingual of man and the submaxillary of man and ape (Fig. 191). These are the mixed or' mucosalivary glands. In these the great number of acini are serous-i.e. small-with small lumen, and lined with albuminous cells, whereas there are al ways present a few acini exactly like those of a mucous glind. The two kinds of acini are in direct continuity with one another. In some conditions there are only very few nuucous acini to be met with within the lobule-so few sometimes that they seem to be altogether absent; in other's they are numerous, but even under most favourable conditions they form only a fraction of the number of the serous acini. In the sublingual of man they are much more frequent, and for this reason this gland possesses a great resemblance to the sublingual of the dog.

What appear to be crescents in the mucous acini of the human gland are an oblique view of albuminous cells lining the acini at the transition between the mucous and serous part of the same gland-tube.

239. The colmmnar salivary cells lining the acini of the submaxillary of the guinea-pig in some conditions show two distinct portions: an outer homogeneous or slightly and longitudinally striated substance, and an inuer, more transparent, granular-looking part, and 
in this respect the cells resemble those of the pancreas. (See pp. 330-2.)

240. Langley has shown (Fig. 193) that during the period preparatory to secretion the cells lining the acini of the serous salivary glands become enlarged and filled with coarse granules: during secretion these granules become used up, so that the

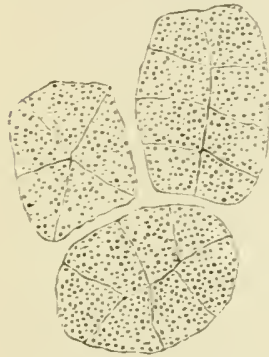

A

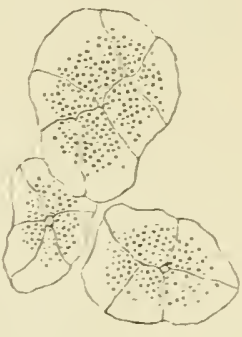

B

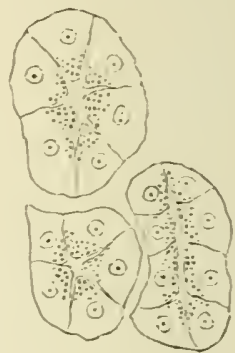

c

Fig. 193.-Acini of Serous Gland. (Langley.)

A, At rest; $B$, fir $=t$-tage of secretion; $c$, prolonged secretion.

cell-substance grows more transparent, beginning from the outer part of the cell and gradually advancing towards the lumen of the acini. These granules may be seen in the fresh gland, but reagents very rapiclly destroy them. Salivary glands hardened by the usual reagents, though not themselres showing the granules, may, however, present appearances corresponding to the removal of the granules from the outer zone of the alveolus. It is found that in such cases the outer zone stains more deeply (Fig. 192), an appearance frequently met with in the pancreas.

When the outer part of the alreolus is devoid of granules, the alveolus is said to be actire or partially exhausted; when the granules reach practically to the outermost part of the cells, the alveolus is said to be resting. Under normal conditions 
secretion in the saliviry grands never approaches exhaustion, though in the pancreas it is not uncommonly the case.

\section{Blood-vessels amd lymphatics.-The} lobules are richly supplied with blood-vessels. The arteries break up into numerous capillaries, which with their dense networks surround and entwine the acini. Between the interalveolar connective tissue carrying the capiliary blood-vessels and the membrana propria of the acini exist lymph spaces surrounding the greater part of the circumference of the acini and forming an intercommunicating system of spaces. They open into lymplatic vessels accompanying the intralobular ducts, or at the margin of the lobule directly empty themselves into the interlobular lymphatics. The connective tissue between the lobes contains rich plexuses of lymphatics.

242. The nerve-branches form plexuses in the interlobular tissue. In connection with them are larger or smaller ganglia (Fig. 168). They are very numerously met with in the submaxillary, but are absent in the parotid. Some ganglia are present in connection with the nerve-branches surrounding the chief duct of the sublingual gland.

Pflüger maintains that the ultimate nerve fibres are connected with the salivary cells of the acini in man and mammals, but this remains to be proved. 


\section{CHAPTER XXV.}

THE MOLTH, PIARYYX AND TONGUE.

243. Whe glands.-Into the cavity of the mouth and pharynx open very numerous minute glands, which, as regards structure and secretion, are either serous or mucous. The latter occur in the depth of the mucous membrane corering the lips, in the buccal mucous nembrane, in that of the hard palate, and especially in that of the soft palate and the uvula, in the depth of the mucous nembrane of the tonsils, at the back of the tongue, and in the mucous membrane of the pharynx. The serous glands are found in the back of the tongue, in close proximity to the parts containing the special organs for the perception of taste - the taste goblets or buds (see below). All the glands are very small, but when isolated they are perceptible to the maided eye as minute whitish specks, as big as a pin's head, or bigger. The largest are in the lips, at the back of the tongue and soft palate, where there is something like a grouping of the al reoli around the small branche's of the duct, so as to form little lobules.

244. The chief duct generally opens with a narrow mouth on the free surface of the oral cavity; it passes in a vertical or oblique direction through the superficial part of the mucous membrane. In the cleeper, looser part (submucous tissue) it branches in two or more small ducts, which take up a number of alveoli. Of course, on the number of minute ducts and alveoli depends the size of the gland. 
In man, all ducts are lined with a single layer of columnar epithelial cells, longer in the larger than in the smaller ducts; in mammals the epithelium is a single layer of polyhedral cells. No fibrillation is noticeable in the epithelial cells. At the transition of the terminal ducts into the acini there is occasionally a slight enlargement, called the infundibulum; here the granularlooking epithelial cells of the duct change into the columnar transparent mucous cells lining the acini.

245. The acini of these glands are identical with those of the mucous glands described above (Fig. 194)-e.g. the sub-

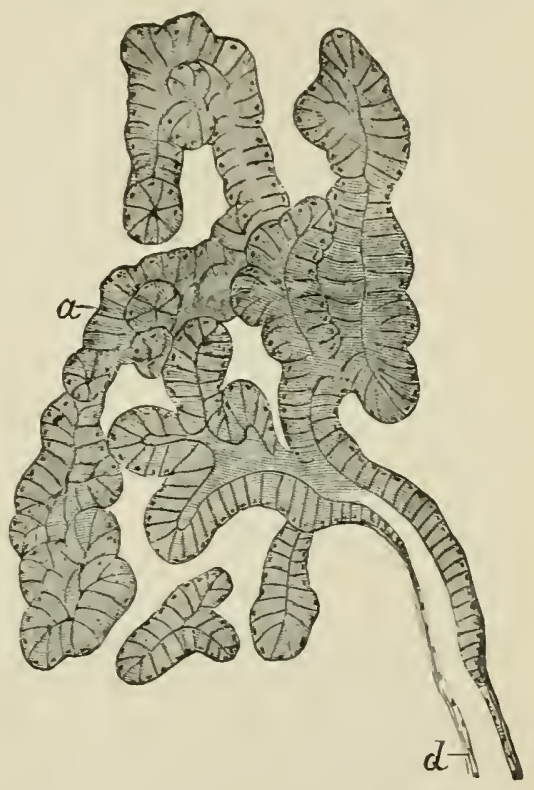

Fig. 194.-Part of a Lobule of a Mucous Gland in the Tongue of Dog. (Atlas.)

a, Gland tubes (alveoli) viewed in various directions: they are lined with transparent "mucous cesls"; $d$, duet lined with small polyhedral cells.

lingual gland as regards size, tubular branched nature, the lining epithelium, and lumen.

In some instances (as in the soft palate and tongne) the duct near the opening is lined with ciliated columnar epithelium. The stratified epithelium of the surface is generally continued a short distance into the mouth of the duct.

246. The serous glands at the root of the tongue (von Ebner) differ from the mucous chiefly in the epithelium, size, and lumen of the acini. These 
are of exactly the same nature and structure as those of the serous or true salivary glands.

247. Saliva obtained from the mouth contains numbers of epithelial scales detached from the surface of the mucous membrane, groups of bacteria and micrococci, and lymph corpuscles. Some of these are in a state of disintegration, while others are swollen up by the water of the saliva. In these there are contained numbers of granules in rapid oscillation, called Brownian molecular novement.

248. The mucous membrame lining the cavity of the mouth consists of a thin membrane covered on its free surface with a thick stratified pavement epithelium, the most superficial cells being scales, more or less changed into horn.

Underneath the epithelium is a somewhat dense feltwork of fibrous comnective tissue, with numerous elastic fibrils in networks. This part is the corium or mucosa, and it projects into the epithelium in the shape of cylindrical or conical papille.

According to the thickness of the epithelium, the papille differ in length. The longest are found where the epithelium is thickest-e.g. in the mucosa of the lips, soft palate, and urula.

Numerous lymph corpuscles are found in the mucosa of the palate and uvula. Sometimes they amount to diffuse adenoid tissue. The deeper part of the mucous membrane is the submucosa. It is looser in its texture, but it also is composed of fibrous connective tissue with elastic fibrils. The glands are here embedded; adipose tissue in the shape of groups of fat cells or continuous lobules of fat cells are here to be met with. The large vascular and nervous trunks pass to and from the submucosi.

249. striped muscular tissue is found in the submucosa. In the lips, soft palate, uvula, and palatine arches it forms a very conspicuous portion : 
namely, the sphincter orbicularis, with its outrmners into the mucous membrane of the lips, the muscles of the palate, uvula (levator and tensor palati), and thes arcus palato-pharyngeus and palato-glossus.

250 . The last branches of the arteries break up in

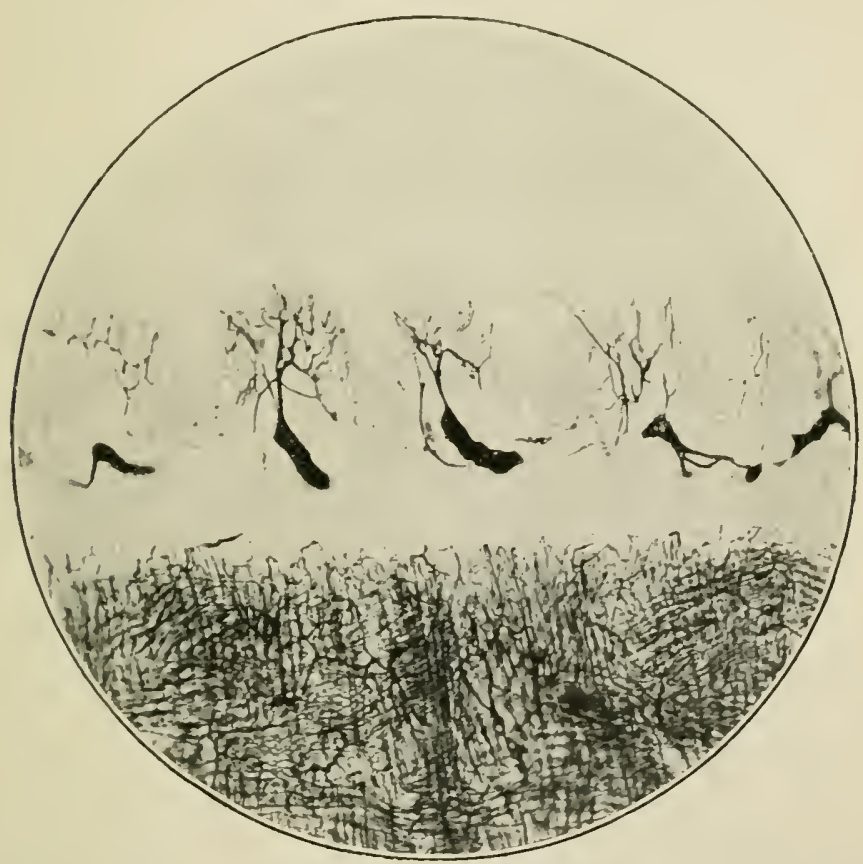

Fig. 195.-Section throngh the Tongue of Cat; the Blnod-ressels injecter. The lower part of the figure shows the injecterl muscular tissue, in the middle part the mucous membrane with large vessels ; the ulper part shows the japillæe filiformes, with their capillary blood-vessels. (Photograph by $M r$. A. Pringle.)

a dense capillary neticork on the surface of the mucosa, and from it loops ascend into the papillæ. Of course, fat tissue glands and muscular tissue receive their own supply. There is a very rich plexus of veins in the superficial part of the mucosa. They are conspicuous by their size and the thinness of their wall. 
The lymplatics form networks in all layers of the mucosa, including the papillae. The large efferent trunks are situated in the submucosa. The last outrunners of the nerve-branches form a pleirs of nonmedullated fitres in the superficial layer of the mucosa, whence numerous primitive fibrille ascend into the epithelium to for'm networks. Meissner's tactile corpuscles have been found in the papillie of the lips and in those of the tongue.

251. In the pharyux the relations remain the same, except in the upper or nasal part, where we find many places covered with columnar ciliated epithelium. As in the palatine tonsils, so also here, the mucosa is infiltrated with diffise adenoid tissue, and with lymph follicles in great numbers. This forms the pharyngeal tonsil of Luschka.

In the palatine tonsil and in the pharyngeal tonsil there are numerous crypts leading from the surface into the depth. This is due to the folding of the infiltrated mucosa. Such crypts are, in the pharynx, sometimes lined all through with ciliated epithelium, although the parts of the free surface around them are covered with stratified parement epithelium.

25. The tomgue is a fold of the mucous membrane. Its bulk is made up of striped muscular tissue (genio-, hyo-, and strlo-glossus; according to direction: longitudinalis superior and inferior, and transversus lingux). The lower surface is corered with a delicate mucous membrane, identical in structure with that lining the rest of the oral carity, whereas the upper part is covered with a membrane, of which the mucosa projects over the free surface as exceedingly numerous fine and short hair-like processes, the papillu tiliformes, or as less numerous, isolated, somewhat longer and broader mushroom-shaped papille fungiformes. The papilla, as well as the pits between them, are covered with stratified parement epithelium. Each has numbers 
of minute secondary papillie. Their substance, like the mucous membrane of the tongue, is made up of tibrous connective tissue. The mucous membrane is on the whole thin, and is firmly and intimately connecter

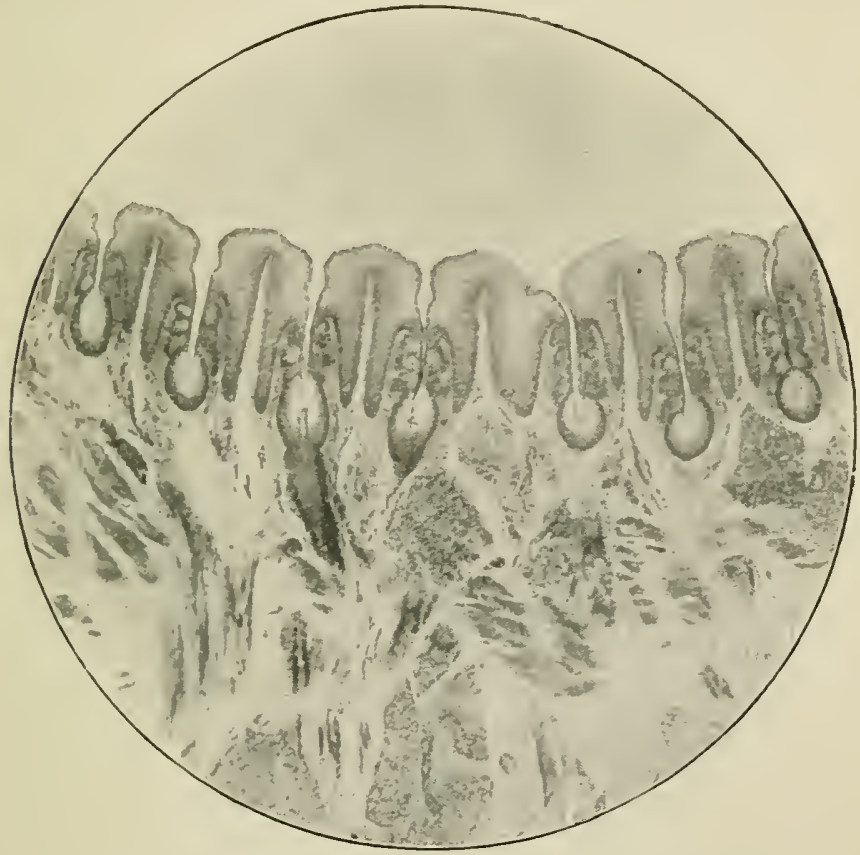

Fig. 190.- Section through the Papilla Foliata of Rabbit, slıwing the Taste Buds amongst the Epithelium. In the depth are bundles of muscular filres and glands. Magnifying power, 40. (Photograph by Mr. A Pringle.)

with the fibrous tissue forming the septa between the muscular bundles of the deeper tissue. It contains large vascular trunks, amongst which the plexus of veins is very conspicuous (Fig. 195). On the surface of the mucosa is a rich network of capillary blood-ressels, extending as complex loops into the papillæ. Lymphatics form rich plexuses in the mucosa and in the deep muscular tissue. Adipose tissue is common 
between the muscular bundles, especially at the back of the tongue.

253. There are two varieties of glands present in the tongue, the mucous and serous. The latter occur only at the back, and in the immediate neighbourhoor

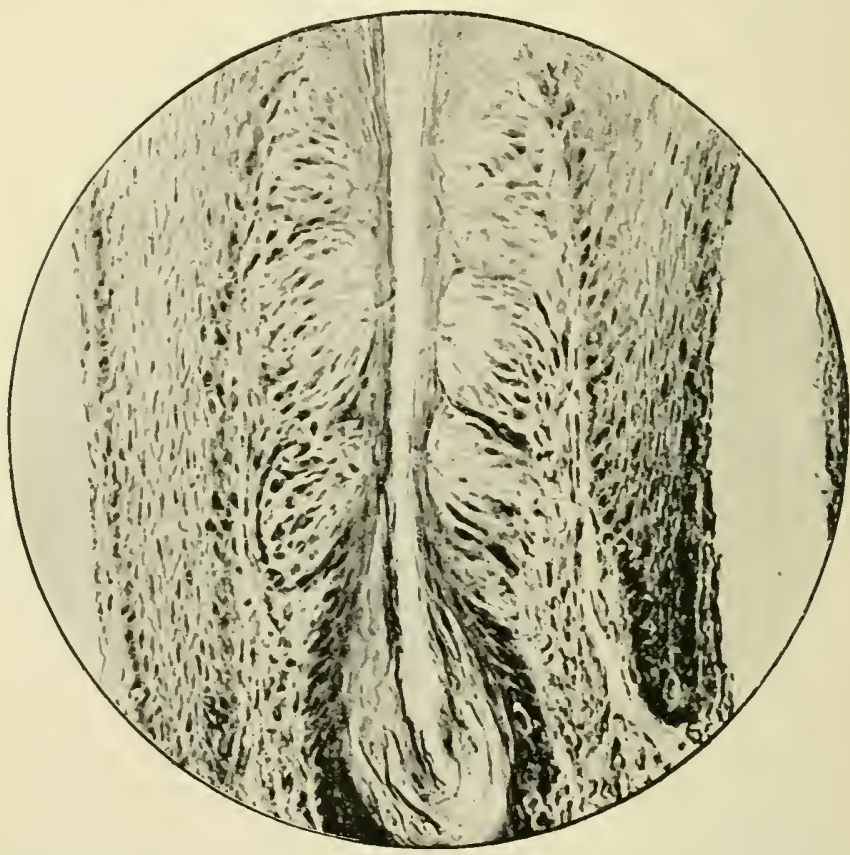

Fig. 197.- Section through Taste Organ (Papilla Foliata.) From same preparation as Fig. 196, more magnified, to show the taste buds. (Photograph by Mr. A. Pringle.)

of the taste organs; the mucous glands are chiefly present at the back; but in the human tongue there are small mucous glands (glands of Nuhn) at the tip. All the glands at the back are embedded between the bundles of striped muscular tissue, and thus the movements of the tongue have the effect of squeezing out the secretion of the glands. About the glands 
numerons nerve bundles are found connected with minute ganglia.

At the root of the tongue the mucous membrane is much thicker, and contains in its mueosa numerous lymph follicles and diffuse adenoid tissue. Thus numerous knob-like or fold-like prominences of the mucosa are produced. There are also minute pits or crypts leading into the depth of these prominences.

254. The papilla circumvallatas are large papillice fungiformes, each surrounded by a fold of the mucosa. They contain taste goblets or buds-i.e. the terminal taste or'gans. At the margin of the tongue, in the region of the circumvallate papille, there are always a few permanent folds, which also contain taste goblets. In some domestic animals these folds assume a definite organisation-e.g. in the rabbit there is an oval or circular organ composed of numbers of parallel and permanent folds, papilla foliata (Fig. 196).

255. The papille fungiformes of the rest of the tongue also contain in some places a taste goblet. But most of the taste goblets are found on the papilla cireumvallatie and foliate. In both kinds of structures the taste goblets are placed in several rows close round the bottom of the pit, separating, in the papilla circumvallate, the papillie fungiformes from the fold of the mucosa surrounding it: in the papilla foliata the pits are represented by grooves separating the individual folds from one another.

256. The taste goblets or taste buds are barrel-or flask-shaped struetnres (Fig. 197) extending in a vertical direction through the epithelium, from the free surface to the mucosa. Each is covered with flattened, elongated epithelial cells, forming its periphery ; these are the tegmental cells. 'The interior of the goblet is made up of a bundle of spindle-shaped or staff-shaped taste cells. Each includes an oval nucleus, and is drawn out into an outer and an inner fine extremity. 
The former extends to the free surface, projecting just through the mouth of the goblet, and resembles a fine hair; the latter is generally branched, and passes towards the mucosa, where it probably becomes comnected with a nerve fibre. The mucosa of these parts contains rich plexuses of nerve fibres.

According to Retzius the medullated nerve fibres

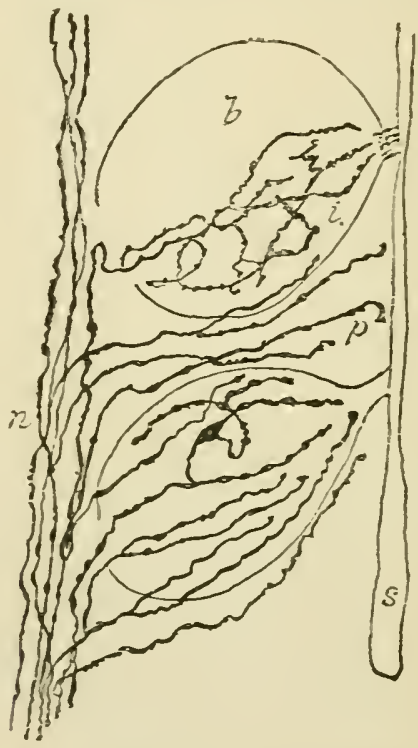

Fig. 10s.-Ending of Nerve Fibres in and around Taste Buds of Rabbit. ( $F$. Petzius, from (quain.)

$n$, Terve fibres; $u$, taste bud; $i$, intrabulbar ramification of nerve fil,rils: $p$, peribulhar ramification of nerve fibrils; $\varepsilon$, sulcus between two adjacent folds of the payilla foliata.

entering from the mucosa lose their medullary sheath and continue their course, either as peribulbar ramifications between the tegmental cells, or as intrabulbar fibres between and amongst the taste cells. Both sets of tibres terminate with free knoblike endings (Fig. 19s).

Into the pits surrounded by taste goblets open the ducts of the serous glands only (ron Ebner). 


\section{CHAPTER NXVT.}

THE (ESOPHAGUS AND STOMACH.

257. I. The asophagus.-Beginning with the (esophagus, and ending with the rectum of the large intestine, the wall of the alimentary canal consists of an inner coat or mucous membrane, an outer or muscular coat, and outside this a thin fibrous coat, which, commencing with the cardia of the stomach, is the serous covering, or the visceral peritoneum.

The epithelium lining the inner or free surface of the mucous membrane of the esophagus is a thick, stratified, parement epithelium.

In Batrachia, not only the oral cavity and pharynx, but also the cesophagus, are lined with ciliated columnar epithelium.

The mucous membrane is a fibrous connectivetissue membrane, the superficial part of which is dense-the mucosa; this projects, in the shape of small papillie, into the epithelium.

The deeper, looser portion of the mucous membrane is the submucosa; in it lie small mucons glands, the ducts of which pass in a rertical or oblique clirection through the mucosa, in order to open on the free surface. In man these glands are comparatively scarce; in carnivorons animals (dog, cat) they form an almost continuous layer (Fig. 199).

25s. Between the mucosa and submucosa are longitudinal bundles of non-striped muscular tissue. At the beginning of the esophagus they are absent, but soon make their appearance-at first as small 
bundles separated from one another by masses of connective tissue; but lower down, about the middle, they form a continnous stratum of longitudinal bundles. This is the muscularis mucosce (Fig. 200).

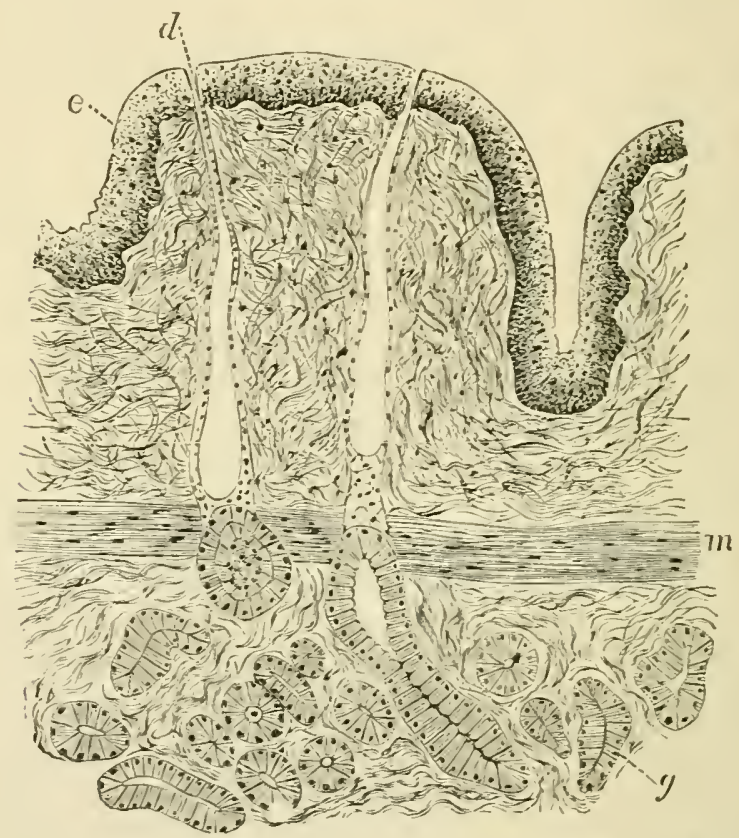

Fig. 199.-From a Longitudinal Section through the Mucous Membrane of the CEsophagus of Dog. (Atlas.)

$\epsilon$, Stratified pavement epithelium of the surface; $m$, muscularis mucosæ; between the two is the mucosa; $y$, mucous slands; $d$, duct of same.

Outside the submucosa is the muscularis externa. This consists of an inner thicker circular and an outer thinner longitudinal coat. And outside this is the outer, or limiting, fibrous coat of the esophagus. In man the outer muscular coat consists of non-striped muscular tissue, except at the beginning (about the upper thircl, or less) of the cesophagus, which is composed of the striped variety; but in many 
mammals almost the whole of the external muscular coat, except the part nearest the cardia, is macle up of striped fibres.

259. The large ressels pass into the submucosa,

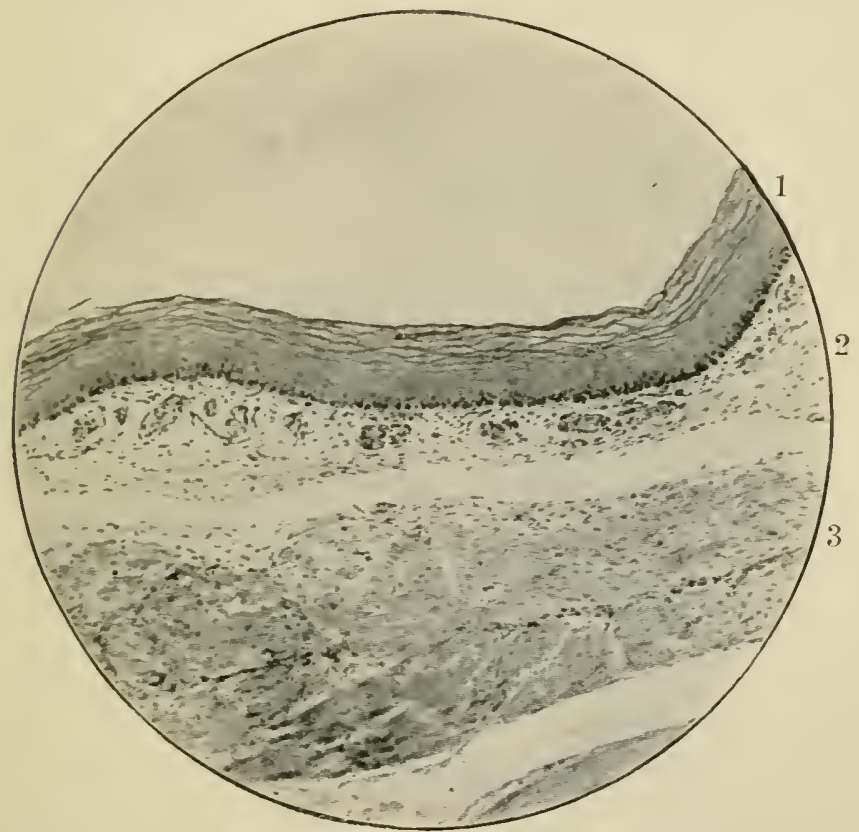

Fig. 200.-Transverse Section through the Esophagus of a Newly-born Child. (Photograph. Low magnification.)

1, Stratified epithelium of the inner surface: 2, mucosa containing cross-cut bundles of non-striped muscle, muscularis micosæ ; 3 , outer muscular cost.

whence their finer branches pass to the surface parts. The superficial part of the mucosa and the papillae contain the capillary networks. The onter muscular coat and the muscularis mucosie have their own vascular supply.

There is a rich plexus of lymphatics in the mucosa, and this leads to a plexus of larger ressels in the submucosa (Teichmann). The nerres form rich 
plexuses in the outer fibrous coat; these plexuses include numerous ganglia. A second plexus of nonmedullated fibres lies between the longitudinal and circular muscular coat; a few ganglia are connected with this plexus. In the submucosa are also plexuses of non-medullated fibres. Now and then a small ganglion is connected also with this plexus.

260. II. The stomach.-Beginning with the cardia, the mucous membrane of the stomach is covered with a single layer of beautiful thin columnar epithelial cells, most of which are mucus-secreting goblet cells. On the surface of the mucous membrane of the stomach open numerous fine ducts of glands, placed rery closely side by side. These extend, more or less vertically, as minute tubes, into the depth of the mucous membrane. In the pyloric end, where the mucous membrane presents a pale aspect, the glands are called the pyloric glands : in the rest of the stomach, the mucous membrane presents a reddish or red-brown appearance, and here the glands have a different character. This second variety of gland is typical of the cardiac end of the stomach as distinct from the pyloric, and hence is described as the cardiac gland.

261. The part of the mucous membrane containing the glands is the mreosa; outside this is a loose connective tissue containing the large vessels-this is the submucosa. Between the two, but belonging to the mucosa, is the muscularis mucosip, a thick stratum of bundles of non-striped muscular tissue, ar'vanged in most parts of the stomach as an inner circular and an outer longitudinal layer. The tissue of the mucosa contains the gland tubes, arranged more or less in small groups. Between them is a delicate connective tissue, in which the minute capillary blood-vessels pass in a direction vertical to the surface. Numerous small bundles of non-striped muscular fibres pass from the muscularis mucosie towards the surface-np 
to near the epithelium of the surface-forming longitudinal nuscular sheiths, as it were, around the gland tubes.

The plica villose of the superficial part of the
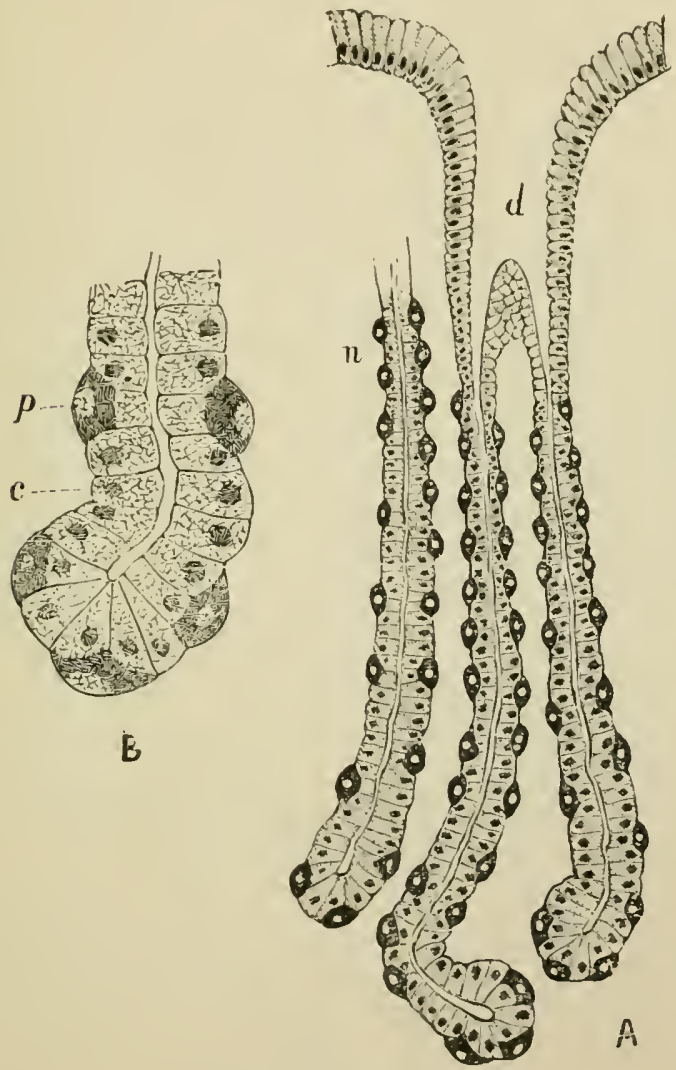

Fig. 201.-Cardiac Glands.

A, Cnder a low porer; $d$, duct; n, neck. $B$, part of the fundus of a gland tube under a high power ; $p$, parietal cells ; $c$, chief cells.

mucosa contain fibrous connective tissue and numerous lymphoid cells. 
262. The cardiac glands (Fig. 201) are more or less wavy tubes, extending down to the muscularis mucosæ. The deep part is broader than the rest, and is more or less curved, seldom branched. This is the fundus of the gland; near the surface of the mucosa is the thinnest part of the tube; this is the neck. Two or three neighbouring glands may join and open into a short cylindrical duct. The duct is lined with a layer of columnar epithelial cells, continuous and identical with that covering the free surface between contiguous glands. The duct may be really represented by a shallow depression from the surface; it is then more usual to speak of the mouth of the gland.

263. The epithelinm covering the surface consists of mucous cells. The outer two-thirds stain very slightly as a rule, the nucleus is oval and situated in the inner third of the cell, where the cell substance stains more deeply. At the base of these cells more deeply staining replacement cells may be seen. The neck and fundus of the cardiac gland is made up of two kinds of cells. The first variety occupies in general a more central position around the lumen, the cells are as a rule very indistinct in their outlines, the nucleus is in the outer half of the cell and usually somewhat shrunken. These cells are usually spoken of as the central, peptic, or chief cells. The shape of these cells is cubical or short columnar. The other variety of cell is characterised by a more peripheral position-at any rate, in the fundus of the gland, their outlines are much more distinct; the nucleus is oval and situated in the centre of the cell. These cells may impinge on the lumen at the neck of the gland, where they are most numerous; in the funclus they are scattered and placed between the investing membrane and the central cells. These cells are spoken of as parietal, oxyntic, or ovoid cells. The cardiac glands may present appearances showing the secretion in the 
condition of granules in the cells. Granules are observable both in the parietal and central cells; they are more conspicuous and more easily preserved in the latter.

264. 'The pyloric gramds (Fig. 202).-The duct

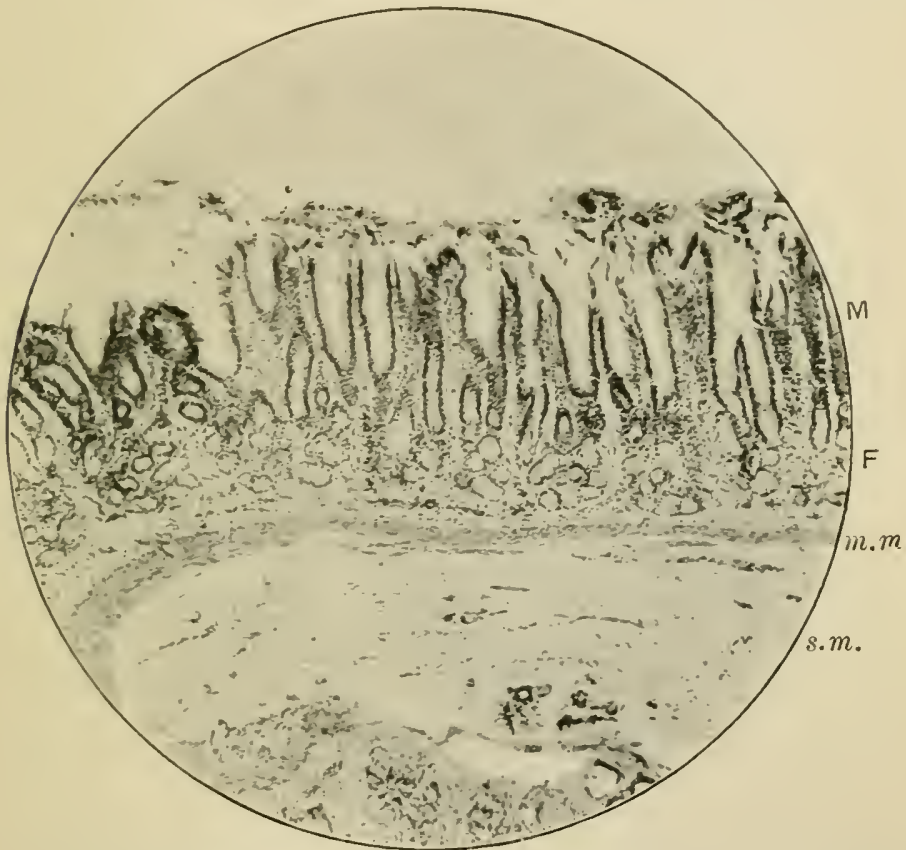

Fig. 202.-Tertical Section through the Pyloric Region of the Gastric Mucous Membrane. (Microphotograph.)

The wide funnel-shaped mouths are seen at the level 3 , the twisted ends cut across in various planes at level $\mathrm{F}$; the darkish bond at level $m . m$. is the unscularis mucose ; s.m., submucous layer.

of each pyloric gland is several times longer than that of the cardiac. The duct of the former oceupies in some places as much as half of the thickness of the mucosa, whereas that of the latter does not exceed, in the fundus of the stomach or in the cardia, more than onefourth or one-fifth of the thickness. 
The epithelium lining the duct of the pyloric glands is similar to that of the free surface. Several tubes open into one duct by a short neck. The fundus or tube is much conroluted and generally branched. It is lined by only one rariety of cell,

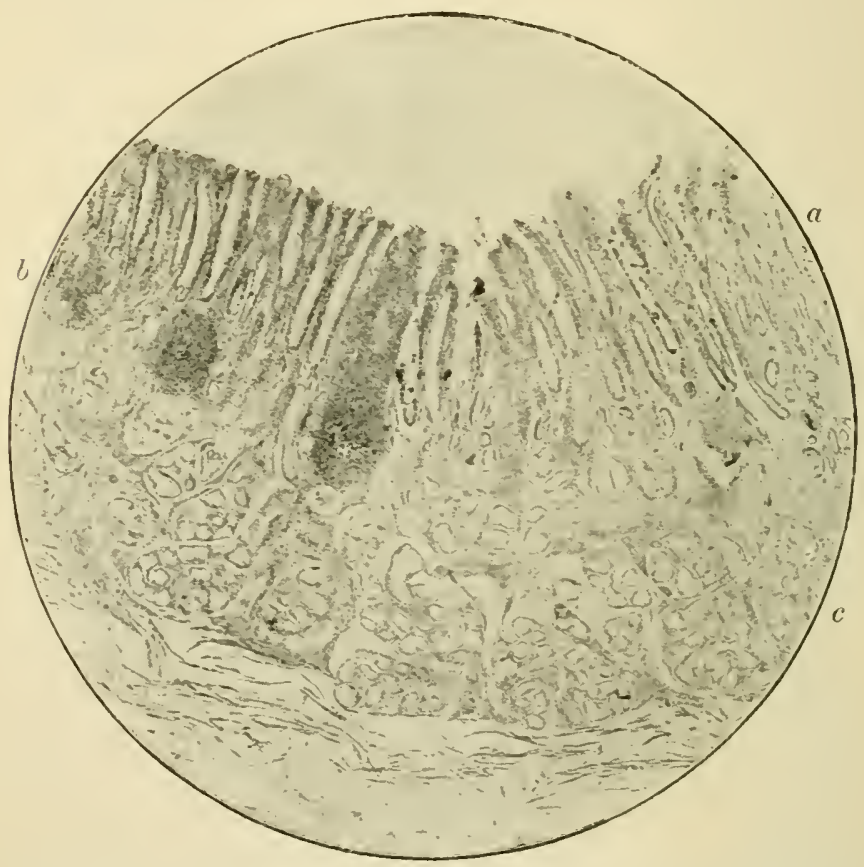

Fir. 203.-From a Section through the Transition of the Pylorus into the Duodenum. (Microphotograph. Low pover.)

a, Duorlenal mucous membrane with rilli; b, prloric mucosa with Iymph follicles; $c$, Brumber's glands directly continuous with the pyloric glands.

which bears some resemblance to the central cell of the cardiac glands. It is difficult to make out any appearance of granules either in the fresh or hardened conclition.

265. Between the mucous membrane with cardiac glands and the pyloric end of the stomach with pyloric 
glands there is a narrow intermediate zone, in which the cardiac glands appear by degrees to merge into the pyloric glands. 'That is to say, the short duct of the former gradually elongates, the gland tubes get shorter in proportion and convoluted, their lumen gradually enlarges, and the parietal cells become fewer and ultimately disappear.

266. The mucosa contains isolated lymph follicles, the so-called glandule lenticulares (Fig. 203).

The spaces between the glands themselves and between the glands and the muscularis mucose are filled up by a delicate connective tissue somewhat condensed immediately around the tubes. Lencocytes are plentiful in the meshes of this network. One particular variety of leucocyte, the so-called basophile cell, may under certain conditions be very conspicuous.

267. The submucosa is of very loose texture, and enables the mucosa to become easily folded in all directions.

268. The muscular coat is very thick, and consists of an outer longitudinal and an inner thicker circular stratum of non-striped muscular tissue. Numerous oblique bundles are found in the inner section of the circular stratum.

The gland tubes are ensheathed in a network of capillary blood-vessels derived from the arteries of the submucosa. 'This network forms on the surface a special dense horizontal layer, from which the venous branches are derived. The outer muscular coat and the muscularis mucose possess their own vascular supply.

269. The lymphatics form a network in the mucosa near the funclus of the slands. Into this plexus lead lympathics which run longitudinally between the glands; they anastomose with one another freely, and extend to near the inner surface (Lovèn). Another plexus is found in the submucosa. 
Between the longitudinal and circular stratum of the onter muscular coat, and extending parallel to the surface, is a plexus of non-medullated nerve branches with a few ganglia in its nodes. This corresponds to the plexus of Auerbach of the intestine, and is destined for the outer muscular coat. A second plexus of nonmedullated nerve branches with ganglia also extending parallel to the surface lies in the submucosa. This corresponds to the plewus of Meissner of the intestine, and is destined for the muscularis mucosie and the mucosa.

According to Rabe, the gastric gland tubes in the horse are surrounded by a rich plexus of nerve fibres, terminating in peculiar spindle-shaped cells. 


\section{CHAPTER XXVTI.}

TIE SMALL AND LARGE INTESTINE.

270. THE epithelium covering the inner or free surface of the mucous membrane of the small and large intestine is a single layer of columnar cells, their protoplasm more or less distinctly longitudinally

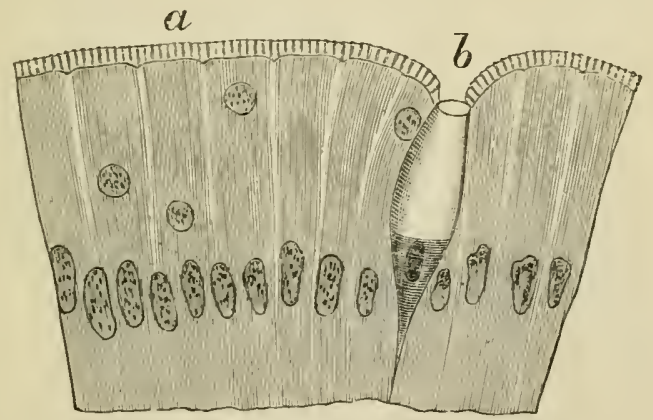

Fig. 201.-Epithelium covering the Surface of a Villus of sinall Intestine. (Atlas.)

$a$, Striated free border; $b$, goblet cell.

fibrillated; their free surface appears covered with a vertically and finely striated fiee border (Fig. 204). Many cells are goblet cells. Underneath the epithelium is a basement membrane, the sub-epithelial endothelium of Debove.

As in the stomach, so also in the small and large intestine, the mucosa is connected with the outer muscular coat by a loose-textured fibrous submucosa, in which lie the large vascular trunks, and in many places larger or smaller groups of fat cells and lymph corpuscles. Between the mucosa and submucosa, but 
belonging to the former, is a layer of non-striped muscular tissue, the muscularis mucosce. This is in many places composed of inner circular and outer longitudinal bundles, but there are a good many places, especially in the small intestine, where only a layer of longitudinal bundles can be made out.

The tissue of the mucosa is similar in structure to allenoid tissue (Fig. 205), consisting of a reticular

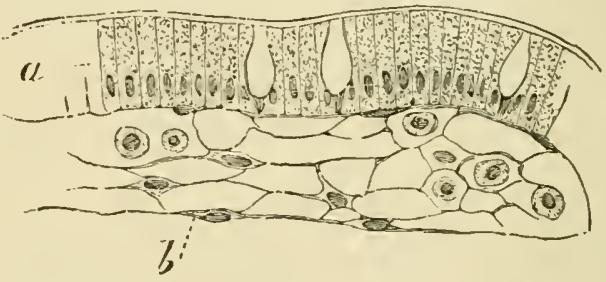

Fig. 205.-From a Longitudinal Section through a Villus of the Small Intestine.

a, Epithelium of the surface; $b$, non-striped muscular flbres. Immediately underneath the epithelinm is a basement membrane with oblong nuelei ; the tissue of the villus is made up of a reticulum of cells; in its meshes are lymph corpuscles.

matrix with flattened large nucleated endotheloid cells and numerous lymph corpuscles. These are either small lymph corpuscles like leucocytes, or they are somewhat larger and filled with coarse granules -plasma cells. The mucosia of the small and large intestine contains simple gland tubes, the crypts or follicles of Lieberkiühn (Fig. 206); they are placed vertically and closely side by side, extending from the free surface, where they open, to the muscularis mucose. These glands possess a large lumen, and are lined with a single layer of columnar epithelial cells, many of them goblet cells.

271. In the small intestine the mucosa projects beyond the surface as numerous longer or shorter, cylindrical, conical, or leaf-shaped villi (Fig. 206). These are, of course, covered with the columnar 
epithelium of the general surface, and their tissue is the same as that of the mucosa-i.e. adenoid tissue (Fig. 207 ) — with the addition of: (a) One or two central wide chyle (lymph) vessels (Fig. 209), their wall being a single layer of endothelial plates. (b) Along these

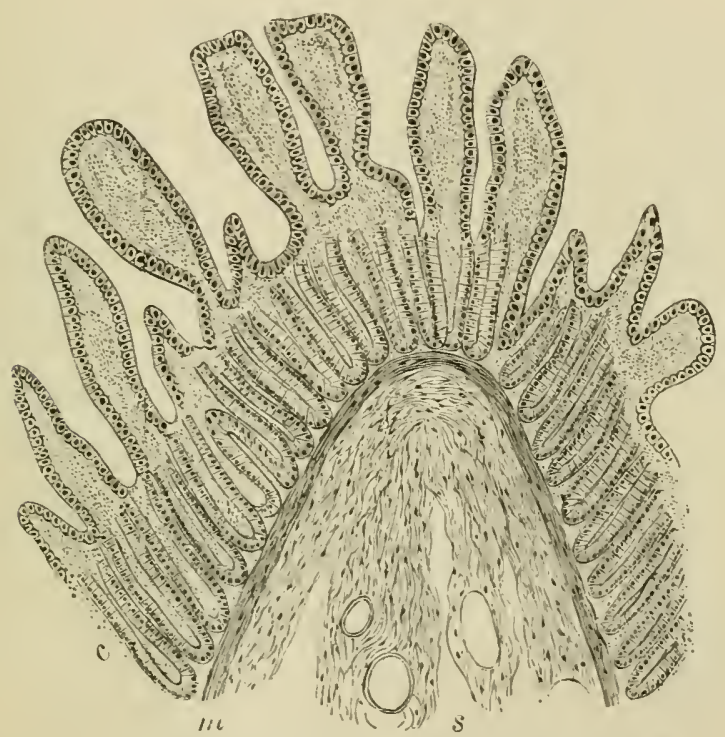

Fig. 206.-From a Vertical Section through a Fuld of the Mucuus Membrane of the Jejumum of Dog. (Atlcts.)

c, Mucosa, containing the crypts of Lieberkithn, and projecting as the villi; $m$, muscularis mucosæ; $s$, submucosa.

chyle vessels are longitudinal bundles of non-striped muscular tissue, extending from the base to the apex of the villus, terminating in connection with the cells of the basement membrane-i.e. the sub-epithelial endothelium. (c) A network of capillary blood-vessels extending over the whole of the villus close to the epithelium of the surface (Fig. 208). This capillary network derives its blood from an artery in about the middle or upper part of the villus. Two venous vessels carry away the blood from the villus. 
The Lieberkühn's crypts open between the bases of the villi.

About the base of the villi of the small intestine,

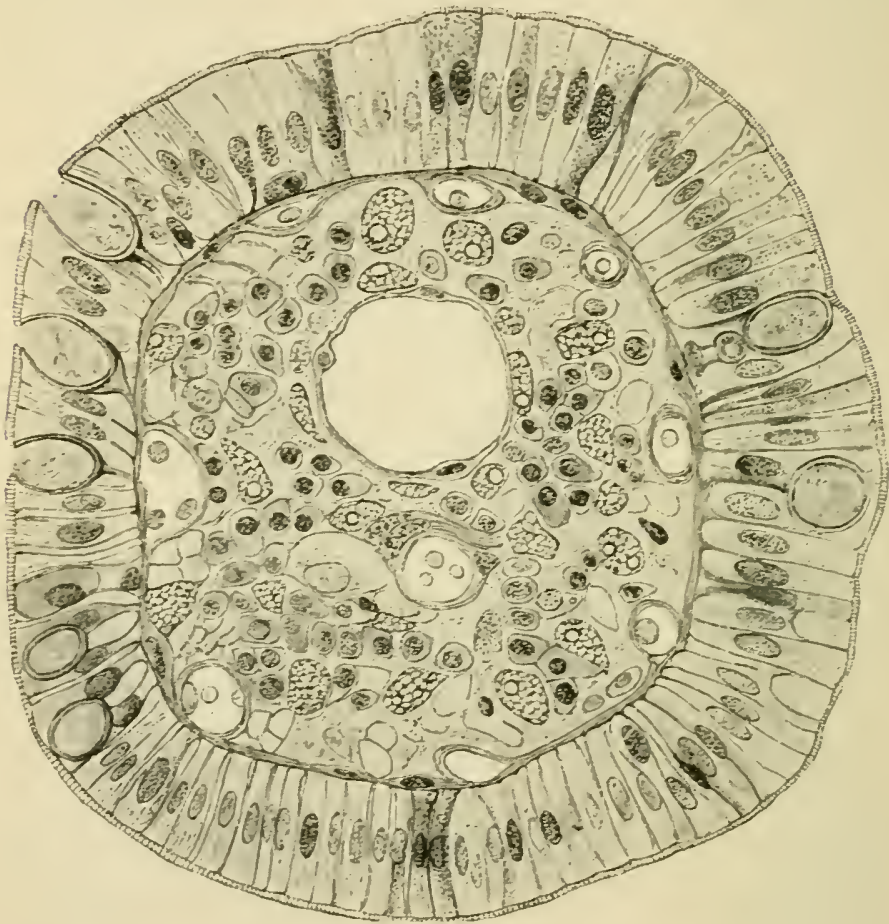

Fig. 20-. -Transverse Section through Villus of Sinall Intestine of Dog. (Heidenhain.)

Shoring the columnar epithelium lining the free surface, the adenoid tissne formins the sroundwork; anongst the lymph cells of this adenoid tissue there are numerons large cells filled with fat-droplets; the central lacteal as alsu the capillary blood-ressels are shown cut across.

and about the base of the plicæ villosa of the stomach (p. 311), there exist amongst the epithelium of the surface peculiar goblet-shaped groups of epithelial cells, which, as Watney has shown, are due to local multiplication of the epithelial cells.

272. Lymph follicles occur singly in the submucosa, 
and extend with their immer part or summit through the muscularis mucosie into the mucosa to near the interual free surface of the latter (Fig. 209). These are the solitary lympl follicles of the small and large intestine; in the latter they are larger than in the former.

Agminated glands, or Peyer's glands, are larger or smaller groups of lymph follicles, more or less fused with one another, and situated with their main part in the submucosa, but extending with their summit to the epithelium of the free surface of the mucosa (Fig. 210). In the lower part of the il e $\mathrm{um}$ these Peyer's glands are very numerous. The epithelium covering the sum-

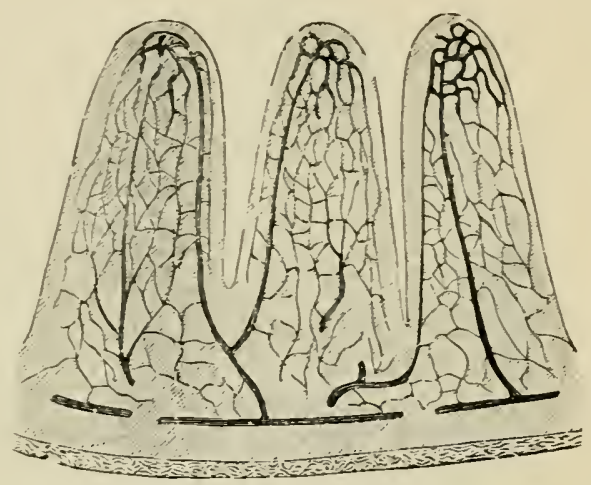

Fig. 208.-From a Vertical Section through the smal] Intestine of Mouse; the blood-ressels are injected. (Atlas.)

The networks of the capillaries of the villi are well slown. mits of these lymph follicles is invaded by, and more or less replaced by, the lymph corpuscles of the adenoid tissue of the follicles (Watney), similar to what is the case in the tonsils (see par. 124). Isolated lymph corpuscles are met with amongst the epithelium also of other parts of the intestine-e.g. the epithelium covering the villi (Fig. 204).

The outer muscular coat consists of an inner thicker circular and an outer thinner longitudinal stratum of non-striped muscular tissue.

In the large intestine, in the "ligamenta," only the longitudinal layer is present, and is much thickened. 
273. The blood-ressels form separate systems of capillaries for the serous corering, for the outer muscular coat, for the muscularis mucosit, and the richest of all for the mucosa with its Lieberkühn's crypts. The capillary network of the villi is connected with that of the rest of the mucose (Fig. 208).

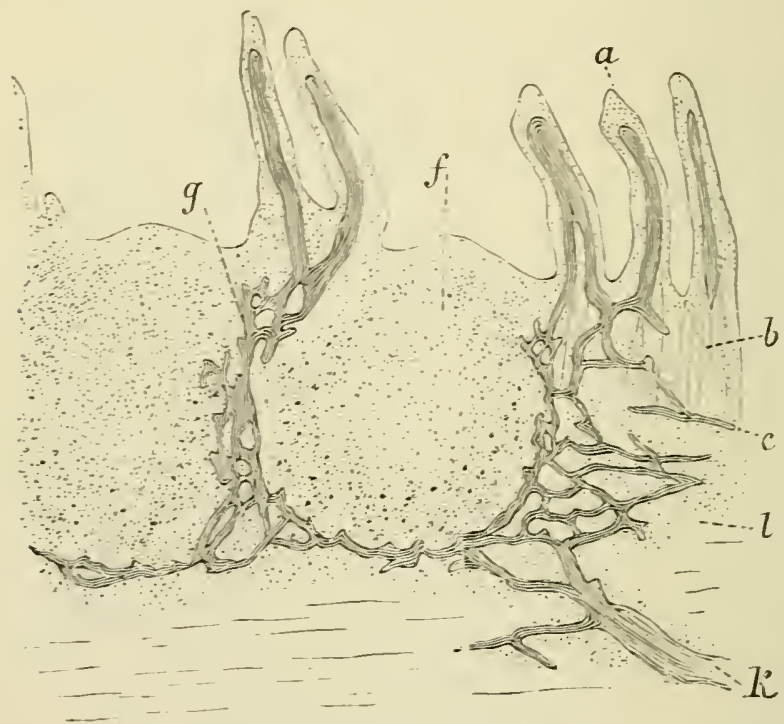

Fig. 209.-From a Section through a part of a Human Peyer's Pateh, showing the distribution of the lrmphatic ressels in the mucosa and submucosa. (Frey.)

$a$, Villi, with central cly-le yessel; $b$, Lieberkün's crry,ts : $c$, region of muscularis mucosie: $f$. Jrmph fullicle; $g$, network of lrnihatics around the lymph follicle; $l$, lomphatic network of suljuucosa $k$, efferent lymphatic trunk.

The chrle vessel, or ressels of the villi, commence with a blind extremity near the apex of the villi. At the base the chrle vessel becomes narrower and empties itself into a plexus of lymphatic ressels and sinuses belonging to the mucosa, and situated between the crrpts of Lieberkuilnn (Fig. 209). This 


\section{SHALI AND LARGE INTESTINE.}

network is the same both in the small and large intestine, as is also that of the lymphatics of the submucosa with which the former communicates. The lymph follicles are generally surrounded with sinuous ressels of this plexus. The efferent trunks of the

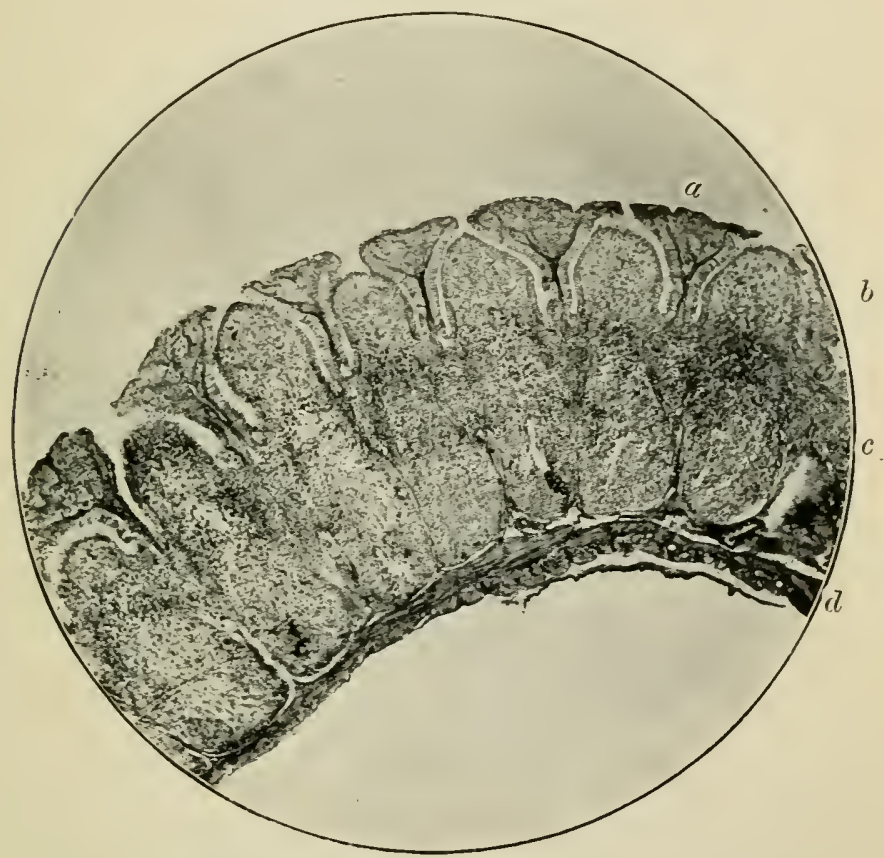

Fig. 210.-Cross section through the Cxcum of Rabbit, showing a Peyer's Patch.

$a$, Mucous membrane; $b$, summits of the $15 \mathrm{mph}$ follicles reaching the free surface; $c$, body of the lymph follicles in the submucous tissue: $d$, outer muscular coat. (Photo. Lou Magnificution.)

submucous plexus, while passing through the outer muscular coat in order to reach the mesentery, take up the efferent vessels of the plexus of the lymphatics of the muscular coat. 
274. The chyle, composed of granules and fat globules of different but minute sizes, passes from the inner free surface of the mucous membrane of the small intestine through the epithelium into the spaces

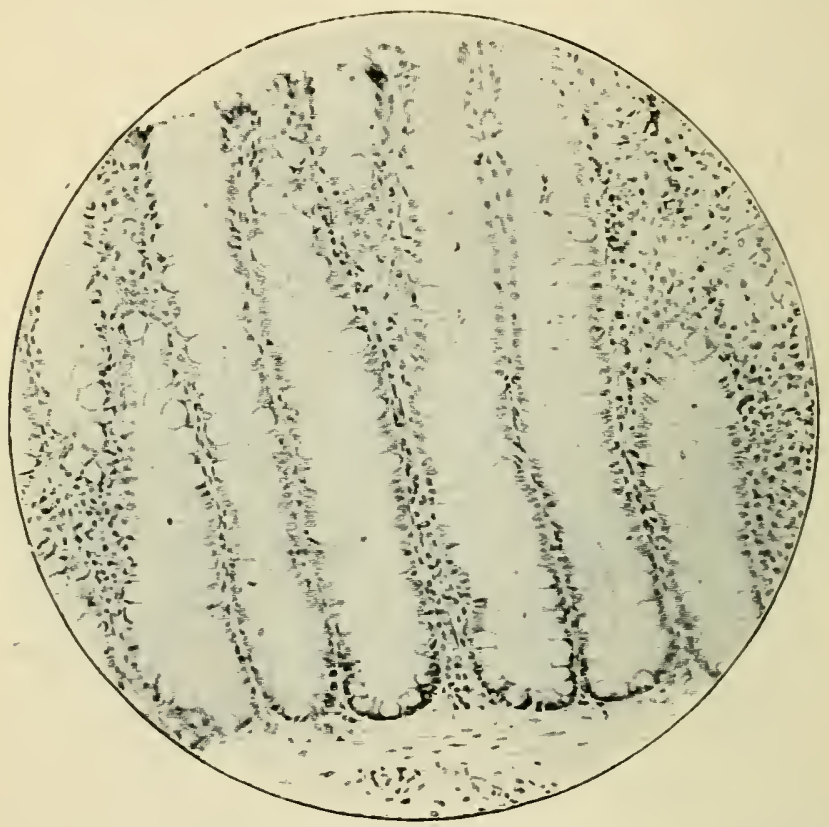

Fig. 211.- Vertical Section throngh the Mucous Membrane of the large Intestine. (Mirrophotograph.)

Some six glands are sbown occupring almost the full heisht of the photograph.

I lue lumen of the cland is large, the glauds being hardened in the distended condition. The elithelium lining ss seen to include a very larse number of roundish, clear, and but slightly staining cells. lliese being goblet cells. The nucleated cells of the sub-epilhelial reticular tissue are seen between the glands.

of the reticulum of the rilli, and from here into the central chyle ressels. The plasma-corpuscles in the reticulum of the matrix may, and sometimes do, take up chyle globules: but it is a mistake to ascribe to these lymph cells an important rôle in 
passing chyle globules from the epithelium into the central chyle ressel (Fig. 21t).

Owing to the peripheral disposition of the capillaries in the villi, and owing to the greater filling with blood of the capillaries during digestion,

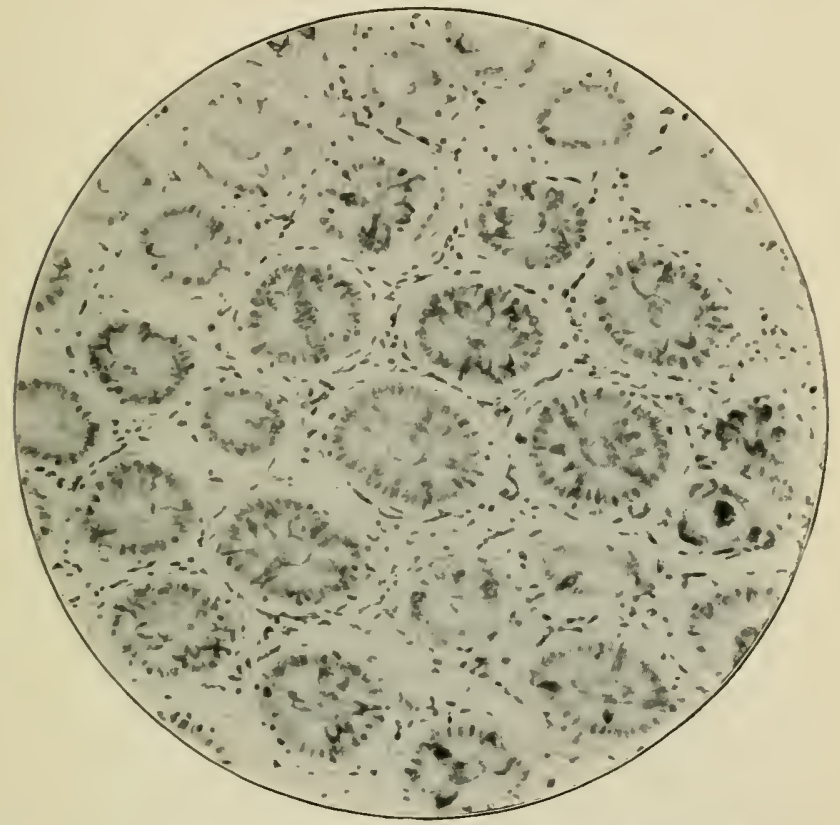

Fig. 212.-From a Horizontal Section through the Mucous Membrane of Large Intestine of Pig, sliowing the grland tubes of Lieberkühn in cross-section, their lining columnar epithelium with numerous goblet cells anongst them. Between the gland is the tissue of the mucosa. (Photo. Moderately magnified.)

the villi are thrown into a state of turgescence during this period, in consequence of which the central chyle ressels are kept distended. Absorption is thus greatly supported. The contraction of the muscular' tissue of the rilli and of the muscular coat of the intestine greatly facilitates the absorption and discharge of the chyle. 
275. The non-medullated nerves form a rich plexus, called the plexus myentericus of Auerbach (Fig. 215), with groups of ganglion cells in the nodes; this plexus lies between the longitudinal and circular muscular coat. Another plexus connected

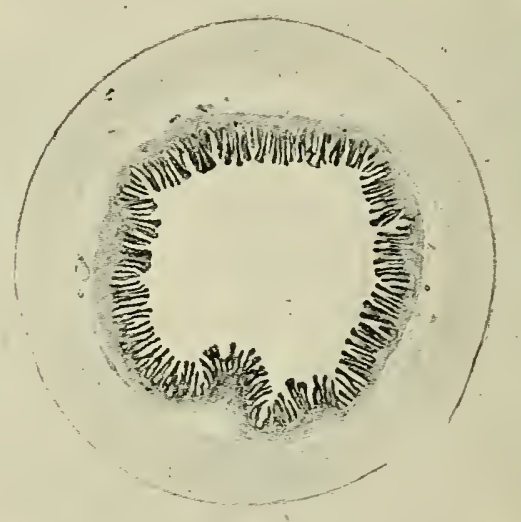

Fig. 213.-Transverse Section througl the Human Appendix Vermiformis ; showing the mucons membrane with the densely arranged glands of Lieberkithn, the subnucons layer with the cross-cut large ressels, and the outer muscular coat covered by the peritoneal layer. (Photo. Lour pouer.)

with the former lies in the submucous tissue; this is the plexus of Meissner, with ganglia. (Fig. 172.) In both plexuses the branches are of a very variable thickness: they are groups of simple axis cylinders, held together by a delicate endothelial sheath. 


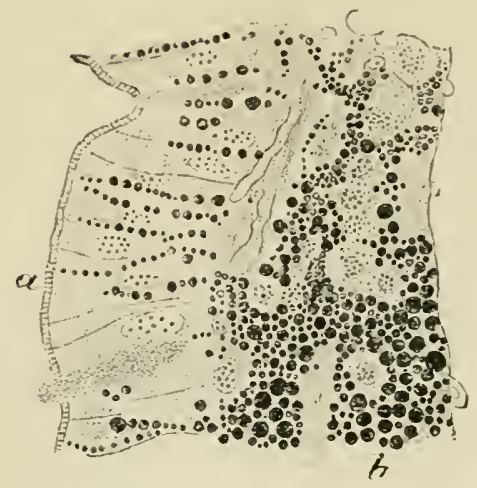

Fig. 214.- Part of a Villus filled with Chyle, from the intestine of a puppy four clayss old. (Heidenhain.)

$a$, Epithelium of surface of villus; $b$, tissue filled with chyle globules.

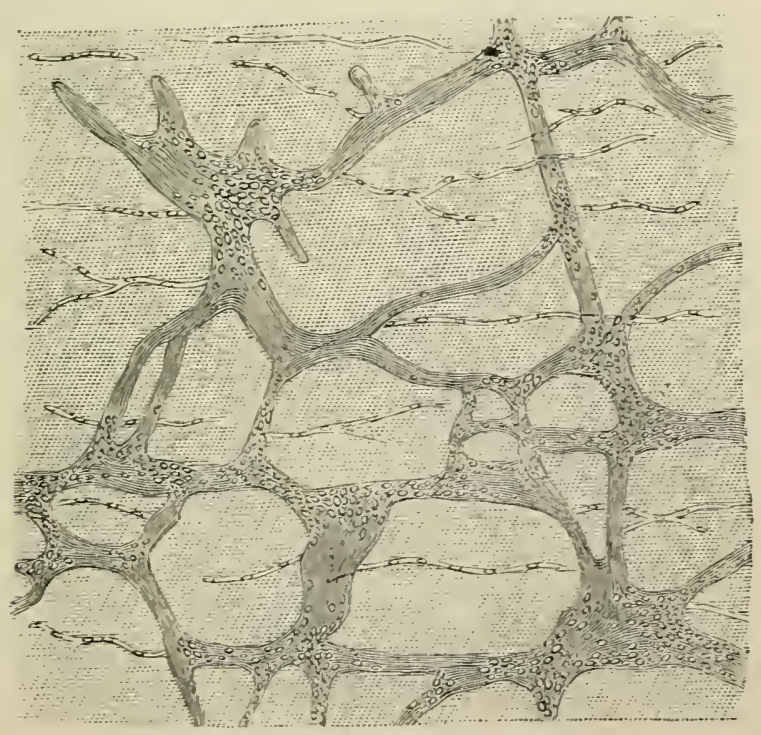

Fig. 215.-Plexus Myentericus of Auerbach of the small intestine of a newly-born child. (Allas.)

The minute circles and ovals indicate ganglion cells. 


\section{CHAPTER XXVIII.}

THE GLANDS OF BRUNNER AND THE PANCREAS.

276. A the passage of the pyloric end of the stomach into the duodenum (Figs. 203,216 ), and in the

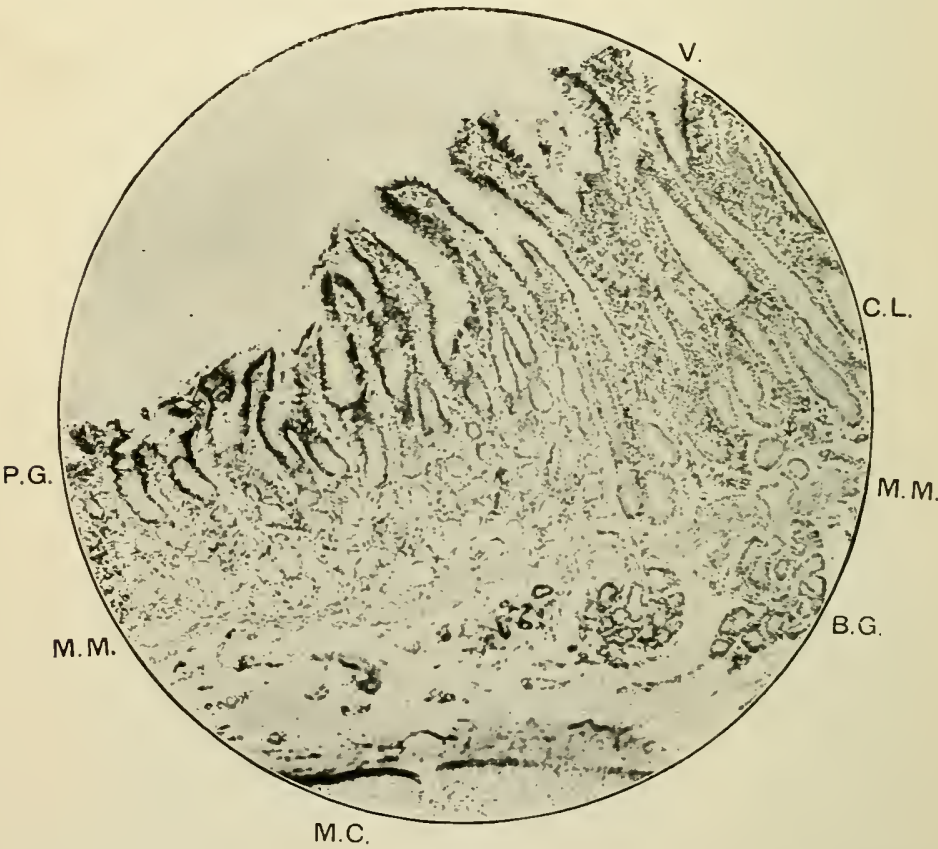

Fig. 216,-Section through the Gastro.lnodenal Junction. (Nicrophotograph.)

A band is seen running across from M.M. to M.M., the muscularis mucosi. Iu the smbmucous coat heneath on the riglut side are seen Brunuer's glands, 3.G. In the mncons coat wrloric glands are seen on left side, P.G. ; villi, $Y$. and crypts of Lielserkuhn, C.L., on right side. A small piece of inuscnlar coat is seen at M.C. 
first part of the latter, is a continuous layer of gland tissue in the submucosa, composed of convoluted, more or less branched tubes grouped into lobules, and permeated by bundles of non-striped muscular tissue,

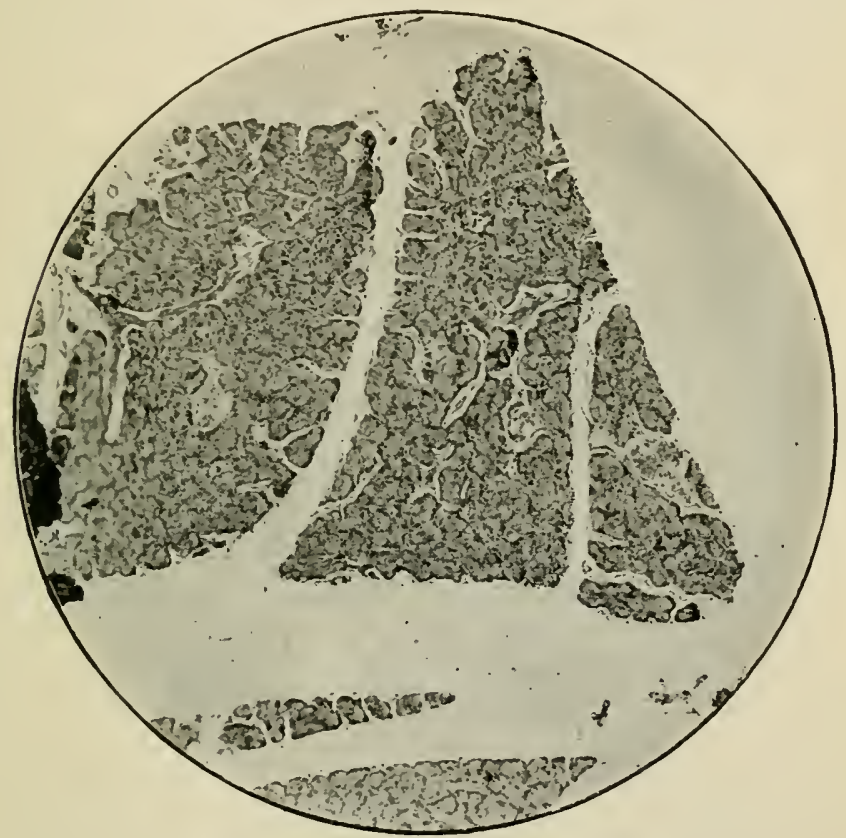

Fig. 217.-Section through Pancreas of Cat. (Microphotograph.)

Three lohules are cut across. In the middle of the small lobule on the right a lighter patch is seen; this is an interlobnlar clump. similar clumps are seen on the other lobules.

outrunners of the muscularis mucosre. These are the glands of Brunner. Numerous thin ducts lined with a single layer of columnar epithelial cells pass through the mucosa and open with the crypts of Lieberkithn between the bases of the villi. The gland tubes of Brumner's glands are identical in structure with the pyloric glands, with which they form a direct anatomical continuity. 
277. The pancreas (Fig. 217 ) is in most respects identical in structure with a serous or true salivary gland. The distribution of the blood-vessels and lymphatics, and the arrangement of the connective tissue, so as to separate the gland tissue in lobes and lobules, with the corresponding inter-and intra-lobular

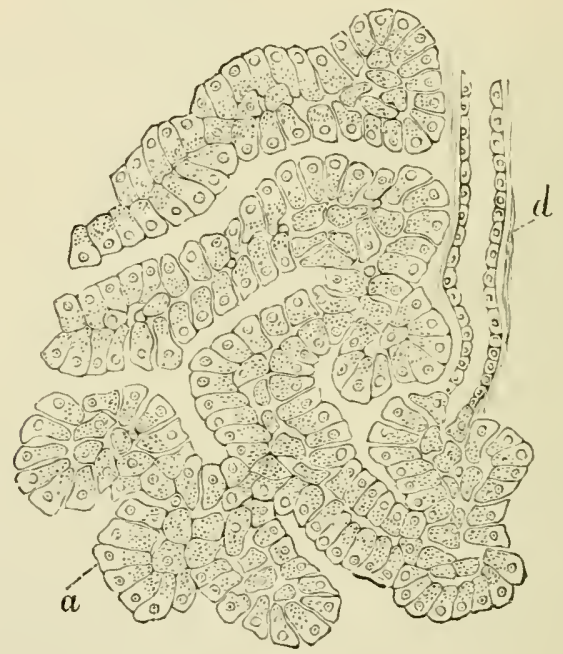

Fig. 215.-From a Section through Pancreas of Dog. (Atlas.)

$a$, Alveoli (tubes) of the gland: the linlng cells show an onter homogeneous and au inner glanular-looking portion; $d$, minute duct.

ducts, are similar in both cases. The epithelium lining the latter ducts is only faintly striated, not by any means so distinctly as in the salivary tubes. The alveoli or acini are much more elongated than is the case in the serous salivary glands, and in section the tubular character of the alveoli is marked (Fig. 218). The intermediate part of the duct leading to the alveolus resembles the ductule of the salivary gland. The cells of the alveolus are somewhat pyramidal, and show in specimens hardened by ordinary reagents an outer more deeply staining zone rarying in width, 
and an inner less deeply staining area (Fig. 218). 'This lighter zone represents the part of the cell in which the secretory granules are collected (Fig. 219). The outer more deeply staining zone may

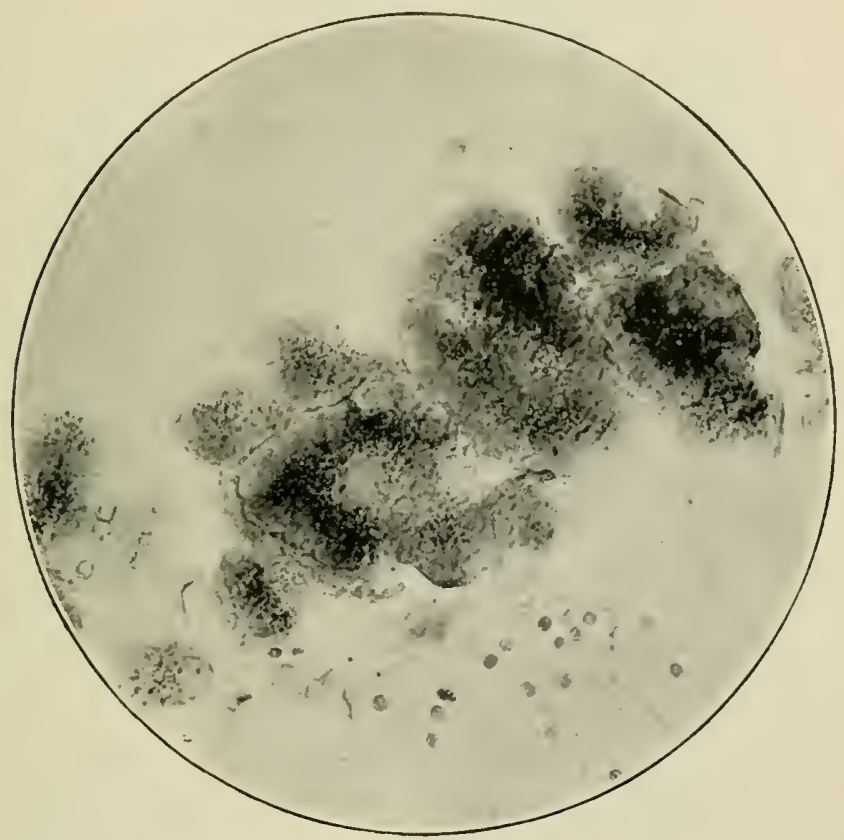

Fig. 219.-Section through Pancreas. (Mierophotograph of specimen hardened in asmic acid.)

Several alveoli are seen, the darker masses in the centre of each being accumulations of secretor:" granules.

sometimes show a radial striation. In some animals the cells lining the ductule appear to be continued as an internal lining into the al reolus. These constitute the so-called centro-acinous cells of Langerhans. There are also to be seen in the pancreas of most animals masses of cells possessing no alveolar arrangement, staining less deeply, but having large oval 
nuclei, which masses lie here and there between the alveoli. These groups of cells are very well

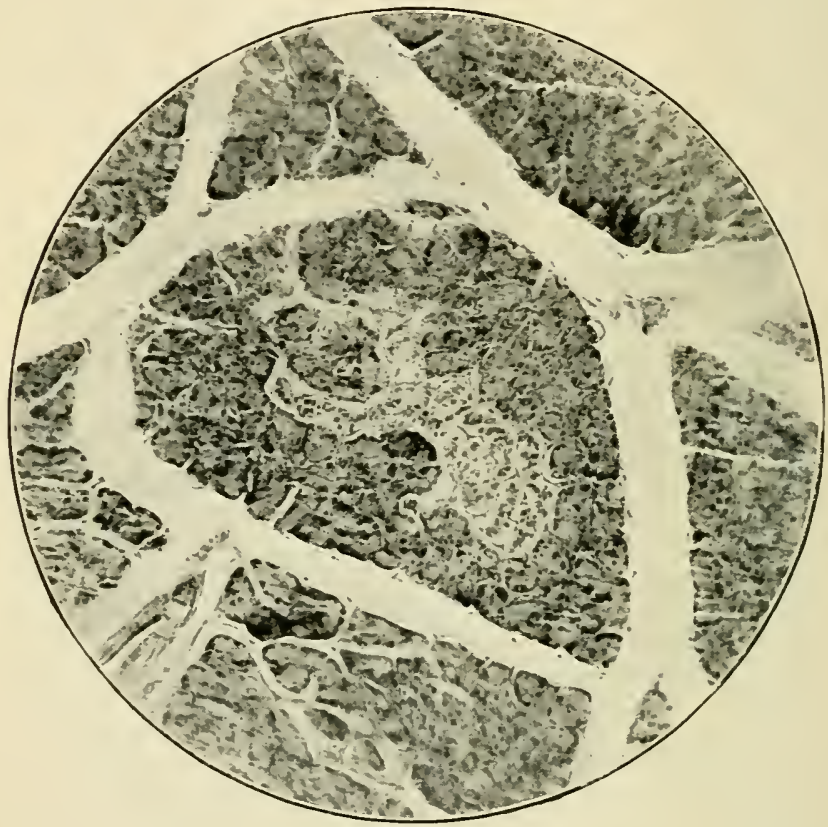

Fig. 220.- Section through the Pancreas of Cat. (Microphotograph.)

In the central lobule is seen a large, slightly-stained mas, which is an inter. tubular clump.

supplied with blood-ressels, and are spoken of as intertubular clumps, or interalveolar cell islets (see Fig. 220). 


\section{CHAPTER IXTX.}

\section{THE LIVER.}

278. ThE outer surface of the liver is covered with a delicate serous membrane, the peritoneum, which, like that of other abdominal organs, has on its free surface a layer of endothelium. It consists chiefly of fibrous connective tissue.

At the hilum or porta hepatis this connective tissue is continued into the interior, where it joins the connective tissue of the Glisson's capsule, or the interlobular connective tissue (connective tissue of the portal canals). This tissue is fibrous, and more or less lamellated;

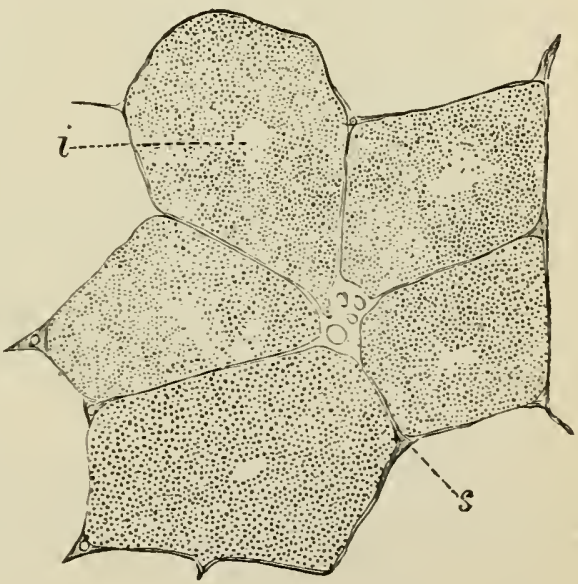

Fig. 221.-From a Section through the Liver of Pig. Five lobules are shown. They are well separated from one another by the interlobular tissue. (Atlas.)

$s$, Interlobular connective tissue, containing the interlobular blood-ressels, i.e., the branches of the hepatic artery and portal vejn, and the interlobular bile ducts ; $i$, jntralobular or central by it the substance velu.

of the liver is subdivided into numerous, more or less polyhedral, solid lobules or acini (Fig. 221), each about $\frac{1}{20}$ of than inch in diameter. According to 
whether the interlobular tissue forms complete boundaries or not, the acini appear well defined from one another (pig, ice-bear), or more or less fused (nnan and carnivorous animals and rodents).

Within each acinus there is only rery scanty connective tissue, in the shape of extremely delicate

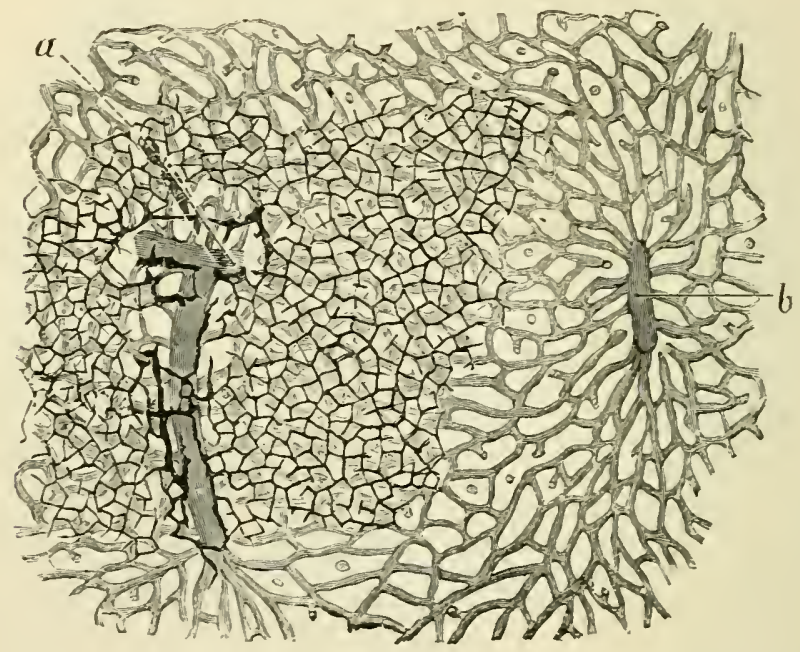

Fig. 222. - From a Vertical Section through the Liver of Rabbit; the bloodvessels and bile-ressels injected. (Atlas.)

a, lnterlobular reins surronnded by interlobular bile ducts; these latter take up the network of fine intralobular bile capillaries; the meshes of this net-

work correspond to the lirer cells ; $b$, intralobular or central vein.

bundles and flattened connectire-tissue cells. Occasionally, especially in the young liver, lymph cells are to be met with in the acini and in the tissue between them.

-279. The vena portie having entered the hilum gives off rapidly numerous branches, which follow the interlobular tissue in which they are situated, and they form rich plexuses around each acinus; these are the interlobular veins (Fig. 222). Numerous 
capillary blood-ressels are derived from these reins. These capillaries pass in a radiating direction to the centre of the acinus, at the same time anastomosing with one another by numerous transrerse branches. In the centre of the acinus the capillaries become confluent into one large rein, the central or intralobulai vein. The intralobular veins of several neighbouring acini join so as to form the sublobular veins, and these lead into the efferent veins of the liver, or the liepatic veins, which finally pass into the vena cara inferior.

2ะ0. The substance of each acinus

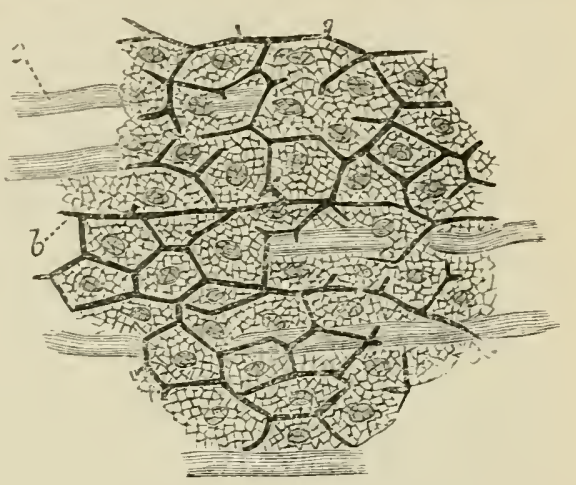

Fig. 223.-From a Lobule of the Liver of Rabbit, in which bloor-and hile-vessels har been injected, more highly magnified than in Fig. 2.2.2. (Atlas.)

$\iota$, Bile capillaries between the liver cells, which are well shown as nucleated polygonal cells, each with a distinct reticulum; $c$, capillary l,lood-vessels.

\section{-i.e. the tissue}

between the capillary blood-vessels - is composed of uniform polygonal protoplasmic epithelial cells, of about $\frac{1}{1000}$ th of an inch in diameter; these are the liver cells. Owing to the peculiar, more or less radiating, arrangement of the capillaries, the liver cells appear to form columns or cylinders, also more ol less radiating from the periphery towards the centre of the acinus. The cells contain particles of glycogen in various amounts. According to Brunton and Delépine, the amount sradually increases in the rabbit's liver after a meal, and reaches its maximum between the third and eighth hour. They also contain pigment sranules, which, being derived from the disintegration of hremoglobin in the spleen, include 
iron. Each liver cell shows a more or less fibrillated protoplasm ( $K$ upfer), and in the centre a spherical nucleus with one or more nucleoli.

The liver cells are joined by an albuminous cement substance, in which are left fine channels; these are the bile copillaries (Figs. 223 and 224). In a successfully injected preparation the liver cells appear separated everywhere from one another by a bile capillary, and these form for the uhole acinus a continuous intercommunicating netuorl of minute channels. Where the liver cells are in contact with a capillary bloodvessel, there are no bile capillaries.

281. At the margin of the acinus the bile capillaries are connected with the lumen of minute tubes; these possess a membrana propria and a lumen lined with a single layer of transparent polyhedral epithelial cells. These are the small interlobular bile ducts (Fig. 22.2). Their epithelial cells are in reality continuous with the liver cells. These ducts join and form larger interlobular bile ducts, lined with more or less columnar epithelium. The first part of the bile duct lined with polyhedral cells corresponds to the intermediary part of the ducts of the salivary glands. The interlobular bile ducts form networks in the interlobular tissue. Towards the hilum they become of great diameter, and their wall is made up of fibrous tissue, and in it are bundles of non-striped muscular cells. Snall mucus-secreting glands are in their wall, and open into their lumen.

The wall of the hepatic duct, and of the gall bladder, are merely exaggerations of a large bile duct.

282. The hepatic artery follows in its ramification the interlobular veins. The arterial branches form plexuses in the interlobular tissue, and they supply the capillary blood-ressels of the interlobular connective tissue, and especially of the bile ducts. The capillary blood-vessels of the bile ducts join so as to form 
small veins, which finally empty themselves into the hepatic reins. 'The anastomoses between the capillary blood-vessels, flerived from the arterial branches, and the capillary blood-ressels of the acini,

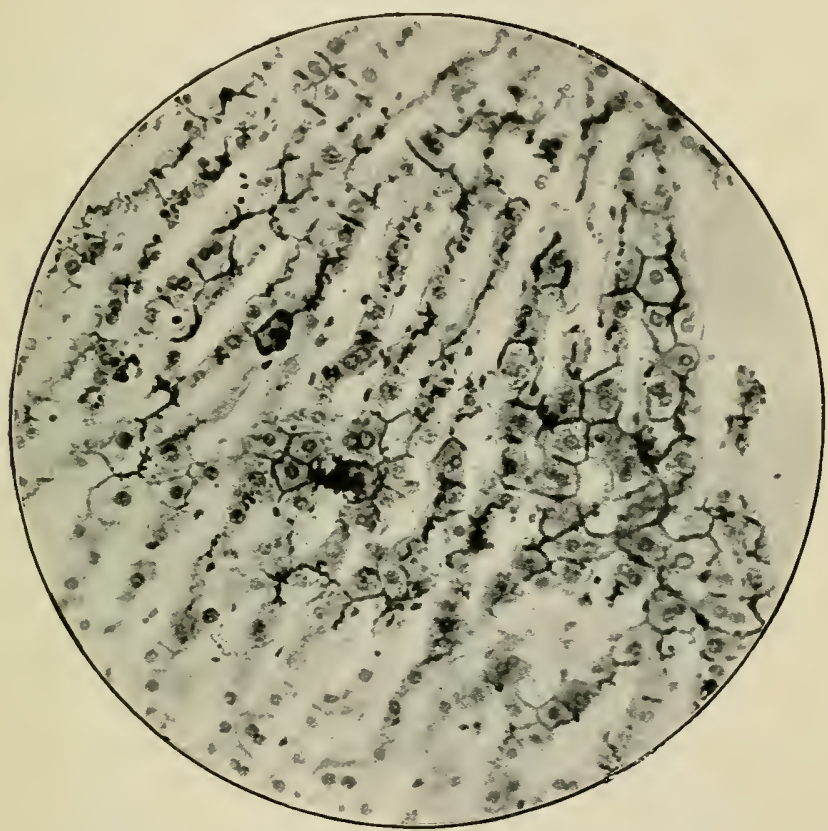

Fig. 224.-From a section through the Liver of Rabbit, of which the bile ducts had been injected; showing the distribution of the bile capillaries and their branchlets between the liver cells. (Photograph. Moderately magnified.)

are insignificant (Cohnheim and Litten). The serous covering of the liver contains special arterial branches - rami capsulares. Networks of lynphatics-deep lymphatics - are present in the interlobular connective tissue, forming plexuses around the interlobular bloodvessels and bile ducts, and occasionally forming a perivascular lymphatic around a branch of the hepatic vein. Within the acinus, the lymphatics are repre- 
sented only by spaces and clefts existing between the liver cells and capillary blood-vessels; these are the intralobulur lymphatics (Macgillivray, Frey, and others). They anastomose at the margin of the acinus with the interlobular lymphaties.

In the capsule of the liver is a special network of lymphatics called the superficial lymphatics. Numerous branches pass between this network and the interlobular lymphaties. 


\section{CHAP'ER IXX.}

THE ORGANS OF RESPIRATION.

283. I. 'Whe Iarynx.-The supporting framework of the larynx is formed by cartilage. In the epiglottis the cartilage is elastic and reticulated-i.e. the cartilage plate is perforated by numerous smaller and larger holes. The cartilarges of Santorini and Wrisbergii, the former attached to the top of the arytenoid cartilage, the latter enclosed in the arytenoepiglottic fold, are also elastic. The thyroid, cricoid, and arytenoid cartilages are hyaline. All these are corered with the usual perichondrium.

A small notule of elastic cartilage is enclosed in the front part of the true vocal cord. This is the cartilage of Luschka.

The mucous membrane lining the carity of the larynx (Fig. 225) has the following structure :-

The internal or free surface is covered with ciliated stratified columnar epithelium; the most superficial cells are conical cells with cilia on their free surface; then between the extremities of these cells are wedged in spindle-shaped and inverted conical cells. Numerous goblet cells are found amongst the superficial cells. The two surfaces of the epiglottis and the true vocal cords are covered with stratified parement epithelium.

Underneath the epithelium is a basement membrane separating the former from the mucous membrane proper.

28t. The mucous membrane is delicate connective 
tissue with numerous lymph corpuscles. In the posterior surface of the epiglottis, in the false rocal cords, and especially in the ventricle of the larynx, this

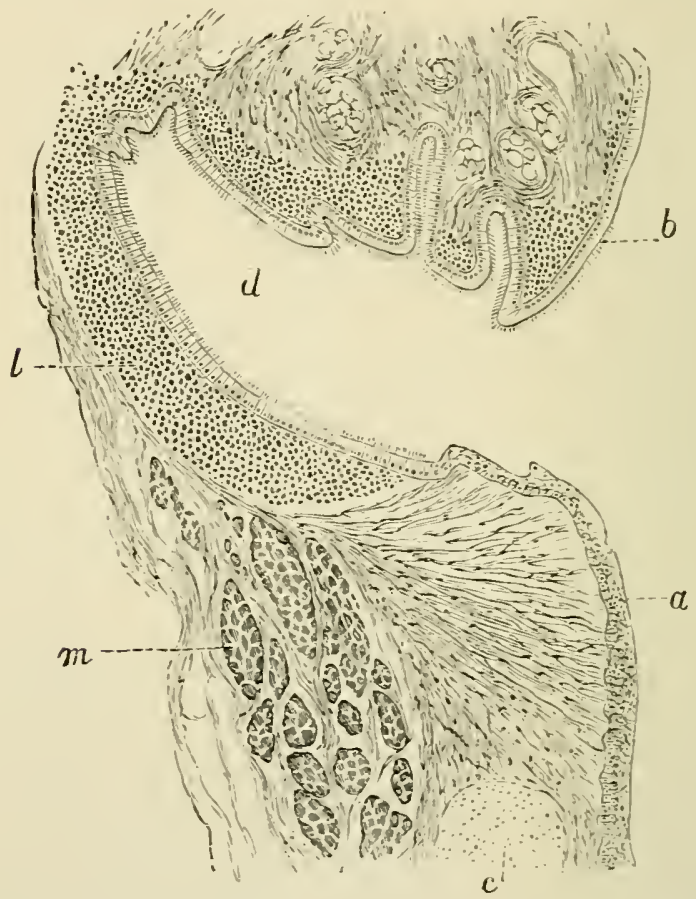

Fig. 225.-.From a Longitudinal Section through the Ventriele of the Larvnx of a Child. (Atlos.)

$a$, True vocal cord: $b$, false rocal cord ; $c$. nodule of elastic cartilage (cartilage of Luschka): $d$, ventricle; $l$, lrmphatic tissue; $m$, bundles of the thrroargtenoid muscle in transverse section.

infiltration amounts to diffuse adenoid tissue, and even to the localisation of this as lymph follicles. In both surfaces of the epiglottis, and in the true vocal cords, the mucosa extends into the stratified pavement epithelium in the shape of minute papilla.

In the lower part of the larynx the mucous mem. brane contains bundles of elastic fibres connected into 


\section{IARINA!}

networks, and ruming in a longitudinal direction. These elastic tibres are found chiefly in the superficial parts of the mucous membrane. In the true vocal

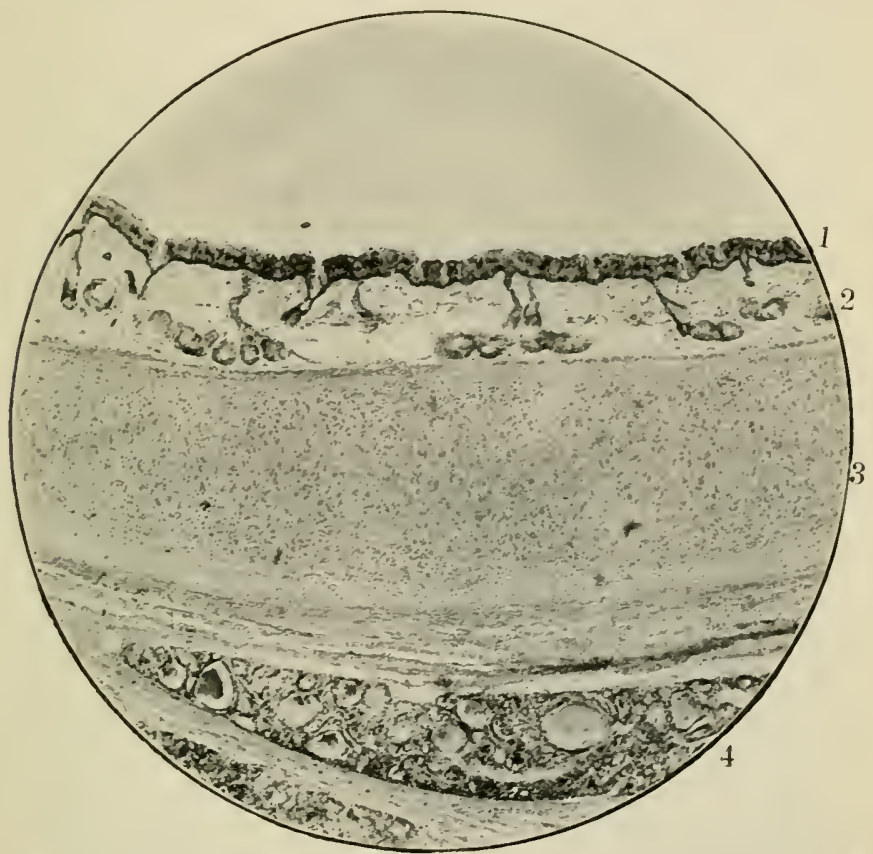

Fig. 226. - Section through Trachea of Foetus. $\times$ 40. (Photograph by $\mathrm{Mr}$ A. Pringle.)

1, Ciliated columnar epithelium of internal surface; 2 , mucous membrane with its glauds; 3 , eartilage; 4 , ontside this the thyroid gland.

cords the mucosa is entirely made up of elastic fibres extending in the direction of the vocal cords.

285. The deeper part of the mucous membrane is of loose texture, and corresponds to the submucosa; in it are embedded numerous mucous glands, the ducts of which pass through the mucosa and open on the free surface. The alveoli of the glands are of the nature of mucous alveoli-i.e. a considerable lumen lined with a layer of mucous goblet cells. There are, 
however, also alveoli lined with columnar albuminous cells, and such as have both side hy side, as is the case

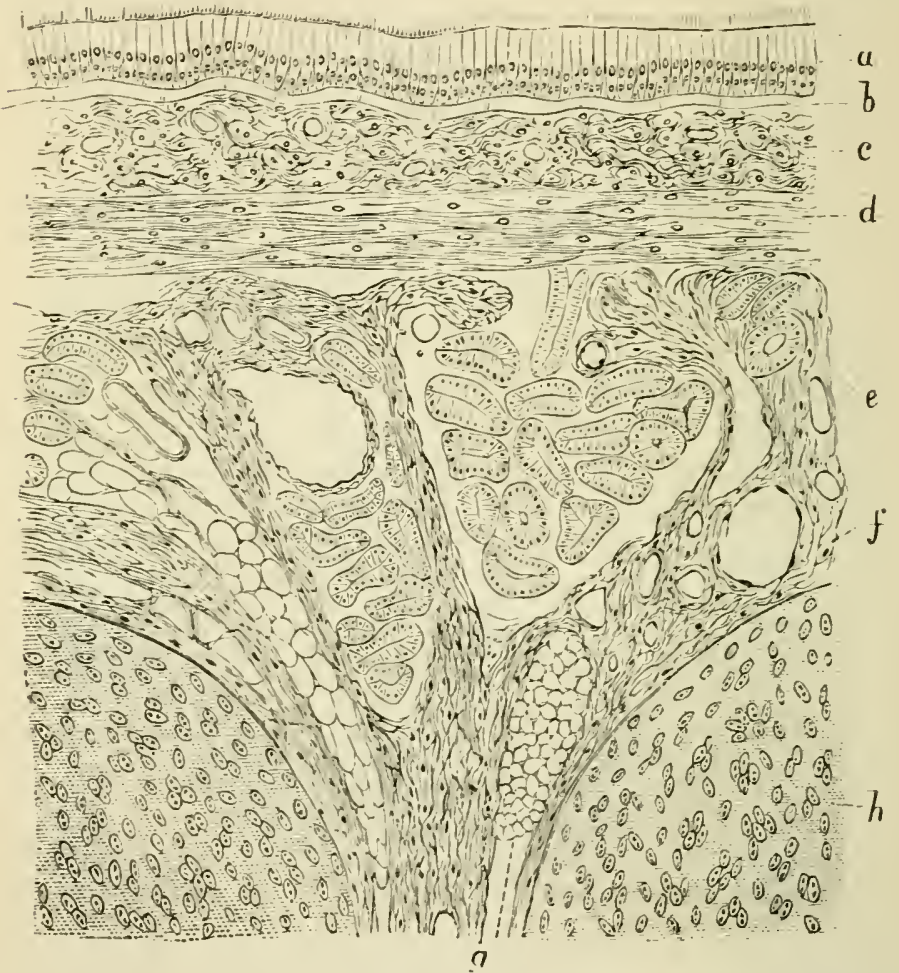

Fig. 227.-From a Longitudinal section thronsh the Trachea of a Child. (Atlas.)

o, Stratified columnar ciliated epithelium of the internal free surface: $b$, basement membrane; $c$, muccsa ; $d$. networks of longitudinal elastic fibres; the oral nuclei between them indiate connective-tissue corpuscles; $e$, submucous tissue containing mucous glants: $f$, large blood-ressels: $g$, fat cells; $h$, hyaline cartilage of the trachenl rings.

in the sublingual gland of the dog. The ciliated epithelium of the surface in some places extends also for a short distance into the ducts. The true vocal cords have no mucous glands.

The blood-ressels terminate with the capillary net. 


\section{TRACHEA.}

work in the superficial-i.e. suh-epithelial-layer of the mucosa: where there are papillae-i.e. in the epiglottis and true vocal cords-these receive a loop of capillary blood-vessels. The lymphatics form superficial networks of fine ressels and deep submucous networks of large vessels. These are of enormous width and size in the membrane of the anterior surface of the epiglottis. 'The finer nerves form superficial plexuses of non-medullated fibres, some of which terminate, according to Luschka and Boldyrew, as end bulbs. Taste bucls have been found in the epithelium of the posterior surface of the epiglottis ( $V$ irson, Schotield, Davis), and also in that of the deeper parts of the larynx (Davis).

286. II. The trachea.-The trachea is very similar in structure to the lower part of the larynx, from which it differs merely in possessing the rings of hyaline cartilage, and in containing, in the posterior or membranous portion, transverse bundles of non. striped muscular tissue, extending horizontally between the ends of the rings. Its component parts are (Figs. $226,227,228):-$

(a) a stratified columnar ciliated epitheliun ;

(b) a basement membrane;

(c) a nucosa, with the terminal networks of capillary blood-vessels, and infiltrated with adenoid tissue;

(d) a layer of longitudinal elastic fibres connected into networks;

(e) a loosely textured submucous tissue, containing the large ressels and nerves and small mucous glands. Oceasionally the gland or its duct is embedded in a lymph follicle.

\section{III. The bronchi and the lung.-}

The bronchi ramify within the lung dendritically into finer and finer tubes. The finest branches are the terminal bronchi. In the bronchi we find, instead of rings of hyaline cartilage, as in the trachea, larger 
and smaller oblong or irregularly-shaped plates of hyaline cartilage distributed more or less uniformly in the circumference of the wall. Towards the small microscopic bronchi these cartilage plates gradually diminish in size and number. The epithelium, the

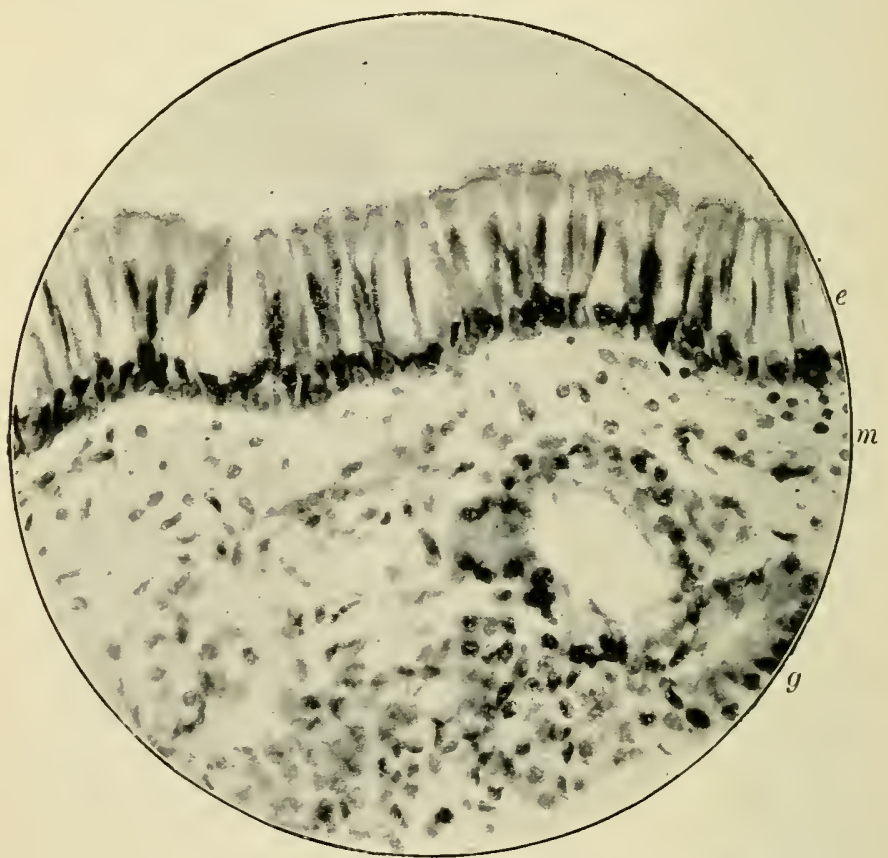

Fig. 22S.-From a Section through the Tracheal Mncons Membrane of a Newly-born Child. (Photo. Highly magnified.)

$e$, Ciliated columnar epithelium ; amongst the cillated cells are numerons goblet cells ; $m$, mucosa ; $y$, acini of mucous glands.

basement membrane, the sub-epithelial mucosa, and the layer of longitudinal elastic fibres, remain the same as in the trachea. The submucous tissue contains small mucous glands.

288. Between the sub-epithelial mucosa and the submucosa is a continuous layer of circular nonstriped muscular tissue. In the smaller microscopic 
bronchi this layer is one of the most conspicuous. By the contraction of the circular muscular coat the mucosa is placed in longitudinal folds.

The state of contraction and distension of the small bronchi bears an important relation to the aspect of the epithelium, which appears as a single layer of columnar cells in the distended bronchus, and as stratified when the bronchus is contracted.

The distribution of the blood-ressels is the same as in the trachea. Lymph follicles are met with in the submucous tissue of the bronchial wall in animals and man.

The lymphatic networks of the bronchial nucous membrane are very conspicuous. Those of the submucous tissue-i.e. the peribronchial lymplaticsanastomose with those surrounding the pulmonary blood-vessels.

Pigment and small particles can be easily absorbed through the cement substance of the epithelium into the radicles of the superficial lymphatics, whence they pass readily into the (larger) peribronchial lymphatics.

In connection with the nerve branches in the bronchial wall are minute ganglia.

289. Each terminal bronchiole branches into several wider tubes called the alveolar ducts, or infundibula; each of these branches again into several similar ducts. All ducts, or infundibula, are closely beset in their whole extent with spherical, or, being pressed against one another, with polygonal vesiclesthe air cells or alveoli-opening by a wide aperture into the alveolar duct or infundibulum, but not communicating with each other. The infundibula are much wider than the terminal bronchioles, and also wider than the alveoli.

290. All infundibula with their air cells, belonging to one terminal bronchiole, represent a conical structure, the apex of which is formed by the terminal 
bronchus. Such a conical mass is a lobule of the lung; and the whole tissue of the lung is made up of such lobules closely aggregated, and arranged as lobes. The lobules are separated from one another by delicate fibrous connective tissue; this forms a continuity

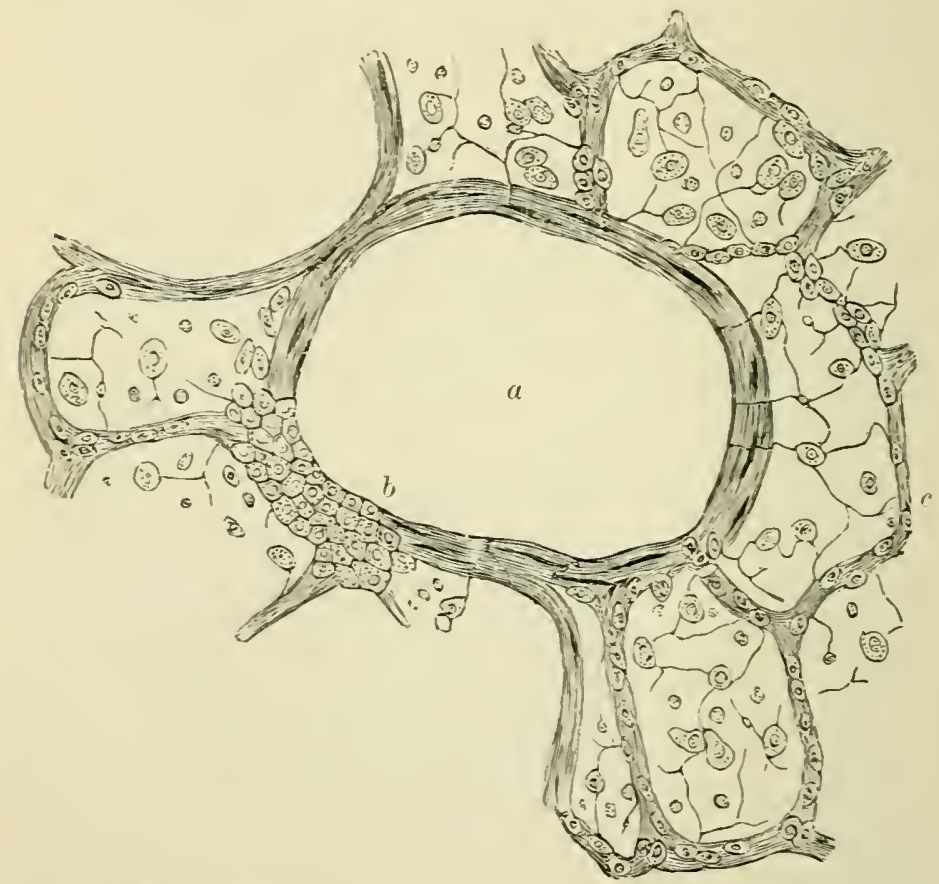

Fig. 229.-From a Section throngh the Lung of Cat, stained with nitrate of silver. (Atlas.)

$a$, Infundibulum or alreolar duct in cros-section; $b$. gronps of polrhedral cells lining one part of the infundibulum, the rest being lined with flattened transparent epithelial scales; $c$, alveoli lined with flattened epithelial scale: ; here aud there between them is seen a polshedral granular epithelial cell.

with the connective tissue accompanying the bronchial tubes and large rascular trunks, and with these is traceable to the hilum. On the other hand, the interlobular connective tissue of the superficial parts of the lung is continuous with the fibrous tissue of the 
surface called the plemra pulnomalis. This membrane contains numerous elastic tibres, and on the free surface is corered with a layer of endothelium.

In some instances (guinea-pig) the pleura pulmonalis contains bundles of non-striped muscular tissue.

The lobes of the lung are separated from one another by large septa of connectire tissue - the ligamenta pulmonis.

291. The termina I bromchi contain no cartilage or mucous glands in their wall. This is made up of three coats: (a) a delicate epithelium-a single layer of small polyjeedral giamular-lonking cells; (b) a circular coat of non-striped muscular tissue and (c) a fine adventitia of elastic fibres, arranged chiefly as longitudinal networks.

292. Tracing the elements constituting the wall of a terminal bronchiole into the infundibula and air cells (Fig. 229) we find the following changes: $(a)$ the polyhedral granular-looking epithelial cells forming a continuous lining in the terminal bronchiole are traceable into the infundibulum only as larger or smaller groups; between these groups of small polyhedral granular-looking cells large, flit, transparent; homogeneous, nucleated, epithelial scales make their appearance. The farther away from the terminal bronchiole, the fewer are the groups of polyhedral granular-looking cells. In all infundibula, howerer, the transparent scales form the chief lining. This becomes still more marked in the air cells. There the small polyhedral granular-looking cells are traceable only singly, or in groups of two or three (Elens), the rest of the carity of the sir cells being lined with the large transparent scales.

In the foetal state all cells lining the infundibula and air cells are of the small polyhedral granularlooking variety (Kiittner). With the expansion of the lungs during the first inspiration many of these 
cells change into the large transparent scales, in order to make up for the increment of surface. A lung expanded ad maximum shows much fewer or none of the small polyhedral cells; while a lung that is collapsed shows them in groups in the infundibula, and isolated or in twos or threes in the alveoli.

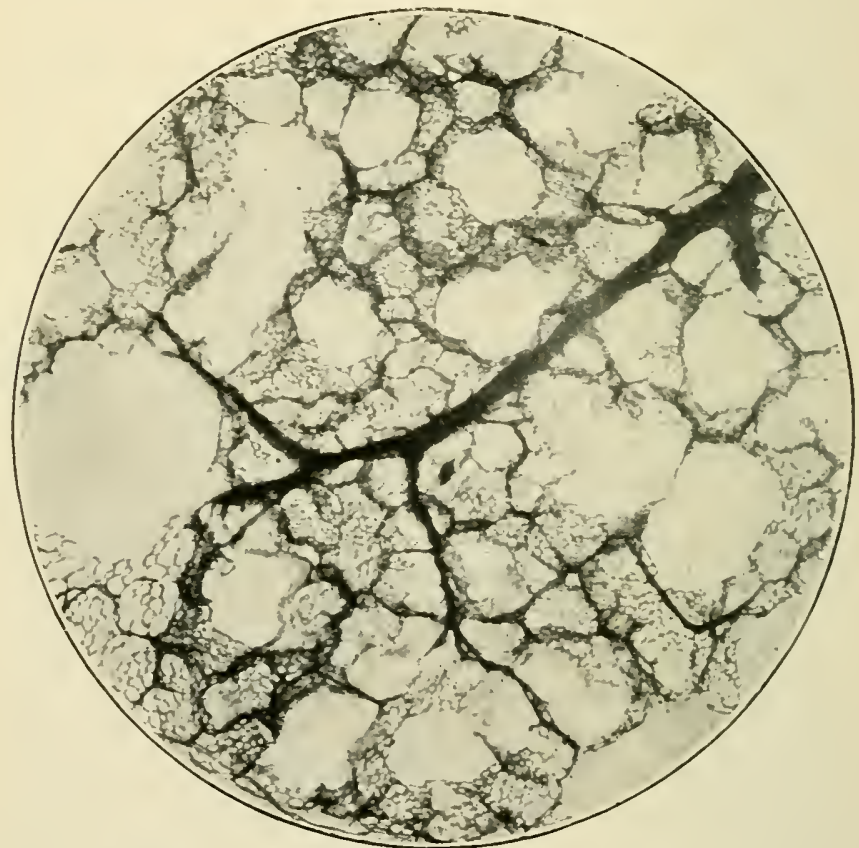

Fig. 230.-Network of Capillary Bloor-vessels surrounding the Alreoli of the Human Luug. (Photograph by . . Fr. A. Pringle.)

293. (b) The circular coat of non-striped muscular tissue of the terminil bronchiole passes as a continuous circular coat - but slightly thimner-on to the alveolar ducts or infundibula, in their whole extent, but not beyond them, i.e. not on to the air cells.

(c) The adrentitia of elastic networks is continued on the infundibula, and thence on the air cells, where 
it forms an essential part of the wall of the alveoli, being its framework.

Amongst the network of elastic fibres forming the wall of the alveoli is a network of branched connective-tissue cells, contained as usual in similarly-shaped branched lacume, which are the radicles of the lymphatic vessels.

\section{4. 'The blood-vessels and lymphaties.-}

The branches of the pulmonary artery and veins are contained within the connective tissue separating the lobes and lobules, whence they can be tracell into their finer ramifications towards the infundibula and air cells. Each of these latter is surrounded by a sort of basket-shaped dense network of capillary bloodvessels (Figs. 230 and 231). The capillary networks of adjacent alveoli are continuous with one another, and stand in communication on the one hand with a branch of the pulmonary artery, and on the other with branches of the pulmonary vein. The branches of the bronchial artery belong to the bronchial walls, which are supplied by them with capillary networks.

The lacume and canaliculi in the wall of the alveoli, mentioned above, are the rootlets of lymphatic vessels, which accompany the pulmonary vessels, and form a network around them; these are the deep lymphatics, or the perivascular lymplatics. They are connected also with the networks of lymphatics surrounding the bronchi, i.e. the peribronchial lymphatics. The rootlets of the superficial air cells empty themselves into the sub-pleural plexus of lymplatics, a rich plexus of large lymphatics with valves. All these lymphatics lead by large trunks into the bronchial lymph glands.

295. Between the flattened transparent epithelial cells lining the alveoli are minute openings, stomata (Fig. 229), leading from the cavity of the air cells into the lymph lacumæ of the alveolar wall. These stomata. 
are more distinct during expansion, i.e. inspiration, than in the collapsed state. Tnspiration, by its expanding the lungs, and consequently also the lymphatics, greatly favours absorption. Through these stomata, and also through the interstitial cement

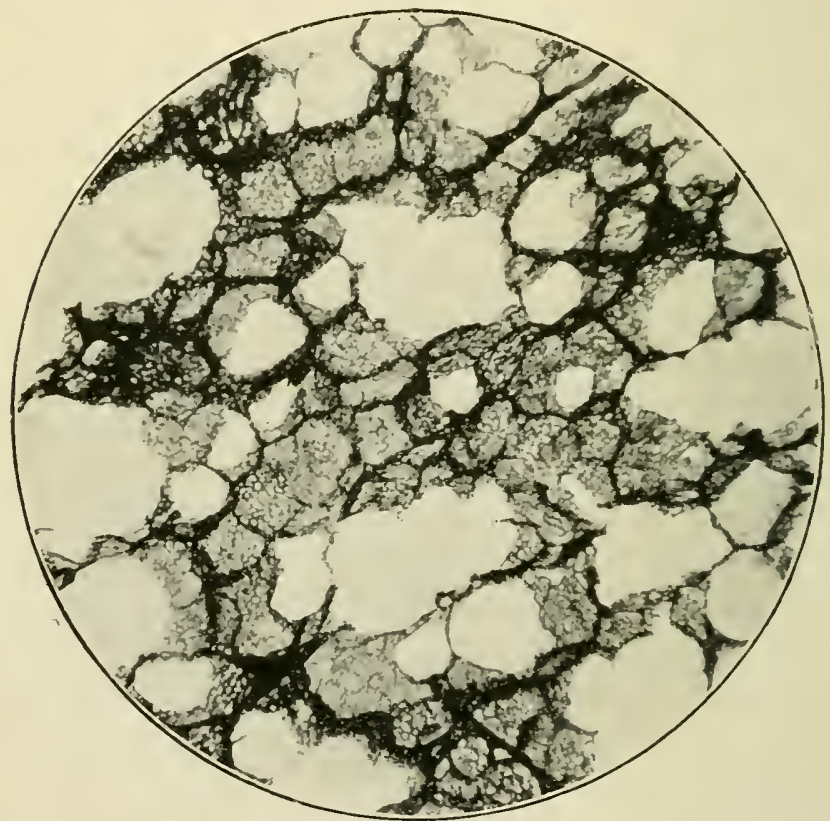

Fig. 231.- Injected Lung of Cat. (Photograph.)

substance of the lining epithelium, formed particles - such as soot particles of a smoky atmosphere, pigment artificially inhaled, cellular elements, such as mucous or pus corpuscles, bacteria, etc.-find their way into the radicles of the lymphatics, thence into the perivascular and sub-pleural lymphatics, and finally into the bronchial glands.

The cellular elements just mentioned, containing particles of soot, are spoken of as "dust cells." 


\section{CHAPTER XXXI.}

IHE SPLEEN.

296. The capsule enveloping the spleen is a serous membrane-the peritoneum. It is a connec-

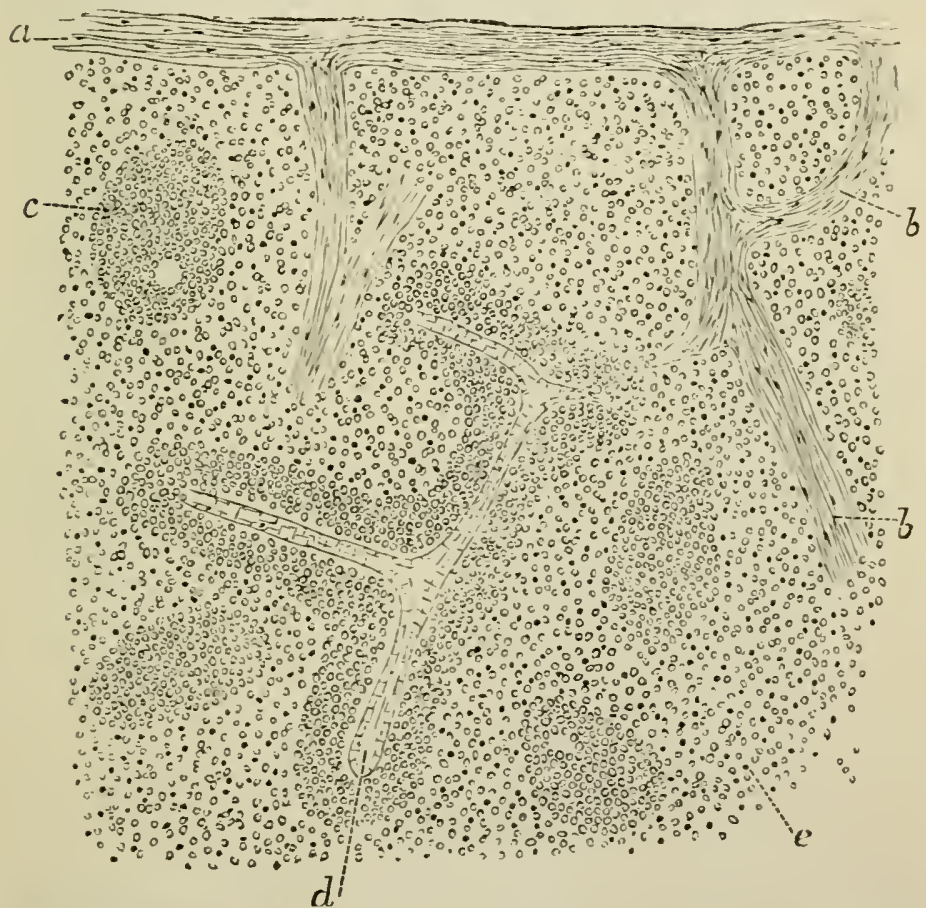

Fig. 232.-From a Vertical Section through the Spleen of Ape. (Atlas.) $a$, Capsule ; $b$, trabeculæ: $c$, Malpighian corpuscle: $d$, artery ensheathed in a Ialpighian corpuscle; $e, p u l p$ tissue.

tive-tissue membrane with networks of elastic fibres, and covered on its free surface with an endothelium. 
The deep part of the capsule contains bundles of nonstriped muscular tissue forming plexuses. In man the bundles are relatively thin, but in some mammals - e.g. dog, pig, horse-they are continuous masses arranged sometimes as a deep longitudinal and a superficial circular layer (Fig. 232).

In connection with the capsule are the trabeculce. (Fig. 232). These are microscopical, thicker or thinner cylindrical bands branching and anastomosing, and thus making a framework in which the tissue of the spleen is contained. Towards the hilum the trabeculie are larger, and they form there a continuity with the connective tissue of the hilum. They are the carriers of the large rascular branches. The trabeculie in the liuman spleen consist chiefly of fibrous tissue with an admixture of longitudinal

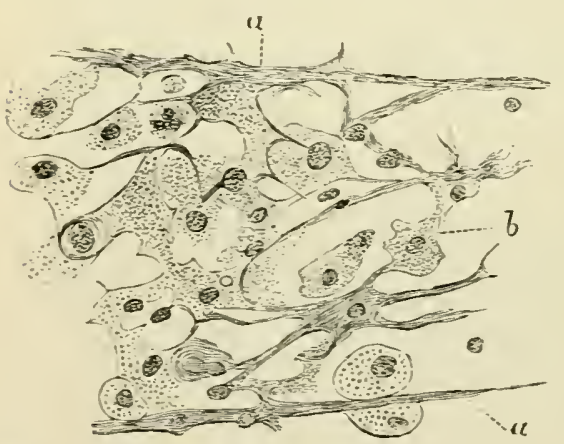

Fig. 233.-From a Section through the Pul ' of the spleen of Pig. (Atlas.)

a, Last outrunners of the muscular trabeculæ; $b$, flattened cells forming the honercombed matrix of the pulp: in the meshes of this matrix are contained lympoid cells of rarious sizes.

elements of that part of the spleen pulp (Fig. 233).

The meshes of the network of the trabecula are filled up with the parenchyma. This consists of two non-striped inuscular tissue. This is more pronounced in the dog, horse, pig, guinea-pig, in which the trabeculie are chiefly composed of non-striped muscular tissue. Followingasmall trabecula after it is given off from a larger one, we find it branching into stillsmaller ones, which ultimately lose themselves amongst the spleen tissue called 
kinds of tissues: ( 1 ) the Malpighian corpuscles ; and (b) the pulp tissue.

297. The Malpighian corpuscles are masses of adenoid tissue connected with the branches of the splenic artery. Following the chief arterial trunks as they pass in the big trabeculie towards the interior of the spleen, they are seen to give off numerous smaller branches to the spleen parenchyma; these are ensheathed in masses of arlenoid tissue, which are either cylindrical or irregularly-shaped, and in some places form oval or spherical enlargements. These sheaths of adenoid tissue are traceable to the end of an arterial branch; and in the whole extent the adenoid tissue or Malpighian corpuscle is supplied by its artery with a network of capillary blood-ressels.

298. The rest of the spleen parenchyma is made up of the pulp. The matrix of this is a honeycombed, spongy network of fibres and septa, which are the processes and bodies of large, flattened, endotheloid cells, each with an oval nucleus. In some, especially young, animals, some of these cells are huge and multinucleated. The spaces of the honeycombed tissue are of different diameters, some not larger than a blood corpuscle, others large enough to hold several. All spaces form an intercommunicating system. The spaces contain nucleated lymph corpuscles, more or less connected with and derived from the cell plates of the matrix. But they do not fill the spaces, so that some room is left, large enough to allow blood corpuscles to pass.

The spaces of the honeycombed pulp matrix are in communication, on the one hand, with the ends of the capillary blood-vessels of the Malpighian corpuscles, and, on the other, they open into the renous radicles or sinuses (Fig. 234), which are oblong spaces lined with a layer of more or less polyhedral endothelial cells. These sinuses form networks, and lead into the large 
venous branches passing in the big trabeculæe to the hilum. The renous sinuses in man and ape possess a special adrentitia formed of circular elastic fibrils.

Not all arterial branches are ensheathed in

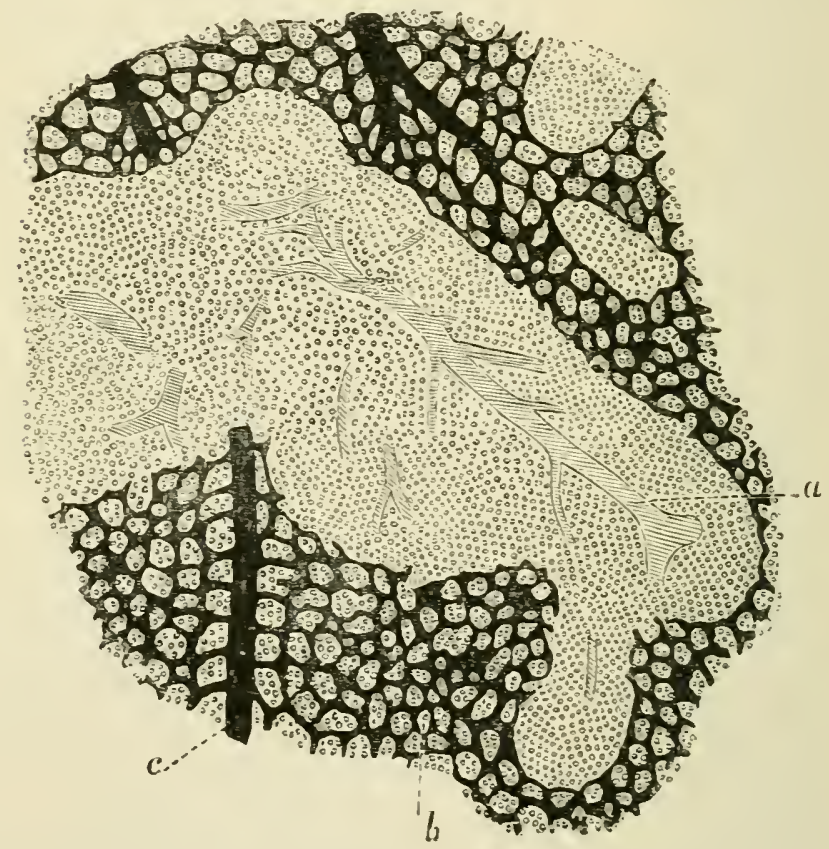

Fig. 234.-From a Section through the Spleen of a Guinea-pig ; the bloodressels had been injected. (Atlus)

$a$, Arters of Malpighian corpuscle: $h$. pulp; hetween it cells are the minute blood-channels openung into $c$, the radicles of the reins.

Malpighian corpuscies; some few fine arterial branches open directly into the reins of the pulp matrix, being invested in a peculiar reticular or concentrically arranged cellular tissue (not adenoid). 'These are the capillary sheaths of Schweigger Seidel.

299. The blood passes then from the arterial branches through the capillaries of the Malpighian 
corpuscles, whence it travels into the labyrinth of minute spaces in the honeycombed pulp matrix; thence it passes into the renous sinuses, and finally into the venous trunks. The current of blood on its passage through the pulp tissue becomes, therefore, greatly retarded. Under these conditions numerous red blood-corpuscles appear to be taken up by the cells of the pulp, some of which contain several in their interior. In these corpuscles the blood discs become gradually broken up, so that finally, only granules and small clumps of blood pigment are left in them. The presence of blood pigment in the corpuscles of the pulp is explained in this way; and it is therefore said that the pulp tissue is a destroyer of red blood-corpuscles.

The pulp tissue is most probably the birthplace of colourless blood-corpuscles; and according to Bizzozero and Salrioli it is also the birthplace of red bloodcorpuscles.

The lymphatics form plexuses in the capsule (Tomsa, Kyber). These are continuous with the plexus of lymphatics of the trabecule; and these again with the plexus of lymphatics in the adrentitia of the arterial trunks.

Fon-medullated nerve fibres have been traced along the arterial branches. 


\section{CHAPTER XXXII.}

THE KHDNEY, URETER AND BLADDER.

\section{A. The framework.}

The kidney possesses a thin investing capsule composed of fibrous tissue, more or less of a lamellar arrangement. Bundles of fibrous tissue pass with blood-ressels between the deeper part of the capsule and the parenchyma of the periphery. According to Eberth, a plexus of non-striped muscle cells is situated underneath the capsule.

The ureter entering the hilum enlarges into the pelvis of the kidney, and with its minor recesses or prolongations forms the calices. Both the pelvis and the calices are limited by a wall which is a direct continuation of the ureter. The internal free surface is lined with stratified transitional epithelium. Underneath the epithelium is a fibrous connective-tissue membrane (the mucosa), containing the networks of capillary blood-ressels and fine nerve fibres. Outside the mucosa and insensibly passing into it is the loose-textured submucosa, with groups of fat cells. There are present in the submucosa bundles of non-striped muscular tissue, continued from the ureter, in the shape of longitudinal and circular bundles.

In the pelvis of the kidney of the horse small glands (simple or branched tubes), lined with a single layer of columnar epithelial cells, have been observed by Paladino, Sertoli, and Egli. The last-named mentions also that in the pelvis of the human kidney 
there are gland-tubes similar in structure to sebaceous follicles.

301. The large vascular trunks enter, or pass from the tissues of the calices into the parenchyma of the kidney between the cortex and medulla, and they are accompanied by bundles of tibrous connective tissue and a few longitudinal bundles of non-striped muscular tissue, thereby separating the individual Malpighian pyramids.

The parenchyma itself contains very scanty fibrous connective tissue, chiefly around the Malpighian corpuscles and around the arterial vessels, especially in the young kidney. In the papillat there is relatively a great amount of fibrous tissue. On the surface of the papillie (facing the calices) there is a continuous layer of tibrons tissue, and this on its free surface is covered with stratified transitional epithelium.

The parenchyma of the kidney consists entirely of the urinary tubules and the intertubular blood-ressels, and there is an interstitial or intertubular connectivetissue framework in the shape of honeycombed hyaline membranes with flattened nucleated branched or spindle-shaped cells. The meshes of the honeycomb are the spaces for the urinary tubules and blood-vessels.

302. B. The parenchyma.- T. The urinary tubules (Fig. 235). - Tn a transverse or longitudinal section through the kidney we notice the cortex, the boundary layer of Lndwig and the papillary portions, the last terminating in the conical prepille in the cavity of the calices.

The boundary layer and the papillary portion form the medulla. A papilla with the papillary portion and boundary layer, continuous with it, constitutes a Malpighian pyramid. The medulla of the human kidney contains about a dozen of such Malpighian pyramids.

303. The cortex contains vast numbers of 


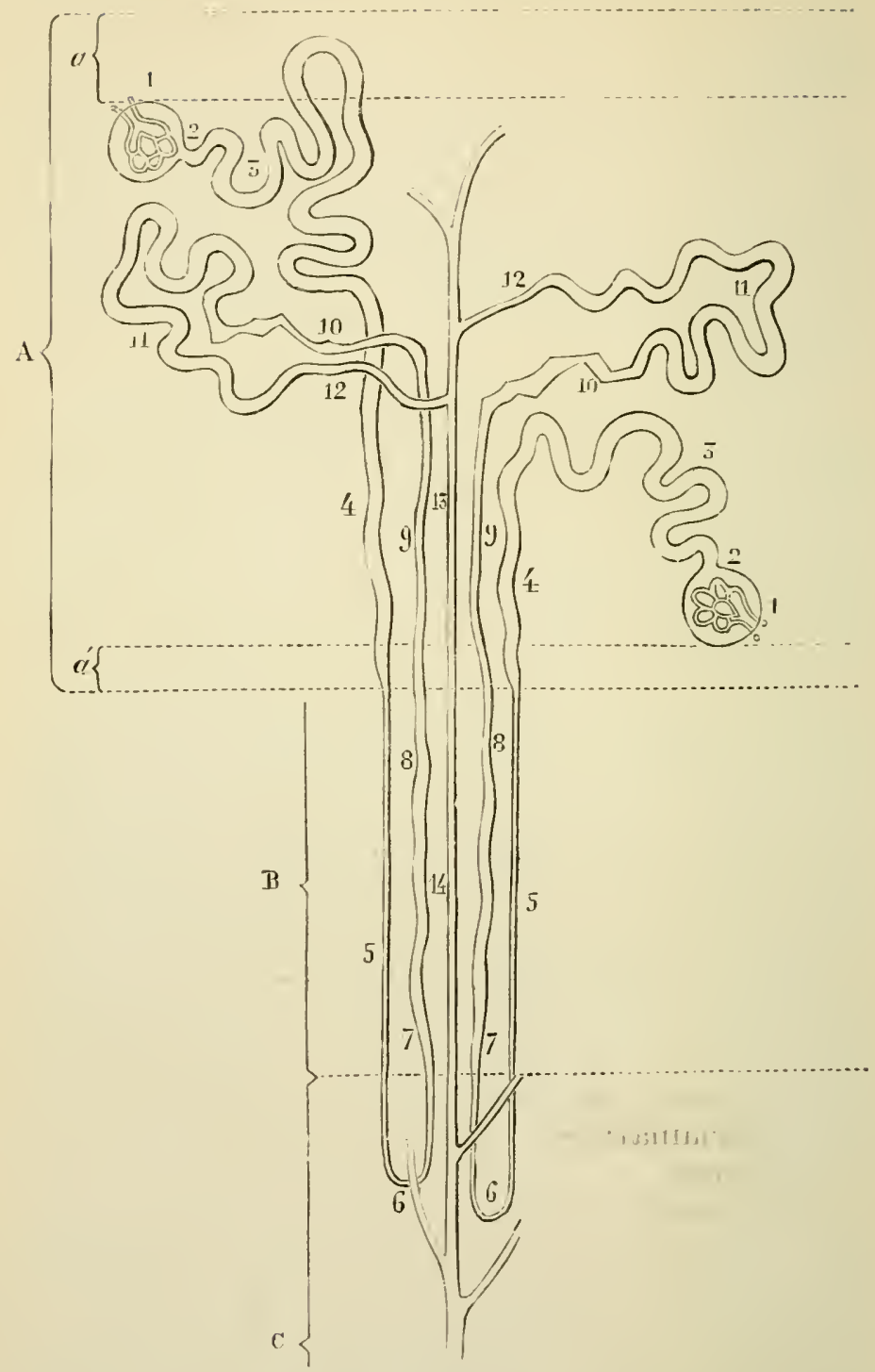

Fig. 235.-Diagram showing the course of the Uriniferous Tubules in the different prarts of the cortex and medulla. (Atlas.)

(For description of this Fig. sce foot of next page.) 
conroluted tubules with their ceeeal origin in the Malpighian corpuscles; this is the lab!yinth separated into mumerous divisions of equal breadth by regularlydisposed straight strie originating a short distance from the onter capsule, and radiating towards the boundary layer through which they pass. Each of these stria is a bundle of straight tubules, and represents a medullury ray. The boundary layer shows a uniform vertical striation, in which opaque and transparent strie alternate with one another. The opaque striae are continuations of the medullary rays, the transparent striat are bundles of blood-ressels.

The papillary portion is miformly and vertically striated.

Tracing a medullary ray from the boundary layer into the cortex, it is seen that its breadth gradually diminishes, and it altogether ceases at a short distance from the outer capsule. A medullary ray is, consequently, of a conical shape, its apex being situated at the periphery of the cortex, its base in the boundary layer. Such a pyramid is called a pyramid of Ferrein.

304. All urinary tubules commence as convoluted tubules in the part of the cortex named the labyrinth, but not in the medullary rays, with a cacal enlargement called a Malpighicun corpuscle, and terminate-having previously joined with many other tubules into larger and larger ducts - at one of the many minute openings or mouths at the apex of a papilla. On their way the tubes several times alter their size and nature.

A, Cortex limited on it free surface by the capsule; a, subcapsular layer not contaiuiug IIalpighion corpuseles; $a^{\prime}$ inner stratum of cortex without

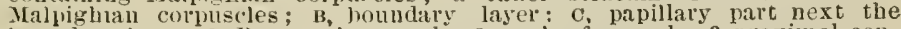
boundary layer ; 1 , Bowman's capsule; 2 , neck of capsule ; 3 , proximal convoluted tube; 4, spiral part; 5 , descending limb of Henle's loop-tube ; 6 , the loop itself; 7,8 , and 9 , the ascending limb of Henle's loop-tube; 10 , the irregulat tubule; 11 , the distal cumvoluted tubule; 12 , the first part uf the collecting tube; 13 and 14 , larger collecting tube; in the papilla itself, not represented here, the collecting tube joins others, and forms the duct. 
From its start to its end there is a continuous fine memtirana propiria forming the boundary wall of the urinary tubule, and this mentsana propria is lined with a single layer of eprithetial cells differing in

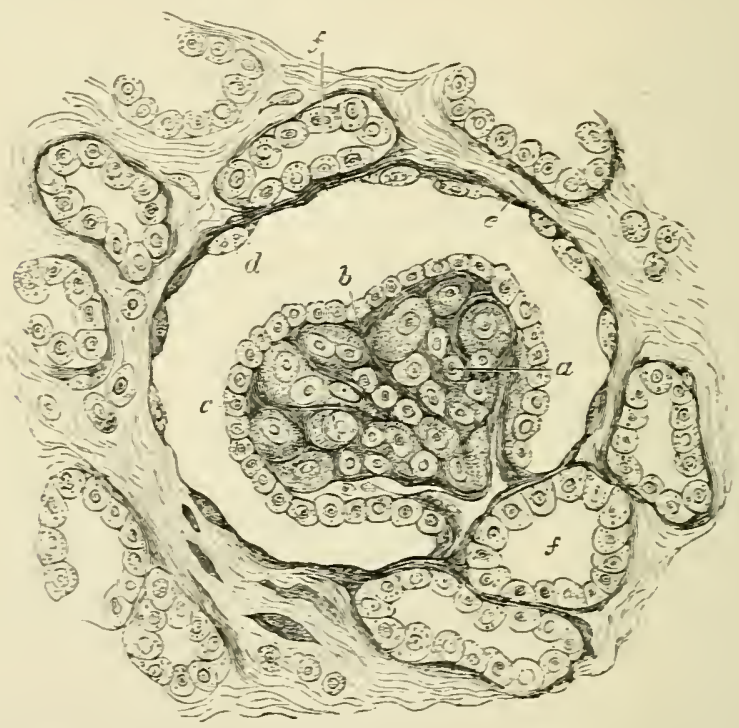

Fig. 231.-From a section through the Cortical sulstance of the Kidney of a human Foetus, showing a Malpighian corpuscle. (Handboli.)

$a$, Glomerula - $b$, tissue of the glomeralus : $c$. epithelium covering the glomerulus: $d$. flattened epithelimm lining Bowman; can-ule ; $\epsilon$, the capsule it-elf ; $f$, uriniferons tubules in cross section.

size, shape: and structure from place to place; in the centre of the tubule is a lumen, differing in size according to the size of the tubule.

305. (1) Each Malpiglian corpuscle (Fig. 2:36) is composed of the capsule - the capsule of Boumanand the glomerulus, or Malpighian tuft of capillary blood-ressels.

The capsule of Bowman is a hyaline membrana propria, supported, as mentioned above, by a smali amount of connectire tissue. On its inner surface 
there is a continuous layer of nucleated epithelial cells, in the young state of polyhedral shape, in the adult state squamons.

The glomerulus is a network of convoluted capillary blood-vessels separated from one another by scanty connective tissue, chiefly in the shape of a few connective-tissue corpuscles. The capillaries are grouped together in two to five lobules. The whole surface of the glomerulus is lined with a delicate membrana propria, and a continuous layer of nucleated epithelial cells, polyhedral, or even columnar in the young, squamous in the adult state. The membrana propria and epithelium dip in, of course, between the lobules of the glomerulus, and represent in reality the visceral layer of the capsule of the Malpighian corpuscle, the capsule of Bowman being the parietal layer. The glomerulus is connected at one pole with an afferent and efferent arterial ressel, the former being the larger of the two.

Between Bowman's capsule and the glomerulus there is a space, the size of which differs according to the state of secretion, being chiefly dependent on the amount of fluid present.

The Malpighian corpuscles are distributed in the labyrinth of the cortex only, with the exception of a thin peripheral layer near the outer capsule, and a still thinner layer near the boundary layer. The Malpighian corpuscles near the boundary layer are the largest, those near the periphery the smallest ; in the human kidney their mean diameter is about $\frac{1}{120}$ of an inch.

306. (2) On the side opposite to that where the afferent and efferent arterioles join the glomerulus, the capsule of Bowman passes through a narrow neck into the cylindrical urinary tubule in such a way that the membrana propria and epithelium of the capsule are continued as the membrana propria and 
lining epithelium of the tubule respectively, and the space between the capsule of Bowman and
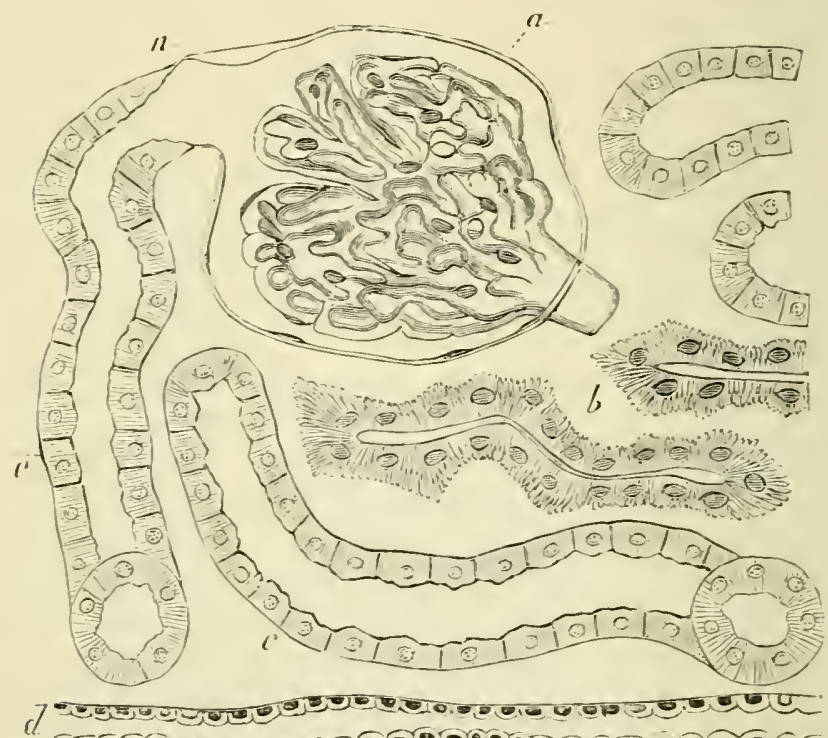

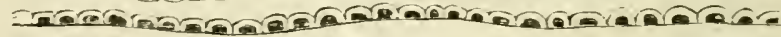
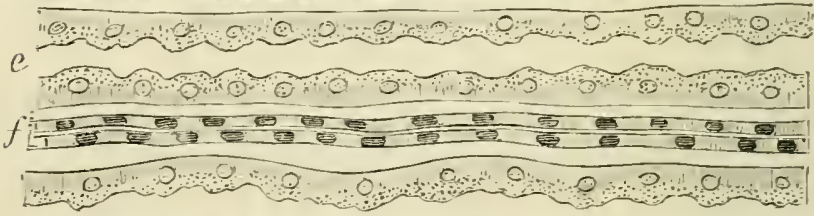

e.

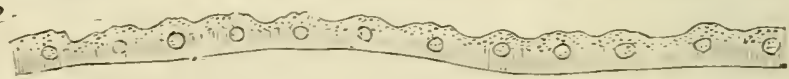

Fig. 237.-From a Vertical Section through the Kidney of Dog, showing part of the labyrinth aud the adjoining medullary ray. (Atlas.)

a, Capsule of Bowman; the capillaries of the gimerulus are arranged in lobules; $n$, neck of capsule; $b$, irregular tubule: $c$, proximal convoluted tubules; $d$, collecting tube; $e$, part of the spiral tubule: $f$, portion of the - ascending limb of Henle's loop-tube; $d, e, f$, form the medullary ras.

the glomerulus becomes the carity or lumen of the urinary tubule.

$30 \%$. (3) After it has passed the neck, the urinary tubule becomes convoluted: this is the proximal con- 
roluted tubule (Fig. .37). It is of considerable length and is situated in the labyrinth. It has a distinct lumen, and its epithelium is a single layer of polyhedral or short, columnar, angular, or club-shaped cells, each with a spherical nucleus. These cells commence generally at the neck, but in some animals-e.g. in the mouse - they already have begun in the Malpighian corpuscle. 'The outer part of the cell protoplasm-i.e. next the membrana propria-is distinctly striated, owing to the presence of rod-shaped fibrils (Heidenhain) vertically arranged. The inner part of the cell substance-i.e. between the nucleus and the inner free margin-appear's granular. Epithelial cells the protoplasm of which possesses the above rod-shaped tibrils will in the following paragraphs be spoken of as fibrillated cells.

The proximal convoluted tube appears sometimes thicker than at other times: in the first case, its lumen is smaller, but its lining epithelial cells are distinctly more columnar. This state is probably connected with the state of secretion.

308. (4) The convoluted tube passes into the spiral tubule (Schachowa). This clitters from the former in being situated not in the lahyrinth, but in a medullary ray, in which it forms one conspicuous element, and in not being convoluted, but more or less straight, slightly warr, and spiral. Its thickness and lumen are the saine as in the former: its epithelium is a single layer of polyhedral cells, with distinct indication of fibrillation.

309. (5) Precisely at the line where the cortex joins the boundary laser, the spiral tube becomes. suddenly greatly reduced in thickness; it becomes at the same time rery transparent; its lumen is distinct: its membrana propria is now lined with a single layer of scales, each with an oval flattened nucleus. This altered tubule is the descending loop-tube of 


\section{ELEMENTS OF HISTOLOGY.}

Henle, and it pursues its course in the boundary layer as a straight tubule, in the continuation of the medullary ray.

In aspect and size this part of the urinary tubule resembles a capillary blood-ressel, but differs from it inasmuch as, in addition to the lining layer of flattened epithelial cells, it possesses a membrana propria.

310. (6) The so-constituted descending Henle's loop-tube passes the line between the boundary layer and papillary portion, and having entered this latter, pursues its course for a short distance, when it sharply bends backwards as the loop of Henle's tube; it now runs back towards the boundary layer, and precisely at the point of entering this becomes suddenly enlarged. $\mathrm{Up}_{\mathrm{p}}$ to this point the structure and size of the loop are exactly the same as those of the descending limb.

311. ( $T$ and 8 ) Having entered the boundary layer it pursues its course in this latter to the cortex in a more or less straight direction within the medullary ray as the ascending loop-tube. Besides being bigger than the descending limb and the loop, its lumen is comparatively smaller, and its lining epithelium is a layer of polyhedral, distinctly fibrillated epithelial cells. The tube is not quite of the same thickness all along the boundary layer, but is broader in the inner than in the outer half; besides, the tube is not quite straight, but slightly wary or even spiral.

(9) Having reached the cortex, it enters this as the cortical part of the ascending loop-tube, forming one of the tubes of a medullary ray; it is at the same time narrower than in the boundary layer, and is more or less straight or wavy. Its lumen is very minute, its lining cells are flat polyhedral with a small flattened nucleus, and there is an indication of fibrillation ( $\mathrm{Fi} \underset{\check{c} .237}{ }$ ).

(10) Sooner or later on its way in the cortex in 
a medullary ray it leaves this latter to enter the labyrinth, where it winds between the convoluted tubes as an angular irregular tubule (Fig. 237). Its shape is very irregular, its size alters from place to place, its lumen is very minute, its epithelium a layer of polyhedral, pyramidal, or short columnar cells -according to the thickness of the tube; each cell possesses a flattened oval nucleus next to the lumen, and a very coarsely and conspicuously fibrillated protoplasm.

312. (11) This irregular tubule passes into the distal convoluted tubule or intercalated tubule of Schweigger Seidel. This forms one of the convoluted tubes of the labyrintl, and in size, aspect, and structure is identical with the proximal convoluted tubule.

(12) The distal convoluted tube passes into a short, thin, more or less curved or wavy collecting tubule, lined with a liner of transparent, flattened, polyhedral cells; this is still contained in the labyrinth.

(13) This leads into a somewhat larger straight collecting tube, lined with a layer of transparent polyhedral cells and with distinct lumen. This tube forms part of a medullary ray, and on its way to the boundary layer takes up from the labyrinth numerous curved collecting tubules.

(14) It then passes unaltered as a straight collecting tube through the boundary layer into the papillary portion.

313. In this part these tubes join under acute angles, thereby gradually enlarging. They run in a straight direction towards the apex of the papilla, and the nearer to this, the fewer and the bigger they become. These are the ducts or tubes of Bellini. They finally open on the apex into a calix. The lumen and the size of the lining epithelial cells-namely, 


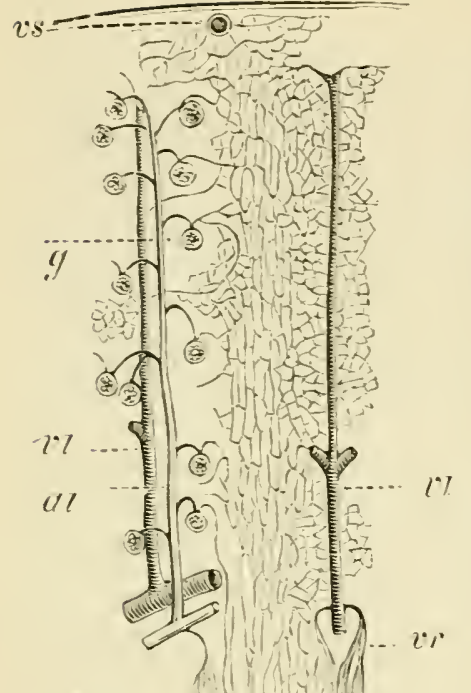

[I]
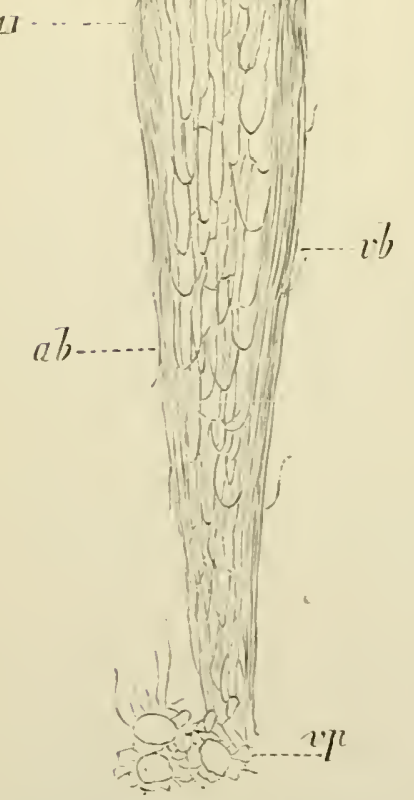

Fic. 23s.-Diagram of the Tessels of the Kidney. (Lucluig, in stricker's Ianual.) whether more or less columnar-are in direct relation to the size of the collecting tube. The substance of the epithelial cells is a transparent protoplasm, and the nucleus is more or less oval.

314. In many places nucleated cells, spindleshaped or branched, can be traced from the membrana propria of the tubule between the lining epithelium ; and, in some cases, eren a delicate nucleated membrane can be seen lining the surface of the epithelium next the lumen. In the frog, the epithelium lining, the Malpighian corpuscles, and the exceedingly long neck of the urinary tubule, are possessed of long filamentous cilia, rapidly moving during life. In the neck of some of the urinary tubules in mammals there is also an indication of cilia to be noticed.

ai, Interlobular artery : $\imath^{\circ} i$, interlobular vein: $g$, glomerulns of Malpighian cornu-cle; $\tau s$, veua stellata; $a r$, arteria rect $x ; r$, vena recta; $a b$, mudle of arterix rectæ: $v b$. bundle of rena rectx; $v p$, network of ressels around the mouth of the dnets at the arex of the papilla. 
Heidenhain las shown that indigo-sulphate of sodium, injected into the circulating blood of the dog and rabbit, is excreted through certain parts of the urinary tubules only-viz. those which are lined with

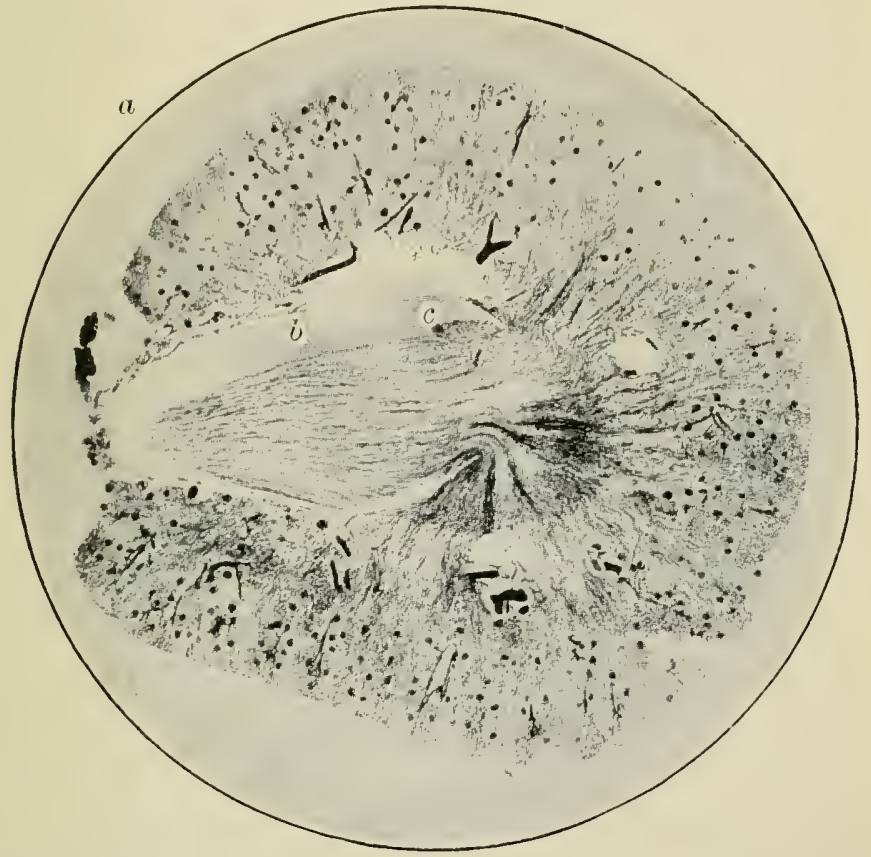

Fig. 239.-Vertical Section through the entire Kirlney (injected) of a Rat. (Photo. L,ow Power.)

a, Cortex ; $b$, papilla ; $c$, boundary layer.

"fibrillated" epithelium. He maintains that this excretion is effected through the cell substance; but, in the case of carmine being used as pigment, I have not found the excretion to take place through the substance of the epithelial celis, but through the homogeneous interstitial or cement substance between the epithelial cells.

315. II. The blood-vessels (Figs. 238 and 239). 
The large branches of the renal artery and rein are situated in the submucous tissue of the pelvis, and they enter, or pass out respectively from, the part of the parenchyma corresponding to the junction of the cortex and boundary layer, where they follow a more or less horizontal course, and give off, or take up respectively, smaller branches to or from the cortex and medulla.

(1) In the cortex the arterial trunks give off to the cortex small branches, which singly enter the labyrinth in a direction rertical to the surface of the kidney. These are the interlobular arteries. Each of these, on its way towards the external capsule of the kidney, gives off, on all sides of its circumference, shorter or longer lateral branches; these are the afferent arterioles for the Malpighian corpuscles, each one entering a Malpighian corpuscle and breaking up into the capillaries of the glomerulus.

On their way towards the external capsule, the arteries become greatly reduced in size, and finally enter the capillary network of the most peripheral part of the cortex; but some of these arterioles may be also traced into the outer capsule, where they become connected with the capillary networks of this latter. The efferent ressel of a Malpighian glomerulus at once breaks up into a dense network of capillary blood-ressels, which surround in all directions the urinary tubules of the labyrinth. This network is continuous with that of the capillaries of the medullary rays, the meshes being here elongated, and the capillary blood-vessels, for obvions reasons, more of a straight arrangement. The capillaries of the whole cortex form one continuous network.

316. The reins which take up the blood from this network are arranged in this manner:-There are formed renous ressels underneath the external capsule, taking up like rays on all sides, minute 
radicles connected with the capillaries of the most peripheral part of the cortex. These are the vence stellate; they pass into the labyrinth of the cortex, where they follow a verticil course in company with the interlobular arteries. On this passage they communicate with the capiliaries of the labyrinth, and ultimately open into the large venous branches situated between cortex and boundary layer.

317. (2) In the medulla. From the large arterial trunks short branches come off, which enter the boundary layer, and there split up into a bundle of minute arterioles, which pass in a straight direction rertically through the boundary layer into the papillary portion. These are the arterice rectre (Fig. 238). The number of ressels of each bundle is at the outset increased by the efferent vessel of the Malpighian corpuscles nearest to the boundary layer.

On their way through the boundary layer, and through the papillary portion of the medulla, these arterioles give off the capillary network for the urinary tubules of these parts, the network, for obvious reasons, possessing an elongated arrangement.

From this network originate everywhere minute veins, which on their way towards the cortical margin increase in size and number; they form also bundles of straight vessels-vence recte-and ultimately enter the venous trunks situated between the boundary layer and cortex.

The bundles of the arteriæ rectæ and venæ rectæ form severally, in the boundary layer, the transparent strix mentioned on a previous page as alternating with the opaque strix, these latter being bundles of urinary tubules.

At the apex of each papilla there is a network of capillaries around the mouth of each duct. 
318. The outer capsule of the kidney contains a network of capillary hlood-ressels: the arterial branches leading into them are derived from two sources: (a) from the outrunner's of the interlobular

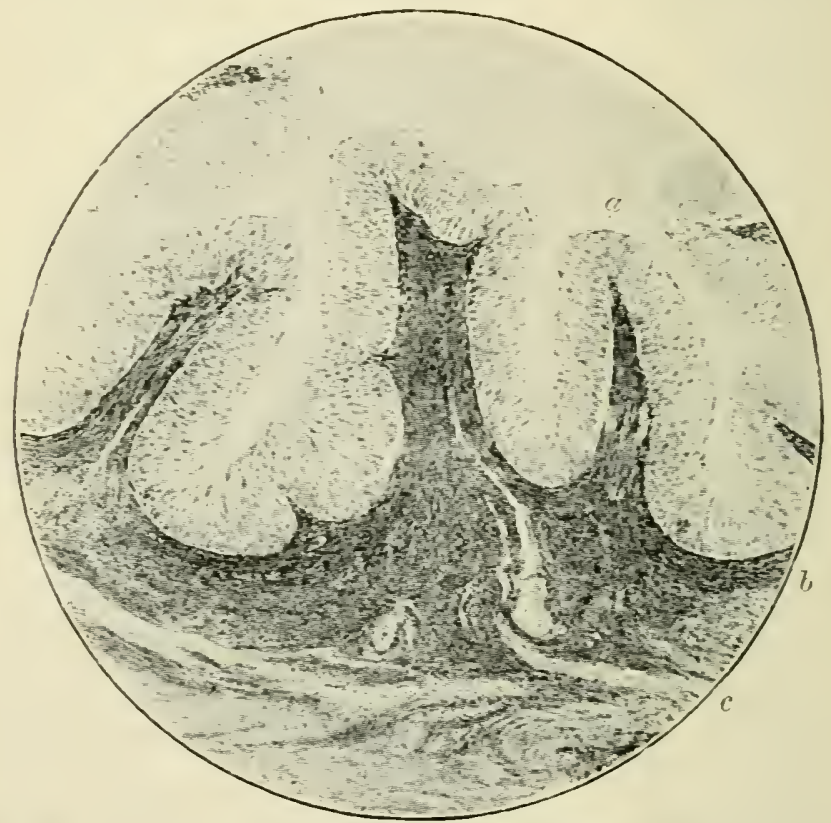

Fig. 240.-From Transverse Section through Urinary Bladder of Dog. (Photo. Lou Pouer.)

a, Inner surface of folded mucous membrane, corered with stratified transitional epithelium; $b$, mucons membrane : $c$, outer coat of non-striped muscle.

arteries of the cortex, and (b) from extra-renal arteries. The reins lead $(a)$ into the renæ stellatæ, and $(b)$ into extra-renal reins.

The l!mpluritic ressels form a plexus in the capsule of the kidney. They are connected with lymph spaces between the urinary tubes of the cortex. The large blood-ressels are surrounded by a plexus of lrmphatics, which take up lrmpl spaces between the 
urinary tubules, both in the cortex and the boundary laver.

:319. The meter is lined with stratified transitional epithelium. Underneath this is the mucosa, a connective-tissue membrane with capillary bloodressels. The submucosa is a loose connective tissue. Then follows a muscular coat composed of nonstriped muscular tissue, arranged as an inner and outer longitudinal and a middle circular coat. Then follows an outer limiting thin tibrous coat or adrentitia. In this last have been observed minute ganglia in connection with the nerre-branches.

320. The bladder is similar in structure, but the mucous membrane and muscular coat are rery wuch thicker. In the latter, which consists of nonstriped fibres, can be distinguished an inner circular, a micklle oblique, and an outer longitudinal stratum. The last is best dereloped in the fundus (Fig. 240).

Numerous sympathetic ganglia, of various sizes, are found in connection with the nerre-branches underneath the alventitia (peritoneal covering), and in the muscular coat (F. Darwin). The epithelium lining the bladder is stratifier transitional, and it greatly varies in the shape of its cells and their stratification, according to the state of expansion of the bladiler. 


\section{CHAP'TER XXXIII.}

THE MALE GENITAL ORGANS.

321. (1) The testis of nan and mammals is enreloped in a capsule of white fibrous tissue, the tunica adnatu. This is the visceral layer of the tunica vaginalis. Like the parietal layer, it is a serous membrane, and is therefore covered with endothelium. Minute villi are occasionally seen projecting from this membrane into the cavity of the tunica vaginalis. These villi are generally covered with germinating endothelium. Inside the tunica adnata, and firmly attached to it, is the tunica albuginea, a fibrous connective-tissue membrane of lamellar structure. Towards the posterior margin of the human testis its thickness increases, and forms there (Fig. 241) a special accumulation-in cross section more or less conical, with posterior basis - the mediastinum testis, or corpus Highmori.

Between the tunica adnata and tunica albuginea is a rich plexus of lymphatics, which, on the one hand, takes up the lymphatics of the interior, and on the other leads into the efferent vessels that accompany the vas deferens.

The testis of the dog, cat, bull, pig, rabbit, etc., have a central corpus Highmori; that of the mole, hedgehog, and bat a peripheral one; while that of the rat and mouse have none (Messing).

32.2 . 'The frameworlk. - From the anterior margin of the corpus Highmori spring numerons 
septa of connective tissue, which, passing in a radiating direction towards the alluginea, with which they form a continuity, subdivide the testis into a large

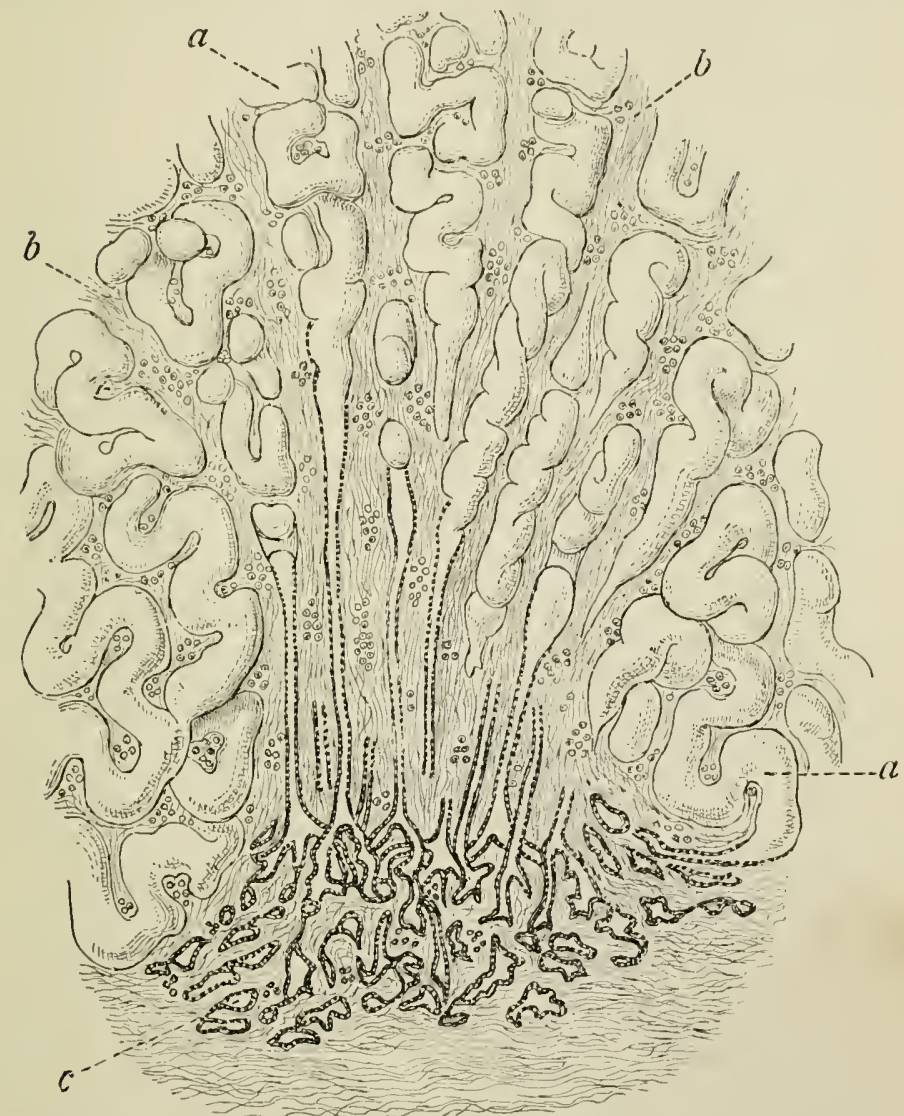

Fig. 241.-Passage of Convoluted Seminiferous Tubules into Straight Tubules and into the Rete Testis. (Mihalkovics, Quain's "Anatomy.") $a$, Seminiferous tubules; $b$, fibrous tissue : $c$, rete testis.

number of more or less conical compartments, or lobules, the basis of which is situated at the tunica albuginea, the apex at the corpus Highmori. Kölliker: 
mentions that non-striped muscular tissue occurs in these septa.

From these septr thin connective-tissue lamellae pass into the compartments, and they form the supporting tissue for the blood-ressels, and also iepresent the interstitial connective tissue betreen the seminal tubules.

This intertubular or interstitial tissue is distinctly lamellated, the lamellre being of different thicknesses, and consisting of thin bundles of fibrous connective tissue-arranged more or less as fenestrated membranes-ind endotheloid connective plates on their surface. Between the lamellie are left spaces, and these form, through the fenestra or holes of the lamellæe, an intercommunicating system of lrmph spaces being, in fact, the rootlets of the lymphatics (Ludwig and Tomsa).

Within the lamellæe are found peculiar cells, which are much larger than lymph cells, and which, in some instances (e.g. gruinea-pig), include pigment granules. They contain a spherical nucleus. In man, dog, cat, sheep, especially in the boar, these cells form large, continuous groups-plates and cylinders-and the cells are polyhedral, and exactly similar to epithelial cells. They are separated from one another within the group by a thin interstitial cement substance. Their resemblance with epithelium is complete. They are remuants of the epithelial masses of the Wolthian body of the foetus.

\subsection{The seminal tubmes (Fig. 24:2).}

Within each compartment, above mentioned, lie numerous seminel tubules, twisted and convoluted in many ways, and extending from the periphery to near the corpus Highmori. The tubules, as a rule, are rarely branched; but in the young state, and especially towards the periphery, branching is not uncommion. 
Each seminal tubule consists of a membrana propria, a lining epithelium, and a lumen. The membrana propria is a hyaline membrane, with oval nuclei at regular intervals. In man it is thick and lamellated, several such nucleated membranes being

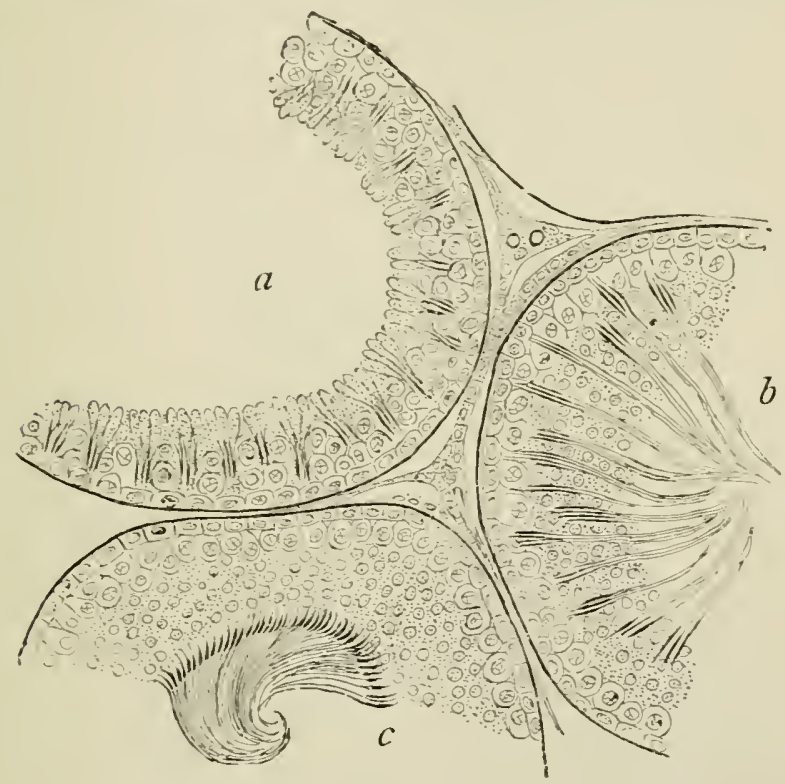

Fig. 24:. - Section of parts of three seminiferous Tubules of Rat. (E. A. Schiifer.)

$a$, With the spermatozoa least adranced in development; $b$, more, and $c$, most advanced. Between the tubules are strinds of interstitial cells.

superimposed over one another. The lumen is in all tubes distinct and relatively large. The lining epithelium, or the seminal cells, differ in the adult in different tubules, and even in different parts of the same tubule: being dependent on the state of secretion.

324. Before puberty all tubules are uniform in this respect, being lined with two or three layers of polyhedral epithelial cells, each with a spherical 
nucleus. After puberty, however, the following different types can be distinguished.

(a) Tubules or purts of tubules similar to those of the young state-viz. several layers of polyhedral epithelial cells lining the membrana propria. These are considered as (a) the outer and $(b)$ the inner seminal cells. The former are next to the membrana
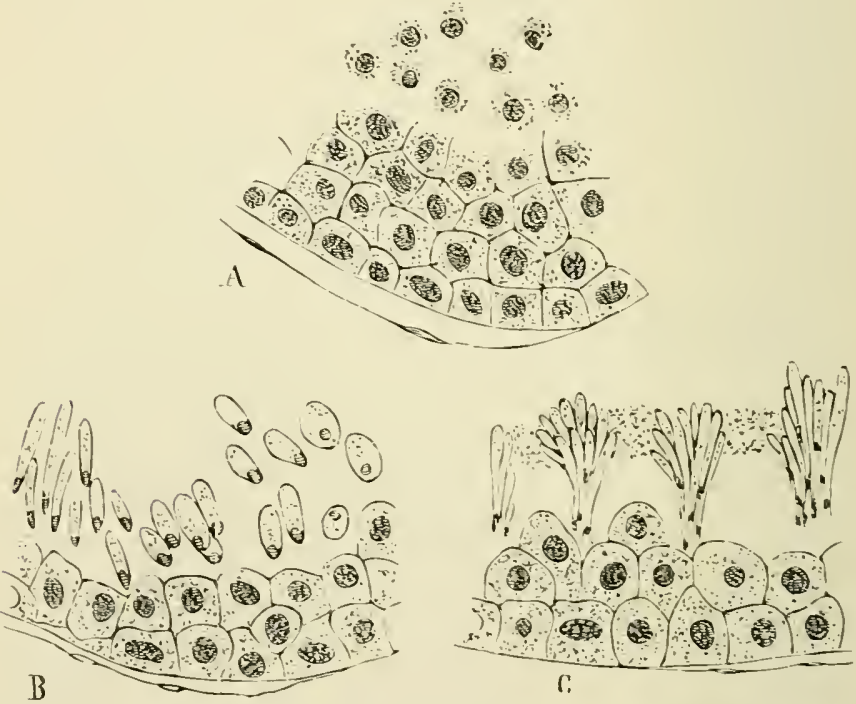

Fig. 243.-From a Section through the Testis of Dog, showing portions of three seminal tubules. (Atlas.)

A. Seminal ejithelial cells and numerous small cells loosely arrauged; 13, small cells or spermatohlasts becoming converted into spermatozoa; $\mathrm{c}$, grums of these in a further stage of development.

propria; they are polyhedral in shape, transparent. and the nucleus of many of them is in the process of karyomitosis or indirect division (see par. 8) ; in some the nucleus is oval transparent, but containing a distinct network. The inner seminal cells generally form two or three layers, and are more loosely connected with one another than the outer seminal cells, and therefore possess a more rounded appearance. 
Between these a nucleated reticulum of fine fibres is sometimes noticed, the germ reticulum of von Ebner. But this is merely a supporting tissue, and has nothing to do with the germination of the cells or the spermatozoa (Merkel). The inner seminal cells show very abundantly the process of indirect division of the nucleus, almost all being seen in one or another phase of it.

325. The division of the inner seminal cells yields numerous small spherical cells; these lie nearest the lumen, and are very loosely connected with one another. It is these which are transformed into spermatozoa, and hence are appropriately called spermatoblasts (Fig. 242).

Amongst the seminal cells, especially of cat and dog, are found occasionally, but not very commonly, large multinuclear cells, the nuclei of which are also in one or other stage of karyomitosis.

(b) The innermost cells - i.e. the spermatoblasts become pear-shaped, the nucleus being situated at the thinner extremity, becoming at the same time flattened and homogeneous (Fig. 24:3). The elongation of the spermatoblasts gradually proceeds, and in consequence of this we find numerous elongated, club-shaped spermatoblasts, each with a flattened nucleus at the thin end. These are the young spermatozoa, the nucleated extremity being the head.

(c) At the same time these young spermatozoa becone grouped together by an interstitial granular substance, in peculiar fan-shaped groups: in these groups the head-i.e. the thin end containing the flattened homogeneous nucleus-is directed towards the inner seminal cells, while the opposite extremity is directed into the lumen of the tube. Meanwhile the inner seminal cells continue to divide, and thus the groups of young spermatozoa get more and more buried, as it were, between them. 
326. The original cell-body of the spermatoblasts goes on elongating until its protoplasm is almost, but not quite, used to form a rod-shaped middle piece (Schweigger Seidel) of the spermatozoa; from the distal end of this, a thin long hair-like filament, called the tail, grows out. Where this joins the end of the middle piece, there is present, even for some time afterwards, a last remnant of the granular cell-body of the original spermatoblast. Some of the inner seminal cells not used for the formation of spermatozoa disintegrate and yield the gramular substance between the spermatozoa of the groups, and also between these latter.

When the granular interstitial substance holding together the spermatozon of a group has become dis. integrated, the spermatozoa are isolated. While this derelopment of the spermatozoa goes on, the inner seminal cells continue to produce spermatoliasts, some of which are converted into spermatozoa.

327. spermatozoa (Fig. 24t).-Fully formed spermatozoa of man and mammals consist of a homogeneous flattened and slightly convex-concave herd (the nucleus of the original spermatoblast), a rodshaped middle piece (derived directly from the cellbody of the spermatoblast), and a long hair-like tail. While living, the spermatozoa show very rapid oscillatory and propelling movement, the tiil acting as a flagellum or cilium; its morements are spiral.

In the newt there is a tine spiral thread attached to the end of the long, curred, spike-like head, and by a hraline membrane it is fixed to the middle piece; it extends beyond this as the tail. Also in the mammalian and human spermatozoa, a similar spiral thread, closely attached to the middle piece, and terminating as the tail, has been observed (H. Gibbes).

32. . The seminal tubules of each lobule pass into a short straight tubule, the vas rectum. This is 
narrower than the seminal tubule, and is lined with a single layer of polyhedral or short colummar epithelial cells. The vasa recta form, in the corpus Highmori, a dense network of tubular chamnels, which are irregular in diameter, being at one place narrow clefts, at

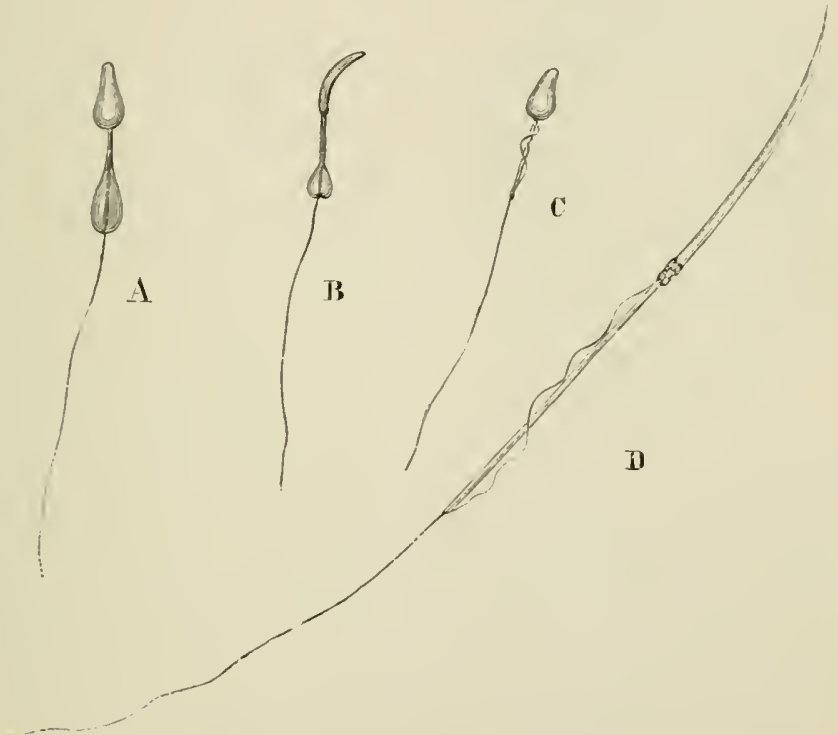

Fig. 244.- Tarious Kinds of Spermatozoa.

A, Spermatozonn of guinea-pig not yet completely ripe; $B$, the same seen sideways, the head of the spermatozoon is flattened from side to side; slerinatuzoon of horse; D, slermatozon of newt.

another wide tubes, but never so wide as the seminal tubules; this network of channels is the rete testis.

329. (2) The epididymis.-From the rete testis we pass into the vasa efferentia, each being a tubo wider than those of the rete testis, and each leading into a conical network of coiled tubes. These are the coni vasculosi. The sum total of all the coni vasculosi forms the globus major or hearl of the epididymis.

330. The vasa efferentia and the tubes of the coni 
vasculosi are about the size of the seminal tubules, but, unlike them, are lined with a layer of beantiful columnar epithelial cells, with a bundle of cilia (Fig. 245). Ontside these is generally a layer, more or less continuous, of small polyhedral ceils. The sub-

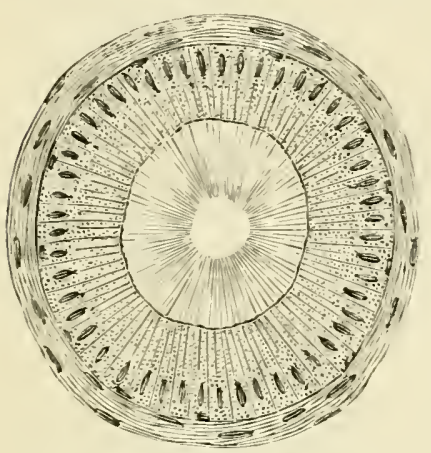

Fig. 245.-Tubule of the Epi. didynis in cross-section.

The wall of the tubule is made up of a thick layer of roncentrically arranged non-striped muscular tissue, a laver of columnar epithelial cells with extraotdinarily long cilia projecting into the lumen of the tube. stance of the columnar cells is distinctly longitudinally fibrillated. 'The membrana propria is thickened by the presence of a circular layer of non-striped muscular fibres. The rest-i.e. the globus minor, or tail of the epididymis - is made up of a continuation of the tubes of the globus major, the tubes diminishing gradually in number by fusion, and thereby at the same time becoming larger. The columnar epithelial cells, facing the lumen of the tubes of the globus minor, are possessed of cilia of unusual length.

The tubes of the epididymis are separated from one another by a larger amount of connective tissue than those of the testis.

The tubes of the organ of Giraldé, situated in the beginning of the funiculus spermaticus, are lined with columnar ciliated epithelium. So is also the pedunculated hydatid of Morgagni attached to the globus major.

331. The seminal tubules and the tubes of the epididymis are surrounded by a rich network of capillary blood-vessels. Between the tubes of the testis and epididymis are lymph spaces, forming an intercommunicating system, and emptying themselves 
into the superficial networks of lymphatics-i.e. those of the albuginea; the arrangement of these networks is somewhat different in the testis and epididymis.

\section{2. (3) Vas deferens and vesiculac semi-}

nales.-The tubes of the globus minor open into the vas deferens. This is, of course, much larger than the former, and is lined with stratified columnar epithelium. Underneath this is a dense connectivetissue mucosa, containing a rich network of capillary blood-vessels. Beneath this mucosa is a thin submucous tissue, which in the ampullat is better developed than in other parts, and therefore allows the mucous membrane to become folded. Outside the submucous tissue is the muscular coat, which consists of non-striped muscular tissue, arranged as an inner circular and an outer longitudinal stratum. At the commencement of the vas deferens there is in addition an inner longitudinal layer. There is finally a fibrous tissue adventitia. This contains longitudinal bundles of non-striped muscular tissue, known as the cremaster internus (Henle). A rich plexus of veins-plexus pampiniformis - and a rich plexus of lymphatic trunks, are situated in the connective tissue of the spermatic cord. The plexus spermaticus consists of larger and smaller nerve-trunks, with which are connected small groups of ganglion cells and also large ganglionic swellings.

333. In the vesiculce seminales we meet with exactly the same layers as constitute the wall of the vas deferens, but they are thinner. This refers especially to the mucosia and the muscular coat. The former is placed in numerous folds. The latter consists of an inner and outer longitudinal and a middle circular stratum. The ganglia in connection with the nerve trunks of the adventitia are very numerous.

334. In the ductus ejaculatorii we find a lining of 
columnar epithelial cells : outside of this is a delicate mucosi and a muscular coat, the latter consisting of an inner thicker longitudinal and an outer thinner circular stratum of non-striped muscular tissue.

When passing into the resicula prostatica the columnar epithelium is gradually replaced by stratified pavenent epithelium.

33.). (4) Whe prostate gland.-Like other glands, the prostate consists of a framework and the gland tissue proper or the parenchyma.

The framevork, unlike that of othur glands, is essentially muscular, being composed of bundles of non-striped muscular tissue, with a relatively small admixture of tibrous comnective tissue. The latter is chiefly limited to the outer capsule and the thin septa passing inwards, whereas the non-striped muscular tissue surrounds and separates the individual gland alveoli.

336. The paremchyma consists of the chief ducts, which open at the base of and near the colliculus seminalis, and of the secondary ducts, minor branclies of the former, which ultimately lead into the alveoli. These are longer or shorter, wary or convoluted branched tubes with numerous saccular or club-shaped branches. The alveoli and ducts are limited by a membran: propria, have a distinct lumen, and are lined with columnar epithelium. In the alveoli there is only a single layer of beautiful columnar epithelial cells, the substance of which is distinctly and longitudinally striated. In the ducts there is an inner layer of short columnar cells, and an outer one of small cubical, polyhedral or spindleshaped cells.

At the mouth of the ducts the stratified pavement epithelium of the pars prostatica of the urethra passes a short distance into the duct.

The alveoli are sirrrounded by dense networks of capillary blood-ressels. 
In the peripheral portion of the grand numerous ganglia are interposed in the rich plexus of nerves. Also Pacinian corpuscles are to be net with.

$3: 37$. (5) 'Wle urethra.-The mucons membrane of the male urethra is lined with simple columnar epithelium, except at the commencement-the pars prostatica - and at the end-the fossa naviculariswhere it is stratified pavement epithelium.

The mucous membrane is fibrous tissue with very numerous elastic fibres. Ontsicle of it is a muscular coat composed of non-striped muscular tissue, and arranged as an inner circular and an onter longitudinal stratum, except in the pars prostatica and pars membranacea, where it is chiefly longitudinal. In the latter portion the muscular bundles pass also into the mucous membrane, where they follow a longitudinal course between large veins arranged in a longitudinal plexus. These veins empty themselves into small efferent veins. This plexus of large veins with the muscular tissue between represents a rudiment of a cavernous tissue (Henle).

The mucous membrane forms peculiar folds surrounding the lacune Morgagni. There are small mucous glands, lined with columnar epithelium, embedded in the mucous membrane; they open into the cavity of the urethra and are known as Littré's glands.

338. (6) The grands of Cowper. - Each gland of Cowper is a large compound tubular gland, which, as regards structure of ducts and alveoli, resembles a mucous gland. The wall of the chief ducts possesses a large amount of longitudinally arranged non-striped muscular tissue. The epithelium lining the ducts is composed of columnar cells. The alveoli possess a large lumen and are lined with cohmnar mucous cells, the outer portion of the cell being distinctly striated (Langerhans). In the cell the reticulum is 
also distinct. In this respect the alveoli completely resemble those of the submaxillary of the dog, but there are no real crescents in the alveoli of Cowper's gland.

339. (7) The corpus somgiosum.-The corpus spongiosum of the urethra is a continuation of the rudimentary corpus cavernosum above-mentioned in comnection with the pars membranacea of the urethra. It is essentially a plexus of large reins arranged chiefly longitudinally, and leading into small efferent veins. Between the large veins are bundles of non-striped muscular tissue. 'The capillary blood-ressels of the mucous membrane of the urethra open into the reins of the plexus. The outer portion of the corpus spongiosum, including the bulbus urethre, shows, however, numerous venous sinuses, real carerne, into which open capillary bloodvessels.

340. The glans penis is of exactly the same structure as the corpus spongiosum. The outer surface is covered with a delicate fibrous tissue membrane, which on its free surface bears minute papilla, extending into the stratified parement epithelium. At the corona glandis exist small sebaceous follicles, the glands of Tyson; they are continued from the inner lamella of the prepuce, where they abound. The papille of the glans contain loops of capillary blood-vessels. Plexuses of non-medullated nerve fibres are found underneath the epithelium of the surface of the glans. With these are comnected the end bulbs described in a former chapter as the genital nerve-end corpuscles.

341 . (8) The corpora cavemosa penis.Each corpus cavernosum is enveloped in a tibrous capsule, the albuginea, made up of lamellæ of fibrous connective tissue. Numerous Pacinian corpuscles are met with around it. The matrix of the corpus 
cavernosum consists of trabecule of filsous tissue, between which pass bundles of non-striped muscular tissue, all in different directions. Innumerable carcrue or sinuses, intercommunicating with one another, are present in this matrix, capable of such considerable repletion that in the maximum degree of this state the sinuses are almost in contact, and the trabeculie compressed into very delicate septa. The sinuses are lined with a single layer of flattened endothelial plates, and their wall in many places is strengthened by the bundles of non-striped muscular tissue. The sinuses during erection become tilled with blood, being directly continuous with capillary blood-ressels. These are derived from the arterial branches which take their course in the above trabecula of the matrix. The blood passes from the simuses into small efferent veins. But the blood passes also directly from the capillaries into the efferent veins, and this is the course the blood takes under passive conditions, while during erection it passes chiefly into the above sinuses.

342 . In the peripheral part of the corpus cavernosum there exists a direct communication between the sinuses and minute arteries (Langer), but in the rest the arteries do not directly communicate with the sinuses except through the capillary bloodressels. In the passive state of the corpus cavernosim, the muscular trabeculie forming part of the matrix are contracted, anıl the minute arterial branches embedded in them are therefore much coiled up; these are the arteria helicinie. 


\section{CHAPTER XXXIV.}

THE FEMALE GENITAL ORGANS.

343. (1) 'The ovary (Fig. 246).-- In the ovary, as in other glands, the framework is to be distinguished from

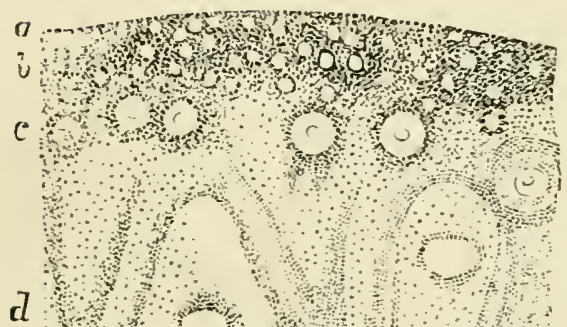
the parenchyma. In the part of the ovary next to the hilum there are numerous blood-ressels, in a loose fibrous connective tissue, with numerous longitudinal buncles of noll-striped muscular tissue directly continuous with the same tissues of the ligamentum latum. This portion of the ovary is the zona rasculosa (IV aldeyer). All parts of the zona vasculosa - i.e. the bundles of tibrous commective tissue, the blood-ressels, and the bundles of non-striped muscular tissue-are traceable into the parenchyma. 
'The stroma of this latter, howerer, is made up of bundles of shorter or longer transparent spindleshaped cells, each with an oval nucleus. These bundles of spindle-shaped cells form, by crossing and interlacing, a tolerably dense tissue, in which lie embedded in special distribution the Graatian follicles. Around the larger examples of the latter the spindle-shaped cells form more or less concentric layers. In the human orary bundles of fibrous tissue are also met with.

The spindle-shaped cells are most probably a young state of connective tissue.

Between these bundles of spindle-shaped cells occur cylindrical or irregular streaks or groups of polyhedral cells, each with a spherical nucleus; they correspond to the interstitial epithelial cells mentioned in the testis, and they are also derived from the foetal Wolthian body.

344. According to the distribution of the Graatian follicles, the following layers can be distinguished in the ovary:

(a) The albuginea. This is the most peripheral layer not containing any Graafian follicles. It is composed of the bundles of spindle-shaped cells, intimately interworen. In man, an outer and inner longitudinal, and a middle circular, layer can be made out (Henle). In some mammals an outer longitudinal, an inner circular, or slightly oblique layer can be distinguished in the albuginea.

The free surface of the albuginea is covered with a single layer of polyhedral, or short columnar granular-looking epithelial cells, the germinal epithelium (Waldeyer). This epithelium, in its shape and aspect, forms a marked contrast to the transparent, flattened, endothelial plates covering the ligamentum latum.

345. (b) The cortical layer (Schrön).-This is a 
layer containing the smallest Graafian follicles, either agorregated as a more or less continuous layer (cat and rabbit), or in small groups (human), separated by the stroma. These follicles are spherical or slightly oval, of about $\frac{1}{1000}$ inch in diameter, and each of them is limited by a delicate membrana propria. Inside of

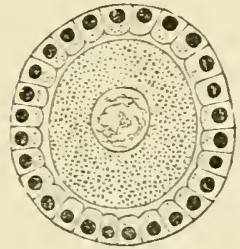

Fis. 247.-A small Graatian Follicle, from the Orary of Cat. (Atlas.)

The follicle is lined with a layer of columnar epitheliat cells - the nembrana grauulosa. The ormm fills out the carity of the follicle; it is surrounded $b_{j}$ a thin zona pellucilla, and it includes a germinal vesicle or nucleus with the intranuclear reticulnm.

this is a layer of flattened, transparent, epithelial cells, each with an oval, Hattened nucleus; this is the membrana gramulosa. The space within the follicle is occupied by, and filled up with, a spherical cellthe orum cell, or ovum. This is composed of a granular-looking protoplasm, and in this is a big spherical, or slightly oval, nuclens - the germinal cesicle. The substance of this is either a fine reticulum, limited by a delicate nembrane, with one or more nucleoli or germinal spots, or it is in one of the phases of indirect division or karyomitosis, thus indicating division of the ovum.

346. (c) From this cortical layer to the zona vasculosa we find embedded in the stroma isolated Graatian follicles of various sizes, increasing from the former to the latter. The biggrest follicles measure in diameter about $\frac{1}{20}$ inch. Those of the mildle layers are of medium size (Fig. 24i). In them we find inside the membrana propria the membrania granulosa, made up of a single layer of transparent, columnar, epithelial cells. The ovum, larger than in the small cortical follicles, fills out the cavity of the follicle, and is limited by a thin hyaline cuticle---the zonu pellucida. This appears as an excretion of the cells of the membrana granulosa. The protoplasm of 
the orum is fibrillated. The part surrounding the germinal resicle is more transparent, and stalins differently in osmic acid than the peripheral part. The big nuclens, or germinal resicle, is limited hy a distinct nembrane, and inside this membrane is a reticulum with generally one hig nucleolus or germinal spot.

Between these mediumsized follicles and the small follicles of the cortical laver. we tind all intermediate degrees as regards size of the follicle and the ovim, and especially as regrards the shape of the cells of the membrana granulosa, the

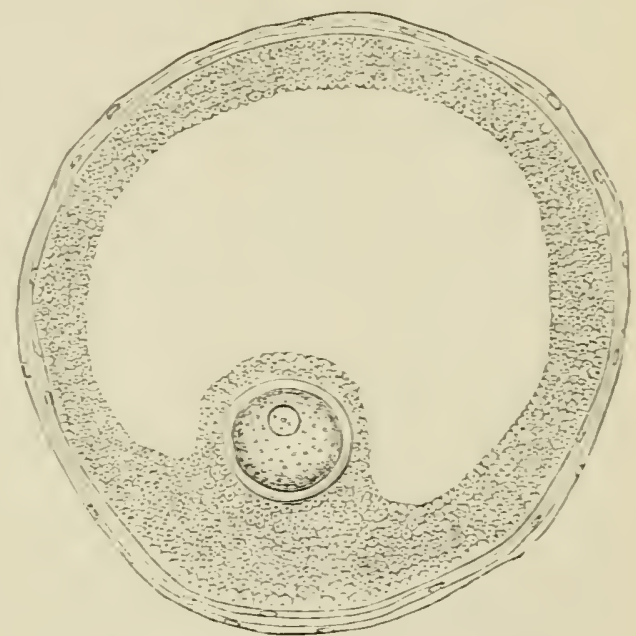

Fig. 245.-Large Graafian Follicle of the Ovary of Cat.

The follicle is limited by a capsule. the theca follicmli : the nembrana graulosa is composed of several layers of elithelial cells. The ormm with its distinct lyaline zona pellucida is embedded in the epithelial cells of the discus proligerns. The cavisy of the follicle is filled with fluid, the linnor folliculi.

intermediate sizes of follicles being lined by a granulosa made up of a layer of polrhedral epithelial cells.

347 . The deeper Graafian follicles--i.e. those that are to be regarded as big follicles-contain an ovum, occasionally two or eren three ora, which is similar to that of the previous follicles, except that it is larger, and its zona pellucida thicker. The orum does not fill out the whole carity of the follicle, since at one side, between it and the membrana granulosil, 
there is an albuminous fluid, the rudiment of the liquor folliculi.

348. The largest or most adranced follicles are of great size, easily risible by the naked eye, and contain a large quantity of this liquor folliculi (Fig. 248). In fact, the orum occupies only a small part of the carity of the follicle. The orum is big, surrounded by a thick zona pellucida, is situated at one side, surrounded by the discus proligerus. This consists of layers of polyhedral cells, except the cells immediately around the zona pellucida, which are columnar. The orum with its discus proligerus is comnected with the membrana granulosa. This latter consists of stratified parement epithetium, forming the entire lining of the follicle. The outermost layer of cells is columnar. The membrana propria of these big follicles is strengthened by concentric layers of the stroma cells, and this represents the tunica fibrosa (Henle) or outer coat of the follicle-theca folliculi externa. Numerous blood capillaries connected into a network surpound the big follicles.

In those follicles that contain a greater or smaller amount of the liquor folliculi we notice in the fluid a variable number of detached granulosa cells in rarious stages of vacuolation, maceration, and disintegration.

349. In connection with the medium-sized and large Gratian follicles are seen occasionally smaller or larger solid cylindrical or irregularly-shaped outgrowths of the membrana granulosa and membrana propria; they indicate a new formation of Gratian follicles, some containing a new orum. When these sirle branches become by active growth converted into larger follicles, they may remain in continuity with the parent follicle, or may be constricted off altogether. In the first case, we have one large follicle with two or three ova, according as a parent follicle las giren origin to one or two new outgrowths. 
Amongst the epithelial cells constituting the stratified membrania granulosa of the ripe follicles we notice a nucleated reticulum.

Many follicles reach ripeness, as far as size and constituent elements are concerned, long before puberty, and they are subject to degeneration; but this process of degeneration involves also follicles of smaller sizes.

350. Before menstruation, generally one, occasionally two or more of the ripe follicles become very hyperhemic. They grow, in consequence, very rapidly in size; their liquor folliculi increases to such a degree that they reach the surface of the ovary; finallyi.e. during menstruation - they burst at a superficial point; the ovum, with its discus proligerus, is ejected, and brought into the abdoninal ostium of the oviduct. The cavity of the follicle collapses, and a certain amount of blood, derived from the broken capillaries of the wall of the follicle, is effused into it. The follicle is converted into a corpus luteum by an active multiplication of the cells of the granulosa. New capillaries with connective-tissue cells derived from the theca folliculi externa gradually grow into the interior-i.e. between the cells of the granulosa. This growth gradually fills the follicle, except the centre; this contains blood pigment in the shape of granules, chiefly contained in large cells, and a few new bloodvessels, "the blood pigment being the remains of the original blood effused into the follicle. But, ultimately, all the pigment disappears, and a sort of gelatinous tissue occupies the centre, while the periphery-i.e. the greater part of the follicle-is made up of the hypertrophier granulosa, with young capillary vessels between its cells. The granulosa cells undergo fatty degeneration, becoming filled with several small fat globules, which gradually become confluent into a big globule. In this state the corpus 
lutemm is complete, and has reached the height of its progressive growth. The tissue is then gradually alsorbed, and cicatricial tissue is left. When this shrinks it prorluces a shrinking of the corpus lutem. This represents the last stage in the life of a Graafian follicle. The corpus luteum of Graatian follicles, of which the orum has been impregnated, grows to a much larger size than under other conditions, the granulosa becoming by overgrowth much folded.

\section{Development of the ovary and Graa-}

fiam follicles.-The germinal epithelium of the surface of the fotal ovary at an early stage undergoes rapid multiplication, in consequence of which the epithelium becomes greatly thickened. The vascular stroma of the ovary at the same time increases, and permeates the thickened germinit epithelium. The two tissues, in fact, undergo mutual ingrowth, as is the case in the development of a!l glands-namely, the epithelial or glandular part suffers mutual ingrowth with the vascular connective-tissue stroma.

In the case of the ovary, larger and smaller islands or nests (Balfour) of epithelial cells are thus gradually differentiated off from the superficial epithelium. These nests are largest in the depth and smallest near the surface. They remain in connection with one another and with the surface for a considerable period. Even some time after birth some of the superficial nests are still connected with the surface epithelium, and with one another (Fig. 249). These correspond to the ovarial tubes (Pfliiger). While in the rabbit these nests are solid collections, in the dog they soon assume the character of tubular structures (Pfliiger, Schäfer). The cells constituting the nests undergo multiplication (by karyomitosis), in consequence of which the nests increase in size, and even new nests may be constricted off from old ones (see also above). 


\section{FI:ATAE GENTTAI. ORGAMS.}

3.). At the earliest stages we notice in the germinal epithelimm some of the cells becoming enlarged in their cell body, and especially their nucleus : these represent the primitire ora. When the germinal epithelium undergoes the thickening above mentioned, and whon this thickened epithelimm separates

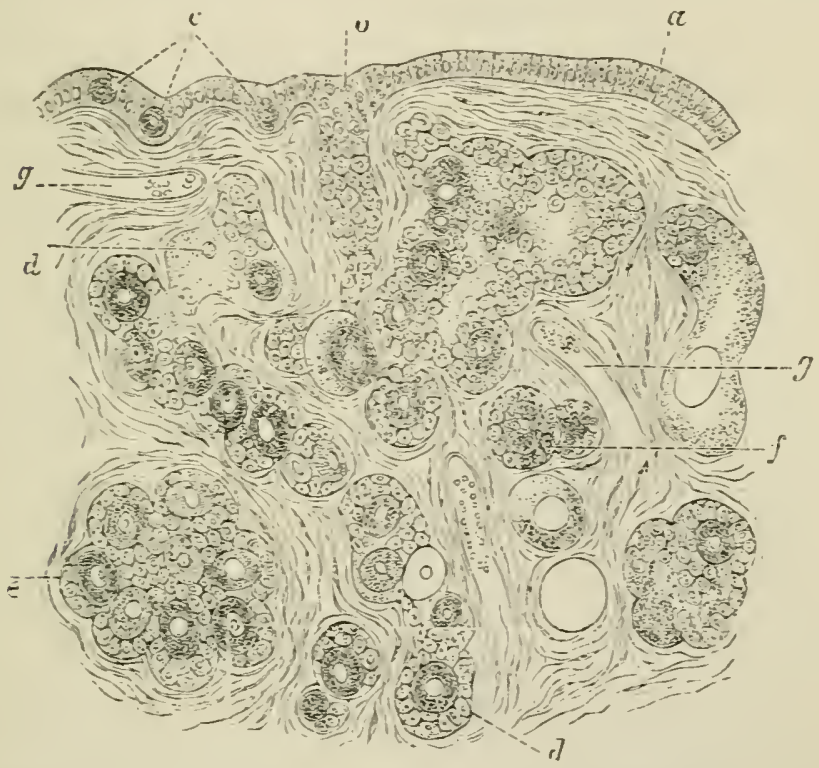

Fig. 24?.-From a Vertical section throngh Orary of a Newly-born Chilı. (Waldeyer, in stricher's Manual.)

$a$. Ferminnl ejithelium; $b$ ovarian tulue; $c$ primitive ova; $d$, longer tuhes he. coming constricted off into several Graifian follicles; $e$, large nests; $i$, iso'ated finisher Grafian follicles: $g$, blood-ressels.

into the nests and orarial tubes, there is a continued formation of primitive ora-i.e. cells of the nests undergo the enlargement of cell-body and nucleus by which they are converted into primitive ova. Like the other epithelial cells, the primitive ora of the nests and ovarial tubes undergo division into two or even more primitive ova after the mode 
of karyomitosis (Balfour). Thus each nest contains a series of ova.

35.3. The ordinary small epithelial cells of the nests and ovarial tubes serve to form the membrana granulosa of the Graafian follicles. According to the number of ova in a nest or in an orarial tube, a subdivision takes place in so many Graatian follicles, each consisting of one orum with a more or less complete investment of small epithelial cells-i.e. a membrana granulosa. This subdivision is brought about by the ingrowth of the stroma into the nests.

The superficial nests being the smallest, as above stated, form the cortical layer of the small Graatian follicles; the deeper ones give origin to larger follicles. Thus we see that the ovum and the cells of the membrana granulosa are derived from the primary germinal epithelium; all other parts-membrana propria, theca externa, stroma, and vessels-are rlerived from the fœtal stroma.

There is a good deal of evidence to show that ora and Graafian follicles are, as a rule, reproduced after birth (Pflïger, Kölliker), although other observers (Bischoff, Waldeyer) hold the opposite view.

354 . (2) The oviduct.- The oviduct consists of a lining epithelium, a mucous membrane, a muscular coat, and an outer fibrous coat - the serous covering, or peritoneum. The epithelium is columnar and ciliated. The mucous membrane is much folded; it is a connective-tissue membrane with networks of capillary blood vessels. In man and mammals there are no proper glands present, although there are seen appearances in sections which seem to indicate the existence of short gland tubes; but these appearances are explained by the folds of the mucous membrane. The muscular coat is composed of nonstriped muscular tissue of a pre-eminently circular arrangement; in the outer part there are a few 
oblique and longitudinal bundles. The serous covering contains numerous elastic fibrils in a connectivetissue matrix.

35.5. (3) The uterus. - The epithelium lining the carity of the uterus is a single layer of columnar cells, each with a bundle of cilia on their free surface. These are rery easily detached, and therefore difficult to find in a hardened and preserved specimen. But in the fresh and well-preserved human uterus (Friedländer), as well as in that of mammals, the cells are distinctly ciliated. The whole canal of the cervix is in the adult lined with ciliated epithelium, but in children, according to Lott, only in the upper half. The surface of the portio raginalis uteri is, like that of the ragina, corered with stratified pavement epithelium.

356. The mucous membrane of the cerrix is different from that of the fundus. In the former it is a fibrous tissue possessed of permanent foldsthe palmæ plicatr. Few thin bundles of non-striped muscular tissue penetrate into these from the outer muscular coat. Between the palme plicata are the openings of minute gland-tubes, more or less crlindrical in shape. They possess a membrana propria and a distinct lumen lined with a single laye! of columnar epithelial cells, which, according to some observers, are ciliated in the newly-born child, but, according to Friedländer, are always non-ciliated. Goblet cells are met with amongst the lining epithelium. Sereral observers (Kölliker, Hennig, Tyler Smith, and others) maintain the existence of minute, thin, and long vascular papillie projecting above the general surface of the mucous membrane in the lower part of the cervix; these apparent papilla are, however, only due to sections through the folds of the mucous nembrane. The mucous membrane of the fundus is a spongy plexus of tine bundles of tibrous 
tissue, covered or lined respectively with numerous small endothelial plates, each with an oval flattened nucleus. The spaces of this spongr substance are lymph spaces, and contain the glands and the bloodressels (Leopold).

357. The glands - glaudulae uterina - ale short tubular glands lodged in the mucous membrane and opening into the uterine cavity. During puberty their number and their size increase considerably, new glands being formed by the ingrowth of the surface epithelium into the mucous membrane (Kundrat and Engelmann). During menstruation, and especially during pregnancy, they greatly increase in length. They are more or less wavy and branched at the bottom. A delicate membrana propria forms the boundary of the tube; a distinct lumen is seen in the middle, and this is lined with a single layer of ciliated columnar epithelium (Allen Thomson, Nylander, Friedlïnder, and others).

358. During menstruation the thickness of the mucous membrane increases, the epithelium of the surface and of the greater part of the glands being destroyed by fatty degeneration, and tinally altogetlier detached. Afterwards its restitution takes place from the remnant in the depth of the glands. But according to J. Williams and also Wyder, the greater part of the mucous membrane, in addition to the epithelium, is destroyed dming menstruation.

The muscular coat forms the thickest part of the wall of the uterus; it is composed entirely of the nonstriped rariety.

In the cormua uteri of mammals the muscular coat is generally composed of an inner thicker circular and an outer thinner longitudinal stratum, a few oblique bundles passing from the latter into the former. In the human uterus the muscular coat is composed of an outer thin longitudinal, a middle thick 


\section{Fi:MATE GEVITAL ORGANS.}

layer of circular bundles, and an inner thick one of oblique and circular bundles. Within these layers the bimdles form plexuses.

3.59. The arterioles in the cervix and their capillaries are distinguished by the great thickness of their wall. The mucous membrane contains the capillary netrorks. These discharge their blood into veins situated in the muscular coat. Here the reins are very numerous and arranged in dense plexuses, those of the outer and inner stratum being smaller than those of the middle stratum, where they correspond to huge irregular sinuses, the bundles of muscular tissue of the muscular coat giving special support to these sinuses. Hence the plexus of venous sinuses of the middle stratum represents a sort of carernous tissue.

360. The Iymphatics are very numerous; in the connectire tissue of the muscular coat are lymph sinuses and lymph clefts forming an intercommunicating system; they take up the lymph sinuses of the mucous membrane above mentioned, and on the other hand lead into a plexus of efferent lymphatic ressels with valves, situated in the subserous connective tissue.

The nerves entering the mucous membrane are connected with ganglia. According to Lindgren, there is in the mucous membrane a plexus of nonmedullated nerve fibres which, near the epithelium, break up into their constituent primitive fibrillæ.

361. (4) The vagina.-The epithelium lining the mucous membrane is a thick, stratified parement epithelium. The superficial part of the mucous membrane-i.e. the mucosa - is a dense, fibrous connective tissue with numerous networks of elastic fibres; it projects into the epithelium in the shape of numerous long, simple or compound papille, each with a single or complex loop of capillary blood-vessels. The mucosa with the covering epithelium projects above 
the general surface in the shape of longer or shorter, conical or irregular, pointed or blunt, permanent folds-the ruga. These contain a plexus of large reins, between which are bundles of non-striped muscular tissue; hence they resemble a sort of cavernous tissue.

Outside of the mucosa is the loose submucosa, containing a second renous plexus; its meshes are elongated and parallel to the long axis of the ragina. Outside of the submucous tissue is the muscular coat, consisting of an inner circular and an outer longitudinal stratum of non-striped muscular tissue. Oblique bundles pass from one stratum into the other. From the circular stratum bundles may be traced into the submucosa and mucosa. A layer of fibrous tissue forms the outer boundary of the wall of the ragina, and in it is the most conspicnous plexus of reins, the plexus venosus raginalis. This plexus also contains bundles of non-striped muscular tissue, and therefore resembles a caremous tissue (Gussenbaur). It is not quite definitely ascertained whether or not there are secreting glands in the mucous membrane of the vagina. Von Preuschen and also Hennig described tubular glands in the upper part of the fornix and in the introitus vagina.

The lymplatics form plexuses in the mucosa, sub. mucosa, and the muscular coat. The first are small vessels, the second are larger than the third and possess valves. The efferent ressels form a rich plexus of large trunks with saccular dilatations in the outer fibrous coat.

There are in the mucous membrane solitary lymph follicles and diffuse adenoid tissue (Loevenstein).

Numerous ganglia are contained in the nerve plexus belonging to the muscular coat.

End bulbs in connection with the nerre fibres of the mucosa have been mentioned in Chapter XV. 
362. (5) 'Whe methra.- The structure of the female urethra is similar to that of the male, except that the lining epithelium is a sort of stratified transitional epithelium, the superficial cells being short, columnar, or club-shaped ; underneath this layer are several layers of polyhedial, or cubical cells. Near the orificium externum the epithelium is stratified pavement epithelium.

The muscular coat is composed of an inner longitudinal, and an outer circular, layer of non-striped muscular tissue.

363. (6) 'E'he nymphae, clitoris, and vestibulum.-These are lined with thick stratified epithelium; underneath is a fibrous connective-tissue mucous membrane, extending into the epithelium in the shape of cylindrical papillie with capillary loops and nerve endings (end bulbs). The nymphre contain large sebaceous follicles, but no hairs.

The nympha contain a plexus of large veins with bundles of non-striped muscular tissue; lience it resembles a cavernous tissue (Gussenbaur). The corpora cavernosa of the clitoris, the glans clitoridis, and the bulbi restibuli, correspond to the analogous parts in the penis of the male. The glands of Bartholin correspond in structure to the glands of Cowper in the male. 


\section{CHAPTER XXXV.}

THE II II YA R Y F LA Y D.

364. This, like other glands, consists of a framework and parenchyma. The former is lamellar fibrous connective tissue subdividing the latter into lobes and lobules and containing a certain amount of elastic fibres. In some animals (rabbit, guinea-pig) there are also small bundles of non-striped muscular tissue. From the interlobular septa fine bundles of fibrous tissue with branched connectire-tissue corpuscles pass between the alveoli of the gland substance. The amount of this interalreolar tissue varies in different places, but in the active gland is always relatively scanty.

Migratory or lymph corpuscles are to be met with in the interalveolar connective tissue of both active and resting glands. In the latter they are more numerous than in the former. According to Creighton, they are derived, in the resting gland, from the epithelium of the gland alveoli. Granular large sellow (pigmented) nucleated cells occur in the connective tissue, and also in the alveoli of the resting gland, and Creighton consider's them both identical, and derived from the alveolar epithelium. And according to this author, the production of these cells would constitute the principal function of the resting gland.

The large ducts as they pass from the gland to the nipple acquire a thick sheath, containing bundles of non-striped muscular tissue. These latter are 
derived from the bundles of nom-striped muscular tissue present in the skin of the nipple of the lneast.

The small ducts in the lobules of the gland tissue possess a membrana propria, and a lining-a single layer of longer or shorter columnar epithelial cells.

The terminal branches of the ducts-i.e. just

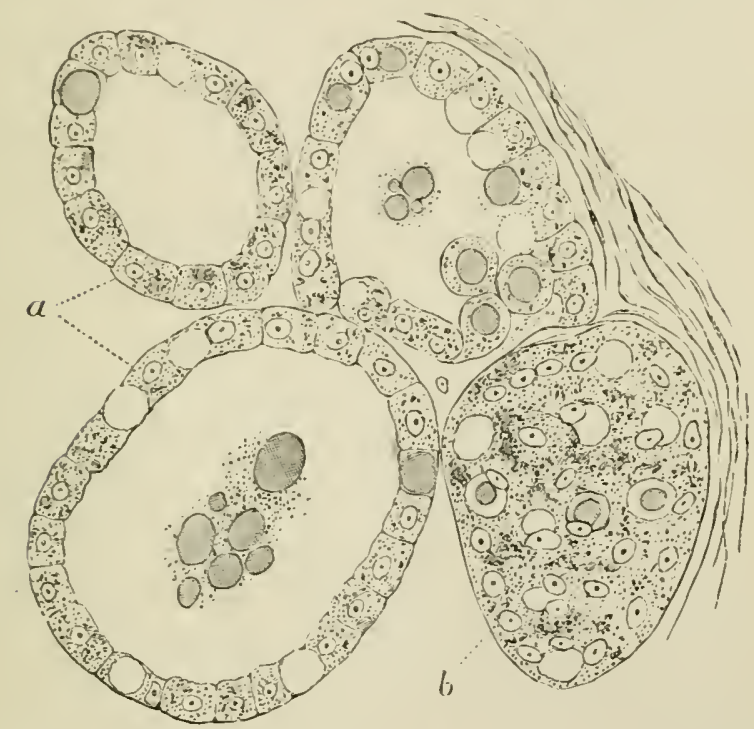

Fig. 250.-From a Section through the Mammary Gland of Cat in a late stage of pregnancy. (Atlas.)

$a$, Epithelial cells lining the gland-alveoli, seen in profile; $b$, the same, seen from the surfacc. Many elithelial cells contain an vil globule. In the cavity of some of the alreoli are milk globules and granular matter.

before these latter pass into the alveoli-are lined with a single layer of flattened parement epithelium cells; they are analogous to the intermediate portion of the ducts of the salivary glands (see Chap. XXIII.).

365. Each of these terminal branches divides and takes up several alveoli (Fig. 250). These are wavy tubes, saccular or flask-shaped. The alreoli are larger in diameter than the intralobular ducts. Each 
alveolus in the active gland has a relatively lange cavity, varying in different alveoli; it is lined with at single layer of polyhedral, granular-looking, or short columnar epithelial cells, each with a spherical nucleus ; a membrana propria forms the onter limit. This membrana propria, like that of the salivary, lachrymal and other glands, is a basket-work of branched cells.

In the active gland each epithelial cell is capable of forming in its interior one or more smaller or larger oil globules. These may, and generally do, become confluent, and, pressing the nucleus towards one side of the cell, give to the latter the resemblance of a fatcell. The oil globules tinally pass out from the cell protoplasm into the lumen of the alveolus, and represent now the milk globules. The cell resumes its former solid character, and commences again to form oil globules in its protoplasm. The epithelial cells, as long as the secretion of milk lasts, go on again and again forming oil globules in the above manner without being themselves destroyed (Langer). The milk globules, when in the lumen of the alveoli, are enveloped in a delicate cuticle the albumin membrane of Ascherson, which they receive from the cell protoplasm.

According to the state of secretion, most epithelial cells lining an alveolus may be in the condition of forming oil globules, or only some of them; and according to the rate in which milk globules are formed and carried away, the alveoli differ in the number of milk globules they contain.

According to Schmid, the epithelial cells, after having secreted milk globules for some time, finally break up, and are replaced by new epithelial cells derived by the division of the other still active epithelial cells.

366. The resting gland-i.e. the gland of a non-presnant or non-suckling individual-contains, compara- 
tively speaking. few alveoli, but a great cleal of fibrous comective tissue: the alveoli are all solid cylinders, containine within the limiting membrana propria masses of polyhedral granular-looking epithelial cells. During pregnancy these solid cylinders undergo multiplication, elongation, and thickening, owing to the rapid division of the constituent epithelial cells.

Finally, when milk secretion commences, the cells occupying the central part of the alveolus mndergo the fatty degeneration just like the peripheral cells, but they-i.e. the central cells - are eliminated, while the peripheral ones remain. The central cells are the colostrum corpuscles, and consequently they are found in the milk of the first few days only:

$36 \bar{T}$. Ordinary milk contains no colostrun corpus. cles, but only milk globules of many various sizes, from the size of a granule to that of a globule several times as big as an epithelial cell of an alveolus of the milk gland. These large drops are produced by fusion of small globules after haring passed out of the alveoli. Each milk globule is an oil globule surrounded, as stated above, by a thin albuminous envelope-Ascherson's menibrane. The small bits of granular substance met with here and there are probably the remains of broken-down protoplasm of epithelial cells.

368. Eacli gland alveolus is surrounded by a dense netroork of capillary blood-ressels. The alreoli are surrounded by lymple spaces like those in the salivary grands (Corne), and these spaces learl into networlis of lymplatic ressols of the interlobular connective tissue. 


\section{C'HAPTER XXXVT.}

THF: SKIX.

369. THe skin consists of the following layers (Fig. 252):--(1) The epidormis; (2) the corium, or cutis rera, with the papille; (3) the subcutaneons tissue, with the adipose layer or the adipose tissue.

370. (1) The epidermais (Fig. 25), in all its constituent elements, has been minutely described in Chapter III. Its thickness varies in different parts, and is chiefly dependent on the variable thickness of the stratum comeum. This is of great thickness in the palm of the hand and the sole of the foot. The stratum Malpighii fits into the depressions between the papilla of the corium as the interpapillary processes. The presence of prickle cells, of pigment granules, and of branched interstitial nucleated cells, etc., has been mentioned in Chapter III.

There occur in the stratum Malpighii migratory cells of granular aspect; they appear to migrate from the papillary laver of the corium into the stratum Malpighii (Biesiadecki).

In the coloured skin -. - . \% of the negro--pigment granules are abundant in the cell substance of the stratum Malpighii, especially in the deeper layers; but there is present an almost continuous layer of pigment in the superficial layers of the stratum corneum (Fig. 251).

371. (2) The corimm is a dense feltwork of bundles of fibrous connective tissue, with a large admixture of networks of elastic fibres. From the 
surfice of the eorium project small conical or eylinchical meillu'. 'These are best developed in those parts where the skin is thick-e.g. volar side of land and foot, scalp, lips of mouth, etc. Between

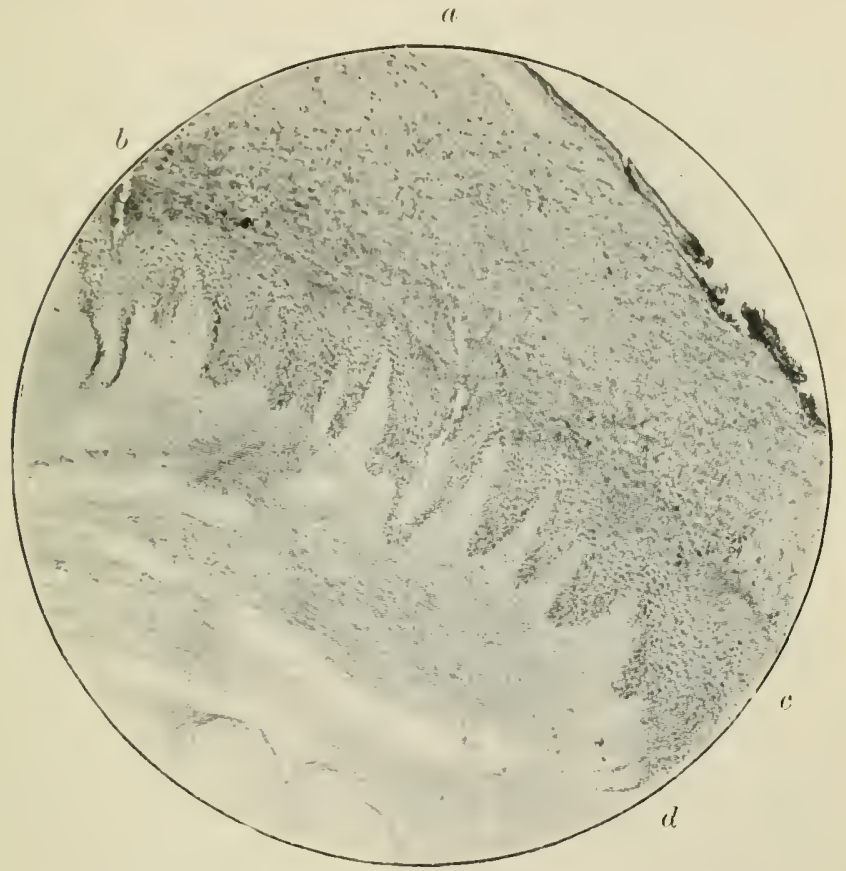

Firr. 251.-From Vertical Section through Epidermis of Skin of Finger of Negro. (Photo. Moderate magnification.)

1, surface of stratum cornemm, much pigmented: b, stratum corneum: $c$, stratum Malpighii, containing pigment in its cells; $d$, corium with papille extending into the stratum Malpiwhi.

the surface of the coriun and the epidermis there is a basement membrane. Migratory cells, with and without pigment granules in their interior, are met with, especially in the superficial part of the corium; they, as well as the fixel or branched connectivetissue corpuscles (see par. 40), and otlier structures, as vessels and nerves, lie in the interfascicular spaces. 
372. (3) The superficial part of the subculameous tissue insersibly merges into the deep part of the corium : it consists of bundles of fibrous connective tissue agrregated into trabeculæ crossing one another and interlacing in a complex manner. Numerous

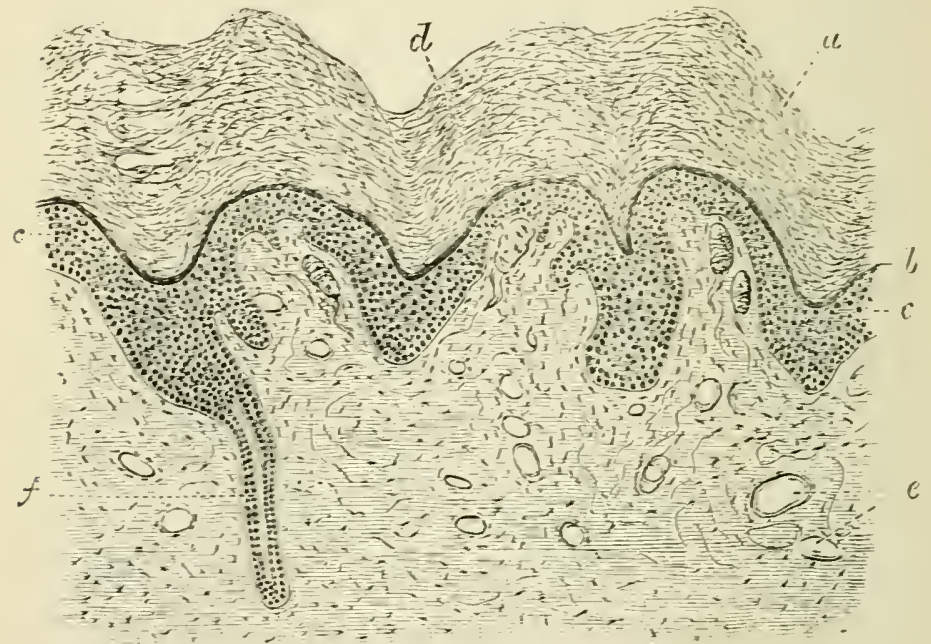

Fig. 252.- Tertical Section through the Skin of Human Finger.

$a$, Stratum corneum: $b$, stratum Jucidum : $c$, stratum Malpighii ; $d$, Meissner wr tactile corjuscle; $\epsilon$. blood-re-sels cut across: $f$, sudoriferous canal or duct.

elastic fibres are attached to these trabeculæ. It contains groups of fat cells, in many places arranged as more or less continuous lobules of fat tissue, forming the stratum adiposum. These lobules are separated by septa of fibrous connective tissue: their structure and development, and the distribution of the bloodressels amongst the fat cells, have been described (Fig. 41, and on pp. 55 and 56). The deep part of the subcutaneous tissue is loose in texture, and contains the large vascular trunks and big nerve branches.

373 . The superficial part of the subcutaneous 
tissue, or, as sume have it, the deep part of the corium, contains the sudoriparous or sweert glands. Wach gland is a single tube coiled up into a denss matss of about $\frac{1}{60}$ of an inch in diameter-in some places, as in the axilla, reaching as much as six times this size. From each gland a duct-the sudoriferous crinal-passes through the corium in a slightly way and vertical direction towards the epidermis; it penetrates more or less spirally through the interpapillary process of the stratum Malpighii and the rest of the epidermis, and appears with an open mouth on the free surface of the skin.

'The total number of sweat giands in the human skin has been computed by Krause to be over two millions ; but it varies greatly in different parts of the borly, the largest number occurring in the palm of the hand, the next in the sole of the foot, the next on the dorsum of the hand and foot, and the smallest in the skin of the dorsum of the trunk.

374. The suctoriferous canal and the coiled tube possess a distinct lumen : this is lined with a delicate cuticle, especially marked in the sudoriferous canal and in the commencement of the coiled tube. In the epidermis the lumen bordered by this cuticle is all that is present of the sudoriferous camal. It receives a continuation from the deep layers of the stratum Malpighii and from the basement membrane; the former is the lining epithelium, the latter the limiting membrana propria of the sudoriferous canal. The epithelium consists of two or three layers of small polyhedral cells, each with a spherical or oval nucleus.

375. The structure of the sudoriferous canal is, then, a limiting membrana propria, an epithelium composed of two or three layers of polyhedral cells, an internal delicate membrane, and, tinally, the central cavity, or lumen.

The first part-about one-third or one-fourth- 
of the coiled tube (Fig. 253) is of the same structure, and is directly continuous with the sudoriferous canal, with which it is identical, not only in structure, but in size. The remainder of the coiled tube-i.e. the distal part-is larger in diameter, and differ's in these essential respects, that its epithelium is a single layer

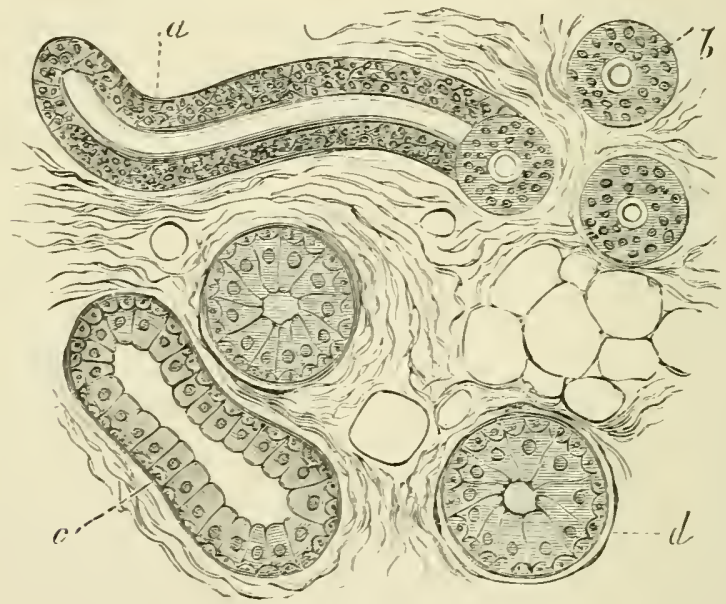

Fig. 253.-From a Section through Human Skin, showing the sweat gland tubes cut in various directions. (Atlas.)

$a$, First part of the coiled tube seen in longitudinal section; $b$, the same seen in cross-section; $c$, distal lart speu in fongitudinal section; $d$, the same seen in cross-section.

of transparent columnar cells, and that there is between this and the limiting membrana propria a layei of non-striped muscle cell. (Köliker) arranged parallel with the long axis of the tube. In some places, as in the palm of the hand and foot, in the scrotum, the nipple of the breast, the scalp, hut especially in the axilla, this clistal portion of the coiled tuhe is of very great length and breadtl, and its epithelial cells contain a variable amount of granules.

It appears to me that the cells resemble in this respect those of the serous salivary glands and the 
chief cells of the wastric glands (Langley), inasmuch as they produce in their interior larger or smaller granules which are used up during secretion, from the periphery towards the lumen.

376 . The cermunous glands of the meatus anditorius externus are of the same structure as the distal portion just described, except that the inner pirt of the cell protoplasm. of the epithelium contains yellowish or brownish pigment, found also in their secretion-i.e. in the wax of the ear.

Around the anus there is an elliptical zone, in the skin of which are found large coiled gland tubes- the circum-anul glands of A. Gay-which are identical in structure with the distal portion of the sweat glandtubes.

377 . The sweat gland develops as a solid cylindrical outgrowth of the stratum Malpighii of the epidermis, which gradually elongates till it reaches the superficial part of the subcutaneous tissue, where it commences to coil. The lumen of the tube is of later appearance. The membrana propria is derived from the tissue of the cutis, but the epithelium and muscular layer are both derived from the original outgrowth of the epidermis.

378. The lanir-follicles (Fig. 254).-The skin almost every where contains cylindrical follicles, planted more or less near to one another, and in groups. In each of them is fixed the root of a hair; that part of the hair which projects beyond the general surface of the skin is the shaft.

A very few places contain no hair follicles, such, for instance, as the volar side of the hand and foot, and the skin of the penis.

In size, the hairs and hair-follicles differ in different parts. Those of the scalp, the cilia of the eyelids, the hair's of the axillat and pubic region, those of the male whiskers and monstache, are coarse and 
thick, while the hairs of other places-e.g. the onter surface of the eyelids, the inside of the ar'm and forearm, etc.-are very minute; but as regards structure, they are all very much alike.

379. A complete hair and hair-follicle-that is,

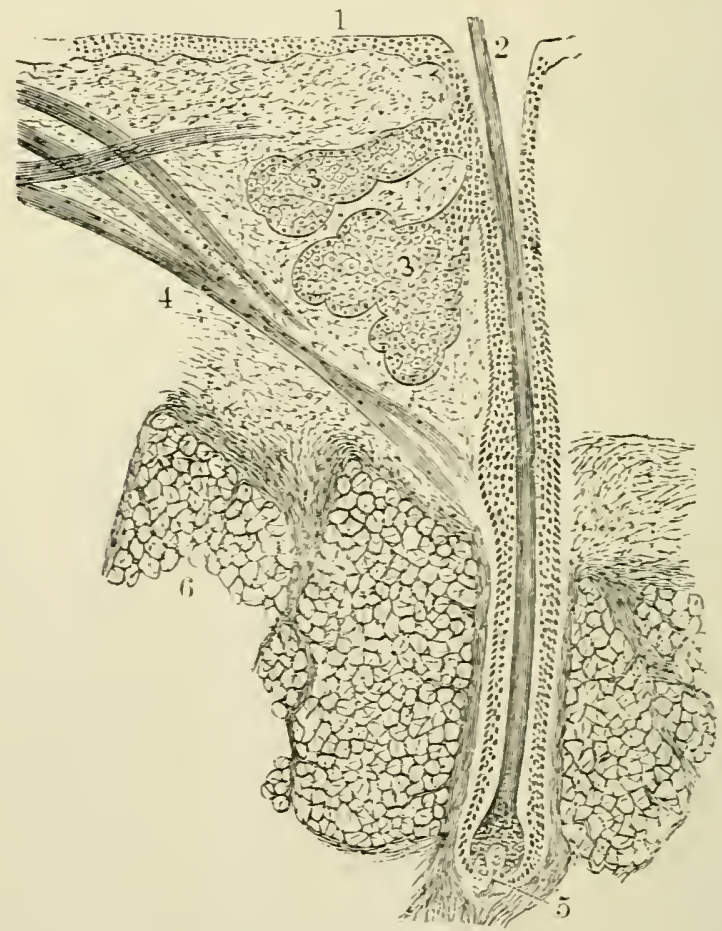

Fig. 254.-Longitudinal Section through a Human Hair. (Atlas.)

I, Epidermis: 2, mouth of hair follicle: 3, sebaceous follicle; 4, musculus arrector pili ; 5 , papilla of hair ; 6 , adipose tissue.

the papillary hair of Unna-shows the following structure :-

The hair-follicle. Each hair-follicle commences on the free surface of the skin with a fumnel-shaped opening or mouth; it passes in an ollique direction 
throunh the corium into the subcutaneous tissue, in whose middle strati-i.e. in the stratum adiposumit terminates with a slightly enlarged extremity, with which it is invaginated over a relatively small fungusshaped papilla. This latter is of fibrous tissue, containing numerous cells and a loop of capillary bloodressels.

Minute hairs do not reach with their follicles to such a depth as the large coarse hairs, the former not extending generally much farther than the deep part of the corium. Degenerating and imperfect hairs (see below) also do not reach to such a depth as the perfect large hair.follicles. In individuals with "woolly" hair-e.g. the negro race (C. Stewart), and in animais with "woolly" hair, such as the fleece of sheep-the deep extremity of the hair-follicle is curred, sometimes eren slightly upwards.

380 . The structure of a hair-follicle is as follows (Fig. 255): 'There is an outer coat composed of fibrous tissue : this is the fibrous coat of the laair-sac. It is merely a condensation of the surrounding fibrous tissue, and is continuous with the papilla at the extremity of the hair-follicle. About the end of the hair-follicle, or sometimes as much as in the lower fourth, there is insicle of this fibrous layer of the hairsac a single continuous layer of transversely or circularly-arranged spindle-sliciped cells, each with an oval flattened or staff-shaped nucleus, completely resembling, and generally considered to be, non-striped musclecells. Inside of this layer of the hair-sac is a glassylooking. hraline, basement membrane, which is not very clistinct in minute hairs, but is sufficiently conspicuous in large adult hair-follicles. This glassy membrane, as it is called, is a direct continuation of the basement membrane of the surface of the corium, and it can be traced as a delicate membrine also orer the surface of the hair-papilla. 
381. Next to the glassy membrane is the outer. root-sheath, the most conspicuous part of the hairfollicle. It consists of a thick stratified epithelium of exastly the same nature as the stratum Malpighii of

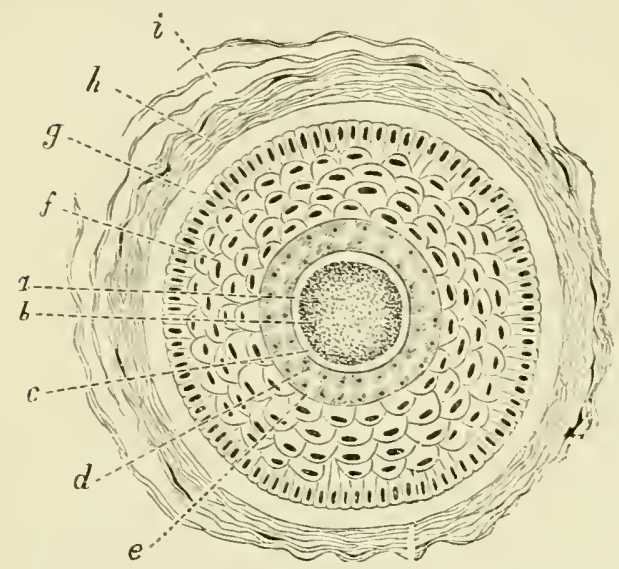

Figr. 255.-Cross-section through a Human Hair aud Hair-follicle.

a. Marrow of hair; b. cortex of hair; c, cuticle of hain: $d$, Huxley's layer of inuer root-sheath; $e$, Henle s layer of inmer rout-sheath; $f$, onter root-lieath : $q$, glassymembrane: $h$, fibrous coat of hairsitc : $i$, lympli slaces in the sime. the epidermis, with which it is directly colltinuous, and from which it is developed. In the outer root-sheath the layer of cells next to the glassy membrane is colummar, just like the deepest layer of cells in the stratum MIalpighii ; then follow inwards several layers of polyhedral cells; and, tinally, flattened nucleated scales form the innermost boundary of the outer root-sheath. The stratum gramlosm of the stratum Malpighii is not continued beyond the mouth of the hair-follicle, but there it is generally very marked. The outer root-sheath becomes greatly attenuated at the papilla - in fact, it is there continuons with the cells constituting the lair-bulb.

38.2. The centre of the hair-follicle is occupied by the root of the hair, which terminates with an enlarged extremity-the hair-bull : this grasps the whole papilla. 'The hair-bulb is composed of polyhedral (mithelial colls, separated from one another by cement substance, and continnous with the cells of the ex- 
tremity of the outer root-sheath, firom which they originate in the first instance; just over the papillat there is a special row of short columnar cells, which are in an active state of multiplication, in consequence of which new cells are constantly being formed over the papillar. As a result of this there is a gradual pushing outwatels, within the cavity of the hairfollicle, of the cells previously formed; these cells form the hair itself. Nearest to the papilla all the cells of the hair are polyhedral, farther outwards-i.e. towards the surface of the skin-they become more elongated and spindle-shaped, and constitute the cells of the hair-substance; except in the very centre of the hair, where they remain polyhedral, so as to represent the cells of the marrow of the hair, and in the periphery of the laair, where they remain more or less polyhedral, so as to form the inner root-sheath.

"3S:3. The root of the hair, except at the hairbulb, shows the following parts: The substance of the hair, the cuticle, and the inner root-sheath. The substance of the hair is composed of the lacir-fibresi.e. long thin fibres, or narrow long scales, each composed of hyaline horny substance, and possessed of at thin staff-shaped remnant of a nucleus. These are held together by a certain amount of interstitial cement substance. 'Towards the bulb they gradually change into the spindle-shaped cells above mentioned. They can be isolated by strong acids and alkalies. In pigmented hairs there occur numerous pigment granules between the hair-fibres, but also diffiused pigment in their substance. The same is noticed with reference to the hair-bulb-namely, pigment granules being present in the intercellular cement, and pigment also in the cell substance. In the centre of many hairs is a cylindrical marrone, containing generally one row of polyhedral cells, which are, to a great extent, filled with air. 
:384. On the surface of the hair-substance is a thin cuticle, a single layer of holny non-nucleated hyaline scales arranged more or less transversely; they are imbricated, and, according to the degree of imbrication, the cuticle shows more or less marked projections, which give to the circumference

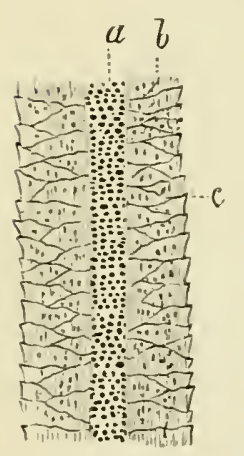

Fir. 25ti.-Longitudinal View of the Shaft of a Pigmented Human Hair.

a, Marrow of hair; $b$, fibres of lairsubstance ; cuticle. of the hair the appearance of minute teeth, like those of a saw.

385 . The inner root-sheath in well-formed, thick hairs is rery distinct, and consists of a delicate cuticle next to the cuticle of the hair ; then an inner, or Hurley's, layer, which is a single, or sometimes double, layer of horny cubical cells, each with a remnant of a nucleus; and, finally, an outer, or Henle's, layer-a single layer of non-nucleated homy cubical cells.

The shaft of the hair (Fig. 256), or the part projecting over the free surface of the skin, is of exactly the same structure as the root, except that it possesses no inner root-sheath.

386. As mentioned above, at the hair-bulb the polyhedral cells constituting this latter gradually pass into the different parts of the hair-i.e. marrow-substance, cuticle, and inner root-sheath-and the continual new production of cells over the papilla causes a gradual progression and conversion of the cells, and a corresponding growth in length of the hair.

Pigmented hairs, as mentioned above, contain pigment granules between-i.e. in the interstitial substance cementing together-the hair-fibres, and diffuse pigment in their substance. According to the amount of these pigments, but especially of the intersticia! pigment gramules (Pincus), the colour of the hair is 
of a wreater or lessel dark tint. In red hair's there is chiefly ditfuse pigment. In white or albino hairs neither the one nor the other pigment is present: in grey there is air at least in the superficial laver's of the hair substance, besides alosence of pigment.

Sleek hair's are circular, curly oval, in cross-section. sleek hair's are implanted with their hair-bulb straight; in curly hairs the hair-bulb forms a more or less pronounced hook. This is the cause for the more or less spiral twisting of the hair-shaft of curly hairs during its growth outwards.

357. New formation

\section{of hair (Fig. 25\%).-} Every hair, be it fine and short or thick and long, under normal conditions, has only a limited existence, for its hair-follicle, including the papilla, sooner or later undergoes degeneration, and subsequent to this a new papilla and a new hair are formed in its place. What happens is this-the lower part of the hair-follicle, including the papilla and hair-bulb, degenerate and are gradually absorbed. Then there

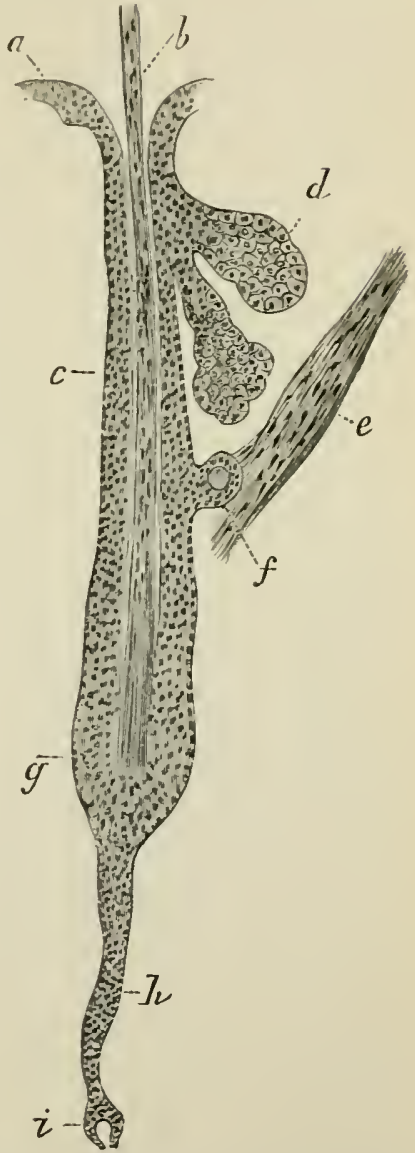

Fis. 25\%.-From a section throngh Human Scalp, showing a degen. erating hair. (Atlas.)

$a$, Epidermis; $b$, hair ; $c$, onter rootsheath of hair follicle; $d$, sebacewus follicle; $\epsilon$, arrector pili ; $f$, cyst grown nut of the outer rootsheath; $g$, hair-kuob; $h$, new vutgrowith of the outer root-sheath ; $i$, uew papilla. 
is left only the upper part of the fullicle, and in the centre of this is the remainder-i.e. non-degenerated portion-of the hair-root. The fibres of this are at the extremity fringed out and lost anongst the cells of the onter root-sheath of the follicle. This represents the lacir-livol, (Henle). Now, from the outer root-sheath a solid crlindrical outgrowth of epithelial cells into the depth takes place : against the extremity of this a new papilla is formed. In comnection with this new papilla, and in the centre of that crlindrical outgrowth, a new hair-bull, and hair are formed, and as the latter gradually grows ontwards towards the surface, it lifts, or rather pushes, the old hair-i.e. the hair-knob-out of the follicle. The onter part of the follicle of the old hair persists.

Thus we find in all parts of the skin where hairs occur complete or papillary hairs side by sicle with degenerating hairs or hair-knobs.

3.s. Development of hair.--In the human fotus the hair-follicles make their first appearance about the end of the third month, as solid cylindrical outgrowths from the stratum Malpighii. This is the rudiment of the outer root-sheath. After having penetrated a short distance into the corium, this latter becomes condensed around it as the rudiment of the hair-sac, and at the distal extremity forms the papilla growing against the outer root-sheath and invaginating it. On the surface of the papilla a rapid multiplication of the epithelial cells of this extremity of the outer root-sheath takes place, and this forms the hair-bulb, by the multiplication of whose cells the hair and the inner root-sheath are formed. As growth and multiplication proceed at the hair bulb, so the new hair, with its pointed end, gradually reaches the outer surface. It does not at once penetrate the epidermis, but remains growing and burrowing its way for some time in the stratum corneum of the 
epidermis in a more or less horizontal direction, till it finally lifts itself out of this beyond the free surface.

$3 \wedge 9$. In many mammals occur, amongst ordinary laiis, special large hairs, with huge hair-follicles planted deeply into the subcutaneous tissue; such

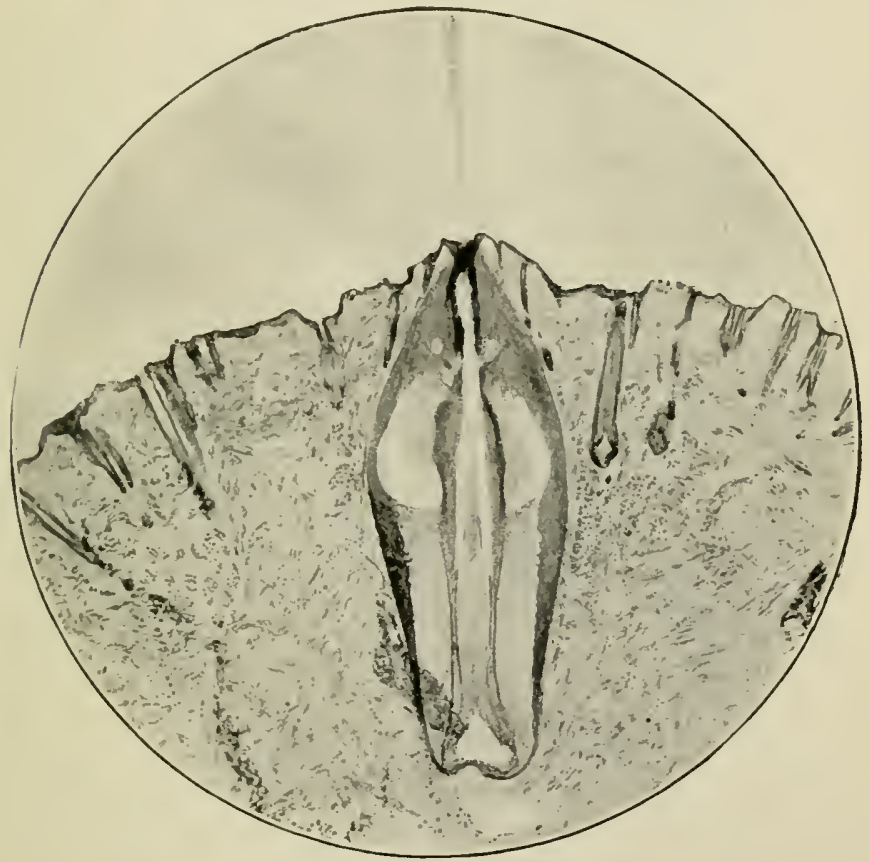

Fig. 25S.-Section through the skin of the Lip of a Rabbit's Mouth. (Photograph. Low poiver.)

Small ordinary hair-follicles, one lirge tactile hair and hair-follicle. The dark thick boundars is the tissue of the hair-sac. the clear parts inside are the masses of bloud spaces, the dark line next to the hair itself is the outer root-sheath.

are the big hairs in the skin about the lips of the mouth in the dog, cat, rabbit, guinea-pig, mouse and rat, etc. These are the tactile hairs (Fig. 258). Their hair-follicle possesses a thick hair-sac, in which are contained large sinuses intercommunicating with one another and with the blood system; these sinuses are separated 
b5 trabeculie of non-striped muscular tissue, and represent, therefore, a cavernous tissue. The papilla is large, and so is the outer root-sheath and the hair-root in all its parts. There are vast numbers of nerve-fibres, distributed and terminating amongst the cells of the outer root-sneath (Arnstein).

390. With each hair.follicle are comnected one or two sebraceous follirles. These consist of sereral tlaskshaped or oblong alreoli, joined into a common short luct opening into the hair-follicle near the surfacei.e. that part called the neck of the hair-follicle.

The alveoli have a limiting membrana propria: next to this is a layer of small polyhedral, granularlooking epithelial cells, each with a spherical or oval nucleus: next to this, and filling the entire cavity of the alveolus, are large polyhedral cells, each with a spherical nucleus: the cell substance is filled witls minute oil globules, between which is left a sort of honeycombed reticulated stroma. The cells nearer to the centre of the alveolus are the largest. Towards the duct they become shrivelled up into an amorphous mass. The duct itself is a continuation of the outer root-sheath.

As multiplication goes on in the marginal lajer of epithelial cells_i.e. those next the membrana proprix - the products of this multiplication are gradually shifted forward towards the duct, and through this into the neck and mouth of the hair-follicle, where they constitute the elements of sebum.

There is a very characteristic misproportion between the size of the hair-follicle and that of the sebaceous gland in the embryo and newly-born, the sebaceous gland being there so large that it forms the most conspicuous part, the minute hairs (lanugo) being situated, as it were, in the duct of the sebaceous follicle.

391. In comnection with each hair-follicle, espe- 
cially where they are of good size as in the scallythere is a bundle, or rather group of bundles, of nonstriped muscular tissue; this is the arrector pili. It is inserted in the hair-sac near the bulbous portion of the

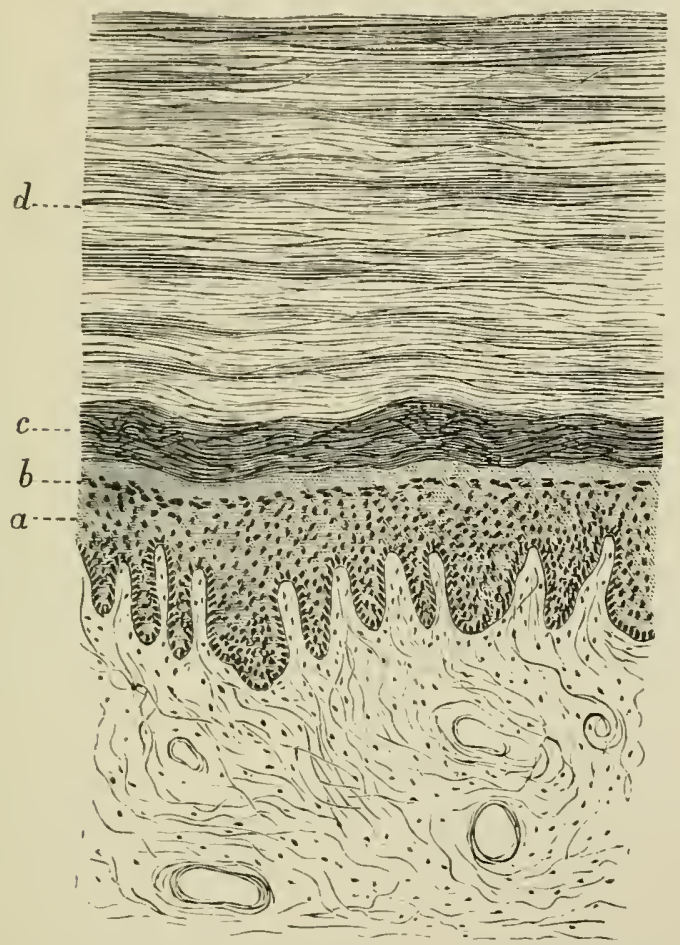

Fig. 259.- Vertical Section through the Human Nail and Nail-bed.

", stratum Malpighii of nail-bed; $b$, stratum granulosum of nail-bed ; $c$, deep
layers of nail sulstance; $d$, superticial layers of same.

hair-follicle, and passes in an oblique direction towards the surface of the corium, grasping, as it were, on its way the sebaceous follicle, and terminating near the papillary layer of the surface of the corium. The arrector pili forms with the hair-follicle an acute angle-this latter being planted into the skin in an 
ublique direction, as mentioned above-and consequently, when the arrector contracts, it has the effect of raising the hair-follicle and hair (cutis anserina"groose's skin"), and of making the hair assume a more upright position (causes it, as we say, to "stand on end"). At the same time, it compresses the sebaceous follicle, and thus facilitates the discharge of the sebum.

392. The corium of the scrotum, of the nipple of the breast, of the labia pudendi majora, and of the penis, contains numbers of bundles of non-striped muscular tissue (Kölliker), independent of the hairs ; these run in an oblique and horizontal direction, and form plexuses.

39.3. The mails (Fig. 2.59).- We distinguish the body of the nail from the free margin and from the root: the body is the nail proper, and is fixed on to the nail-bed, while the nail-root is fixed on the nailmatrix-i.e. the posterior part of the nail-bed. The nail is inserted, with the greater part of its lateral and with its posterior margin, in the mail-yroore, a fold by which the nail-matrix passes into the surrounding skin.

394. The substance of the nail is made up of a large number of strata of lomogeneous horny scalesthe nail-cells - each with a stati-shaped remnant of a nucleus.

'The corium of the nail-bed is highly vascular: it is firmly fixed by stiff bands of fibrous tissue on the subjacent periosteum; it is corered with a stratum Malpighii of the usual description, except that the stratum granulosum is absent in the nail-matrix, but is present in a rudimentary state in the rest of the nail-bed. The nail itself represents the stratum lucidum, of course of exaggerated thickness, situated over the stratum Malpighii of the nail-bed. There is no stratum corneum orer the nail. 
The -tratum Malpighii and corium of the nail-bed are placed into permanent minute folds, and the nail pussecises on its lower surface corresponding linear indentations.

395. In the fietal nail-bed the stratum Malpighii is covered with the usual stratum lucidum and stratum corneum. but the former is the larger; by a rapid multiplication of the cells of the stratum IIalpighii, and a conversion of its superficial cells into the scales of the stratum lucidum, the feetal nail is produced. At this early stage the nail is corered by stratum corneum. By the end of the fifth month the nail margin breats through this stratum corneum, and by the serenth month the greater part of the nail has hecome clear of it.

396. The blood-ressels of the skin.-The l, lood-ressels are arranged in different srstems for the different parts of the shin (Tomsa) :-

(a) There is, first, the vascular srstem of the adipose tissue, differing in no way from the distribution of blood-ressels in fat tissue of other places.

(b) Then there is the rascular srstem of the hairfollicle. The papilla has a capillary loop, or rather a minute arteriole, a capillary loop, and a descending rein. and the filorous tissue of the hair-sac possesses capillaries arranged as a network with elongated meshes, with its afferent arteriole and efferent vein.

(c) The sebaceous follicle has its afferent arteriole and efferent vein, and capillary networks surrounding the alveoli of the gland. The arrector pili and other bundles of non-striped muscular tissue possess capillary networks with elongrated meshes.

(d) The sweat glands have an afferent arteriole, from which proceeds a rery rich network of capillaries, twining and twisting round the gland-tube. The duct possesses its separate afferent arteriole and capillaries, forming elongated meshes. 
(e) The last arterial branches are those that reach the surface of the corium, and there break up into a dense capillary network with loops for the papillæ. In connection with these capillaries is a rich plexus of reins in the superticial layer of the corimm.

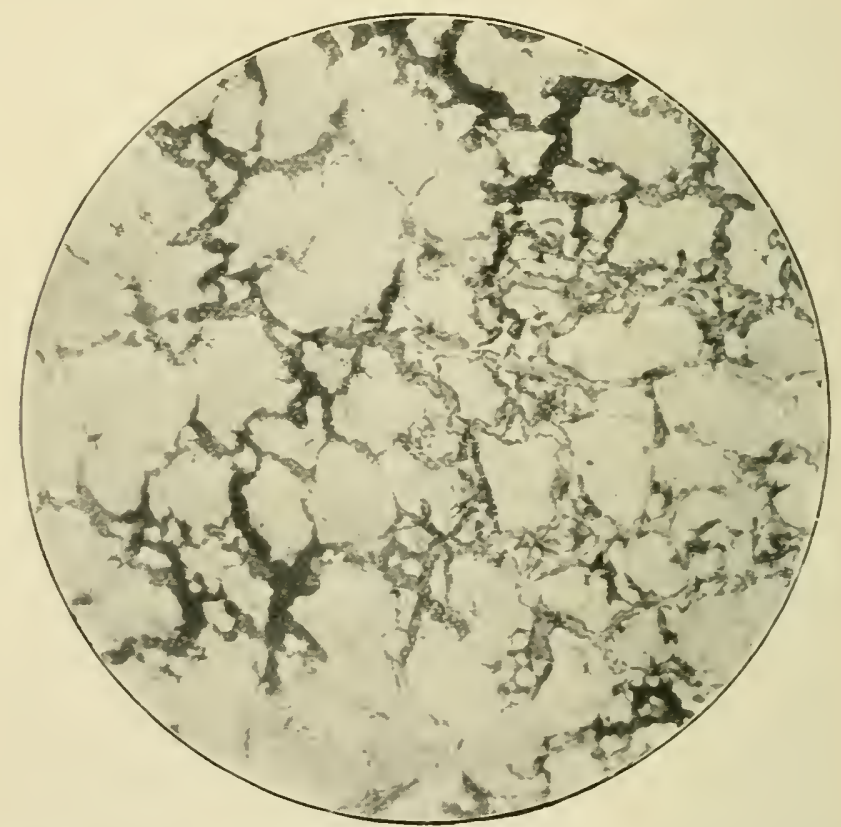

Fig. 260. - Skin of the Web of Frog of which the lymphatics had been iniected, showing the dense plexus of lymphatic ressels. (Photograph. Lou pover.)

(f) In the nail-bed are dense networks of capillaries, with loops for the above-named folds.

397. The lymphatics (Fig. 260). - There are networks of lymphatic ressels in all strata of the skin; they are, more or less of horizontal expansion, with oblique branches passing between them. Their wall is a single laser of endothelial cells, and some of them possess valves. Those of the surface of the corium 
take up lymphatics of the papillie. The sulcutaneous lymphatics are the biggest. The fat tissue, the sweatglands, and the hair-follicles possess their own lymphatic clefts and sinuses. The interfascicular spaces of the corium and subcutaneous tissue are directly continuous with the lymphatic ressels in these parts.

398. The nerves. - The nerve-branches break up into a dense plexus of fine nerve fibres in the superticial layer of the corium. This plexus extends horizontaliy, and gives off numerous elementary fibrils to the stratum Malpighii, in which they asceud rertically and in a more or less way fashion towards the stratum lucidum (Langerhans, Podkopaeff, Eberth, Eimer, Ranvier, and others). According to some, they terminate with a minute swelling; according to others, they form networks: according to more recent obserrations, some of the fibrils terminate also in the substince of the deep epithelial cells (see Chap. XIV.).

The subcutaneous nerve-branches of some places - palm of hand and foot, and skin of penis-give oft single medullated nerve fibres, terminating in at Pacinian corpuscle, mentioned in a former chapter. In the rolar side of the fingers and toes there occur in some of the papillie of the corium the tactile or Meissner's corpuscles, each connected with one or two medullated nerve fibres, as described in a previous chapter. The onter root-sheath of the hair-follicles contains the terminations of tine nerve fibres, in the shape of primitive fibrille (Jobert, Bonnet, and Arnstein). According to Jobert, the nerve tibres entwine the hair-follicle in circular turns. The tactile hairs possess a greater supply of nerves than the ordinary hair-follicles. 


\section{CHAPTER XXXYII.}

THE COYJEYCTIVA AYD ITS GLAYDS.

399. (1) The eyelids (Fig. 261). -The outer layer of the evelids is slin of ordinary description; the inner is a delicate, highly vascular membranethe conjunctiva palpebro. This includes a firm plate - the tarsal plate-which is not cartilage, but rery dense, white, fibrous tissue. In it lie embedded the Meitomian glands. These extend in each eyelid in a vertical direction from the distal margin of the tarsal plate to the free margin of the eyelid; in the posterior angle of this margin lies the opening or mouth of each of the Meibomian glands.

The duct of a Meibomian gland is lined with a continuation of the stratified parement epithelium, lining the free margin of the lid; it passes in the tarsal plate toward its distal margin, and takes up on all sides short minute dncts, each of which becomes enlarged into a spherical, saccular, or flask-shaped alreolus. This is identical in structure and secretion with the alreoti of the sebaceous follicles of the skin.

400. The conjunctival laver is separated from the subcutaneous tissue of the skin layer of the eselid by the bundles of the splincter nobicularis-striped muscular tissue. Some bundles of this extend near the free margin of the lid, and represent what is known as the musculus ciliaris Riolani. This sends bundles around the mouth of the Meibomian ducts.

401. At the anterior angle of the free margin of the lid are the eyelashes or citin, remarkable for their 
thickness and rapid reproduction. Near the cilia, lut towards the Meibomian ducts, open the ducts of

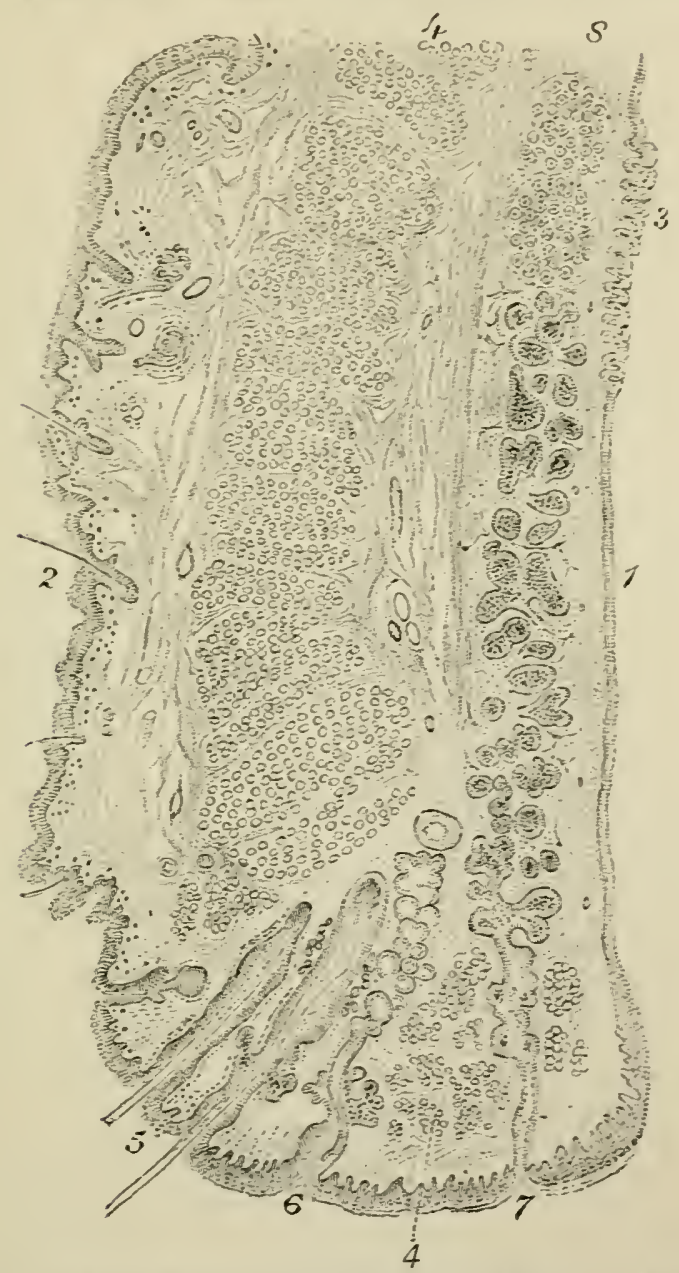

Fir. 201. - Vertical section through the Lpper Eyelid. (Waldeyer.)

1, ('onjunctiva; 2, skin; 3 . Dermanent folds of the conjunctisa; 4 , bundles of the sphincter orlicularls; 5 , erelashe-: 6 , mouth of the eland of Mohl ; : duct of the Meifomian gland: $\therefore$, tar-al glabd.

peculiar large glands-the gleseds of Moll. Each of these is a wary or spiral tube: passing in a rertical 
direction fiom the margin of the lid towards its distal part; it conpletely. coincides in structure with the large portion of a sweat gland-i.e. that part containing a columnar epithelial lining, and between this and the membrana propria a longitudinal layer of nonstriped muscular cells.

The free margin is corered, as mentioned above, with stratified pavement epithelium, into which the mucous membrane extends in the shape of minute papillæ. In the conjunctiva palpebre the epithelium is a thin stratified pavement epithelium; there are no papillae, but the sub-epithelial mucosa - that is, the layer situated between the epithelium of the surface and the tarsal plate-contains a dense network of capillary blood-vessels.

402. Passing from the eyelids on to the eyeball, we have the continuation of the conjunctiva palpebra -i.e. the fornix conjunctiva-ind, further, the conjunctiva fixed to the sclerotic, and terminating at the margin of the cornea - the conjunctiva bulbi. The epithelium covering the conjunctiva fornicis and conjunctiva bulbi is stratified epithelium, the superficial cells being short columnar' next to the fornix the superficial cells are beautiful columnar, and the mucosa underneath the epithelium is placed in regular folds (Stiedis, Waldeyer). Towards the cornea the epithelium of the conjunctiva assumes the character of stratified pavement epithelium, and minute papillie extend into it from the mucosa.

403. The mucous membrane is fibrous tissue, containing the networks of capillary blood-ressels.

Into the fornix lead minute mucous glands, embedded in the conjunctiva fornicis; they are the glands of Krouse. Similar glands exist in the distal portion of the tarsal plate.

404. The blood-vessels of the conjunctiva terminate as the capillary network of the superficial 
layer of the nucosit, and as capillan y networks for the Meibomian glands, Krause's gland, etc. Around the corneal margin the conjunctival vessels are particulanly dense, and loops of capillaries extend from it into the very margin of the cornea.

405. The Iymphatics form a superficial and deep network. Both are connected by short branches. The deep vessels are possessed of valves. The superficial plexus is densest at the limbus cornex, and they are in direct connection with the interfascicular lymph clefts, both of the sclerotic and comea. In the margin of the lid the superficial lymphatics of the skin anastomose with those of the conjunctiva.

Lymph follicles occur in groups in the conjunctiva of many mammals about the inner angle of the eye. In the lower eyelid of cattle they are very conspicuons, and known as the glands of Bruch. They are also well marked in the third lid of many mammals.

According to Stieda and Morano, isolated lymph follicles occur also in the human conjunctiva.

406. The merves are very numerous in the conjunctiva ; they form plexuses of non-medullated filmes underneath the epithelium. From these plexuses fine fibrils pass into the epithelium of the surface, between whose cells they terminate as a network (Helfreich, Morano). End bulbs of Krause occur in great number's in man and calf. They have been mentioned in a former chapter.

407 . (2) The lachrymal glands are identical in structure with the serous or true salivary glands. The arrangement of the connective-tissue stroma, the nature and structure of the ducts-especially of the intralobular ducts-and alveoli, the distribution of blood-vessels and lymphatics, are exactly the same as in the true salivary slands. Reichel has found that the epithelial colls lining the alveoli are woll defined, conical or cylindrical, transparent, and slightly 
granular during rest; but during secretion they grow smaller, more opaque and more granular, their outlines are not well defined, and the nucleus becomes more spherical and placed more centrally.

408. In most mammals there is in the inner angle of the eye, and closely placed against the surface of the eyeball, a gland called Harder's gland. According to Wendt, this is either a true serous gland, like the lachrymal-as in the ox, sheep, and pig-or it is identical in structure with a sebaceous gland, as in the mouse, rat, and guinea-pig; or it consists of two portions, one of which (white) is identical with a sebaceous, while the other (rose-coloured) is a true serous gland: such is the case in the rabbit and hare According to Giacomini, a rudiment of Harder's gland exists also in the ape and man. 


\section{CHAPTER XXXVITI.}

CORNEA, SCLWROTIC, HIGAMENTUA PECTINATUM AND CILIARY MUSCLE.

109. T. 'THe cornea (Fig. 262) of man and many mimmals consists of the following layers, counting from front to back :-

(1) The epithelium of the anterior surface (see Fig. 26). This is a very transparent, stratified pavement epithelium, such as has been deseribed in par. 2.2 . It is directly continuous with the epithelium of the conjunctiva, but it is more transparent; in dark pigmented eyes of mammals the epithelium of the conjunctiva is also pigmented. In these cases the pigment, as a rule, does not pass beyond the margin of the cornea.

410. (2) Next follows a homogeneous elastic membrane, Bowman's membrone, or elastica anterior. It is hest shown in the human eye, but is present, even though only rudimentary, in the eye of mammals.

(3) Then follows the ground substance, or substantia propria, of the cornea. 'This is composed of iamella of bundles of fibrous comnective tissue. Neighbouring lamellie are connected with one another by oblique bundles.

The fibre bundles within each lamella run parallel to the surface of the cornea, but may cross one another under various angles.

In the anterior linyer of the ground substance some of the bundles pass through several lamellie in an oblique manner; they represent the fibræ arcuatie. 
The tibrils within the bundles, and the loundles, and the lamellae of bundles are held together by an

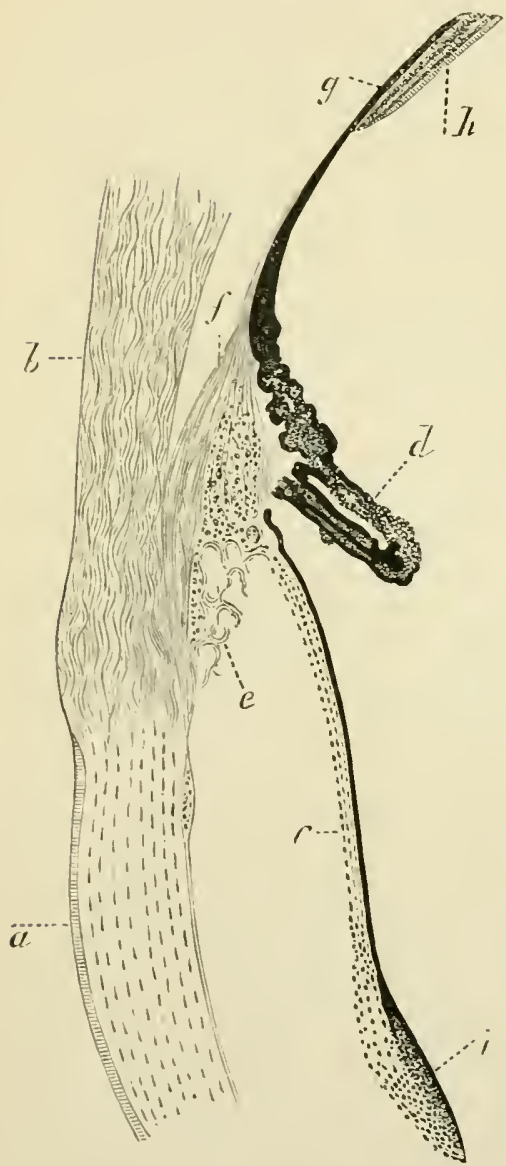

Fig. 262.-From a Vertical Section through the Membranes of the Eye of a Child. (Atlas.)

$a$, Cornea ; $b$, sclerotic ; $c$, iris ; $l$, processus ciliaris; $e$, ligamentum pectinatum : $f$, ciliary muscle, it - meridiomal bundles : ! clopoid membrane; $h$, retina of the orit serrata; $i$, sphincter pupilae in crosssection. interstitial, albuminous, semi-fluid cement substance, which, like other similar interstitial substances, helongs to the globulins, and is soluble in 10 per cent. saline solution (Schweigger Seiclel). A few elastic fibrils are seen here and there. Between the lamella are left the lacunie and canaliculi for the branched, flattened, nucleated, cornerl corpuscles, described in a previous chapter (Figs. 37, 38). They anastomose witl one another within the same plane, and also, to a limited degree, with those of neighbouring planes.

411. (4) The mem-

brama Descemeti, or elastica posterior, is a resistant elastic membrane, conspicuous by its thickness in all comere.

(5) The posterior surface of this membrane is covered with 
a mosilic of beautitul polygonel enerlothelial cells, each with an ovil nucleus-the endothelium of Descemet's membrane. Under stimulation these cells contract. At first they appear slightly and numerously branched, but gradually their processes become longer and fewer, and ultimately they are reduced to minute clumps of nucleated protoplasm, each with a few long processes.

There are no blood-ressels in the normal cornea, except in fotal life, when there is underneath the anterior epithelium a plexus of capillaries.

The lymphatics are represented as the intercommunicating lympli-canalicular system-i.e. the lacune and canaliculi of the corneal corpuscles; and in connection with these are lymph channels lined with a continuous endothelium and containing the nerve bundles.

412. The nerves (Figs. 10:3, 105, 106) are distributed as the nerves of the anterior layers, and as those of the Descemet's membrane. The first form rich plexuses of fibrillated axis cylinders, with triangular nocial points (Cohnheim), in the anterior layers of the ground substance; from this plexus pass obliquely through Bowman's membrane short branches - the rami perforantes (Kölliker) - and these immediately underneath the epithelium break up into their constituent prinitive tibrils, the latter coming off the former brush-like (Cohnheim). These primitive fibrillæe ultimately ascend into the anterior epithelium (Hoyer, Colmheim, and others), where they branch, and nearly reach the free surface. They always rum between the epithelial cells, and are connected into a network. According to some observer's, they terminate with free ends, pointed or knobbed; but according to others these apparent free ends are not in reality fiee endings (Figs. 107, 26:3 and 261). 
413. The nerres of Descemet's membrane form also a plexus of non-medullated fibres in the posterior lavers of the ground substance: from them come off' rast number's of primitive fibrille, running a more

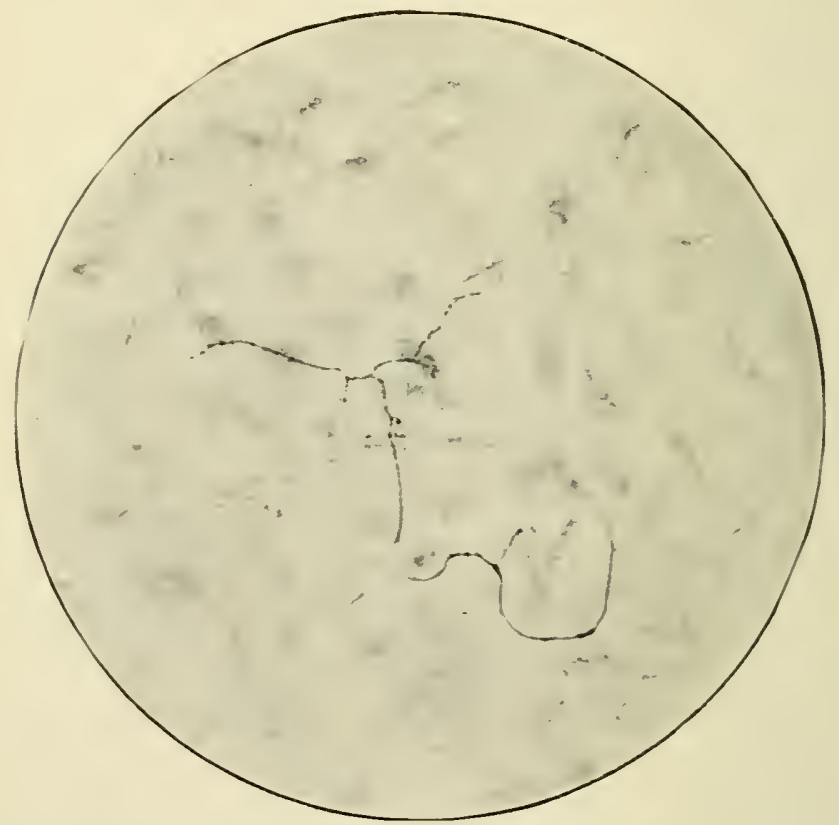

Fig. 263.-From a Horizontal Section throngh the Gold-stained Cornea of Rabbit; the corneal (branched) cells are faintly indicated, but the nerve fibrillæ are well marked, also their lateral branchlets, terminating aplarently with a minute knob. (Photograph. Morlerate magnification.)

or less straight and long course, crossing one another often under right angles; they give off very fine fibrils, which are closely associated with the corneal corpuscles, without, howerer, really becoming continuous with their protoplasm.

414. IT. The sclerotic consists of lamellie of tendinous tissue. The bundles of fibrous tissue are opaque as compared with those of the cornea, although 
they pass insensibly into them. There are lymph clofts between the lamellax and trabecula, and in them lie the flattencel connective-tissue corpuscles, which, in the dark eyes of some mammals only, contain

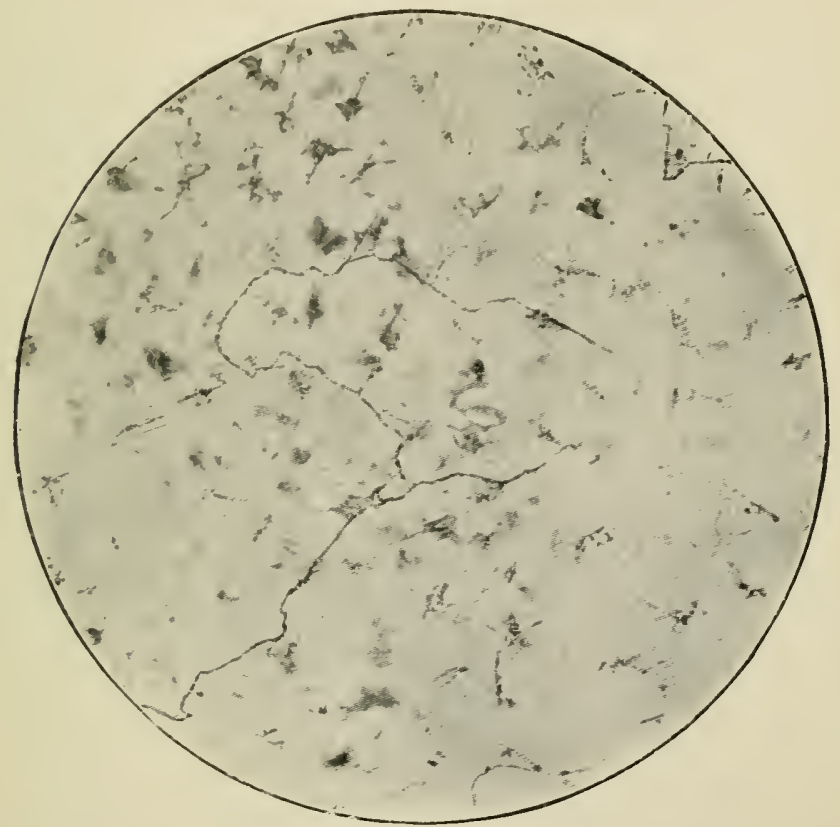

Fig. 264.-Fron the same fureparation as in precerling figure, slowing the tine Nerve Fibrils plassing along the processes and bodies of the branched corneal cor] uscles. (Photograph. Maderate magnification.)

pigment granules. Numerous elastic fibrils are met with in the inner layers of the sclerotic.

415. Between the sclerotic and choroid membrane is a loose fibrous tissue, which acts also as the supporting tissue for the blood-ressels passing to and from the choroid. The part of this loose tissue next to the sclerotic, and forming part, as it were, of the sclerotic, contains, in dark eyes of mammals, numerous pigmented connective-tissue corpuscles; it 
is then called lrmina fisca. The rest-i.e. next to the choroid nembrane-is the supra-choroidal tissue.

416. There are blood-ressels in the sclerotic, which belong to it; they are arterioles, capillaries; and reins: in addition to these are the vascular branches passing to and from the choroid.

417. I I I. The I igan ent um pectinatum iridis (see Fig. 262 ) is a conical mass of spongy tissue joining firmly the cormea and sclerotic to the iris and ciliary processes. It forms an intimate connection, on the one hand, with the junction of cornea and sclerotic, and on the other, with that of the iris and ciliary processes. This ligament is composed of trabeculre and limella of stiff elastic fibres, forming a continuity, on the one hand, with the lamina Descemeti of the cornea and the elastic fibres of the sclerotic, and on the other with the tissue of the ciliary border of the iris. The trabecula anastomose, so as to form a honeycombed plexus, and the spaces in this plexus are lined with a layer of Hattened endothelial cells, directly continuous with the endothelium of Descemet's membrane on the one hand, and with the layer of endo. thelial cells corering the anterior surface of the iris on the other hand. In some mammals, the spraces in the ligamentum pectinatum near the iris are very considerable, and are called the spaces of Fontana.

'The interlamellar and interfascicular lymph spaces of the sclerotic form an intercommunicating system.

The nelves form a dense plexus of non-medullated tibres in the tissue of the sclerotic (Helfreich).

At the point of junction of the comea and sclerotic, but belonging to the latter, and in the immediate neighbourhood of the ligamentum pectinatum iridis, is a circular camal-the comal of Schlemm; this is 
lined with endothelium, and is considererl by some (Schwalbe) as a lymphatic canal ; by other's (Leber) as a venous ressel.

418. TV. The riliany muscke (Fig. 26.2 ), or tensor choroidese, is fixed to this ligamentum pectinatum ; it is composer of bundles of non-striped muscular tissue. This muscle consists of two parts : (a) one of circular bundles nearest to the iris-this is the portio Mülleri ; $(b)$ the greater part is composed of radiating bundles, passing from the ligamentum pectinatum in a mericlional direction for a considerable distance backwards into the tissue of the choroid membrane. It occupies the space between the ligamentum pectinatum, sclerotic, ciliary processes, and the adjoining portion of the choroid membrane. The bundles of the muscle are arranged more or less in lamellie: within each lamella they form plexuses.

A rich plexus of non-medullated nerve fibres, with groups of ganglion cells, belongs to the ciliary muscle. 


\section{CHAPTER XXXTX}

IRIS, CILIARY PROCESSES AND CHOPOID.

419. I. THE iris consists of the following layers:-

(1) The endothelium of the anterior surface: transparent, flattened, or polyhedral cells, each with a spherical or slightly oral nucleus; in dark-coloured eyes of man and mammals brown pigment granules are contained in the cell substance.

(2) A delicate hyaline basement membrane: it is continuous throngh the trabeculie of the ligamentum pectinatum with the membrana Descemeti of the cornea.

(3) The substantia propria: this is the gromel substance ; it consists of fibrous connective tissue in bundles, accompanying the blood-ressels, which are very numerous in the tissue of the iris. Many connective-tissue corpuscles are found in the substantia propria: they are more or less branched, and many of them contain, in all but albino and blue eyes, yellowish-brown pigment granules. The depth of the colour varies according to the number of these pigmented comnective-tissue cells, and to the amount of the pigment granules present in them.

(4) A hyaline delicate basement membrane limits the substantia propria on the posterior surface: this is an elastic membrane, and is continned orer the ciliary processes and choroid as the lamina vitrea.

420. (5) The last layer is the epithelium of the posterior surface; this is a layer of polyhedral cells, filled with dark pigment granules, except in albinos, 
where there al'e no pigment granules 'This endothelium is called the nvea, or iapetum nigrum. The interstitial cement substince between the cells is not pigmented, but transparent.

The name "uvea" is sometimes applied to the whole of the iris, ciliary processes, anci choroirl membrane.

Tn blue eres the posterior epithelium is the only pigmented part of the iris, and so it is also in new-born children, whose iris appears blue. In all cases where the iris appears blue, this is due to the dark back --i.e. the pigmented epithelium of the posterior surface-being viewed through a dull laveri.e. the substance of the iris.

421. Near the pupillary border the posterior section of the suhstantia propria contains a broad layer of circular bunclles of non-striped muscular tissue: this is the splineter pupillu. In connection with this are bundles of non-striped muscular fibres, passing in a radiating direction towards the ciliary margin of the iris : these are the bundles of the dilatator prepilla, forming a sort of

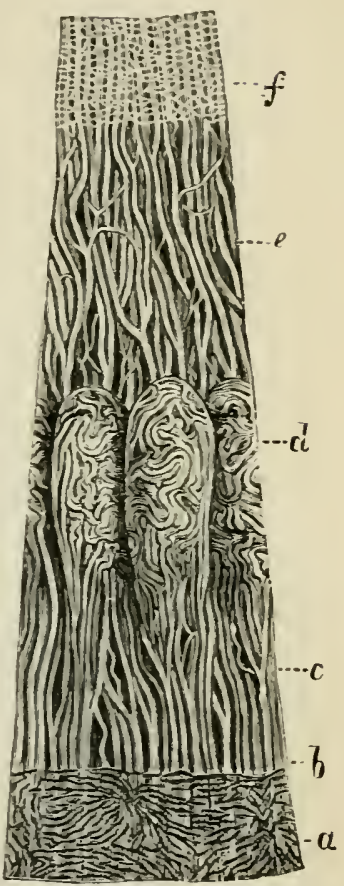

Fig. 205.-Blood - ressels (injected) of the Iris and Choroid Membrane of the Eye of a Child. (Kölliker, (ifter Arnold.)

a, Capillaries of the choroid; b. ora serrata; $c$, Hoodve-sels connected with, $d$, those of the ciliary processes, and with $e$, those of the iris; $f$, capillary network of the pupillary spbincter.

thin membrane near the posterior surface of the iris (Henle and others). At the ciliary margin the bundles take a circular direction and form a plexus (Iranoff). 
42.). The blood-vessers (Fig. 265) of the inis are rery numerous. 'The arteries are derived from the circulus ateriosus iridis major, situated at the ciliary margin of the iris, and from the arteries of the ciliary processes. These arteries rum in a radiating direction towards the pupillary margin, where they terminate in a dense network of capillaries for the sphincter pupillae. But there are also numerous cipillary blood-ressels of a more or less longitudinal direction near the posterior surface of the iris. The veins accompany the arteries, and both are situated in the middle stratum of the substantia propria.

In the sheath of the blood-ressels are lymple clefts and lymph sinuses: there appear to be no other lymphatics.

423. The merve fibres are rery numerous (Arnold, Formad), and in the outer or ciliary portion of the iris form a rich plexus, from which are derived: (a) netrorks of non-medullated fibres for the dilator pupilla; (b) a network of fine non-medullated fibres for the anterior surface; and $(c)$ a network of nonmedullated fibres for the sphincter pupillie.

The capillary blood-ressels are also accompanied hy fine nerve fibres (A. Meyer), and, according to Faber, there exist ganglion cells in these nerve networks.

424. IJ. The ciliary processes are similar in structure to the iris, except, of course, that they do not possess an anterior endothelium or an anterior basement membrane. The substantia propria is fibrous tissue with elastic fibres and numerous branched cells, pigmented in dark (but not in blue) eyes. The posterior basement membrane is rery thick, and is called the lamina vitrea: in it may be detected bundles of tine fibrils. It possesses permanent folds arranged in a network (H. Müller). The inside of it is corered with a layer of pigmented poly- 
hethal epithelium, the tupetum nigrmm: the cells are polygonal when riewed from the surface. The individual cells are separated by thin lines of a transparent cement substance. This pigmented epitheliun is covered with a liayer of tramsparent columnar

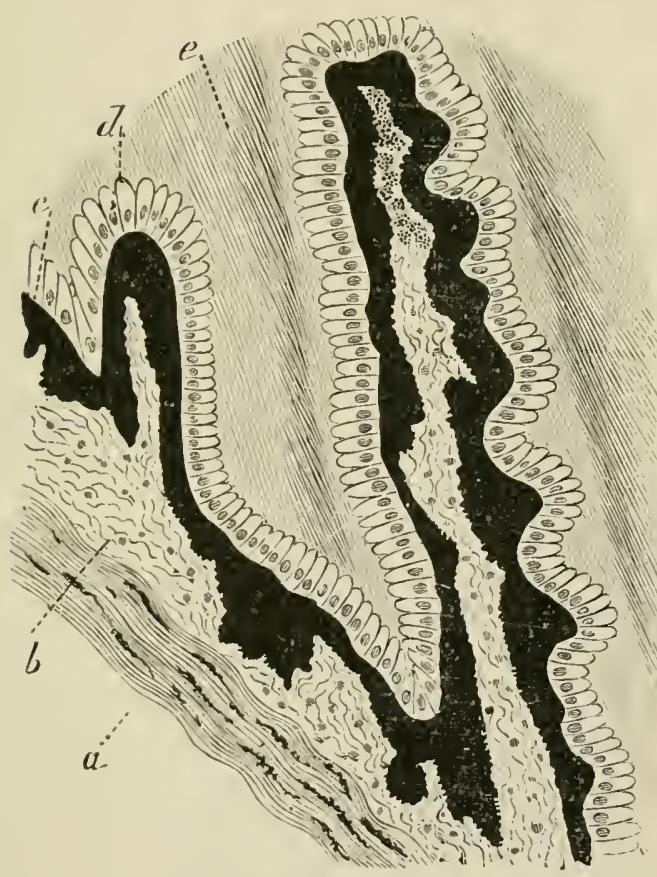

Fig. 26it.-From a Vertical fiction throngh the C'iliary Processes of the Ox's Eye. (Aflas.)

a. Filmous tissue with pigmented cell-; $b$, loose filmous tissue forming the

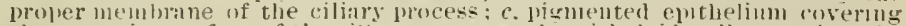
the posterion smface uf the ciliaty process; $d$, elitheloid cells, forming the

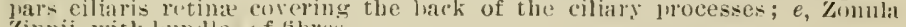
Zinnii, with lumbles of fibres.

epitheloid cells, each with an oval nucleus. These are closely fixed on the tapetum nigrum, and are the continuation of the retina over the ciliary processes: this is the pars ciliaris retince (Fig. 266).

425. The arterial branches for the ciliary processes 
and muscle are chiefly deriverl from the circulus arteriosus iridis major, and form a lease network of capillaries for the former; each ciliar'y process possesses a conical group of capillaries (Fig. 265).

426. III. The choroid membrane consistscounting from outwards, i.e. from the sclerotic, iowards, i.e. towilrds the retina - of the following layers :-

(1) The membrana supra-chornidea. This is a continuation of the sclerotic, with which it is identical

Fis. 267.-Pigmenterl Connective-tissue Cells of the Clioroid Coat. (Atles.) instructure; thespaces between its lamellae are lined with endothelium, and represent lymph spaces (Schwalbe).

(2) Next follows an elastic layer which contains networks of elastic fibres, the branches of the arteries and veins, and, in its outer portion, pigmented cells (Fig. 267).

427. (3) Then follows the membrana chorio-capillaris, a dense network of capillary blood-ressels embedded in a tissue containing numerous branched and unbranched pigmented and unpigmented connectivetissue cells.

(4) The lamina vitrea ; and, finally,

(5) The tapetum nigrum, or the pigmented epithelium, which, however, is considered part of the retina. In the region of the ora serrata of the retina-i.e. next to the cilialy processes-also this zone of the choroidea is lined with a layer of transparent, columnar, epitheloid cells, representing the par's ciliaris retine.

428. The arterix ciliares breres and reculrentes, situated in the outer part of the choroidal tissue, form 
ultimately the dense networks of capillaries for the chorio-capillaries. The veins terired from this pass inte the outer part of the choroid, where they anastomose so as to for'm the peculiar large veins, which are called the rence rorticose.

In the eyes of some anim tls (eat, dog, sheep, ox) there exists a special layer of cells (cat, dog) or tilmes (herbiroral). which, owing to its capability of reflecting a great deal of light, is called the tapetum lncidum or me ubrana versicolor of Fielding. This laver when present is situated between the stroma of the choroid (layer 2 ) and the membrana choriocapillaris (layer 3 ). 


\section{CHAPTER XT.}

THE LENS AND VITREOUS BODY.

429. (1) 'Whe leus consists of a thick, firm, elastic capsule and of the lens substance. The former shows fine longitudinal strixe, and diminishes in thickness towards the posterior pole of the lens. The surface of the capsule facing the anterior surface of the lens substance is lined with a single layer of polyhedral, granular-looking, epithelial cells, each with a spherical or oval nucleus. This epithelium stops as such at the margin of the lens, where its cells, gradually elongating, pass into the lens fibres. The nuclei of these lie in a curved plane belonging to the anterior late of the lens: this is the nuclear zone. The lens substance consists of the lens fibres. These are band-like, lexagonal in transverse section; their outline is beset with numerous fine ridges and furrows, which in neighbouring fibres, fitting the one into the other, form a firm connection between the fibres (Valentin, Henle, Kolliker, and others). The fibres of the peripheral portion are broarler and thicker, and their substance is less firm than those of the centre-i.e. of the lens nucleus. The substance of the lens fibres is finely granular and delicately and longitudinally striated.

430. The lens fibres (Fig. 268) are arrauged in concentric lamella, each consisting of a single layer of fibres joined by their broad surfices. Each fibre is slightly enlarged at the extremities; and in each lamella the fibres extend from the anterior to the posterior surface. Their extremities are in contact 
with the ends of the fibres of the same lamella in the sutures, or the rays of the so-called lens strins. In the lens of the newly-borm ehild, the stars of both anterior and posterior lamella possess three such rays, while in the adult each of these rays has secondary rays. In these rays there is a lomogeneous thin layer of an albuminous cement substance; a similar substance in minute quantity is also present between the lamellie, and in it occur smaller or larger clefts and channels, which evidently carry the nutritious fluid for the lens fibres.

431. (2) The virreous body is a fluid substance enclosed in a delicate hyaline capsule-the membrenc hyuloidea. This membrane, at the margin of the fossa patellaris of the vitreous body-i.e. the fossa in which the lens is lodged-and without covering this fossi, passes as the zonula ciliaris, or zonula Zimnii, or suspensory ligament of the lens, to the margin of the latter, to which it is firmly adhering. So it adheres also to the surface of the ciliary processes. The zonula Zinnii is hyaline and firm, and is strengthened by numbers of bundles of minute stiff fibrils.

Between the suspensoly liga-

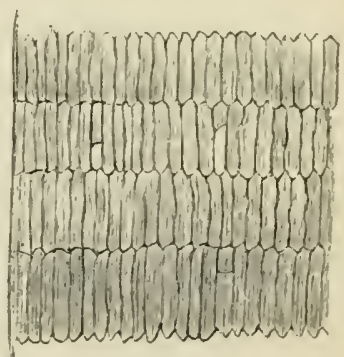

Fig. 2is.-From a Section through the Lens of Dog. (Atlus.)

showing four lanellæ; in each the component lens fibres are cut across; thes appear as flattened hexigons.

ment of the lens, the margin of the lens and of the fossa patellaris is a circular lymph space, called the canalis Petiti.

Beneath the membrana hyaloidea are found isolated nucleated granular-looking cells (the sub-hyaloid cells of Ciaccio), possessed of amoboid movement (I vanoff").

432. The substance of the corpus vitreum appears 
differentiated by clefts, concentric in the peripheral, radiating in the central part (Brïcke, Hannover, Bowman, Iranoff, Schwalbe). But these do not contain any distinct membranous structures (Stilling, Iranoff, Schwalbe).

The canalis hyaloideus, or canal of Stilling, extends from the papilla nervi optici to the posterior capsule of the lens, and is lined with a continuation of the membrana hyaloidea.

433. In the substance of the corpus ritreum occur isolated nucleated cells, possessed of amœboid morements, and some contain vacuoles, indicating commencing degeneration. They are all identical with white blood-corpuscles (Lieberkiibn, Schwalbe).

Fine bundles of fibrils are occasionally seen in the substance of the vitreous body. 


\section{CHAPTER XLI.}

THE RETINA.

434. The retina (Fig. 269) consists of the following layers, counting from inwards towards the choroir membrane :

The membrana limitans in terna, which is next to the membrana hyaloidea of the ritreous body; the nerve fibre layer ; (3) the layer of ganglion cells; (t) the inner granular or inner molecular layer; (5) the layer of inner nuclei; (6) the outer granular, or outer molecular, or internuclear layer : (i) the layer of outer nuclei; (\&) the membrana limitans externa; (9) the layer of rods and cones;

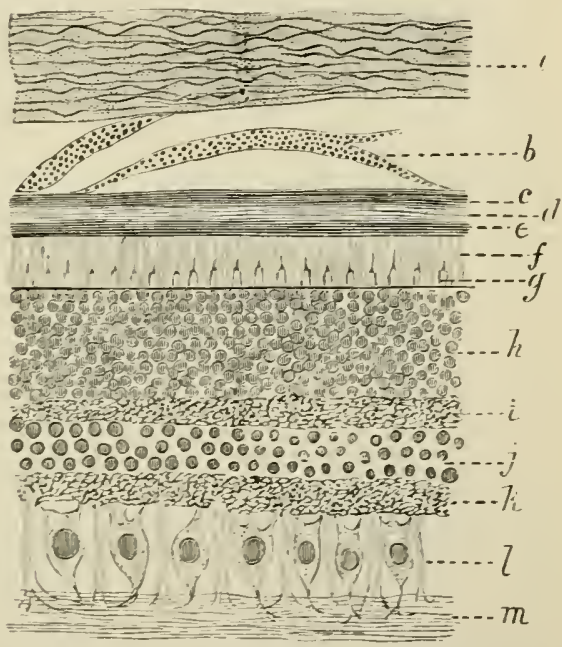

Fir. 2h9.-From a Transverse section through the Eye of Sheel'; peripheral portion of retina. (Atlcis.)

$a$, Inner nart of sclerotic; $b$, supra-choroidal (pigmented) lamellæ; c. d. lasers of clioroid crat; $\%$ pigmented elithelium of retina; $f$. laver of rods; $g$. cones ; $h$, layer of outer nuclei ; $i$, outer molecular laser; $j$, laser of inner nuclei ; $k$, inner molecular layer; $l$, layer of kanglion cells, with the radial or Muiller's fibres between; $m$, laser of nerve fibres. and (10) the pigmented epithelium of the retina, or the tapetum nigrum mentioned above (p. 439), which forms, at the 
same time, the inner lining epithelium of the choroir membrane.

435. From this arrangement are excepted (r) the
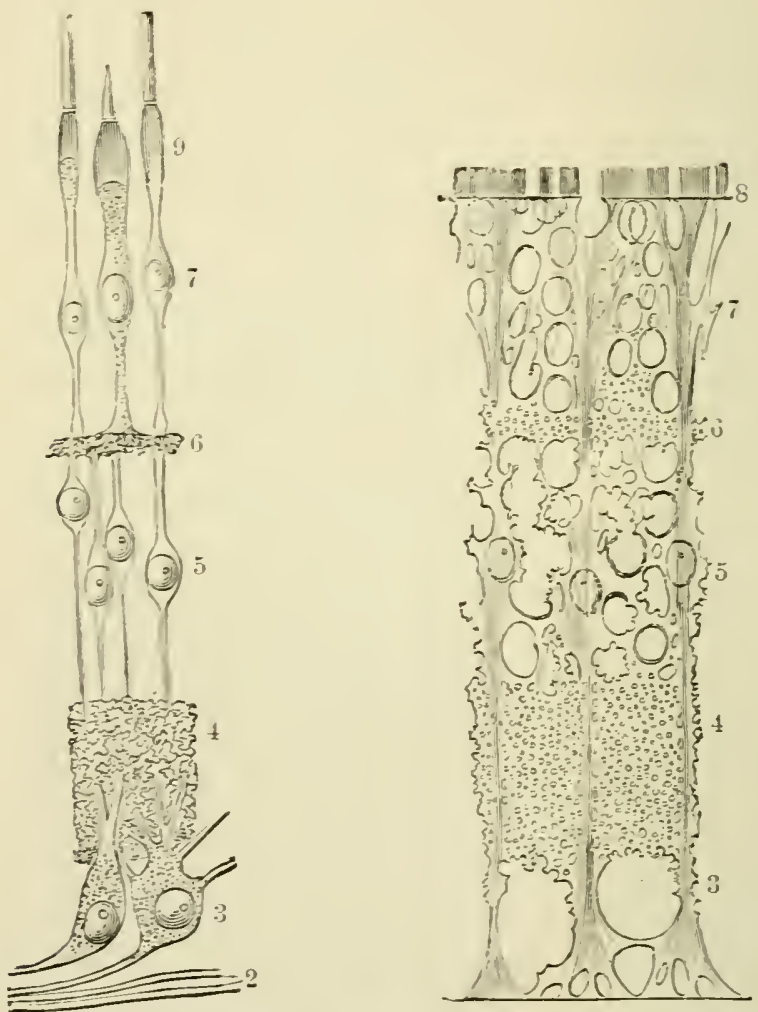

Fi_. -270.-Diasram of the Yer- Fig. 271.-Diactan of the Connectiveviss Elements of the Retina.

$\because$ Verve fibes: $3,9+n$ rion cells: 4 , inner molecular layer; 5 , inner nuclear layer ; 5 . oucer molecular laser; $\because$, nuter nuclear lay er ; $;$ membrana limitans externa; 4 , rols and cones. (Max : chultze.)

papilla nervi optici, (b) the macula lutea and forea centralis retinx, and (c) the ora serrata of the retina. (a) The papilla nerri optici, or the blind spot of 
the retina, reperesuts the entrance of the optic nerve filures into the retina; thence, as from a contre, they spread out in a radiating direction into the saucershaped retina, of which they form the internal layer. No other elements of the retina are present at the papilla, except a continuation of the limitans interna. At the papilla nervi optici the arteria and vena centralis nervi optici also enter, and spread ont with their branches in the imner layers of the retina. A large lympl space is also found there.

(b) The macula lutea and fovea centralis will be considered after the various layer's of the retina have been described.

(c) At the ora serrata all circular and muclear elements of the retina-except the pigmented epithelium-and the nerve fibres, come to an end: but the limitans interna, with its peculiar radial or Mïller's fibres, is continued orer the ciliary processes in the shape of columnar epitheloid nucleated cells mentioned above: this is the pars ciliaris retinat.

436. Structure of the layers of the retina (Eigs. $270,271)$.

(1) The membrama limitams interna is composed of more or less polygonal areas, which are the ends or bases of pyramidal, tinely-striated fibres - the radial fibres of Miiller. Each radial fibre passes from the limitans interna in a vertical direction through all layers to the limitans externa, and on its way gives off numerous lateral branchlets, fibrils and membranes, which anastomose with one another so as to form a honeycomber stroma or matrix for all cellular and nuclear elements of the retinal layers. In the nerve fibre layer the radial fibres are thickest, this being, in fact, the pyramidal basis: in the imner nuclear layer each possesses an oval nucleus.

4:37. (2) 'rhe Iayer of nerve fibres.-The optic nerve fibres at their entrance into the eyeball 
lose their medullary sheath, and only the transparent axis cylinder is prolonged into the retina. In man, medullated nerve fibres in the retina are rery exceptional: in the rabbit there are two bundles, whose tibres retain their medullary sheath in the retina

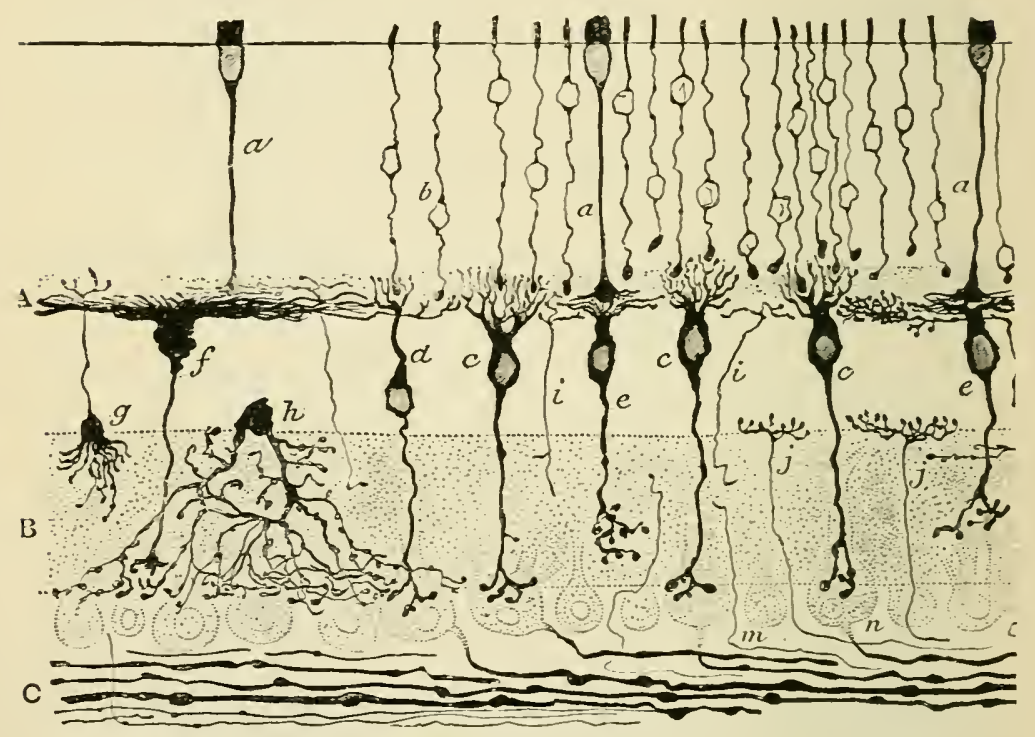

Fig. 272. - Section of Retina of Dog. ¿After Cajal, from_Quains "Anatomy.")

$a$, Cone fibre; $b$, rod fibre and nuclens ; $c, d$, bipolar cells with inner nuclei, with vertical ramifications to receive the knohbed ends of the rod fibres, $\ell, f$, with Hattened ramifications for the arborising ends of the cone filsres; $g$, ganglion cell sending an axon to the outer moledular laser; $h$, soneroblast ; $i$, nerve fibres pa-sing to the outer molecular layer; $j$, centrifugal nerve fibres passing into, and terminating in, inner molecular laver: $m$, nerve fibres passing to inner molecular layer: $n$, ganglion cells: $A$, outer molecular laver: $\mathrm{B}$, inner molecular layer; $\mathrm{C}$, nerve fihre layer.

(Bowman). The nerve fibres remain grouped in bundles in the retina, and even form plexuses. For obvious reasons, the number of nerve tibres in the nerve fibre layer diminishes towards the ora serrata.

438. (3) The Iayer of gamolion cells.-There is one stratum of these cells only, except in the macula lntea, where they form several strata. Each 
cell is multipolin. and possessed of a larige nuclens. One process is directed inwats and becomes the axon, being a fibre of the nerve fibre layer. Severat branched processes or dendrites pass from the opposite sicle of the cell into the next outer laver-i.e. the inmer molecular layer.

From the researches of Ramón y Cajal, it is clear

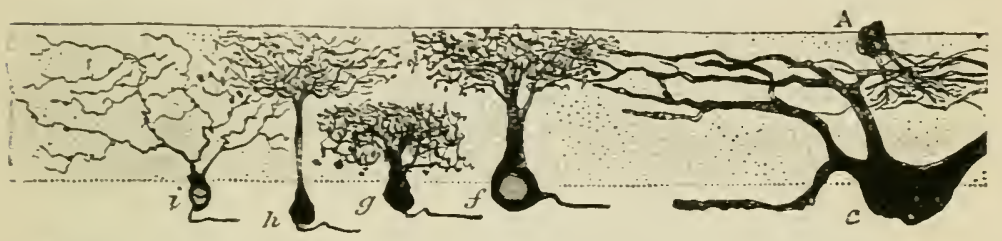

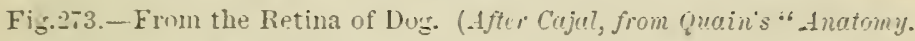

$\Lambda$, small amacrine (-pongiollast) of the inner molecular layer : $c$, large ganslion

cell; $f, g, h, i$, small sanslion cells arburisins in the inner molecular laser.

that the dendrites terminate by arborisitions or dendrons in the next or inner molecular layer (sep Figs. $27: 2,273$, and $27 \pm$ ).

The ganglion cells are separated from one another by the radial fibres of Miuller.

439. (t) The immer molecular nayer is a fine and dense reticulum of fibrils, witl a small amount of granular matter between. The fibrils are commected with lateral branchlets of the radial fibres of Miiller. This layer is, on account of its thickness, a conspicnous part of the retina. In lower vertebrates it appear's stratified.

As mentioned just now, it contains the terminal arborisations of the dendrites of the ganglion cells.

440. (5) The immer murlear layer contains in a honejcombed matrix of a hyaline stroma numerous nuclei, in two, three, or four layers'. In the amphibian retina these form a larger number of layers. Some oblong nuclei of this layer belong, as has been mentioned ahore, to the radial fibres of Miiller: 
Next to the molecular larer are small nuclei belonging to flattened branched cells (Tintecligau). the spongioblasts of W. Müller. These cells have been shown by Golgi's method to be possessed of rich arborisations, which extend horizontally into the outer and immer

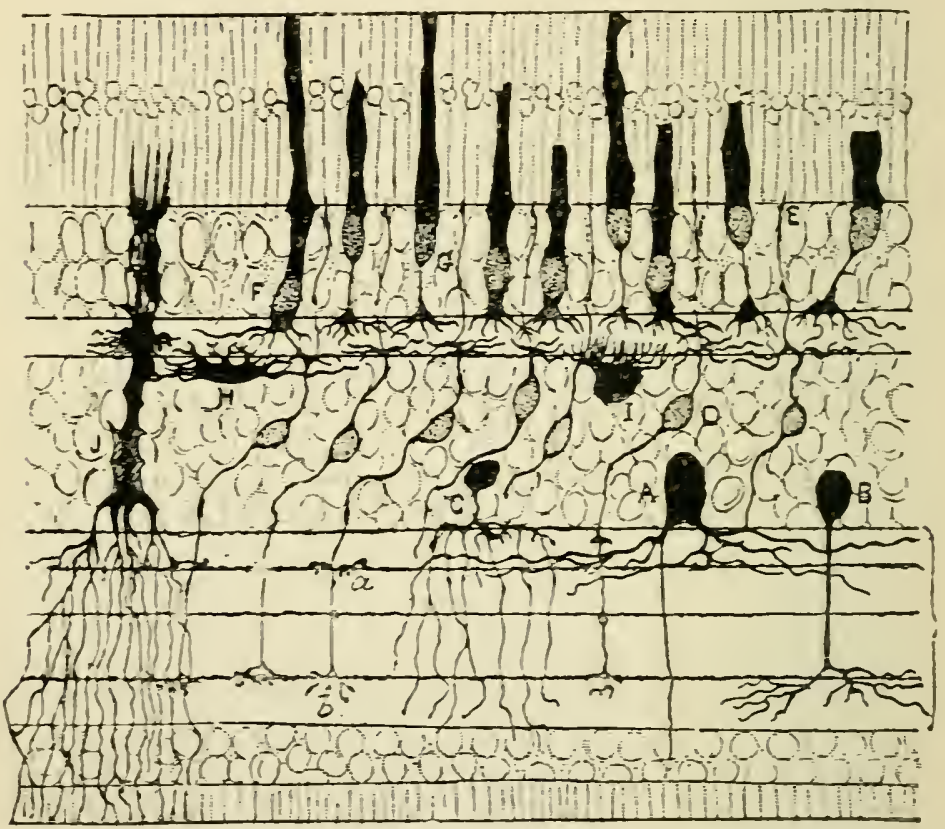

Fig. 2-4.-Section of Retina of Bird. (After Cajal, Jrom Gurtin's "Anatomy.")

A, B. Large spongioblast of inner nnclear larer: C. small spongioblast ; I.

timlar cell of inner nuclear laser with $a$ and $b$ arburising in inner molecnlar larer and also terminating at $E$ at the limitans externa; $F$, fr, rod and cone nuclei; H, I, cell- with arborisations in outer molecular larer; J, radial fibre of Yüller.

molecular larers (see Fig. 272). Ramón y Cajal designates them as amacrines. But the great majority of the nuclei of this laver are slightly oral, with a reticulum in their interior. Each belongs to a spindle-shiped cell, with a small amount of protoplasm around the nucleus; it is, in fact, a bipolar 
ganglion cell (Max Schultze), of which one process (the inner) passes as a fine varicose fibre into the inner molecular layer, where it terminates as a delicate dendron, while the other or onter process passes into the next outer layer of the retina-i.e. the outer molecular layer, to terminate here by a rich arborisation or dendron (Fig. 272).

(6) The ourer molecular layer is of the same structure as the inner molecular layer-i.e. a fine reticulum of fibrils-but is considerably thinmer than the latter. It also contains the dendrons of cells inside and outside it (Fig. 272 ).

441. ( 7 ) The outer muclear Iayer contains, in a honeyeombed matrix, a large number of oval nuclei. In the retina of man and mammals these nuclei are always present in considerably greater numbers or layer's than those of the inner nuclear layer, but in the amphibian animals the reverse is the case. They are smaller than the nuclei of the inner nuclear layer, and show often a peculiar transversely-ribbed differentiation of their contents (Henle, Kranse). The honeycombed matrix of this layer is in connection with lateral branchlets of the radial fibres of Müller, with which it forms a sort of limiting delicate membrana propria at the outer surface of the layer; this is

442. (8) The limitans externa.-The nuclei of the outer nuclear layer next to this limitans externa are connected, in the retina of man and mammals, with the cones, while the nuclei farther inwards from the limitans externa are connected with the rods. In both instances the comnection is established through holes in the limitans externa. Each nucleus of the outer nuclear layer is, in reality, that of a spindle-shaped cell with a minute amount of protoplasm; this is prolonged outwards, as the outer part of the rod-or cone-fibre, to become connected with a 
rod or cone respectively, while inwards it passes into a longer; more conspicuous fibre, the inner part of the rod- or cone-fibre (Fig. 272). According to Ramón y Cajal, the cone-fibre terminates as a flat denclron in contact with the tufty arborisation of the outer process of the cells of the inner nuclear layer-i.e. in the outer molecular layer" : the rod-fibre on the other hand terminates in the outer molecular layer as a small knob (Fig. 272) in the outer dendron of the same cells

443. (9) The rods and cones. Each rod is of cylindrical shape, with rounded or conical outer extremity ; it consists of an outer and inner member, joined by linear cement. Its substance is bright and glistening, and that of the outer member is composed of the neurokeratin of Kühne and Ewald. In the fresh state the outer member shows a more or less fine and longitudinal striation, due to longitudinal fine ridges and furrows (Hensen, Max Schultze). After certain reagents, such as serum, liquor potasse, the outer rod-member disintegrates into numerous transverse, thin, homogeneous-looking discs (Hannover). The inner member in the human rods is slightly broader than the outer ; it is pale or finely and longitudinally striated, and contains in many instances a peculiar lenticular structure; in the human and mammalian retina this is absent, but in its stead is a mass of longitudinal tibrils (Max Schultze). The inner member passes through a hole in the limitans externa, and becoming thinner, represents the outer part of the rod-fibre.

444. Each cone is composed of an outer, short, pointed, conical member, and an inner larger member with convex surface: this is the body of the cone. The outer member of the cone separates under certain conditions also into thin transverse dises. The body of the cone is longitudinally and finely striated. The 
outer extremity of the body of the cones in many birds, reptiles, and amphibia contains a spherical corpuscle of red, orange, yellow, green, or even blue colouration.

'The cones are shorter than the rods, the pointed end of the former not reaching much farther than the junction between the outer and inner members of the rods.

In the macula lutea and forea centralis of man and most mammals there are present cones only, and towards the peripheral portion of the retina they gradually decrease in numbers; in the peripheral part there are only rods. But in birds the cones exceed the rods everywhere.

In the bat and mole the macula lutea possesses no cones, and in the owl, rat, mouse, guinea-pig and rabbit they are few and small.

445. The outer members of the rods (only) show in the fresh and living state a peculiar diffuse purplish colour (Leydig, Boll, Kühme) : this is the visual purple or Rhodopsin of Kiilme. When exposed to sunlight it passes through red, orange, and yellow, and finally disappears altogether -becomes bleached. There is

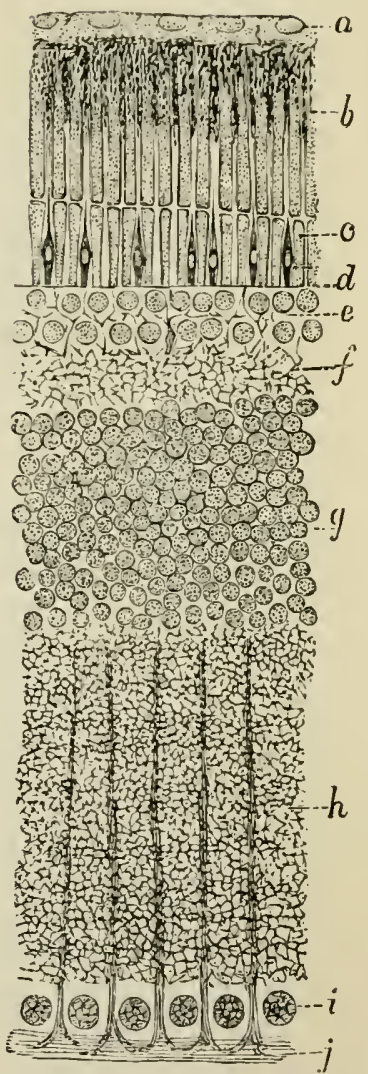

Fig. 275.-Vertical Section through Retina of Frog. (Atlas.)

$a$, Pigmented epithelium of retina or tapetum nigrum; $b$, outer nembers of rods, those of cones between them; $c$, inner memliers of rods and cones; $d$, limitans externa ; $e$, outer uuclei ; $f$, outer molecular layer ; $g$, inner nuclei ; $h$, inner molecular layer; $i$, nnclei of ganglion cells; $j$, nerve fibres; the pyramidal extremities of the radial filles are well shown. 
no visual purple in the rods of Phinolophus hipposideros, fowl and pige on: in those retina in which the cones contain coloured globules (se, above) the surrounling rods are wanting in the visual purple.

The visual purple stands in an intimate relation to the pigmented epithelium of the retina, since a retina regains its visual purple after bleaching, when replaced on the pigmented epithelium (Kiihne). This holds good, of course, only within certain limits.

$4+6$. (10) The pigmemted epirhelimm (Fig. 27.j), or tapetum nigrum, is composed of polygonal protoplasmic cells, which, when viewed from the surface, appear as a mosaic, in which they are separated from one another by a thin laser of cement substance. Each cell shows an outer non-pigmented part, containing the slightly Hattened oral nucleus, and an inner part next to the rods and cones, which is full of pigmented crystalline rods (Frisch). This part is prolonged into numerous tine fibrils, each containing a row of the pigmented particles, and these fibrils pass between the outer members of the rols, to which they closely adbere, and which in reality become almost entirely ensheathed in them (MI. Schultze). Each cell supplies a number of rods with these fibrils. Sunlight causes a protrusion of these fibrils from the cell body, whereas in the dark they are retracted (Kühne), in a manner similar to what takes place in pigmented connectivetissue cells. (See par. 13.) The tint of this pigment is clarker in clark than in light eves. It is bleached by the light in the presence of oxyen (Kühne), but it persists in the absence of oxygen (IIafs).

4t7. The macula Intea (Fig. 276) of man anrl ape contains a cliffuse vellow pigment, between the elements of the retina (M. Schultze). In man and most mammals, as mentioned above, there are hardly any rods here, but cones only; these are 
longer than in other parts, and in the fovea centralis they are longest, and, at the same time, very thin. since there are only cones here, the nuclei of the outer nuclea layer are limited to a very few layers (generally about two) next to the membrana limitans

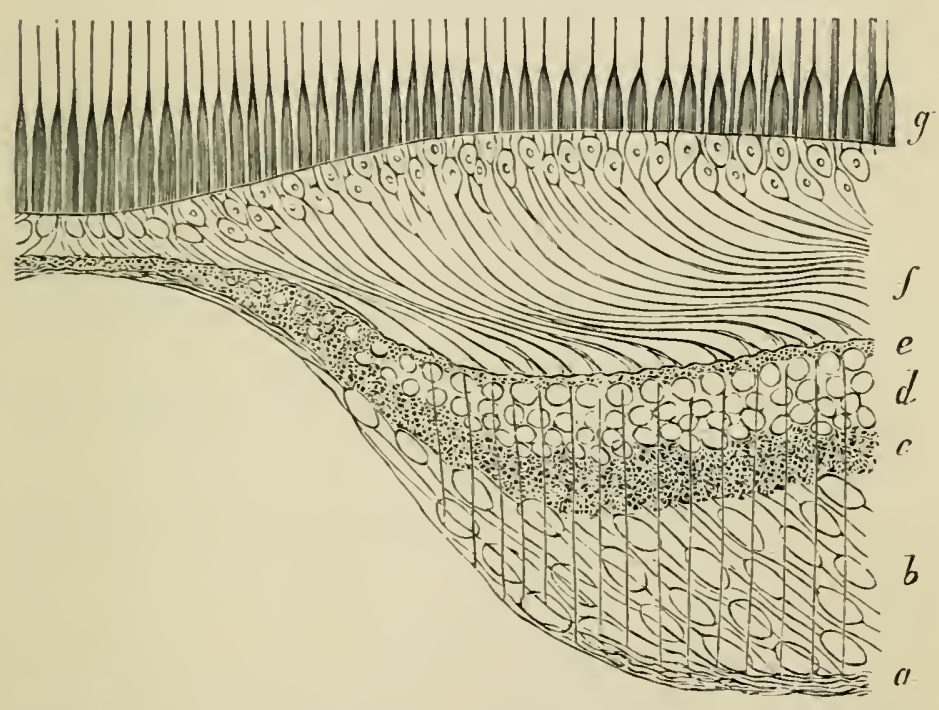

Fig. 276.-Fron a Vertical Section through the Macula intea and Fovea centralis. (Diagram by .Iax Schultze.)

$\iota$, Nerve fibre-; $b$, ganclion cells : $c$, inuer molecular layer ; $d$, inner nuclei; $e$, outer molecular layer; $f$, cone-fibres with their onter nuclei; $g$, cones.

externa. For this reason, the rest of the outer nuclear layer is occupied by the cone-fibres only, which in the forea centralis pass in a slanting, or almost lorizontal, direction sideways into the outer molecular layer. The ganglion cells form several strata in the macula lutea. In the forea centralis are present the cones (very long and thin), the limitans externa, the few nuclei representing the outer nuclear layer, a thin continuation of the inner molecular layer, and the linitans interna. 448. In the embryo, the primary optic vesicle 
becomes invaginated so as to form the optic cup, which consists of two lavers - an outer, giving origin to the pigmented epithelimm : and an imner, the retina proper. In this latter the rods and cones, with their fibres and the nuclei of the outer nuclear laver, are represented by colummar epithelial cells (the sensory epithetium), while all the other lavers-i.e. the outer molecular, imer nuclear, inner molecular layer, ganglion cells, nerve fibres, and limitans interna-are represented by a separate larer: Bricke's tunica nervea or Henle's stratum nerreum.

449. The blodd-ressels of the retina. The branches of the arteria and rena centralis of the optic nerve can be traced into the retina in the layer of nerve tibres and ganglion cells, while the capillaries connecting the arteries with the veins extend as far as the outer molecular layer.

The lymplatics of the retina exist as pelivascular lrmphaties of the retinal reins and capillaries (His). Lrmpl channels are present in the nerve fibre laver.

450. The Iamima cribrosa is the part of the sclerotic and choroid membrane through which the optic nerve fibres have to pass in order to reach the papilla nervi optici. In the optic nerve the fibres are grouped in larger or smaller groups - not bundles in the sense of those present in other nerves and surrounded hy perineurium (see (hapter XIV.): these groups are surrounded by septa of connective tissue, and they pass through corresponding holes of the sclerotic and choroid.

451. The optic merve possesses three sheaths, composed of fibrous competive tissue: an outer, or dural ; a middle, or arachnoidal : and an inner, or pial, sheath-all continuations of the membranes of the brain. The pial sheath is the perineurium, the optic nerve being comparable to a compound nerve- 
bundle (spe Chapter XIV.). The dural sheath of the optic nerve, at its entrance into the lamina cribrosa, passes into the outer strata of the sclerotic, while the arachnoidal and pial sheaths pass into the inner stratia of the sclerotic. Outside the dural sheath is a lymph space-the supravaginal space: and also between these various sheaths are lymph spaces-the subdural or subraginal space of schwalbe, and the subarachnoidal space. The supravaginal and subraginal spaces anastomose with one another (Michel).

45. . Around the sclerotic is a lrmph space limited by a tibrous membrane-the Terronian capsule: the space is called the Temonicn space. The supraraginal space anastomoses with this Tenonian space, and into it pass also the lymph clefts in the suprachoroidal tissue (Schwallse), by means of the lrmph canalicular srstem of the sclerotic (Waldeyer). The suprachoroidal Jymph spaces communicate also with the subarachnoidal space of the optic nerve. 


\section{CHAPTER XLII.}

THF, OUTER AND IIDDLE EAR.

453. The meatus auditorius externus is lined with a delicate skin, in structure identical with, but thinner than, the skin of other parts. The ceruminous glands have been mentioned and described before. The cartilage of the auricula and its continuation into the meatus auditorius externus is elastic cartilage.

454. The membrana tympani separating the outer from the middle ear has for its matrix a firm stratum of stiff trabecula of fibrous connective tissue, with numerous elastic fibrils and elastic membranes. This is the midcle and chief stratum of the membrane: outwards it is covered with a delicate continuation of the skin of the meatus auditorius externus, and inwards with a continuation of the delicate mucous membrane lining the carum tympani. In the middle stratum of the membrana tympani the trabeculie radiate more or less from the junction of the manubrium mallei with the membrane; but towards the periphery many are also arranged in a circular direction. The former belong to the outer, the latter to the inner, portion of the middle stratum.

The mucous membrane lining the tympanic surface of the membrane is delicate connective tissue, covered with a single layer of polyhedral epithelial cells.

The blood-vessels form capillary networks for all three layers-i.e. a special network for the skin layer, a second for the middle stratum, and a third one for the mucous layer; the lymphatics are also arranged in 
this way. An intercommunicating system of lymphatic sinuses and clefts (Kessel) is left between the trabeculie. The non-medullated nerve fibres form plexuses for the skin and mucoms layer; from these pass oft fine fibrils, which form a sul,-epithelial network, and from this the fibrils pass into the epithelium.

455. The tuba Eustachii is lined with a nucous membrane, which is a continuation of that lining the upper part of the pharynx, and therefore, like it, is covered on its immer or free surface with columnar ciliated epithelium. As in the pharynx, so also here, we find a grood deal of adenoill tissue in the mucons membrane.

The cartilage of the tuba Eustachii in the adult approaches in structure the elastic cartilages of other parts.

456. The cavum tympani, including the cellulæ mastoidere and the surface of the ossicula auditus, is lined with a delicate connective-tissue membrane. Its free surface is covered with a single layer of polyhedral epithelial cells in the following regions: on the promontory of the inner wall of the cavity, on the ossicula auditus, on the roof of the cavity, and in the cellulæ mastoider ; in all other parts it is columna ciliated epithelium, like that lining the tuba Eustachii.

457. The three ossicula amditus are osseous substance coverel with periosteum, which is covered with the delicate mucosa just described. The ligaments of the bones are, like other ligaments, made up of straight and parallel bundles of fibrous connective tissue. The articulation surface of the head of the malleus, of the incus, of the extremity of the long process of the incus, and of the stapes, are covered with hyaline (articular) cartilage. 


\section{CHAPTER XLIII.}

TH E I Y T E R I A L EA R.

458. THe osseous labyrinth consists of the restibule, prolonged on one side into the cochlea, and on the other into the three semicircular canals, each of which possesses an aupulla at one extremity. The restibule shows two divisions-the forea hemispherica next to the cochlea, and the fovea hemi-elliptica next to the senticircular canals. The cochlea consists of two and a half turnings twisted round a bony axis-the modiolus. From this a bony lamina extends towards the outer wall for each turn, but does not reach it: this is the lamina spiralis ossea. It extends through all turus, and it subdivides the cavity of each turn into an upper passage, or scala restibuli, and a lower, or scala tympani. At the top of the cochlea the two scalie pass into one another by the helicotrema. The scala restibuli opens into the forea hemispherica, while the scala tympani at its commencement-i.e. at the proximal end of the first turn-would be in communication, by the fenestra rotunda, with the carum trmpani, were it not that this fenestra rotunda is closed by a membrane-the secondary membrane.

4.59. The semicircular canals start from, and return to, the forea hemi-elliptica of the vestibule.

The fenestra ovalis leads from the carum tympani into the restibule-its hemispheric division; and this fenestra ovalis is, in the fresh condition, filled out by a membrane, in which the basis of the stapes is fixed, the circumference of this being nearly as great as that of the fenestra. 
460. The osseous labyrinth in all parts consists of ordinary osseous substance, with the usual periostem lining its outer surface and its inner cavities. These cavities contain the albuminous fluid called perilymph. But they are not filled out by this, since, in each of the two divisions of the restibule, in each of the semicircular canals, and in the cochlea, is a membranous structure, analogous in shape to the corresponding division of the labyrinth. These membranous structures possess a cavity filled with the sime albuminous fluid as above, called the endolymph. These structures are disposed thus: in the fovea hemispherica is a spherical sac, called the saccule; in the fovea hemi-elliptica is an elliptical sac, the utricle; in each of the three semicircular canals is a membranons semicircular tube, which possesses also an ampulla corresponding to the ampulla of the bony canial.

461. Tn the cochlea is a membranous canal, triangular in cross-section - the scala media or cochlear duct-which also twists two and a half times fiom the basis to the apex of the cochlea, and is placed against the end of the lamina spiralis ossea so as to occupy a position between the peripheral part of the scala vestibuli and scala tympani.

462. The different divisions of the membranous labyrinth are comnected with one another in this manner : the three semicircular (membranous) canals open into the utricle; this does not form a direct continuity with the saccule, but a narrow canal comes off both from the saccule and utricle; the two canals join into one minute membranous tube situated in the aqueductus restibuli. At its distal end it enlarges into the saccus endolymphaticus, situated in a cleft of the dura mater, covering the posterior surface of the petrous bone. The saccule is in communication with the cochlear canal, or scala media, by a short narrow tube-the canalis reuniens of Reichert. Thus the 
cavity of the whole membranous labyrinth is in direct communication throughout all divisions, and it represents the inner lymphatic space of the labyrinth. There is no communication between the perilynuph and endolymph, and the cavity of the nembranous labyrinth stands in no direct relation to the carum tympani, since the fenestra oralis and fenestra rotunda both separate the perilymphatic space, or the cavity of the bony labyrinth, from the cavum tympani. The vibrations of the membrana tympani, transferred ly the ossicula auditus to the fenestra ovalis, directly affect, therefore, only the perilymph. The fluctuations of this pass from the restibule, on the one side, towards and into the perilymph of the semicircular canals; and on the other side, through the scala vestibuli, to the top of the cochlea, then by the helicotrema into the scala tympani, and find their conclusion on the membrana secundaria closing the fenestra rotuncla. On their way they affect the membrane of Reissner, which separates the scala media from the scala restibuli, and also the membrana basilaris separating the scala media from the scala tympani; the vibrations of these membranes affect the endolymph, and therefore the nerve-endings (see below).

\section{Structure of semicircular canals,}

utricle and saccule. The membranous semicircular canals are fixed hy stiff bands of fibrous tissue to the inner periosteum of the one (convex) side of the osseous canal, so that towards tlie concave side there is left the space for the perilymph. A similar condition olstains with regard to the saccule and utricle, which are fixed by the immer periosteum to one side of the bony part.

The structure of the wall is the same in the semicircular canals, utricle and saccule. The above-mentioned fibrous ligaments of the periosteum form an outer coat; inside this is a glassy-looking tunica 


\section{I.NERNAL EAR.}

mopria. At one side (the one away from the bone) this tunica propria forms numerous papillary projections. The internal surface of the membrane is covered with a single layer of polyhedral epithelial cells. 46t. Each of the branches of the nerrus vestibuli -i.e. one for the saccule, one for the utricle, and three for the three ampulla - possesses a ganglionic swelling. The nerve - branch, having passed through the membranous wall, enter's special thickenings of the tunica propria, on that part of the membranous wall next to the bone: in the saccule and the utricle the thickening is called macula acustica, in the ampullie crista acustica (Fig. 27 (M. Schultze). This thickening is a large villous or fold-like projection of the tunica propria, into which pass the nerve fibres of the several branches. These

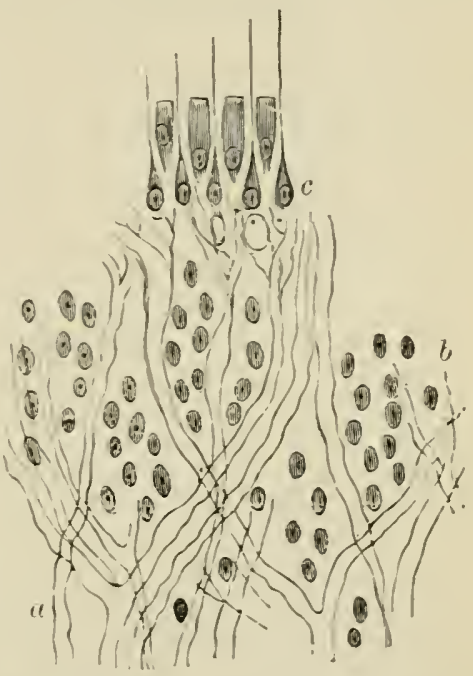

Fig. 2-7.-From a Transverse Section through the Macula acustica of the Utricle of the Labyrinth of Guineapig. (Atlos.)

$a$, Medullated nerve fibres, forming plexuses; $b$, nuclei of the membrane: $c$, sensory epithelimn (diagrammatic); the spindle-shaped sensory cells possess long auditory hairs lrojecting between the conical epithelial cell- lesond the free surface.

fibres are all medullated nerve fibres, and, ascending towards the internal or free surface of that projection, form a plexus. In this plexus are interspersed numerous nuclei. From the medullated fibres pass off minute bundles or primitive fibrillæ, which enter the epithelium that covers the free surface of the projection.

46.5. This epithelium is composed of a layer of 
columnar or conical cells, between which are wedged in spindle-shaped cells; both kinds possess an oral nuclens. According to Max Schultze and others, each of the spindle-shaped cells is connected by its inner process with the nerve fibrille coming from underneath: whereas, towards and beyond the free surface,

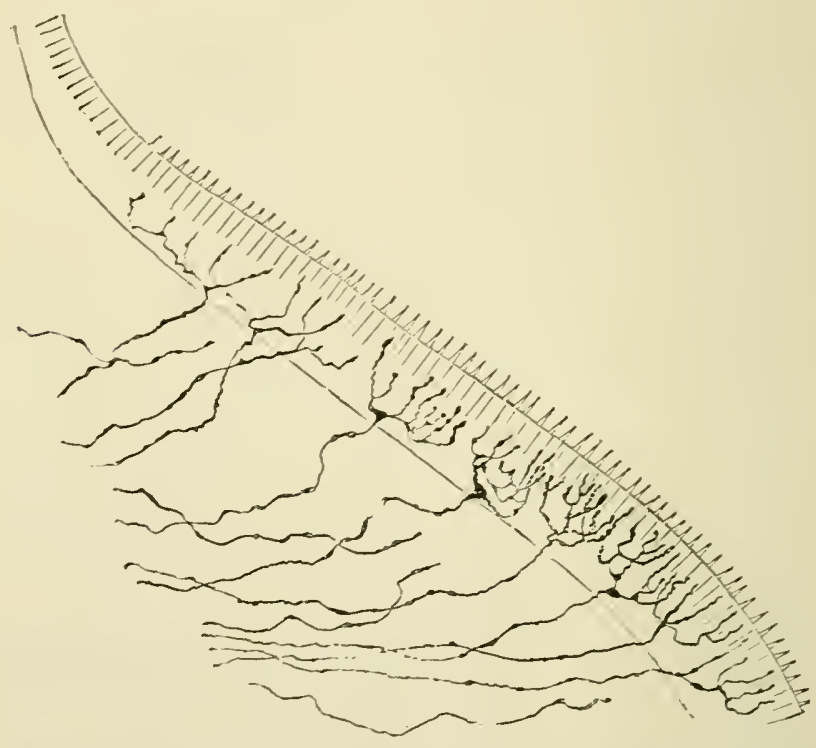

Fig. 2-5.- Nerve Terminations in the Elithelium of the Macula acustica.

The nerve fibres form dendrons in the epithelial layer. (After Retzius, from Quciin.)

its outer process is prolonged into a long, thin, stiff, anditory hair. Max schultze, therefore, calls the columnar cells epithelial; the spindle-shaped ones, sensoiry.

Petzius, on the other hand, maintains that, in the case of fishes at any rate, the epithelial cells are those which are connected each with a bundle of nerve fibrillx, and that each sends out orer the internal free 


\section{JVTERNAL IEAR.}

surface a bundle of fine stiff hair's - the anditory hairs. 'The spindle-shaped cells of Max schultze, according to this theory, are only supporting cells. The free surface of the epithelium is covered with a homogeneous cuticle, perforated ly holes which correspond to the epithelial cells and the auditory hairs.

By Golgi's method Retzius has, however, obtained eviclence (Fig. 27s) which shows that fine nerve fibres terminate by arborisations or dendrons amongst the epithelial cells ( Fig $17 \bar{T}$ ).

On the intermal surface of the macula and crista acustica are found the otolithe, rhombic crystals, and amorphous masses, cliiefly of carbonate of lime, embedded in a gelatinous or glanular'-looking basis.

466. The cochlea (Fig. 279), as has been mentioned abore, consists also of a bony shell and it membranous canal, the former surrounding the latter in the same way as the bony semicircular canal does the membranous-i.e. the latter is fixed to the outer or convex side of the former. The difference between the cochlea and the semicircular canals is this, that in the cochlea there is a division of the perilymphatic space by an osseous projection-the lamina spiralis ossea - and by the scala media into two scalæ, viz. the (upper) scalia restibuli and the (lower) scala tympani.

467. In the osseous modiolus are numerons parallel canals for bundles or groups of the fibres of the cochlear branch of the auditory nerve; these canals open into the porus internus, in which lies a large ganglion connected with the nerre.

The nerve bundles are situated in the canals of the modiolus, and opposite the lamina spiralis ossea are comnected with ganglionic masses - composed of bipolar ganglion cells-called the ganglion spirale of Corti. From this ganglionic mass the nerve fibres (all merlullated) can he traced into the lamina spiralis ossea, in which they form rich plexuses extending to its outer E F 


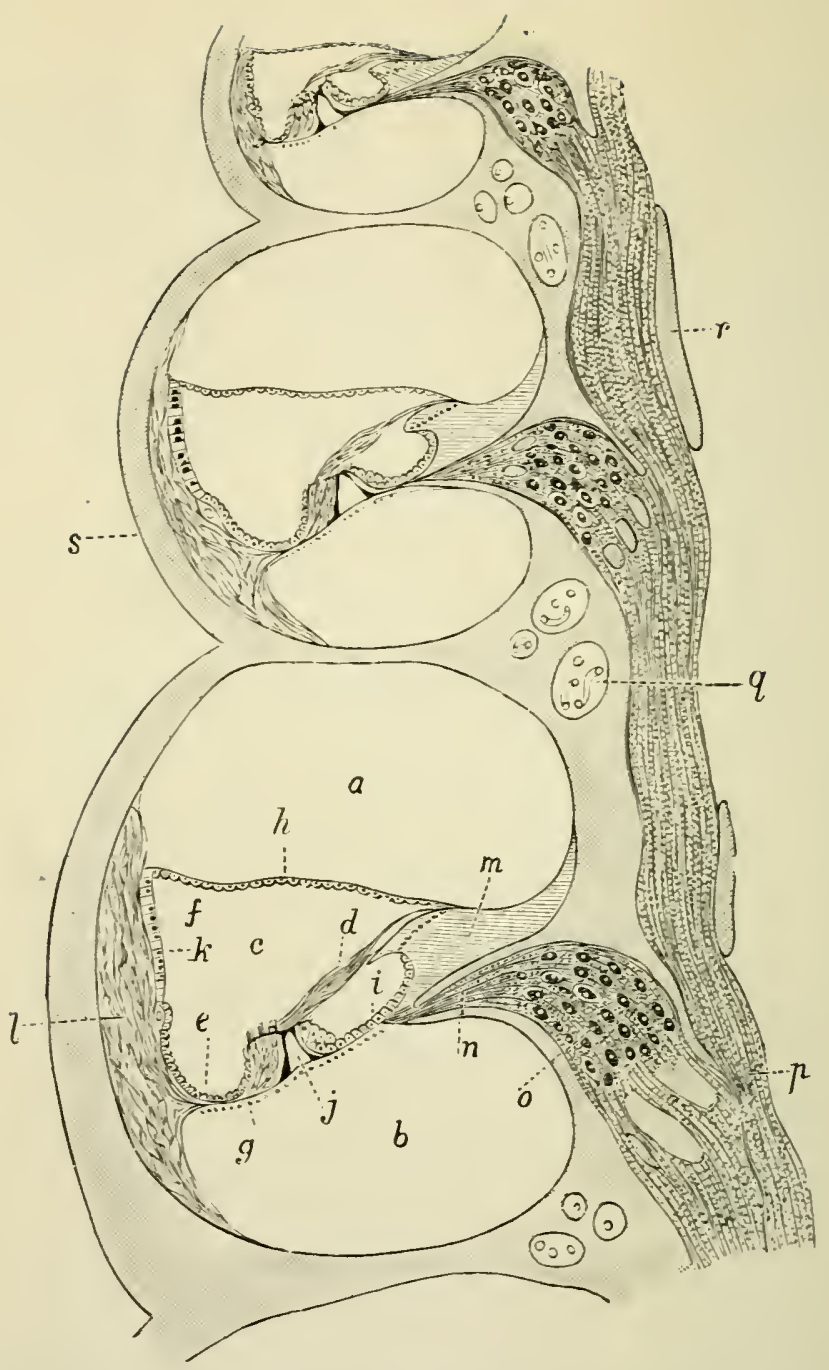

Fig. 279.-From a Vertical Section through the Cochlea of Ear of Guinea. lig, seen in the long axis of the Modiolus. (Atlas.)

$a$, Scala vestimuli $b$, scala trmpani; $c$, scala media; $d$, membrana tectoria ; $e$. cells of Claudius; $f$, upper outer augle of scalit media; $g$, region of outer hair cells on membrana basilaris; $h$, membrane of Reissner; $i$, epithelium linine sulcus spiralis (internus) ; $j$, tunnel of Corti's arch; $k$, stria rascularis; $l$, ligameutum spirale; $m$, crista spiralis; $n$, nerve tibres in lamina spiralis ossea ; $o$, ganglion spirale; $p$, nerve fibres in modiolus; $q$, channels in bone containing blood-ressels; $r$, masses of bone in modiolus; $s$, outer bony capsule. 
margin-i.p. as far as the memblana basilaris of the Scialia media (sep helow).

46s. From the margin of the lamina spiralis ossea to the external hony shell extends the membrana basilaris (Fig. 279), forming the lower and chief wall of the scala media, while the upper wall of the canal is formed by the membrane of Reissner, extending uncler an acute angle from near the margin of the lamina spiralis ossea to the outer bony shell.

On a transverse section through the scala media we see the following structures :

469. (1) Its outer wall is placed close against the periostem lining the internal surface of the bony shell; it consists of lamellar fibrous tissue, with numerous stitt elastic bands, and is the restibular part of a peculiar ligament-the ligamentum spirale (Kiblliker)-semilunar in cross-section, and with its middle angular projection fixed to the onter end of the membrana basilaris.

470. (2) Its immer wall is represented by an exceedingly delicate membiane-the membrane of Peissner: this is also its upper wall, extending under an acute angle from the upper outer angle of the scala media to the lamina spiralis ossea. But here it is not fixed on the osseous substance, but on a peculiar projection on this latter-the crista spiralis (Fig. 279, m) -which is a sort of tissue intermediate between fibrous and osseous tissue, and is added to the restibular surface of the lamina spiralis ossea. This crista spiralis has on one surface-i.e. that directed towards the scala media-a deep sulcus, called the sulcus spiralis, or sulcus spiralis internus; so that of the crista spiralis there are two labia to be distinguished-the labium vestibulare and the labium tympanicum; the former being the upper, the latter the lower, boundary of the sulcus spiralis (Fig. 279).

471. (3) The Iower wall of the scala media 
is the membirand basitaris, extending in a straight line between the labium tympanicum of the crista spiralis and the above-mentioned projection of the ligamentum spirale. The scala media is lined on its whole internal surface with epithelium, this only being derived from the epithelium forming the wall of the auditory resicle of the embryo, peculiarly modified in certain places. The scala tympani and scala restibuli are likewise lined with a continuous layer of flattened cells - an endothelium, which on the lower or trmpanic surface of the membrana basilaris is somewhat modified, being composed of granular-looking irregular cells.

472. As regards the scala media, the epithelium lining its internal surface is of the following aspect:Starting with the lower outer angle-i.e. where the membrana basilaris is fixed to the ligamentum spirale - we find a single laser of polyhedral or short columnar transparent cells, lining this outer anglethe cells of Claudius: ascending on the ligamentum spirale, the cells become shorter, more squamous: as such ther are found over a slight projection on the outer wail-i.e. the ligamentum spirale accessoriumcaused br a small blood-ressel, the vas prominens.

473. Then we come to the stria vascularis. lining nearly the upper two-thirds of the outer wall of the scala media. It consists of a layer of columnar and spindle-shaped epithelial cells, between which extend capillary blood-ressels from the ligamentum spirale, and in some animals (guinea-pig) clumps of pigment granules are found between them.

47. Then we pass from the upper angle of the scala on to the membrane of Reissner. This consists of a homogreneous thin membrana propria, covered on its outer restibular surface with a layer of flattened endothelium, and on its inner surface-i.e. that facing 
the scala media-with a layer of less flattened, smaller, polyhedral epithelial cells.

45 . We come next to the restibular labium of the crista spiralis, on which are found cylindrical horizontal projections anastomosing with one another : these are the auditory teeth (Huschke). The epithelium of Reissner's membrane is continued into the groores and pits between the auditory teeth as small polyhedral cells, but orer the tecth as large, Hattened, squamous cells, which, passing on, line the sulcus spiralis and corer also the tympanic labium of the crista spiralis. Now we arrive at the membrana basilaris, on which the epithelium becomes modified into the organ of Corti.

476. The membrama basilaris consists of a hyaline basement membrane, on which the organ of Corti is fixed; underneath this is the tunica propria, a continuation of the tissue of the ligamentum spirale, composed of fine parallel stiff fibrils (Hannover, Henle) stretched in a very regular and beautiful manner in the direction from the ligamentum spirale to the crista spiralis ( $\mathrm{N}$ uel). On the tympanic sicle there is also a hyaline basement membrane. The endothelial cells corering this on the tympanic surface have been mentioned above.

t 77 . The organ of Corti (Fig. 280). - Passing outwards from the epithelium lining the sulcus spiralis, we meet with small polyhedral epithelial cells in the region of the termination of the lamina spiralis ossea, next which are columnar-looking cells - the inner supporting cells: next to these is the inner hair-cella columnar, or conical, epithelial cell, with a bundle of stiff hair's, or rods, extending beyond the surface. The inner hair-cells form a single file along the whole extent of the two and a half turns of the scala media.

47. Next to the inner hair-cell is the inner rod, or inner pillar, of Corti, and next to this the outer rod, 
or outer pillar, of Corti. Each forms a single file for the whole extent of the two and a lialf tums of the scala media. The two rods are inclined towards one another: and in contact with their upper extremity,

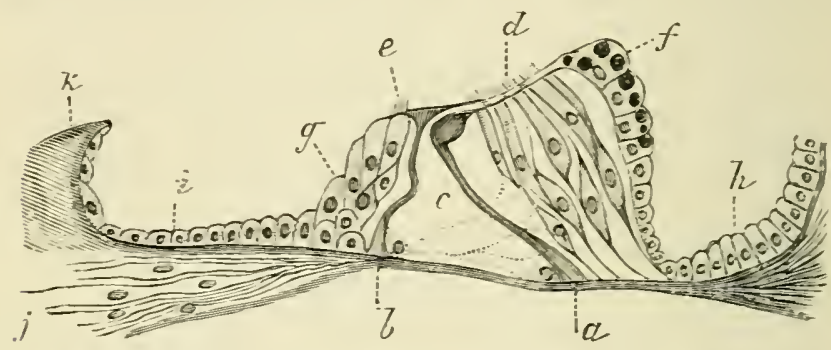

Fig. 2s0. - Organ of Corti of the Cochlea of Guinea-pig. (Atlas.)

$a$, Outer rod or pillar of Corti $; b$, juner rud or pillar of Corti; $c$, tunnel of arch of Corti; $d$, onter hair-cell-; $\epsilon$, inner hair-cell ; $f$, outer supporting cells containing fat globules: $q$, inner supporting cells; $h$, cells of Claudius: $i$, epithelial cell- lining the sulcus s liralis interuus; $j$, nerve fibres; $k$, part of crista spiralis.

or lead; whereas the opposite extremity, the foot, rests under an acute angle on the membrana basilaris, on which it is firmly fixed. The rest of the rod is a slender, more or less crlindrical, piece - the body. The outer rod is larger and longer than the inner, the latter being slightly bent in the middle. Owing to the position of the rods, the two files form an archthe arch of Corti. Between it and the corresponding part of the basilar membrane is a space-the turinel of the arch, triangular in cross-section.

479. The substance of the rods, or pillars, of Corti is bright, highly refractive, and slightly and longitudinally striated.

The head of the inner rod is triangular, a short process exterding inwards towards the inner hair-cell, a long process extending ontwards orer the head of the vuter pillar. Outwards, the triangular head possesses a concare surface grasping the convex surface of tise head of the outer rod. 'This latter' 
possesses a process directed outwards, which is firmly applied to the onter process of the head of the inner rod, the two together forming part of the membrana reticularis (see below).

The relation in size between the outer and inner rods is such that the head of one onter rod fits into those of about two inner rods.

480. At the foot, each rod has, on the side directed towards the tunnel, a granular, nucleated mass of protoplasm, probably the remmant of the epithelial cell from which the lower half of the rod is derived; the upper part sometimes has a similar nucleated remnant, proving that this also has been formed by an epithelial cell, so that each rod is in reality derived from two epithelial cells (Waldeyer).

481. Next follow three or four rows of outer lacircells, similar in size and structure to the inner haircells. Each of the outer hair-cells seen in a section belongs to a file of hair-cells, extending on the membrana basilaris along the whole extent-i.e. two and a half turns - of the scala media. Each hair-cell possesses an oval nucleus and a number of stift rods, or hairs, disposed in the shape of a horseshoe in the outer part of the free surface of the cell.

Four, and even tive, rows or files of hair-cells (Waldeyer), arranged in an alternating manner, are found in man.

The outer hair-cells are also called the cells of Corti ; they are conical, and more or less firmly connected with a nucleated spindle-shaped cell-the cell of Deiters. The two cells are more or less fused together in their middle part ( $\mathrm{Nuel}$ ). The cell of Corti is fixed by a branched process to the membrana basilaris, while the cell of Deiters sends a process towards the surface, where it joins the membrana reticularis (see below).

482. Farther outwards from the last row of outer 
hair-cells are columnar epithelial cells, called the outer supporting cells of Hensen: they form the transition

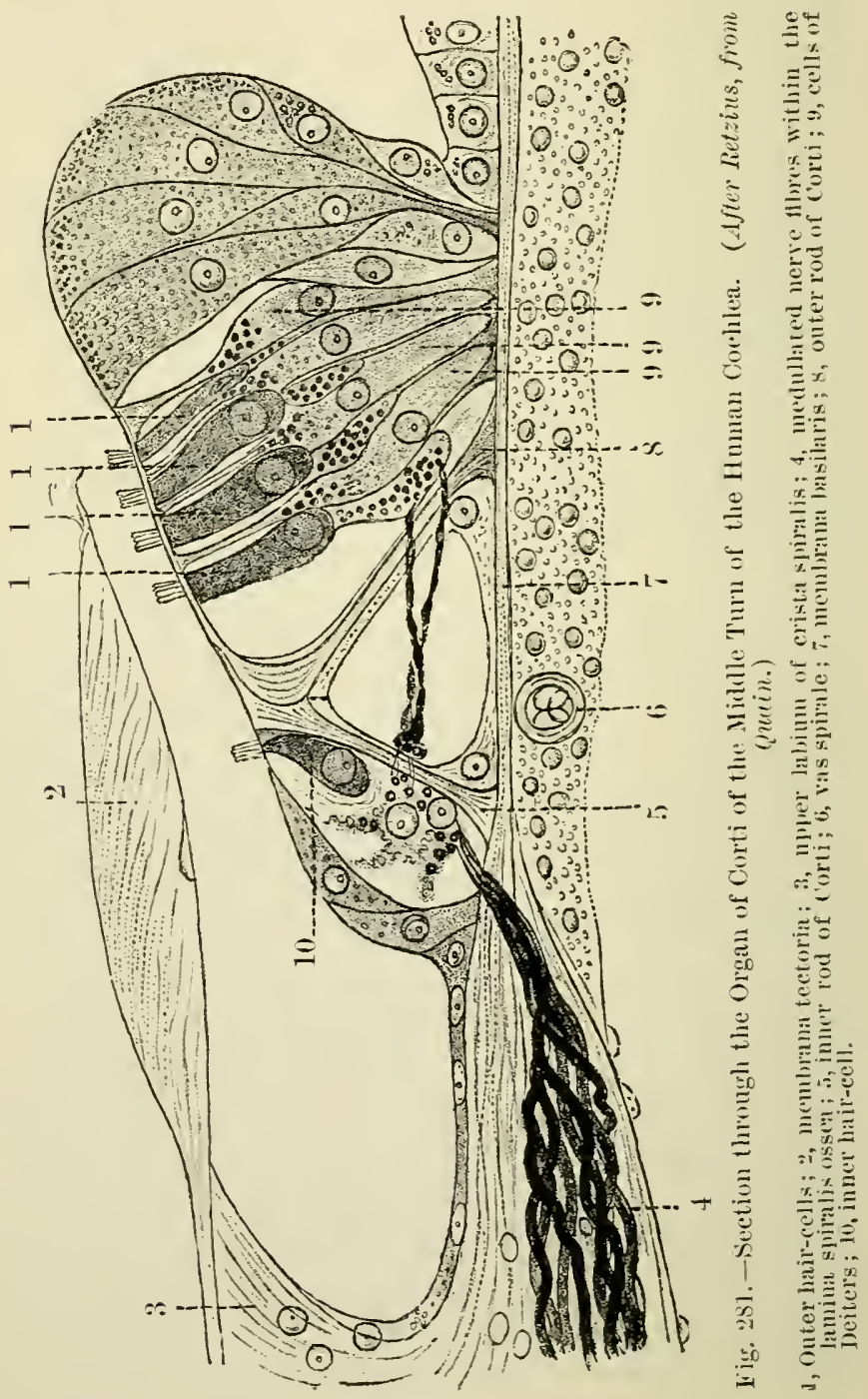


to the epithelium lining the outer angle of the scala media-i.e. to the cells of Claudius.

In the guinea-pig, the outer supporting cells include fat globules.

48.3. The medullated nerve fibres, which we traced in a former page to the margin of the lamina spiralis ossea, form rich plexuses in this, and pass through holes in it, in order to reach the organ of Corti on the membrana basilaris. Looking from the surface on this part, we notice a row of holes - the habenulu perforata of Kölliker - a little to the inside of the region of the inner hair-cells. Numerous primitive fibrille pass there among small nucleated cells situated underneath the inner hair-cells: these are the granular cells. Some of these nerve fibrilla - the inner bundle of spiral nerve fibres--become connected with the inner hair-cells; while other'sthe three outer bundles of spiral fibrils (Waldever) pass, between the inner rods of Corti, right through the tunnel; and, further, penetrating between the outer rods of Corti, they reach the outer hair-cells, with which they become connected (Gottstein, Waldeyer). (Fig. 281.)

48t. In connection with the outer process of the head of the inner and outer rods of Corti, mentioned above, is an elastic hyaline membrane - the lamina or membrana reticularis. It extends outwards over the organ of Corti to the supporting cells of Hensen, and possesses holes for the tops of the outer hair-cells and their hairs. The parts of this membrane between the heads of the rods of Corti and between the onter hair-cells appear of the shape of narrow phalanges phalanges of Deiters. A cuticular membrane extends from the head of the inner rods of Corti inwards to the inner supporting cells: it possesses holes for the tops of the inner hair-cells.

485. From the restibular labium of the crista 
spiralis to the outer hair-cells of the organ of Corti extends a peculiar fibrillated membrane-the membrance tectoria. By means of it the sulcus spiralis internus is bridged over: and so converted into a canal.

486. As we ascend towards the top of the cochlea, all parts in the scala media decrease gradually in size. The organ of Corti, being of an epithelial nature, possesses no blood-ressels. From the anatomical relations of the organ of Corti, it appears most probable that the pillars, or rods, of Corti act as the supporting tissue, or framework, around which the other elements are grouped: and it seems likely that the hair-cells, witl their rod-like hairs projecting freely into the endolymph, are the real sound-perceiving elements of the organ of Corti. Their connection with the terminal tibrilla of the nerves points in the same direction.

As indicated on p. 460 , all structures of the scala media, described in the foregoing pages, form an uninterrupted succession through all the turns of the cochlea. 


\section{('HAPTER XLTV.}

THE NASAL MUCOUS MENBRANE.

487. The lower part of the nasal cavity is lined with a mucous membrane which has no relation to the olfactory nerve, and therefore is not connected with the organ of smell. It is covered with a stratified, columnar, ciliated epithelium of exactly the same nature as that of the respiratory passages-e.g. the larynx and trachea. Large numbers of nucus-secreting goblet cells are met with in it. Below the epithelium is a thick hyaline basement membrane, and underneath this is a mucosa of fibrous tissue, with numerous lymph corpuscles in it. In many places this infiltration with lymph corpuscles amounts to diffuse adenoid tissue or to perfect lymph follicles.

488. The mucosa contains in its most superficial layer the network of capillaries, but in the rest it includes a rich and conspicuous plexus of venous ressels.

In the deeper parts of the mucous membranei.e. in the submucosa-are embedded smaller and larger glands, the ducts of which pass through the mucosa and open on the free surface. Some of the glands are mucous; others are serous. In some cases (e.g. guinea-pig) almost all glands are serous, and of exactly the same nature as those of the back of the tongue. In some places the mucous membrane is much thicker than in other's, and then it contains larger glands, and between them bundles of non-striped muscular tissue. 
489. In the upper or olfactory region (Fig. 2s:2) of the nasal carity the mucous membrane is of a different tint, being more of a brownish colour; it

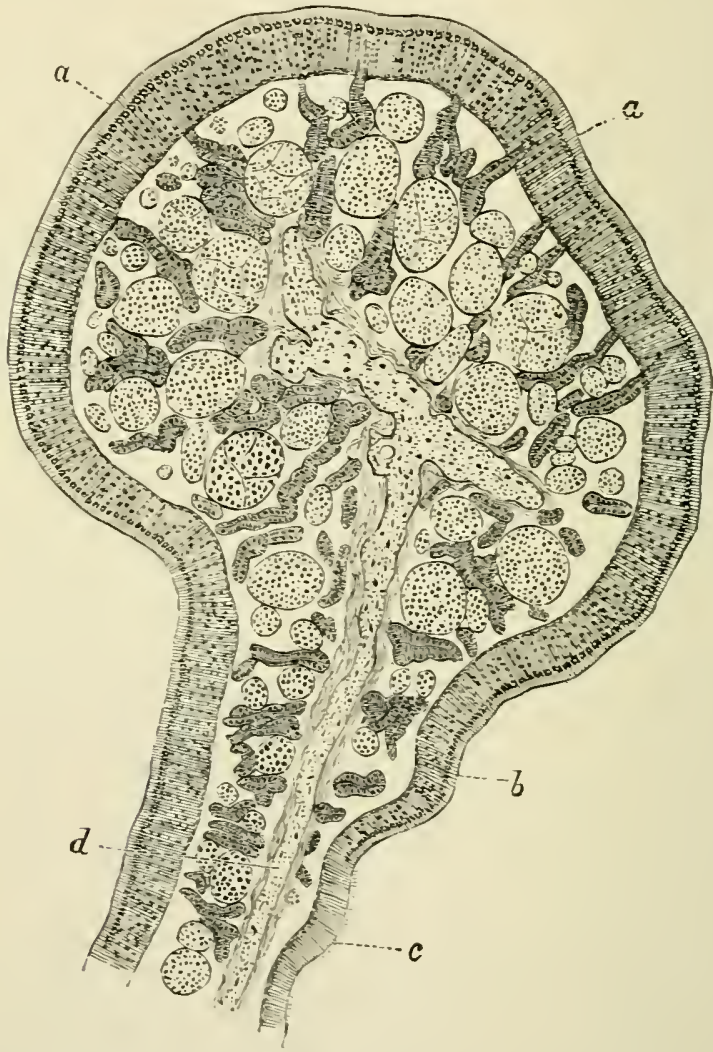

Fig. 2s.?.-From a section through the Ulfactory Regirm of Guinea-pig. (Atlas.)

$a$, Thick olfactors epithelium; $b$, thin olfactors epithelium ; $c$, ciliated nonolfactors epithelium; $d$. bone. The transverse sections of the olfactory nerve bundle and the tubular glands of Bowman are well seen.

contains the ramifications of the olfactory nerve, and is the seat of the organ of smell.

490. 'The free surface is covered with a columnar' 
epithelium, composed of the following kinds of cells (Fig. 28:3) :

(a) A superticial layer of long columnar, or rather conical, epithelicil cells, each with an oval nucleus. In

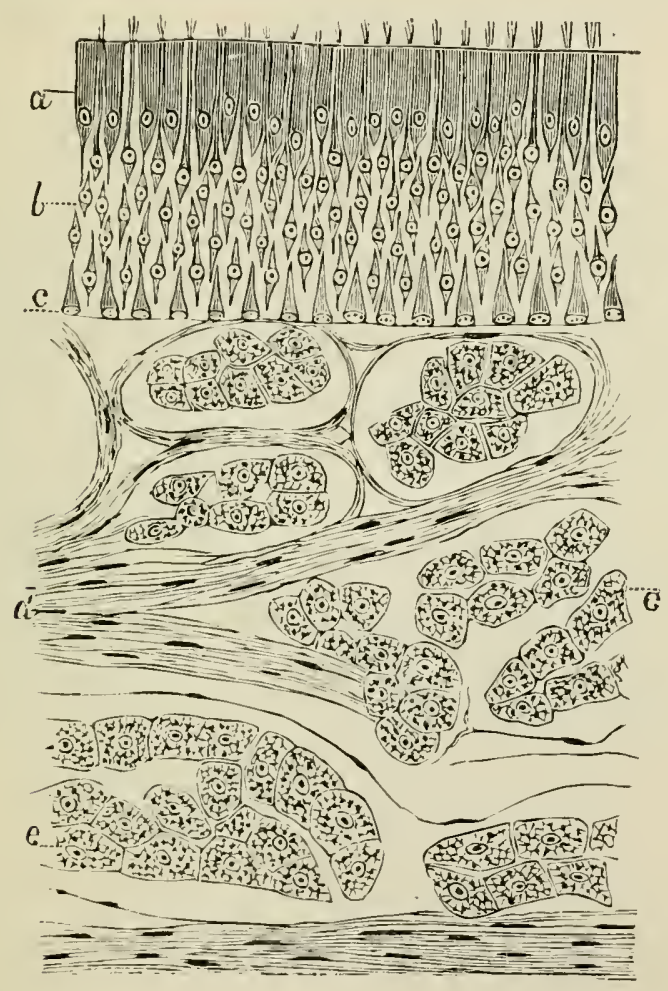

Fig. 283.-From a Vertical Section through the Olfactory Mucous Membrane of Guinea-pig. (Atlas.)

$a$, Epithelial cells ; $b$, sensury or olfactory cells; $r$, deep epithelial cells ; $a$, bundles of olfictory nerve fibres; $e$, the alveoli of serous (Buwman's) glands.

some places the free surface of these cells is covered with a bundle of cilia, similar to the superficial cells of the respiratory part of the nasal cavity; in most places, however, the cilia are absent; the former 
condition obtains in those places which are in close proximity to the respiratory region.

(b) Between the epithelial cells extend spindleshaped cells, each with a spherical, or very slightly

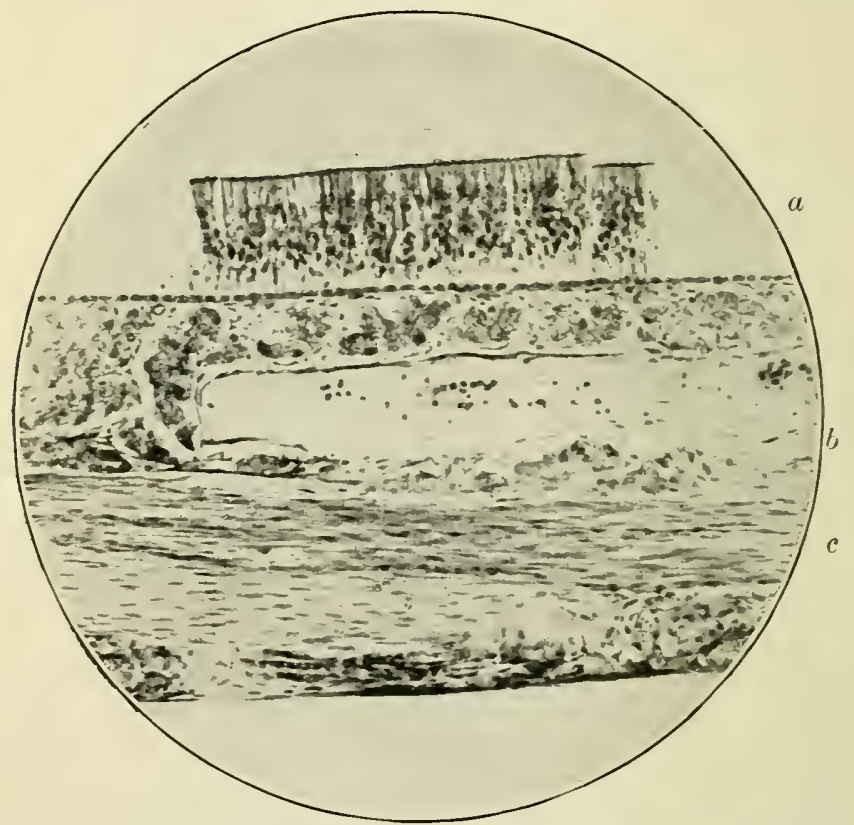

Fig. 284.-From a Vertical Section through Olfactory Membrane of Guinea. pig. (Photo. Moderate magnificcition.)

$a$, Olfactory epithelium: $b$, mncous membrane with blood-re-sel and glands ; $c^{\prime}$ olfactory nerve fibres cut longitudinalls.

oval, nucleus-the sensory cells (Max Schultze). Each cell sends one broad process towards the free surface, over which it projects in the shape of a small bundle of shorter or longer rods; whereas a fine varicose filament passes from the cell body towards the mucosa, and, as shown first by M. Schultze, becomes connected with a fibrilla of the plexus of the olfactory nerve fibres. 
(c) In some places there is a deep layer of epithelial cells, each with a spherical nucleus of an inverted conical shape, their pointed extremity passing between the other cells just mentioned and their broad basis resting on the basement membrane (Fig. 283).

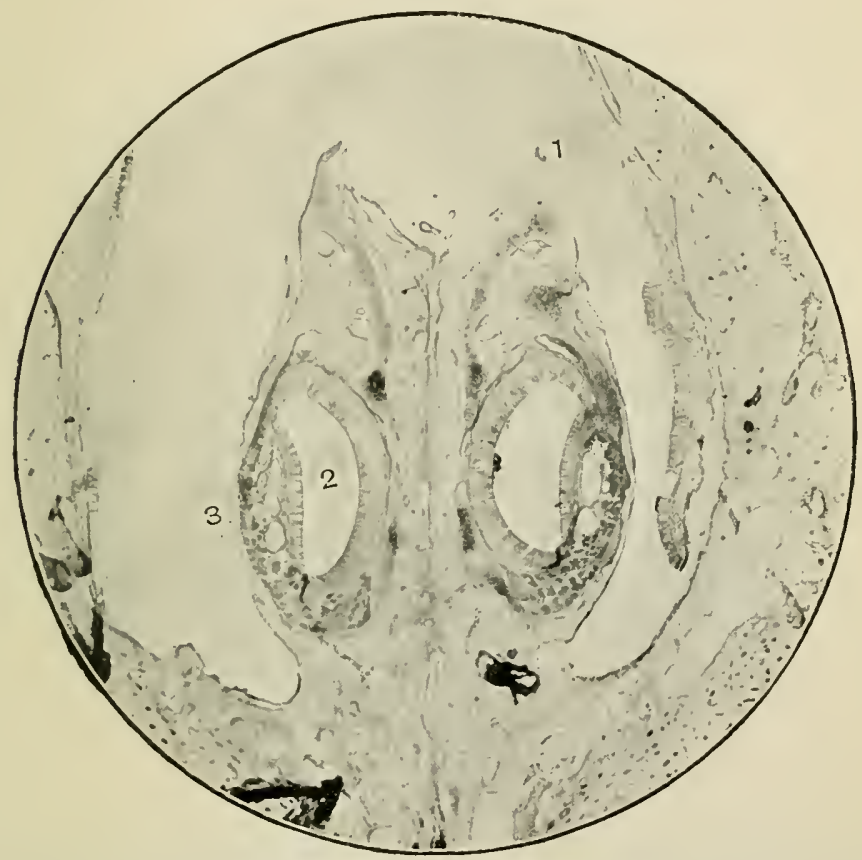

Fig. 285.-Transterse Section through the Lower Part of the Nasal Septum, showing the (bilateral) Organ of Jacobson in cross section. (Photo. Lou pouer.)

1, Cartilage extending above and lartially around the organ; 2, cavity of the tubular organ, showing on its mesial wall olfactory evithelium, on it: lateral wall columnar evithelium; 3, cavernous tissue in the lateral wall.

Von Brunn has shown that there is on the free surface of the epithelium a sort of cuticle-a delicate limitans externa.

491. The mucous membrane is of loose texture, and contains a rich plexus of bundles of olfactory 
nerve fibres, extending chietly in a direction parallel to the surface (Fig. 2st). Each nerve fibre is nonmedullated - i.e. is an axis r.rlinder composed of minute or primitive fibrillie, and invested in a neurilemma witl

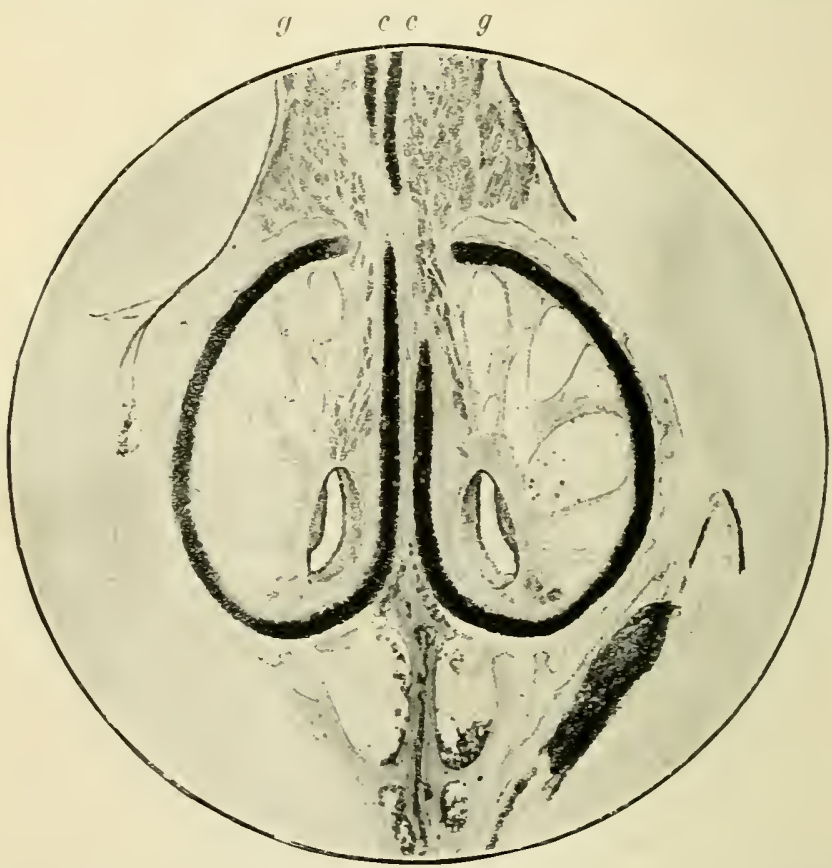

Fig. 2S6. - Section through the Front Part of Nisal Septum of Rabbit. showing the bilateral orcan of Jacobson in transrerse section. The tube of the organ of Jacobson is lined on its mesial wall with olfactory equithelinm. (Photo. J.ou pourer.)

g, Glabdsextending from the uner part of the sejtum to the junction of the me-ial and lateral wall of the organ of Jacohout ; $c$, cartilage extending as a nearly complete capsule around each organ of Jacobson. The lateral wall of the urgan contains cilvernou-ti-rue.

the nuclei of the nerve corpuscles. Near the surface the fibres of the plexus are thin, and they split up into the constituent fibrils which are directly con. tinuous with the fine varicose processes of the sensorry cells above named (Fig. 17ミ).

492. The blood-ressels supply with capillary net- 
works the superficial part of the mucous membrane and the numerous glands. These are the glonds of Bonoman, extending through the thickness of the mucous membrane. They are tubes, slightly branched,

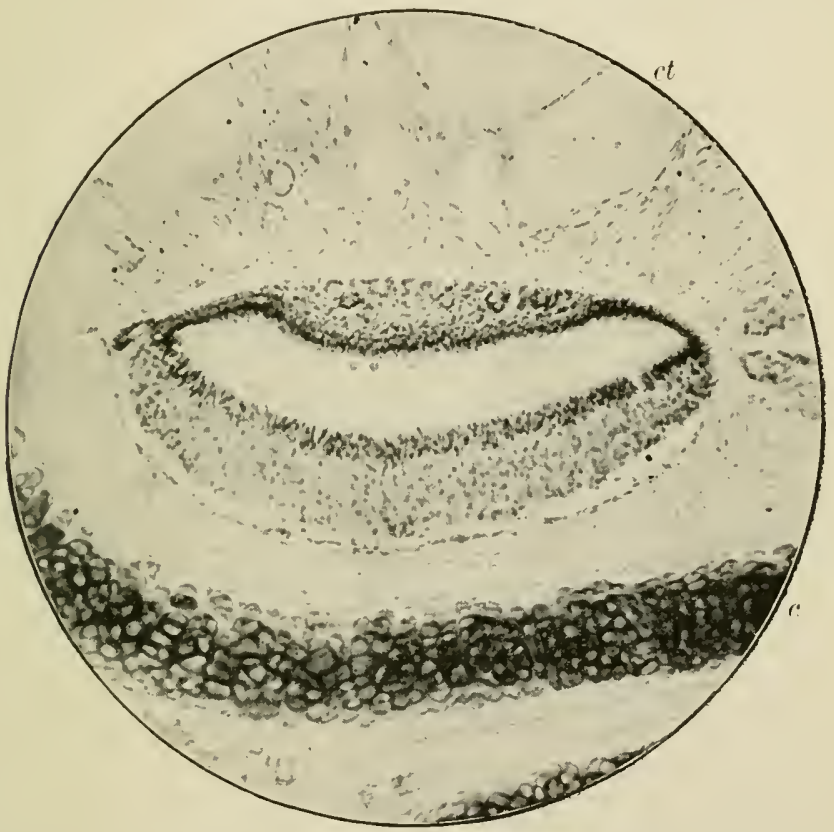

Fis, 25i. - Fron the same Section through the Organ of Jacolson as in the precerling figure, nore luagnified. (1'/loto.)

c, cartilage of mesial wall ; ch. crvernous tissue of lateral wall. The mesial wall is lined with thick olfactory epithelium.

and gradually enlarging towards their distal end; in some parts they are more or less straight. In structure they are identical with serous glands, possessing a minute lumen, and being lined with a layer of columnar albuminous cells. The duct is a very fine canal; it is that part of the gland which is situated in the epithelium of the free surface; it passes rertically throngh this, and consists of a fine limiting 
membrane, the continuation of the membrana propria of the gland tube, and a layer of rery flattened epithelial cells.

493. There is a definite relation between the size and number of the bundles of the olfactory nerve tibres, the thickness of the olfactor $y$ epithelium, and the length of the gland tubes. The size and number of the bundles of the nerve fibres are determined by the thickness of the epithelium-i.e. by the number of the sensory cells; the number and thickness of the olfactor's nerre bundles determine the thickness of the mucous membrane, and the thicker this is, the longer are the glands of Bowman.

494. The organ of Jacobson (Figs. 2.5. $286,2 \mathbf{2}$ ) is a minute tubular organ present in all mammals, and, as has been shown br Dursy and Killiker, also in man. In mammals it is a bilateral tube, compressed from side to side, and situated in the anterior lower part of the nasal septum. Each tube is supported by a hyaline cartilage, in the shape of a more or less ploughshaped capsule-the cartilage of Jacobson-and opens in front directly into the nasal furrow (guineapig, rabbit, rat, etc.); or it leads into the canal of Stenson ( $\left(\log ^{\circ}\right)$, which passes through the canalis naso-palatinus, and opens immediately belind the incisor teeth on the palate. In all instances, however, it terminates posteriorly with a blind extremity.

495. The carity of the tube is lined with stratified columnar epithelimm, which on the lateral wall is ciliated in the guinea-pig and $\log$, and non-ciliated in the rabbit. The median wall-i.e. the one next to the middle line-is lined with olfactory epithelium identical with that of the olfactory legion of the nasal carity. Branches of olfactory nerve tibres also jass into the median wall, and behave in exactly the same mamner as in the olfactory region. Numerous serous 
slinds-belonging chiety to the upper and lower wall-open into the cavity of the olgan of Jacobion.

In the lateral wall there is in many instances a plexus of reins, extending in a longitudinal direction, and between the ressels are hundles of non-striped muscular tissue, thus constituting a sort of carelnous tissue. 


\section{CHAP'TER XLT.}

THE DU ( T L ES G L A D S.

496. I. The nypophysis cemeni.-The uper or smaller lobe belongs to the central nerrous srstem. The lower or larger lobe is smrounded by a fibrous capsule, which sends numerous minute septi into the interior. 'These split up into numerous trabeculie of fibrous tissue, which, by dividing and reuniting, form a clense plexus, with smaller and larger, spherical or oblong, or even cylindrical spaces - the alreoli. In these lie spherical or oblong masses of epithelial cells. These epithelial cells are columnar, prramiclal, or̃ polyhedral, each with an oral or spherical nuclens. Between the epithelial cells of the same group are found here and there small branched or spindle-shaped cells, with a small flattened nucleus. In some of the gromps or alveoli of epithelial cells is a cavity, a sort of lumen, filled with a homogreneous gelatinous substance.

The interalreolar connective tissue contains a network of capillaries. Between the alreoli and the interalreolar tissue there are lymph sinuses. like those around the alveoli of other glands-e.t. the salivary glands.

497. II. The thyoid gland ( $\mathrm{Fig}$.2ミs).-The framework of this gland is in many respects similar to that of other glands, there being an outer fibrous capsule, thicker and thinner septa, and finally the fine trabeculie forming the septa between the gland alreoli. These are closed resicles of a spherical or oval shape, and of various sizes. Each vesicle is lined with a 
single layer of polyherlat or columnar epithelial cells, ealch with in spherical or oral nneleus. There is a carity, which differ's in size according to the size of the vesicle. It contains, and is more or less filled with, a homoseneous, viseirl, albuminous fluid - the so-called colloid. Th this often oceur degenerating nucleated lymph corpuscles and coloured hlood corpusctes (Biller).

$49 \therefore$. The vesicles are surounded by networks of blood capillaries. Th the connective-tissme framework lie networks of lymphatics: between the framework and the surface of the vesicles are lymph sinuses lined with enclothelium (Baber). The large and small lymphatics are often filled with the same colloid material as the vesicles, and it is probable that this colloid material is

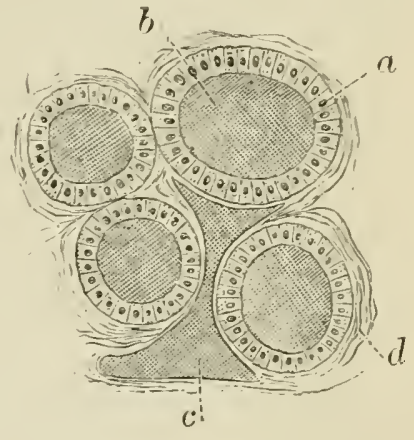

Fin.2.s. - From a section through the Thyroid Gland of Dog.

$u$, Epithelium lining the re-icle-; $b$, colloid contents of the resicles; $c$. lymphatic filled with the same miterial as the vesicles : $d$, flbrous tissue between the gland vesicles.

produced in the vesicles and carried away by the lymphatics, to be finally discharged into the circulating blood.

499. Its formation in the resicles is probal,ly due to an active secretion by the epithelial cells of the resicles, and to a mixture with it, or maceration by it, of the effused blood mentioned aloove. In some instances Baber found the amount of blood effused into the cavity of the vesicles very considerable, and hence it is justifialle to assume that the destruction of red blood corpuscles forms one of the functions of the thyroid gland.

500. III. The supra-remal bodies (Fig. 289). - The supra-renal body is enveloped in a fibrous cap- 
sule; in connection with this are septa and trabeculæe

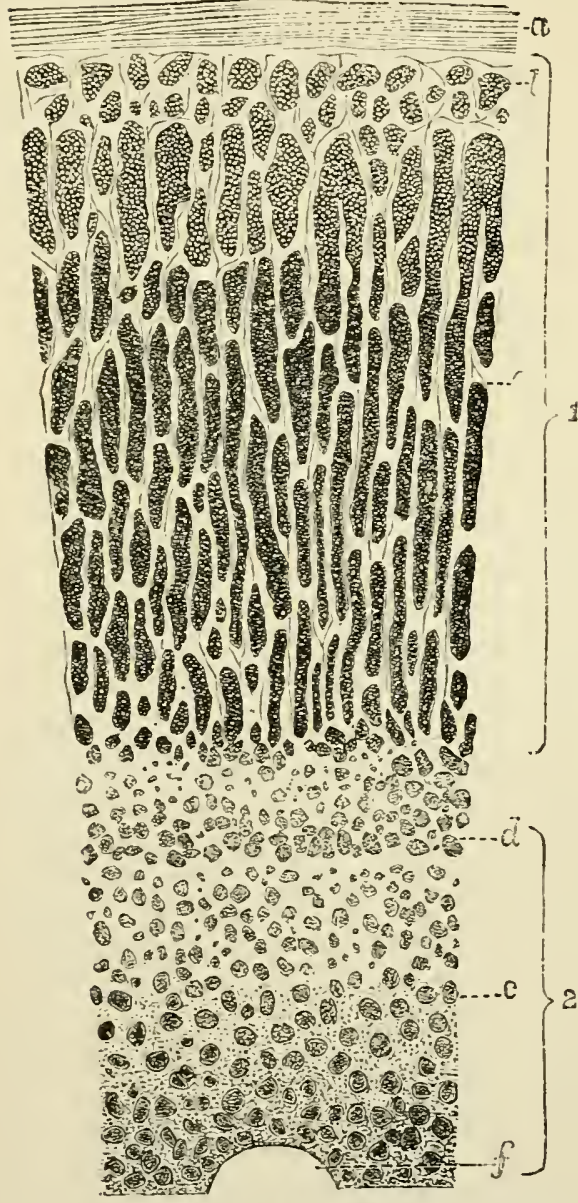

Fis. 28?.-From a Vertical section through the Supra-renal Body of Man. (Eberth, in Striclier's Manual.)

1, Cortical sulsstance: 2, nedullary jart ; $a$, outer capsule ; $b$, zona glomerulosa : $c$. zona fasciculata; $d$, zona reticulalis ; $e$, medulla; $f$, large rein.

discerned in some of these cell masses. passing inwards, and they are arranged differently in the cortex and in the medulla of the gland, as will be seen presently.

The cortex of the gland consists of an outer, middle. and inner zone, all three being directly continuous with one another. The outer one is the zona glomerulosa ; it contains numerous spherical, or, more commonly, elongated, masses of epithelial cells, The cells are polyhedral or cylindrical, each with a spherical or oval nucleus. In some animals-as the dog, horsethe cells are thin and colummar, and arranged in a transverse manner. Occasionally a sort of lumen can be 


\section{DUCTLESS GLANDS.}

501. Next follows the midlle zone, or zom fasciculutr. This is the most conspicuous and hroadest part of the whole gland. It consists of vertical columns of polygonal epithelial cells, each with a spherical nucleus. The cell substance is transparent, and often contains an oil globnle. The columms anastomose with their neighbours. Between the columms are fine septa of connective tissue carrying blood capillaries.

Between the cell columns and the connective septa are seen here and there lymph spaces, into which lead fine chamels, grooved out between some of the cells of the columns.

502. Next follows the inner zone, or zona reticularis, composed of smaller or larger groups of polyhedral cells, with more or less rounded edges. These cell groups anastomose with one another. The individual cells are slightly larger, and their substance is less transparent than those of the zona fasciculata. In the human subject they are slightly pigmented.

503. In the medulla we find cylindrical streaks of very transparent cells ; the streaks are separated by vascular connective tissue. The cells are polyhechral, columnar, or branched. These cell streaks anastomose with one another and are directly continuous with the cell groups of the zona reticularis of the cortex.

504. The cortex is richly supplied with dense networks of capillary blood-vessels; their meshes are polyhedral in the outer and inner zone, elongated in the middle zone, or zona fasciculata. In the medulla numerous plexuses of veins are met with. In the centre of the supra-renal body lie the large efferent venous trunks. In the capsule (Kölliker, Arnold), and in the connective tissue around the central veins, are plexuses of lymphatic tubes with valves. The nerves are very numerous and composed of non- 
medullated filses; in the medulla they form rich plexuses. In connection with these and with those of the outer capsule are small ganglia (Holm, Eborth).

505 . IV. The gliandula coceysea and inter-randiran. The first of these is a minute corpuscle situated in front of the apex of the os coccysis, and was discovered by luschka. The ghandula carotica of Luschka (ganglion intel-caroticum) is of exactly the same structure as the gylandula cocergea.

506. Its firmework is of about the same nature as that of other glands-a filorous capsule and inner fibrous septa and trabeculie. The septa and trabeculie contain in some places bundles of non striped muscular tissue (Sertoli).

507 . The spaces of the frimework are occupied by the parenchyma. This consists of spherical or cylindrical masses of cells connected into networks. The individual cells are polyhedral epithelial cells, each with a spherical nucleus. According to Luschka, in the newly-born child they are ciliated. In the centre of each of the cell masses lies a capillary blood-ressel, much convoluted and wary.

Numerous non-medullated nerve fibres forming a plexus are situated in the framework of the gland. 


\section{N D E X.}

Ablucens, 22-2

Alsrrytion (see Lymphatics)

Accessory nucleus, 210

Achromatin, 11

-1cini of glands, $29 \cdot 2$

- of liver, 333 of pancreas, 330

Acoustic ganglion, 219

Adenoid reticnlum, 12, 126 tissue, 120

Armaxillary glands, ?\$9

Arrentitia of arteries, 10 s of capillaries, 111 of veiss, 110

_- lympliatic ressels, $11 \mathrm{~s}$

Agminated glands, 130

Air cells, $34^{\circ} 5$

Ale nasi, is

Albuginea of ovary, 35 i of testis, $37:$

Albumin membrane of Aschersou, 402

Albuminous cells, 293

Alloplasmatic organs, 6

Alveolar carity, 2-5 ducts, 345

Alveoli of glands, 292

of lung, 345

of pancreas, 330

Alveus, 249

Amacrines, 450

Amitotic division, 12

Ainueboid corpuscles, 1

morement, $4,5,24,5$

Amplophile cell.; 구

Ampulla, 460

Anterior column of corl, 17i

corpus quadrigeninum, 231

grey commissure. 17 t

horn of corrl, 173

lateral tract, 179

nerve-roots froin cord, 15i

white commissure, 15i

Aorta, 109

Aponeurosis, 47

Anneductus Sylvij, 220;

restibnli, 4631

Arachnoid membrane of spinal cort, 170

$-\longrightarrow$ of brain, 235

Arachnoidal villi, 23;

Arborisation, 151

Arenate tilures of merlulla, 213

Areolar tissue, fs

Arrector pili, 419

Arterice ciliares breves, 440

- recurrentes, 4 to

— helicinie, 3.5.

- rectie, $36:$

Arteries, $10 \mathrm{~s}$

Arterioles, Afferent, 5.5

- of uterus, 397

Articular cartilage, $13,>2$

- nerve-corpuscles, 161

Arytenoid cartilage, 339

Ascending degeneration, 180

- loop-tube, $36 \pm$

- root of glosso-pharyngeal nerve,

210

- of the eighth nerve, 215

of the fifth nerve, 2.21

Aster stage in nucleus, 15

Attraction sphere, 9

Auditory hairs, 4 tist

- nerve, Origin of, 217

- - teeth, Division of, 219

Anerluach's plexus, 32i;

Auricle of heart, $10^{-}$

Auriculo-ventricular valves, 10 ;

Axilenmua, 145

Axis cylinder, 114

- process of sympathetic ganglion cell, 263

Axon, $1 \pm 4$

Bartholin's glands, 392

Basement ineinbranes of skin, 40 ; 
Basilar membrante of cochlea, $46: 4$

Basket cells of cerebellum, 241

Basophile cells, 2-

Bellini's ducts, 36.5

Bile-incts, 3315

Bile capillaries, 336

Bilirubin, 23

Bioblasts, ?

Bladder, 57, 371

Blastoderm of click, 2

Blood, 19

— corpuscles, 19

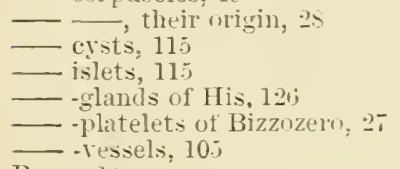

Bone, bs

- cartilage, is

_ cells, il

- corpuscles, 71

- Development of, it

- trabeculit, it

Bimman's capsule, 360

_- elastica anterior, 429

_- glands, 4 S1

- membrane, $4: 29$

- sarcous elements, :4

Brachia, 233

Brain nembranes, 23.5 structure, $: 43$

Bronchi, 343

Brownian molecular movement, 300

Bruch, Glands of, $4.2-$

Bricke's elementary organisms, ;

- oikoil and zooid, 22

- tunica nervea, $451 ;$

Brunner's glands, 32s

Buccal glands, 29s

Bulbus olfactorius, 250

Bitschli's nuclear spindle, 15

Calcification of bone, S.; of cartilage, 65 of clentine, $2 \$ 3$

Calices of kilner, 350

Canal of Schlemm, 434

of Stenson, 4 S?

of stilling, 444

Canalis hyaloideus, 32-2, 414

Petiti, $\$ 13$

reuniens, tor

Canaliculi in bone, 70

in cartilage, 15.5

Capillaries of narrow-bone, 111
Capillaries of nerve sistem, 111

Capillary bile-elnct., 33 ti

- blood-resisels. 111

lympliatics, 119

lietwork in mucosa, 301

slieatlis, 3.j4

Cajsule of Bowman, 34 in

of ganglion cells, 2.5.

of Glisson, 333

of kidney. 3515

of the spleen, 351

Cartilage, 133

-.., Articular, 64

capsule, 64

cells, ti:

- - Elastic, 67

-..., Filrous, tit;

- Hyaline, 13

_- Lacunit, 63

1) Jacolsim, 48 ?

of Luschka, 339

Caremons tissue in tactile laars, 415

- in orean of Jaculson. 4:3 tissnes in genital organs, 354

Cavities of temdon sheatlis, 121

Carum tympani: 459

Cell enclosures, ?

- protoplasin, i

Cells, 5

_, Muscular, of blood-ressels, ss

- - of intestine, $\mathrm{sS}$

___ _ of respiratory organs, so

__ _ of stomach, ss

—_, of urinary argans, ss

in tadpole's tail, 50

of Claudius, 465

of Corti, 471

of Deiters, $230,4 i 1$

of Golgi, 242

of Mlartinotti, $246^{\circ}$

of Purkinje, $2: 39$

Cellula mastoidere, 459

Cellular tissue, ts

Cement of tectl1, $: 259$

substance, 30

—— of endothelimm, to

- of epithelium, 30

of filorous tissme, 4 -

Central canal, 185 grey nucleus, 15.5

Centroacinous cells, 331

Centrosome, ?

Cerebellnm, 237

Cerebrum, 243

Ceruminous glands. 409

Cervix of uterns, 395

Chalice cells, $30^{\circ}$

Chondrin, 46, 63 
Cliondroclasts, xi

Choroiclal portion of eiliary muscle, si

Clioruil nembrane, 440

C'hmonatic granules in ganglion cells, $1: 4$

Cliromatin, 11

('hromosonnes, 11

Chyle, 3ㄴt

- vessels, $31 !$

Ciliary musele, 435

- nerves, 430

- processes, 430

('ilia, 404

C'iliaterl ceells, 3;

Cireulus arteriosns in iris, 4:35

C'ircumanal glands, 40!'

Circuncellnhar plexus, 265

Cisterna lymphatica magna, 1:21

Clarke's eolumns, 1!12

Cleavage of ovum, 2

- of white blool corpuscles, 25

Clitoris, 390

Cochlea, 465

Cohnheim's areas, 93

Colloid, 455

Culostrum cor unscles, 403

Colomred blood corpuseles, 19

rolomiless blood corpuscles, 23

Columnar epithelial cells, 30

Cummatract, $17 ?$

Commissme, Grey, of spiual cord, 173

- White, of spinal cord, $15 i$

Compound lymphatic glands, 134

Concentric bodies of Hassall, 132

lamellie, 72

Cone fibre, 451

Cones of retina, 452

Coni vasculosi, 379

Conjunetiva, $42+4$

- blook-ressels, 420

bulbi, $4265^{\circ}$

lymphatics, 427

nerves, 4.7

palpebræ, 424

Comnective tissue, 46

Contractility of corneal eorpuseles, 52

- of pigment cells, 5t

Contraction of muscle, 99

- wave, 99

Cowvolution of brain, 243

in nucleus, 13

Corda teudinex, $100^{\circ}$

Cords of adenoid tissue, 127

Corium, 404

Cornea, 50, 429

nerves in, 431
Corneal cells, 50

- corpuscles, 50, 430

Cornuain eord, 173

Cornua uteri, 390

Corpora cavernosa, 304

_ geniculata, 270

- qualrigemina, 22.96 striata, 249

Corpus callosim, 24!

- Highmori, 3i:

- lutemm, 391

- restiforme, 209

- spongiosum, :iS4

Corpuscles, Malpighian, 353, 359

— of blood, 20 , 223

of lone, 71

- of comnertive tissue, ts

- of Grandry, 160

of Herbst, $15 \mathrm{~s}$

-_ of lympl, 123

— of Meissller, 158

- of muscle, 94

of nerve, 145

— of Paemi, 155, 423

— of Vater, 155

- Tactile, 159, 4:23

Corti's arch, 470

- cells, 471

- gauglion, 405

—orgau, 469 rocls, 469

Cortical layer of ovary, $35 i$

_- lympli-siuus, $136^{\circ}$

Costal cartilages, 63

- pleura, 122

Cowper's glauds, 353

Cremaster internus, 381

Crenate blood corpuscles, 21

Crescents of Gianuzzi, 294

Cricoid cartilage, 389

Crista acustica, 335

- spiralis, $3+2,3 \pm 7$

C'rus cerebri, 229

- Crusta of, 233

Crusta petrosa, 463

Cryjts, 129 of Lieberkiihn, $31 \mathrm{~S}$

Cuticle of Nasmytl, 254

Cntis anserina, 420

- vera, 404

Crstic duet, ss

Cytogenous tissue, 120

Cytoplasm, T

Deiter's' cells, 236,47 phalanges, 4.3

Demilunes of Heidenhain, 294 
Dendrite, 197

Dendron, 151

Dentinal canals, 27i

— fibres, $27 T$

— sheaths, 27

- tubes, 5.5

Dentine, 8.5

Descemet's membrane, b1, $4: 30$

Diapedesis, 113

Diauhragm, $4+122$

Diaster stage in nucleus, 10

Diffuse adenoid tissue, 127

Dilatator purilla. 437

Direct division, 12

"Dise tactil," 161

Discus proligerns, $3: 0$

Disdiaclasts, 104

Dispireme, 16

Distal convoluted tubes, 365

Division, Remak's mole of, 12

Doyère's nerve-mount, 165

Ductless glands, 454

Ducts of pancreatic gland, 330

$\longrightarrow$ of salivart gland, 201

Ductus ejaculatorii, $3-1$

Dura mater, 170

Dural sheatl, 45T

Ear, Extermal, 45s

- Internal, $40^{\circ} 0$

Ectoplasm, s

Eosinophile cells, 2-T

Efferent lymphatics, $13 \mathrm{~S}$

medullated nerve-fibres. 155

veins, 56

Elastic fenestrated membrane of Henle, 61

Elastiu, 60

Electric nerve, 148

Eleidin, 33

Elementary fibrille, 145

- fibrils, 47

- or fanisms, 5

Enamel, 275

- cap, $28 \mathrm{I}$

— cells, 281

- organ, 250

- mrisins, 275

End-bulbs of Kranse, 15:

Endocardium, 105

Endochondral formatio of bone, 75

Endolympli, 461

Endolymphangial nodules, 125

Endomysium, 91

Endoneurium, $1 \pm 2$

Endoplasm, 8
Endothelial cells, structure, 40 membrane, 40

Endothelium, 40

Endotheloid cell-plates, 120

Energid, 6

Engrelmann's intermediate disc, 95

Ependyma, 211

Epidermis, 33, 404

Epididymis, 379

Epiglottis, 5\%, 339

Epineurinm, 141

Epithelial cells, 30

— - Division of, 38

Epithelinum, 30

Ergastic structures, 6

Erythroblasts, 28

Enstachian tube, 459

External arcuate fibres, 213

Eyeball, 426

- -lashes, 1.24 -lids, 424

Fascire 45.42

Fascia dentata, 249

Fascicles, 91

Fasciculus cuneatus, 17s

— of Goll, 179

— of Lissauer, 179

- pyramidal, IF

Fat cells, 55

- and starvation, 5s

Fenestra ovalis, 400 rotunda, 460

Fenestrated inembrane, 45,45 of Henle, 61

Fertilisation of orum, ?

Fibre arcuate, 213

Fibres, Connective tissue, 40

_ Elastic tissue, 60

- of muscle, $\$ 6,91$

- of nerves, 140

— of Purkinje, 106

Fibrille of connective tissue, 47

_ of muscle, 9 ? of nerre, 145

Fibro-cartilage, 60

Fibrous tissue development, 5?

Fillet, 2.25

Fissura orbitalis, ss

Fissure of Rolando, $\approx+3$

Fissures of spinal cord, Iij

- of medulla, 202

Foetal tooth papilla, 2s0

Follicles, Hair, 409

—, Lieberkühn's, $31 \mathrm{~s}$ 


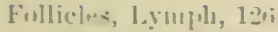

—. Nelncems. 41

—, Thyूute, 131

Foruix conjunetive, $4 \boldsymbol{Z}^{\prime}$

vacinat, 3.八

lu...al gleunilalis, iti

_._. navicularis. 3-3

- pitellari-, 44:,

Fisvea ceutralis, fy;

- lemielliptica, fort lien ispheric-1, srio

Fumlus of pertic slanıl, 31:

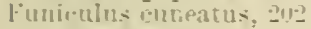

- Eracilis, $20=$

Gall-bladfer, $33 n^{\circ}$

Gan_lia. Cerel,ru-spinal. 25:3

$\longrightarrow$, smpathetic, $25: 4$

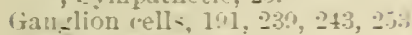

(inserian fanglion, 253

Gulatinons tisste, $i 2$

Geniculate sauglion, --90

Genital corpuscles of hrause, leiol

— end-coryu-cle-, 1.j

— organs (male), $3-$-?

$\longrightarrow$ (female), 3>t5

(ierm reticulum of won Ebatr, 3\%

Germinating cells, $1 t$

eudothelial cells, 43

epithelium, 35-

spots, 1, 3:s

- vesicle, 1. 3=s

Giraldés organ, 3:y

Glaurl, Prostate, $3=2$

Glands, agminaterl, 130, 3:1

—, Bartholini, 3!!

- Bronchial, 34?

—, Brunner, 325

_- Buccal, wis

_. Carutic, ts

- - Ceruminots, $40 \% 1$

- Coceyceal, t:

- Hariler, tos

, Krause, 420

—, Lachirymal, 4-7

- Lieberkihn s, 31

Litire: $3: 3$

Lymlhtie, 120, 134

Meibmian, 124

Mohl, 4:55

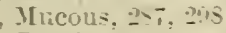

_- Peptic. 312

—. Peyer, 3:1

—, Pyloric, 313

—, Salivar!, $2=1$

_-, sebaceous, 411=

_-, serous, 2si, 249
Glauls, silitary, 1:0

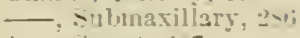

- S sweat, f1"

—. Thym11:, 131

__, Thisuil. I>t

Glau lule asminate, 1:0

— Ienticulare: : :1;

_ Parchienti, :-:;

—uterina. : s'"

filans clitorilis, 3.1!

In: nis. 3-4

fila-ty menbrane, 411

Glisinn's atpule, 333

iglołulin. 21

Globus major, 350

Glomeruli. 251. 30\%

Glreogen, $\because 2.23 .335$

Griblet cril-, $3{ }^{\circ}$

Golyi: cells. 는?

methin, $1=2$ - tenion spindlos, 1:

Goll's tract, li!

Graatian tollicles, 3s:

Grandry 's corpusiles, 100

Granular leucocyter. 20, 5

Granules in blord, - -

Granulosa, membrana, $3 心$

frey commissnre, 17t

Grotud lamellat, 73

- plexus of Arnold, $11 ; 2$

__ substance, $\frac{1}{4} \cdot j$

Growing capillaries, 113

Habenula lerfintata, 4.2

Hitmatin, 23

Hæmatoiliu, 23

Hiematoplasts, -7

Hemin crystals, 23

Hamoglobin, -2.

Hair. $\frac{14}{4}$

— Dulb, $41: 2$

- tibres, 413

fillicles. 409

knol, 41 ij

—. Marrow of, 413

—, Jew formation of, 41 .

_ japilla, 111

- Poot rif. $\$ 13$

- slieath of, 41 ?

$\mathrm{sar}, 411$

- Sliaft of. $41 \frac{1}{4}$

Hariler's slanil. 42s

Haversian canals, 7:lamellip. $\rightarrow: 2$

spaces, :- 
Heart and blond-vessels, 105

Helicotrema, 469

IIenle. Fenestraterl membranes of, 61,108

- Fibres of. 62

, Sheath of, 142

—. Stratum nervenu of, 456

- Tules of, $36+i$

Hensen's cells, $4 \div \cdot 2$

- median rlisi, 9s

Hepatic rells, 33.5

- duct, $336^{\circ}$

- n lobules, 333

veins, 335

Herbst, Corpuseles of, 15 .

Hilum of lymph glands, 134

— of salivary glands, 291

of spleen, 352

Hippocampus, 249

Homogenents elastic membranes, b1

Howship 's lacmma, s.j

Huxley's layer, 414

Hyaline cartilage, 63 levercyte, $20^{\circ}$

Hyaloid membrane, 143

Hyaloplasm, ?

Hypophysis, 454

1leum, ::21

Incremental lines of Salter, $2-2$

linelis, 459

Indirect division, 13

Infundibula, ss

— of moncliole, 345

- of gland, 292

Inner molectlar layer, 449

nuclear laver, $\$ 4 !$

Interarticulal cartilages, , ti6

Interfascicular splaces. 4 !

Interglobular spaces of Czerınak, $27 \mathrm{~S}$

Interlobar ducts, 291

Interlobular bile-ducts, $33 h^{2}$

- connective tissue of liver, 333 ducts, 291

Intermediate cartilage, $66^{\circ}$

- disc, 96

plexus, 162

- zone, $31 \%$

intermenbranous formation of bone, 83

Interuuscular fibrils, $16 i^{2}$

Intermal arcuate fibres, $21: 3$

capisule of brain, $2: 33$

Intervertebral fliscs, 60

Intestiue, Large, $31 \div$
Intestine, Small, 317

Intiua of arteries, $10 \mathrm{~S}$

Intralobular bile-capillaries, 33t; veins, 335

Intranuclear network, 11

Iris. $430^{\circ}$

-, Blood-ressels of, 43s

- Lymph-clofts rif, 43 S

- Lymph-sinuses of, $43 \mathrm{~s}$

_, Terre-filures of, 438

Jacoluson's orgall, 482

Karyokinesis, 13

karyomitosis, 13

Faryoplasm, 11

lieratin, 33

Findner, 350

_- Atferent asterioles uf, $36 \mathrm{~s}$ blood-ressels, 3i;

- glomerulus, 360

- lymphatics, 370

- parenclyma, $35 \%$ vessels, 367

Koilliker's mnscle buds, 102, 160

— muscle spindle, $10^{\circ}$ osteoclasts, 8.5

tract cells, 197

Kïlune's nerve-endiug in muscle, 164

- rhablia, 9:2

- rhodopsin, 453

sarcoslia, ] 00

Labia pudendi majora, 420

Labium tympanicum, 415

- vestibulare, $45 i$

Labyrinth, Ossenus, 460

Lachrymal glands, 4:2

Lacunze Morcagni, 353

- of bone, $; 0$

- of cartilage, 63

- of lympliatics, 51

Lamellæ of bone, $; 0$

- of cornea, 429 of lens, 44 ?

Lamina cribrosa, 456 clastica of cornea, 420

__usca, 134

— Jeticularis, 473

— spiralis ossea, tio vitrea, $43 \mathrm{~s}$

Langerhans' granular layer, 34 
Jaryux, 33.

lateral fillet, 220

- lorn, 174

— $116 \cdot$ ] 1 เ. .211 tract, 175

Lenmisens, 211

I. ens, 44:2

tilores, 442 stars, $4+3$

Lenticular glands, 1:30

I.ellcamia, 20

Lellcocyte, 23

L.

Lencopenia, 20

Ligamentum renticulatım, 171

latum, 256

- pectinatum, 434

pulmouis, $34 \overline{7}$

spirale, 465

suspensors of lens, 443

Limitans, externa, 451 interna, 447

Lines of Salter, $27 s$ - of Sclireger, 279

Liquor folliculi, 390 sanguinis, 19

Littré's glanrls, 383

Liver, 333

Tessels of, 335

Lobes of pancreas, 330

— of salivary gland, 290

of thynuls gland, $1: 1$

of lung. $346^{\circ}$

Lobules of liver, 333

of lung, 346

of salivary glanrls, 290

of thymus gland, 131

Locus coeruleus, 228

Lung, 346

blood-vessels, 349

lympliatics, 349

Lrimph, 123

Lymphatic capillaries, 119

clefts, 119

- glands, 126, 134

rootlets, 119

sinuses, 120

tisstue, $62,1: 5$

ressels, 11 i

Lyupliatics, 117

in mucosa, 302

Lympylh-canal system in cornea, 51 -canalicular system, 119

cavities, 1:20

corpuscles, 12:3

follicles, 126

hearts, 123

Lrmphocyte, 25, 5s, 123

Lym]hoid cells, 25
IIacula acustica, 463 lntea, 454

Malleus, $4: 9$

Malpighian corpuscles of kidney, $35 ! 1$

of spleen, $35 \%$

lyramids of kidney, $3 \%$

stratum of skin, 33

Mamnin ry gland, 101

Mannbrium nallei, 459

Marclii's metlind, 182

Marrow of bone, 68

Iatiix of osseous substance, 70

IIeatus anditorius externus, $4.5 \mathrm{~s}$

Neckel's ganglion, 253

Media of arteries, $10 \mathrm{~s}$

Yedian fillet, $2: S$ lateral fissure, 176

Merliastinum testis, 372

II dulla oblongata, 202 of gland, $] 34$

IIedullary cylinders, 135

- Iymph-sinus, 136

ras, 359 sheath of nerve-fibres, 115

Mednllated nerve-fibres, 143

Meihomian glands, 424

Meissner's corpuscles, I5S, 423

- plexus, $261,266,326$

Membrana basilaris, 469

- chorio capillaris, 441

- Descemeti, 430

-_ granulosa, 358

- hyaloidea, 443

- reticularis, 473

- secundaria, 460

_- supra-choroirlea, 434 tectoria, $47 \pm$

tympani, 458

Membrane of Krause, 96

Mesencephalon, 229

Mesentery, 12:2

Mesogastrinm, 45

Metakinesis, 15

Microcytes, 20

II icrosomes, ?

IIigratory cells, 44

IIilk, 403

-globules, 402 tonth, 253

Mitoma, 11

Mitral cells, 251

Morliolus, 465

Ionaster, 15

Intor ganglion cells, 19-

Moss fibres, $2+3$

Iorement of cilia, 35

Incin, 37

Mucosa, 300 
Mncosa, Lymph follicles wf, 128

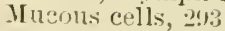

— membrane, 300

Munco-salivary glands, 2Ss

IIuris, Formation of, 36

Iiiller's fibres, $4+7$

- miniscle, 435

In ucle l,undles, $5 \pi, 9]$

- burls, 102

-_- cells, 56

— column, 92

— rorpuscles, 94

- 1ilises, 86, 90

- librille, 6.2

- sheath, 87

- spindle, 102

- tissue, Striped, 50

Yu. Non-striperl, sk

Iuscrular compartments, 9s

Muscularis externa, $30 \mathrm{~s}^{\circ}$

- $117 n \mathrm{cos} x, 30 \mathrm{~s}$

Musculus ciliaris Riolani, 4.24

Myeloplax, 7, 85

Mycloplaxes of Robin, 8.5

Tail, 420

- calls, 120

- sruove +20

- substance, 4:0

Sasal mueous membrano, ti5

- septinn, 63

Verve bundles, 141

- corpuscles, 145

- enrl plate, 160

- enclings, 155

- fibres, 140

— plexus, 143,150

- unit, 2 is

Network of tibrill:e, 153,167

Neurilemma, 145

Neurorlia, 182

—_ells, 184

— fibrils, 183

— of Virchow, 182

- tissue, t2

Neuraxon, 144

Neuron, 268

Neurokeratin, 146

Nentrophile cells, 27

Nipple, 401

Non-medullaterl neve-filses, 1ts

Niclear layer in bulbus olfuctorius, 251

- nembiane, 11

substance, 11

zone, 44:
Nucleoli, 11

Nucleoplasin, 11

Nuclens, Structure of, 11

Nurlens anbiortus, 215

- - arciformis, 21 ?

- cuneatus, 206 ;

-- gracilis, 206 ;

Nuclei, Inncr, of retina, 44,4

- Outer, of retina, 451

Dymulist, 395

Glontoljasts, $27 \%, 2>0$

(Esopliagus, :07

()lfactory bulb, 250

- cells, $47 \mathrm{~s}$

- glomeruli, 251

- nerves, 148,480

Olivary borlies, 206, 207

- muclets, $20{ }^{-}$

()inentum of cat, 44

- of from, 12.

— of guiliea-pig, 45

of rat, 45

, structure of, $4 \mathrm{~s}$

()ptic chiasma, 270

- lobes, 231

- nerve, 456

- nerve-fibres, $44 i$

— tract, 270

- vesicle, 455

(Tra serrata, 447

Organ of Corti, 469

- of Giralue, 380

of Jacolsson, 452

Ossein, 70

Osseons labyrinth of ear, 460

- lamellie, 70

substance from osteolulasts, 85

Ossicula aulitus, 459

Ossifying cartilage, $7 \pi$

Osteolulasts forming bone, $\$ t$

()steoclasts, 8.;

(1)stergenetic layer, 6 is

()tolitlıs, 33!

Oral nucleus, 41

Ovary, 3sit

—, Development of, 392

, Lymplaties uf, 252

_- Nerves of, 25:2

0 viduct, 394

Orum, 1, 3ss

oxyntic cells, 312

()xyphile cells, 2-

Pacinjan corpuscles, 155

Palate, 298 
Palme plicater, 30\%

l'alpebra, 4:4

l'ancerso, $3: 30$

l'alpilla r.jreum vallatal, 30.5

_ filiformis, 30:

—_ foliata, :005

— fungitormis, 30 -2

- nervi optici, $4+6^{\circ}$

Papillary hair of Unua, 410

Parmscle, 10xi

Paraglobulin, 를

Paramlelei, 1s

Paraplasm, 51

Parenchynua of killney, $35 \pi$

Parencliymatous cirtilage, 66

Parietal cells, 31.2

Pars ciliaris retinte, 439

_ membranacea, 383

--. prostatica, 383

Pedunculated liydatid of Mor'gagni, 3\0

Pedunculus cerebelli, 2.38

Penis, 384

_ corpura cavernosil, 384

- nerve-endings, 160

Peptic glands, 31:

Peribronchial lymphatics, 349

Pericardial cavity, 1:1

Pericellular space, 201

Perichondrium, 63

Perilymuh, 461

Perilymphangial nodules, 1:28

Perinysimm, 91

Perineurium, $1+1$

Periosteal bone, 75

— formation, 84

processes of Virchow, $i 5$

Periostemin, 6s

Peripleral nerve-endings, 155

Peritoneal cavity, 1:21

Peritonenm, 41

Perivascular lympluatics, 119

— lymplo sjaces. 201

Peyer's glands, 321

- - patih, 130

Phagocytes, 25, 5!

Pharynx, 20s

tollsil, 302

Pia mater, 170, 235

Pial sheath, 456

Pigment cells, 52

Plasma, 19

- cells, 59

Pleura pulmonalis, 347

Plemral cavities, 121

Plexus choroideus, 235

— myentericus, 326

Veissuer, $3: 6$

renoslls raginalis, 398
Plica villosi, 311

Polar bodies, is

Pons Varolii, 2.06;

l'orta liepratis, $33: 3$

Portio Niilleri, 435

— vaginalis 11 eri, $: 295$

Posterior nelve roots from spinal reorel, 158

P'ostganglionic fibres, 2 it

Pratginglionic fibres, 245

Prickle cells, 37

Primitive dental groove, 280

- tilrill:t, 150

— librils, 92 ova, $39: 3$

Prostate, 38:

Protoblast, 6

Protoplasm, 1, 7

- istructure of, 7

Protoplasmie nembrane, 5i

Proxinal convoluterl tubule, 362

Pulp tissue, 27:

Purkinje's ganglion cells, 239

Pyiorie glands, 313

Pyramicl of Ferrein, 359

Pyramidal lecussation, 204 tracts, 177

Rami capsulares, 337

Ràmón y Cajal's discoreries, 152, $189,449,450$

Ranvier's constrictions, 146

- nodes, 146

Raphe, 209

Red blood corpuscles, 20

Red mucleus, 2:30

Reissner's membrane, 46

Remak's librous layer, $10 \mathrm{~s}$

- nerve-fibre, $74 \mathrm{~s}$

Rete Malpighii, 33

— mucosum, 33

- testis, 37 !

Reticular cartilage, $t i$

—_ formation, 20!

Restiform body, 20!

Retina, 44j

- , Blind spot of, $4+6$

_., Blood-vessels of, 456

_-, Ganglion cells of, 448

- Lymphatics of, $45 t$

Rhabdia of Kithne, $9: 2$

Rlodopsin of Kinlne, 453

Rorls and cones, 452

Rollett's secondary substance, 413

Rosette stage in nuclens, 13

Rugae, 398 
Rutherforl's scheme of muscle contraction, 99

Siccules, th?

saccus endolym

saliva, 300

salivary cells, 293

- rlands. 256

_- - Bloorl-vessels of, 207

- - Ducts of, 29I

- Lobes of, 200

— L. Lobules of, 200

- - Lymphatics of. 297

Tartes of, -99 .

Sarcode of Dujardin, $;$

sarcoglia, 100

sarcolemina, 91

Sarcoplasma, 92

Sarcoplasts, 101

Sarcous elements. 91

Scala tympani, 465

- vestibuli, 335, 465

schultze s protorlasin, 5

Solnwann's cells, 5

sclerotic, 43:

scrotum, si

Sebaceous follicles. 418

Semicircular canals, te?

Seminal cells, $3 \%$

- tubules, $3 i t$

Sensory decussation. 20\%

- end-orcans in muscie, 10 i

— in tendon, $16 \mathrm{~s}$

_ fanglion cells; 197

Septum cisteruæ lymplotice, 4.j

serous qlands, 256. 299

- membranes. 12.2

Ssamoid cartila res, hin

Sharpey"s perforating ibres, if

Sheath of Henle, 14.? of Schwann. 145

Simple asis cylinulers, 193

- lympliatic glands, $126^{\circ}$

Skin, 401

-, Blooul-vessels of $4: 21$

- L Limluatics of, ti2?

Nerves of, 423

Solitary glauds, 130

_... Iymph fiollicles, 3.21

spaces of Fontana, 434

spermatroblasts, $3 \because ;$

spermatozoa, 3is

slincter jujillie, 43 ;

sphincters, ss

sipinal accessory, 203

- corrl, 1\%0.

_- grey matter, 1'1
Spinal cord white matter, $1 \leqslant 1$

Spiral fitore. 2nis

- tubule. 8 is

spireme, convolution, 13

spleen, 3 il

—, Capsule of 331

_- Lymphatics of, 355

—, Nerve-tibres of, 242.355

- Parench rma of, 352

- Pulp of, 353

_- Red blood corpuscles of, 25

- Trabeculie of, 352

spon cioblast, 450

spongioplasn, -

spongy bone substance, it

squamous e pithelial cells, 32

Sternal cartilage, 63

Stigmata, 112

stomach, 310

stomata, 11:2, 121, 349

strafified columuar epitl:elium, 35

- parement epithclium. 32

stratum anliposum, touj

—_ cinereum, 231

- corneum, 33

— clomerulosim. 251

- Granulosmm, 34,250

- lacnnosum, 249

- lemmisci, 231

- lucidum, 33

— Malpighii, 33

- opticum, 232

- radiatum, 24 ?

_ zonale, 231

strice acnsticit 220

Stria rascularis, 463

Strolua, 2-2

subarachnoirlal spaces, 121,170

- tissue, 171

subcutaneous lymphatics, 420

- tissue, $400^{\circ}$

suldural spaces, 121,170

subendocardial tisone, 10:

subepithelial enrothelium if $\mathrm{D}_{\mathrm{c}}$ -

bove, jl

subhyaloid cells, $4+3$

submaxillary ganglion, 253

subnucosa, 300

subuucous lymphatics, 121

suhpericarlial nerve lianches, 10 ;

— tissue, 106

substantia ferruginea, 22.

- gelatinosa, Iso

- nigra. 229

Subvaginal space. $4 \%$

suloriferous canal, 407

snlens hippocampi, 24?

- spiralis, 460

superior pedunculus cerebelli, -2.23 
suprachoroidal tissue, $43+$

suprarenal bodies, 45.5

Supravaginal space, 45

suspensiry liginent, 4 ::

sweat glanels, 40 -

symplatic systell, 2.js

symitsis, 199

symovial ratities, 1:21

Tactile corpuscles, 158,423 lairs, 41 j

Tapetum nigrum, 439, 454

Tarsal plate, 424

Taste buds, 305

- cells, 305 goblets, 305

Teeth, 275

- rement, 27?

— develojment, 2>0 l'ulp, $2-1 !$

Tegmental cells, 305

Tegmentum, 231

Teichmann's crystils, 23

Tenclon cells, 49 spindles, 167

Terirlons, 49

Tendril fibres, 243

Tenonian capsule, 457

- space, 457

Tensor choroideæ, 435

Terminal bronchi, 347

Testis, 372

Thuracic luet, 117

'I'hymus follicles, 131

-_ glanı, 131

Thyroil eartilage, 63

- yland, $4 \$ 4$

Tongne, 302

- Selous glands of, $30 \mathrm{t}$

Tunsils, 12?

Tonch-cells of Merkel, ItiI -corpuscles of Merkel, 160

Trabeculæ carnet, 106

- of lymphatics, 134 of spleen, 352

Trachea, 343

Tracts of white matter in cold, 17T

Trar.t cells, 1!T

Transitional epithelium, 35

Transverse lisc, 65

Trapezuil nuclens, 21S

Trapezium, 218,226

Tula Eustachii, 459

Truberele of Roland', 20:2

Tuluerculuu acusticun, 21!3

T'nbes of ejididymis, 37 !

Tunik a dnata, $37:-$
Tunica albuginea, 372

- lartos, 88

— tilurusa. 390

- prupliı, tis! varinalis, 37:-2

Tysou's slands, 294

Lreter, 371

Urethra, Female, 394

- Male, 883

Urinary tubules, 3il

Uterus, $3 ! 5$

Utricle, $46: 2$

U'vea, 437

\section{Vagina, 397}

Varicose nerve-tibres, Iti

Vas deferens, $3 \$ 1$

rectum, $37 \mathrm{~s}$

Vasa efferentia, 37!

Vascularisation of cartilage, 75

Vater's corluuscles, 155

Feins, 110

-, Intima of, 110

Media of, 110

of the bones, 110

Veins of the lorain, cord, gravid uterus, membranes, and retina, 110

- Valves of, 110

Tena axillaris, azygos, cava, crilralis, hepatica, intima, iliara, mesenterica, poplitea, renalis, spermatica, and umbilicalis, 110

- jugularis, and subclavia, 110

Vence rectie, 369

— stellatie, 370

- vorticosæ, $4+1$

Venous radicles, 353

Tenuses, 353

Ventricle, Fourth, 211

Ventricles, $100^{\circ}$

Vesicula seminales, $3 s 1$

Vestibulum of labyrintl, 460

Virchow's erystals, 23

Visceral pericardium, 105

- perituneum, 333

Visual purple, 453

Vitreous body, 443

Wandering cells, js

Weigert's methoi, 15?

White blood corpuscles, 23 
White commissure, 187

fibrons tissine, 46

substance of brain, 237 of cord, 1s;

- - of Schwann, $1+5$

Wolftian horly, 374, 35

Wreatlı arrangement of uncleus, 14

Yellow elastic cartilage, iti
Yellow elastic tissue, to

Kona fasciculata, $4 \mathbf{i}$

- _ glomerulosa, 486

_- pellucida, 1, 3ss

- retienlaris, tsi

- - vasculosit, 3sti

Konula ciliaris, $4+3$

-.- Zimnii, 443

J'rinter by Cassell \& Compaxy, Linted. La Belle Sanvage, Londun, E.C. 



Q 45.51

Kle in
K672

1808 


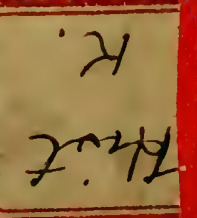

